\title{
DEVELOPMENT OF A NOVEL PHOTOCATALYST FOR THE PHOTOCATALYTIC TREATMENT OF INDUSTRIAL WASTEWATER
}

\author{
by \\ Mohsen Nasirian \\ Bachelor of Applied Chemistry \\ Tehran University \\ Tehran, Iran, 1990 \\ Master of Applied Science in Water Chemistry \\ Tehran University \\ Tehran, Iran, 1993
}

Doctor of Philosophy in Environmental Analytical Chemistry

The National University of Malaysia

Malaysia, 2006

\author{
A dissertation \\ presented to Ryerson University \\ in partial fulfilment of the \\ requirements for the degree of \\ Doctor of Philosophy \\ in the Program of \\ Environmental Applied Science and Management
}

Toronto, Ontario, Canada, 2017

(C) Mohsen Nasirian 2017 


\section{AUTHOR'S DECLARATION FOR ELECTRONIC SUBMISSION OF A DISSERTATION}

I hereby declare that I am the sole author of this dissertation. This is a true copy of the dissertation, including any required final revisions, as accepted by my examiners.

I authorize Ryerson University to lend this dissertation to other institutions or individuals for the purpose of scholarly research.

I further authorize Ryerson University to reproduce this dissertation by photocopying or by other means, in total or in part, at the request of other institutions or individuals for the purpose of scholarly research.

I understand that my dissertation may be made electronically available to the public. 


\section{ABSTRACT \\ Development of a Novel Photocatalyst for the Photocatalytic Treatment of Industrial \\ Wastewater}

Doctor of Philosophy, 2017

Mohsen Nasirian

Environmental Applied Science and Management

Ryerson University

Heterogeneous semiconductor photocatalysts have been shown to be efficient for the degradation of refractory organics into simple compounds. Among all photocatalysts, $\mathrm{TiO}_{2}$ is the most used one. Two issues that arise with the use of unmodified $\mathrm{TiO}_{2}$ as a photocatalyst are the unwanted fast recombination of electron/hole pairs and the lower effectiveness in the presence of visible light irradiation. Doping a transition metal or a non-metal into $\mathrm{TiO}_{2}$ and its combination with another photocatalyst have been used to enhance its photoactivity. This study is to develop a new photocatalyst by the combination of $\mathrm{TiO}_{2}$ with another semiconductor oxide $\left(\mathrm{Fe}_{2} \mathrm{O}_{3}\right)$ and its doping with transition metal such as Ag. Combined photocatalysts of $\mathrm{Fe}_{2} \mathrm{O}_{3} / \mathrm{TiO}_{2}$ (with different mass ratio of $\mathrm{Fe}: \mathrm{TiO}_{2}$ ) is synthesized and then silver ion is doped to combine photocatalysts (with different mass ratio of $\mathrm{Ag}: \mathrm{TiO}_{2}$ ) to produce a new composite photocatalyst of $\mathrm{Ag} / \mathrm{TiO}_{2} / \mathrm{Fe}_{2} \mathrm{O}_{3}$. A new method of UV-assisted thermal synthesis is also employed to prepare the new composite photocatalyst. Methyl orange (MO) and Congo red (CR), as model pollutants, are used to test the developed photocatalyst. In addition, nitrogen-doped titanium dioxide photocatalyst $\left(\mathrm{N}-\mathrm{TiO}_{2}\right)$ with heterojunction structures is synthesized by three different approaches including new UV- 
assisted thermal synthesis, annealing, and microwave techniques. The novel UV-assisted thermal synthesis has produced encouraging results as a preparation method to prepare $\mathrm{N}-\mathrm{TiO}_{2}$ at lower temperature and atmospheric pressure as well as a lower cost. Design of Experiment (DOE) along with response surface methodology (RSM) is used to optimize the photocatalytic activity of N$\mathrm{TiO}_{2}$ as well as the affecting parameters (wavelength, light intensity, $\mathrm{pH}$, and initial TOC) for decomposition of organics. The structure of all synthesized composite photocatalysts are investigated by X-ray diffraction (XRD). Scanning electron microscopy (SEM) combined with energy-dispersive X-ray spectroscopy (EDS) is employed to evaluate surface characteristics and elemental analysis of synthesized photocatalysts. Specific surface area of photocatalysts is measured based on Brunauer, Emmett and Teller (BET) technique. Results show that bare $\mathrm{TiO}_{2}$ has the lowest photocatalytic activity in degradation of organics. When silver is doped to $\mathrm{TiO}_{2}$, the degradation of MO is slightly enhanced at specific mass ratio. The presence of $\mathrm{Fe}_{2} \mathrm{O}_{3}$ in the new composite causes a red shift and enhances the potential to absorb higher range of visible light. Results from XRD confirmed that $\mathrm{Fe}^{3+}$ substitutes with $\mathrm{Ti}^{4+}$ in the crystal lattice of $\mathrm{TiO}_{2}$ and crystal defect occurs. The degradation of $\mathrm{MO}$ in presence of $\mathrm{Ag} / \mathrm{TiO}_{2} / \mathrm{Fe}_{2} \mathrm{O}_{3}\left(\mathrm{Ag} / \mathrm{TiO}_{2}=0.005\right.$ $\mathrm{w}: \mathrm{w}$ and $\left.\mathrm{Fe}: \mathrm{TiO}_{2}=0.01 \mathrm{w}: \mathrm{w}\right)$ reached to $95.6 \%$ under sunlight in three hours with a red shift towards visible light. It is observed that there is an optimum specific surface area of photocatalysts by doping and combining photocatalysts.

Keywords: $\mathrm{Ag} / \mathrm{TiO}_{2} / \mathrm{Fe}_{2} \mathrm{O}_{3}$ photocatalyst; Doping and combining photocatalysts, N-TiO wastewater treatment; UV-assisted thermal method. 


\section{ACKNOWLEDGMENTS}

First, I want to thank God for helping me in all of my careers, specifically my academic career and I believe that without his favor I could not accomplish anything.

I would like to express my best appreciation to my supervisor, Dr. Mehrab Mehrvar, a professor in the Department of Chemical Engineering at Ryerson University for his supervision, assistance, extensive discussions around my work and his financial support throughout the successful completion of this research.

I would also like to express my warm and sincere thanks to Dr. Ajay Ray (the external examiner), of the Department of Chemical and Biochemical Engineering, Western University, London, Ontario, Dr. Ramdhane Dhib and Dr. Yaser Dahman, of the Department of Chemical Engineering, Ryerson University, and Dr. Vadim Bostan, of the Department of Chemistry and Biology, Ryerson University, for serving as committee members on my PhD dissertation.

I warmly thank the Engineering Technologists of the Department of Chemical Engineering, Ali Hemmati, Tondar Tajrobekar and Danniel Boothe for their technical support and assistance on my experimental setup. I would also like to convey my appreciation to the Mechanical and Industrial Engineering Department and especially to Qiang Li, technical officer for helping me to use the Scanning Electron Microscope, Energy Dispersive Spectroscope (EDS) and X-Ray Diffraction (XRD) and analysis of samples. My sincere thanks and gratitude to the Chemistry and Biology Department at Ryerson for providing supplies, support and kindness throughout my project.

I am greatly indebted to my wife, Dr. Noushin and my son Parsa. They have lost a lot due to my research. I would like to express my love and thanks to them for their love, patience and understanding during a difficult period in our lives. Without their encouragement and 
understanding, it would have been impossible for me to finish this work. They allowed me to spend most of my time working in the laboratory and on this thesis.

My special gratitude is due to my mother, brother and sister for their loving support, encouragement, intellectual support of me and understanding my situation. Although they will not read this, I want them to know how much I love them. I owe my parents everything and I hope to make them proud. I will never ever forget their suffering and their support for me from the day I was born.

I am very grateful to all my friends, students and lab mates, Dr. Mehrvar's research group, Dr. Dina Hamad, Ping Lin, Sofija Katic, Dr. Argang Kazemzadeh, and especially to Dr. Ciro Fernando Bustillo Lecompte for keeping in touch and helping me during the lab work and writing this dissertation.

This work was mainly supported by the Ryerson University and Research funding from the Natural Sciences and Engineering Research Council of Canada (NSERC), Ontario Graduate Scholarship (OGS) Program, the Yeates School of Graduate Studies, and the Graduate Programs in the Environmental Applied Science and Management. The financial support of Ryerson University and all above-mentioned programs during my education is gratefully acknowledged. 


\section{TABLE OF CONTENTS}

Page

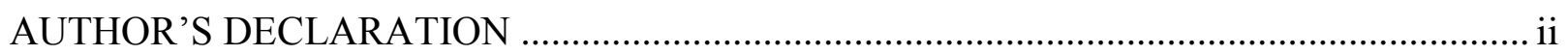

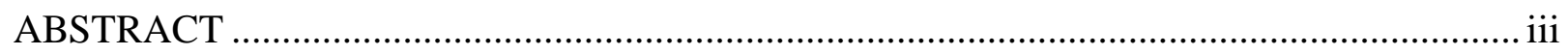

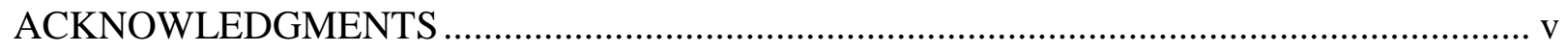

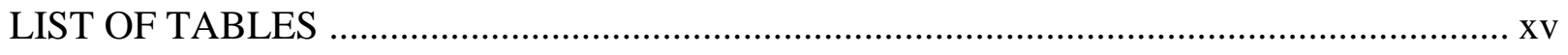

LIST OF FIGURES ..................................................................................... xvii

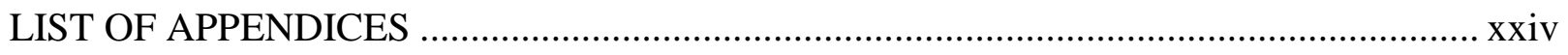

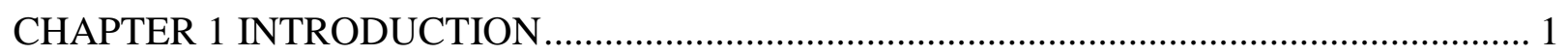

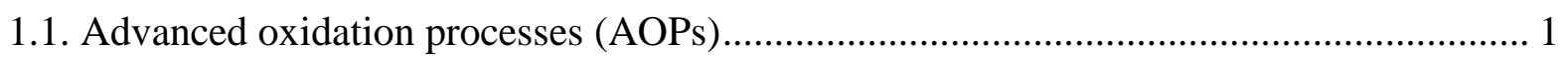

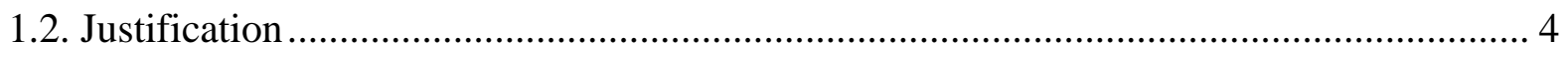

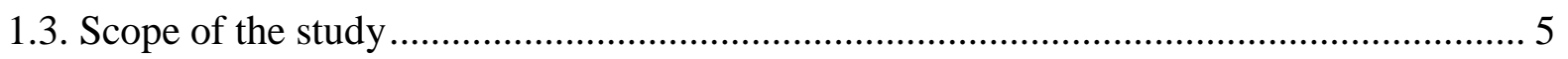

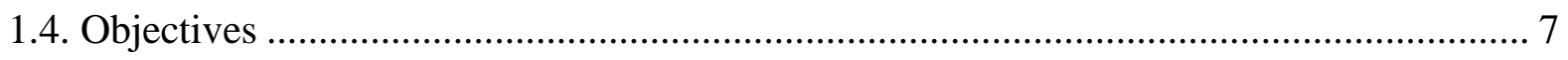

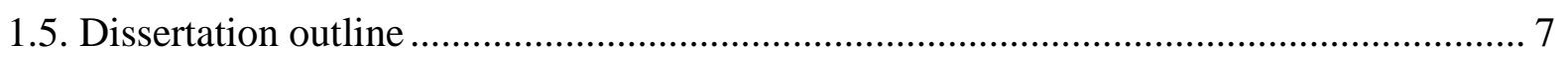

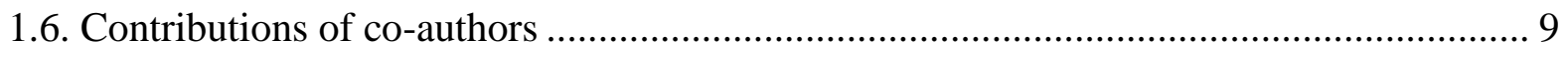

CHAPTER 2 LITERATURE REVIEW .................................................................. 10

2.1. Definition and function of a photocatalyst ...................................................... 10

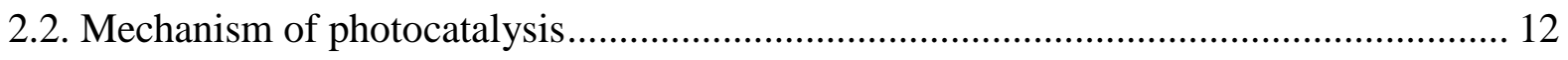

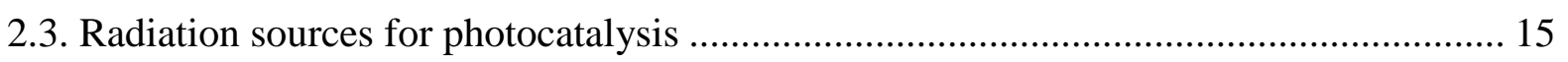

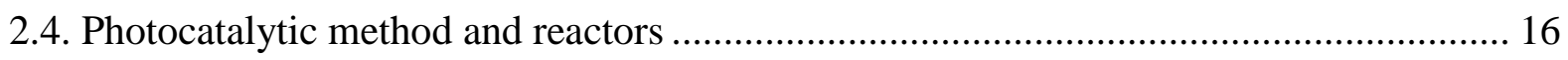

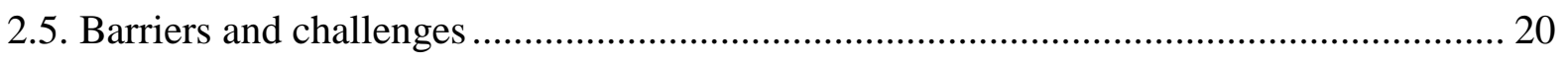

2.5.1. Limitations of existing photocatalysts ........................................................ 20

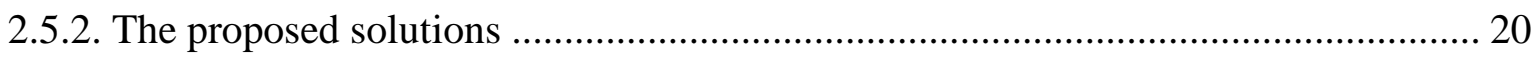




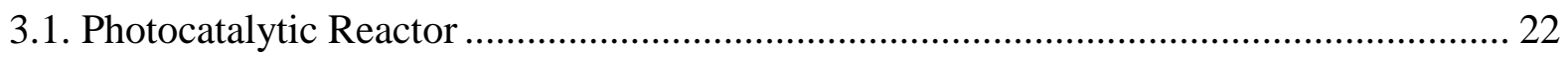

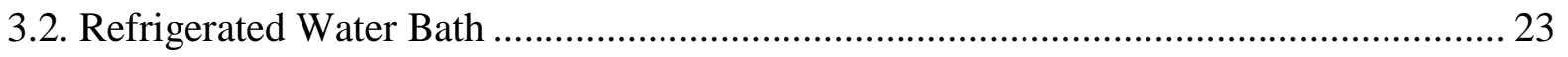

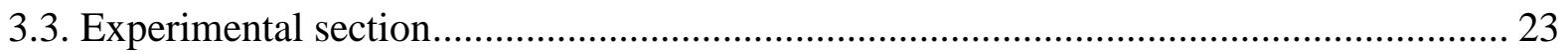

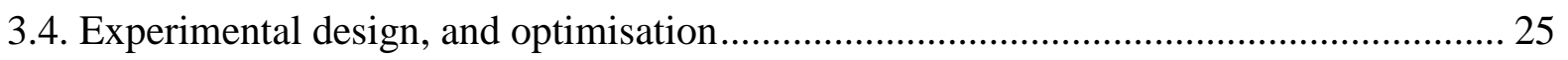

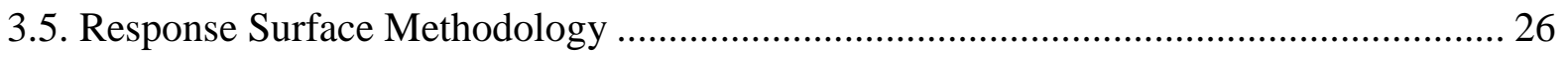

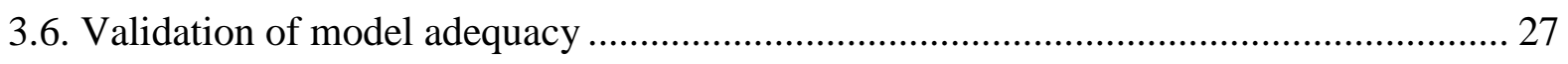

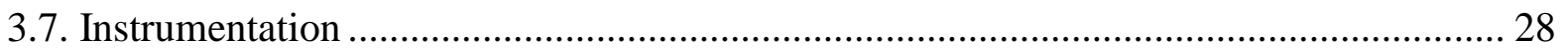

3.7.1. Total organic carbon (TOC) Analyser …………….......................................... 28

3.7.2. Brunauer, Emmet, and Teller (BET) analysis ..................................................... 29

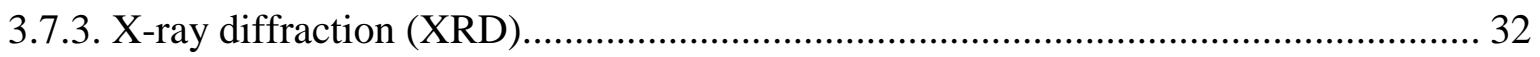

3.7.4. Scanning electron microscopy (SEM) .............................................................. 33

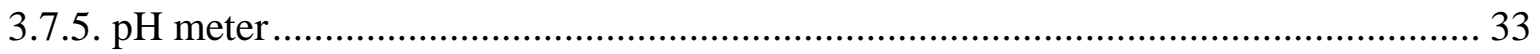

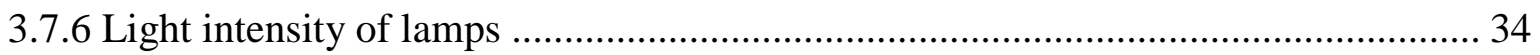

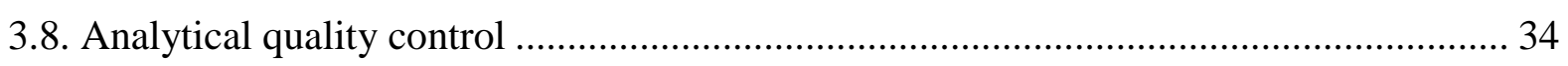

3.8.1. Quality control in laboratory analysis ................................................................. 34

3.8.2. Instrumental calibration and calibration curve ………………………………..... 35

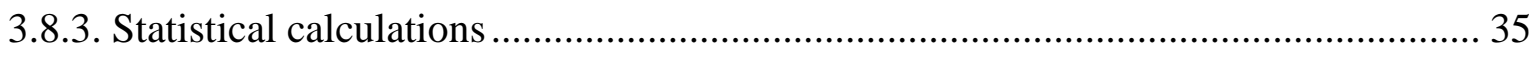

$\begin{array}{llllllll}\text { CHAPTER } & 4 & \text { MODIFICATION } & \mathrm{OF} & \mathrm{TiO}_{2} & \mathrm{TO} & \text { ENHANCE } & \text { PHOTOCATALYTIC }\end{array}$ DEGRADATION OF ORGANICS IN AQUEOUS SOLUTIONS ……………………........... 37

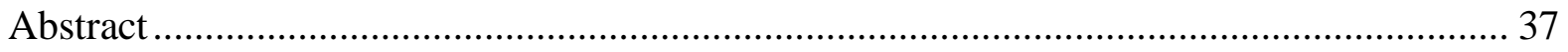

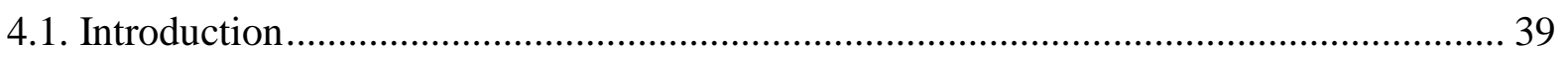

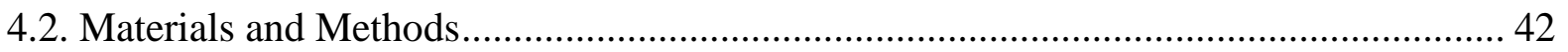




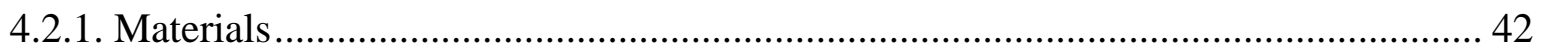

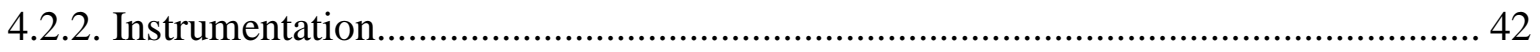

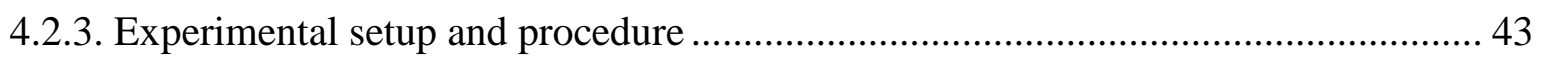

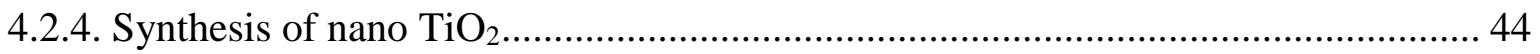

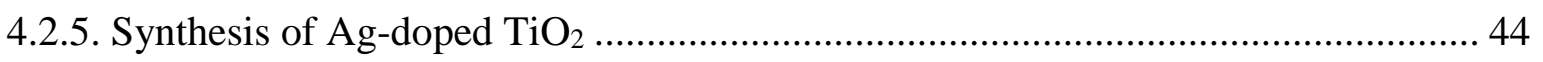

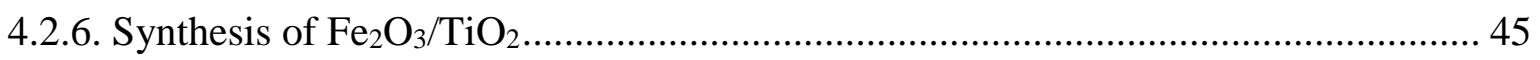

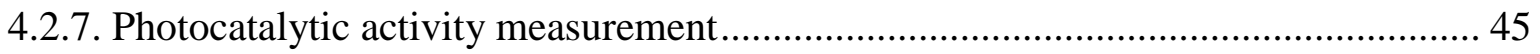

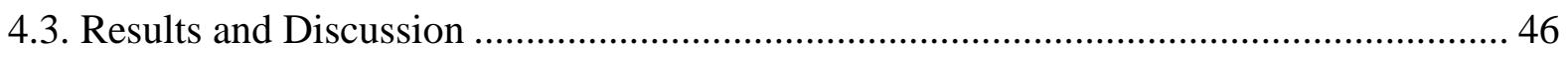

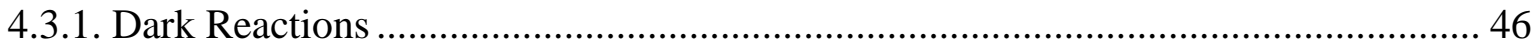

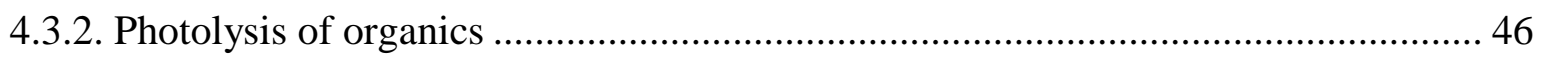

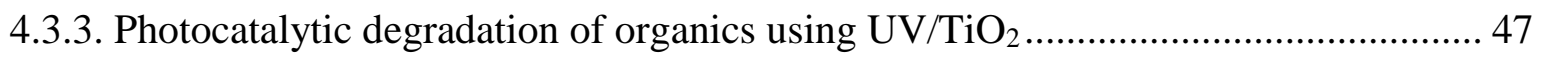

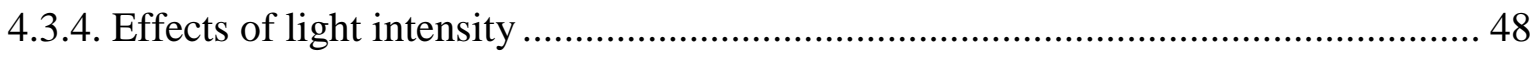

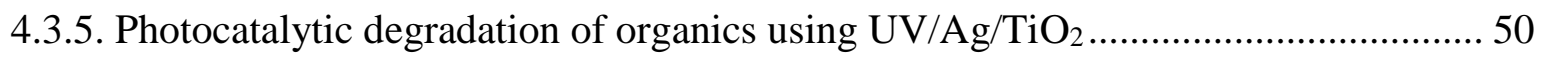

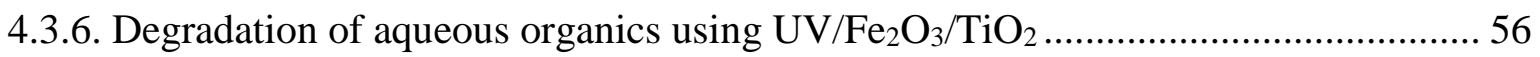

4.3.7. Photocatalyst efficiency and light absorption analysis ............................................ 66

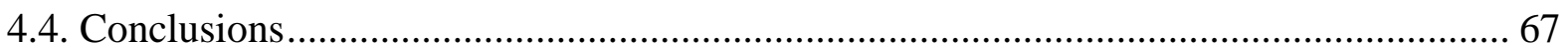

CHAPTER 5 PHOTOCATALYTIC EFFICIENCY OF $\mathrm{Fe}_{2} \mathrm{O}_{3} / \mathrm{TiO}_{2}$ ON THE DEGRADATION

OF TYPICAL DYES IN THE TEXTILE INDUSTRY: EFFECT OF CALCINATION TEMPERATURE AND UV-ASSISTED THERMAL SYNTHESIS ........................................ 68

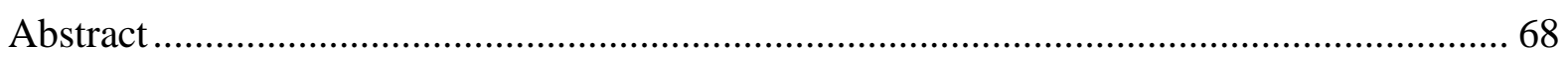

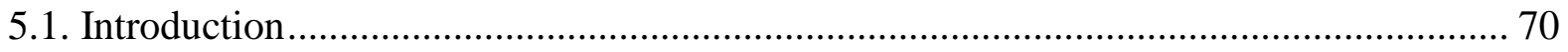

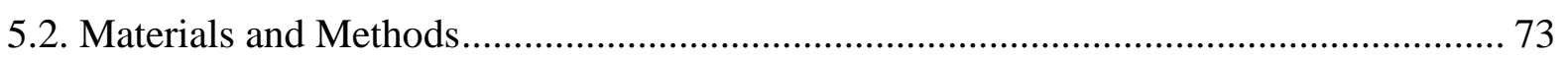

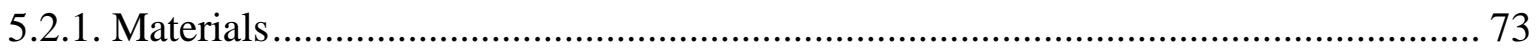




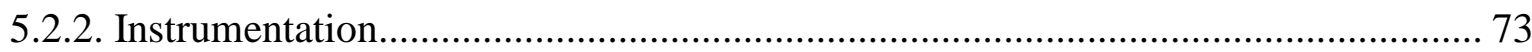

5.2.3. Experimental setup and procedure ..................................................................... 74

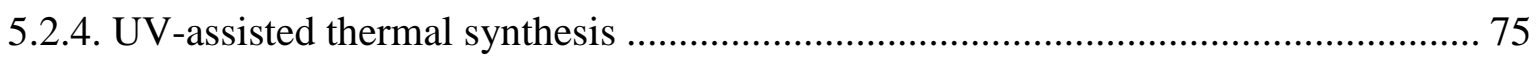

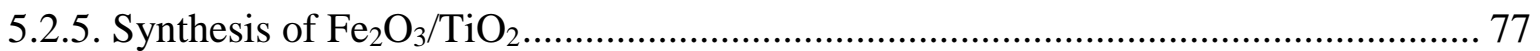

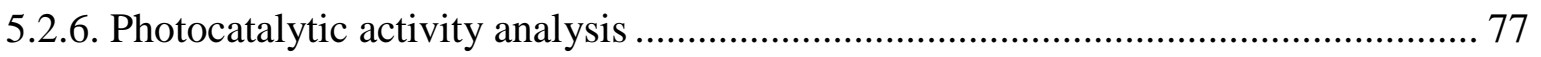

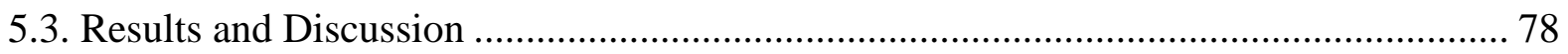

5.3.1. Photocatalytic degradation of organics: preliminary results ................................... 78

5.3.2. Characterization of the $\mathrm{Fe}_{2} \mathrm{O}_{3} / \mathrm{TiO}_{2}$ photocatalyst ............................................... 78

5.3.3. Effects of specific surface area and calcination temperature on the photocatalytic

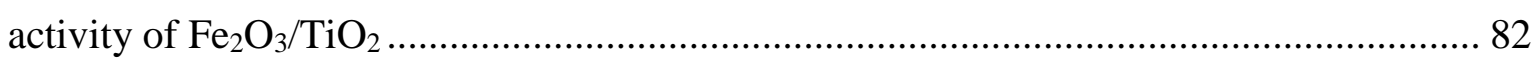

5.3.4. Crystallinity of the $\mathrm{Fe}_{2} \mathrm{O}_{3} / \mathrm{TiO}_{2}$ photocatalyst..................................................... 87

5.3.5. Fourier-transform infrared (FTIR) analysis......................................................... 93

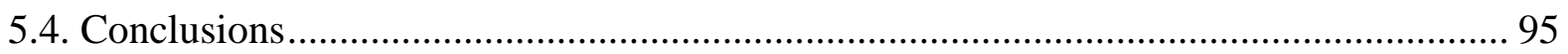

CHAPTER 6 PHOTOCATALYTIC ACTIVITY ENHANCEMENT OF TITANIUM DIOXIDE USING NON-METAL DOPING METHODS UNDER VISIBLE LIGHT: A REVIEW .......... 97

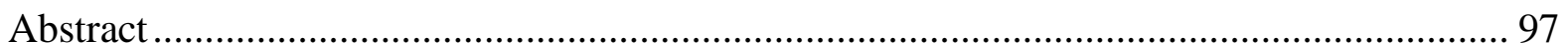

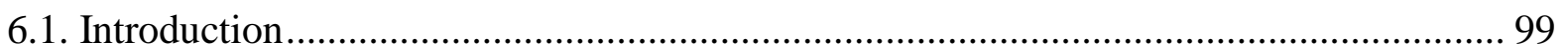

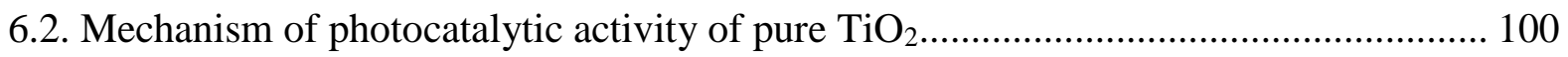

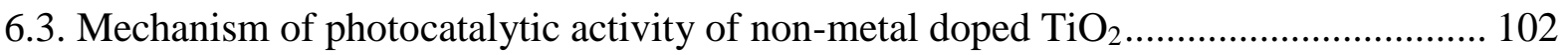

6.4. Advantages of Non-Metal Doped $\mathrm{TiO}_{2}$ over Metal Doped Composites ........................ 105

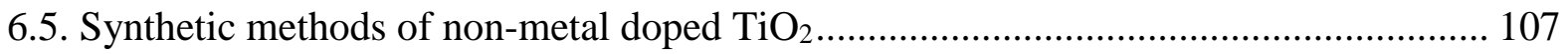

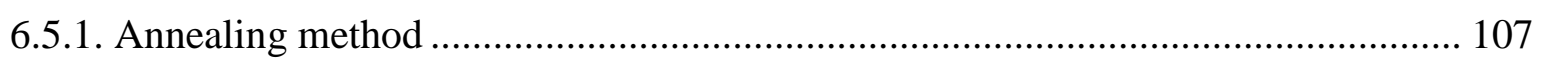

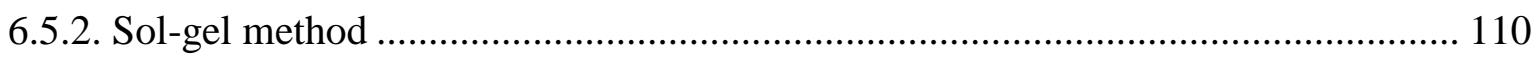




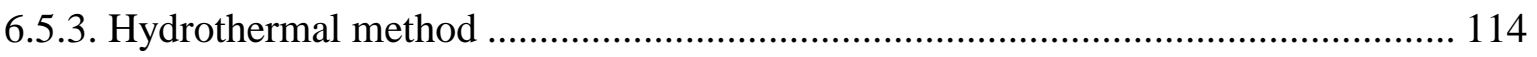

6.5.4. Microwave-assisted method .............................................................................. 117

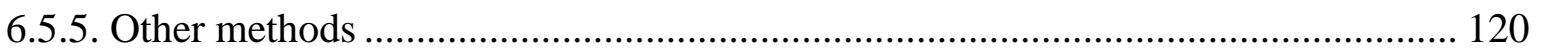

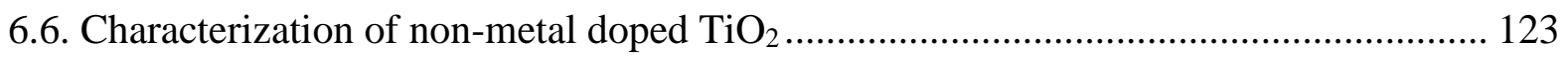

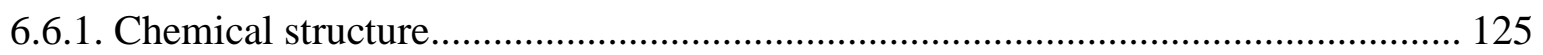

6.6.2. Physical structure: morphology and crystal structure ……………….................. 125

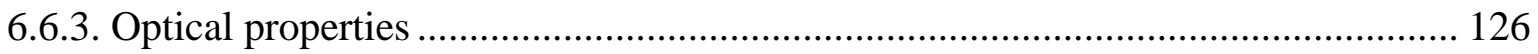

6.7. Potential parameters during synthesis and photocatalytic reactions............................. 128

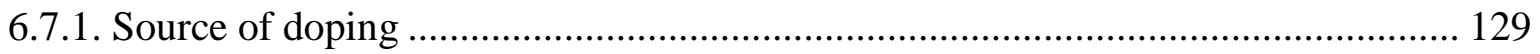

6.7.2. Solvent used in the synthesis process............................................................... 131

6.7.3. Concentration of dopants in the photocatalyst ....................................................... 131

6.7.4. Calcination temperature in the synthetic process ................................................. 132

6.7.5. Catalyst loading and initial concentration of organic pollutant ............................ 133

6.7.6. Effect of $\mathrm{pH}$ on the efficiency of photocatalytic reactions....................................... 134

6.7.7. Degradation of organic pollutants in tap water .................................................... 135

6.7.8. Photocatalyst stability and recycling .................................................................. 135

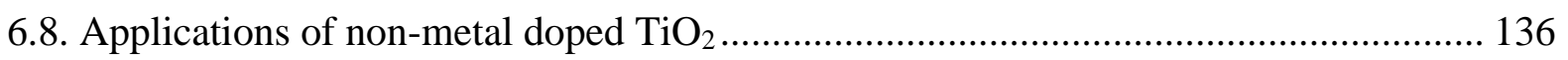

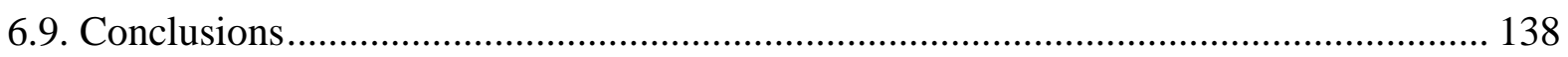

CHAPTER 7 PHOTOCATALYTIC DEGRADATION OF AQUEOUS METHYL ORANGE USING NITROGEN-DOPED TiO 2 PHOTOCATALYST PREPARED BY NOVEL METHOD

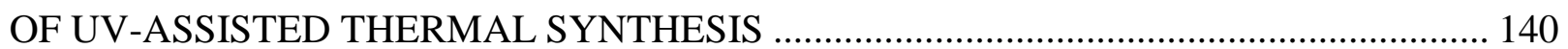

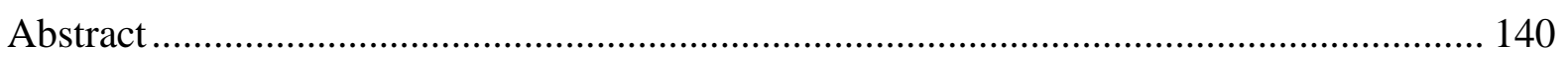

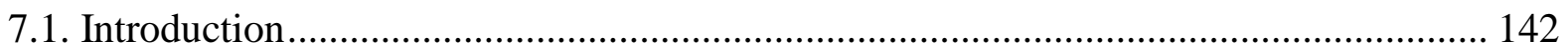




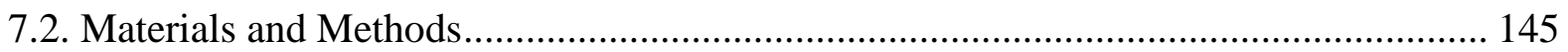

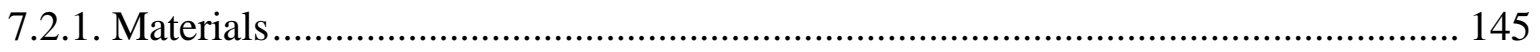

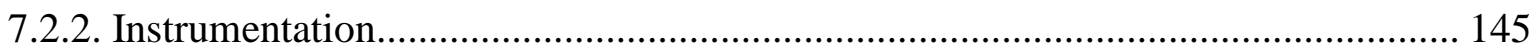

7.2.3. Experimental setup and procedure ..................................................................... 146

7.2.4. Doping methods for the synthesis of the $\mathrm{N}^{-\mathrm{TiO}_{2}}$ photocatalyst............................. 148

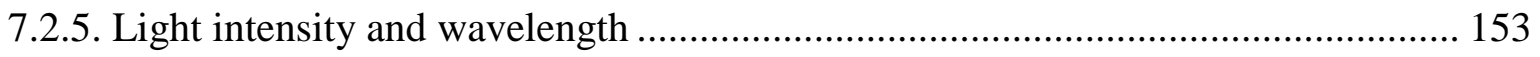

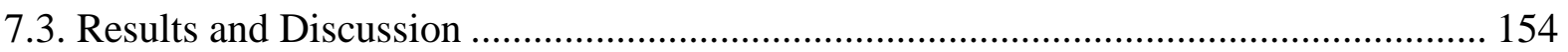

7.3.1. Photolytic degradation of aqueous Methyl Orange using different light sources ... 154

7.3.2. Photocatalytic degradation of aqueous Methyl Orange using different $\mathrm{TiO}_{2} \ldots \ldots \ldots . .156$

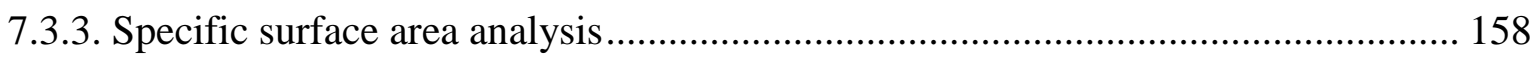

7.3.4. Photocatalytic degradation of aqueous Methyl Orange using synthetized $\mathrm{N}-\mathrm{TiO}_{2} 161$ 7.3.5. Diffractogram analysis of synthetized $\mathrm{N}-\mathrm{TiO}_{2}$ photocatalyst by $\mathrm{UV}$-assisted thermal

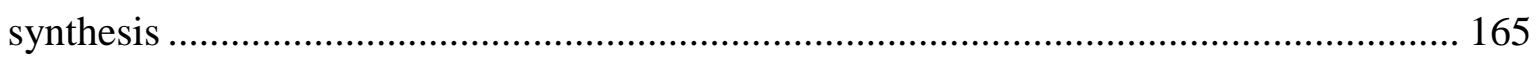

7.3.6. SEM and mapping of $\mathrm{N}-\mathrm{TiO}_{2}$ synthetized by UV-assisted thermal method........... 167

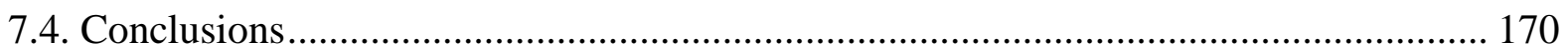

CHAPTER 8 OPTIMIZATION OF THE PHOTOCATALYTIC ACTIVITY OF N-DOPED $\mathrm{TIO}_{2}$ FOR THE PHOTOCATALYTIC DEGRADATION OF AN AZO DYE ....................... 171

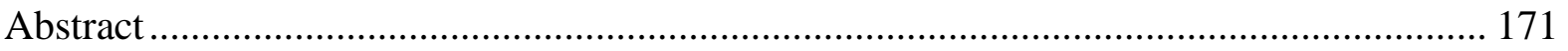

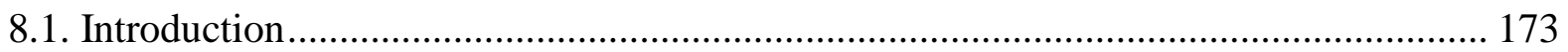

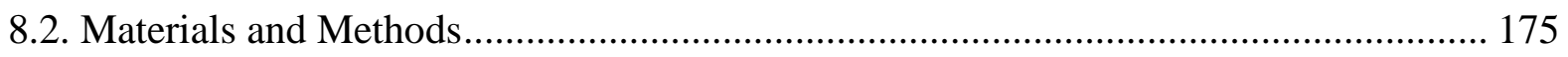

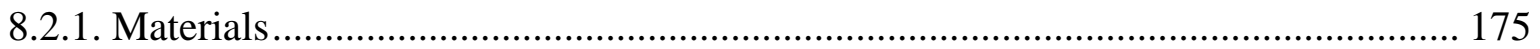

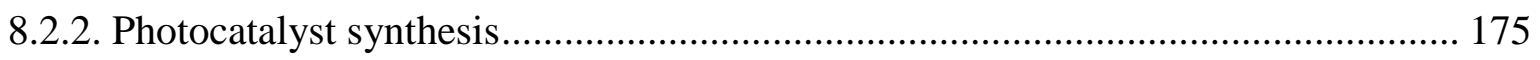

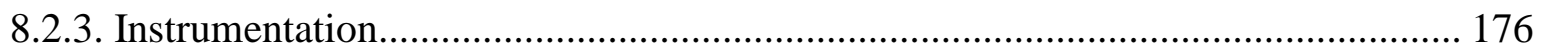




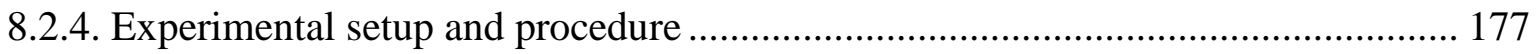

8.2.5. Statistical experimental design ....................................................................... 179

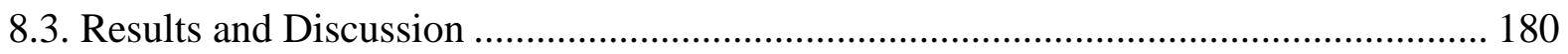

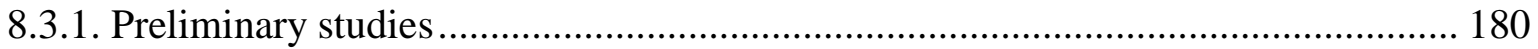

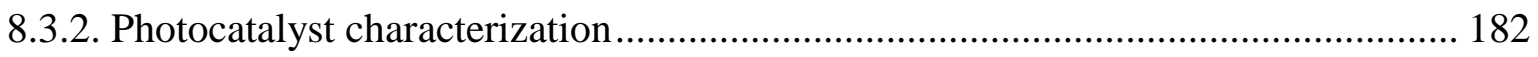

8.3.3. Statistical analysis and optimization studies ...................................................... 185

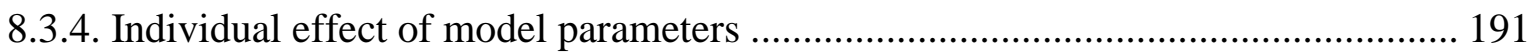

8.3.5. Interaction of model parameters, 2D contour plots, and 3D response surface........ 192

8.3.6. Optimization of experimental conditions and process parameters.......................... 197

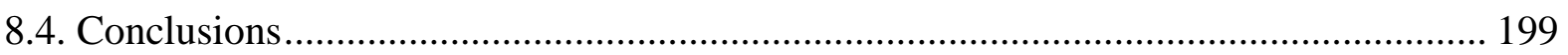

CHAPTER 9 DEVELOPMENT OF A NOVEL PHOTOCATALYST FOR WASTEWATER TREATMENT APPLYING UV-ASSISTED THERMAL SYNTHESIS AS AN

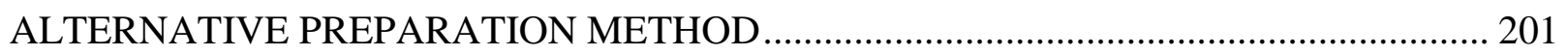

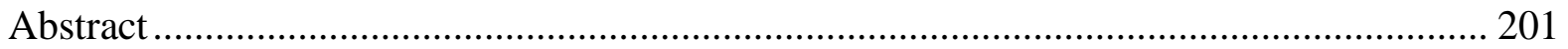

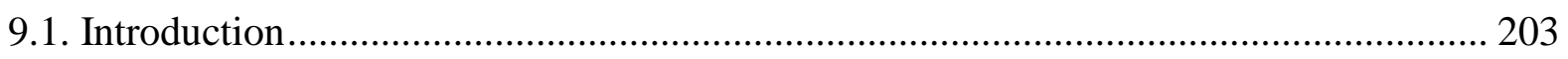

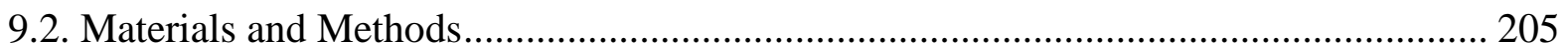

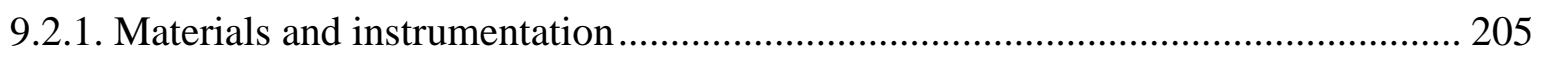

9.2.2. Analytical techniques and instrumentation ....................................................... 205

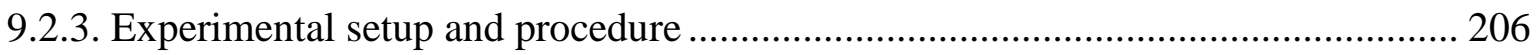

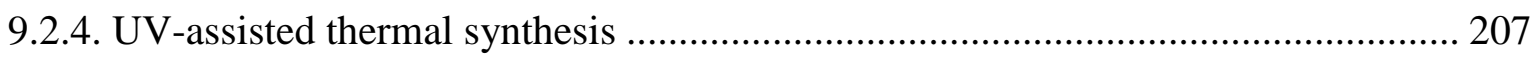

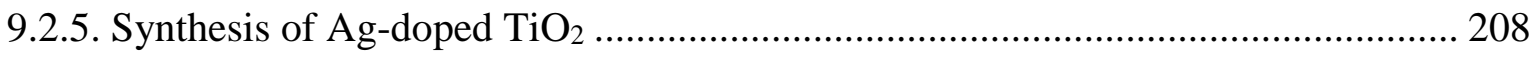

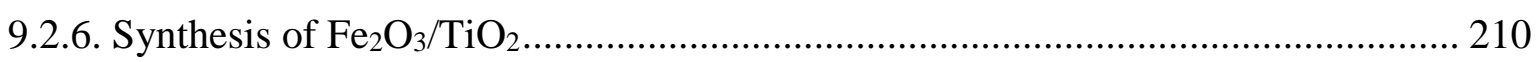

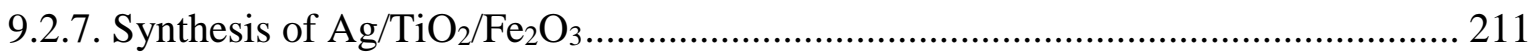


9.3. Results and Discussion 212

9.3.1. Photocatalytic degradation of methyl orange: preliminary results....................... 212

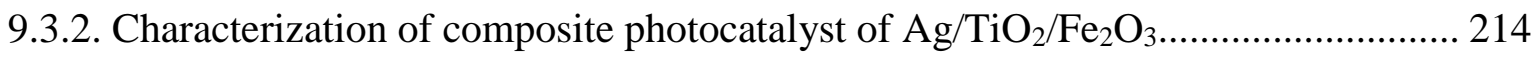

9.3.3. Crystallinity of $\mathrm{Ag} / \mathrm{TiO}_{2} / \mathrm{Fe}_{2} \mathrm{O}_{3}$ photocatalyst.............................................. 217

9.3.4. Photocatalytic degradation of organics using $\mathrm{UV} / \mathrm{Ag} / \mathrm{TiO}_{2} / \mathrm{Fe}_{2} \mathrm{O}_{3} \ldots \ldots \ldots \ldots \ldots \ldots \ldots . . . . . . . . .221$

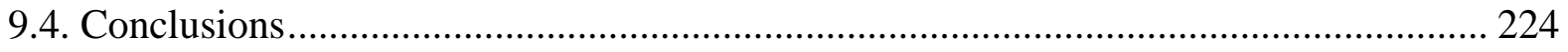

CHAPTER 10 CONCLUSIONS AND RECOMMENDATIONS ..................................... 225

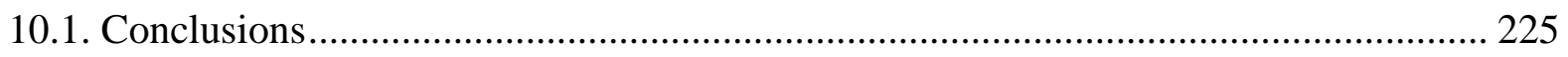

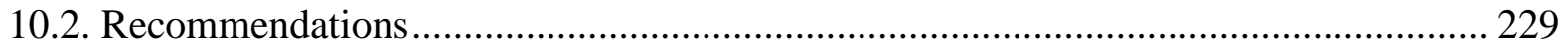

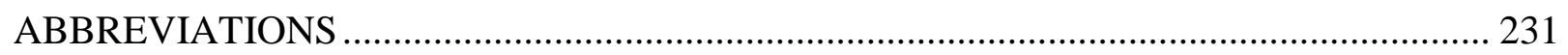

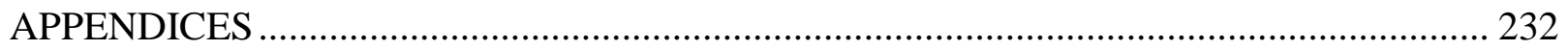

Appendix A. The first page of the publications ........................................................ 232

Appendix B. Synthesis flowchart of photocatalysts .................................................. 235

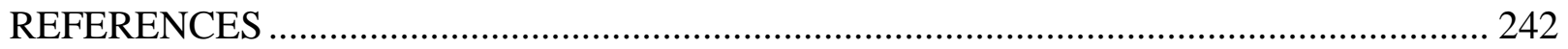




\section{LIST OF TABLES}

Page

Table 2.1. Matching solar energy wavelength with a band gap of the semiconductor. ............ 15

Table 3.1. Characteristics of the laboratory scale photocatalysis reactor............................... 23

Table 4.1. Point analysis of $\mathrm{Fe}_{2} \mathrm{O}_{3} / \mathrm{TiO}_{2},\left(\mathrm{Fe}: \mathrm{TiO}_{2}=0.05\right)$ by SEM/EDS............................ 62

Table 6.1. Non-metal doped onto $\mathrm{TiO}_{2}$ by annealing method........................................ 109

Table 6.2. Non-metal doped onto $\mathrm{TiO}_{2}$ by sol-gel method. ............................................ 112

Table 6.3. Non-metal doped onto $\mathrm{TiO}_{2}$ by hydrothermal method...................................... 116

Table 6.4. Non-metal doped onto $\mathrm{TiO}_{2}$ by microwave method........................................ 119

Table 6.5. Non-metal doped onto $\mathrm{TiO}_{2}$ by other methods............................................. 124

Table 6.6. Characteristics of non-metal doped $\mathrm{TiO}_{2}$ prepared via seven different doping methods.

Table 6.7. Characteristics of $\mathrm{S}-\mathrm{TiO}_{2}$ prepared via sol-gel doping methods using four different

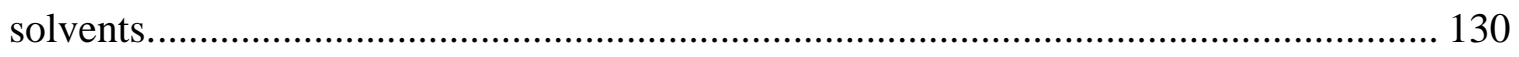

Table 7.1. Light intensity of several lamps and sunlight at different distances (The solar light

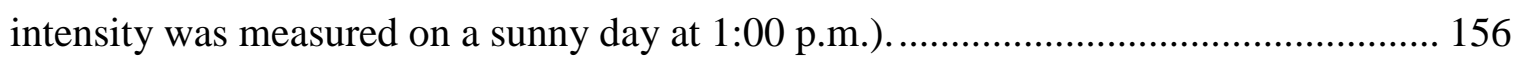

Table 7.2. Specific surface area of several photocatalysts with different synthesis methods, sources of doping, and concentrations.

Table 8.1. Experimental design and independent variables based on RSM for the optimization of the photocatalytic activity of $\mathrm{N}$-doped $\mathrm{TiO}_{2}$ in the degradation of methyl orange. 179

Table 8.2. Four-factor BBD for RSM, along with the observed and predicted percent TOC and color removals in the optimization of the photocatalytic activity of $\mathrm{N}$-doped $\mathrm{TiO}_{2}$ for the degradation of an azo dye. 
Table 8.3. ANOVA of percent TOC removal by quadratic modeling in the optimization of the photocatalytic activity of $\mathrm{N}$-doped $\mathrm{TiO}_{2}\left(0.15 \mathrm{w}: \mathrm{w} \mathrm{N}-\mathrm{TiO}_{2}\right)$ for the degradation of an azo

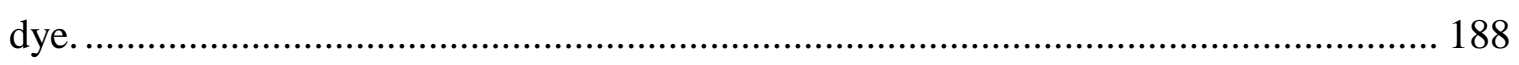

Table 8.4. ANOVA of percent color removal by quadratic modeling in the optimization of the photocatalytic activity of $\mathrm{N}$-doped $\mathrm{TiO}_{2}\left(0.15 \mathrm{w}: \mathrm{w} \mathrm{N}-\mathrm{TiO}_{2}\right)$ for the degradation of an azo dye. 189 


\section{LIST OF FIGURES}

Page

Figure 2.1. Schematic diagram of the $\mathrm{TiO}_{2}$ photocatalysis mechanisms. ............................. 14

Figure 2.2. Trapping of photo-induced electrons by doped transition metals......................... 18

Figure 3.1. Laboratory scale reactor for experimental setup ........................................... 22

Figure 3.2. Typical multipoint BET plot. .................................................................... 30

Figure 4.1. Schematic diagram of the laboratory scale slurry photoreactor........................... 43

Figure 4.2. Photocatalytic degradation of aqueous methyl orange and Congo red using $\mathrm{UV} / \mathrm{TiO}_{2}$. The initial concentration of each organic material=20 mg/L, $\left[\mathrm{TiO}_{2}\right]=300 \mathrm{mg} / \mathrm{L}$, UV light power $=9 \mathrm{~W}$ 47

Figure 4.3. Effect of light intensity on the photocatalytic degradation of (a) methyl orange and (b) Congo red using $\mathrm{UV} / \mathrm{TiO}_{2}$. The initial concentration of each organic material=20 $\mathrm{mg} / \mathrm{L}$, $\left[\mathrm{TiO}_{2}\right]=300 \mathrm{mg} / \mathrm{L}, \mathrm{UV}$ light power $=9 \mathrm{~W}$. 49

Figure 4.4. Comparison of the photocatalytic degradation of (a) methyl orange and .............. 51

Figure 4.5. SEM image of $\mathrm{Ag}$ doped $\mathrm{TiO}_{2}$ (a) $0.01 \mathrm{Ag} / \mathrm{TiO}_{2}(\mathrm{w} / \mathrm{w})$, and (b) $0.05 \mathrm{Ag} / \mathrm{TiO}_{2}(\mathrm{w} / \mathrm{w})$.

Figure 4.6. Elemental point analysis of $\mathrm{Ag} / \mathrm{TiO}_{2}$ (a) $0.005 \mathrm{Ag} / \mathrm{TiO}_{2}$ (w/w) point analysis, (b), (c), and (d) point analysis of three different locations for $0.01 \mathrm{Ag} / \mathrm{TiO}_{2}(\mathrm{w} / \mathrm{w})$. 54

Figure 4.7. Diffractogram of $\mathrm{Ag} / \mathrm{TiO}_{2}(0.05 \mathrm{w}: \mathrm{w})$, taken by XRD. 56

Figure 4.8. Comparison of the photocatalytic degradation of (a) methyl orange and (b) Congo red by different $\mathrm{Fe}_{2} \mathrm{O}_{3} / \mathrm{TiO}_{2}$. The initial concentration of each organic material $=20 \mathrm{mg} / \mathrm{L}$, $\left[\mathrm{TiO}_{2}\right]=300 \mathrm{mg} / \mathrm{L}, \mathrm{UV}$ light power $=45 \mathrm{~W}$ 57 
Figure 4.9. Comparison of the photocatalytic degradation of (a) methyl orange and (b) Congo red using $\mathrm{UV} / \mathrm{TiO}_{2}, \mathrm{UV} / \mathrm{Ag}-\mathrm{TiO}_{2}$, and $\mathrm{UV} / \mathrm{Fe}_{2} \mathrm{O}_{3} / \mathrm{TiO}_{2}$, at optimum condition. The initial concentration of each organic material $=20 \mathrm{mg} / \mathrm{L},\left[\mathrm{TiO}_{2}\right]=300 \mathrm{mg} / \mathrm{L}, \mathrm{UV}$ light power $=$ $45 \mathrm{~W}$. 58

Figure 4.10. SEM images with different magnifications for (a) $\mathrm{Fe}_{2} \mathrm{O}_{3} / \mathrm{TiO}_{2}\left(\mathrm{Fe}: \mathrm{TiO}_{2}=0.05\right)$; (b) $\mathrm{Fe}_{2} \mathrm{O}_{3} / \mathrm{TiO}_{2} \quad\left(\mathrm{Fe}: \mathrm{TiO}_{2}=0.05\right) ;$ and (c) $\mathrm{Fe}_{2} \mathrm{O}_{3} / \mathrm{TiO}_{2} \quad\left(\mathrm{Fe}: \mathrm{TiO}_{2}=0.15\right)$ with different magnification. 59

Figure 4.11. Elemental analysis based on weight percent of $\mathrm{Fe}_{2} \mathrm{O}_{3} / \mathrm{TiO}_{2}\left(\mathrm{Fe}: \mathrm{TiO}_{2}=0.05\right)$ at different points of whole sample for different spectrums taken by SEM/EDS. The details of each spectrum is shown in Table 1.

Figure 4.12. $\mathrm{SEM}$ images of $\mathrm{Fe}_{2} \mathrm{O}_{3} / \mathrm{TiO}_{2}\left(\mathrm{Fe}: \mathrm{TiO}_{2}=0.15\right)$, (a) image of the whole sample, (b) image of iron particles, and (c) image of titanium particles. 61

Figure 4.13. Comparison of diffractograms of a) $\mathrm{Fe}_{2} \mathrm{O}_{3} / \mathrm{TiO}_{2}(0.05 \% \mathrm{w} / \mathrm{w})$ and b) pure commercial $\mathrm{TiO}_{2}$ (Anatase). 64

Figure 4.14. Comparison of bare $\mathrm{TiO}_{2}$ and composite of $\mathrm{Fe}_{2} \mathrm{O}_{3} / \mathrm{TiO}_{2}(0.05 \mathrm{w} / \mathrm{w})$ photocatalysts for the degradation of MO under UV-A light (UV light power $=45 \mathrm{~W})$ and sunlight...... 66

Figure 5.1. Schematic diagram of the laboratory-scale batch suspension photoreactor. 75

Figure 5.2. Comparison of the degradation of (a) methyl orange and (b) Congo red using $\mathrm{TiO}_{2}$ photocatalyst and composites of $\mathrm{Fe}_{2} \mathrm{O}_{3} / \mathrm{TiO}_{2}$ photocatalysts (Initial concentration of each organic material $=30 \mathrm{mg} / \mathrm{L}$, concentration of each photocatalyst $=300 \mathrm{mg} / \mathrm{L}, \mathrm{UV}$ light power $=45 \mathrm{~W})$. 79 
Figure 5.3. SEM image of $\mathrm{Fe}_{2} \mathrm{O}_{3} / \mathrm{TiO}_{2}\left(0.10 \mathrm{w}\right.$ : w mass ratio of $\left.\mathrm{Fe}: \mathrm{TiO}_{2}\right)$, and elemental analysis based on weight percent of $\mathrm{Fe}_{2} \mathrm{O}_{3} / \mathrm{TiO}_{2}\left(\mathrm{Fe}: \mathrm{TiO}_{2}=0.10 \mathrm{w}\right.$ :w $)$ at different points taken by EDS. 80

Figure 5.4. Comparison of specific surface areas of several photocatalysts calcined at $300^{\circ} \mathrm{C}$ (in all photocatalysts, w:w means mass ratio of $\mathrm{Fe}: \mathrm{TiO}_{2}$ ) 81

Figure 5.5. (a) Effect of mass ratio of $\mathrm{Fe}: \mathrm{TiO}_{2}$ on the specific surface area of $\mathrm{Fe}_{2} \mathrm{O}_{3} / \mathrm{TiO}_{2}$ calcined at different temperatures; and (b) Effect of calcination temperature on the specific surface area of $\mathrm{Fe}_{2} \mathrm{O}_{3} / \mathrm{TiO}_{2}$ at various mass ratios of $\mathrm{Fe}: \mathrm{TiO}_{2}$. 83

Figure 5.6. Effect of calcination temperature on the degradation of (a) methyl orange; and (b) Congo red in the presence of $\mathrm{Fe}_{2} \mathrm{O}_{3} / \mathrm{TiO}_{2}$ (0.01 w:w Fe:TiO 2,5 UV-A lamps, and photocatalyst concentration of $300 \mathrm{mg} / \mathrm{L})$. 86

Figure 5.7. Comparison of diffractograms of $\mathrm{Fe}_{2} \mathrm{O}_{3} / \mathrm{TiO}_{2}$ calcined at $300^{\circ} \mathrm{C}$ for mass ratios of (a) 0.01 w:w Fe:TiO 2 ); (b) 0.05 w:w Fe:TiO 2 ); and (c) commercial $\mathrm{TiO}_{2}$ (anatase). 88

Figure 5.8. Diffractogram of the $\mathrm{Fe}_{2} \mathrm{O}_{3} / \mathrm{TiO}_{2}$ photocatalyst $\left(0.05 \mathrm{w}: \mathrm{w}\right.$ Fe: $\left.\mathrm{TiO}_{2}\right)$ calcined at (a) $500^{\circ} \mathrm{C}$; and (b) $900^{\circ} \mathrm{C}$ 90

Figure 5.9. FTIR spectra of $\mathrm{Fe}_{2} \mathrm{O}_{3} / \mathrm{TiO}_{2}\left(0.05 \mathrm{w}\right.$ : $\mathrm{w}$ Fe: $\left.\mathrm{TiO}_{2}\right)$ at different calcination temperatures:

(a) $300^{\circ} \mathrm{C}$; (b) $500^{\circ} \mathrm{C}$; and (c) $700^{\circ} \mathrm{C}$. 94

Figure 6.1. Photoreaction process of $\mathrm{TiO}_{2}$ under UV radiation. 101

Figure 6.2. Possible photoreaction mechanism of (a) pure $\mathrm{TiO}_{2}$ and (b) $\mathrm{N}-\mathrm{TiO}_{2}$ under visible light irradiation. 101

Figure 6.3. Potentials (V) of $\mathrm{TiO}_{2}$ (anatase) and transition metals (Ag, $\left.\mathrm{Cu}, \mathrm{Fe}, \mathrm{Zn}\right) \ldots \ldots \ldots \ldots . . . .106$

Figure 6.4. Annealing method for doping non-metal onto $\mathrm{TiO}_{2}$ photocatalyst..................... 108

Figure 6.5. Sol-gel method for doping non-metal onto $\mathrm{TiO}_{2}$ photocatalyst. 111 
Figure 6.6. Hydrothermal method for doping non-metal onto $\mathrm{TiO}_{2}$ photocatalyst. 115

Figure 6.7. Microwave assisted method for doping non-metal onto $\mathrm{TiO}_{2}$ photocatalyst......... 118

Figure 6.8. Anodic oxidation method for doping non-metal onto $\mathrm{TiO}_{2}$ photocatalyst.............. 121

Figure 6.9. Electrochemical anodization method for doping of non-metal onto $\mathrm{TiO}_{2}$ photocatalyst 122

Figure 7.1. Schematic diagram of the laboratory-scale batch photoreactor. 147

Figure 7.2. Effects of (a) photolysis on the degradation of Methyl Orange solution with the initial concentration of $30 \mathrm{mg} / \mathrm{L}$ using different light wavelengths; and (b) degradation of Methyl Orange in the presence of $\mathrm{P} 25$ with the $\mathrm{TiO}_{2}$ concentration of $500 \mathrm{mg} / \mathrm{L}$. 155

Figure 7.3. Effects of different wavelengths on the degradation of Methyl Orange in the presence of three commercial forms of $\mathrm{TiO}_{2}$ photocatalyst. The initial concentrations of Methyl Orange and $\mathrm{TiO}_{2}$ are $30 \mathrm{mg} / \mathrm{L}$ and $250 \mathrm{mg} / \mathrm{L}$, respectively. 157

Figure 7.4. Specific surface area for all $\mathrm{N}-\mathrm{TiO}_{2}$ photocatalyst synthesized by different methods. 161

Figure 7.5. Degradation of Methyl Orange and comparison of specific surface area (SSA) for the $\mathrm{N}-\mathrm{TiO}_{2}$ photocatalyst synthesized with different methods: (a) annealing with urea; (b) UVassisted thermal synthesis with urea; (c) microwave with urea; (d) UV-assisted thermal synthesis with $\mathrm{HNO}_{3}$; and (e) microwave method with $\mathrm{HNO}_{3}$ (The initial concentrations of Methyl Orange and $\mathrm{TiO}_{2}$ concentrations are 30 and $500 \mathrm{mg} / \mathrm{L}$, respectively). UV: ultraviolet 162

Figure 7.6. Efficiency of different photocatalysts for the degradation of Methyl Orange under UV-A irradiation using $500 \mathrm{mg} / \mathrm{L} \mathrm{N}-\mathrm{TiO}_{2}$ at the mass ratio $0.15 \mathrm{~N}: \mathrm{TiO}_{2}$. The initial concentration of Methyl Orange was $30 \mathrm{mg} / \mathrm{L}$. 164 
Figure 7.7. Diffractogram of the $\mathrm{N}_{-} \mathrm{TiO}_{2}$, with the mass ratio of $0.15 \mathrm{~N}$ : $\mathrm{TiO}_{2}$, prepared by UVassisted thermal synthesis with $\mathrm{HNO}_{3}$ as the nitrogen source. 167

Figure 7.8. SEM and mapping images of the (a) $\mathrm{N}-\mathrm{TiO}_{2}$ photocatalyst $\left(0.15 \mathrm{~N}: \mathrm{TiO}_{2} \mathrm{w}: \mathrm{w}\right.$ and $\mathrm{HNO}_{3}$ as the nitrogen source) by the UV-assisted thermal method and the elemental distribution of (b) nitrogen, (c) titanium, and (d) oxygen for the photocatalyst prepared by UV-assisted thermal synthesis. UV:ultraviolet. 169

Figure 8.1. Schematic diagram of (a) the laboratory-scale batch suspension reactor and (b) the lid for UV lamps distribution. 178

Figure 8.2. Degradation of methyl orange in the presence of the synthesized $\mathrm{N}-\mathrm{TiO}_{2}$ photocatalyst $(500 \mathrm{mg} / \mathrm{L})$ with different mass ratios of nitrogen at $180 \mathrm{~min}$ of UV-A irradiation time, and comparison with the specific surface area of photocatalysts.

Figure 8.3. (a) SEM image of the as-prepared $\mathrm{N}-\mathrm{TiO}_{2}$ photocatalyst $\left(0.15 \mathrm{w}: \mathrm{w} \mathrm{N}-\mathrm{TiO}_{2}\right)$ by the annealing method and (b) Diffractogram of the as prepared $\mathrm{N}-\mathrm{TiO}_{2}$ photocatalyst taken by XRD. 183

Figure 8.4. Mapping images of (a) $\mathrm{N}^{-\mathrm{TiO}_{2}}\left(0.15 \mathrm{w}: \mathrm{w} \mathrm{N}-\mathrm{TiO}_{2}\right)$ photocatalyst and the elemental distribution of (b) titanium, (c) oxygen, and (d) nitrogen in the photocatalyst prepared by annealing method.

Figure 8.5. Validation of the percent TOC removal (left side) and color removal (right side) models using different plots: (a) internally studentized residuals versus predicted values and (b) observed experimental data versus predicted values.

Figure 8.6. Individual effect of the (a) light wavelength; (b) initial TOC concentration; (c) light intensity; and (d) $\mathrm{pH}$ on the percent TOC removal and color removal using $0.15 \mathrm{w}: \mathrm{w} \mathrm{N}-$ $\mathrm{TiO}_{2}$. The dashed lines represent the model TOC removal, whereas the marker points 
represent the model color removal. Error bars represent the standard deviation of the experimental data. 192

Figure 8.7. Interaction effects of different parameters on the percent TOC removal using 3D response surface and 2D contours: (a) light wavelength and initial TOC concentration $\left(X_{1} X_{2}\right)$; (b) light wavelength and intensity $\left(X_{1} X_{3}\right)$; (c) light wavelength and $\mathrm{pH}\left(X_{1} X_{4}\right)$; (d) initial TOC concentration and light intensity $\left(X_{2} X_{3}\right)$; (e) initial TOC concentration and $\mathrm{pH}$ $\left(X_{2} X_{4}\right)$; and (f) light intensity and $\mathrm{pH}\left(X_{3} X_{4}\right)$ 194

Figure 8.8. Interaction effects of different parameters on the percent color removal using 3D response surface and 2D contours: (a) light wavelength and initial TOC concentration $\left(X_{1} X_{2}\right)$; (b) light wavelength and intensity $\left(X_{1} X_{3}\right)$; (c) light wavelength and $\mathrm{pH}\left(X_{1} X_{4}\right)$; (d) initial TOC concentration and light intensity $\left(X_{2} X_{3}\right)$; (e) initial TOC concentration and pH $\left(X_{2} X_{4}\right)$; and (f) light intensity and $\mathrm{pH}\left(X_{3} X_{4}\right)$ 195

Figure 8.9. Desirability 2D plots maximizing the percent TOC and color removals at optimum factor settings of light intensity in terms of 5 lamps, light wavelength of $418 \mathrm{~nm}$ (visible light range), initial TOC concentration of $10.54 \mathrm{mg} / \mathrm{L}$, and $\mathrm{pH}$ of 5.14 for the photocatalytic treatment of azo dyes in aqueous solution using the composite $\mathrm{N}-\mathrm{TiO}_{2}$ photocatalyst. . 198

Figure 9.1. The actual photos of (a) the nano-synthesized $\mathrm{TiO}_{2}$ and $\mathrm{Ag} / \mathrm{TiO}_{2}$ photocatalysts; (b) the synthesized $\mathrm{Fe}_{2} \mathrm{O}_{3} / \mathrm{TiO}_{2}$ at different calcination temperatures with different mass ratios of $\mathrm{Fe}: \mathrm{TiO}_{2}\left(\mathrm{Fe}: \mathrm{TiO}_{2}=0.01,0.05,0.1\right.$, and 0.30); and (c) the synthesized $\mathrm{Ag} / \mathrm{TiO}_{2} / \mathrm{Fe}_{2} \mathrm{O}_{3}$ photocatalysts with different mass ratio of $\mathrm{Ag}: \mathrm{TiO}_{2}$ and $\mathrm{Fe}: \mathrm{TiO}_{2}$. 209

Figure 9.2. Comparison in degradation efficiencies of methyl orange in the presence of (a) several types of $\mathrm{TiO}_{2}$ photocatalysts; (b) commercial $\mathrm{Fe}_{2} \mathrm{O}_{3}$, bare anatase $\left(\mathrm{TiO}_{2}\right)$ and composite $\mathrm{Fe}_{2} \mathrm{O}_{3}-\mathrm{TiO}_{2}$ with different mass ratios of $\mathrm{Fe}: \mathrm{TiO}_{2}$; and (c) anatase $\mathrm{TiO}_{2}, \mathrm{Ag}$ doped $\mathrm{TiO}_{2}$ 
(Ag: $\mathrm{TiO}_{2}=0.05$ w:w) and $\mathrm{Fe}_{2} \mathrm{O}_{3} / \mathrm{TiO}_{2}\left(\mathrm{Fe}: \mathrm{TiO}_{2}=0.01\right.$ w:w). The concentration of all photocatalysts was $500 \mathrm{mg} / \mathrm{L}$. The initial concentration of MO was $30 \mathrm{mg} / \mathrm{L}$. Experiments

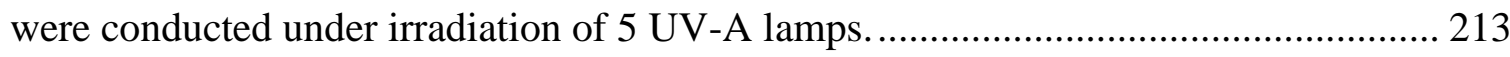

Figure 9.3. (a) $\mathrm{SEM}$ image of $\mathrm{Ag} / \mathrm{TiO}_{2} / \mathrm{Fe}_{2} \mathrm{O}_{3}\left(\mathrm{Ag}\right.$ : $\mathrm{TiO}_{2}=0.01 \mathrm{w}: \mathrm{w}$ and $\left.\mathrm{Fe}: \mathrm{TiO}_{2}=0.05 \mathrm{w}: \mathrm{w}\right)$ from whole sample; (b) Elemental analysis of whole sample of $\mathrm{Ag} / \mathrm{TiO}_{2} / \mathrm{Fe}_{2} \mathrm{O}_{3}\left(\mathrm{Ag}: \mathrm{TiO}_{2}=0.01\right.$

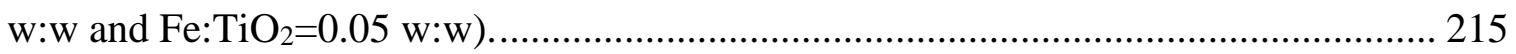

Figure 9.4. Comparison of specific surface area of photocatalysts (all mass ratios are based on

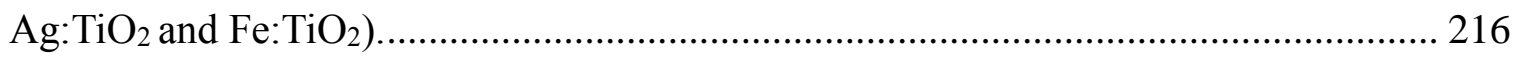

Figure 9.5. (a) Diffractogram of the as-prepared $\mathrm{Ag} / \mathrm{Fe}_{2} \mathrm{O}_{3} / \mathrm{TiO}_{2}$ photocatalyst $\left(\mathrm{Ag}: \mathrm{TiO}_{2}=0.005\right.$ $\mathrm{w}: \mathrm{w}$ and $\mathrm{Fe}: \mathrm{TiO}_{2}=0.01 \mathrm{w}: \mathrm{w}$ ); (b) Comparison of three diffractograms (XRD) of $\mathrm{Ag} / \mathrm{Fe}_{2} \mathrm{O}_{3} / \mathrm{TiO}_{2}$ with different mass ratios of $\mathrm{Ag}$ and $\mathrm{Fe}$; and (c) diffractogram of pure commercial anatase. 219

Figure 9.6. Degradation of methyl orange in presence of composites of $\mathrm{Ag} / \mathrm{Fe}_{2} \mathrm{O}_{3} / \mathrm{TiO}_{2}$ photocatalyst at different mass ratios of $\mathrm{Fe}$ and $\mathrm{Ag}$ under (a) UV-A 45W and (b) natural sunlight irradiation (Concentration of photocatalyst in each case $=500 \mathrm{mg} / \mathrm{L}$ ) 223 


\section{LIST OF FIGURES IN APPENDIX B}

Page

Figure B.1. Flowchart synthesis of nano $\mathrm{Ag} / \mathrm{TiO}_{2}$ photocatalyst with different mass ratio...... 235

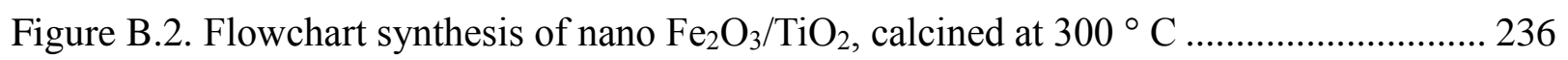

Figure B.3. Synthesized $\mathrm{Fe}_{2} \mathrm{O}_{3} / \mathrm{TiO}_{2}$ with different mass ratio of $\mathrm{Fe}: \mathrm{TiO}_{2}$ at different calcination temperatures.

Figure B.4. Synthesized nitrogen doped $\mathrm{TiO}_{2}$ by different preparation methods and different mass ratios. 238

Figure B.5. Continued (synthesized nitrogen doped $\mathrm{TiO}_{2}$ by different preparation methods and different mass ratios) 239

Figure B.6. Flowchart synthesis of $\mathrm{Ag} / \mathrm{TiO}_{2} / \mathrm{Fe}_{2} \mathrm{O}_{3}$ photocatalyst in different mass ratio of ... 240 Figure B.7. Synthesized photocatalyst of $\mathrm{Ag} / \mathrm{TiO}_{2} / \mathrm{Fe}_{2} \mathrm{O}_{3}$ with different mass ratio of $\mathrm{Ag}: \mathrm{TiO}_{2}$ and $\mathrm{Fe}: \mathrm{TiO}_{2}$ w:w (all mass ratios are based on $\mathrm{Ag}: \mathrm{TiO}_{2}$ and $\mathrm{Fe}: \mathrm{TiO}_{2}$ 


\section{CHAPTER 1}

\section{INTRODUCTION}

\subsection{Advanced oxidation processes (AOPs)}

The most important water and wastewater treatment processes include sedimentation, coagulation-flocculation, filtration, adsorption, distillation, ionic processes, crystallisation, extraction, membrane, biological method (only for wastewater), and advanced oxidation processes (AOPs). Some current water treatment processes such as coagulation-flocculation or adsorption merely shift pollutants to different phases, concentrating, but not destroying them (Matthews, 1991; Crittenden et al., 1997; Padmanabhan et al., 2006). The transfer of pollutants in water, from

one phase to another is not a perfect treatment. The best solution is the complete destruction of these harmful compounds. Thus, research and development are necessary to introduce new ways to degrade these pollutants (Matthews, 1991; Bustillo-Lecompte and Mehrvar, 2015; BustilloLecompte et al., 2016a; Nasirian and Mehrvar, 2016; Nasirian et al., 2017).

Other issues that many water treatment processes, such as sedimentation, filtration, and membrane methods, face is that they are overly expensive (Gaya and Abdullah, 2008). In above methods (sedimentation, filtration, and membrane), although there is not any chemical reaction or production of intermediate, they produce harmful by-products into the environment as pollutants. Biological treatment of wastewater results in a significant amount of organic substances (sewage sludge) that are not biodegradable to remain (Rulkens, 2008). Thus, tertiary treatment is required after these processes to lower the amount of sludge produced. After conventionally treating water, the most common method to disinfect water is the use of chlorination, which results in mutagenic and carcinogenic by-products (Yang and Liu, 2007). 
Advanced oxidation processes (AOPs) are alternative technologies in the treatment of wastewater, including recalcitrant organic materials and are being studied for more than three decades. AOPs are considered as powerful methods, which are capable of transforming almost all organic pollutants into harmless materials such as water and carbon dioxide. AOPs can effectively, degrade refractory, dangerous and poisonous organic materials, and are based on the production of highly potent, reactive, and oxidising hydroxyl radicals (Valenzuela et al., 2002; Choi, 2006; Bustillo-Lecompte et al., 2016a; Nasirian and Mehrvar, 2016). The oxidation-reduction potential of hydroxyl radical is $2.85 \mathrm{~V}$. It means hydroxyl radical has a strong capability of oxidizing and can eradicate unselectively all organic pollutants in wastewater (Ince and Tezcanlí, 2001; Cao et al., 2008; Bustillo-Lecompte et al., 2013, 2014, 2015, 2016a, 2016b; Mowla et al., 2014; Hamad et al., 2014, 2016; Bustillo-Lecompte and Mehrvar, 2015, 2016).

Some materials such as hydrogen peroxide, ozone, semiconductor catalysts $\left(\mathrm{TiO}_{2}, \mathrm{ZnO}\right.$, $\left.\mathrm{Fe}_{2} \mathrm{O}_{3}\right)$ or some ions $\left(\mathrm{Fe}^{3+}\right)$ in existence/non-existence of ultraviolet/visible and even ultrasonic radiation source can generate oxidising radicals. The major parts of AOPs involve $\mathrm{UV} / \mathrm{H}_{2} \mathrm{O}_{2}$, $\mathrm{UV} / \mathrm{TiO}_{2}, \mathrm{UV} / \mathrm{TiO}_{2} / \mathrm{H}_{2} \mathrm{O}_{2}, \mathrm{UV} / \mathrm{O}_{3}, \mathrm{UV} / \mathrm{O}_{3} / \mathrm{H}_{2} \mathrm{O}_{2}$, Fenton $\left(\mathrm{Fe} / \mathrm{H}_{2} \mathrm{O}_{2}\right)$, photo-Fenton $\left(\mathrm{UV} / \mathrm{Fe} / \mathrm{H}_{2} \mathrm{O}_{2}\right)$, $\mathrm{UV} / \mathrm{Fe}_{2} \mathrm{O}_{3}$ and applying other forms of the homogeneous and heterogeneous photocatalytic method. Each of these methods has their own strength and weaknesses. The photocatalytic method is a type of AOPs.

According to literature (Kang et al., 2002; Mrowetz and Selli, 2006), hydrogen peroxide is a powerful oxidant with a standard potential of $1.8 \mathrm{~V}$ at $\mathrm{pH}$ zero and $0.87 \mathrm{~V}$ at $\mathrm{pH} 14$ and is able to remove some organic and inorganic compounds from wastewater. Its oxidation alone is not much efficient to eradicate some refractory pollutants such as chlorinated aromatic compounds and inorganic compounds, for example, cyanides (Philippopoulos and Nikolaki, 2010). 
Oxidation activity of hydrogen peroxide is improved by applying transition metals (e.g. iron salt), UV irradiation, ozone and semiconductors and help to produce hydroxyl radicals, which are much strong oxidant. Reactions 1.1, 1.2, and 1.3 show ozone, iron and UV light in the presence of hydrogen peroxide respectively:

$\mathrm{O}_{3}+\mathrm{H}_{2} \mathrm{O}_{2} \rightarrow \mathrm{HO}+\mathrm{O}_{2}+\mathrm{HO}_{2}$

$\mathrm{Fe}^{2+}+\mathrm{H}_{2} \mathrm{O}_{2} \rightarrow \mathrm{Fe}^{3+}+\mathrm{HO}^{-}+\mathrm{OH}^{-}$

$\mathrm{H}_{2} \mathrm{O}_{2}+\mathrm{UV} \rightarrow 2 \mathrm{HO}$

As noted, the photocatalytic method is a type of AOPs. In general, photocatalysis is a technique where material can absorb light to initiate an oxidation reaction in the environment, meaning that organic compounds close to a photocatalyzed surface (for example with $\mathrm{TiO}_{2}$ ) can be decomposed under UV ray in sunlight or artificial light.

The photocatalytic method is an advanced method compared to conventional processes. In conventional chemical reactions, different oxidising or reducing agents and different reaction medium are required, but in photocatalytic methods, both reactions occur at the same time. Other advantages of utilising, AOPs for example using photocatalyst, is that the method could degrade all by-products. In addition, the process requires ambient temperature and pressure to take place. On the contrary, common chemical reactions produce some hazardous by-products.

Capital and operating costs are the most significant issues about utilising any method in wastewater treatment. Design, construction, operation and maintenance of photocatalytic method are neither too expensive nor complicated system compared to some other various technologies for the treatment of organic materials. Generally, in any chemical process, lower operation time and lower reagent consumption resulted in higher efficiency. The photocatalytic method is 
affordable, because, there is not any consumption of chemical reagent and it only needs a light with proper energy.

\subsection{Justification}

A vast number of studies have been done in the field of AOPs and especially about the photocatalytic degradation of organic materials in wastewater and consequences have been disseminated. Although there are some advantages by employing photocatalytic methods compared to conventional methods or even other AOPs for the purpose of eradication of organic materials, there are still several limitations such as fast recombination of electron-hole (e/h) and in some cases employing only UV activation and also low efficiency, it has not been industrialized and widespread used. According to earlier studies and literature review in photocatalytic processes, lack of information about the following issues is observed and should be considered:

1. Most of the studies about improving efficiencies of photocatalysts are individually conducted in metal doping, or mixing of two photocatalysts and less effort has been carried out in the integration of two improved methods.

2. There is not enough experimental data on the composition of silver doped $\mathrm{TiO}_{2}$ photocatalyst with other semiconductor oxides for the treatment of wastewater.

3. Lack information on the effect of various operating parameters by employing composite photocatalysts (metal or non-metal doped combined with semiconductor oxides) is observed.

4. Less effort has been made to investigate the effect of different parameters such as light intensity, light wavelength, initial concentration of pollutants, and $\mathrm{pH}$ of solution on the efficiency of treatment in a batch mode photocatalytic reactor. 
5. There is not enough information about the effect of cross-factor interactions to obtain optimal responses of experiments on the degradation of azo dyes and not enough information of statistical model on the metal or non-metal doped $\mathrm{TiO}_{2}$ to predict $\mathrm{TOC}$ removal for the photocatalytic treatment of the azo dyes.

6. Degradation effectiveness in some cases is not very high (less than 60\%), or their operation time is long (more than 150 minutes); hence, further studies are required.

7. Metal/non-metal doped $\mathrm{TiO}_{2}$ are mostly prepared in sol-gel or hydrothermal methods. Less effort was made to consider other methods and comparison of differently doping methods.

\subsection{Scope of the study}

This study focuses on developing a novel method of photocatalytic water and wastewater treatment. Selection of objectives and scope of the study will be centred on these requirements. According to the literature review, it is important to note that:

- Among different kinds of semiconductor photocatalysts, $\mathrm{TiO}_{2}$ is the most evident due to its stability, powerful oxidative abilities, no toxicity, and solar activation. The restriction of titanium dioxide is that it can only be activated in the presence of UV irradiation, because of intrinsic nature especially its large band gap energy $(3.2 \mathrm{eV})$. In addition, it absorbs merely $5 \%$ of the energy from the solar spectrum. On top of this, the fast rate at which the electron-hole pairs are recombined limits $\mathrm{TiO}_{2}$ 's chances of having established applications for common use. Thus, these are some restrictions, which require solving and are receiving immediate attention and remediation. Therefore, developing a solar or visible light activation photocatalyst with high efficiency is extremely required. 
- The surface amendment of $\mathrm{TiO}_{2}$ photocatalyst by doping with transition/noble metals ions such as Ag has been investigated (Choi, 2006; Cao et al., 2008; Tryba et al., 2010). It was proven that doping $\mathrm{Ag}$ with $\mathrm{TiO}_{2}$ can effectively remove a broad range of organic substance. A higher efficiency is achieved when electron scavenging occurs due to the doping of $\mathrm{Ag}$ to $\mathrm{TiO}_{2}$ and hinders recombination of electron/hole pairs. The existence of silver deposited on the $\mathrm{TiO}_{2}$ cause to impede quick recombination by acting as an electron sink and making an easy surface electron transfer to oxygen. Electron reacts with oxygen and produce superoxide, then in a series of reaction produce hydroxyl radicals which attack to organics.

- Out of all semiconductor oxides, $\mathrm{Fe}_{2} \mathrm{O}_{3}$, with a low band gap energy (2.2 eV) has the capability to absorb a broad range of visible light and the benefits of low price, high chemical and physical stability, and exists in large quantity in earth (Peng et al., 2010). Despite its advantages, $\mathrm{Fe}_{2} \mathrm{O}_{3}$ possess a weak electrical conductivity; it is not easy to separate the electron/hole pairs, and it causes a recombination. Thus, these disadvantages have restricted its great applications.

- To our knowledge, research on preparation, characterization and usage of new combined $\mathrm{Ag} / \mathrm{TiO}_{2} / \mathrm{Fe}_{2} \mathrm{O}_{3}$ photocatalyst in wastewater treatment have not been investigated. In this study, decomposition of chemical reagents, such as Congo red (CR), and methyl orange (MO), as two detrimental azo-dyes, by employing a photocatalytic reactor will be investigated. These results will be compared with degradation efficiency of contaminants employing bare, binary and metal doped, metal-doped composite and non-metal doped photocatalysts. 


\subsection{Objectives}

The objectives of this study are:

The objectives of this study are:

1. To develop a new photocatalyst by combining of two semiconductor oxides and then doping of a transition metal to the combined photocatalyst simultaneously to produce a novel composite photocatalyst.

2. To improve the efficiency of photocatalysts for the treatment of organic materials in the visible range.

3. To optimize operating parameters including structure of the photocatalyst, $\mathrm{pH}$, concentration of pollutant, light intensity and light wavelength, which affect the performance of photocatalytic degradation of organic materials.

4. To develop a novel method of UV-assisted thermal synthesis for the preparation of metal and non-metal doped $\mathrm{TiO}_{2}$ photocatalysts and novel composite of $\mathrm{Ag} / \mathrm{TiO}_{2} / \mathrm{Fe}_{2} \mathrm{O}_{3}$ photocatalyst.

\subsection{Dissertation outline}

This study focuses on introducing a new synthesis method of metal/non-metal doped $\mathrm{TiO}_{2}$ and synthesising a novel photocatalyst for the treatment of water and wastewater. Some synthetic wastewater containing methyl orange and Congo red dye were prepared, and then proper photocatalytic reactions were done to reduce the rate of organic pollution in the samples.

The thesis was written based on a manuscript format such that the chapters can be read independently. A general literature review is presented in Chapter 2. The materials and methods used in the present dissertation are presented in Chapter 3. The reader might find a few repetitions 
in the subsequent chapters due to the format of this dissertation. Nevertheless, all chapters were integrated into a logical progression from chapter to chapter to create a unified and consistent dissertation. Chapters 4 to 9 have been submitted to refereed journals.

The following publications resulted from this $\mathrm{PhD}$ work and are listed in the order of presentation in this dissertation:

1. Nasirian, M., Mehrvar, M., 2016. Modification of $\mathrm{TiO}_{2}$ to Enhance Photocatalytic Degradation of Organics in Aqueous Solutions, Journal of Environmental Chemical Engineering 4 (4A), 4072-4082 (Chapter 4).

2. Nasirian, M., Bustillo-Lecompte, C.F., Mehrvar, M., 2017. Photocatalytic efficiency of $\mathrm{Fe}_{2} \mathrm{O}_{3} / \mathrm{TiO}_{2}$ for the degradation of typical dyes in textile industries: Effects of calcination temperature and UV-assisted thermal synthesis, Journal of Environmental Management, 196, 487-498 (Chapter 5).

Chapters 6 to 9 have been submitted to refereed journals as following:

3. Photocatalytic activity enhancement of titanium dioxide using non-metal doping methods under visible light: a review. It has been submitted to Journal of Water Process Engineering (Chapter 6).

4. Nasirian, M., Mehrvar, M., 2017. Photocatalytic degradation of aqueous methyl orange using nitrogen-doped $\mathrm{TiO}_{2}$ photocatalyst prepared by novel method of $\mathrm{UV}$-assisted thermal synthesis. Journal of Environmental Sciences (in press), (Chapter 7).

5. Optimization of the photocatalytic activity of n-doped $\mathrm{TiO}_{2}$ for the photocatalytic degradation of an azo dye. It has been submitted to Journal of Materials Research Innovation (in revision), (Chapter 8). 
6. Development of a novel photocatalyst for wastewater treatment applying UV-assisted thermal synthesis as an alternative preparation method. It has been submitted to Journal of Environmental Management (Chapter 9).

Finally, Chapter 10 outlines the main findings and conclusions of this study as the original contribution of the dissertation to the advancement of knowledge in the research area of industrial wastewater treatment, as well as the recommendations for future work. Finally, some supplementary materials are provided in Appendix to complement chapters presented in this dissertation.

\subsection{Contributions of co-authors}

The principal author, Mohsen Nasirian, wrote all Chapters presented in this dissertation. The principal author was also in charge of and responsible for the design and identification of the research undertaken, performed analysis on all samples, interpreted and analysed data, and prepared manuscripts for submission to refereed journals.

Chapters 4 to 9 have been submitted to refereed journals and were co-authored by Dr. Mehrab Mehrvar, the sole dissertation supervisor, who guided the development and the progress of the project, helped in data interpretation and manuscript revisions and evaluation by providing editorial and technical advice and acted as the corresponding author. Dr. Ciro Fernando BustilloLecompte, Research Associate in the Department of Chemical Engineering at Ryerson University, assisted in data analysis to portions of the work performed in Chapters 5, 6, and 8, and is listed as

a co-author accordingly. Finally, Ms. Yi Ping Lin, undergraduate student in the Department of Chemical Engineering at Ryerson University, provided assistance in samples analysis to portions of the work performed in Chapters 6 and 8 and is listed as a co-author accordingly. 


\section{CHAPTER 2}

\section{LITERATURE REVIEW}

\subsection{Definition and function of a photocatalyst}

A catalyst is defined as a substance, which can modify the rate of a chemical reaction without any effect (consumption) in the catalyst. A catalyst is also able to enhance the rate of chemical reactions, which reduces the activation energy (Liao et al., 2004; Hashimoto et al., 2005; Galian and Perez-Prieto, 2010). Photocatalysis is a chemical reaction which using light causes the activation of a substance, which adjusts the speed of the reaction without any alteration or consumption. Thus, a substance, which adjusts the rate of a chemical reaction, by employing light, is called a photocatalyst.

An example of natural photocatalysis is chlorophyll in plants (Galian and Perez-Prieto, 2010). $\mathrm{TiO}_{2}$ is well known considered as a photocatalyst; it is manufactured by processing the naturally occurring mineral in ilmenite (Blake, 1999; Umar and Aziz, 2013). The difference between a natural photocatalyst "chlorophyll" with a manufactured photocatalyst " $\mathrm{TiO}_{2}$ " is that chlorophyll catch sunlight to change carbon dioxide and water to glucose and oxygen. However, in the presence of sunlight or UV light, $\mathrm{TiO}_{2}$ photocatalyst breaks down organic materials into carbon dioxide and water.

Fujishima and Honda (1972) split water into oxygen and hydrogen using $\mathrm{TiO}_{2}$ in 1972. This innovation caused to initiate of the field of heterogeneous photocatalysis. According to Hashimoto et al., (2005), a series of reports called, "Auto-oxidation by $\mathrm{TiO}_{2}$ as a photocatalyst" may have been one of the first cases outlining the use of $\mathrm{TiO}_{2}$ for its photochemical power.

As early as 1976, photocatalytic detoxification was considered a capable tool for the treatment of wastewater (Carey et al., 1976). The process of photocatalysis, by producing radicals 
such as $\mathrm{HO}$ and $\mathrm{O}_{2}^{-\bullet}$, can significantly lower the amounts of organic waste in the environment. This makes it useful for breaking down organic compounds (Agustina et al., 2005; Chong et al., 2010).

Heterogeneous photocatalysis employing semiconductor catalysts such as $\mathrm{MgO}, \mathrm{ZnO}, \mathrm{CdS}$, $\mathrm{GaP}, \mathrm{ZnS}, \mathrm{TiO}_{2}$, and $\mathrm{Fe}_{2} \mathrm{O}_{3}$, establishes its effectiveness between AOPs in the degradation of various refractory organics to form biodegradable compounds (Zhang et al. 2010).

Among all photocatalysts, $\mathrm{TiO}_{2}$ powders have been utilized more than other photocatalysts. Because of its stability beyond the catalytic cycle, mechanical strength, reasonable price, and resistance to breaking down chemically, all of which have facilitated its increasing span in being applied in water treatment. In contrast, $\mathrm{CdS}$ or $\mathrm{GaP}$, under the same conditions, degrade and produce toxic products. $\mathrm{TiO}_{2}$ can be found in many household materials, such as toothpaste, cosmetics, paper, ointment and more (Malato et al., 2009).

The use of homogeneous or heterogeneous photocatalysis increases the impact of photochemical AOPs. Homogeneous photocatalysis, for example, using $\mathrm{UV} / \mathrm{H}_{2} \mathrm{O}_{2}$ or $\mathrm{UV} / \mathrm{Fe}^{2+}$, is applied in a single phase. On the other hand, heterogeneous photocatalysis, using, for example, $\mathrm{UV} / \mathrm{TiO}_{2}$ or $\mathrm{UV} / \mathrm{ZnO}$ makes use of a slurry form, but it is not in a single phase (Agustina et al. 2005).

$\mathrm{TiO}_{2}$ is the naturally occurring oxide of titanium, which is prepared using ilmenite or raw rutile. Though it has various crystalline forms (allotrope), titanium dioxide is mostly found as anatase and rutile, where anatase has the greatest stability by $8-12 \mathrm{KJ} \mathrm{mol}^{-1}$. The third, brookite, is not common or stable. Anatase-to-rutile conversions are possible when the temperature reaches around $700^{\circ} \mathrm{C}$. Because of its open structure, anatase is more efficient than rutile for the purpose of photocatalysis (Umar and Aziz, 2013). 
$\mathrm{TiO}_{2}$ has many practical uses for the benefit of the environment (Tryba et al., 2010). When exposed to UV rays, $\mathrm{TiO}_{2}$ represents self-decontamination capabilities by being able to eradicate many different organic substances. These substances include persistent organic pollutants (POPs), endocrine disruptive chemicals (EDCs), phenols, pesticides, herbicides, alcohols (Choi, 2006; Tryba et al., 2010), carboxylic acids, humic acid, phenol and its derivatives, chlorinated aromatics, pesticides and herbicides (Agustina et al., 2005), and treatment of oil-contaminated water (Grzechulska et al., 2000). Other than, eradication of organic and inorganic compounds, $\mathrm{TiO}_{2}$ has the capability of destroying microorganisms, pathogens, and algae (Fujishima et al., 2000; Rincón and Pulgarin, 2005).

Another result of $\mathrm{TiO}_{2}$ 's exposure to UV irradiation is the change of the coated surface from hydrophobic to hydrophilic. This effectively creates a layer of water that facilitates cleanliness by stopping unwanted substances from sticking to the surface (Gao et al., 2004; Choi, 2006). Some researchers noted that, when $\mathrm{TiO}_{2}$ is in powdered form and exposed to light, can provide self-sterilisation and self-cleaning properties to the surfaces of different materials such as glass, ceramics, metals, among others. (Hashimoto et al., 2005). Its great benefit is the fact that it does not require the use of much water and detergents for exterior cleaning, and it does not utilise harmful chemicals that are found in other similar products.

\subsection{Mechanism of photocatalysis}

Electronic configuration of $\mathrm{TiO}_{2}$, as a semiconductor, consists of a filled valence band (VB), an energetic gap, and an empty conduction band (CB). Figure 2.1 shows the mechanism of photocatalysis schematically. When $\mathrm{TiO}_{2}$ absorbs UV radiation, in which the photon's energy ( $\mathrm{h} v$ ) is greater or equal to the band gap energy, then an electron/hole (e/h) pair is produced. Under light 
irradiation with proper energy, electron is promoted to the conduction band, thus the negative electron (e-) and positive hole (h+) pair are formed (Gao et al., 2004; Choi, 2006; Cao et al., 2008; Agustina et al., 2005, 2008; Nasirian and Mehrvar, 2016).

During the procedure for oxidative degradation, $\mathrm{HO}$ radicals are formed, which proceed to break down organic molecules. In the mechanism of electron and hole, the electron is considered as a reducing agent and hole as oxidising agent respectively. The oxygen acquires one electron, and $\mathrm{OH}^{-}$releases one electron, as electron attractor and electron donator respectively, which then degrade organics.

Titanium dioxide's positive hole reacts to split water into hydrogen ion and hydroxyl radical, while the negative electron reacts to form the superoxide anion from an oxygen molecule. When light is available, this cycle is continued.

Heterogeneous photocatalytic reactions include complex series of reactions. As of now, there is no complete understanding of the oxidation pathway of heterogeneous photocatalysis. Agustina et al. $(2005,2008)$ described some mechanisms of reactions in photocatalysis.

$$
\begin{array}{ll}
\mathrm{h} v \text { (light) }+\mathrm{TiO}_{2} \rightarrow \mathrm{h}_{\mathrm{vb}}{ }^{+}+\mathrm{e}_{\mathrm{cb}}{ }^{-} & \text {Light absorption } \\
\mathrm{TiO}_{2}\left(\mathrm{~h}_{\mathrm{vb}}{ }^{+}\right)+\mathrm{H}_{2} \mathrm{O}_{\mathrm{ads}} \rightarrow \mathrm{TiO}_{2}+\mathrm{H}^{+}+\mathrm{HO} & \\
\mathrm{TiO}_{2}\left(\mathrm{~h}_{\mathrm{vb}}{ }^{+}\right)+\mathrm{OH}^{-}{ }_{\mathrm{ads}} \rightarrow \mathrm{TiO}_{2}+\mathrm{HO}_{\mathrm{ads}}^{-} &
\end{array}
$$

In photocatalytic reaction, oxygen generally plays a very important role. In the reaction, it catches electron from conduction band and produce superoxide ion $\left(\mathrm{O}_{2}{ }^{-}\right)$. In other words, this reaction restricts recombination of photo-induced electron and hole, which results in increasing of photocatalytic activity. Then superoxide ions make a reaction with hydrogen ions (from splitting water) and produce $\mathrm{HO}_{2}$.

$\mathrm{e}^{-}+\mathrm{h}^{+} \rightarrow$ Heat Recombination (unwanted reaction) 
$\mathrm{TiO}_{2}\left(\mathrm{e}_{\mathrm{cb}}{ }^{-}\right)+\mathrm{O}_{2 \mathrm{ads}} \rightarrow \mathrm{TiO}_{2}+\mathrm{O}_{2}{ }^{-}$

$\mathrm{O}_{2}{ }^{-}+\mathrm{H}^{+} \rightarrow \mathrm{HO}_{2}{ }^{\cdot}$

$\mathrm{HO}_{2}{ }^{\circ}$ and $\mathrm{H}^{+}$can react and produce $\mathrm{H}_{2} \mathrm{O}_{2}$ (Reaction 2.7):

$\mathrm{TiO}_{2}\left(\mathrm{e}_{\mathrm{cb}}{ }^{-}\right)+\mathrm{HO}_{2}{ }^{\cdot}+\mathrm{H}^{+} \rightarrow \mathrm{H}_{2} \mathrm{O}_{2}$

Splitting of $\mathrm{H}_{2} \mathrm{O}_{2}$ also results $\mathrm{HO}$ (Reactions (2.8), (2.9), and (2.10):

$\mathrm{H}_{2} \mathrm{O}_{2}+h v \rightarrow 2 \mathrm{HO}$

$\mathrm{H}_{2} \mathrm{O}_{2}+\mathrm{O}_{2}{ }^{-} \rightarrow \mathrm{HO}+\mathrm{O}_{2}+\mathrm{OH}^{-}$

$\mathrm{H}_{2} \mathrm{O}_{2}+\mathrm{TiO}_{2}\left(\mathrm{e}_{\mathrm{cb}}{ }^{-}\right) \rightarrow \mathrm{HO} \cdot+\mathrm{OH}^{-}+\mathrm{TiO}_{2}$

$\mathrm{R}-\mathrm{H}+\mathrm{HO} \rightarrow \mathrm{R} \cdot+\mathrm{H}_{2} \mathrm{O} \rightarrow$ Degradation of pollutants

Organic Contaminants $+\left(\mathrm{TiO}_{2}-\mathrm{h} v\right) \rightarrow$ Intermediates $\rightarrow \mathrm{CO}_{2}+\mathrm{H}_{2} \mathrm{O}$

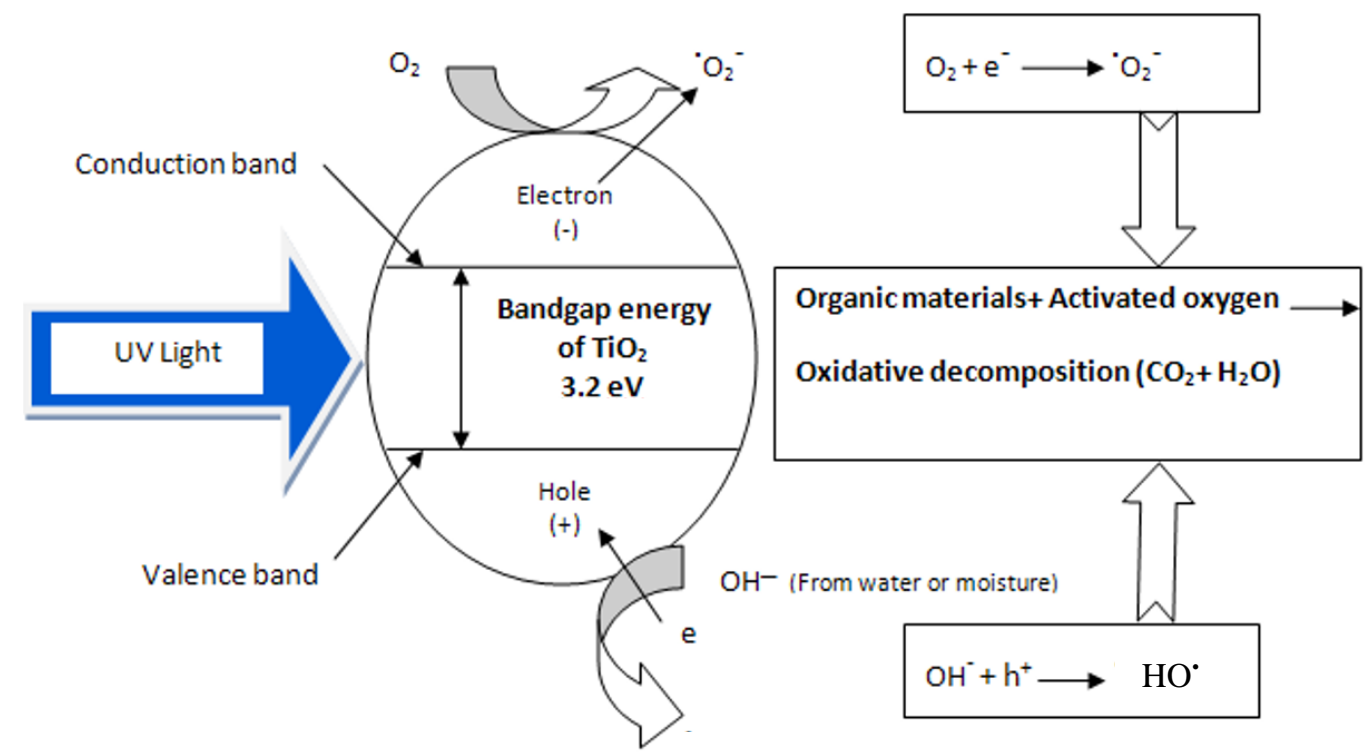

$\mathrm{HO}^{\circ}$

Figure 2.1. Schematic diagram of the $\mathrm{TiO}_{2}$ photocatalysis mechanisms.

(Adapted from Tung and Daoud, 2011) 


\subsection{Radiation sources for photocatalysis}

A strong photocatalytic reaction needs an adequate radiation source, a catalyst, and a reactor. There are various radiation sources in photocatalytic processes. The primary radiation sources are artificial UV lamps and sunlight (Umar and Aziz, 2013).

Mercury artificial UV lamps are the most regular sources of UV illumination. Mercury UV lamps are classified into high, medium and low pressure. Sunlight can be utilized as a UV source, but less than $5 \%$ of the sunlight rays that struck the earth's surface, are in the wavelength range of $300-400 \mathrm{~nm}$.

Light wavelength and light intensity are two key parameters that must consider about photocatalytic methods. According to Rincón and Pulgarin (2005), radiation of UV spectrum is classified as UV-A, UV-B, and UV-C. UV-A has a light wavelength from 315 to $400 \mathrm{~nm}$ (3.10$3.94 \mathrm{eV})$, UV-B is $280-315 \mathrm{~nm}(3.94-4.43 \mathrm{eV})$, and UV-C ranges from 100 to $280 \mathrm{~nm}(4.43-12.4$ $\mathrm{eV})$. The majority of projects use UV-A for the catalyst's photonic activation and generation of hole and electron. In Table 2.1, the band gap energies and corresponding radiation wavelengths for the excitation of conventional semiconductors, are placed accordingly with the solar energy wavelength.

Table 2.1. Matching solar energy wavelength with a band gap of the semiconductor.

\begin{tabular}{lccc}
\hline Semiconductor & Band gap energy $(\mathbf{e V})$ & wavelength $(\mathbf{n m})$ & Solar energy wavelength \\
\hline $\mathrm{TiO}_{2}$ (rutile) & 3.0 & 413 & Vis (near UV-A) \\
$\mathrm{TiO}_{2}$ (anatase) & 3.2 & 389 & UV-A \\
$\mathrm{ZnO}$ & 3.2 & 387 & UV-A \\
$\mathrm{ZnS}$ & 3.7 & 336 & UV-A \\
$\mathrm{BaTiO}_{3}$ & 3.3 & 375 & UV-A \\
$\mathrm{SnO}_{2}$ & 3.9 & 318 & UV-A \\
$\mathrm{SrTiO}_{3}$ & 3.4 & 365 & UV-A \\
$\mathrm{CdS}$ & 2.4 & 516 & Vis \\
$\mathrm{Fe}_{2} \mathrm{O}_{3}$ & 2.2 & 540 & Vis \\
$\mathrm{Al}_{2} \mathrm{O}_{3}$ & 4.9 & 280 & UV-B \\
$\mathrm{CeO}_{2}$ & 2.7 & 490 & Vis \\
\hline
\end{tabular}




\subsection{Photocatalytic method and reactors}

There are two varieties of photocatalytic reactors: suspension (immersion) form and immobilized (thin film catalyst) form (Umar and Aziz, 2013). Each one has definite advantages and disadvantages which are associated with their design and efficacy.

Because of their greater amount of surface area able to touch the reactants, and also let more photons come into contact with the catalyst, the suspension form is more efficient and used (Chong et al., 2010). In this case, separation of the photocatalyst particles is needed after the process (Nasirian and Mehrvar, 2016; Yang and Liu, 2007). These separation methods normally are costly, (Chong et al., 2010).

The immobilized reactors are less complicated than suspension photoreactors. In an immobilized reactor, the catalyst is fixed through physical forces (surface adsorption) or chemical bonds. In this reactor, separation or recovery of the catalyst is not needed (Chong et al., 2010).

In some of the numerous cases that photocatalytic methods are used for wastewater treatment, the complete degradation is slow, and the process is only efficient, in terms of the consumption of energy, for substances that are not very concentrated (Agustina et al., 2005).

Some compounds, with varying chemical roles, are used to combat this issue, including $\mathrm{O}_{3}$, $\mathrm{H}_{2} \mathrm{O}_{2}, \mathrm{Fe}^{2+}, \mathrm{Fe}^{3+}, \mathrm{S}_{2} \mathrm{O}_{8}{ }^{2-}$, or applying some metal or non-metal ions such as $\mathrm{Ag}^{+}$and $\mathrm{Cr}^{3+,} \mathrm{N}^{3-}, \mathrm{S}^{2-}$ (Sánchez et al. 1998).

Despite many advantages of $\mathrm{TiO}_{2}$ as a photocatalyst, because it does not have quite enough photoactivity, especially in the visible region, it is not yet proper for many commercial uses, and there is a limit to its applications (Liao et al., 2004).

The use of conventional $\mathrm{TiO}_{2}$, with no additions, causes a restriction, which leads to only photons with wavelengths shorter than about $390 \mathrm{~nm}$ to react. For this reason, researchers have 
been studying methods to surpass these limitations by modifying its surface and composition (Asahi et al., 2001; Bandara and Ranasinghe, 2007).

So far, an effective method for increasing of photocatalytic activity is improving the surface by doping metal ions such as Au, Ag, Pt, Co, Ni, Fe, Zn (Shah et al., 2002; Zhang et al., 2003; Bandara and Ranasinghe, 2007; Barakat et al., 2005; Colón et al., 2006; Cao et al., 2008; Silva et al., 2009; Gao et al., 2010; Nasirian and Mehrvar, 2016).

Co-deposition of noble metals $(\mathrm{Au}, \mathrm{Ag}$, and $\mathrm{Pt}$ ) that are resistant to oxidation or corrosion on $\mathrm{TiO}_{2}$, combining of two or more photocatalyst, and combining with metal oxides $\left(\mathrm{ZnO}, \mathrm{SnO}_{2}\right.$, $\mathrm{Fe}_{2} \mathrm{O}_{3}$, and $\mathrm{CuO}$ ) are other methods of attempting to increase $\mathrm{TiO}_{2}$ 's activity (Liao et al., 2004; Bandara and Ranasinghe, 2007).

According to Sökmen and Özkan (2002), silver loading $\mathrm{TiO}_{2}$ is more efficient for the decontamination and treating of organic wastewater compared to bare $\mathrm{TiO}_{2}$. Firstly, silver loaded $\mathrm{TiO}_{2}$ helps energized electrons reach silver and oxygen, rather than positive holes, resulting in restraining the recombination. Secondly, a shift of the band gap of the photocatalyst to the visible region (red shift) may be the reason why transitional metal especially noble metals doping $\mathrm{TiO}_{2}$ has an effect on photoactivity. Thirdly, the doped particles are more porous and have a greater specific area than the bare one. Figure 2.2 shows trapping of electrons in conduction band by doped metal. Doping can improve photocatalytic activity of $\mathrm{TiO}_{2}$ and overcome a fast recombination of electron and hole; thus, better absorption of UV/Vis light (Yu et al., 2002; Barakat et al., 2005).

According to Liu et al. (2013) when the oxidation state of the metal ion is enhanced, then the activity of metal ions loaded on $\mathrm{TiO}_{2}$ is enhanced. For example, $\mathrm{Au}^{3+}$ is more active compared to $\mathrm{Cu}^{2+}$ and $\mathrm{Ag}^{+}$. With an increase in oxidation state, electron affinity of the metal ion is increased, 
and then the photoactivity of $\mathrm{TiO}_{2}$ improved. Doping is not only used for improving electron structure, but it can also be used to change the surface of a photocatalyst.

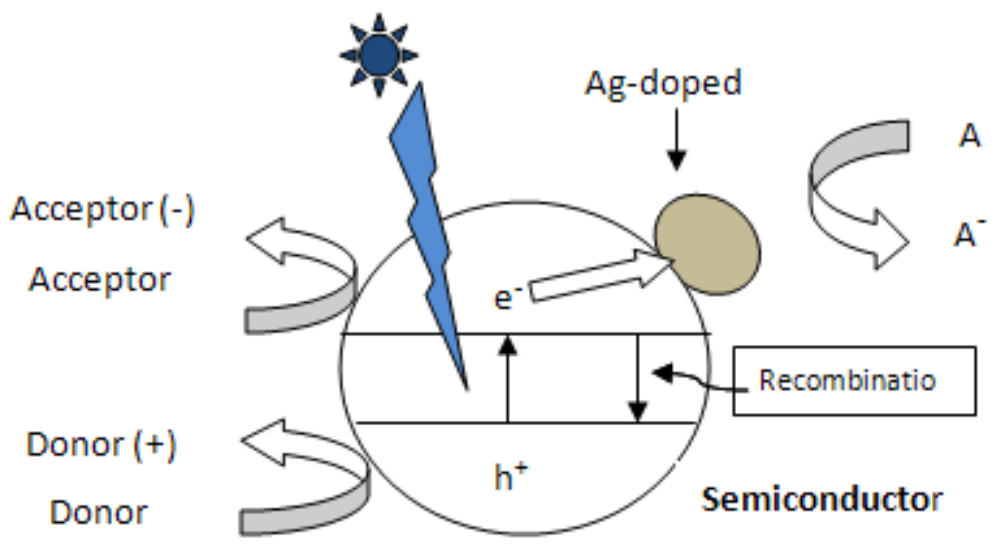

Figure 2.2. Trapping of photo-induced electrons by doped transition metals. (Adapted from Hernández-Alonso et al., 2009).

A number of prominent studies about improving efficiency of photocatalysts by doping are: Pt-doped $\mathrm{TiO}_{2}$ for degradation of acetic acid by Zhang et al. (2003); Pt-doped $\mathrm{TiO}_{2}$ for degradation of TCE and bisphenol A by Zhang et al. (2003); Pt-doped $\mathrm{TiO}_{2}$ for the degradation of Lignin by $\mathrm{Ma}$ et al. (2008); Ag-doped $\mathrm{TiO}_{2}$ for degradation of acetamiprid by Cao et al. (2008); Fe-doped $\mathrm{TiO}_{2}$ in degrading 2,4-DCP by Liu et al. (2013); Fe-doped $\mathrm{TiO}_{2}$ in degrading organics by Chen et al. (2005); $\mathrm{Zr}$-doped $\mathrm{TiO}_{2}$ in eradication of BPA by Gao et al. (2010); Cu-doped $\mathrm{TiO}_{2}$ for degradation of phenol by Colón et al. (2006); Ce-doped $\mathrm{TiO}_{2}$ in degrading 4-CP by Silva et al. (2009); Co-doped $\mathrm{TiO}_{2}$ for eradication of 2-CP by Barakat et al. (2005); Co-doped $\mathrm{TiO}_{2}$ for elimination of 2-CP by by Iwasaki et al. (2000); Pt-doped $\mathrm{TiO}_{2}$ for degradation of 4-CP by Barakat et al. (2005); Ag-doped $\mathrm{TiO}_{2}$ in eradication of 4-CP by Barakat et al. (2005); $\mathrm{Zr}^{4+}$ doped $\mathrm{TiO}_{2}$ for oxidation 4-CP by Venkatachalam et al. (2007); Cu-doped $\mathrm{ZnO}$ for oxidation $\mathrm{Rz}$ by Mohan et al. (2012); Cd-doped $\mathrm{ZnO}$ in oxidation of MB by Zhang and Zeng (2012); Pt-doped $\mathrm{TiO}_{2}$ for breaking 
down Ammonia by Choi, (2006); Ag-doped $\mathrm{TiO}_{2}$ in degradation of $\mathrm{MO}$ and $\mathrm{CR}$ by Nasirian and Mehrvar (2016).

Different metals doped have different efficiency. In the photocatalytic method, the efficacy of a reaction belongs to the specific surface area of particles, in other words, photocatalysis is a surface phenomenon. In brief, metals can modify the surface of the photocatalyst and thus their activity on the degradation of materials.

Combining semiconductors is an important practice to increase the efficiency of photocatalysts (Zhang et al., 2007). It helps to surpass two issues that photocatalysis faces in realworld applications: the swift recombination of electron/hole pairs and the inability to use visible light due to the band edge absorption threshold.

A number of studies about combining semiconductors to progress effectiveness of photocatalysts are: coating of $\mathrm{MgO}$ on $\mathrm{TiO}_{2}$ for oxidation of 2,4-DCP and Aminobenzoic acid by Bander et al. (2004); combining of $\mathrm{TiO}_{2}$ and $\mathrm{ZnO}$ for $\mathrm{MO}$ degradation by Zhang et al. (2010); mixing of $\mathrm{Bi}_{2} \mathrm{O}_{3}$ and $\mathrm{MgO}$ for degrading $\mathrm{RhB}$ by Li et al. (2011); $\mathrm{MgO}$ coated $\mathrm{SnO}_{2}$ for breaking down 2-CP by Bandara and Ranasinghe (2007); combining of $\mathrm{ZnO}$ and $\mathrm{Fe}_{2} \mathrm{O}_{3}$, for the removal of phenol by Valenzuela et al. (2002); combination of $\mathrm{Fe}_{2} \mathrm{O}_{3}$ and $\mathrm{SnO}_{2}$ for breaking down acid blue 62 by Xia et al. (2008); combining of $\mathrm{Fe}_{2} \mathrm{O}_{3} / \mathrm{SrTiO}_{3}$ for the degradation of Methanol by Zhang et al. (2007); combining $\mathrm{Fe}_{2} \mathrm{O}_{3} / \mathrm{SrTiO}_{3}$ for removing Orange II by Peng et al. (2010), $\mathrm{Fe}_{2} \mathrm{O}_{3}, \mathrm{WO}_{3}$ and CdS deposited on $\mathrm{ZnO}$ for degradation of DCA, by Sakthivel et al. (2002); combining $\mathrm{TiO}_{2}$ and $\mathrm{Fe}_{2} \mathrm{O}_{3}$ for degradation of RB, MO, TB and BG by Zhang et al. (2007) and Ghorai et al. (2011).

Binary metal oxides such as $\mathrm{TiO}_{2} / \mathrm{WO}_{3}, \quad \mathrm{TiO}_{2} / \mathrm{MoO}_{3}, \quad \mathrm{TiO}_{2} / \mathrm{SiO}_{2}, \quad \mathrm{TiO}_{2} / \mathrm{ZrO}_{2}$ and $\mathrm{Fe}_{2} \mathrm{O}_{3} / \mathrm{TiO}_{2}$ (Shaogui et al., 2004; Zhang et al., 2007; Ghorai et al., 2011; Nasirian and Mehrvar, 2016), or ternary heterogeneous mixed oxides such as $\mathrm{Y}_{2} \mathrm{O}_{3} / \mathrm{Fe}_{2} \mathrm{O}_{3} / \mathrm{TiO}_{2}$ (Ismail, 2005) are 
prominent in scientific literature, because of their extraordinary chemical, physical, and photocatalytic characteristics and considered more efficient to degrade organic materials than bare $\mathrm{TiO}_{2}$.

\subsection{Barriers and challenges}

\subsubsection{Limitations of existing photocatalysts}

The photocatalytic oxidation method is considered as a capable and versatile alternative for treatment of wastewater compare to the conventional methods. As noted before, among all photocatalysts, titanium dioxide has some unique characteristics. These features make $\mathrm{TiO}_{2}$ a popular photocatalyst (Choi, 2006).

Despite the benefits of titanium dioxide, there is a significant problem in its fast rate of electron/hole pair recombination (Venkatachalam et al., 2007; Zhang et al., 2010). More than 90\% of the electron-hole generated are lost within nanoseconds of their generation, leading to the photocatalyst having insufficient photoactivity. Another great concern is the fact that $\mathrm{TiO}_{2}$ can only be activated in the presence of ultraviolet irradiation $(\lambda \approx 330-390)$.

$\mathrm{TiO}_{2}$ requires UV light irradiation to excite and generates electron/ hole (Xia et al., 2014; Li et al., 2011). It is necessary to keep the electron-hole pairs apart as efficiently as possible to raise the efficiency of photons. Also, developing of a new photocatalyst to facilitate and expand the absorption wavelength range into the visible light region is extremely required.

\subsubsection{The proposed solutions}

To date, too many attempts have been made to enhance the activity of semiconductor photocatalysts by improving the surface or bulk properties. These methods including, doping 
transition/noble metals or non-metals, coating with an insulating oxide layer; and combination with other semiconductors and metal oxides such as $\mathrm{MgO}, \mathrm{TiO}_{2}, \mathrm{ZnO}, \mathrm{SnO}_{2}, \mathrm{Fe}_{2} \mathrm{O}_{3}, \mathrm{SrTiO}_{3}$. The efficacy of photoactivity of $\mathrm{TiO}_{2}$ has been improved through other alternative methods, by employing photosensitizers (Ola and Maroto-Valer, 2015) or by adding oxidants such as $\mathrm{H}_{2} \mathrm{O}_{2}$ (Cuerda-Correa et al., 2016), adding Ferro ions (Pignatello, 1992), using peroxidisulfate, and periodate ions (Oyama, 2000), or injection of $\mathrm{O}_{3}$ (Kopf et al., 2000).

Between all alternatives, the improving of semiconductors by doping transition metals has been considered a successful method to increase separation of hole/electron pairs and to extend its photo-response into visible light. In other words, by improving the surface of semiconductors and surface properties, a red shift (higher wavelength absorption and lower energy) occurs, and the photocatalytic activity is increased. 


\section{CHAPTER 3}

\section{MATERIALS AND METHODS}

\subsection{Photocatalytic Reactor}

In order to find the efficiency of photocatalysts and optimum condition and to investigate the effect of the parameters, it is necessary to design and make a simple laboratory-scale reactor. A well-mixed batch photocatalyst reactor including 1-5 UV/Vis light source was made to achieve this goal. The multi-lamp reactor is employed to find the effects of intensity of light on the efficacy of degradation of organic materials. Figure 3.1 shows a simple batch, photocatalytic reactor, including the main glass reactor along with 1-5 compartments for multi-lamps and a cooling tank. The one ended lamps directly immersed in the solution. In the optimum condition, length of lamps and photoreactor height should be the same size. The reactor is covered with aluminium foil to enhance the effectiveness of the light irradiation. A magnetic stirrer is applied for proper mixing. A refrigerated water bath/circulator (RTE-211) was used to control the temperature of the reactor. The characteristics of the reactor are described in Table 3.1.

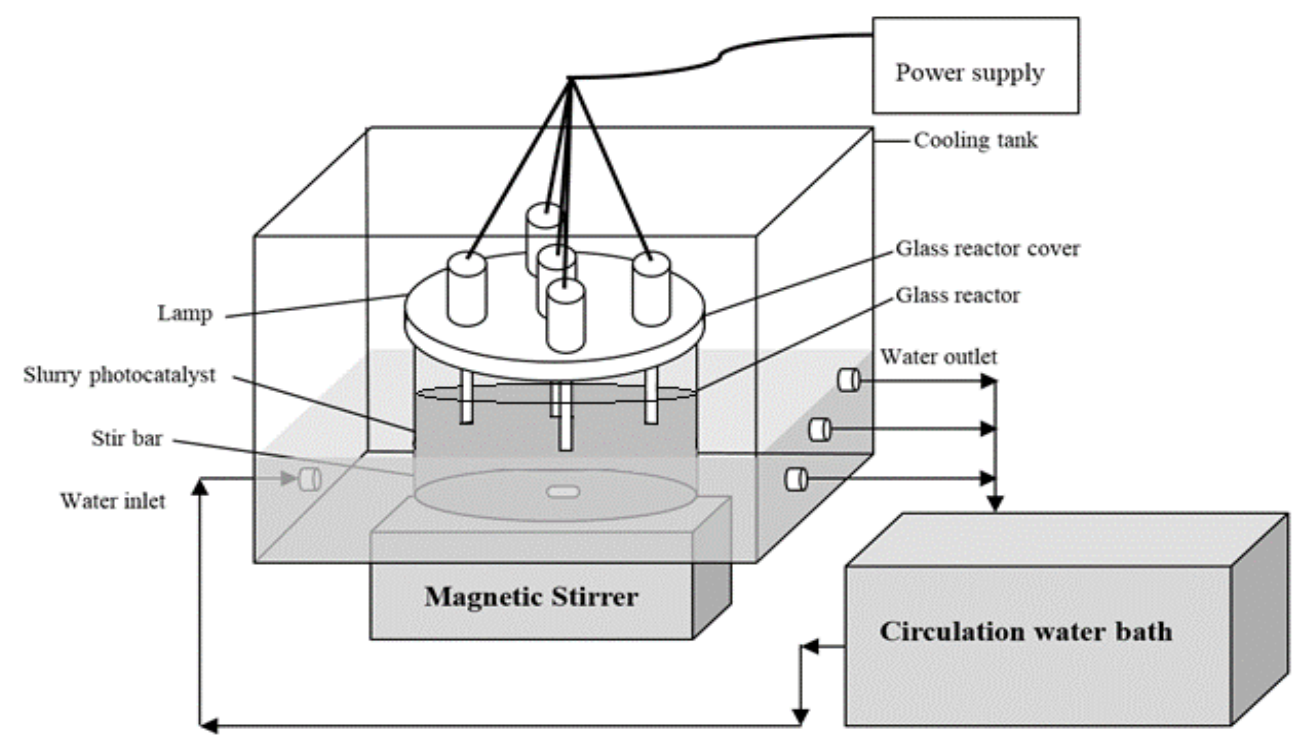

Figure 3.1. Laboratory scale reactor for experimental setup 
Table 3.1. Characteristics of the laboratory scale photocatalysis reactor.

\begin{tabular}{ll}
\hline Item & Specification \\
\hline Reactor material & Glass \\
Volume of reactor & $3,500 \mathrm{~mL}$ \\
Mode & Batch \\
Length of lamp (Base face) & $128.8 \mathrm{~mm}$ \\
Overall length & $167 \mathrm{~mm}$ \\
Lamp wavelength & Vis, Large emission band centred at $470 \mathrm{~nm}$ \\
Lamp wavelength & UV-A, Large emission band centred at $365 \mathrm{~nm}$ \\
Lamp wavelength & UV-B, Large emission band centred at $310 \mathrm{~nm}$ \\
Lamp wavelength & UV-C, Large emission band centred at $254 \mathrm{~nm}$ \\
Lamp wattage & $9 \mathrm{~W}$ \\
Lamp Voltage & $60 \mathrm{~V}$ \\
Temperature & $25^{\circ} \mathrm{C}$ \\
Pressure & $1 \mathrm{~atm}$ \\
\hline
\end{tabular}

\subsection{Refrigerated Water Bath}

A refrigerated water bath circulator (RTE-211) is used to control the temperature of the reactor. Water bath circulator along with a water tank $(20 \mathrm{~L})$ equipped with a thermostat is utilized to keep the process isothermal. The application of a water bath with temperature control helps to investigate the effect of temperature on the efficacy of photocatalytic reaction.

\subsection{Experimental section}

In the first part of the experimental work, after setting up the photocatalytic reactor, some preliminary experiments were done. Then, according to procedures (details in next chapters), silver doped $\mathrm{TiO}_{2}$ with different mass ratio of $\mathrm{Ag}_{\mathrm{TiO}}$ (w:w) was synthesized. In a subsequent stage, degradation efficiency of organic materials was examined by employing metal-doped $\mathrm{TiO}_{2}$. In the next part of the study, $\mathrm{Fe}_{2} \mathrm{O}_{3} / \mathrm{TiO}_{2}$ with different mass ratios of $\mathrm{Fe}: \mathrm{TiO}_{2}(\mathrm{w}: \mathrm{w})$ was prepared. Then, a new composite photocatalyst of $\mathrm{Ag} / \mathrm{TiO}_{2} / \mathrm{Fe}_{2} \mathrm{O}_{3}$ with various mass ratios of $\mathrm{Ag}$, $\mathrm{Fe}$ and $\mathrm{TiO}_{2}$ (w;w) was developed. 
The structure of all photocatalysts was investigated by X-ray diffraction (XRD). Brunauer, Emmet and Teller (BET) was used for the measuring of the specific surface area of all photocatalysts. Scanning electron microscopy (SEM) joint with electron dispersive spectroscopy (EDS) was employed to evaluate the morphology and elemental analysis of synthesized photocatalysts. The concentration of organic compounds for all water samples was measured based on total organic carbon (TOC). More explanation on XRD, BET, SEM, and TOC techniques has been presented in instrumentation section.

In the second part of the experimental study, degradation of MO and CR was investigated by employing several different processes. The concentration of organic compounds for all water samples was measured in terms of TOC. Briefly, degradation of organic materials in all water samples was carried out by employing following methods:

1. Photolysis, applying only UV irradiation

2. Applying dark $\mathrm{TiO}_{2}$ (employing $\mathrm{TiO}_{2}$ without UV light)

3. Applying $\mathrm{UV}$ and $\mathrm{TiO}_{2}$ photocatalyst $\left(\mathrm{UV} / \mathrm{TiO}_{2}\right)$

4. Appling $\mathrm{UV}$ and $\mathrm{Fe}_{2} \mathrm{O}_{3}$ photocatalyst $\left(\mathrm{UV} / \mathrm{Fe}_{2} \mathrm{O}_{3}\right)$

5. Applying $\mathrm{UV}$ and $\mathrm{Ag} / \mathrm{TiO}_{2}$ photocatalyst $\left(\mathrm{UV} / \mathrm{Ag} / \mathrm{TiO}_{2}\right)$

6. Applying $\mathrm{UV}, \mathrm{Ag} / \mathrm{TiO}_{2}$ and $\mathrm{Fe}_{2} \mathrm{O}_{3}$ photocatalysts $\left(\mathrm{UV} / \mathrm{Ag} / \mathrm{TiO}_{2} / \mathrm{Fe}_{2} \mathrm{O}_{3}\right.$ )

7. Applying Vis, $\mathrm{Ag} / \mathrm{TiO}_{2}$ and $\mathrm{Fe}_{2} \mathrm{O}_{3}$ photocatalysts (Vis/ $\mathrm{Ag} / \mathrm{TiO}_{2} / \mathrm{Fe}_{2} \mathrm{O}_{3}$ )

8. Applying different light's sources with $\mathrm{N} / \mathrm{TiO}_{2}$ photocatalysts $\left(\mathrm{UV} / \mathrm{N} / \mathrm{TiO}_{2}\right.$ and $\mathrm{Vis} / \mathrm{N} / \mathrm{TiO}_{2}$ )

The main purpose of next part of the research was to provide appropriate experiments, which include easy guidelines to calculate kinetic of reactions on eradication of organic materials employing photocatalytic reactor. Kinetics deals with the rate of a chemical reaction and 
investigates how various tests can affect or manipulate the speed of a reaction. Some factors can significantly influence degradation of organic materials in the photocatalytic reaction. In this study, the effect of following parameters, which affect the performance of photocatalytic degradation, were investigated:

1. Structure and size of the photocatalyst

2. $\mathrm{pH}$

3. Initial concentration of pollutant

4. Light intensity

5. Light wavelength

\subsection{Experimental design, and optimisation}

In this study, two methods were used for the optimisation of operating parameters:

1. Individual effect

2. Multivariable or cross-factor effects

In individual methods, each time only one parameter is manipulated and the effect of changing one parameter is investigated. In the case of cross factor effect, interactions between parameters are also investigated. In other words, in cross factor effect, several parameters are simultaneously manipulated.

The design of experiment (DOE) is used to overwhelmed the restrictions of conventional methods, in terms of time, materials, and the number of experimental trials, to optimise the factors involved in the treatment process. The DOE permits the optimisation of all parameters and considers the combined effects of all the factors involved. The response surface methodology (RSM) were applied to analyse multifactor systems and to optimise the operation parameters in 
chemical treatment processes. In RSM a combination of mathematical and statistical techniques is applied and then optimal response with minimum experiments obtained (Bustillo-Lecompte et al., 2016a, 2016b; Bustillo-Lecompte and Mehrvar, 2016, 2017). RSM is useful for developing, improving and optimising processes with fewer resources, for example, less time, chemical reagent and experimental work. In order to evaluate the influence of operating parameters on the degradation of organics, four main parameters and for each one, three levels were selected.

\subsection{Response Surface Methodology}

Response surface methodology (RSM) is a combination of mathematical and statistical techniques that is an effective tool for developing, improving, and optimising different processes. In addition to the important applications in the design, development, and formulation of new products, it could be used in the improvement of existing product designs. The most important application of RSM is in industrial processes, particularly when different input variables or factors influence some performance measure or quality characteristic of the process. This performance measure or quality characteristic of the process is called response. In many real applications of RSM, there is more than one response. The input variable or the factors are called independent variables, and the conventional designs are either a Box-Behnken Design (BBD) or a Central Composite Design (CCD), depending on the number of factors and their levels. In optimisation, the responses could be coupled to selected variables by linear or quadratic models. A quadratic model equation for predicting the response functions (organic degradation and TOC removal efficiencies) could be developed using a second order polynomial expression as follows (BustilloLecompte et al., 2016a, 2016b; Bustillo-Lecompte and Mehrvar, 2016, 2017): 
$Y_{i}=\beta_{o}+\sum_{i=1}^{k} \beta_{i} X_{i}+\sum_{i=1}^{k} \beta_{i i} X_{i}^{2}+\sum_{i=1}^{k-1} \sum_{j=2}^{k} \beta_{i j} X_{i} X_{j}+c$

where $\beta_{o}, \beta_{i}, \beta_{i i}$, and $\beta_{i j}$ are the constant, linear, quadratic, and cross-factor interaction coefficients, respectively; $X_{i}$ and $X_{j}$ represent the independent variables; $Y_{i}$ is the predicted response; and $k$ and $c$ are the number of factors and the residual term, respectively.

On the other hand, to obtain a simultaneous objective function that represents the geometric mean of all transformed responses, the desirability multiple response method was used to combine the desirable ranges for each response as shown in Equation (2.2) (Myers et al., 2004; BustilloLecompte et al., 2016a, 2016b; Bustillo-Lecompte and Mehrvar, 2016, 2017):

$D=\left(d_{1} \times d_{2} \times d_{3} \times d_{4} \ldots \times d_{n}\right)^{1 / n}=\left(\prod_{i=1}^{n} d_{i}\right)^{1 / n}$

where $D, d_{i}$, and $n$ are the desirability objective function, each response range, and the number of responses, respectively. For a simultaneous optimisation, each response requires low and high values for the optimisation. Otherwise, if any response is found outside of its desirability range, the overall desirability becomes equal to zero.

\subsection{Validation of model adequacy}

Generally, in RSM, it is always essential to (i) validate the fitted model to ensure that it provides an adequate approximation to the actual system, and (ii) verify that none of the least square regression assumptions is violated. Proceeding with exploration and optimisation of a fitted response surface could give misleading results unless the model provides a satisfactory fit. The residual from the least square fit, which refers to the difference between the model prediction and the observation, is a good indicator of the model adequacy. A validation of the normality assumption is made by constructing a normal probability plot of the residuals. If the residual plot 
lies on the straight line, then the normality assumption is satisfied. Another plot to validate the model adequacy is the plot of residuals over the predicted response. If the residuals scatter randomly in the form of a "gunshot pattern", the model is adequate (Mehrvar et al., 2000). However, the scaled residuals are often more preferable as they convey more information than the ordinary least square residuals. One of the scaled residuals more widely used is the studentized residual. The studentized residuals are found by dividing the residuals by their standard deviations. If the points scatter randomly between the outlier detection limit of -3 and +3 , the model adequacy is satisfied.

\subsection{Instrumentation}

\subsubsection{Total organic carbon (TOC) Analyser}

Total organic carbon (TOC) analyser is required because of measuring organic materials in wastewater samples. TOC analyser is broadly utilized not only in the determination of the quality of water but also in other industries such as pharmaceuticals, petroleum, semiconductors and environmental research. In addition, TOC analyser performs determination of the amount of organic carbon in clay, soil, and sediment.

In this study, a TOC analyser (Teledyne Tekmar Apollo 9000 Combustion) equipped with an automated sampler is employed to determine carbon content in wastewater samples. TOC analyser works based on catalytic combustion of organic materials and is capable of determining total carbon (TC), total organic carbon (TOC), inorganic carbon (IC), purgeable organic carbon (POC), and nonpurgeable organic carbon (NPOC).

Potassium hydrogen phthalate (KHP) as an organic carbon source was added to distilled water to achieve determined levels of carbon. First, the KHP was dried in an oven at $105^{\circ} \mathrm{C}$ for 2 
$\mathrm{h}$ prior to the preparation of the stock standard solution and then stored in a desiccator to reach to room temperature. For preparation of a 1,000 $\mathrm{mg} / \mathrm{L}$ of KHP stock standard solution, an accurate 2,125 mg of KHP was dissolved in distilled water and diluted to $1 \mathrm{~L}$. From primary standard, a standard solution of $500 \mathrm{mg} / \mathrm{L}$ and then from $500 \mathrm{mg} / \mathrm{L}$, a standard solution of $100 \mathrm{mg} / \mathrm{L}$ was prepared. From $100 \mathrm{mg} / \mathrm{L}$ a series of standard solutions, including 50, 25, 10 and $5 \mathrm{mg} / \mathrm{L}$ was prepared. Through running TOC standard solutions, a calibration curve was obtained. TOC instrument compares all reading from unknown concentration with the calibration curve. TOC removal efficiencies were determined using the influent (in) and effluent (eff) values for each parameter based on Equations (3.3.).

$\mathrm{TOC}=\frac{\left(\mathrm{TOC}_{\text {in }}-\mathrm{TOC}_{\text {eff }}\right)}{\mathrm{TOC}_{\text {in }}} \times 100 \%$

\subsubsection{Brunauer, Emmet, and Teller (BET) analysis}

One of the most important characteristics of a semiconductor photocatalyst is surface area and porosity, which affect the property and efficiency of the photocatalyst in degradation of pollutants (Legagneux et al., 2002; Gaya and Abdullah, 2008). It is evident that a photocatalyst with a high specific surface area has a higher performance in the eradication of contaminants. The most preferred model utilized to determine the area of a solid is the Brunauer, Emmet, and Teller (BET) method. In this method, first, samples are heated, and at the same time, gas over samples is depleted to eliminate released contaminants. Then by employing liquid nitrogen, the samples are cooled. Finally, the volume of gas (usually $\mathrm{N}_{2}$ or $\mathrm{Kr}$ ) that is adsorbed on the surface is measured.

In this study, a BET specific surface area analyzer (Quantachrome Nova-e 1200) was used, which nitrogen gas is adsorbed at $77 \mathrm{~K}$. Prior to using of BET for measuring specific surface area, the instrument was calibrated using Silica-Alumina Pellet as surface area reference material 
(SARM) with specific surface area of $774.47\left(\mathrm{~m}^{2} / \mathrm{g}\right)$ and applying a special procedure. The BET method is the most widely used procedure for the determination of the surface area of solid materials and involves the use of the BET equation (3.4.):

$$
\frac{1}{W\left(\left(\frac{P_{0}}{P}\right)-1\right)}=\frac{1}{W_{m} C}+\frac{C-1}{W_{m} C}\left(\frac{p}{P_{0}}\right)
$$

where, $\mathrm{W}$ is the weight of gas adsorbed at a relative pressure, $\mathrm{P} / \mathrm{P}_{0}$, and $\mathrm{W}_{\mathrm{m}}$ is the weight of adsorbate constituting a monolayer of surface coverage. The term $\mathrm{C}$ is related to the energy of adsorption in the first adsorbed layer, and consequently, its value is an indication of the magnitude of the adsorbent/adsorbate interactions.

The BET equation (3.4) requires a linear plot of $1 /\left[\mathrm{W}\left(\mathrm{P}_{0} / \mathrm{P}\right)-1\right]$ vs. $\mathrm{P} / \mathrm{P}_{0}$ which for most solids, using nitrogen as the adsorbate, is restricted to a limited region of the adsorption isotherm, usually in the $\mathrm{P} / \mathrm{P}_{0}$ range of 0.05 to 0.35 . This linear region is shifted to lower relative pressures for microporous materials. A typical BET plot is shown in Figure 3.2.

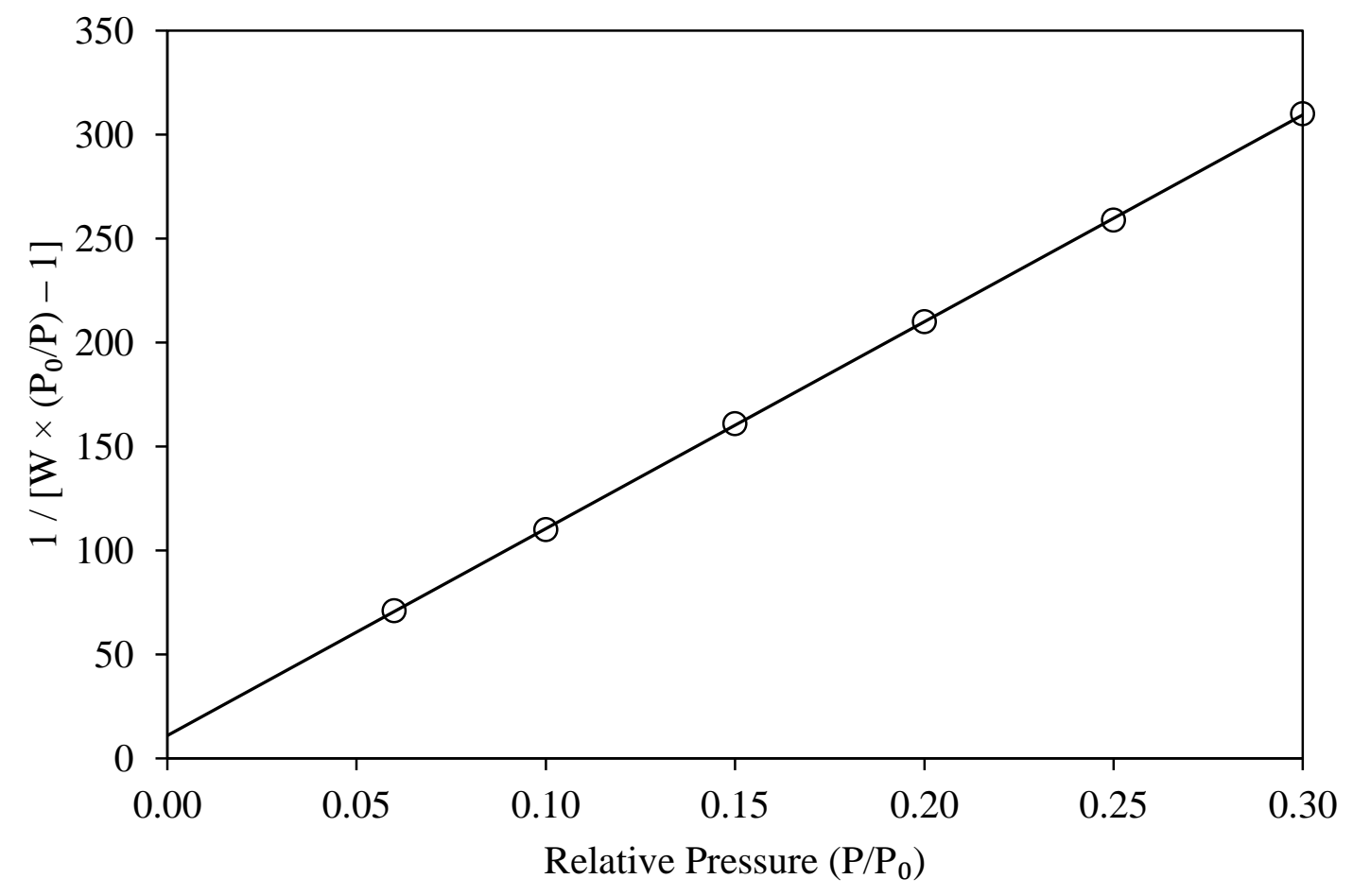

Figure 3.2. Typical multipoint BET plot. 
The standard multipoint BET procedure requires a minimum of three points in the appropriate relative pressure range. The weight of a monolayer of adsorbate $\mathrm{W}_{\mathrm{m}}$ can then be obtained from the slope $\mathrm{S}$ and intercept $i$ of the BET plot. From equation (3.4):

$$
\begin{aligned}
& \mathrm{s}=\frac{\mathrm{C}-1}{\mathrm{~W}_{\mathrm{m}} \mathrm{C}} \\
& \mathrm{i}=\frac{1}{\mathrm{~W}_{\mathrm{m}} \mathrm{C}}
\end{aligned}
$$

Thus, the weight of a monolayer $\mathrm{W}_{\mathrm{m}}$ can be obtained by combining equations (3.5) and

$$
\mathrm{W}_{\mathrm{m}}=\frac{1}{\mathrm{~S}+\mathrm{i}}
$$

The second step in the application of the BET method is the calculation of the surface area. This requires knowledge of the molecular cross-sectional area Acs of the adsorbate molecule. The total surface area $\mathrm{S}_{\mathrm{t}}$ of the sample can be expressed as:

$\mathrm{S}_{\mathrm{t}}=\frac{\mathrm{W}_{\mathrm{m}} \mathrm{NA} \mathrm{A}_{\mathrm{cs}}}{\mathrm{M}}$

where $\mathrm{N}$ is Avogadro's number $\left(6.0221415 \times 10^{23}\right.$ molecules/mol), and $\mathrm{M}$ is the molar mass (molecular weight) of the adsorbate.

Nitrogen is the most widely used gas for surface area determinations since it exhibits intermediate values for the $\mathrm{C}$ constant (50-250) on most solid surfaces, precluding either localized adsorption or behaviour as a two-dimensional gas.

Since it has been established that the $\mathrm{C}$ constant influences the value of the crosssectional area of an adsorbate, the acceptable range of $\mathrm{C}$ constants for nitrogen makes it possible to calculate its cross-sectional area from its bulk liquid properties. For the hexagonal closepacked nitrogen monolayer at $77 \mathrm{~K}$, the cross-sectional area $\mathrm{A}_{\mathrm{cs}}$ for nitrogen is $16.2 \AA^{2}$. 
The specific surface area $S$ of the solid can be calculated from the total surface area $S_{t}$ and the sample weight $\mathrm{w}$, according to equation (3.9):

$\mathrm{S}=\mathrm{S}_{\mathrm{t}} / \mathrm{W}$

\subsubsection{X-ray diffraction $(X R D)$}

X-ray powder diffraction (XRD) as a fast and reliable analytical instrument with a broad range of applications is capable of recognising minerals and crystalline materials. XRD is able to identify the proportion of the different minerals existing in a mixture. The degree of crystallization, deviations of ideal crystallisation, replacement of elements in a crystal, and hydration degree in a crystal are other information that can be achieved from a compound employing XRD (Shaogui et al., 2004).

Briefly, fundamental principles of XRD is that, when X-ray beam strikes to a layer of atoms, a part of beam transmitted, and the remaining could be absorbed, refracted, scattered, or diffracted. Diffracted X-rays are different from one mineral to another. The distance between the planes of the atoms (d-spacing) in a sample can be measured by employing diffracted X-rays and utilising Bragg's Law.

In this study, structure and crystalline form of all metals doped and mixed-synthesized photocatalysts were investigated and compared with bare $\mathrm{TiO}_{2}, \mathrm{Fe}_{2} \mathrm{O}_{3}$ and other semiconductors. X-ray diffraction (XRD) model PANalytical X'pert P RO was used to study the structure of crystal and conversion phase of $\mathrm{TiO}_{2}$. 


\subsubsection{Scanning electron microscopy (SEM)}

Generally, microscopes use light, but scanning electron microscope (SEM) utilises electron instead of light to produced image, which has various advantages over traditional microscopes. It has an extremely higher resolution, higher control for magnification, much more clear images, and great depth of field compared to conventional microscopes (Beane, 2004; Moecher, 2004).

An electron gun produces a focused beam of high-energy electrons and hits the sample caused to throw out electrons and X-rays from the specimen. Detectors collect these rejected electrons and X-rays and converted to signals. These signals produce images, which display information about surface characteristic, crystalline structure and morphology of materials.

SEM is usually attached to energy dispersive X-ray spectroscopy (EDS) to get more information about elemental analysis of the sample. In this study scanning electron microscopy (SEM) from JEOL, model JSM-6370 LV with accelerating voltage of $30 \mathrm{keV}$, which attached to energy dispersive X-ray spectroscopy (EDS) from Oxford Instrument Model X-Max-N-80 was employed for all synthesized photocatalysts.

\subsection{5. pH meter}

The $\mathrm{pH}$ of all synthesized samples was measured by a $\mathrm{pH}$ meter model Thermo Scientific Orion $230 \mathrm{~A}+$, Ottawa, $\mathrm{ON}$. The $\mathrm{pH}$ meter is equipped with a temperature sensor. The resolution of $\mathrm{pH}$ meter is 0.01 , the accuracy of \pm 0.02 , and working at a temperature range of -5.0 to $105.0^{\circ} \mathrm{C}$, a temperature resolution of $0.1^{\circ} \mathrm{C}$, and a temperature accuracy of $\pm 1.0^{\circ} \mathrm{C}$. The $\mathrm{pH}$ meter was calibrated using three buffer solutions of $\mathrm{pH} 4.01,7.00$ and 10.1. 


\subsubsection{Light intensity of lamps}

It is important to mention that light power and light intensity are two different parameters. Light power is the input energy of lamp but the light intensity is the output energy of the UV or Vis source, and the irradiance is the amount of light arriving at the surface to be treated. Thus, the irradiance of the UV-C, UV-B, UV-A and visible lamps of the photoreactor was measured by direct measurement using a digital radiometer (Spectroline DRC-100X, Spectronics Corp., Westbury, NY).

The radiometer involves two electronic sensors for UV-A and UV-C (Spectroline DIX254A, Spectronics Corp., Westbury, NY) that produces a current proportional to the incident irradiance. The radiometer takes direct measurements in the range of $0-19,990 \mu \mathrm{W} / \mathrm{cm}^{2}$, precalibrated by Spectronics Corp. For each experimental trial, the UV lamps were switched on for $30 \mathrm{~min}$ prior to the start of each experiment to guarantee light intensity stabilisation within the photoreactor and to remove any possible background materials.

\subsection{Analytical quality control}

In all studies, including synthesising of photocatalysts and laboratory analysis, appropriate

quality control procedures required because of errors, which may be occurred. Serious errors may be introduced during preparing of samples and at every stage of the analytical procedures.

\subsubsection{Quality control in laboratory analysis}

In order to analyse water samples, great care and cleanliness must be employed. Furthermore, to make sure which analytical results are reliable and accurate, all equipment's must 
perform ordinary calibration, recovery of known addition, analysis of chemical reagent blanks, analysis of replicate samples and analysis of standard reference materials.

\subsubsection{Instrumental calibration and calibration curve}

As stated before, in this study several analytical instruments including TOC analyzer, BET, XRD, SEM with EDS, pH meter, conductivity meter and etc was used. In order to achieve analytical results with less analytical errors, and high accuracy and precision, the analytical instruments must be optimized prior to each analysis. In this regard, by employing blank and standard solutions, a calibration curve for each instrument was prepared. In addition, all the tests are carried out three times along with replication.

BET, XRD, and SEM were calibrated periodically based on their recommended manual guide. TOC calibrated every two months in addition to measuring known concentration solutions every week. Other analytical instruments such as $\mathrm{pH}$ meter and conductivity meter were standardized alternatively according to manufacturer guidelines.

\subsubsection{Statistical calculations}

There are always errors in any physical quantities and measurements. We can't eliminate all errors but we can reduce the errors and obtain greater confidence that our measurements are closer to the true value.

Experimental error is the difference between a measurement and the true value or between two measured values. Experimental error, itself, is measured by its accuracy and precision. Errors are divided into random errors and systematic errors. Random errors are unpredictable and unknown errors and can be reduced by performing replicated measurement or sometimes by 
refining the measurement techniques. Systematic errors are one sided errors and cannot be reduce by repeating the measurements; hence, they cannot be easily analyzed by statistical analysis. It is hard to detect, but once it is detected, it can be reduced by refining the measurement techniques.

In this study, all experiments were carried out three times with duplicate. Statistical analysis such as mean, standard deviation, standard error of the mean and confidence interval (at a confidence level of $95 \%$ ) were calculated to minimize errors.

$$
\begin{aligned}
& \hat{\sigma}=s=\sqrt{\frac{\sum\left(Y_{i}-\bar{Y}\right)^{2}}{n-1}} \\
& X=\mu \pm(\sigma / \sqrt{n}) Z
\end{aligned}
$$

Where sigma is standard deviation, $\mu$ is mean and n number of tests $(\sigma / \sqrt{n}) Z$ is margin of the error, $\mathrm{z}$ is related to confidence limit which is obtained from confidence interval table based of confidence percentage. 


\title{
CHAPTER 4
}

\section{MODIFICATION OF TiO2 TO ENHANCE PHOTOCATALYTIC}

\section{DEGRADATION OF ORGANICS IN AQUEOUS SOLUTIONS*}

\begin{abstract}
Heterogeneous semiconductor photocatalysis, an advanced oxidation process (AOP), has shown to be efficient in the degradation of numerous refractory organics in aqueous solutions into simple compounds. Two issues that arise with the use of unmodified $\mathrm{TiO}_{2}$ as a photocatalyst are the fast recombination of electron/hole pairs and the lower effectiveness in the presence of visible irradiation. This study aims to develop a photocatalyst by doping of transition metals, especially noble metals such as $\mathrm{Ag}$ onto the original $\mathrm{TiO}_{2}$. The combination of photocatalysts is a method to improve the photocatalytic activity for the degradation of organic compounds in wastewater. In this study, first $\mathrm{Ag}$-doped $\mathrm{TiO}_{2}$ is prepared and then, a composite of $\mathrm{Fe}_{2} \mathrm{O}_{3} / \mathrm{TiO}_{2}$ is synthesized in different mass ratios. A series of experiments is conducted for the treatment of two azo dyes, Congo red (CR) and methyl orange (MO), by photocatalysis under the UV-vis irradiation. The degradation of organic materials is measured in terms of total organic carbon (TOC). Scanning electron microscopy (SEM) combined with energy dispersive X-ray spectroscopy (EDS) along with the Brunauer, Emmet, and Teller (BET) method have been utilized to illustrate the characteristics of the prepared powder photocatalysts. X-ray diffraction (XRD) is used to identify
\end{abstract}

\footnotetext{
* Reprinted, with minor editorial changes to fulfill formatting requirements, from:

Nasirian, M., Mehrvar, M., 2016. Modification of $\mathrm{TiO}_{2}$ to Enhance Photocatalytic Degradation of Organics in Aqueous Solutions. Journal of Environmental Chemical Engineering, 4 (4A), 4072-4082. https://dx.doi.org/10.1016/j.jece.2016.08.008
} 
crystallinity and phase conversion of photocatalyst. Results showed that silver doped $\mathrm{TiO}_{2}$ increases the degradation of MO (12.2\%) and CR (14.5\%) compared to that of bare $\mathrm{TiO}_{2}$. The degradation efficiency of $\mathrm{MO}$ and $\mathrm{CR}$ increases by applying composite photocatalyst of $\mathrm{Fe}_{2} \mathrm{O}_{3} / \mathrm{TiO}_{2}$ in the range of 28.9 and $25.1 \%$, respectively, compared to that of the bare $\mathrm{TiO}_{2}$.

Keywords: Photocatalysis, wastewater treatment, $\mathrm{TiO}_{2}$, doping, combined photocatalysts.

* Reprinted, with minor editorial changes to fulfill formatting requirements, from:

Nasirian, M., Mehrvar, M., 2016. Modification of $\mathrm{TiO}_{2}$ to Enhance Photocatalytic Degradation of Organics in Aqueous Solutions. Journal of Environmental Chemical Engineering, 4 (4A), 4072-4082. https://dx.doi.org/10.1016/j.jece.2016.08.008 


\subsection{Introduction}

For more than three decades, it has been shown that advanced oxidation processes (AOPs) are promising technologies for the degradation of recalcitrant, refractory, dangerous, and poisonous organic materials in various wastewaters. AOPs are effective methods that are capable of transforming almost all organic pollutants into harmless materials such as water and carbon dioxide. The degradation of organic materials by AOPs is based on the production of highly powerful, reactive, and oxidizing hydroxyl radicals (Valenzuela et al., 2002; Choi, 2006; Mowla et al., 2014; Bustillo-Lecompte et al., 2014, 2016a, 2016b; Bustillo-Lecompte and Mehrvar, 2015, 2016; Hamad et al., 2016). The oxidation reduction potential of hydroxyl radical is $2.85 \mathrm{~V}$, which has a strong capability of oxidizing and can eradicate unselectively all organic pollutants in wastewater (Cao et al., 2008; Bustillo-Lecompte et al., 2013, 2015; Mohajerani et al., 2016). Some materials such as hydrogen peroxide, ozone, semiconductor catalysts $\left(\mathrm{TiO}_{2}, \mathrm{ZnO}, \mathrm{Fe}_{2} \mathrm{O}_{3}\right)$, or some ions $\left(\mathrm{Fe}^{3+}\right)$ can generate oxidizing radicals in the presence or absence of ultraviolet or visible light and even under an ultrasonic radiation source. Each of these methods has their own strength and weaknesses.

Photocatalysis is a chemical reaction using light that causes the activation of a substance, which adjusts the speed of a reaction without any alteration or consumption (Liao et al., 2004; Hashimoto et al., 2005). Fujishima and Honda (1972), split water into oxygen and hydrogen using $\mathrm{TiO}_{2}$. This innovation initiated the new field of heterogeneous photocatalysis. According to Hashimoto et al. (2005), a series of reports called, "auto-oxidation by $\mathrm{TiO}_{2}$ as a photocatalyst" may have been one of the primary cases outlining the use of $\mathrm{TiO}_{2}$ for its photochemical power.

The electronic configuration of $\mathrm{TiO}_{2}$, as a semiconductor, consists of a filled valence band, an energetic gap, and an empty conduction band. When $\mathrm{TiO}_{2}$ absorbs UV radiation, in which the 
photon's energy $(h v)$ is greater or equal to the band gap energy, an electron/hole pair is produced (Gao et al., 2004, 2010; Agustina et al., 2005, 2008). During the procedure for oxidative degradation, hydroxyl radicals are formed, which proceed to break down organic molecules. Among different kinds of semiconductor photocatalysts, $\mathrm{TiO}_{2}$ is the most evident due to its stability, effective oxidative abilities, no toxicity, and solar activation (Malato et al., 2009). In contrast, $\mathrm{CdS}$ or $\mathrm{GaP}$, under the same conditions, decompose themselves to produce toxic products. Despite some advantages of the photocatalytic method, there are still several limitations that has not been industrialized. The restriction of titanium dioxide is that it can only be activated in the presence of UV irradiation, which is expensive to produce. It is because of its intrinsic nature especially its large band gap energy $(3.2 \mathrm{eV})$. In addition, it absorbs merely $5 \%$ of the energy from the solar spectrum. Furthermore, the quick rate of electron-hole pairs limits the applications of $\mathrm{TiO}_{2}$ for wastewater treatment. Therefore, developing a solar or visible light activation photocatalyst with high efficiency is extremely of interest.

So far, an effective method to improve the photocatalytic activity is increasing its surface area by doping metal ions such as $\mathrm{Au}, \mathrm{Ag}, \mathrm{Pt}, \mathrm{Co}, \mathrm{Ni}, \mathrm{Fe}, \mathrm{Zn}$ (Bandara et al., 2007; Silva et al., 2009; Tryba et al., 2010). Among all metals in doping process, noble metals ( $\mathrm{Ag}, \mathrm{Au}$, and $\mathrm{Pt}$ ) illustrated the highest efficiency in photocatalytic activity, because they are resistant to oxidation or corrosion. Except doping, mixing two or more photocatalysts, mixing with metal oxides such as $\mathrm{ZnO}, \mathrm{SnO}_{2}, \mathrm{Fe}_{2} \mathrm{O}_{3}$, and $\mathrm{CuO}$, and using oxidant species are other methods of attempting to increase the photoactivity of $\mathrm{TiO}_{2}$ (Liao et al., 2004; Bandara et al., 2007).

Of all semiconductor oxides, $\mathrm{Fe}_{2} \mathrm{O}_{3}$, with low band gap energy ( $\left.2.2 \mathrm{eV}\right)$, has the capability to absorb a wide range of visible light and degrade a broad range of organic materials. It also has the benefits of the low price, high chemical and physical stability, and great quantity on earth (Peng 
et al., 2010). Despite its advantages, $\mathrm{Fe}_{2} \mathrm{O}_{3}$ possesses a weak electrical conductivity, limiting the separation of the electron/hole pairs, which increases their recombination. Thus, these disadvantages have restricted the wide application of $\mathrm{Fe}_{2} \mathrm{O}_{3}$.

Heterogeneous photocatalytic reactions include complex series of reactions. Agustina et al. $(2005,2008)$ described some mechanisms of reactions in photocatalysis as follows:

$$
\begin{aligned}
& h v(\text { light })+\mathrm{TiO}_{2} \rightarrow h_{v b}^{+}+e_{c b}^{-} \quad \text { Light absorption } \\
& \mathrm{TiO}_{2}\left(h_{v b}^{+}\right)+\mathrm{H}_{2} \mathrm{O}_{a d s} \rightarrow \mathrm{TiO}_{2}+\mathrm{H}^{+}+\mathrm{HO}^{\bullet} \\
& \mathrm{TiO}_{2}\left(h_{v b}^{+}\right)+\mathrm{OH}_{a d s}^{-} \rightarrow \mathrm{TiO}_{2}+\mathrm{HO}_{a d s}^{\bullet} \\
& e^{-}+h^{+} \rightarrow \text { Heat } \quad \text { Recombination (undesirable reaction) } \\
& \mathrm{TiO}_{2}\left(e_{c b}^{-}\right)+\mathrm{O}_{2, a d s} \rightarrow \mathrm{TiO}_{2}+\mathrm{O}_{2}^{\bullet-} \\
& \mathrm{O}_{2}^{\bullet-}+\mathrm{H}^{+} \rightarrow \mathrm{HO}_{2}^{\bullet}
\end{aligned}
$$

In this study, the degradation of two dyes, Congo red (CR) and methyl orange (MO), by applying different photocatalytic methods were studied and the results were compared under the same conditions. In addition, the procedure for preparing the $\mathrm{Ag}$-doped $\mathrm{TiO}_{2}$ and the combination of $\mathrm{Fe}_{2} \mathrm{O}_{3}$ onto $\mathrm{TiO}_{2}$ were also investigated. $\mathrm{CR}$ is an azo dye which has chromophore $(-\mathrm{N}=\mathrm{N}-)$. Approximately 50-70\% of dyes are aromatic azo compounds and used in many industries such as textile, pharmaceutical, pulp and paper, and food industries. Azo dyes are hard to degrade and produce some toxic by-products, which are carcinogenic. MO is a strongly colored azo compound, used for dying and printing textile as well as $\mathrm{pH}$ indicator in titration. 


\subsection{Materials and Methods}

\subsubsection{Materials}

All chemical materials were analytical grade and used as purchased from Sigma-Aldrich and Van Waters and Nat Rogers (VWR) Canada, without further purification.

\subsubsection{Instrumentation}

A total organic carbon (TOC) analyzer, Teledyne Tekmar model Apollo 9000, was used for measuring organic materials in samples. The specific surface area of samples was determined using Brunauer-Emmet and Teller (BET) method (Quantachrome Nova-e 1200) by use of nitrogen gas which is adsorbed at $77 \mathrm{~K}$. For measuring topography, morphology and structure of the prepared crystals of photocatalysts, scanning electron microscopy (SEM) JEOL, model JSM-6370 LV with accelerating voltage of $30 \mathrm{keV}$ and for elemental analysis energy dispersive X-ray spectroscopy (EDS) Oxford Instrument Model X-Max-N-80 (which combined with SEM) was employed. Auto sputter coater model Denton Vacuum Desk IV was used for coating samples with a thin layer of gold before analysis. X-ray diffraction (XRD) model PANalytical X'pert PRO was used to investigate structure of crystal and conversion phase of $\mathrm{TiO}_{2}$. All instruments were calibrated according to their procedures. Prior to measure the concentrations of organic materials in water samples by TOC, first samples were centrifuged at 5,000 rpm for 20 min using a centrifuge (Thermo Scientific Heraeus Multifuge X1) and then filtered by filter papers (VMR Qualitative 410). 


\subsubsection{Experimental setup and procedure}

The experimental setup, as shown in Figure 4.1, was a batch photoreactor consisted of a cylindrical glass container with total volume of $3.5 \mathrm{~L}$ for degradation of organic materials. Five UV lamps (UV-A, large emission band centered at $365 \mathrm{~nm}$ from Philips- Actinic BL PL-S 9W/10/2P 1CT) were placed vertically in the reactor as shown in Figure 4.1.

One UV Lamp located in the center of the photoreactor and four UV lamps in the midpoint of the center of the photoreactor and the perimeter symmetrically. The whole reactor was placed in a water container, controlled by a cooling bath (RTE-211, NESLAB Instruments, Inc., Newington, $\mathrm{NH}$ ) by circulating the bath water to the cooling tank.

A magnetic stirrer mixed the solution thoroughly. An aluminum foil was wrapped around the external surface of the cooling water tank to reflect UV radiation to the sample as well as make it safe. The initial concentration of each organic material was $20 \mathrm{mg} / \mathrm{L}$ and the volume of the prepared solution was $2.00 \mathrm{~L}$. The photocatalysts were added in form of slurry to the photoreactor in different amounts. The temperature of the reactor was set at $25^{\circ} \mathrm{C}$.

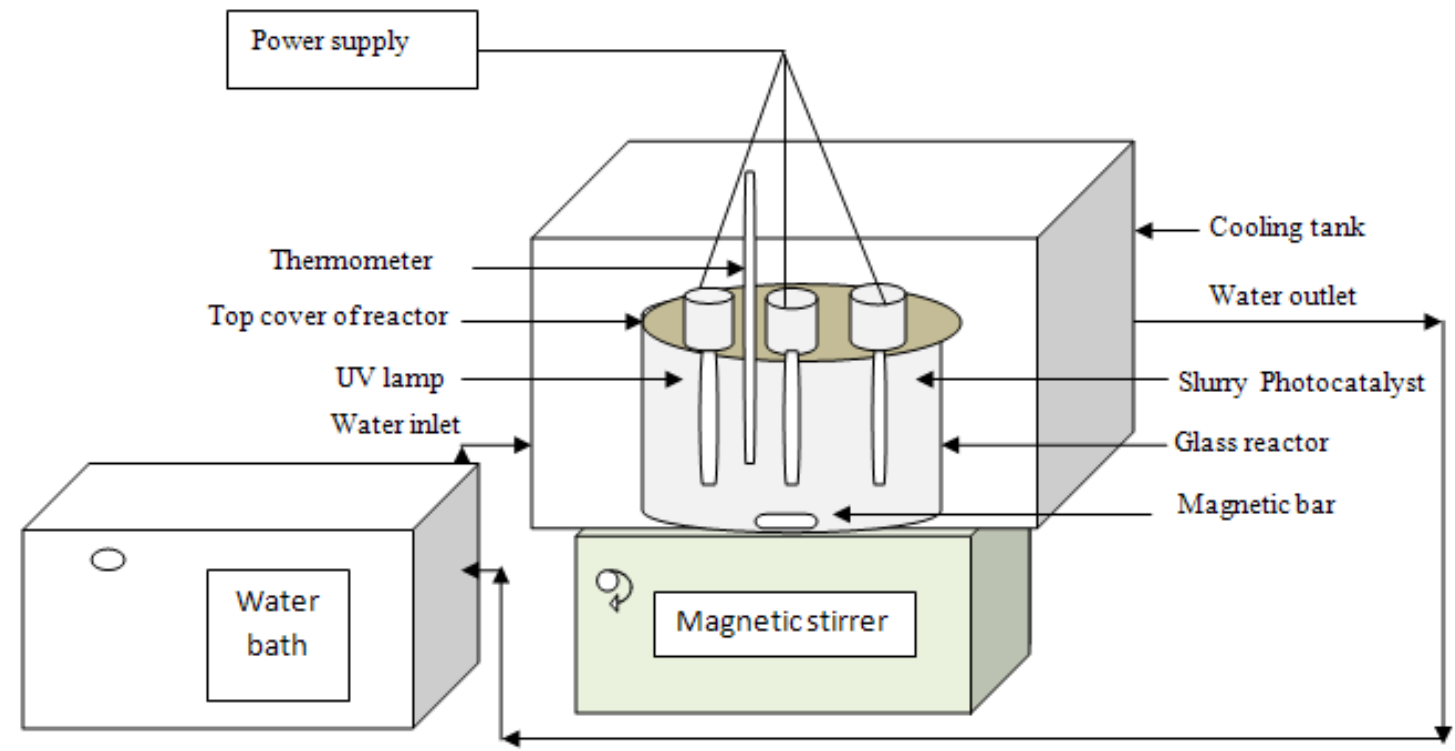

Figure 4.1. Schematic diagram of the laboratory scale slurry photoreactor. Reprinted from J. Environ. Chem. Eng. 4 (2016) 4072-4082, with permission from Elsevier. 


\subsubsection{Synthesis of nano $\mathrm{TiO}_{2}$}

Nano $\mathrm{TiO}_{2}$ particles were prepared since nanoparticles $(<100 \mathrm{~nm})$ have more specific surface area and obviously have more reaction sites. The properties of nano particles are different than those of large particles ( $\mathrm{Qu}$ et al., 2013). The procedure for preparing nano $\mathrm{TiO}_{2}$ was based on the method of Zou et al. (2008) with a minor adaptation. According to the method, $30 \mathrm{~mL}$ of tetrabutoxy titanium was added to $30 \mathrm{~mL}$ ethylene glycol. Then solution heated at $180^{\circ} \mathrm{C}$ for $2 \mathrm{~h}$ while mixing using a magnetic stirrer. The solution was cooled to room temperature and solid products centrifuged and washed with ethanol. The product was dried at room temperature. The synthesized white solid product was titanium glycolate. Finally, the product was calcined at $400^{\circ} \mathrm{C}$ in furnace using Whatman ashless filter paper No. 41 for $2 \mathrm{~h}$ to produce $\mathrm{TiO}_{2}$ nanoparticles.

\subsubsection{Synthesis of Ag-doped $\mathrm{TiO}_{2}$}

There are different methods to synthesize metal-doped $\mathrm{TiO}_{2}$ including sol-gel, wet chemical synthesis, hydrothermal, and plasma oxidative pyrolysis (Tryba et al., 2010; Nasralla et al., 2013). Each method has its own advantages and disadvantages. The sol-gel method is the most convenient and important method because of the easy procedure, low price, high yield of production, and low temperature requirements (ambient temperature).

In combined methods, including the hydrothermal/sol-gel method, the preparation of Agdoped $\mathrm{TiO}_{2}$ was accomplished by weighing $2.00 \mathrm{~g}$ of prepared nano $\mathrm{TiO}_{2}$ (anatase) and adding 50 $\mathrm{mL}$ distilled water to make a suspended sol. Then $0.0157 \mathrm{~g} \mathrm{AgNO}_{3}$ were dissolved in distilled water. Then, the silver nitrate solution was added to a flat bottom flask, equipped with a condenser, comprising $\mathrm{TiO}_{2}$ sol particles suspended in water. The composition was mixed and heated at $105^{\circ} \mathrm{C}$ hydrothermally for at least $48 \mathrm{~h}$ by employing a heater-stirrer. The composition was centrifuged 
and the solid was then separated from the solution. Obtained sediment was washed and then heated in a muffle furnace at $400^{\circ} \mathrm{C}$ for $8 \mathrm{~h}$. Based on the molecular weight and the stoichiometry of the reaction, the ratio of $\mathrm{Ag}$ to $\mathrm{TiO}_{2}$ was 0.005 (0.005 $\mathrm{g} \mathrm{Ag:1.0} \mathrm{g} \mathrm{TiO}$ ). In addition, the Ag-doped $\mathrm{TiO}_{2}$ catalysts were synthesized with the $\mathrm{Ag}$ : $\mathrm{TiO}_{2}$ ratios of 0.01 and $0.05(\mathrm{w} / \mathrm{w})$.

\subsubsection{Synthesis of $\mathrm{Fe}_{2} \mathrm{O}_{3} / \mathrm{TiO}_{2}$}

The synthesis of $\mathrm{Fe}_{2} \mathrm{O}_{3} / \mathrm{TiO}_{2}$ was based on the combination of the sol-gel and hydrothermal method. In this method, $45 \mathrm{~mL}$ of $0.2 \mathrm{M} \mathrm{Fe}\left(\mathrm{NO}_{3}\right)_{3} \cdot 9 \mathrm{H}_{2} \mathrm{O}$ in ethanol were added to $1.65 \mathrm{~g}$ of nanoparticles of $\mathrm{TiO}_{2}$ powder. The mixture was stirred for $40 \mathrm{~min}$ at room temperature and sol was formed. Then, the sol was heated and stirred for at least $8 \mathrm{~h}$. Under these conditions, ethanol was evaporated almost entirely at $80^{\circ} \mathrm{C}$.

The powder was separated using centrifuge and filter paper and then calcined at $300^{\circ} \mathrm{C}$ for $20 \mathrm{~min}$ and then washed with ethanol. The sample was again calcined at $300^{\circ} \mathrm{C}$ for $8 \mathrm{~h}$. According to the stoichiometry of the reaction and the amount of precursors, the mass ratio of $\mathrm{Fe}_{2} \mathrm{O}_{3}$ in the composites is $0.30\left(\mathrm{Fe}: \mathrm{TiO}_{2} \mathrm{w} / \mathrm{w}=0.30\right)$. In addition, different $\mathrm{Fe}_{2} \mathrm{O}_{3} / \mathrm{TiO}_{2}$ photocatalysts were prepared with the ratios of $0.05,0.10$, and $0.15\left(\mathrm{Fe}: \mathrm{TiO}_{2} \mathrm{w} / \mathrm{w}\right)$.

\subsubsection{Photocatalytic activity measurement}

The aqueous slurry was stirred in dark for $180 \mathrm{~min}$ to determine the adsorption of organic materials onto the surface of photocatalysts and to reach equilibrium between adsorption and desorption of organic materials on the surface of $\mathrm{TiO}_{2}$ photocatalysts.

For measuring equilibrium time, several concentrations of each organics were prepared, and the reduction of organic materials was monitored using the TOC concentration. In the early 
part of the experimental study, the degradations of MO and CR were investigated in the presence of only UV irradiation (photolysis), dark $\mathrm{TiO}_{2}$, and $\mathrm{UV} / \mathrm{TiO}_{2}$. All experiments were done in a batch photoreactor.

\subsection{Results and Discussion}

\subsubsection{Dark Reactions}

After almost 50 and $60 \mathrm{~min}$, the adsorption of CR and MO was equilibrated onto the surface of $\mathrm{TiO}_{2}$ photocatalysts, respectively (figures are not shown). It was observed that regardless of the initial concentrations of the parent compounds, the steady state adsorption of CR and MO was obtained after 50 and 60 min, respectively. The process was continued for $4 \mathrm{~h}$ and no significant reduction was observed for both compounds.

\subsubsection{Photolysis of organics}

In separate experiments, one water sample containing $\mathrm{CR}$ and another containing only $\mathrm{MO}$ with $20 \mathrm{mg} / \mathrm{L}$ each were exposed to the UV irradiation alone and their degradations were monitored using the TOC concentration. It was observed that the photolytic process (UV-A alone) was not able to degrade $\mathrm{CR}$ and $\mathrm{MO}$, meaning a negligible amount of organic materials were degraded after $3.5 \mathrm{~h}$ under UV irradiation alone.

The TOC removal efficiencies were less than $4 \%$ and $11 \%$ for CR and MO, respectively,

after $3.5 \mathrm{~h}$. Since the subsequent experiments were conducted in about $3.5 \mathrm{~h}$, the degradation of both compounds due to the UV alone was not considered significant compared to that of the photocatalytic process. 


\subsubsection{Photocatalytic degradation of organics using $\mathrm{UV} / \mathrm{TiO} \mathrm{O}_{2}$}

As Figure 4.2 illustrates, organic materials can be degraded by employing a $\mathrm{TiO}_{2}$ photocatalyst in the presence of the UV irradiation. The results also show that the efficiency of the reaction still was not remarkable, because the rates of eradications of organic materials were very low.

The degradation efficiencies were 19.7 and $40.1 \%$ for CR and MO, respectively, after 210 min of the UV irradiation. The results from current study supported earlier research studies that $\mathrm{TiO}_{2}$ is able to degrade a broad range of organics (Agustina et al., 2005; Choi, 2006; Tryba et al., 2010).

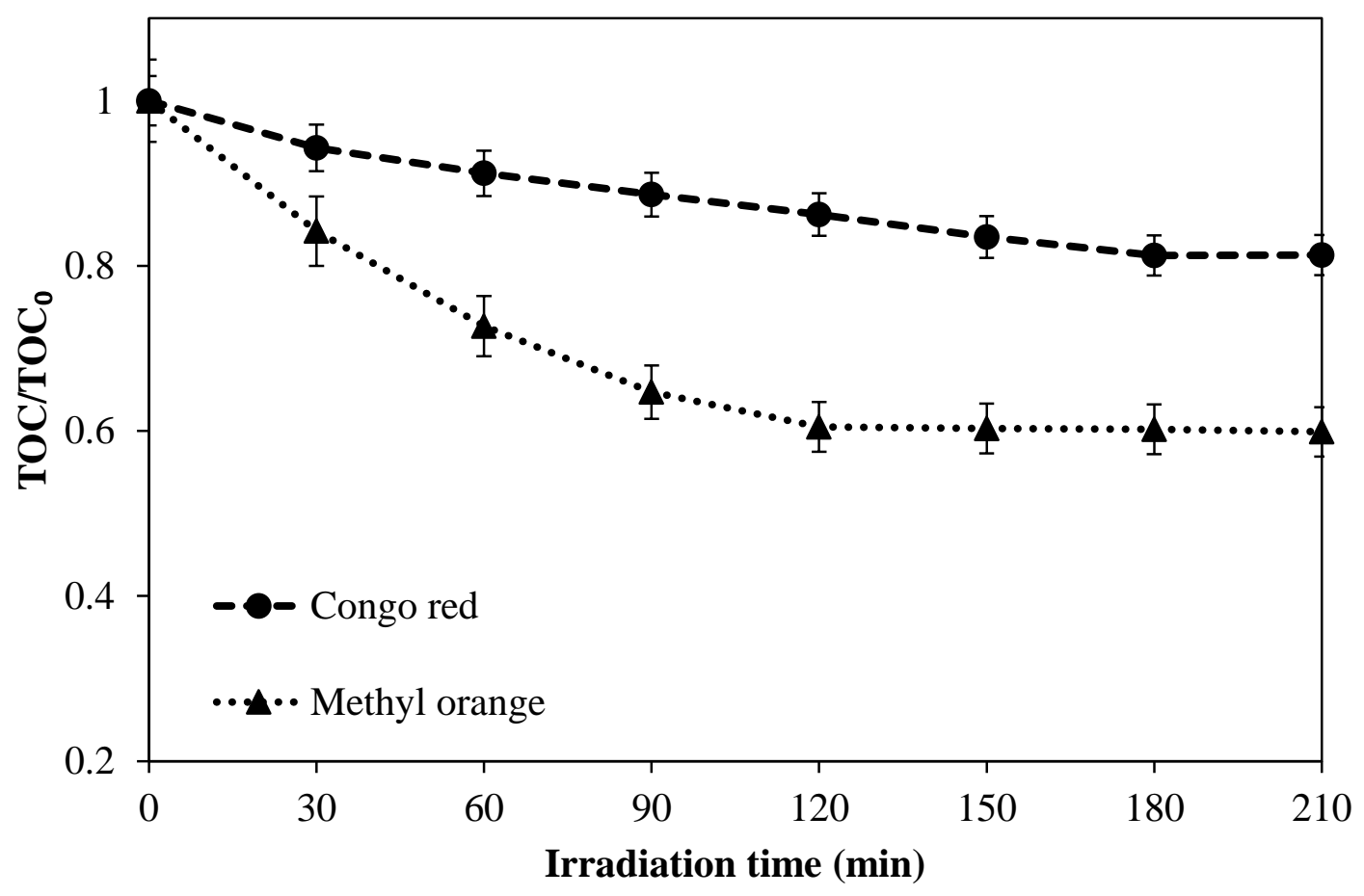

Figure 4.2. Photocatalytic degradation of aqueous methyl orange and Congo red using UV/TiO 2 . The initial concentration of each organic material $=20 \mathrm{mg} / \mathrm{L},\left[\mathrm{TiO}_{2}\right]=300 \mathrm{mg} / \mathrm{L}$, UV light power $=9 \mathrm{~W}$.

Reprinted from J. Environ. Chem. Eng. 4 (2016) 4072-4082, with permission from Elsevier. 


\subsubsection{Effects of light intensity}

In this study, the irradiation source was UV-A lamps, with maximum light intensity at 365 $\mathrm{nm}$ (Philips). The light intensity of the lamps was measured by a Spectroline Digital Radiometer (model DRC-100X). The maximum light intensity was $16 \mathrm{mw} / \mathrm{cm}^{2}$ and it was in the middle and very adjacent to the lamp. It was reduced to $10,5,3$ and $2 \mathrm{mw} / \mathrm{cm}^{2}$ when the distance was increased from the lamp at 2, 4, 6 and $8 \mathrm{~cm}$, respectively. In order to investigate the effect of the light intensity, a solution of MO was prepared, and its eradication was examined by employing one, three, and five UV lamps in the presence of $\mathrm{TiO}_{2}$ with the initial concentration of $300 \mathrm{mg} / \mathrm{L}$ of each model compound in separate experiments.

Results showed that the degradation efficiency of MO was $37.6 \%$ by applying one lamp after 210 min UV irradiation. By utilizing three and five lamps, the efficiency was reached to 45.6 and $49.1 \%$, respectively. Almost the same results were obtained for the degradation of CR, and it was shown that by increasing the light intensity, the rate of the photocatalytic degradation was increased as depicted in Figure 4.3a. Under the same condition, the eradication of CR was reached to $19.7,27.6$, and $33.5 \%$ by applying one, three, and five UV lamps, respectively, as depicted in Figure 4.3b.

It is clear that at higher light intensities, more hole-electron pairs generated and the degradation efficiency was increased. Some previous studies show that there is a linear relationship between the light intensity and the rate of photoreaction up to an optimum light intensity; others observed a square root relationship between the two parameters (Umar and Aziz, 2013). 

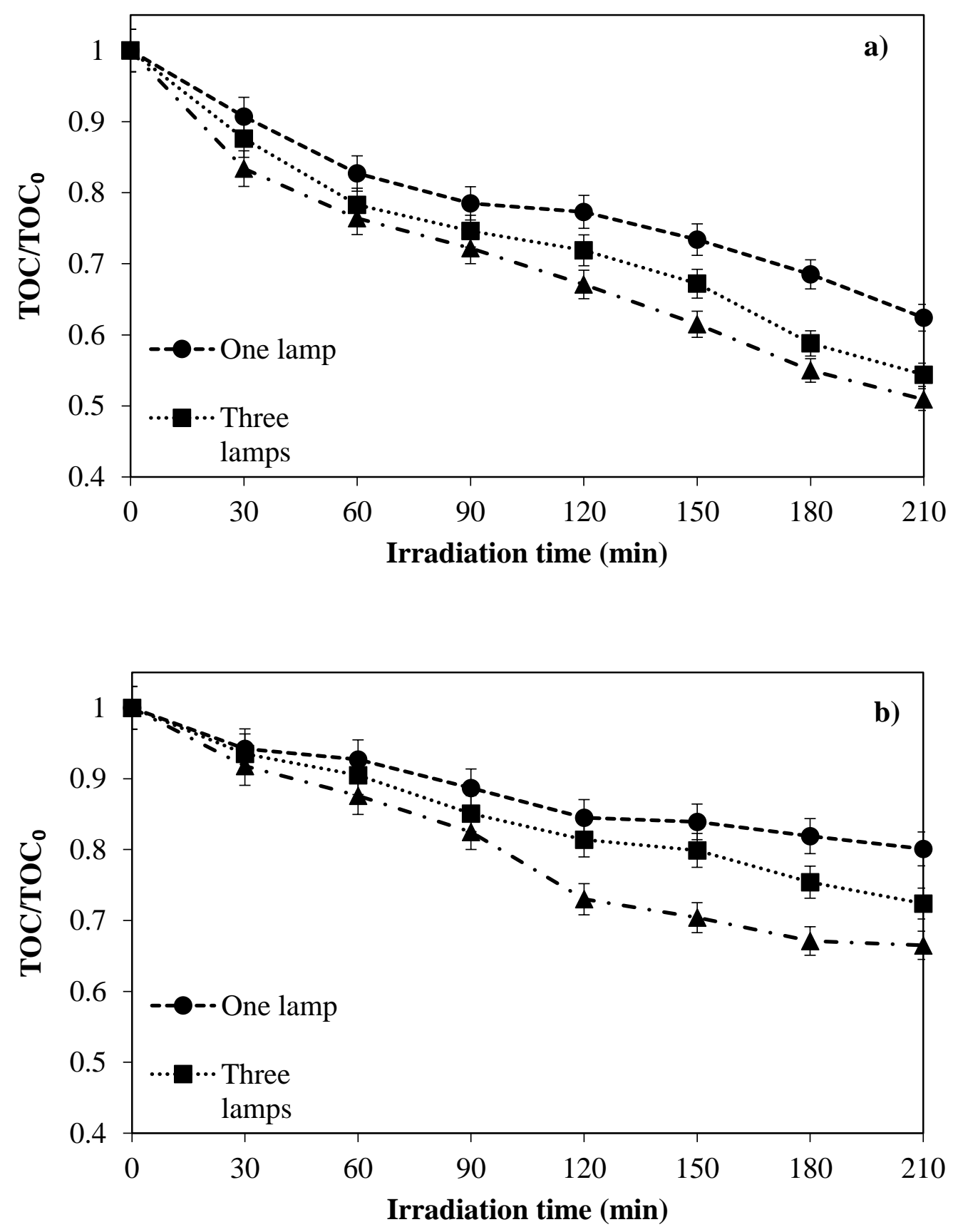

Figure 4.3. Effect of light intensity on the photocatalytic degradation of (a) methyl orange and (b) Congo red using $\mathrm{UV} / \mathrm{TiO}_{2}$. The initial concentration of each organic material $=\mathbf{2 0}$ $\mathrm{mg} / \mathrm{L},\left[\mathrm{TiO}_{2}\right]=300 \mathrm{mg} / \mathrm{L}, \mathrm{UV}$ light power $=9 \mathrm{~W}$.

Reprinted from J. Environ. Chem. Eng. 4 (2016) 4072-4082, with permission from Elsevier. 


\subsubsection{Photocatalytic degradation of organics using $\mathrm{UV} / \mathrm{Ag} / \mathrm{TiO} \mathrm{O}_{2}$}

The photocatalytic degradations of MO and CR were carried out by employing synthesized $\mathrm{Ag} / \mathrm{TiO}_{2} 0.005,0.01$, and $0.05\left(\mathrm{Ag} / \mathrm{TiO}_{2} \mathrm{w} / \mathrm{w}\right)$. Figure 4.4a illustrates the $\mathrm{MO}$ degradation using different methods of photocatalysis. As Figure 4.4a shows, the photolysis and the dark $\mathrm{TiO}_{2}$ did not contribute significantly to the $\mathrm{MO}$ degradation even after $4 \mathrm{~h}$. However, in $\mathrm{UV} / \mathrm{TiO}_{2}$ process with $300 \mathrm{mg} / \mathrm{L} \mathrm{TiO}_{2}$, the degradation efficiency was reached to $40.1 \%$ after $3.5 \mathrm{~h} \mathrm{UV}$ irradiation time.

However, this efficiency was not remarkable yet. By doping $\mathrm{Ag}$ onto $\mathrm{TiO}_{2}$ with the ratio of $0.005\left(\mathrm{Ag} / \mathrm{TiO}_{2} \mathrm{w} / \mathrm{w}\right)$, the $\mathrm{MO}$ eradication was significantly improved. When the amount of $\mathrm{Ag}$ doped $\mathrm{TiO}_{2}\left(\mathrm{Ag}: \mathrm{TiO}_{2}\right)$ was increased, it resulted in less degradation. In other words, the best results obtained in less amount of Ag-doped $\mathrm{TiO}_{2}\left(0.005 \mathrm{Ag} / \mathrm{TiO}_{2}\right.$ w/w $)$ with the efficiency of $52.3 \%$ after $3.5 \mathrm{~h}$, compared to that of 40.2 and $38.2 \%$ by 0.01 and $0.05(\mathrm{w} / \mathrm{w}) \mathrm{Ag} / \mathrm{TiO}_{2}$, respectively.

Almost similar results were observed for the degradation of CR using $\mathrm{Ag}$-doped $\mathrm{TiO}_{2}$. It means that the highest amount of the degradation of CR (34.4\%) was observed at $0.005 \mathrm{Ag}$-doped $\mathrm{TiO}_{2}$. By increasing the mass ratio of Ag-doped $\mathrm{TiO}_{2}$, the degradation efficiency was decreased.

Figure $4.4 \mathrm{~b}$ shows the eradication of $\mathrm{CR}$ at different conditions and mass ratios of $\mathrm{Ag}$ doped $\mathrm{TiO}_{2}$. The higher efficiency is obviously due to the fact that $\mathrm{Ag}$ scavenges electrons and therefore, the recombination of electron/hole pairs is hindered.

These results are in line with previous studies reported earlier in the open literature (Silva et al., 2009; Gao et al., 2010; Liu et al., 2003, 2013). It seems that increasing the concentration of the doped metal after a certain amount causes the coverage of the entire surface of the photocatalyst, reducing light absorption and chemical adsorption/reaction sites, and consequently, the activity of the photocatalyst is reduced. 

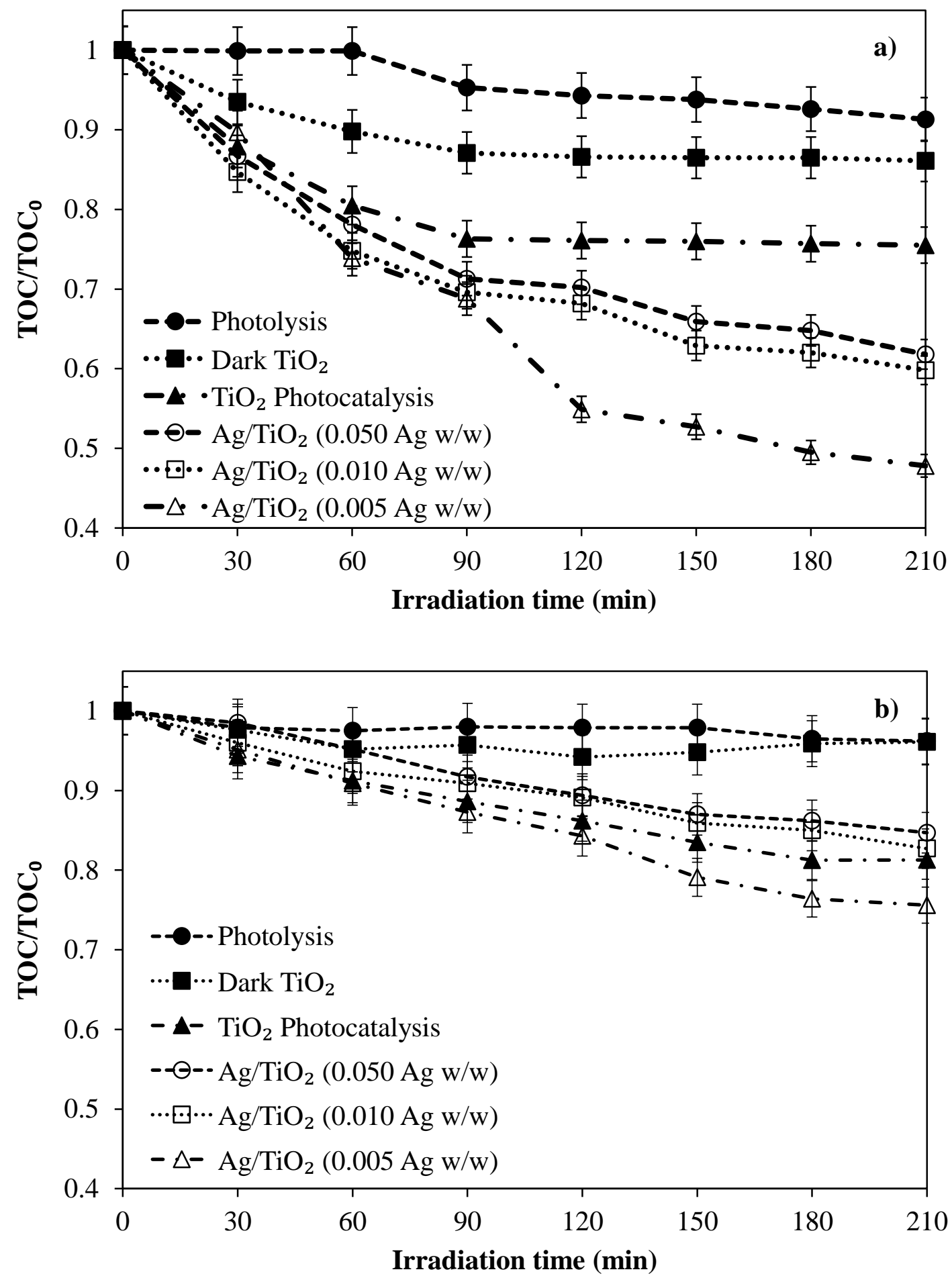

Figure 4.4. Comparison of the photocatalytic degradation of (a) methyl orange and (b) Congo red using UV alone, dark $\mathrm{TiO}_{2}$, and different $\mathrm{Ag}$ doped $\mathrm{TiO}_{2}$. The initial concentration of each organic material $=20 \mathrm{mg} / \mathrm{L},\left[\mathrm{TiO}_{2}\right]=300 \mathrm{mg} / \mathrm{L}, \mathrm{UV}$ light power $=45$ W.

Reprinted from J. Environ. Chem. Eng. 4 (2016) 4072-4082, with permission from Elsevier. 
The topography describes the surface feature of an object and its texture especially hardness and reflectivity. Figure 4.5 shows SEM images of the prepared $\mathrm{Ag} / \mathrm{TiO}_{2}$ for two compositions (0.01 and $0.05 \mathrm{w} / \mathrm{w} \mathrm{Ag} / \mathrm{TiO}_{2}$ ). Ag-doped $\mathrm{TiO}_{2}$ have different sizes and were not uniform (diameter of 10-200 nm). Bright particles represent more Ag presence while dark particles represent more $\mathrm{TiO}_{2}$ content.

The number of pores in the samples depends on several parameters including the nature of the substrate, the method of doping, the temperature of the substrate during of deposition, the concentration of substrate, the temperature of calcination, the crystal lactic, and the thickness of photocatalyst particles. The shape and the size of the particles make up the object such as structure, color, pattern, and strength, and it can be identified using morphology (Akpan and Hameed, 2009: Mazinani et al., 2014).

During hydrothermal synthesis of the Ag-doped $\mathrm{TiO}_{2}$, the amorphous $\mathrm{TiO}_{2}$ colloidal might be produced more than crystalline single nano particles, where on their surfaces, numerous bright silver nanoparticles are attached (Liu et al., 2003, 2013).

There are more disorders and defects in amorphous Ag-doped $\mathrm{TiO}_{2}$ compared to those of the crystalline phase of $\mathrm{TiO}_{2}$, which could have numerous active particles of photocatalyst and obviously accelerate the photocatalytic activity. The Ag-doped $\mathrm{TiO}_{2}$ hybrid micro-structures, which adsorb more organic materials, have higher specific surface area compared to bare $\mathrm{TiO}_{2}$. Figures 4.6a and 4.6b display elemental analysis of 0.005 and 0.01 (w/w) Ag-doped $\mathrm{TiO}_{2}$, respectively, taken by EDS. The elemental analysis of the prepared $\mathrm{Ag} / \mathrm{TiO}$ depicts the weight percentage of silver, titanium, and oxygen and it was proven that silver reacted with $\mathrm{TiO}_{2}$ and produced a composite. 
a)

b)

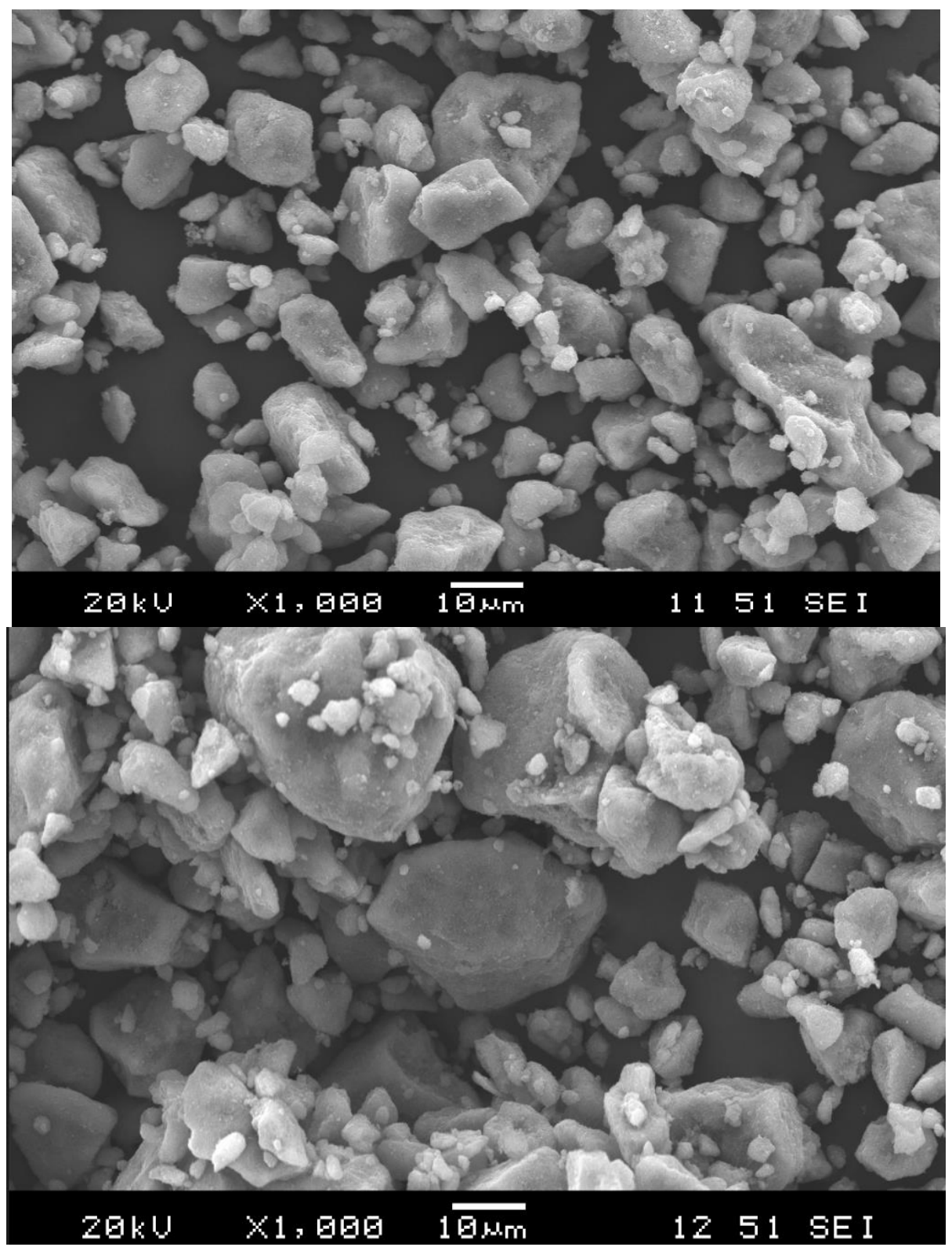

Figure 4.5. $\mathrm{SEM}$ image of $\mathrm{Ag}$ doped $\mathrm{TiO}_{2}$ (a) $0.01 \mathrm{Ag} / \mathrm{TiO}_{2}(w / w)$, and (b) $0.05 \mathrm{Ag} / \mathrm{TiO}$ $(\mathbf{w} / \mathbf{w})$.

Reprinted from J. Environ. Chem. Eng. 4 (2016) 4072-4082, with permission from Elsevier. 

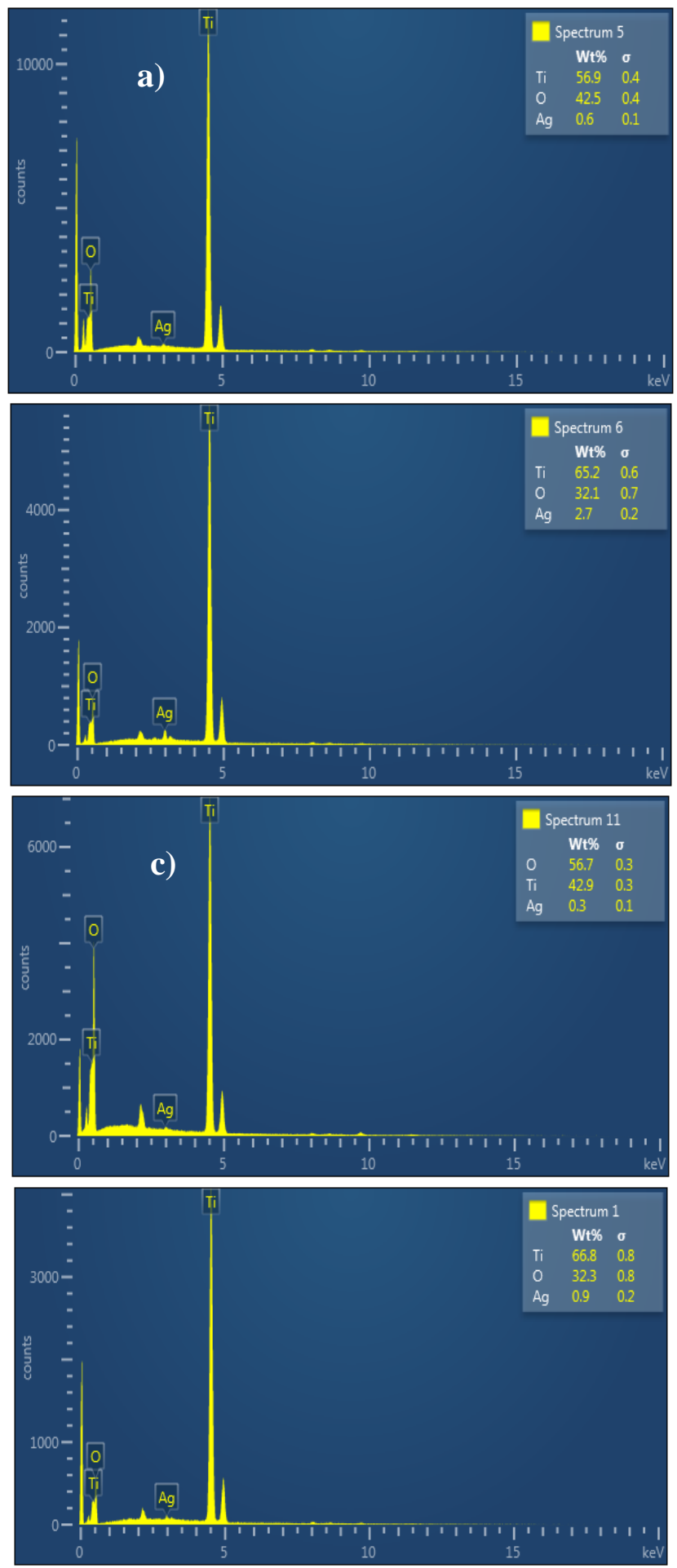

Figure 4.6. Elemental point analysis of $\mathrm{Ag} / \mathrm{TiO}_{2}$ (a) $0.005 \mathrm{Ag} / \mathrm{TiO}_{2}$ (w/w) point analysis, (b), (c), and (d) point analysis of three different locations for $0.01 \mathrm{Ag} / \mathrm{TiO}_{2}(\mathrm{w} / \mathrm{w})$.

Reprinted from J. Environ. Chem. Eng. 4 (2016) 4072-4082, with permission from Elsevier. 
In elemental analysis, different peaks display different positions of electron excitation in the sample. Figures $4.6 \mathrm{c}$ and $4.6 \mathrm{~d}$ show elemental analysis of a bright and dark point on the sample of $\mathrm{Ag} / \mathrm{TiO}_{2}(0.01 \mathrm{w} / \mathrm{w})$, respectively. Silver particles attached to the surface of the photocatalyst $\left(\mathrm{TiO}_{2}\right)$ can act as electron scavengers and then the electrons are transferred to the active oxygen which generates more electron-hole and accelerates the photocatalytic activity.

It is clear that the adsorption capability of organics on the surface of photocatalysts is related to the specific surface area and the structure of the photocatalyst. In other words, the photocatalytic activity of a photocatalyst is practically related to the quantity of reactants which are adsorbed on the surface of the photocatalyst. Obviously, this is directly comparative to the specific surface area of the photocatalyst.

Results of specific surface area by using BET showed that bare $\mathrm{TiO}_{2}$ anatase has the lowest specific surface area $\left(42.28 \mathrm{~m}^{2} / \mathrm{g}\right)$ compared to that of the Ag-doped $\mathrm{TiO}_{2}$ with mass ratios. The Ag-doped $\mathrm{TiO}_{2}(0.005 \mathrm{w} / \mathrm{w})$ had the highest specific surface area of $63.25 \mathrm{~m}^{2} / \mathrm{g}$, followed by 58.91 and $49.09 \mathrm{~m}^{2} / \mathrm{g}$ for 0.01 and $0.05(\mathrm{w} / \mathrm{w}) \mathrm{Ag}-\mathrm{TiO}_{2}$, respectively.

Figure 4.7 shows a diffractogram of $\mathrm{Ag} / \mathrm{TiO}_{2}(0.05 \mathrm{w} / \mathrm{w})$ calcined at $400^{\circ} \mathrm{C}$ taken by XRD. According to the Joint Committee on Powder Diffraction Standards (JCPDS-21-1272) databank, anatase has a main peak at $25.4(2 \theta)$ representative of the 101 planes.

Other anatase peaks are located at 37.8, 48.0, and 54.5, which are related to the 004, 200, 105 , and 211 planes of the anatase phase. While comparing the $\mathrm{Ag} / \mathrm{TiO}_{2}$ diffractogram with the JCPDS-21-1272 database, it was found that the prepared photocatalyst included only the anatase phase and no peak belonging to rutile was observed. 


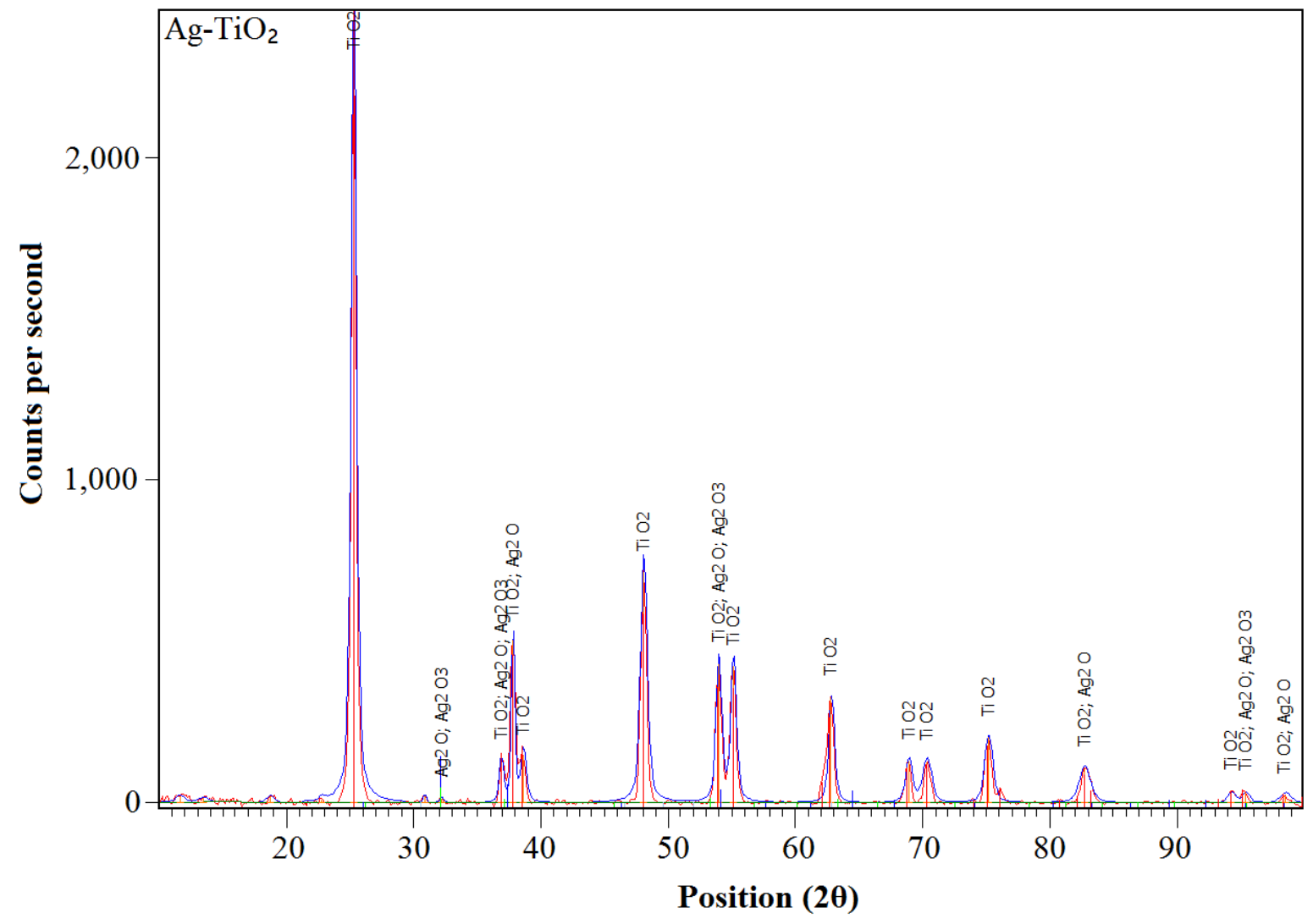

Figure 4.7. Diffractogram of $\mathrm{Ag} / \mathrm{TiO}_{2}(0.05 \mathrm{w}: \mathrm{w})$, taken by XRD.

Reprinted from J. Environ. Chem. Eng. 4 (2016) 4072-4082, with permission from Elsevier.

\subsubsection{Degradation of aqueous organics using $\mathrm{UV} / \mathrm{Fe}_{2} \mathrm{O}_{3} / \mathrm{TiO}_{2}$}

In this step, the photocatalytic degradation of MO (Figure 4.8a) and CR (Figure 4.8b), with the initial concentration of $20 \mathrm{mg} / \mathrm{L}$ each, was investigated in the presence of $0.05,0.10,0.15$, and 0.30 of $\mathrm{Fe}_{2} \mathrm{O}_{3} / \mathrm{TiO}_{2}$ (w/w Fe: $\mathrm{TiO}_{2}$ ). Results showed that $\mathrm{Fe}_{2} \mathrm{O}_{3} / \mathrm{TiO}_{2}$ with the mass ratio of 0.05 had the highest photocatalytic activity for the degradation of both MO and CR in aqueous solutions.

As Figures 4.9a and 4.9b illustrate, the degradation efficiency of the $\mathrm{Fe}_{2} \mathrm{O}_{3} / \mathrm{TiO}_{2}(0.05)$ photocatalytic process was higher than that of the bare $\mathrm{TiO}_{2}$ and $\mathrm{Ag} / \mathrm{TiO}_{2}$ photocatalysis, which reached to $45 \%$ for $\mathrm{CR}$ and $69 \%$ for $\mathrm{MO}$, respectively. Some organic materials still remain in the solution and cannot be degraded. 

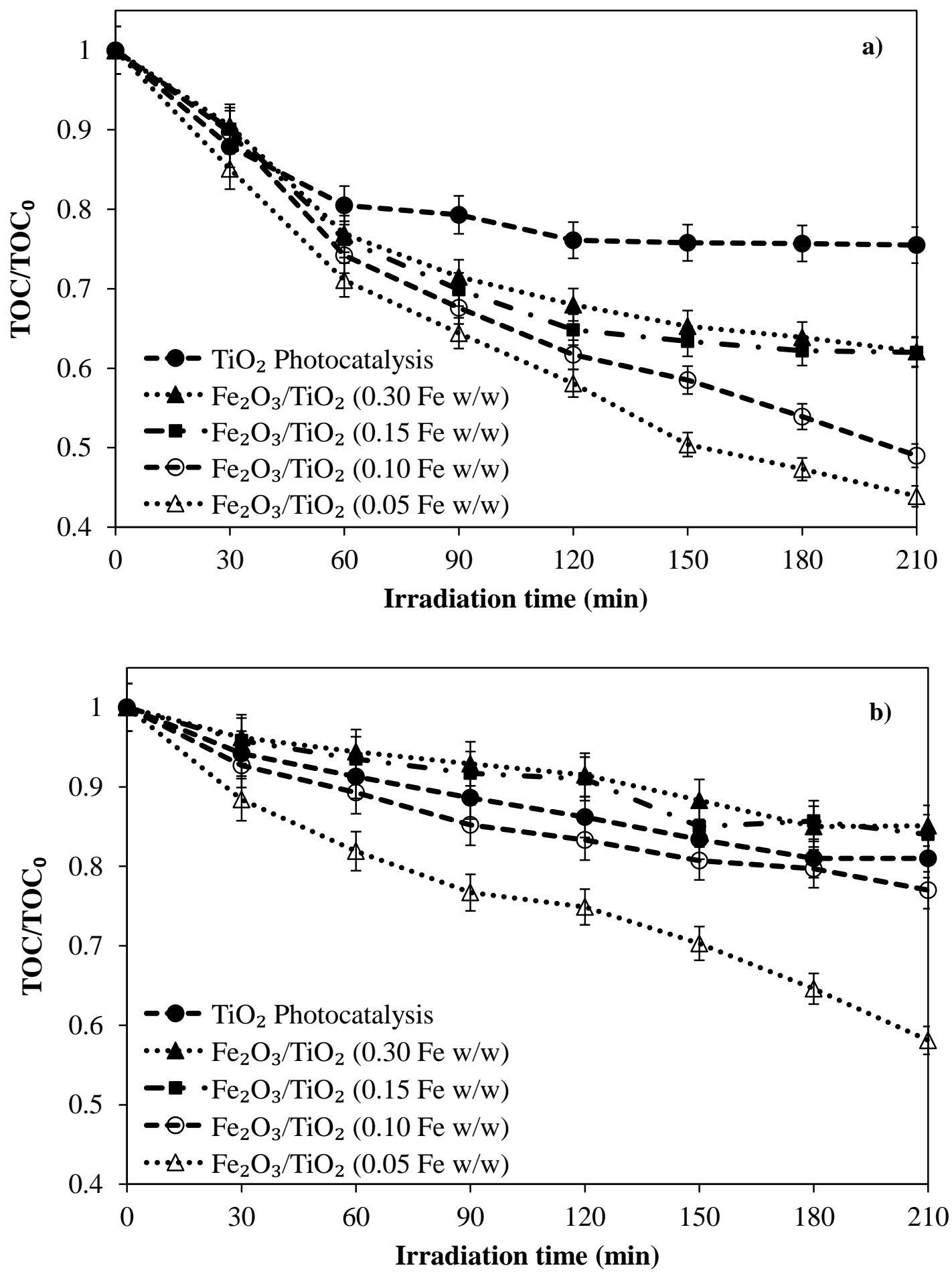

Figure 4.8. Comparison of the photocatalytic degradation of (a) methyl orange and (b) Congo red by different $\mathrm{Fe}_{2} \mathrm{O}_{3} / \mathrm{TiO}_{2}$. The initial concentration of each organic material $=20$ $\mathrm{mg} / \mathrm{L},\left[\mathrm{TiO}_{2}\right]=300 \mathrm{mg} / \mathrm{L}, \mathrm{UV}$ light power $=45 \mathrm{~W}$.

Reprinted from J. Environ. Chem. Eng. 4 (2016) 4072-4082, with permission from Elsevier. 

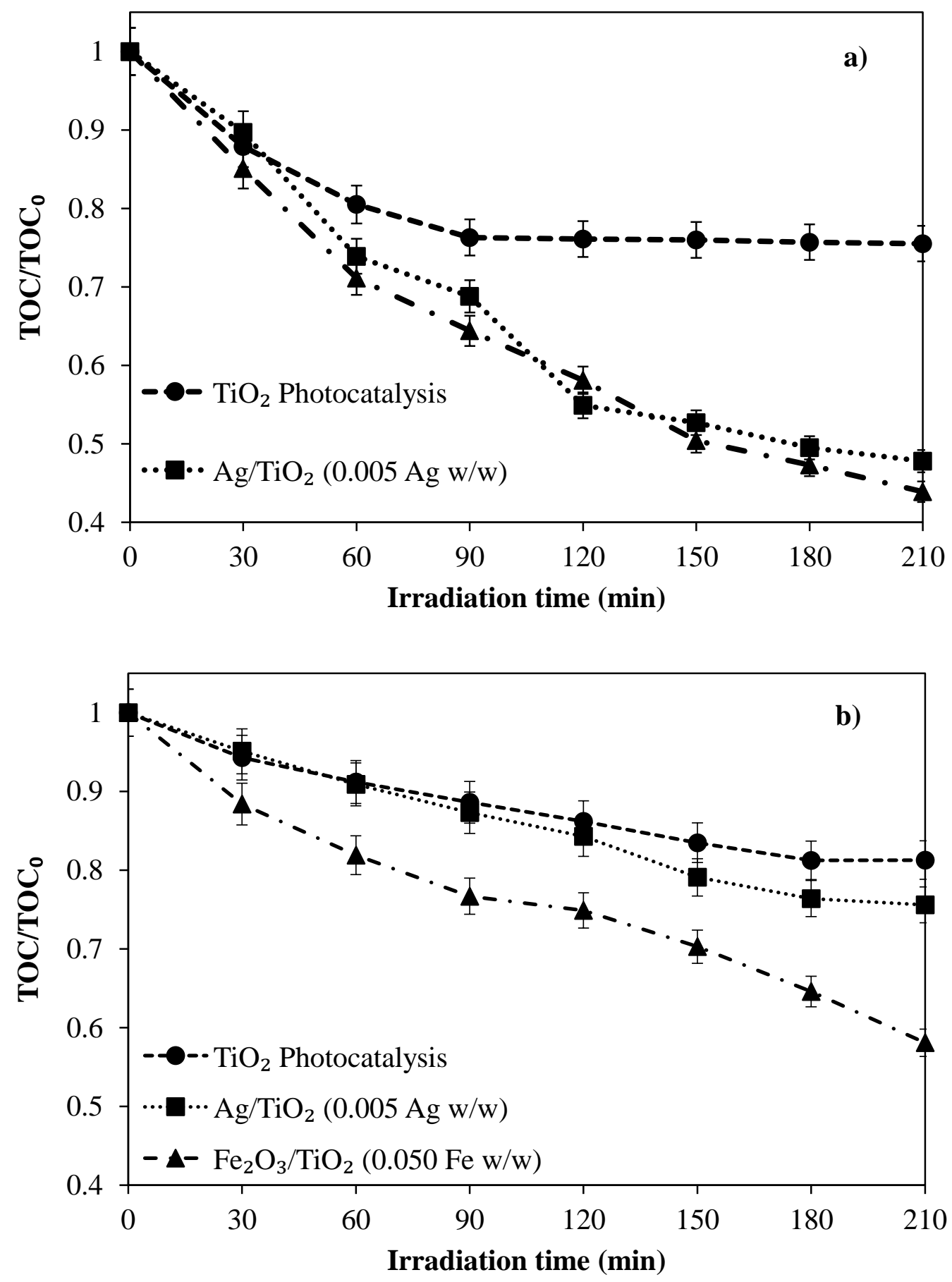

Figure 4.9. Comparison of the photocatalytic degradation of (a) methyl orange and (b) Congo red using $\mathrm{UV} / \mathrm{TiO}_{2}$, $\mathrm{UV} / \mathrm{Ag}-\mathrm{TiO}_{2}$, and $\mathrm{UV} / \mathrm{Fe}_{2} \mathrm{O}_{3} / \mathrm{TiO}_{2}$, at optimum condition. The initial concentration of each organic material $=20 \mathrm{mg} / \mathrm{L}$, $\left[\mathrm{TiO}_{2}\right]=300 \mathrm{mg} / \mathrm{L}$, UV light power $=45 \mathrm{~W}$.

Reprinted from J. Environ. Chem. Eng. 4 (2016) 4072-4082, with permission from Elsevier. 


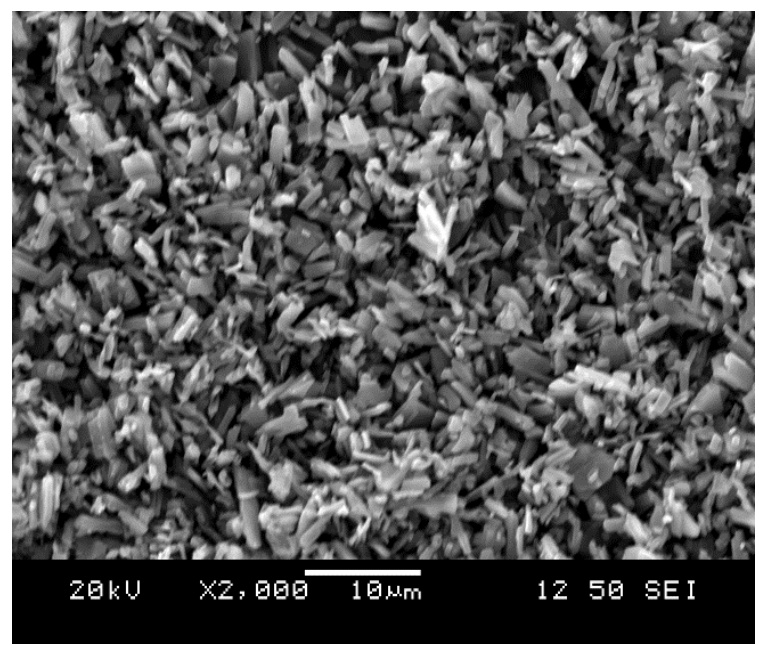

a)

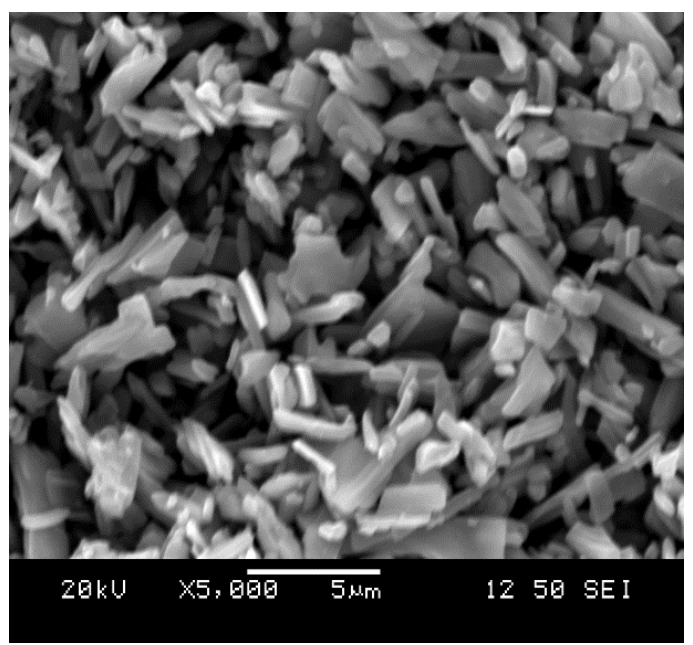

b)

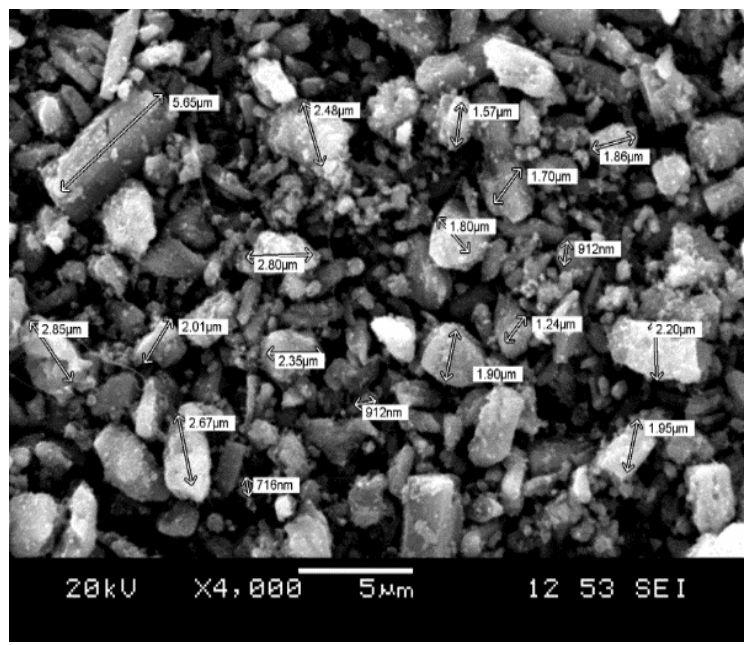

c)

Figure 4.10. SEM images with different magnifications for (a) $\mathrm{Fe}_{2} \mathrm{O}_{3} / \mathrm{TiO}_{2}\left(\mathrm{Fe}: \mathrm{TiO}_{2}=0.05\right)$;

(b) $\mathrm{Fe}_{2} \mathrm{O}_{3} / \mathrm{TiO}_{2}\left(\mathrm{Fe}: \mathrm{TiO}_{2}=0.05\right)$; and (c) $\mathrm{Fe}_{2} \mathrm{O}_{3} / \mathrm{TiO}_{2}\left(\mathrm{Fe}: \mathrm{TiO}_{2}=0.15\right)$ with different magnification.

Reprinted from J. Environ. Chem. Eng. 4 (2016) 4072-4082, with permission from Elsevier.

Scanning electron microscopy combined with energy dispersive X-ray spectroscopy

(SEM/EDS) was also used to identify the surface characterization, composition, and gain some information about the crystallography of the prepared photocatalysts. Microscopic images (SEM) for the composite $\mathrm{Fe}_{2} \mathrm{O}_{3} / \mathrm{TiO}_{2}$ are shown in Figure 4.10, where particles are micro-structure, flat, and irregular with a diameter of about 0.2-2 $\mu \mathrm{m}$. Particles comprise lots of bright (convexity) and dark (concavity) nanoparticles which might include numerous pores on their surfaces. 
Most particles are amorphous without any specific crystalline form. Although it seems that iron oxide covers titanium dioxide, it might be concluded that some particles of titanium dioxide agglomerated and placed on the surface of the iron (III) oxide. It is also possible that some $\mathrm{Fe}^{3+}$ substitute with $\mathrm{Ti}^{4+}$ in the crystal lattice and causes the defect in the crystal lattice (due to same radius of $\mathrm{Fe}^{3+}$ and $\mathrm{Ti}^{4+}$ ). The same discussion similar to silver doped titanium dioxide can be considered for combined $\mathrm{Fe}_{2} \mathrm{O}_{3} / \mathrm{TiO}_{2}$ photocatalysts.
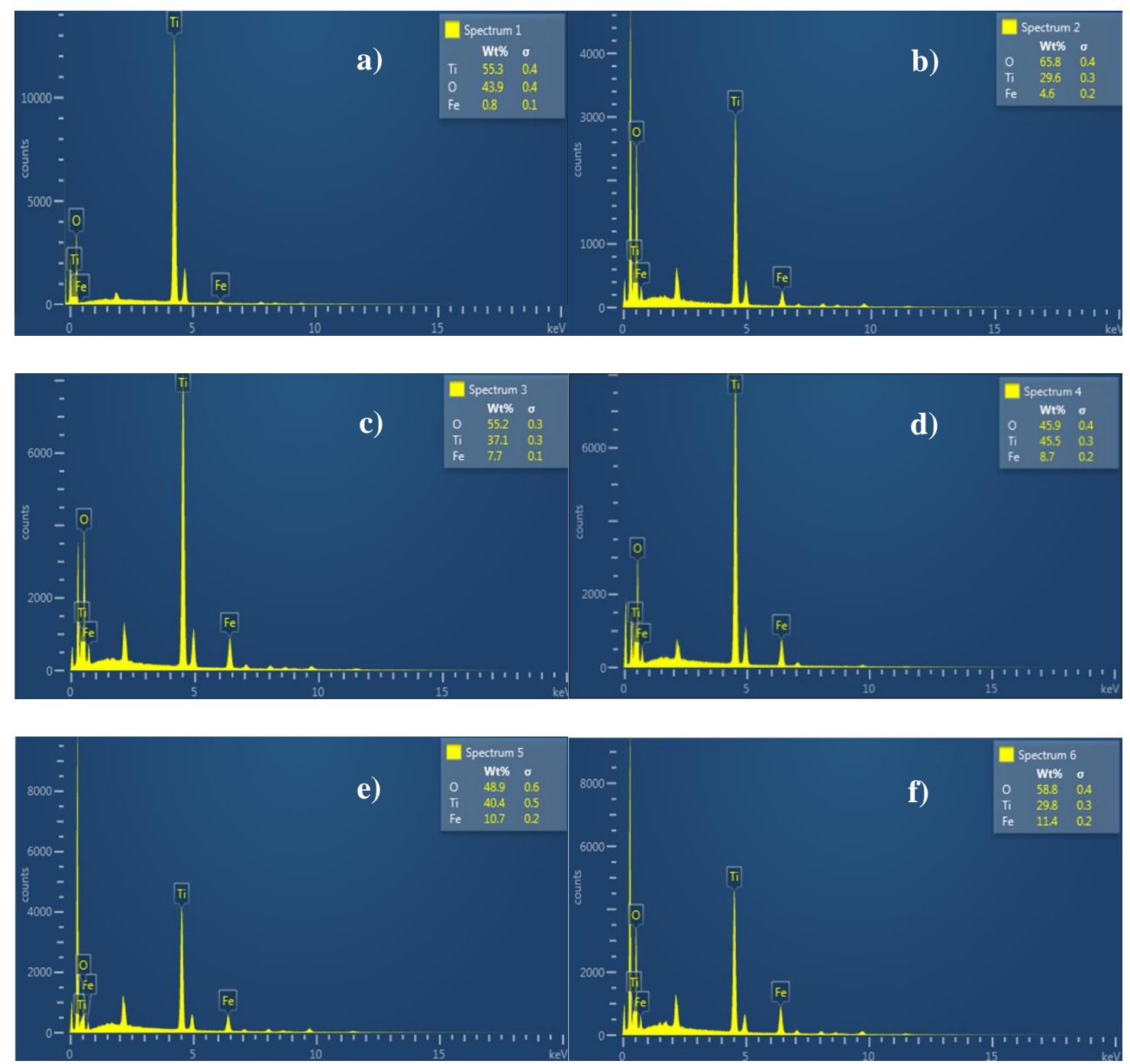

Figure 4.11. Elemental analysis based on weight percent of $\mathrm{Fe}_{2} \mathrm{O}_{3} / \mathrm{TiO}_{2}\left(\mathrm{Fe}: \mathrm{TiO}_{2}=0.05\right)$ at different points of whole sample for different spectrums taken by SEM/EDS. The details of each spectrum are shown in Table 1.

Reprinted from J. Environ. Chem. Eng. 4 (2016) 4072-4082, with permission from Elsevier. 
Figure 4.11 displays elemental analysis of several points of $\mathrm{Fe}_{2} \mathrm{O}_{3} / \mathrm{TiO}_{2}$ catalyst for $\mathrm{Fe}: \mathrm{TiO}_{2}=0.05$ based on weight percent, which depicts the percentage of iron, titanium, and oxygen in samples. Figure 4.12a shows a SEM image of prepared sample with some bright points belonging to iron particles. The analysis of images shows that the bright points on the samples have a high concentration of iron (Figure 4.12b), and dark particles (Figure 4.12c) have more concentration of titanium. Table 4.1 displays the spectrum analysis (point), of the samples by SEM based on Figure 4.11.

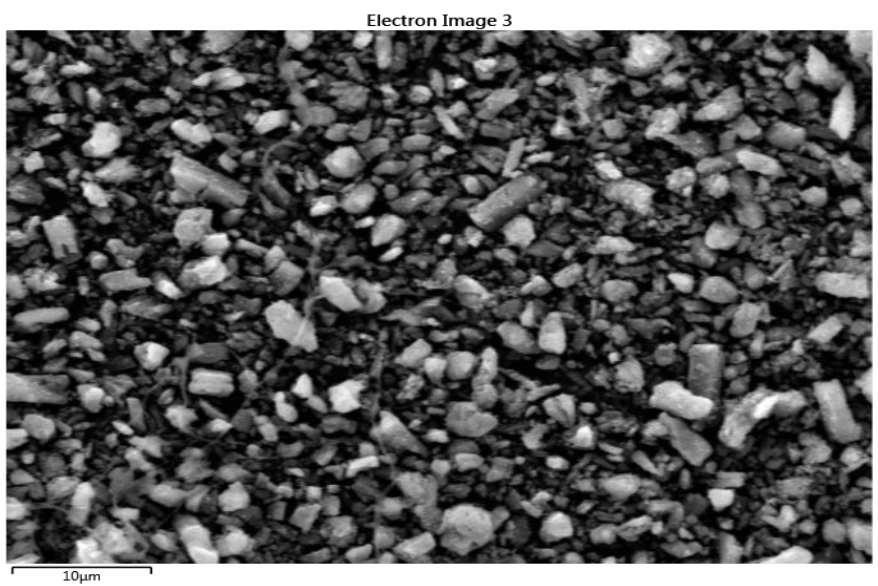

a)

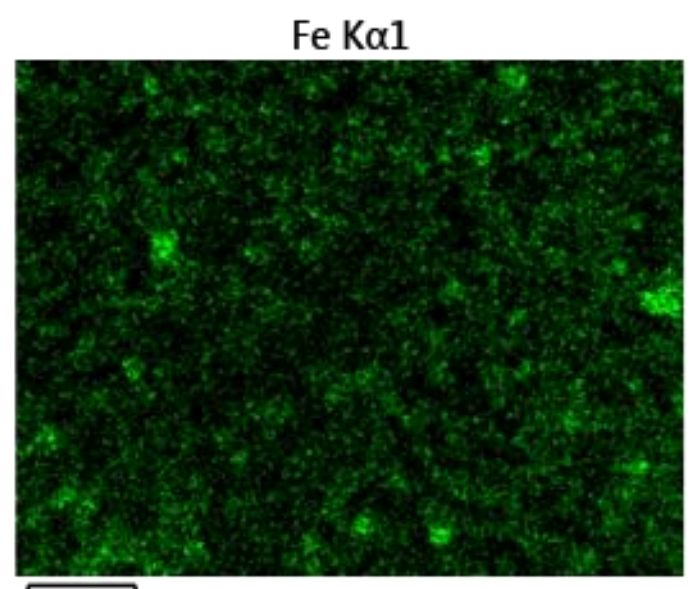

$\widehat{10 \mu \mathrm{m}}$
Ti K $\alpha 1$

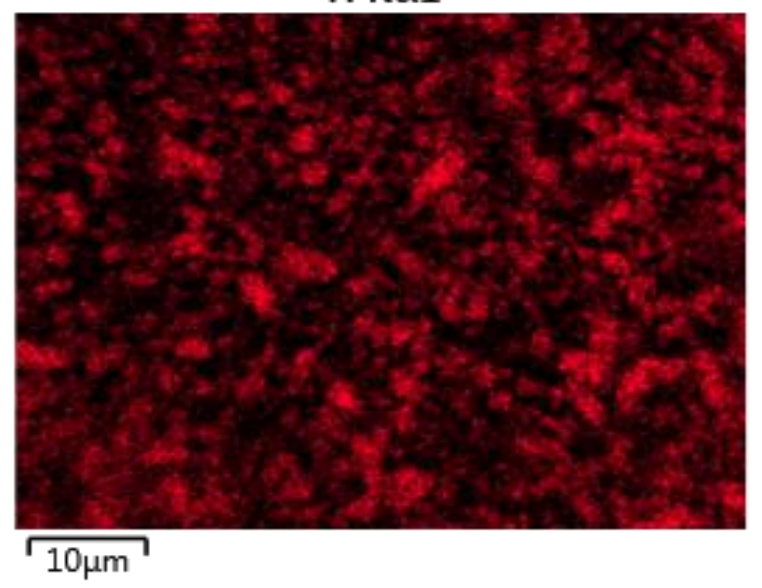

c)

Figure 4.12. $\mathrm{SEM}$ images of $\mathrm{Fe}_{2} \mathrm{O}_{3} / \mathrm{TiO}_{2}\left(\mathrm{Fe}: \mathrm{TiO}_{2}=0.15\right)$, (a) image of the whole sample, (b) image of iron particles, and (c) image of titanium particles.

Reprinted from J. Environ. Chem. Eng. 4 (2016) 4072-4082, with permission from Elsevier. 
Table 4.1. Point analysis of $\mathrm{Fe}_{2} \mathrm{O}_{3} / \mathrm{TiO}_{2},\left(\mathrm{Fe}\right.$ : $\left.\mathrm{TiO}_{2}=0.05\right)$ by $\mathrm{SEM} / \mathrm{EDS}$. Reprinted from J. Environ. Chem. Eng. 4 (2016) 4072-4082, with permission from Elsevier.

\begin{tabular}{lccc}
\hline Point & Ti $(\mathbf{W t}$. \%) & Fe (Wt. \%) & O (Wt. \%) \\
\hline Spectrum 1 & 55.3 & 0.8 & 43.9 \\
Spectrum 2 & 29.6 & 4.6 & 65.8 \\
Spectrum 3 & 37.1 & 7.7 & 55.2 \\
Spectrum 4 & 45.5 & 8.7 & 45.8 \\
Spectrum 5 & 40.4 & 10.7 & 48.9 \\
Spectrum 6 & 29.8 & 11.4 & 58.8 \\
\hline
\end{tabular}

Different values in the table are related to different points in the sample and show that bright particles mostly have more doped metal compared to those of dark particles. Specific surface area and morphology have significant roles in photocatalytic activity of materials. It is clear that the adsorption capability of organics onto the surface of a photocatalyst is related to specific surface area and the structure of the photocatalyst.

In other words, the photocatalytic activity of a photocatalyst, is almost related to the quantity of reactants that are adsorbed on the surface, which is directly comparative to the specific surface area of the photocatalyst.

Measuring specific surface area of samples using Brunauer-Emmet and Teller (BET) method showed that the bare $\mathrm{TiO}_{2}$ (anatase) has the lowest amount $\left(42.28 \mathrm{~m}^{2} / \mathrm{g}\right.$ ) and $\mathrm{Fe}_{2} \mathrm{O}_{3} / \mathrm{TiO}_{2}$ $\left(0.05 \mathrm{w} / \mathrm{w} \mathrm{Fe}: \mathrm{TiO}_{2}\right)$ with $190.17 \mathrm{~m}^{2} / \mathrm{g}$ has the highest specific surface area. $\mathrm{Ag} / \mathrm{TiO}_{2}(0.005)$ has higher specific surface area compares to that of the 0.01 and $0.05 \mathrm{Ag} / \mathrm{TiO}_{2}\left(58.91\right.$ and $49.09 \mathrm{~m}^{2} / \mathrm{g}$, respectively), but it has lower amount compares to those of $0.10 \mathrm{Fe}_{2} \mathrm{O}_{3} / \mathrm{TiO}_{2}(173.92 \mathrm{~m} / \mathrm{g})$ and even $0.30\left(142.94 \mathrm{~m}^{2} / \mathrm{g}\right)$. Results showed that there is a direct relationship between the specific surface area and the activity of photocatalyst. $\mathrm{Fe}_{2} \mathrm{O}_{3} / \mathrm{TiO}_{2}(0.05 \mathrm{w} / \mathrm{w})$ has the highest amount of specific surface area and it has higher photocatalytic activity compare to that of $\mathrm{Ag} / \mathrm{TiO}_{2}$ and bare $\mathrm{TiO}_{2}$. 
Combined photocatalysts have more specific surface area since iron ions might incorporate with the lattice crystals of $\mathrm{TiO}_{2}$ and also attach on the surface of titanium dioxide which act as electron trapping center. The bi-oxide composite photocatalyst creates huge quantities of photogenerated electron and holes by which electrons are transferred to oxygen species and produce more superoxide and in a sequence reactions produce more hydroperoxyl radical.

Photo-generated holes with water or hydroxyl ion generate hydroxyl radicals which directly oxidize organic materials. All reactions mentioned above could accelerate the photocatalytic activity and degrade more organic materials.

Figure 4.13a shows a diffractogram of $\mathrm{Fe}_{2} \mathrm{O}_{3} / \mathrm{TiO}_{2}(0.05 \mathrm{w} / \mathrm{w})$ calcined at $400^{\circ} \mathrm{C}$ taken by XRD. By comparing the $\mathrm{Fe}_{2} \mathrm{O}_{3} / \mathrm{TiO}_{2}$ diffractogram with the diffractogram bank (JCPDS-21-1272), it was observed that the crystallinity of the composite photocatalyst is totally in the anatase phase.

Figure $4.13 \mathrm{~b}$ shows a diffractogram of pure anatase calcined at $400^{\circ} \mathrm{C}$. No peak was found to belong to rutile or even $\mathrm{Fe}_{2} \mathrm{O}_{3}$ after comparison with the JCPDS-21-1272 database. The structure of the composite photocatalyst $\mathrm{Fe}_{2} \mathrm{O}_{3} / \mathrm{TiO}_{2}$ shows that $\mathrm{Fe}^{3+}$ entered in the crystal of $\mathrm{TiO}_{2}$ and substitution with $\mathrm{Ti}^{4+}$ occurred. This substitution was possible because both $\mathrm{Ti}^{4+}$ with $\mathrm{Fe}^{3+}$ have the same ionic crystal radius of 0.68A (Nasralla et al., 2013; Banisharif et al., 2015).

One of the most advantages of $\mathrm{Fe}_{2} \mathrm{O}_{3} / \mathrm{TiO}_{2}$ particles is the easy separation of photocatalyst from the slurry suspension after the process. It is because of the electromagnetic characteristic of $\mathrm{Fe}_{2} \mathrm{O}_{3} / \mathrm{TiO}_{2}$ particles. In other words, the separation of the photocatalyst can be done by applying a proper electromagnetic field or, at least, applying a ferromagnetic material and passing suspension through the field. 

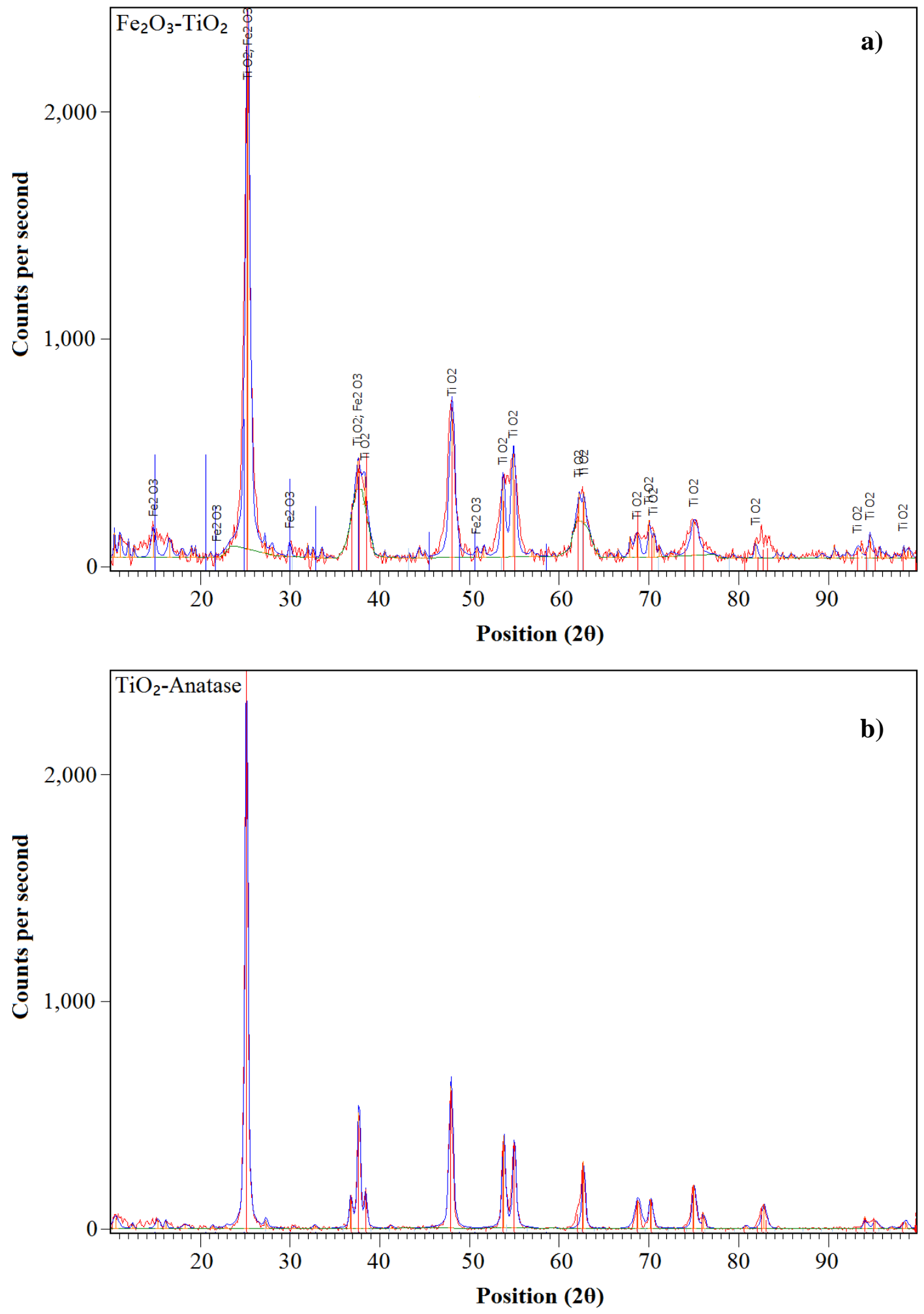

Figure 4.13. Comparison of diffractograms of a) $\mathrm{Fe}_{2} \mathrm{O}_{3} / \mathrm{TiO}_{2}(0.05 \%$ w/w $)$ and b) pure commercial $\mathrm{TiO}_{2}$ (Anatase).

Reprinted from J. Environ. Chem. Eng. 4 (2016) 4072-4082, with permission from Elsevier. 
To evaluate the stability and repeatability of combined photocatalyst $\left(\mathrm{Fe}_{2} \mathrm{O}_{3} / \mathrm{TiO}_{2}\right)$, the decomposition of $20 \mathrm{mg} / \mathrm{L}$ of MO solution was performed in the presence of the photocatalyst and UV irradiation. Then, the photocatalyst was separated and placed in an oven for $60 \mathrm{~min}$ in the presence of UV light. The photocatalyst was weighed and run again for the decomposition of MO in the same condition. Sequential runs were carried out for five times. Results showed that the yield of the decomposition of MO was almost the same, and there was not any failure in the regeneration of the photocatalytic activity.

Properties of photocatalysts are intensively related to the specific surface area, crystal structure, size, and the morphology of the crystal. Although there are many scientific reports related to the preparation of metal-doped $\mathrm{TiO}_{2}$, the configuration and the structure of doping is not clear yet. There are two theories for doping metals on $\mathrm{TiO}_{2}$, the first one is covering metals on the surface of the photocatalyst (Agustina et al., 2005; Liu et al., 2013) and the second one is the incorporation or substitution metal ion instead of $\mathrm{Ti}^{4+}$ in the crystal lattice of $\mathrm{TiO}_{2}$ (Wellia et al., 2011; Nasralla et al., 2013). According to the model proposed by Wellia et al.(2011), the doped metal can be placed in the lattice crystal of $\mathrm{TiO}_{2}$ and change the electronic properties of $\mathrm{TiO}_{2}$. Doping iron on $\mathrm{TiO}_{2}$ is an appropriate example in which iron with an ion radius of $0.64 \AA$ is almost similar to $\mathrm{Ti}^{4+}$ with the ion radius of $0.68 \AA$. It can be concluded that $\mathrm{Fe}^{3+}$ has been joined to the crystal lattice of $\mathrm{TiO}_{2}$.

Results showed that silver doped $\mathrm{TiO}_{2}$ increases the degradation of $\mathrm{MO}(12.2 \%)$ and $\mathrm{CR}$ (14.5\%) compared to that of bare $\mathrm{TiO}_{2}$. The degradation efficiency of $\mathrm{MO}$ and $\mathrm{CR}$ increases by applying composite photocatalyst of $\mathrm{Fe}_{2} \mathrm{O}_{3} / \mathrm{TiO}_{2}$ in the range of 28.9 and $25.1 \%$, respectively, compared to that of bare $\mathrm{TiO}_{2}$. 


\subsubsection{Photocatalyst efficiency and light absorption analysis}

As it mentioned earlier, doping metals onto $\mathrm{TiO}_{2}$ or combining of two photocatalysts might increase absorption of light in visible range which it is appropriate in photocatalytic method for degradation of organics.

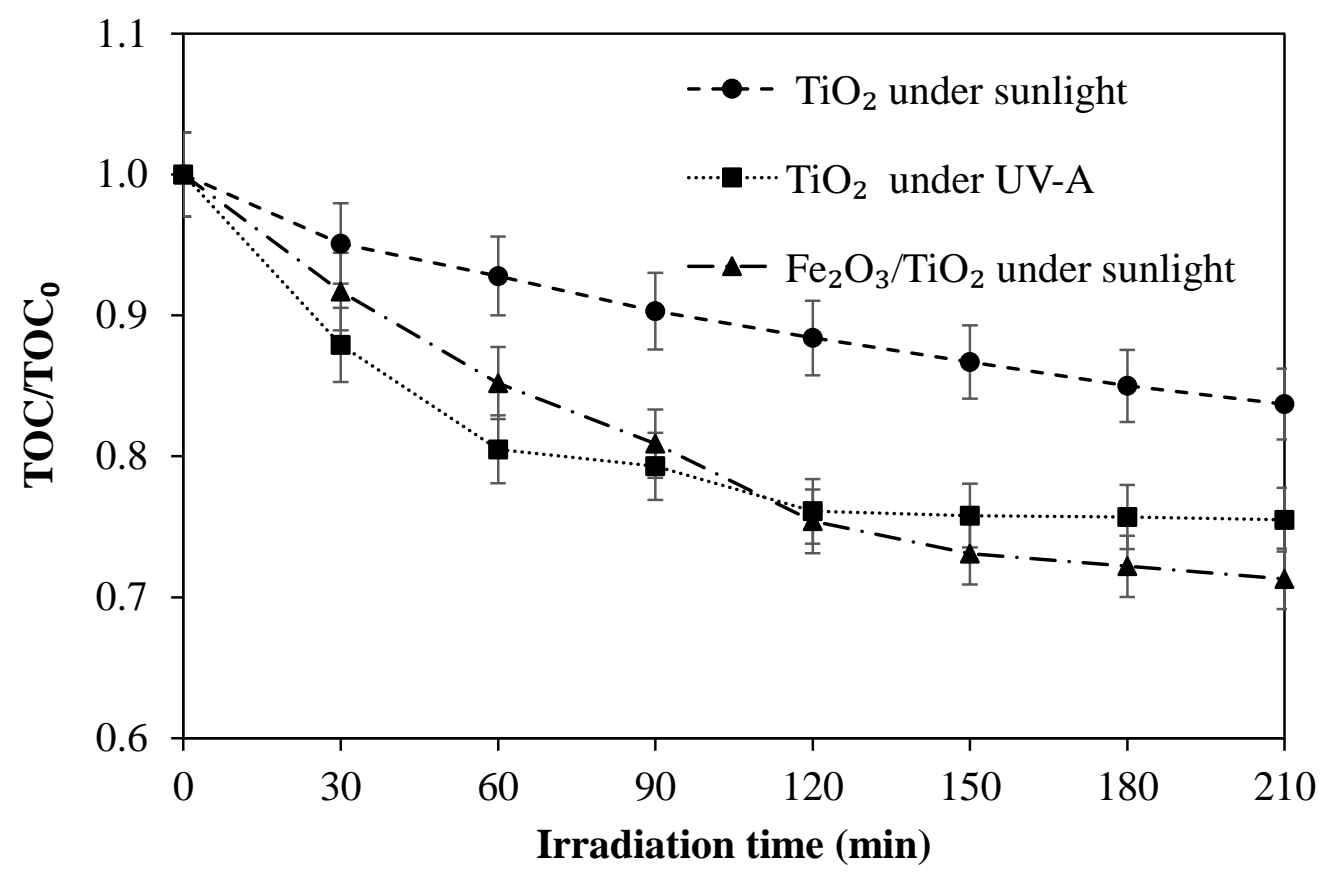

Figure 4.14. Comparison of bare $\mathrm{TiO}_{2}$ and composite of $\mathrm{Fe}_{2} \mathrm{O}_{3} / \mathrm{TiO}_{2}(0.05$ w/w $)$ photocatalysts for the degradation of MO under UV-A light $($ UV light power $=45 \mathrm{~W})$ and sunlight.

Reprinted from J. Environ. Chem. Eng. 4 (2016) 4072-4082, with permission from Elsevier.

Figure 4.14 shows the comparison of bare $\mathrm{TiO}_{2}$ and composite of $\mathrm{Fe}_{2} \mathrm{O}_{3} / \mathrm{TiO}_{2}(0.05 \mathrm{w} / \mathrm{w})$ for the degradation of MO under UV-A light and sunlight. Results showed the degradation of MO in presence of the composite $\mathrm{Fe}_{2} \mathrm{O}_{3} / \mathrm{TiO}_{2}(0.05 \mathrm{w} / \mathrm{w})$ photocatalyst under sunlight was $28.7 \%$ significantly higher than that of bare $\mathrm{TiO}_{2}$ under same conditions under sunlight (16.3\%) and even higher than that under UV-A irradiation (45 watts), which reached up to $24.5 \%$. In other words, the presence of $\mathrm{Fe}_{2} \mathrm{O}_{3}$ in the composite of $\mathrm{Fe}_{2} \mathrm{O}_{3} / \mathrm{TiO}_{2}$ caused a red shift and enhanced the potential 
to absorb a higher range of visible light, which is appropriate for the degradation of organics in photocatalysis.

\subsection{Conclusions}

To get past current restrictions of the fast rate of electron-hole recombination and slight excitation in solar irradiation, doping with noble metals and combination of two semiconductor oxides are two convenient alternatives. The sol-gel hydrothermal method was used to synthesize $\mathrm{Ag} / \mathrm{TiO}_{2}$ and $\mathrm{Fe}_{2} \mathrm{O}_{3} / \mathrm{TiO}_{2}$ with the different mass ratios. Results showed that $0.005 \mathrm{Fe}_{2} \mathrm{O}_{3} / \mathrm{TiO}_{2}$ (Fe: $\left.\mathrm{TiO}_{2} \mathrm{w} / \mathrm{w}\right)$ had the higher efficiency for the degradation of MO (16.7\%) and CR (10.6\%), compared to that of $\mathrm{Ag} / \mathrm{TiO}_{2}$ for $\mathrm{MO}(12.2 \%)$ and $\mathrm{CR}(14.5 \%)$, whereas bare $\mathrm{TiO}_{2}$ for $\mathrm{MO}(25.3 \%)$ and CR (29.0\%), respectively. Doping metals to $\mathrm{TiO}_{2}$ hinders the recombination of electron-hole pairs. Doping different metal ions showed different photoactivity because of various electron affinities (charge transferability) of doped metals, difference in surface area, and their physicochemical properties. The presence of $\mathrm{Fe}_{2} \mathrm{O}_{3}$ in the composite caused a red shift and enhanced the potential to absorb a higher range of visible light. Doping metals or combining photocatalysts could change the electronic structure and band gap energy of the main photocatalyst. 


\title{
CHAPTER 5
}

\section{PHOTOCATALYTIC EFFICIENCY OF $\mathrm{Fe}_{2} \mathrm{O}_{3} / \mathrm{TiO}_{2} \mathrm{ON}$ THE}

\author{
DEGRADATION OF TYPICAL DYES IN THE TEXTILE
}

INDUSTRY: EFFECT OF CALCINATION TEMPERATURE

\section{AND UV-ASSISTED THERMAL SYNTHESIS*}

\begin{abstract}
The inadequate management practices in industrial textile effluents have a considerable negative impact on the environment and human health due to the indiscriminate release of dyes. Photocatalysis is one of the diverse AOPs and titanium dioxide $\left(\mathrm{TiO}_{2}\right)$ is recognized for its high oxidation and reduction power. A composite photocatalyst of $\mathrm{Fe}_{2} \mathrm{O}_{3} / \mathrm{TiO}_{2}$ is synthesized using different mass ratios of $\mathrm{Fe}: \mathrm{TiO}_{2}$ to improve its photoactivity. The composite photocatalyst is calcined at 300 to $900^{\circ} \mathrm{C}$. Their photocatalytic activity for the degradation of Congo red and methyl orange is investigated by total organic carbon (TOC) analysis. The formation and characterization of the as-prepared composite are studied by scanning electron microscopy (SEM) coupled with energy dispersive X-ray spectroscopy (EDS). The effect of calcination temperature of the composite $\mathrm{Fe}_{2} \mathrm{O}_{3} / \mathrm{TiO}_{2}$ photocatalyst is investigated using Fourier transform infrared spectroscopy (FTIR). Photocatalytic activity and phase conversion are studied by X-ray diffraction (XRD).
\end{abstract}

\footnotetext{
"Reprinted, with minor editorial changes to fulfill formatting requirements, from: Nasirian, M., Bustillo-Lecompte, C.F., Mehrvar, M,.2017. Photocatalytic efficiency of $\mathrm{Fe}_{2} \mathrm{O}_{3} / \mathrm{TiO}_{2}$ for the degradation of typical dyes in textile industries: Effects of calcination temperature and UV-assisted thermal synthesis, Journal of Environmental Management, 196, 487-497

http://dx.doi.org/10.1016/j.jenvman.2017.03.030.
} 
Specific surface area of photocatalysts at different calcination temperatures is investigated based on Brunauer-Emmett-Teller (BET) surface area analysis. Results show that the transformation of $\mathrm{TiO}_{2}$ from anatase to rutile is facilitated by high temperature and high concentration of iron while high crystallization and particle size increase occur. An optimum calcination temperature of $300^{\circ} \mathrm{C}$ is found at which the degradation of typical dyes in the textile industry is maximum.

Keywords: Photocatalysis, calcination temperature, $\mathrm{Fe}_{2} \mathrm{O}_{3} / \mathrm{TiO}_{2}$, dye degradation.

* Reprinted, with minor editorial changes to fulfill formatting requirements, from: Nasirian, M., Bustillo-Lecompte, C.F., Mehrvar, M,.2017. Photocatalytic efficiency of $\mathrm{Fe}_{2} \mathrm{O}_{3} / \mathrm{TiO}_{2}$ for the degradation of typical dyes in textile industries: Effects of calcination temperature and UV-assisted thermal synthesis, Journal of Environmental Management, 196, 487-497. http://dx.doi.org/10.1016/j.jenvman.2017.03.030 


\subsection{Introduction}

The industrial textile effluents contain a large variety of dyes that without proper treatment prior to their disposal become toxic to microorganisms and aquatic life. The indiscriminate release of dyes has a considerable negative impact on the environment and human health. Dye by-products can be produced through oxidation, hydrolysis, or other chemical reactions taking place in the wastewater, which may cause eutrophication events. Approximately $20 \%$ of the total dye and worldwide pigment production is lost during the dyeing process and released as part of the textile wastewater effluents (Akpan and Hameed, 2009).

Conventional physicochemical technologies including activated carbon adsorption, membrane technologies, coagulation-flocculation, and ion exchange, have been used for the removal of dyes. However, these traditional methods only transfer organic compounds from the liquid to the solid phase, which requires further treatment and involves regeneration of the adsorbent or membrane replacement, augmenting the overall treatment costs (Tang and An, 1995; Konstantinou and Albanis, 2004). Consequently, the degradation of dyes from industrial textile effluents has received increasing attention to improve the efficiency of treatment methods.

Recent studies have been devoted to the use of advanced oxidation processes (AOPs) for the removal of dyes from wastewater, particularly, because of the ability of these methods to completely mineralize the target pollutants (Visa et al., 2011; De Andrade et al., 2012; Zou, 2015; Mohajerani et al., 2011, 2016; Buthiyappan et al., 2016; Nasirian and Mehrvar, 2016).

Advanced oxidation processes (AOPs) are based on the generation of hydroxyl radicals, which can oxidize almost all organic materials in wastewater (Hamad et al., 2014, 2016; Mowla

et al., 2014; Bustillo-Lecompte and Mehrvar, 2015, 2016; Bustillo-Lecompte et al., 2013, 2014, 2015, 2016a, 2016b). Furthermore, HO', with an oxidation potential of $2.8 \mathrm{eV}$, is the strongest 
oxidant after fluorine $(3.06 \mathrm{eV})$. Fluorine is highly toxic and cannot be used for wastewater treatment; thus, AOPs are used instead for HO generation (Ince and Tezcanlí, 2001; Kim et al., 2010).

Photocatalysis is one of the diverse types of AOPs, and titanium dioxide $\left(\mathrm{TiO}_{2}\right)$ is recognized for its strong oxidation and reduction power among them, being first studied by Fujishima and Honda (1972). Among all photocatalysts, $\mathrm{TiO}_{2}$ have been widely studied as one of the most promising photocatalysts for wastewater treatment because of its superior properties, including high reactivity, non-toxicity, high physicochemical stability, and low price (Akpan and Hameed, 2009). Despite all advantages of $\mathrm{TiO}_{2}$, there are two major limitations in its photocatalytic activity including its activation only in the ultraviolet range under $387 \mathrm{~nm}(3.2 \mathrm{eV})$ and a high rate of electron-hole recombination. The efficiency of the photocatalysis depends on how well a photocatalyst can prevent this charge recombination. Other limitations include the recovery of the $\mathrm{TiO}_{2}$ particles after treatment of wastewater in slurry form and the low adsorption capacity for hydrophobic contaminants (Peng et al., 2010; Liu et al., 2015; Nasirian and Mehrvar, 2016).

To overcome the limitations of $\mathrm{TiO}_{2}$ as a photocatalyst, a variety of methods are applied to improve its photocatalytic activity. These improving methods include metal and non-metal doping, combining different semiconductor photocatalysts, photo-synthesizing composites, and adding some oxidant species. Each method has its own strengths and weaknesses (Etacheri et al., 2015; Sudha and Sivakumar, 2015; Fagan et al., 2016; Reddy et al., 2016).

An effective method to increase the photocatalytic activity is to improve the surface area by doping metal ions such as $\mathrm{Au}, \mathrm{Ag}, \mathrm{Pt}, \mathrm{Co}, \mathrm{Ni}, \mathrm{Fe}$, and $\mathrm{Zn}$ into $\mathrm{TiO}_{2}$ (Shah et al., 2002; Zhang et al., 2003; Barakat et al., 2005; Colón et al., 2006; Bandara and Ranasinghe, 2007; Cao et al., 
2008; Silva et al., 2009; Gao et al., 2010). Other doping methods include the co-deposition of noble metals $(\mathrm{Au}, \mathrm{Ag}$, and $\mathrm{Pt})$ that are resistant to oxidation or corrosion on $\mathrm{TiO}_{2}$ (Zhang et al., 2003; Bandara and Ranasinghe, 2007).

Iron (III) oxide $\left(\mathrm{Fe}_{2} \mathrm{O}_{3}\right)$ with a low band gap energy of $2.2 \mathrm{eV}$ could be activated under visible light and has the advantages of low cost, non-toxic, and high chemical and physical stability. Nevertheless, there are some disadvantages for using $\mathrm{Fe}_{2} \mathrm{O}_{3}$ as a photocatalyst alone, including low electrical conductivity and difficulty to isolate photo-induced electron and hole to prevent fast recombination. Consequently, $\mathrm{Fe}_{2} \mathrm{O}_{3}$ has been considered as a capable semiconductor for combining with titanium dioxide to increase the photocatalytic activity. However, doping is not only used to improve the surface area of a photocatalyst, but it can be also used to change its crystallinity and molecular structure. The structural properties of $\mathrm{TiO}_{2}$, including its crystalline phase, size, surface area, and pore distribution, are important parameters for the improvement of the photocatalytic activity (Cai et al., 2016).

Calcination is a thermal treatment process of solids by heating a material at a very high temperature, and it is usually done in the presence of air or nitrogen gas. This action initiates the repulsion of some volatile materials such as water, organic materials, and carbon dioxide from the sample without any fusion. Sometimes calcination is used to change physicochemical properties or constitution of materials (changing phase or changing metal to metal oxide). The calcination temperature is a central parameter in the synthesis of photocatalysts and can play a critical role in controlling their physicochemical properties and photocatalytic activity (Yu et al., 2002; Chen and Dionysiou, 2006; Zhou et al., 2008; Vijayan et al., 2010; Lv et al., 2011; Fan et al., 2012; Cai et al., 2016). Therefore, it is important to evaluate the effect of the calcination temperature on the photocatalytic activity and mechanical stability of the photocatalysts. 
In this study, a series of $\mathrm{Fe}_{2} \mathrm{O}_{3} / \mathrm{TiO}_{2}$ at various mass ratios of $\mathrm{Fe}$ : $\mathrm{TiO}_{2}$ is synthesized using a novel UV-assisted thermal method, as an alternative approach to conventional individual methods to improve photocatalytic activity. Additionally, the effects of the calcination temperature of photocatalysts on structural change and on the degradation of methyl orange (MO) and Congo red (CR), as typical dyes in textile industries, were investigated.

\subsection{Materials and Methods}

\subsubsection{Materials}

All chemical materials were analytical grade, purchased from Sigma-Aldrich (Oakville, ON) and Van Waters and Nat Rogers (VWR, Mississauga, ON). All chemicals were used as received.

\subsubsection{Instrumentation}

Total organic carbon (TOC) analyzer (Teledyne Tekmar, model Apollo 9000, Mason, OH) was used to measure the concentration of organic materials in samples. All samples were first centrifuged at $4000 \mathrm{rpm}$ for 30 min using a centrifuge (Thermo Scientific Heraeus Multifuge X1, Mississauga, ON). After centrifugation, samples were filtered by filter papers (VMR Qualitative 410, Mississauga, ON) and then analyzed by the TOC analyzer.

All prepared photocatalysts were dried in BINDER oven model ED 115- UL. Programmable furnace Thermo Scientific model Lindberg Blue M was used for the calcination of samples at different temperatures. Scanning electron microscopy (SEM) (JEOL, JSM-6370LV, Calgary, AB) coupled with energy dispersive spectroscopy (EDS) (Oxford Instrument Model X- 
Max-N-80, Concord, MA) was used to obtain the combined information of morphology and chemical composition of individual particles.

An auto sputter coater (Denton Vacuum Desk IV, Moorestown, NJ) was used for coating samples with a thin layer of gold before analysis by SEM. Brunauer-Emmett-Teller (BET) method was used to measure the specific surface area of the dried photocatalyst powders (Quantachrome Nova-e 1200, Burlington, ON). X-ray diffraction (XRD) model PANalytical X'pert PRO (St Laurent, QC) was used to investigate the crystal structure and conversion phase of $\mathrm{TiO}_{2}$. The scanning range of XRD was $10-100^{\circ}(2 \theta)$. Additionally, Fourier-transform infrared (FTIR) spectra were obtained by spectrophotometry (Agilent Cary 630, Mississauga, ON) to determine functional groups and the structure of photocatalysts at different calcination temperatures. The FTIR has a diamond attenuated total reflection (ATR) crystal accessory that allows for rapid analysis. All instruments were calibrated per their procedures.

\subsubsection{Experimental setup and procedure}

The photocatalytic activity of as-prepared photocatalysts was tested using a batch photoreactor as illustrated in Figure 5.1. The experimental setup consists of a 3.5-L cylindrical glass container for degradation of organic materials. Five UV-A lamps (each 9 watts) with the maximum peak of $365 \mathrm{~nm}$ (Philips-Actinic BLPL-S) were placed vertically in the photoreactor.

The photoreactor was placed inside a water container, controlled by a cooling bath (RTE211, NESLAB Instruments, Inc., Newington, NH) to recirculate the bath water in the cooling tank for temperature control (photoreactor temperature was set at $25^{\circ} \mathrm{C}$ ). A magnetic stirrer was used to mix the solution thoroughly in the photoreactor. Aluminum foil was wrapped around the external surface of the cooling water tank to reflect the UV radiation to the sample. The initial 
concentration of dyes (MO and CR) was $30 \mathrm{mg} / \mathrm{L}$. The photocatalyst powder was added into the photoreactor as a slurry, and then mixed by the magnetic stirrer.

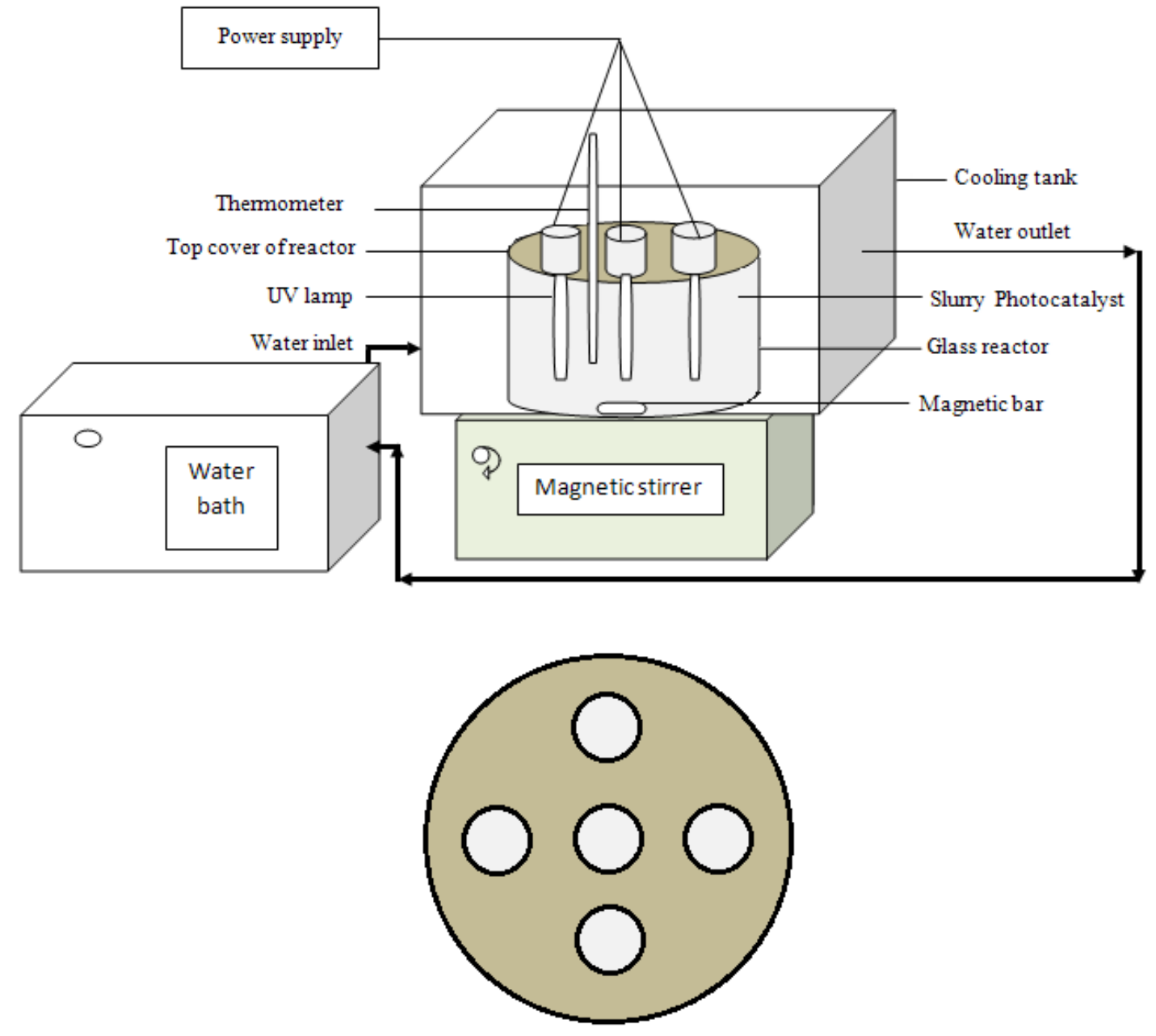

UV lamps distribution

Figure 5.1. Schematic diagram of the laboratory-scale batch suspension photoreactor. Reprinted from J. Environ. Manage. 196 (2017) 487-498, with permission from Elsevier.

\subsubsection{UV-assisted thermal synthesis}

Different doping methods are proposed to enhance the activity of photocatalysts, especially in the range of visible region. These methods include sol-gel, hydrothermal, combination of solgel and hydrothermal, chemical vapor deposition, plasma or microwave assisted methods. 
Several factors such as the concentration of reactants, temperature, surface area of photocatalysts, and light with proper energy affect the rate of photochemical reactions. The short wavelength of the UV light can be considered as a good source of energy and is able to overcome the activation energy barrier to break chemical bonds and produce new products. If the UV light intensity increases, more particles are activated, collisions are more frequent, and the speed of reaction also increases (Ranjan and Sasselov, 2016). The heating of any mixture of reactants by the strong electron beam greatly changes the chemical kinetics of reactions compared to those of thermal processes.

It has been proven that the electron irradiation significantly speeds up the synthesis process of reactions at low temperatures for different oxide systems $\left(\mathrm{NaFeO}_{2}, \mathrm{BaTiO}_{3}, \mathrm{NiFe}_{2} \mathrm{O}_{4}, \mathrm{LiFe}_{5} \mathrm{O}_{8}\right.$, $\mathrm{MnFe}_{2} \mathrm{O}_{4}, \mathrm{ZnFe}_{2} \mathrm{O}_{4}$, among others) (Surzhikov et al., 2014). According to Ranjan and Sasselov (2016), UV photons are very energetic to change the structure of molecules by splitting bonds (photolysis), exciting molecules into a higher level of energy (photoexcitation) or ionization of molecules (photo-ionization).

In this study, a novel UV-assisted thermal synthesis was used due to its effectiveness for the enhancement of the photocatalytic activity. This approach is presented as an alternative to conventional methods and the latest advances in photocatalytic treatment (Reddy et al., 2016). To increase the productivity, UV-C was used to assist the thermal treatment method while minimizing the additional heating requirements. The photoactivity of the prepared photocatalysts was measured by degradation of $\mathrm{MO}$ and $\mathrm{CR}$ at $25^{\circ} \mathrm{C}$. The UV-C glass tubes were transparent with no phosphorus coating and maximum light emission at $254 \mathrm{~nm}(85-90 \%)$ and $185 \mathrm{~nm}(10-15 \%)$. Fuse quarts eliminates light centered at $185 \mathrm{~nm}$ (Moussavi et al., 2016); thus, only the UV-C peak centered at $254 \mathrm{~nm}$ passes through the glass tube. 


\subsubsection{Synthesis of $\mathrm{Fe}_{2} \mathrm{O}_{3} / \mathrm{TiO}_{2}$}

First, nano- $\mathrm{TiO}_{2}$ photocatalyst was synthesized using tetrabutoxy titanium with ethylene glycol using sol gel synthesis. The synthetized nano- $-\mathrm{TiO}_{2}$ was placed in furnace then calcined at $300^{\circ} \mathrm{C}$ for $8 \mathrm{~h}$. Subsequently, the $\mathrm{Fe}_{2} \mathrm{O}_{3} / \mathrm{TiO}_{2}$ composite was synthesized using the precursor of as prepared nano- $\mathrm{TiO}_{2}$, iron (III) nitrate nonahydrate in ethanol, and applying the UV-assisted thermal synthesis by setting up a glassware reactor at atmospheric pressure and at a temperature of $90^{\circ} \mathrm{C}$ (Figure 2 appendix B).

In the UV-assisted thermal synthesis, for the preparation of the $\mathrm{Fe}_{2} \mathrm{O}_{3} / \mathrm{TiO}_{2}$ photocatalyst, all reactants with specific amounts were put in a Pyrex flat bottom flask $(100 \mathrm{~mL})$. Then, the flask was placed on an electrical heater with magnetic stirrer plate to continuously mix the reactants. A long glass condenser was used to recover the condensed vapor. Three UVC lamp (PL-S-9W/TUVUV Germicide, and 110-120V-G23 Base) were placed vertically outside and almost $2 \mathrm{~cm}$ from the flask. Reaction was conducted at $90^{\circ} \mathrm{C}$, atmospheric pressure, and using conventional glassware for $5 \mathrm{~h}$ to produce the $\mathrm{Fe}_{2} \mathrm{O}_{3} / \mathrm{TiO}_{2}$ photocatalyst. Samples were centrifuged, dried at $120^{\circ} \mathrm{C}$, and then the composite photocatalyst was divided into eight portions. Each portion was calcined at a specific temperature, starting at 200 and each time increased by $100^{\circ} \mathrm{C}$; thus, the last portion was calcined at $900^{\circ} \mathrm{C}$. Based on the stoichiometry of the reaction and by applying different amounts of the components, the composite photocatalyst $\mathrm{Fe}_{2} \mathrm{O}_{3} / \mathrm{TiO}_{2}$ was prepared in $0.005,0.01$, $0.05,0.10$, and $0.30 \mathrm{w}: \mathrm{w}$ mass ratios of $\mathrm{Fe}: \mathrm{TiO}_{2}$.

\subsubsection{Photocatalytic activity analysis}

All photocatalytic experiments were carried out in slurry form within a batch photoreactor. For all experiments, the equilibrium time for adsorption/desorption of the organic materials on the 
surface of the composite photocatalysts in dark was considered and monitored by measuring the TOC concentration. Each experiment was repeated in triplicates, and the mean values were reported.

\subsection{Results and Discussion}

\subsubsection{Photocatalytic degradation of organics: preliminary results}

The bare $\mathrm{TiO}_{2}$ photocatalysts in the presence of UV irradiation was able to degrade MO and CR, as shown in Figure 5.2. It is evident that the range of degradation using bare $\mathrm{TiO}_{2} / \mathrm{UV}$ for dyes is not high. Figure 5.2 also shows that the degradation efficiency of organics in the presence of bare $\mathrm{Fe}_{2} \mathrm{O}_{3}$ and UV light reached up to 24.3 and $15.4 \%$ for MO and CR, respectively, which does not represent a high-efficiency value either.

The composite $\mathrm{Fe}_{2} \mathrm{O}_{3} / \mathrm{TiO}_{2}$ photocatalyst was also assessed with different mass ratio of the dopant $\left(0.01,0.05,0.10\right.$, and $\left.0.30 \mathrm{w}: \mathrm{w} F: \mathrm{TiO}_{2}\right)$ as a comparison for the degradation of $\mathrm{MO}$ (Figure 5.2a) and CR (Figure 5.2b). Figure 5.2 shows that the maximum degradation efficiencies for MO and CR of 61.5 and $46.8 \%$, respectively, were obtained using the composite $\mathrm{Fe}_{2} \mathrm{O}_{3} / \mathrm{TiO}_{2}$ photocatalyst with 0.01 w:w $\mathrm{Fe}: \mathrm{TiO}_{2}$, which represents an improvement of 40-60\% when compared to the efficiency from bare $\mathrm{TiO}_{2}$ (40.1 and $18.7 \%$ for $\mathrm{MO}$ and $\mathrm{CR}$, respectively).

\subsubsection{Characterization of the $\mathrm{Fe}_{2} \mathrm{O}_{3} / \mathrm{TiO}_{2}$ photocatalyst}

SEM images of the composite $\mathrm{Fe}_{2} \mathrm{O}_{3} / \mathrm{TiO}_{2}$ photocatalyst, prepared by the UV-assisted thermal synthesis, are depicted in Figure 5.3. The $\mathrm{Fe}_{2} \mathrm{O}_{3} / \mathrm{TiO}_{2}$ particles exhibited a heterogeneous shape micrometer-sized. It is confirmed from images that the particle size of the photocatalyst varies between $0.5-4.7 \mu \mathrm{m}$. 

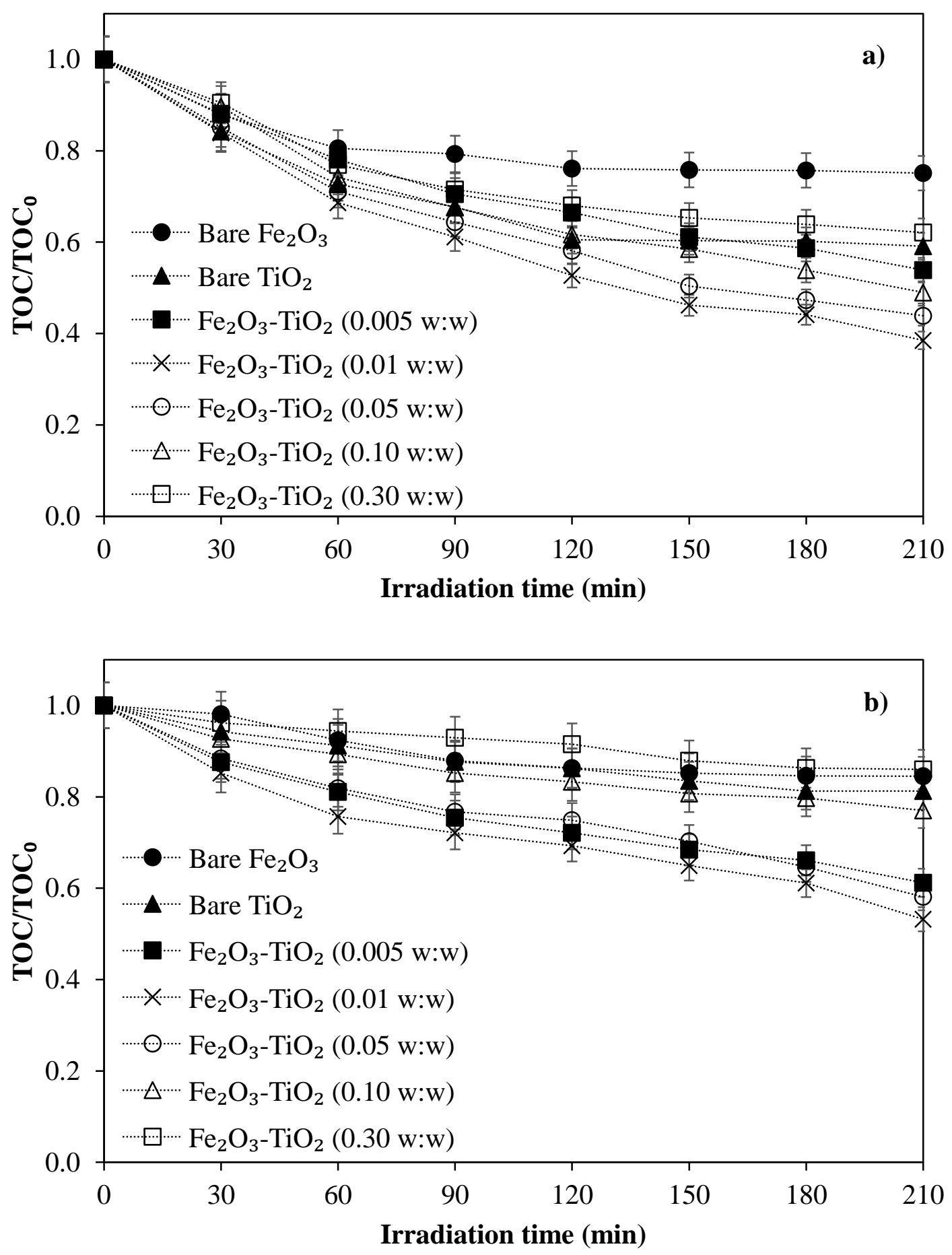

Figure 5.2. Comparison of the degradation of (a) methyl orange and (b) Congo red using $\mathrm{TiO}_{2}$ photocatalyst and composites of $\mathrm{Fe}_{2} \mathrm{O}_{3} / \mathrm{TiO}_{2}$ photocatalysts (Initial concentration of each organic material $=30 \mathrm{mg} / \mathrm{L}$, concentration of each photocatalyst $=300 \mathrm{mg} / \mathrm{L}, \mathrm{UV}$ light power $=45 \mathrm{~W}$ ).

Reprinted from J. Environ. Manage. 196 (2017) 487-498, with permission from Elsevier. 

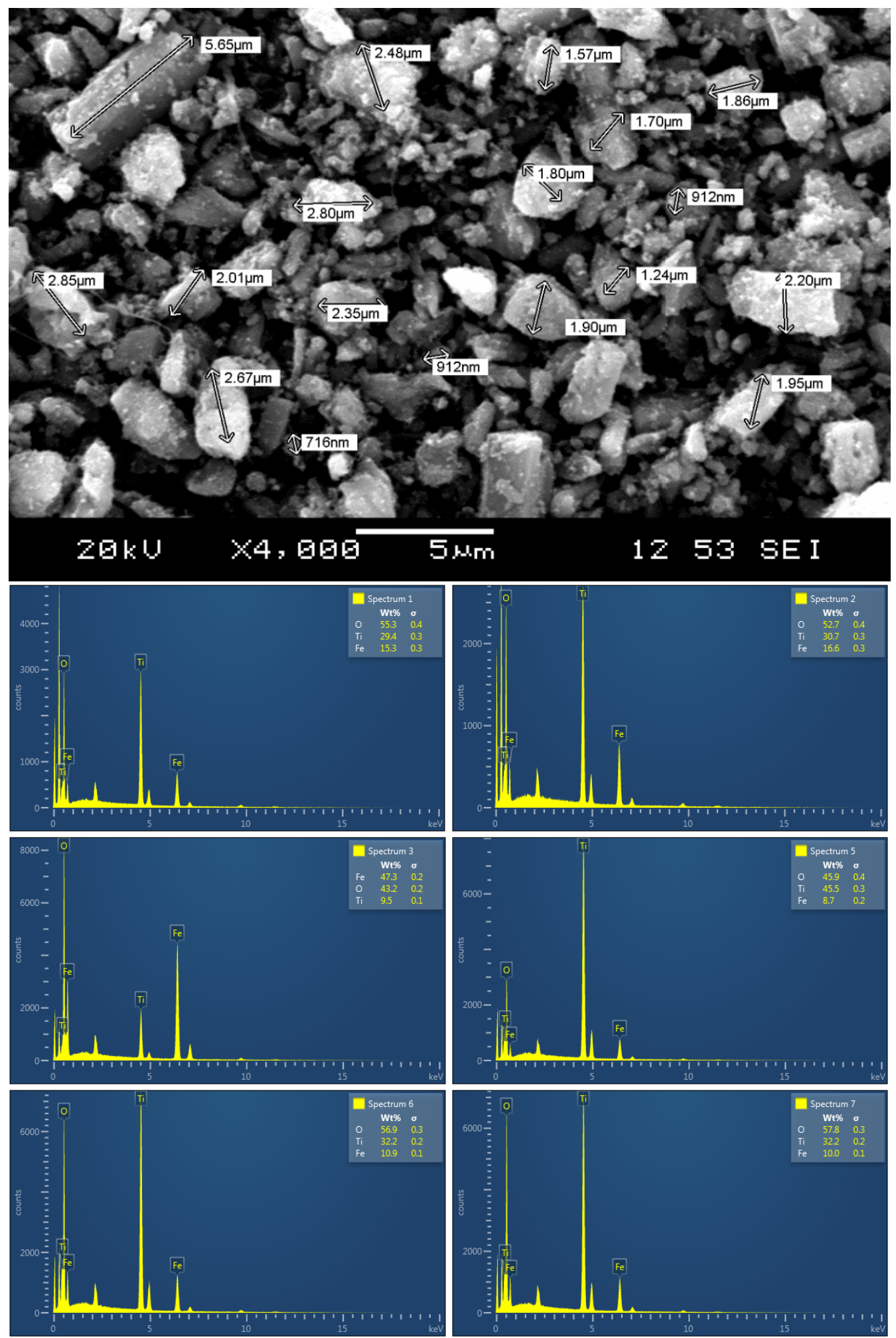

Figure 5.3. SEM image of $\mathrm{Fe}_{2} \mathrm{O}_{3} / \mathrm{TiO}_{2}\left(0.10\right.$ w:w mass ratio of $\left.\mathrm{Fe}: \mathrm{TiO}_{2}\right)$, and elemental analysis based on weight percent of $\mathrm{Fe}_{2} \mathrm{O}_{3} / \mathrm{TiO}_{2}\left(\mathrm{Fe}: \mathrm{TiO}_{2}=0.10 \mathrm{w}: \mathrm{w}\right)$ at different points taken by EDS.

Reprinted from J. Environ. Manage. 196 (2017) 487-498, with permission from Elsevier. 
Figure 5.3 also shows the elemental analysis of the $\mathrm{Fe}_{2} \mathrm{O}_{3} / \mathrm{TiO}_{2}$ photocatalyst $(0.10 \mathrm{w}: \mathrm{w}$ Fe: $\mathrm{TiO}_{2}$ ) by EDS. Results from EDS elemental analysis correspond to the expected concentration. SEM images taken from samples at higher calcination temperature indicated that the size and thickness of the crystal particles composing the flakes were increased.

In order to measure the specific surface area of a powder sample using the BET method, the amount of an adsorbed inert gas such as nitrogen on the photocatalyst powder is measured. The amount of the adsorbed gas corresponds to a monomolecular layer on the surface.

There is a direct correlation between the specific surface area and the performance of a photocatalyst. When the specific surface area is high, the photocatalyst adsorbs more pollutant, a characteristic for the high activity of the photocatalyst (Akpan and Hameed, 2009).

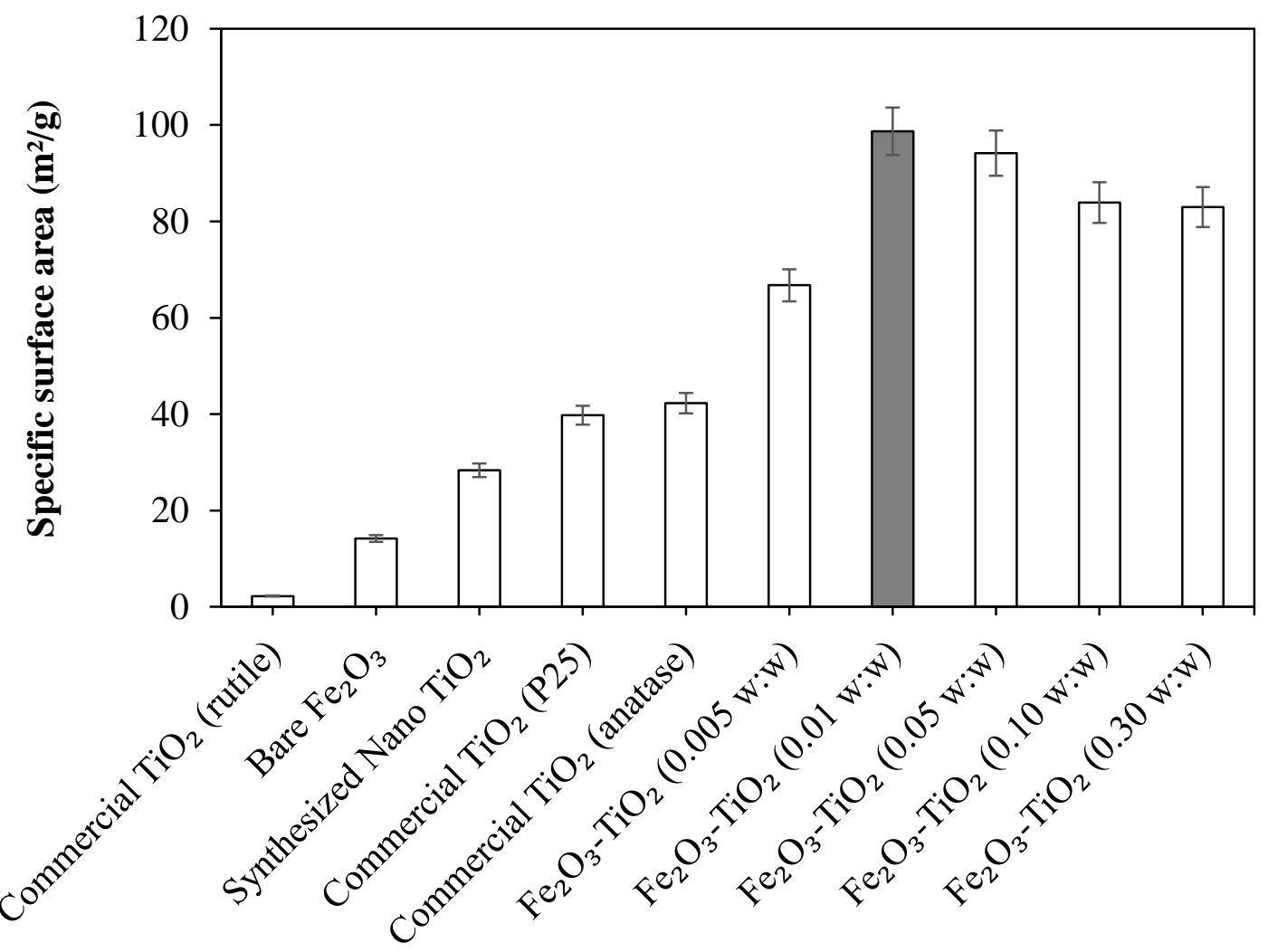

Figure 5.4. Comparison of specific surface areas of several photocatalysts calcined at $300^{\circ} \mathrm{C}$ (in all photocatalysts, w:w means mass ratio of $\mathrm{Fe}: \mathrm{TiO}_{2}$ ).

Reprinted from J. Environ. Manage. 196 (2017) 487-498, with permission from Elsevier. 
Figure 5.4 shows a comparison of the specific surface area of the prepared composite $\mathrm{Fe}_{2} \mathrm{O}_{3} / \mathrm{TiO}_{2}$ photocatalyst with different mass ratios (calcined at $300^{\circ} \mathrm{C}$ ) along with several commercial photocatalysts including rutile, iron (III) oxide, anatase, and P25 with nanosynthesized $\mathrm{TiO}_{2}$.

Results show that rutile has the lowest specific surface area $\left(2.24 \mathrm{~m}^{2} / \mathrm{g}\right)$ and the composite $\mathrm{Fe}_{2} \mathrm{O}_{3} / \mathrm{TiO}_{2}$ photocatalyst $\left(0.01 \mathrm{w}: \mathrm{w} \mathrm{Fe}: \mathrm{TiO}_{2}\right)$ with $98.73 \mathrm{~m}^{2} / \mathrm{g}$ has the highest specific surface area. It is remarkable that the specific surface areas of the bare $\mathrm{Fe}_{2} \mathrm{O}_{3}$ and anatase are only 14.15 and $42.28 \mathrm{~m}^{2} / \mathrm{g}$, respectively. These results confirm that the combination of metal oxide photocatalysts increases the specific surface area, and therefore, the degradation efficiency.

\subsubsection{Effects of specific surface area and calcination temperature on the photocatalytic activity of $\mathrm{Fe}_{2} \mathrm{O}_{3} / \mathrm{TiO}_{2}$}

Decomposition rates of organic materials by applying heterogeneous photocatalysts follow a kinetic model based on Langmuir isotherm surface-adsorbed reactants (Yan et al., 2006; Amano et al., 2010; Hamadanian et al., 2010; Mazinani et al., 2014).

Based on this model, the photocatalytic degradation of organic materials is almost proportional to the number of reactants adsorbed on the surface of the photocatalyst. Thus, the amount of adsorbed pollutants on the surface has a direct relationship to the specific surface area of the photocatalyst.

The specific surface areas of $\mathrm{Fe}_{2} \mathrm{O}_{3} / \mathrm{TiO}_{2}$ at different calcination temperatures and mass ratios are shown in Figures 5.5a and 5.5b. The highest specific surface area was observed for the $\mathrm{Fe}_{2} \mathrm{O}_{3} / \mathrm{TiO}_{2}$ photocatalyst with $0.01 \mathrm{w}: \mathrm{w} \mathrm{Fe}: \mathrm{TiO}_{2}$ calcined at $300^{\circ} \mathrm{C}$. 

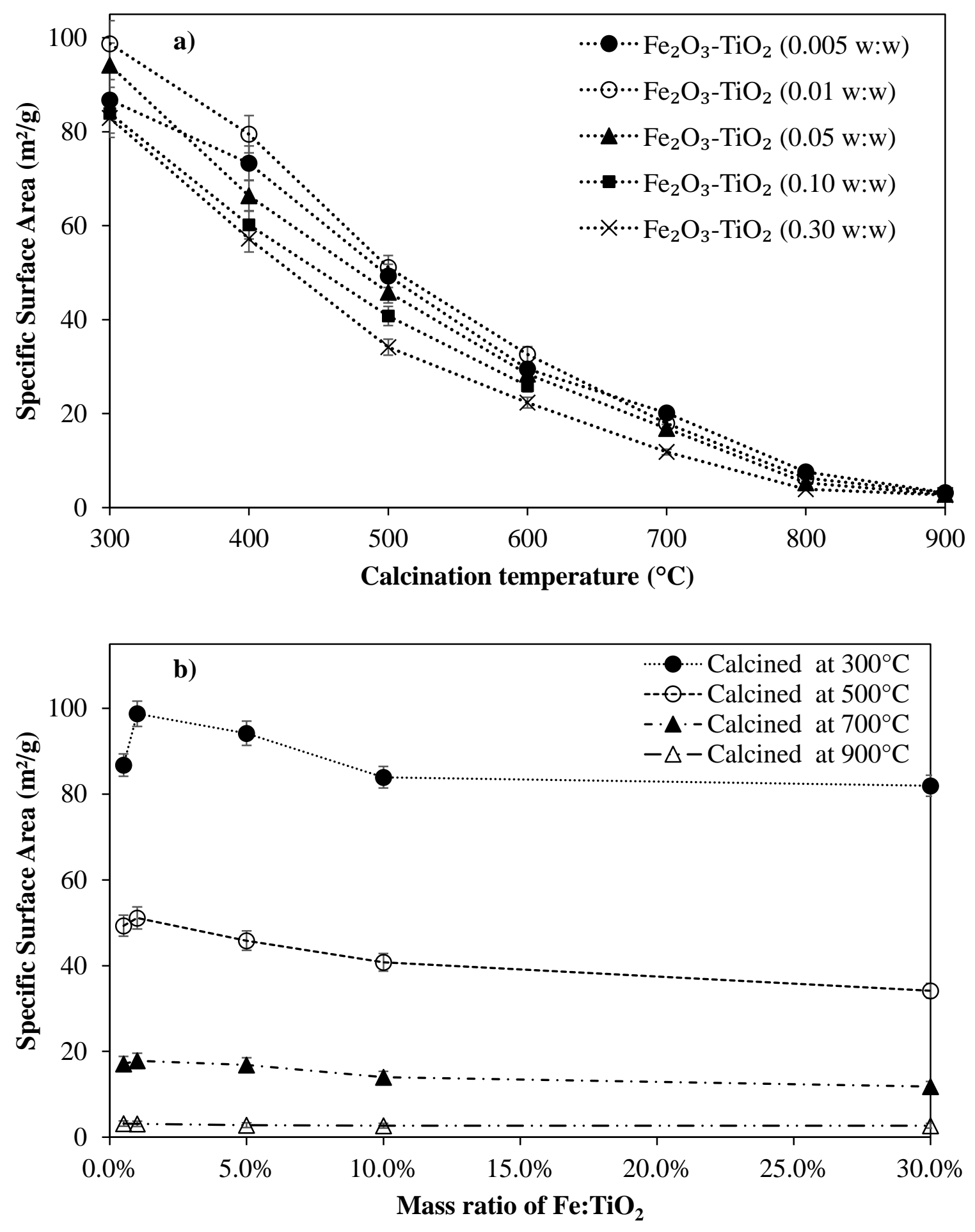

Figure 5.5. (a) Effect of mass ratio of $\mathrm{Fe}$ : $\mathrm{TiO}_{2}$ on the specific surface area of $\mathrm{Fe}_{2} \mathrm{O}_{3} / \mathrm{TiO}_{2}$ calcined at different temperatures; and (b) Effect of calcination temperature on the specific surface area of $\mathrm{Fe}_{2} \mathrm{O}_{3} / \mathrm{TiO}_{2}$ at various mass ratios of $\mathrm{Fe}: \mathrm{TiO}_{2}$.

Reprinted from J. Environ. Manage. 196 (2017) 487-498, with permission from Elsevier. 
Results also show that by increasing the calcination temperature, the specific surface area was significantly decreased. In other words, the isotherm adsorption/desorption for nitrogen gas, using the BET method, significantly decreases. For instance, the specific surface area of $\mathrm{Fe}_{2} \mathrm{O}_{3} / \mathrm{TiO}_{2}\left(0.01 \mathrm{w}\right.$ : $\left.\mathrm{Fe}: \mathrm{TiO}_{2}\right)$ calcined at $300^{\circ} \mathrm{C}$ was reduced from $98.73 \mathrm{~m}^{2} / \mathrm{g}$ to $79.47,51.12$, $32.62,17.82,6.31$ and $3.12 \mathrm{~m}^{2} / \mathrm{g}$ when calcination temperature increased to 400, 500, 600, 700, 800 , and $900^{\circ} \mathrm{C}$, respectively. The same trend was observed for all composite photocatalysts with different $\mathrm{Fe}: \mathrm{TiO}_{2}$ mass ratios.

Significant changes in the specific surface area were observed when calcination temperature reached over $500^{\circ} \mathrm{C}$. After $500^{\circ} \mathrm{C}$, anatase started to convert to rutile; thus, a considerable variation in the specific surface area occurred. At high calcination temperatures, the particle size, the thickness of the crystal, and the degree of crystallinity increase and phase conversion occurs (Hamadanian et al., 2010; Mazinani et al., 2014).

Although both anatase and rutile phases have a tetragonal structure, anatase has a more open structure, and it is more active compared to rutile. Therefore, by increasing the calcination temperature, a lower adsorption of organics on the surface of photocatalyst appears. Results also show that by increasing iron doping into $\mathrm{TiO}_{2}$, the specific surface area also increased and after a certain ratio (0.01 w:w Fe: $\left.\mathrm{TiO}_{2}\right)$, it was reduced again (Figure 5.5b).

It seems that at high concentration of the dopant, the surface of the photocatalyst is entirely covered by the dopant and there is not enough surface area for the photocatalyst to adsorb light and generate electron and hole.

In terms of organics removal, the specific surface area of the photocatalyst and the calcination temperature have a major role. For instance, a degradation efficiency of $62 \%$ was 
achieved for $\mathrm{MO}$ in the presence of $\mathrm{Fe}_{2} \mathrm{O}_{3} / \mathrm{TiO}_{2}\left(0.01 \mathrm{w}: \mathrm{w} \mathrm{Fe}: \mathrm{TiO}_{2}\right)$ calcined at $300^{\circ} \mathrm{C}$ with the highest specific surface area $\left(98.73 \mathrm{~m}^{2} / \mathrm{g}\right)$.

At the same conditions, the degradation efficiency of MO reached to $47.2 \%$ in the presence of $\mathrm{Fe}_{2} \mathrm{O}_{3} / \mathrm{TiO}_{2}\left(0.01 \mathrm{w}: \mathrm{w} \mathrm{Fe}: \mathrm{TiO}_{2}\right.$ ) calcined at $900^{\circ} \mathrm{C}$ (Figure 5.6a). The same trend was observed for the degradation of CR (Figure 5.6b). For instance, the degradation of CR in the presence of $\mathrm{Fe}_{2} \mathrm{O}_{3} / \mathrm{TiO}_{2}\left(0.01 \mathrm{w}: \mathrm{w} \mathrm{Fe}: \mathrm{TiO}_{2}\right)$ varied from 46.8 to $31.9 \%$ when the calcination temperature was 300 and $900^{\circ} \mathrm{C}$, respectively. Results show a linear relationship between the photocatalytic activity and specific surface area of the photocatalyst. These changes are significant when the calcination temperature reach $500^{\circ} \mathrm{C}$ due to the conversion of anatase to rutile. According to Sun et al. (2005), by increasing the temperature during the photocatalyst preparation, the photocatalytic activity for organics removal is improved, especially when using the hydrothermal method for the preparation, doping, or combination of the photocatalysts.

Mazinani et al. (2014) reported that in the hydrothermal method at high preparation temperatures $\left(>130^{\circ} \mathrm{C}\right)$, the thickness of photocatalyst platelets increases as confirmed by SEM images in this study. Moreover, in the hydrothermal method at high preparation temperatures, the XRD peak rises because of the growth of crystals and an increase in their size. In other words, the intensity of the XRD diffractogram is related to the mass of the crystal; by increasing the preparation temperature or during calcination, the height and area below the diffractogram curve also increase. 

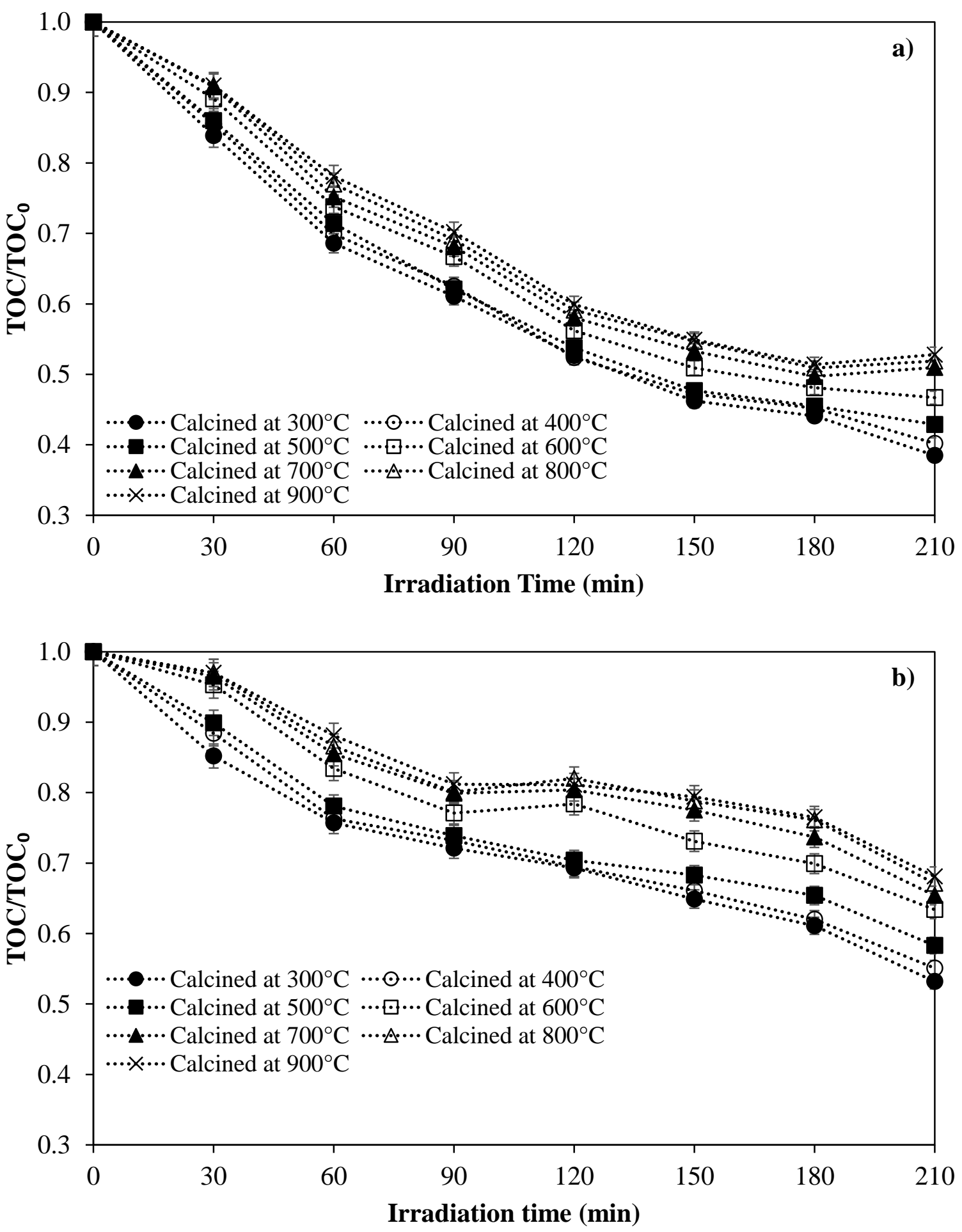

Figure 5.6. Effect of calcination temperature on the degradation of (a) methyl orange; and (b) Congo red in the presence of $\mathrm{Fe}_{2} \mathrm{O}_{3} / \mathrm{TiO}_{2}(0.01$ w:w Fe:TiO, $5 \mathrm{UV}$-A lamps, and photocatalyst concentration of $300 \mathrm{mg} / \mathrm{L}$ ).

Reprinted from J. Environ. Manage. 196 (2017) 487-498, with permission from Elsevier. 


\subsubsection{Crystallinity of the $\mathrm{Fe}_{2} \mathrm{O}_{3} / \mathrm{TiO}_{2}$ photocatalyst}

The main characteristics of a photocatalyst are related to the crystal structure, size, and morphology. Both metal and non-meatal doped $\mathrm{TiO}_{2}$ have been widely investigated, but still, there is a gap in the literature related to the configuration and structure of doped photocatalysts. There are two main viewpoints about doping metals onto $\mathrm{TiO}_{2}$, terrestrial, related to the metal covering the surface of the photocatalyst (Agustina et al., 2005; Liu et al., 2015), and the substitution, where the metal ion enters in the crystal lattice of $\mathrm{TiO}_{2}$ (Wellia et al., 2011; Nasralla et al., 2013; Banisharif et al., 2015).

Diffractograms of $\mathrm{Fe}_{2} \mathrm{O}_{3} / \mathrm{TiO}_{2}$ with mass ratios of 0.01 and $0.05 \mathrm{Fe}: \mathrm{TiO}_{2}$, calcined at $300^{\circ} \mathrm{C}$, were taken by XRD, and are depicted in Figures 5.7a and 5.7b, respectively. Samples calcined at $300^{\circ} \mathrm{C}$ were found to be composed of only anatase with a small crystal size, and there was no peak belonging to rutile. In other words, the location of the peaks was the same in two different samples. The existence of anatase phase was confirmed by comparing the obtained diffractograms with the standard, which present the location of the $\mathrm{TiO}_{2}$ peaks and relative intensities, based on the Joint Committee on Powder Diffraction Standards (JCPDS-21-1272) databank (Dai et al., 2010). Anatase has a main peak at 2 $\theta=25.4$ matching the 101 planes.

Other $\mathrm{TiO}_{2}$ peaks are located at 37.8 and 48.0 corresponding to the planes 004 and 200, respectively. The peak at 54.5 is related to the 105 and 211 planes of the anatase phase. Figure 5.7 also shows a comparison between two diffractograms of $\mathrm{Fe}_{2} \mathrm{O}_{3} / \mathrm{TiO}_{2}\left(0.01\right.$ and 0.05 w:w Fe: $\left.\mathrm{TiO}_{2}\right)$ with pure commercial anatase (Figure 5.7c).

Results revealed that all three diffractograms are similar, and no change in the location of peaks was observed other than the relative height of the peaks which related to $\mathrm{Fe}_{2} \mathrm{O}_{3} / \mathrm{TiO}_{2}$ due to different concentrations of $\mathrm{Fe}^{3+}$. 

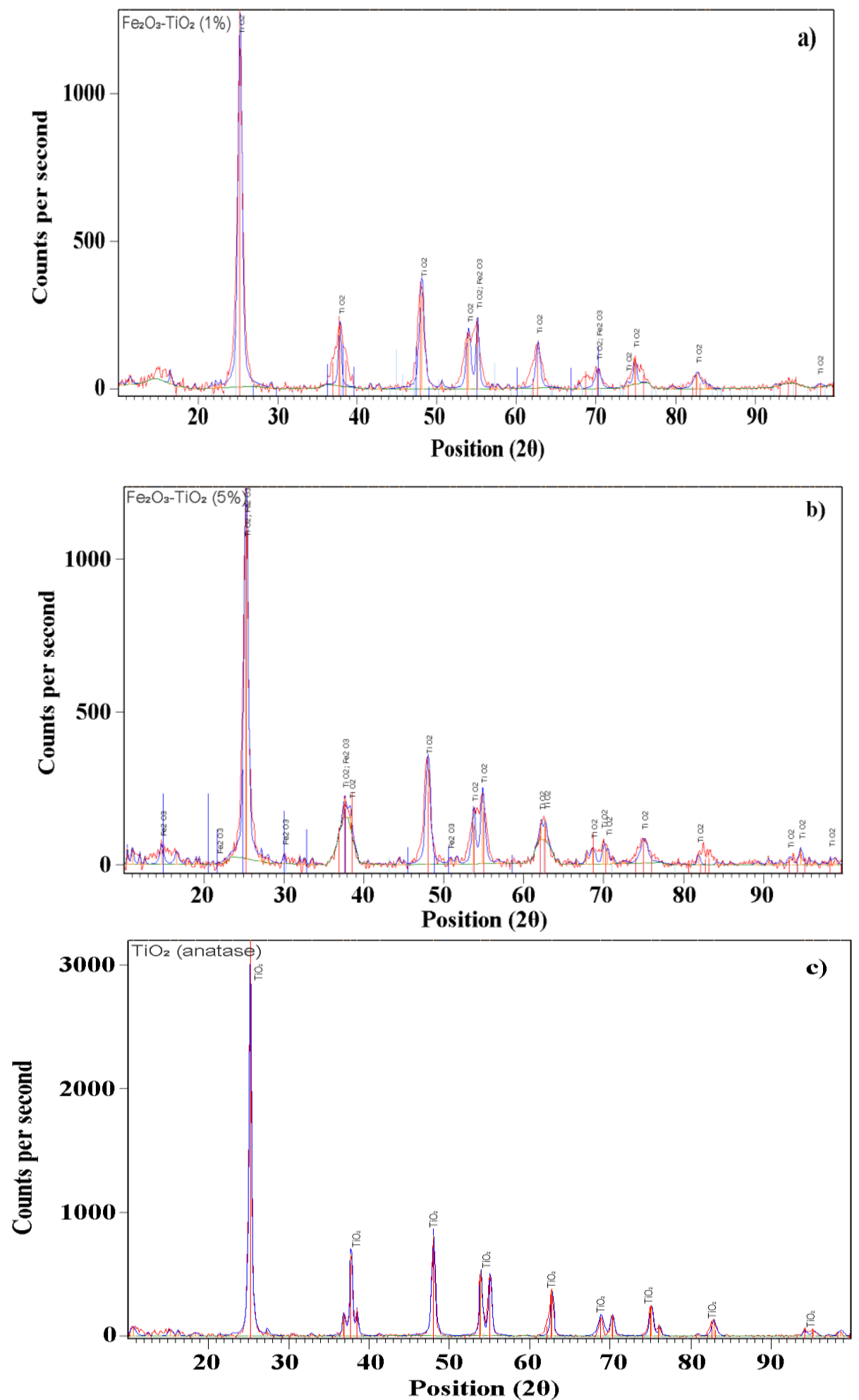

Figure 5.7. Comparison of diffractograms of $\mathrm{Fe}_{2} \mathrm{O}_{3} / \mathrm{TiO}_{2}$ calcined at $300^{\circ} \mathrm{C}$ for mass ratios of (a) $0.01 \mathrm{w}: \mathrm{w}$ Fe:TiO $)$; (b) $0.05 \mathrm{w}: \mathrm{w} \mathrm{Fe}^{\mathrm{TiO}} \mathrm{TiO}_{2}$ ); and (c) commercial $\mathrm{TiO}_{2}$ (anatase).

Reprinted from J. Environ. Manage. 196 (2017) 487-498, with permission from Elsevier. 
The crystal structure of pure anatase and $\mathrm{Fe}_{2} \mathrm{O}_{3} / \mathrm{TiO}_{2}$ is the same, and it can be concluded that iron is a part of the crystal lattice of $\mathrm{TiO}_{2}$ due to the same size of the two ions (Nasralla et al., 2013). It seems that a crystal defect happened.

There are three types of crystal defects, point defect, linear defect, and interfacial defect. Point defect includes lattice vacancy, where one atom is missing from the crystal; in substitution, an atom is replaced with another atom in the crystal; and interstitial impurity, where the same atom from the crystal or a non-belonging atom is added to the crystal. These crystal defects change the structure and properties of the photocatalytic material. A defect in the crystal lattice is one of the most important reasons for increasing the specific surface area of the photocatalyst, and thus its photocatalytic activity.

Wellia et al. (2011) indicated that a metal might be placed in the lattice crystal of $\mathrm{TiO}_{2}$, where it causes the in the electronic properties of the photocatalyst. It is interesting that $\mathrm{Fe}_{2} \mathrm{O}_{3} / \mathrm{TiO}_{2}$ with different dopant concentrations $\left(\mathrm{Fe}^{3+}\right)$, regardless of the height, have the same diffractogram in position.

Most of iron ions in the process of doping substitute the titanium in the crystal lattice of $\mathrm{TiO}_{2}$ and there is a low amount of $\mathrm{Fe}_{2} \mathrm{O}_{3}$ located on the surface of $\mathrm{TiO}_{2}$. When $\mathrm{Fe}^{3+}$ is doped to $\mathrm{TiO}_{2}$, it enters the crystal lattice of $\mathrm{TiO}_{2}$, and a point defect in the crystal occurs because $\mathrm{Ti}^{4+}$ and $\mathrm{Fe}^{3+}$ have similar ion radius of 0.68 and $0.64 \AA$, respectively.

Figures 5.8a, 5.8b, and 5.8c show diffractograms of $\mathrm{Fe}_{2} \mathrm{O}_{3} / \mathrm{TiO}_{2}\left(0.05\right.$ w:w Fe: $\left.\mathrm{TiO}_{2}\right)$ calcined at $300^{\circ} \mathrm{C}, 500^{\circ} \mathrm{C}$, and $900^{\circ} \mathrm{C}$, respectively. It was found that the first sample (calcined at $300^{\circ} \mathrm{C}$ ) contains only the anatase form. Anatase has main peaks at $2 \theta=25.4,37.8$, and 48.0. The third diffractogram (calcined at $900^{\circ} \mathrm{C}$ ) contains only rutile. 

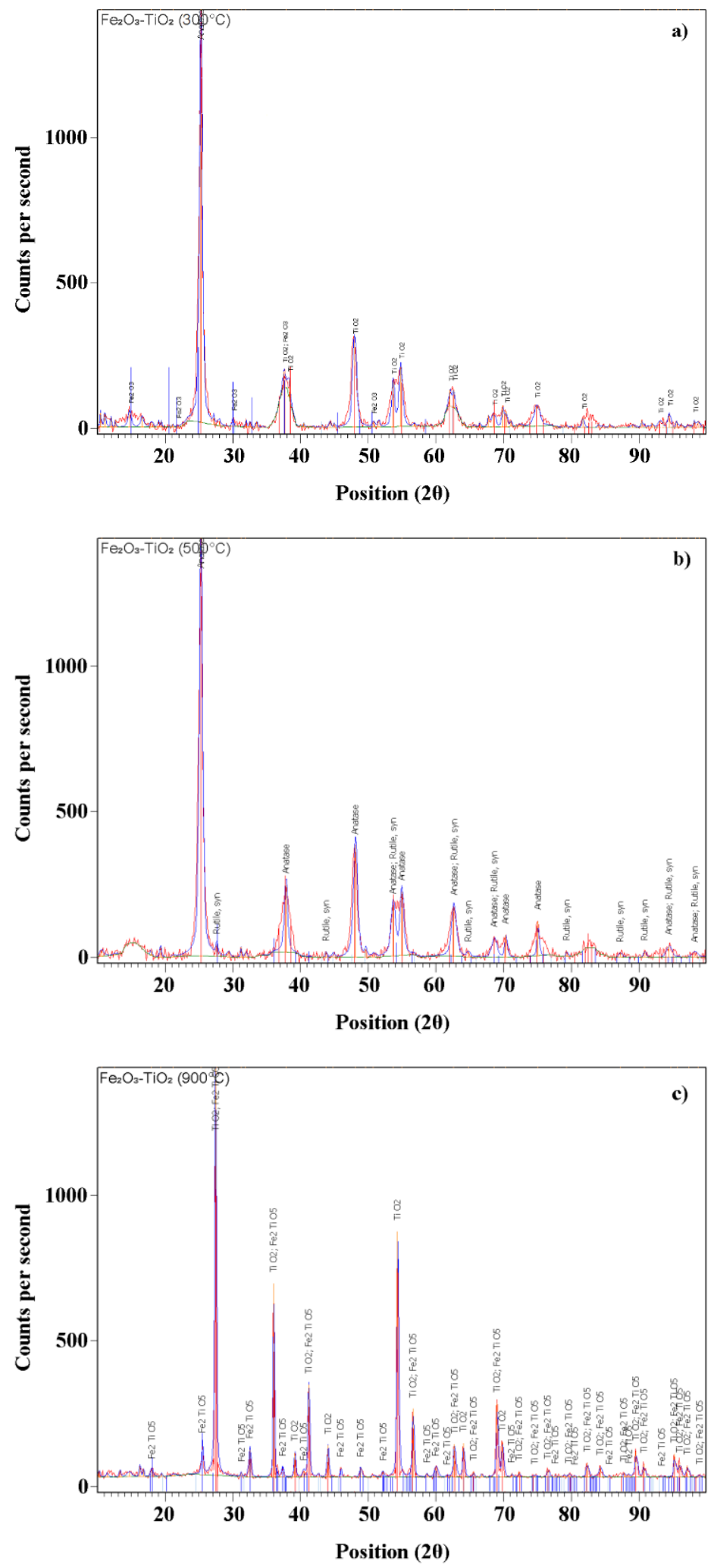

Figure 5.8. Diffractogram of the $\mathrm{Fe}_{2} \mathrm{O}_{3} / \mathrm{TiO}_{2}$ photocatalyst (0.05 w:w Fe: $\left.\mathrm{TiO}_{2}\right)$ calcined at (a) $500^{\circ} \mathrm{C}$; and (b) $900^{\circ} \mathrm{C}$.

Reprinted from J. Environ. Manage. 196 (2017) 487-498, with permission from Elsevier. 
Based on the diffractogram of the standard rutile (JCPDS-21-1276), two main peaks can be found, one at $2 \theta=27.5$ (corresponding to the 110 plane) and the other one at $2 \theta=36.1$ (corresponding to the 121 plane). Rutile may also have another peak at $2 \theta=54.4$, which corresponds to the 211 plane (Pal et al., 1999; Dai et al., 2010). The third diffractogram (calcined at $900^{\circ} \mathrm{C}$ ) is completely matched with standard rutile. The second diffractogram (calcined at $500^{\circ} \mathrm{C}$ ) contains mainly anatase (peak at $2 \theta=25.4,37.8$, and 48.0 ) and very low amount of rutile (very short peak at $2 \theta=27.5,36.1$, and 54.4). Thus, it is confirmed that samples calcined at $500^{\circ} \mathrm{C}$ include a mixture of both anatase and very low amount of rutile phases.

Results show that by increasing the calcination temperature, the intensity of anatase peaks decrease while the intensity of the rutile peak is amplified. At $900^{\circ} \mathrm{C}$, there is only rutile form and no anatase peak was observed. According to Dai et al. (2010), the conversion of anatase to rutile should start at $600^{\circ} \mathrm{C}$. In this study, it is confirmed that at $500^{\circ} \mathrm{C}$ a small amount of rutile was observed. This fact might be related to the existence of $\mathrm{Fe}^{3+}$, which facilitates the transformation of anatase to a stable form of rutile (Pal et al., 1999). All XRD peaks are in agreement with the standard diffractograms.

Cai et al. (2016) reported that at low calcination temperature, most of the $\mathrm{TiO}_{2}$ particles are amorphous and by increasing the temperature above $400^{\circ} \mathrm{C}$, the crystallization of $\mathrm{TiO}_{2}$ occurs with the transformation of the amorphous form to the anatase phase. The strongest peak for anatase and rutile in each diffractogram is obtained at $2 \theta=25.2$ and $2 \theta=27$, corresponding to plane 101 and 110 , respectively.

From the results, it was found that a calcination is required for the treatment of photocatalysts to make a purer crystal, but a high calcination temperature causes a reduction in the photocatalytic activity. For instance, the diffractogram of the $\mathrm{Fe}_{2} \mathrm{O}_{3} / \mathrm{TiO}_{2}\left(0.30 \mathrm{w}: \mathrm{w}\right.$ Fe: $\left.\mathrm{TiO}_{2}\right)$ 
calcined at $900^{\circ} \mathrm{C}$ (Figure 5.8c) shows sharp peaks of rutile along with Ferric Pseudobrookite $\left(\mathrm{Fe}_{2} \mathrm{TiO}_{5}\right)$ based on the standard diffractogram of rutile (JCPDS-21-1276) and Ferric Pseudobrookite (JCPDS- 41-1432). The Pseudobrookite phases are produced from the reaction of $\mathrm{TiO}_{2}$ with $\mathrm{Fe}_{2} \mathrm{O}_{3}$.

As noted earlier, in the diffractogram obtained at the calcination temperature of $900^{\circ} \mathrm{C}$, there is no peak that belongs to the anatase phase, meaning that all anatase forms are transformed into rutile. The formation of $\mathrm{Fe}_{2} \mathrm{TiO}_{5}$ started from almost $800^{\circ} \mathrm{C}$ and was completed at $900^{\circ} \mathrm{C}$.

The comparison of diffractograms of pure $\mathrm{Fe}_{2} \mathrm{TiO}_{5}$ with samples sintered at $900^{\circ} \mathrm{C}$ confirmed the production of ferric Pseudobrookite in the photocatalyst. It can be concluded that a part of $\mathrm{Fe}^{3+}$ ions on the surface of $\mathrm{TiO}_{2}$ diffused into the bulk of $\mathrm{TiO}_{2}$, and $\mathrm{Fe}_{2} \mathrm{TiO}_{5}$ was, therefore, produced. It seems that at first, $\mathrm{Fe}^{3+}$ covered $\mathrm{TiO}_{2}$, and then during the calcination at high temperatures, $\mathrm{Fe}_{2} \mathrm{O}_{3}$ was produced and penetrated the $\mathrm{TiO}_{2}$ lattice, resulting in the formation of mixed oxides such as $\mathrm{Fe}_{2} \mathrm{TiO}_{5}$. However, the XRD diffractogram shows a very low amount of bare $\mathrm{Fe}_{2} \mathrm{O}_{3}$ particles in the mixed oxide system $\left(\mathrm{Fe}_{2} \mathrm{O}_{3} / \mathrm{TiO}_{2}\right)$

According to Robles- Águila et al. (2012), there is a lower solubility of $\mathrm{Fe}^{3+}$ in rutile phase compare to the solubility of $\mathrm{Fe}^{3+}$ in anatase phase. Less than 2-3\% of iron entered the $\mathrm{TiO}_{2}$ crystal and the rest produced $\mathrm{Fe}_{2} \mathrm{TiO}_{5}$ at $900^{\circ} \mathrm{C}$. Furthermore, images taken using SEM and result from EDS elemental analysis showed that $\mathrm{Fe}^{3+}$ particles are homogeneously dispersed in the mixed oxide samples $\left(\mathrm{Fe}_{2} \mathrm{O}_{3} / \mathrm{TiO}_{2}\right)$.

In fact, the ratio of atomic percentage of $\mathrm{Ti}$ and $\mathrm{Fe}$ found by EDS matched the expected concentration. Therefore, it could be concluded that composite photocatalysts contain an excess of $\mathrm{Fe}_{2} \mathrm{O}_{3}$, which has not been diffused into the $\mathrm{TiO}_{2}$ lattice due to the limitation of solubility of $\mathrm{Fe}^{3+}$ 
ions in making a substitutional solid solution. In other words, the excess $\mathrm{Fe}_{2} \mathrm{O}_{3}$ is dispersed on the surface of $\mathrm{TiO}_{2}$.

\subsubsection{Fourier-transform infrared (FTIR) analysis}

In this part of the study, FTIR was used to investigate the effect of different calcination temperatures on the $\mathrm{Fe}_{2} \mathrm{O}_{3} / \mathrm{TiO}_{2}$ photoactivity. Figure 5.9 shows the FTIR spectra of the $\mathrm{Fe}_{2} \mathrm{O}_{3} / \mathrm{TiO}_{2}$ photocatalyst $\left(0.05 \mathrm{w}: \mathrm{w} \mathrm{Fe}: \mathrm{TiO}_{2}\right)$, calcined at 300,500 , and $700^{\circ} \mathrm{C}$, respectively. Results show that the $\mathrm{Fe}_{2} \mathrm{O}_{3} / \mathrm{TiO}_{2}$ photocatalyst calcined at $300^{\circ} \mathrm{C}$ has two strong peaks at 1650 $1 / \mathrm{cm}$ and a wide band at 3400-3700 1/cm, which indicate a straight vibration of $\mathrm{OH}^{-}$from $\mathrm{H}_{2} \mathrm{O}$, alcohol, and Ti-OH.

Cai et al. (2016) reported that the straight vibration of $\mathrm{OH}^{-}$(hydroxide) obtained from water or Ti-OH, inhibit the recombination of photogeneration of electron/hole pairs and interact with photogenerated holes to produce more reactive hydroxyl radicals.

By increasing the calcination temperature, the intensity of these two main peaks gradually decreased. In other words, the photocatalyst sample becomes purer, but the crystallinity also increases; thus, the photoactivity of the photocatalyst is reduced.

The FTIR calcined at 700 or $900^{\circ} \mathrm{C}$ showed that samples have been treated and are purer. At these high temperatures, FTIR peaks belong to $\mathrm{O}-\mathrm{H}, \mathrm{C}-\mathrm{O}$, or $\mathrm{C}=\mathrm{O}$ have been removed, and pure crystal (rutile) is produced. The peak at $33101 / \mathrm{cm}$ represents Ti-O-Fe. It might be a result of a strong interaction between titanium, oxygen, and ferric ion, which can significantly decrease the progress of the crystallinity, suppress the phase transformation and raise the height of the peak. As FTIR spectra for the sample calcined at $300^{\circ} \mathrm{C}$ shows, there are some other adsorption peaks at 
$1051,1988,2231$, and 2300. Each of them belongs to a functional group in the composite photocatalyst or precursors.
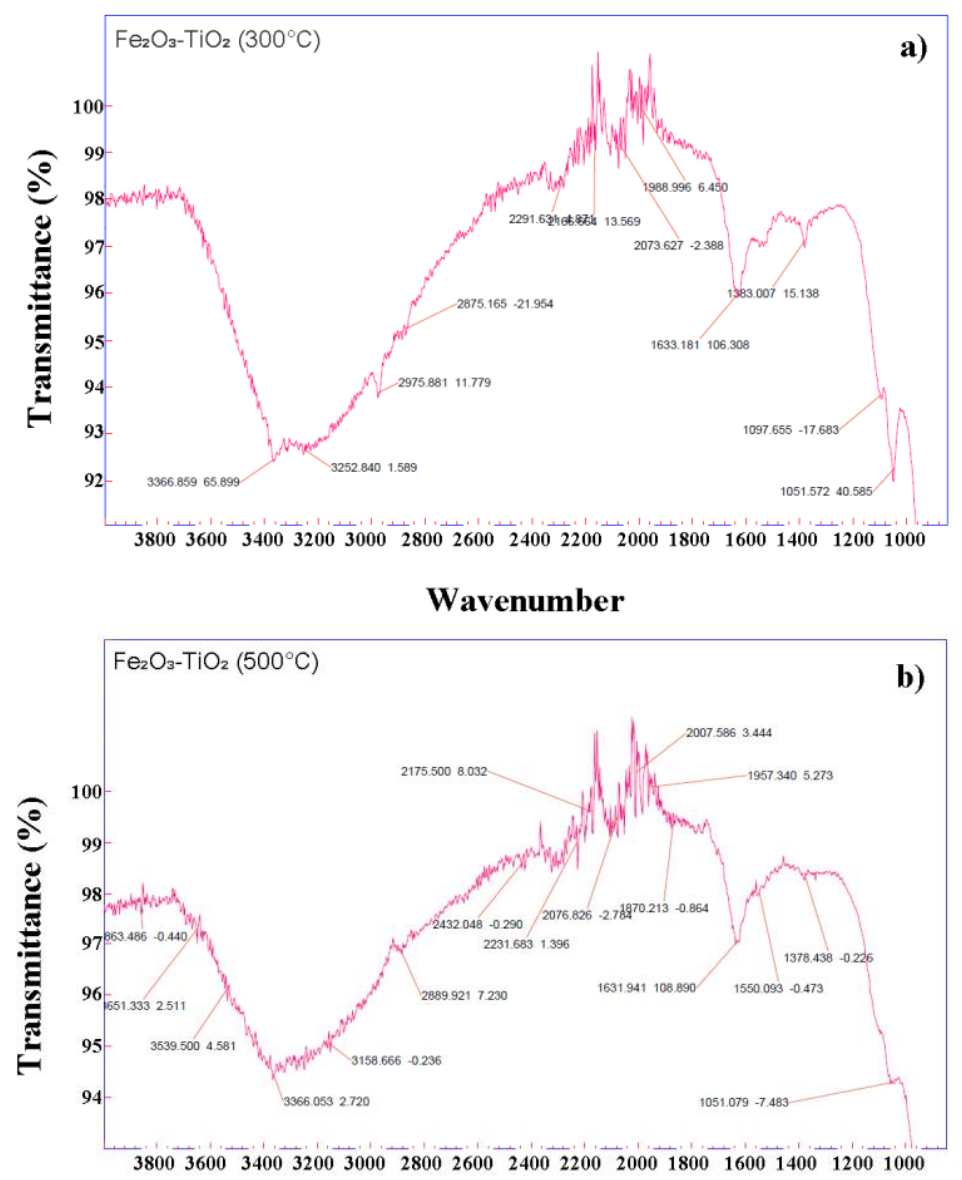

Wavenumber

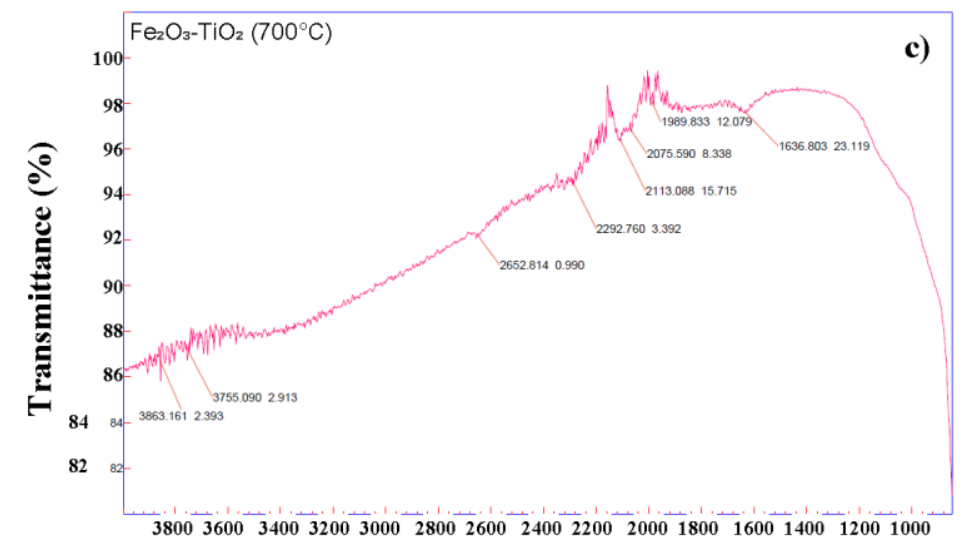

Wavenumber

Figure 5.9. FTIR spectra of $\mathrm{Fe}_{2} \mathrm{O}_{3} / \mathrm{TiO}_{2}\left(0.05\right.$ w:w Fe: $\left.\mathrm{TiO}_{2}\right)$ at different calcination temperatures: (a) $300^{\circ} \mathrm{C}$; (b) $500^{\circ} \mathrm{C}$; and (c) $700^{\circ} \mathrm{C}$.

Reprinted from J. Environ. Manage. 196 (2017) 487-498, with permission from Elsevier. 
The peaks at wavenumbers in the range of 1000-1300 1/cm show a C-O bond. Suresh et al. (2014) reported that the FTIR spectra of $\mathrm{Fe}_{2} \mathrm{O}_{3}$, observed at 638 and $4621 / \mathrm{cm}$, are related to the $\mathrm{Fe}-\mathrm{O}$ bond in $\gamma-\mathrm{Fe}_{2} \mathrm{O}_{3}$ and the bands at 548 are due to the $\mathrm{Fe}-\mathrm{O}$ stretching vibrational mode of $\alpha-\mathrm{Fe}_{2} \mathrm{O}_{3}$. It might be possible that the peaks between $460-6401 / \mathrm{cm}$ are related to a bond between iron and oxygen in different species of $\mathrm{Fe}_{\mathrm{x}} \mathrm{O}_{\mathrm{y}}\left(\mathrm{FeO}, \mathrm{Fe}_{2} \mathrm{O}_{3}\right.$, and $\left.\mathrm{Fe}_{3} \mathrm{O}_{4}\right)$, which are located on the surface of the photocatalyst at a low amount.

Figure 5.9 also shows a slight peak at $23301 / \mathrm{cm}$, which belongs to stretching vibrations of the $\mathrm{C}=\mathrm{O}$ bond, originated from the ethylene glycol added as a precursor during synthesis. No significant peaks were observed before 1000 1/cm; thus, minor peaks are not reported. As a result, the transformation of $\mathrm{TiO}_{2}$ from anatase to rutile is facilitated by high temperature and high concentration of iron while high crystallization and particle size increase occur.

\subsection{Conclusions}

In photocatalyst preparation, calcination is required for the treatment of photocatalysts to make a purer crystal and remove all impurities. The calcination temperatures can change the activity of a photocatalyst because of the variations in the specific surface area, the degree of crystallinity, and the phase conversion.

At high calcination temperatures of $900^{\circ} \mathrm{C}$, the composite $\mathrm{Fe}_{2} \mathrm{O}_{3} / \mathrm{TiO}_{2}$ photocatalyst (regardless of the mass ratio of $\mathrm{Fe}$ to $\mathrm{TiO}_{2}$ ) is entirely in the rutile phase; thus, the photocatalyst has the lowest specific surface area, a high degree of crystallinity, bigger size, but a reduced photocatalytic activity. Conversely, at low calcination temperatures $\left(300-400^{\circ} \mathrm{C}\right)$, the composite $\mathrm{Fe}_{2} \mathrm{O}_{3} / \mathrm{TiO}_{2}$ photocatalyst is in the anatase phase, which is more photoactive. 
Results showed that at an optimum calcination temperature of $300^{\circ} \mathrm{C}$ for the photocatalyst preparation, the specific surface area is maximum, and the photocatalyst has the highest photoactivity, at which the degradation of organic materials is maximum.

Results from this study also demonstrated that the synthesis of composite $\mathrm{Fe}_{2} \mathrm{O}_{3} / \mathrm{TiO}_{2}$ by the novel UV-assisted thermal method enhanced the lifetime of photogenerated electron/hole pairs and increased its photocatalytic activity for the degradation of typical dyes in the textile industry. 


\title{
CHAPTER 6
}

\section{PHOTOCATALYTIC ACTIVITY ENHANCEMENT OF TITANIUM DIOXIDE USING NON-METAL DOPING METHODS UNDER VISIBLE LIGHT: A REVIEW*}

\begin{abstract}
Titanium dioxide is an effective photocatalyst for removing organics in photocatalytic wastewater treatment, but its low photoactivity limits its practical applications in a visible-light-driven chemical reaction. Many efforts have been made in the activation of the visible light absorption property on $\mathrm{TiO}_{2}$ photocatalyst. In this paper, a thorough review of current non-metal doping methods of titanium dioxide $\left(\mathrm{TiO}_{2}\right)$ to improve photocatalyst activation under visible light is presented. The focus of this study is on doping non-metals into $\mathrm{TiO}_{2}$ by several methods to enhance its visible light photoactivity. In addition, the resultant characteristics of the chemical structure, physical structure, and optical properties of the doped photocatalysts are discussed. This review enables a better understanding of current advantages and disadvantages that can arise during the production of non-metal doped $\mathrm{TiO}_{2}$ and its applications. The annealing and hydrothermal methods are found to be more efficient in preparing doped photocatalysts with respect to the time and the cost. When choosing between these two approaches, the hydrothermal method can be applied using a variety of precursors, whereas, the annealing methods is restricted only to solid form precursors. Thus, the hydrothermal method is a more favorable method of non-metal doping of $\mathrm{TiO}_{2}$.
\end{abstract}

\footnotetext{
* Submitted to International Journal of Environmental Science and Technology (2017).
} 
However, studies should focus on the effects of different factors involved in each synthesis/preparation method to determine optimal preparation conditions.

Keywords: Photocatalysis; non-metal doping; $\mathrm{TiO}_{2}$; visible light.

\footnotetext{
* Submitted to International Journal of Environmental Science and Technology (2017).
} 


\subsection{Introduction}

Advanced oxidation processes (AOPs) are promising and environmentally friendly technologies, which are capable of degrading recalcitrant organic matter to nontoxic materials in wastewater treatment. The photocatalytic treatment remains as a popular research area in studying AOPs. Within the broad range of photocatalysts, $\mathrm{TiO}_{2}$ remains as one of the most common photocatalysts owing to its high chemical stability, high photo-reactivity, low cost, and nontoxicity. (Shi et al., 2012; $\mathrm{Xu}$ et al., 2014). However, $\mathrm{TiO}_{2}$ only absorbs light in the ultraviolet range, around 5\% of the solar spectrum, because of its large band gap energy of $3.2 \mathrm{eV}$ (Niu et al., 2014). Moreover, the common usage of such technology is limited due to the rapid recombination rate of the generated electron-hole pairs (Ansari et al., 2016).

Because of the cost effectiveness of photocatalysis, recent studies on $\mathrm{TiO}_{2}$ as photocatalyst are focused on the improvement of its photocatalytic activity under visible light to increase solar energy conversion efficiency while reducing costs (Xu et al., 2014). Visible light absorption can be driven by the doping metal or non-metal elements onto $\mathrm{TiO}_{2}$ by narrowing the band gap of $\mathrm{TiO}_{2}$. According to the substitution theory, metal dopants could substitute the $\mathrm{Ti}^{4+}$ atoms, and their state could mix with either the conduction band or the valence band (Nasirian and Mehrvar, 2016; Nasirian et al., 2017). Based on the terrestrial theory, metals as dopants can be located on the surface of $\mathrm{TiO}_{2}$. In some cases, metal doping could introduce a new energy level in the original band gap of $\mathrm{TiO}_{2}$ (Zaleska, 2008). Although noble metals are more resistant to corrosion, the major drawback of metal doping is the toxicity of the metal element, which could be harmful to the environment when released through the photo-corrosion of the metal-doped photocatalyst during the photocatalytic process (Ansari et al., 2016). Thus, non-metal doping, where dopants are 
introduced onto the $\mathrm{O}^{2-}$ sites to modulate the valence band of $\mathrm{TiO}_{2}$, has become a more feasible methodology in enhancing the visible light photoactivity of $\mathrm{TiO}_{2}$ (Xu et al., 2014).

Non-metal doping of $\mathrm{TiO}_{2}$ has been studied through different doping methods such as annealing, hydrothermal, microwave assisted, and sol-gel methods (Gao et al., 2011; Yan et al., 2014; Shao et al., 2015). Each of these doping methods possesses its advantages and disadvantages such as the preparation time and the resultant photocatalytic efficiency. However, there is scarce of information in the open literature on the comparison of the doping methods of non-metal doped $\mathrm{TiO}_{2}$. This study presents a thorough review of the last five years on different doping methodologies along with the resulting characteristics of the non-metal doped $\mathrm{TiO}_{2}$ for the improvement of the photocatalytic activity under visible light illumination.

\subsection{Mechanism of photocatalytic activity of pure $\mathrm{TiO}_{2}$}

A photocatalytic reaction is based on the generation of electron-hole pairs upon exposure to UV light irradiation. In general, the process of the photocatalytic reaction of $\mathrm{TiO}_{2}$ includes photoexcitation, charge migration, and redox reaction as shown in Figure 6.1. Upon striking the UV radiation on the surface of $\mathrm{TiO}_{2}$, an electron $\left(\mathrm{e}^{-}\right)$and hole $\left(\mathrm{h}^{+}\right)$pair is generated on the surface of the photocatalyst. An electron is promoted to the conduction band (CB), and a hole is formed in the valence band (VB). Then, the electrons and holes migrate to the surface of the photocatalyst. The hole and electron are considered as an oxidizer and a reducer, respectively. After reacting holes with hydroxide ions, hydroxyl radicals $\left(\mathrm{HO}^{*}\right)$ with high redox oxidizing potential are produced on the surface of the photocatalyst. Depending on the exact conditions, the holes, $\mathrm{HO}^{\circ}$, $\mathrm{O}_{2}^{-}, \mathrm{H}_{2} \mathrm{O}_{2}$, and $\mathrm{O}_{2}$ can play important roles in the photocatalytic reaction mechanism (Fujishima et al., 2000). 


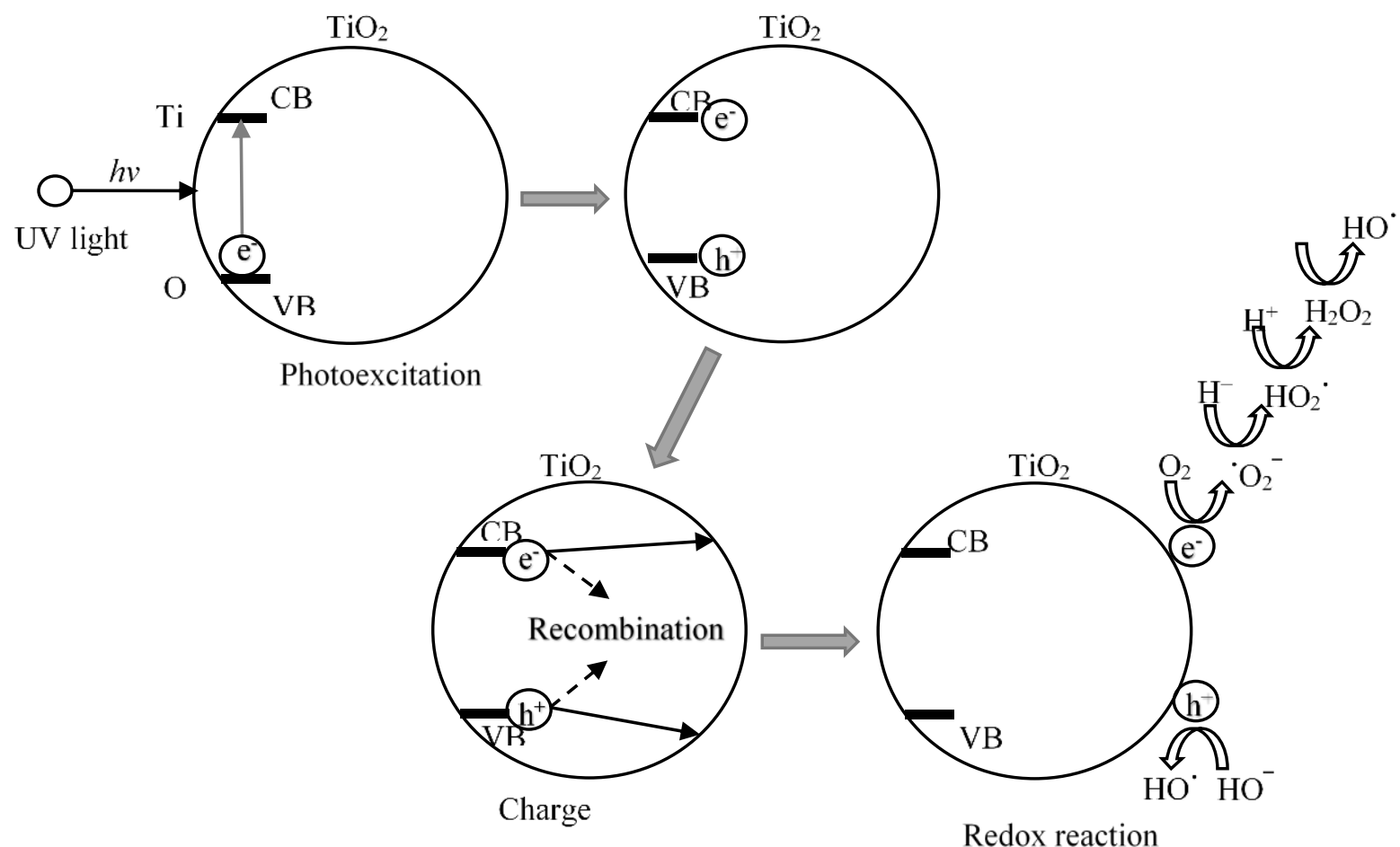

Figure 6.1. Photoreaction process of $\mathrm{TiO}_{2}$ under $\mathrm{UV}$ radiation.

Submitted to Int. J. Environ. Sci. Technol. (2017).

a) Pure $\mathrm{TiO}_{2}$

b) $\mathrm{N}-\mathrm{TiO}_{2}$

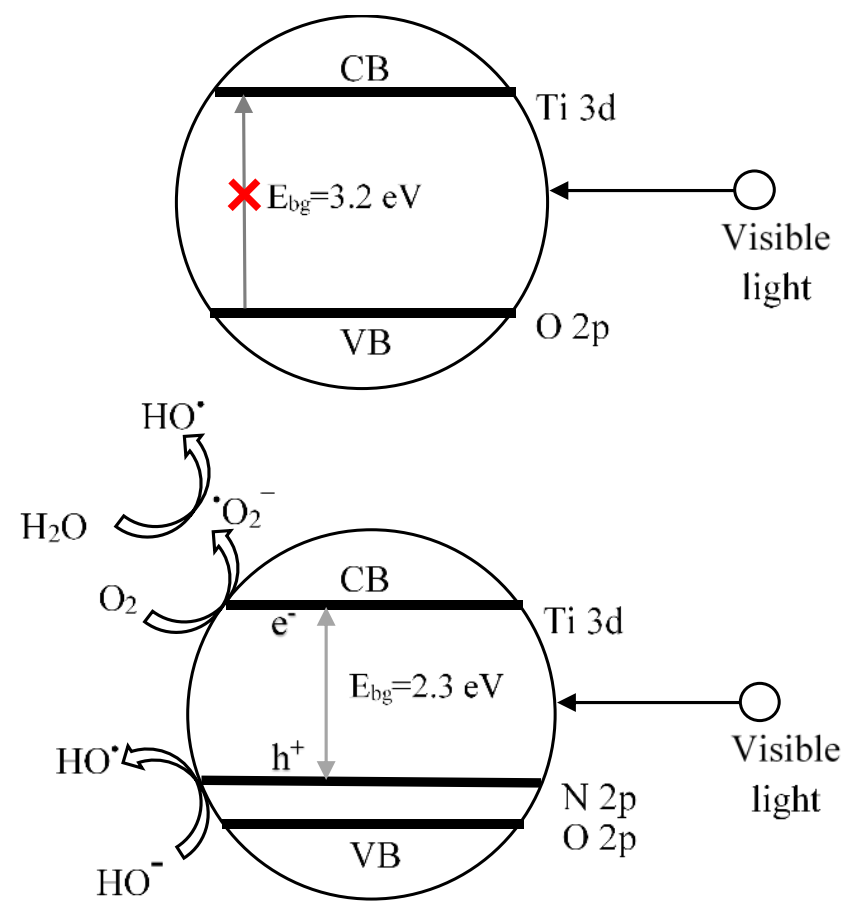

Figure 6.2. Possible photoreaction mechanism of (a) pure $\mathrm{TiO}_{2}$ and (b) $\mathrm{N}-\mathrm{TiO}_{2}$ under visible light irradiation.

Submitted to Int. J. Environ. Sci. Technol. (2017). 
As Figure 6.2 shows, this process of photoexcitation does not happen under visible light irradiation due to the wide band gap of $\mathrm{TiO}_{2}$ (3.20 eV) (Xu et al., 2014; Ansari et al., 2016). On the other hand, when a metal or non-metal species is introduced into the $\mathrm{TiO}_{2}$ lattice, the photocatalyst gains the ability to be activated under optical absorption wavelength in the visible spectrum (>400 nm) (Gao et al., 2011; Yan et al., 2014; Shao et al., 2015).

\subsection{Mechanism of photocatalytic activity of non-metal doped $\mathrm{TiO}_{2}$}

One of the main objectives in modifying a photocatalyst by non-metal doping of $\mathrm{TiO}_{2}$ is to narrow its band gap (Zaleska, 2008). First, when a non-metal species, such as nitrogen with slightly higher energy level than that of oxygen, is introduced into the $\mathrm{TiO}_{2}$ lattice, a new mid-gap energy state is generated (Xu et al., 2014; Ansari et al., 2016).

The generated mid-gap energy level allows the photoexcitation process to happen as the electrons from the mid-gap energy level can be excited upon absorbing visible light; whereas, electrons in the $2 p$ valence band of oxygen could not be excited by the visible light. The excited electron from the mid-gap energy level then migrates to the conduction band generating a hole in the mid-gap energy level. Later, the electron and hole migrate to the surface of $\mathrm{TiO}_{2}$ and participate in the redox reactions. The electrons on the surface of the photocatalyst are scavenged by the dissolved oxygen molecules to yield highly oxidative species such as superoxide and then in a series of reactions produce $\mathrm{HO}^{*}$. Meanwhile, the holes on the surface of the photocatalyst are scavenged by hydroxide ions to generate $\mathrm{HO}^{*}$. These $\mathrm{HO}^{\circ}$ radicals react with the organic pollutants in multiple oxidation steps to oxidize organic compounds to water and $\mathrm{CO}_{2}$. Therefore, the nonmetal species provides the ability for the photocatalyst to be activated under visible light 
irradiation, shifting the optical absorption to the visible light region $(>400 \mathrm{~nm})$ to produce strong oxidizer of hydroxyl radicals (Gao et al., 2011; Yan et al., 2014; Shao et al., 2015).

An example of the photocatalytic reaction mechanism of pure $\mathrm{TiO}_{2}$ and a non-metal doped $\mathrm{TiO}_{2}$ is shown in Figure 6.2. On the other hand, the UV radiation excites the electrons in both the valence band and the mid-gap energy level, whereas, visible light can only excite the electrons in the mid-gap energy level (Zaleska, 2008).

The non-metal doped $\mathrm{TiO}_{2}$ follows a similar trend except that the mid-gap energy is at different energy levels, creating a different amount of shifting of the absorption wavelength towards the visible region of the spectrum, which is known as red shift (Gao et al., 2011; Yan et al., 2014; Shao et al., 2015). Moreover, doping $\mathrm{TiO}_{2}$ with non-metals can increase the density of the catalyst, which has the potential of narrowing or depletion of the region known as the band gap (Zaleska, 2008; Gao et al., 2011; Shi et al., 2012; Niu et al., 2014; Xu et al., 2014; Ansari et al., 2016).

There are two different kinds of doping, interstitial and substitutional when metal or nonmetal elements are being doped onto titanium dioxide (Xu et al., 2014; Ansari et al., 2016). In the non-metal doping of $\mathrm{TiO}_{2}$, the interstitial doping involves the settlement of the non-metal element (N) onto the surface of titanium dioxide by interactive forces, such as dipole-dipole interactions, Van der Waals forces, London forces, and electrostatic interactions. Interstitial impurity atoms are much smaller than the atoms in $\mathrm{TiO}_{2}$ matrix, which can fit into the open space between the bulk atoms in the lattice structure without oxygen replacement.

The substitutional doping of $\mathrm{TiO}_{2}$ involves the replacement of oxygen by non-metal elements in the $\mathrm{TiO}_{2}$ lattice structure. The substitutional doping usually happens when the dopant atoms are close in size (within 15\%) to the bulk atoms $(\mathrm{O})$. As the atomic size of many non-metal 
dopants $(\mathrm{B}, \mathrm{C}, \mathrm{N}, \mathrm{S}, \mathrm{F}, \mathrm{P})$ are approximately within $15 \%$ larger or smaller than that of oxygen atoms in the $\mathrm{TiO}_{2}$ crystal lattice, the substitutional doping is possible while doping $\mathrm{TiO}_{2}$ with a non-metal dopant. According to several studies, a combination of both substitutional and interstitial doping occurs during the doping process of ${\mathrm{N}-\mathrm{TiO}_{2}}_{2}$ (Ansari et al., 2016; Nasirian and Mehrvar, 2016; Nasirian et al., 2017). The combination of substitutional and interstitial doping introduces the mid-gap energy level above the valence band of the non-metal. In addition, the deformation caused by substitutional and interstitial doping forms grain boundaries that hold as potential photocatalytic reaction sites under visible light (Zaleska, 2008).

On the other hand, when the dopant acts as the key to visible light activation of the photocatalyst, the surface chemistry plays an important factor of photoactivity because chemical reactions mainly take place on the surface of the photocatalyst. The photoactivity of the doped photocatalyst is restricted by its surface atomic structure and electronic structure. According to Xu et al. (2014), the surface adsorption/desorption ability and the potential of the photocatalytic reaction are greatly influenced by the percentage of different crystallinity phase, the specific surface area, the concentration of valence surface oxygen, and the facet-dependent electronic band structure. Most of these properties can be determined through physical and chemical analysis. The compositions of the non-metal doped photocatalyst could also be determined through chemical analysis. Although, the photocatalytic activity under visible light has been found to be improved, the photoactivity of photocatalysts changes with different kinds of organic pollutants (Gao et al., 2011; Yan et al., 2014; Shao et al., 2015).

Doping with non-metallic elements has shown to enhance the visible light absorption of $\mathrm{TiO}_{2}$. There are three main mechanisms proposed to account for the shift in absorption band when using non-metal doped $\mathrm{TiO}_{2}$ including band gap narrowing resulting from the mixing of orbitals 
of $\mathrm{TiO}_{2}$ and impurity (Asahi et al., 2001; Serpone, 2006; Grabowska et al., 2012; Di Valentin, Pacchioni, 2013; Banerjee et al., 2015), the generation of oxygen vacancies (Serpone, 2006; Grabowska et al., 2012; Banerjee et al., 2015), and the formation of localized energy levels in the band gap (Banerjee et al., 2015; Di Valentin and Pacchioni, 2013).

\subsection{Advantages of Non-Metal Doped $\mathrm{TiO}_{2}$ over Metal Doped Composites}

The visible light photoactivity of $\mathrm{TiO}_{2}$ can be triggered through metal and non-metal doping of the photocatalyst. The photoactivity of metal doped $\mathrm{TiO}_{2}$ can be explained by a new energy level produced in the band gap of $\mathrm{TiO}_{2}$ by the dispersion of metal nanoparticles in the $\mathrm{TiO}_{2}$ matrix.

As the redox energy states, many transition metal ions lie within the band gap states of $\mathrm{TiO}_{2}$, and an intra-band state near the CB or VB boundary is generated by the substitution of titanium ions with transition metal ions (Figure 6.3).

Unlike pure $\mathrm{TiO}_{2}$, an electron can be excited from the defect state to the $\mathrm{TiO}_{2}$ conduction band by a new photon with the new energy level in metal-doped $\mathrm{TiO}_{2}$. The additional benefit of metal doping is the ability for the metal ions to act as an electron trap to inhibit the electron-hole recombination during charge migration process. The decreased recombination of electron-hole pairs results in the enhanced photoactivity (Grabowska et al., 2012; Devi and Kavitha, 2013).

Although an improvement in the photocatalytic activity of metal ion doped $\mathrm{TiO}_{2}$ under visible light is achieved, few studies have discussed its detrimental effects such as inter-ring metal in the solution during the treatment of the sample. The efficiency of the metal ion dopant greatly depends on its role as a mediator of interfacial charge transfer or as a recombination center. 


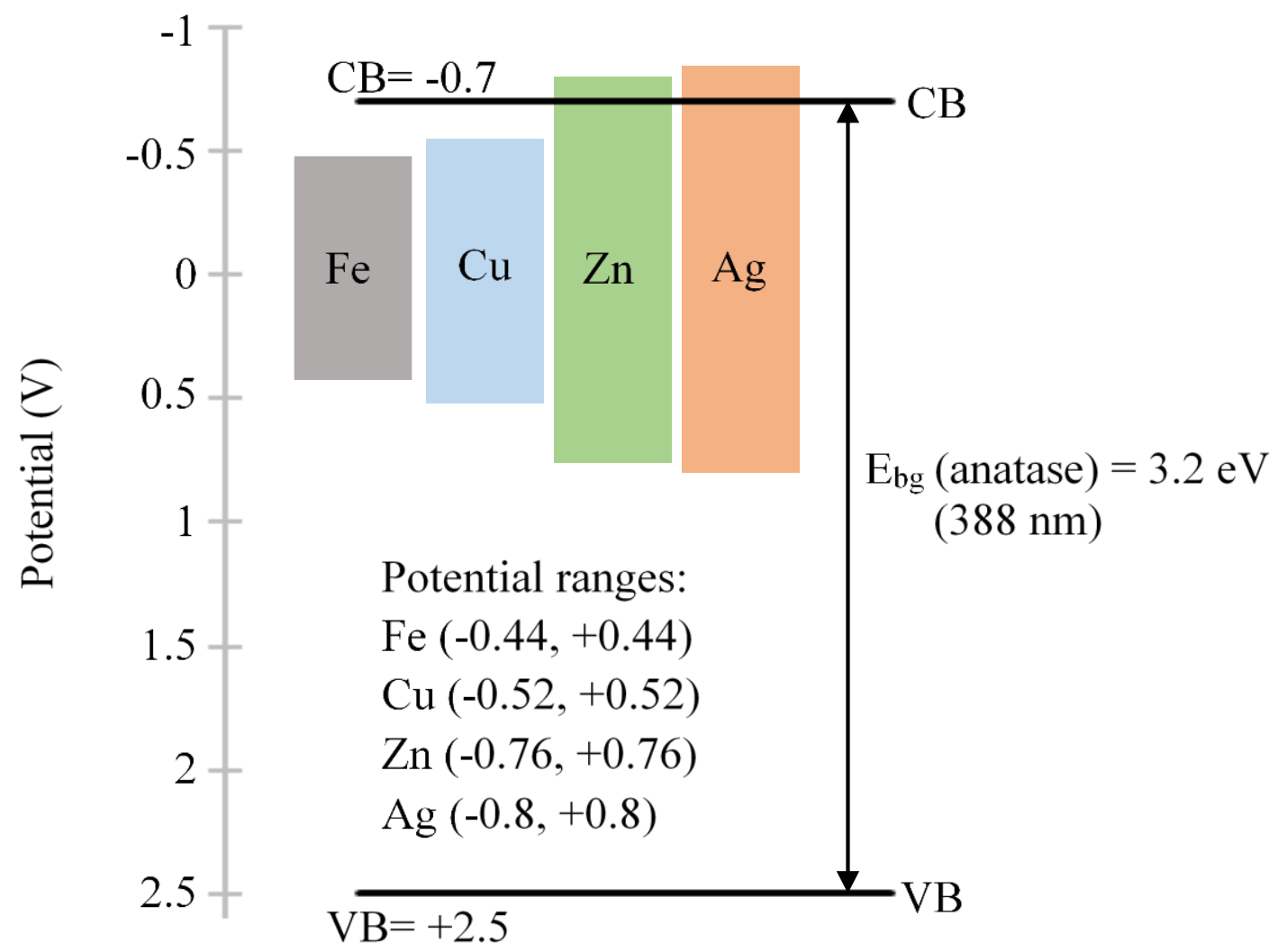

Figure 6.3. Potentials (V) of $\mathrm{TiO}_{2}$ (anatase) and transition metals $(\mathrm{Ag}, \mathrm{Cu}, \mathrm{Fe}, \mathrm{Zn}$ ). Submitted to Int. J. Environ. Sci. Technol. (2017).

Under low light intensity, the metal ion dopants act as effective trapping sites for electrons and alter the rate of electron-hole recombination. However, under high light intensity, the metal ion dopant becomes efficient recombination centers if the available trapping sites are fully occupied. Therefore, the activity of metal ion doped $\mathrm{TiO}_{2}$ appeared to be a complex function of the dopant concentration, the energy level of dopant within the lattice, the electron configuration, the distribution of dopants, the electron donor density, and the incident light intensity (Choi et al., 1994). 


\subsection{Synthetic methods of non-metal doped $\mathrm{TiO}_{2}$}

There are several methods to synthesize the non-metal doped $\mathrm{TiO}_{2}$ including annealing; anodic oxidation; chemical vapor deposition; electrochemical anodization; hydrothermal; microwave; sol-gel; and solvothermal methods (Zaleska, 2008; Gao et al., 2011; Shi et al., 2012; Niu et al., 2014; Xu et al., 2014; Yan et al., 2014; Shao et al., 2015; Ansari et al., 2016). Examples of each method of non-metal doping are described in the following sections.

\subsubsection{Annealing method}

The annealing method involves the mixing and grinding of the $\mathrm{TiO}_{2}$ powder with the nonmetal dopant, heating the mixture, and at the same time the calcination of the solid mixture at a specific temperature to obtain the resulting doped photocatalyst. Such doping method is considerably faster and simpler than other doping methods when the required titanium precursor is already available for use (Figure 6.4).

Thorough mixing of the two solids must be ensured to obtain evenly doped photocatalyst. Due to its single calcination step for doping, the characteristics of the final product can be easily controlled by the temperature and time in the calcination process (Xiang et al., 2011; El-Sheikh et al., 2014; Nawawi and Nawi, 2014; Park et al., 2014; Ha et al., 2015; Zhang et al., 2015; Sun et al., 2016; Zeng et al., 2016).

According to Table 6.1 and based on studies by Nawawi and Nawi (2014), and Park et al., (2014), on $\mathrm{N}-\mathrm{TiO}_{2}$ photocatalysts prepared by the annealing method, the complete degradation of organic pollutants can be achieved in 4 and $7 \mathrm{~h}$, respectively. In contrast, it was shown that more than $99 \%$ degradation of organic pollutants could be reached in $30 \mathrm{~min}$ (Shi et al., 2012). 


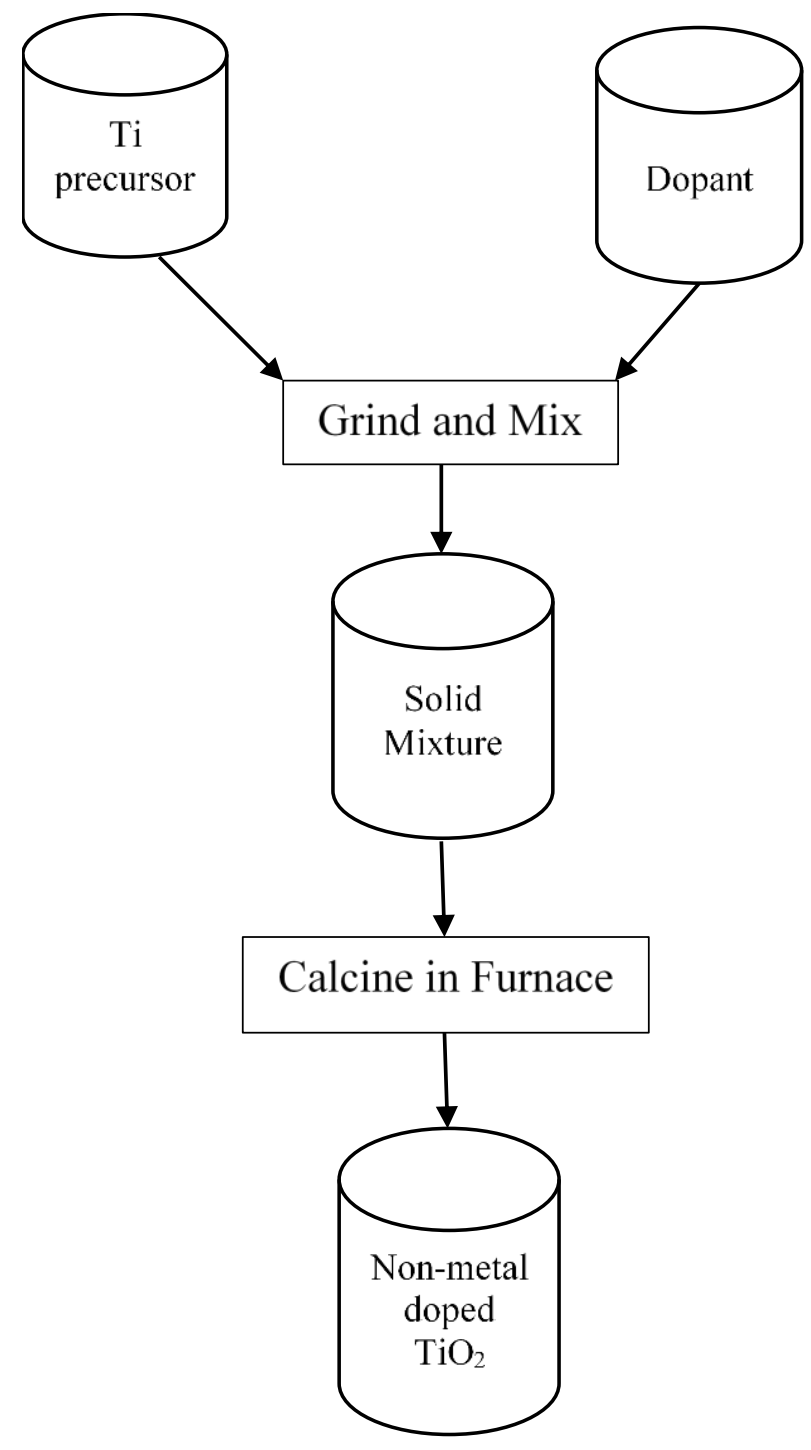

Figure 6.4. Annealing method for doping non-metal onto $\mathrm{TiO}_{2}$ photocatalyst. Submitted to Int. J. Environ. Sci. Technol. (2017). 
Table 6.1. Non-metal doped onto $\mathrm{TiO}_{2}$ by annealing method. Submitted to Int. J. Environ. Sci. Technol. (2017).

\begin{tabular}{|c|c|c|c|c|c|c|c|}
\hline Photocatalyst & Titanium precursors & $\begin{array}{l}\text { Doping } \\
\text { precursors }\end{array}$ & $\begin{array}{l}\text { Source of } \\
\text { Energy }\end{array}$ & $\begin{array}{l}\text { Organic } \\
\text { Pollutants }\end{array}$ & $\begin{array}{l}\text { Degradation } \\
(\%)\end{array}$ & $\begin{array}{l}\text { Degradation } \\
\text { Time (h) }\end{array}$ & Reference \\
\hline $\mathrm{N}-\mathrm{TiO}_{2}$ & $\mathrm{P} 25 \mathrm{TiO}_{2}$ & $\mathrm{NH}_{3}$ & Visible light & MB & 100 & 4.00 & Park et al. (2014) \\
\hline \multirow[t]{3}{*}{$\mathrm{N}-\mathrm{TiO}_{2}$ Carbon coated } & \multirow[t]{3}{*}{$\mathrm{P} 25 \mathrm{TiO}_{2}$} & \multirow[t]{3}{*}{ Urea } & \multirow[t]{3}{*}{ Fluorescent } & RR4 & 100 & 5.00 & \multirow{3}{*}{$\begin{array}{l}\text { Fujishima et al. } \\
(2000)\end{array}$} \\
\hline & & & & MB & 100 & 7.00 & \\
\hline & & & & Phenol & 100 & 7.00 & \\
\hline $\mathrm{N}, \mathrm{S}-\mathrm{TiO}_{2}$ & $\mathrm{TiF}_{4}$ & Thiourea & Visible light & MB & $>99$ & 0.50 & Shi et al. (2012) \\
\hline $\mathrm{N}-\mathrm{TiO}_{2}$ & $\mathrm{TiO}_{2}$ & Ammonia & Visible light & Benzene & 95.5 & 4.00 & Zeng et al. (2016) \\
\hline $\mathrm{N} / \mathrm{C}_{3} \mathrm{~N}_{4}-\mathrm{TiO}_{2}$ & $\mathrm{TiN}$ & Melamine & UV-VIS light & MB & 88.0 & 1.33 & Sun et al. (2016) \\
\hline $\mathrm{N}-\mathrm{TiO}_{2}$ & $\mathrm{TiO}_{2}$ & $\mathrm{~N}_{2}$ (gas) & Visible light & Acephate & 84.0 & 2.00 & Zhang et al. (2015) \\
\hline $\mathrm{C}, \mathrm{N}, \mathrm{S}-\mathrm{TiO}_{2}$ & Brookite/Anatase $\mathrm{TiO}_{2}$ & Thiourea & Visible light & MC-LR & 78.0 & 2.00 & $\begin{array}{l}\text { El-Sheikh et al. } \\
\text { (2014) }\end{array}$ \\
\hline $\mathrm{N}, \mathrm{S}-\mathrm{TiO}_{2}$ & Titanium butoxide & Thiourea & Visible light & $4-\mathrm{CP}$ & 65.0 & 1.50 & Xiang et al. (2011) \\
\hline $\mathrm{N}-\mathrm{TiO}_{2}$ & $\begin{array}{l}\text { Titanium } \\
\text { tetraisopropoxide }\end{array}$ & Urea & Visible light & MB & 40.0 & 2.00 & Ha et al. (2015) \\
\hline
\end{tabular}


The N,S- $\mathrm{TiO}_{2}$ photocatalyst has been synthesized by calcination of the as-prepared $\mathrm{TiO}_{2}$ and doping with a weight ratio of $2: 1(\mathrm{~N}: \mathrm{S})$ at $300^{\circ} \mathrm{C}$ for $2 \mathrm{~h}$ following the annealing method (Shi et al., 2012). The developed $\mathrm{N}, \mathrm{S}-\mathrm{TiO}_{2}$ had the best photocatalytic efficiency such that a high degradation of organic pollutants was achieved in a short time.

\subsubsection{Sol-gel method}

A typical sol-gel process is made up of four steps including the formation of the solution, the formation of a wet gel, the drying of the wet gel, and the calcination of the dried powder. First, the formation of the solution is achieved by suspending the titanium precursor in an aqueous solvent. Another solution is prepared by dissolving the dopant in a different aqueous solvent. Then, the resulting solution is added dropwise to the first solution under constant stirring. In this method and during the processes, stirring must be done until precipitate are formed in the mixture (4-8 h). After the process, the mixture should be kept overnight to complete the reaction. The precipitate formed in this process is in the shape of a wet gel. The wet gel is then washed and dried several times to remove any impurities and to form a solid phase. Finally, the powder is calcined at a specific temperature for a specific amount of time to obtain the desired non-metal doped photocatalyst.

The sol-gel method is the most flexible method of doping $\mathrm{TiO}_{2}$ at room temperature. The characteristics of the final product could be easily controlled depending on the reaction conditions such as solvents, $\mathrm{pH}$, and temperature, as well as calcination conditions (Lin et al., 2011; Iwase et al., 2013; Lin et al., 2013; Han et al., 2014; Azami et al., 2016; Bakar and Ribeiro, 2016a; Giannakas et al., 2016). The sol-gel preparation process is rather a more time-consuming method than an energy-consuming method (Figure 6.5). 


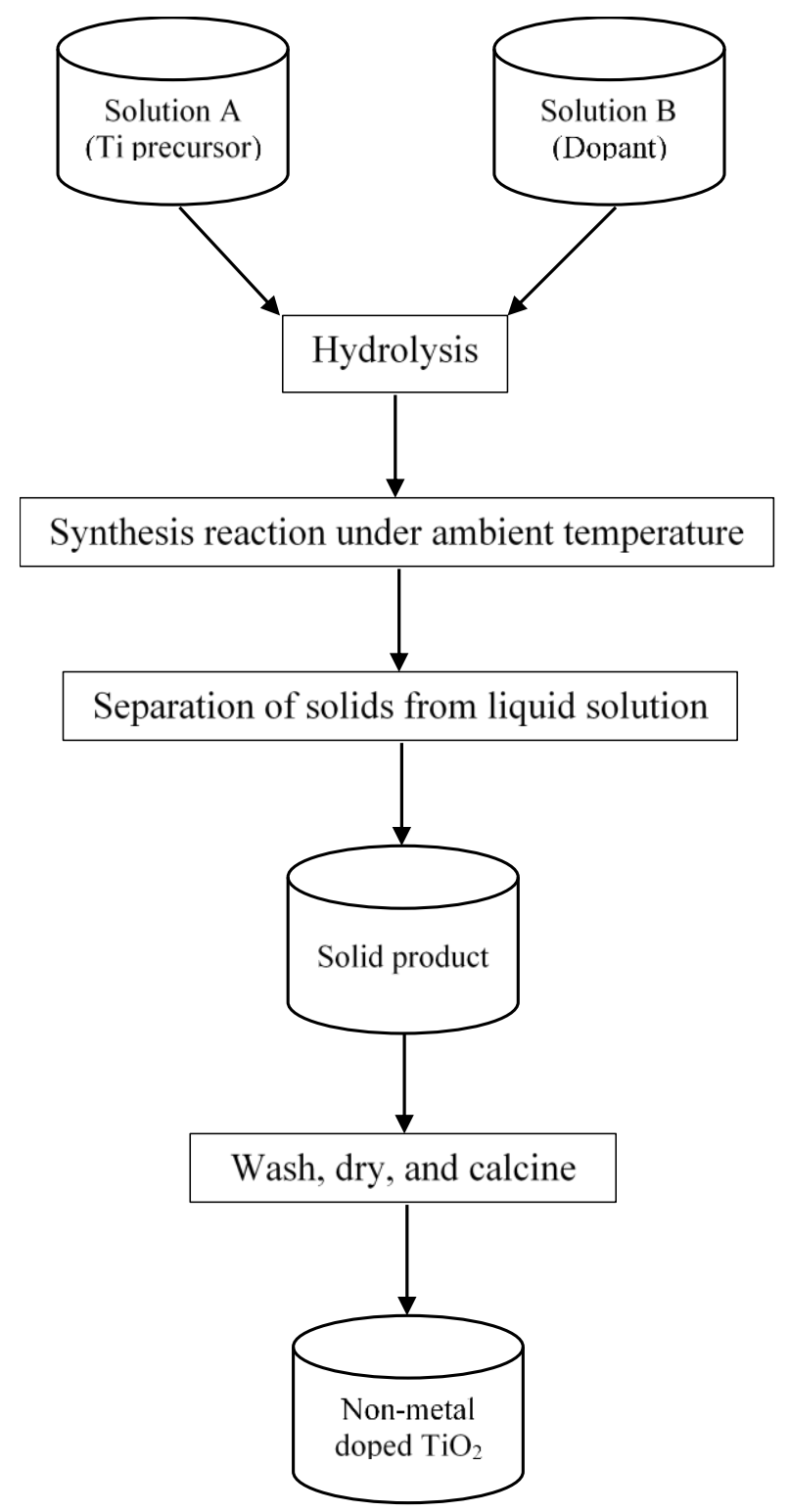

Figure 6.5. Sol-gel method for doping non-metal onto $\mathrm{TiO}_{2}$ photocatalyst. Submitted to Int. J. Environ. Sci. Technol. (2017). 
Table 6.2. Non-metal doped onto $\mathrm{TiO}_{2}$ by sol-gel method.

Submitted to Int. J. Environ. Sci. Technol. (2017).

\begin{tabular}{|c|c|c|c|c|c|c|c|}
\hline Photocatalyst & Titanium precursors & Doping precursors & Source of Energy & Organic Pollutants & $\begin{array}{l}\text { Degradation } \\
(\%)\end{array}$ & $\begin{array}{l}\text { Degradation } \\
\text { Time (h) }\end{array}$ & Reference \\
\hline $\mathrm{N}-\mathrm{TiO}_{2}$ & $\begin{array}{l}\text { Titanium } \\
\text { tetraisopropoxide }\end{array}$ & 1,3-diaminopropane & Solar light & 4-chlorophenol & 100 & 2.00 & Quinones et al. (2015) \\
\hline $\mathrm{S}-\mathrm{TiO}_{2}$ & Titanium butoxide & Thiourea & UVA & MG & 100 & 0.50 & $\begin{array}{l}\text { McManamon et al. } \\
\text { (2015) }\end{array}$ \\
\hline $\mathrm{N}, \mathrm{S}-\mathrm{TiO}_{2}$ & \multirow[t]{3}{*}{ Tetrabutyl titanate } & \multirow{3}{*}{$\begin{array}{l}\text { Thiourea, } \\
\text { dodecylamine }\end{array}$} & \multirow[t]{3}{*}{ Visible light } & \multirow[t]{3}{*}{ MO } & 100 & \multirow[t]{3}{*}{0.33} & \multirow[t]{3}{*}{ Gao et al. (2011) } \\
\hline $\mathrm{N}-\mathrm{TiO}_{2}$ & & & & & 95.0 & & \\
\hline $\mathrm{S}-\mathrm{TiO}_{2}$ & & & & & 70.0 & & \\
\hline $\mathrm{C}, \mathrm{N}, \mathrm{S}-\mathrm{TiO}_{2}$ & Tetrabutyl titanate & $\mathrm{HNO}_{3}$, thiourea & Visible light & $\mathrm{Cr}(\mathrm{VI})$ & 100 & 0.83 & Lei et al. (2015) \\
\hline $\mathrm{C}, \mathrm{N}, \mathrm{S}-\mathrm{TiO}_{2}$ & Titanium Butoxide & $\mathrm{HNO}_{3}$ & Visible light & $\mathrm{TC}$ & $>99$ & 3.00 & Wang et al. (2011) \\
\hline $\mathrm{N}-\mathrm{TiO}_{2}$ & Titanium butoxide & $\mathrm{HNO}_{3}$ & Visible light & Phenol & 99.0 & 9.00 & Mohamed et al. (2015) \\
\hline $\mathrm{N}-\mathrm{TiO}_{2}$ & $\begin{array}{l}\text { Titanium (IV) } \\
\text { isopropoxide }\end{array}$ & $\mathrm{NH}_{3}$ & Visible light (LED) & MB & 94.0 & 1.50 & Vaiano et al. (2015) \\
\hline $\mathrm{F}-\mathrm{TiO}_{2}$ & Titanium isopropoxide & Trifluoroacetic acid & Visible light & Atrazine & 93.4 & 3.00 & Samsudin et al. (2016) \\
\hline \multirow[t]{2}{*}{$\mathrm{B}-\mathrm{TiO}_{2}$} & \multirow[t]{6}{*}{ Titanium butoxide } & \multirow[t]{2}{*}{ Boric acid } & \multirow[t]{4}{*}{ UV-VIS } & $\mathrm{Cr}(\mathrm{VI})$ & 90.0 & 0.50 & \multirow[t]{6}{*}{ Giannakas et al. (2016) } \\
\hline & & & & Benzoic acid & 80.0 & 2.00 & \\
\hline \multirow[t]{2}{*}{$\mathrm{B}, \mathrm{N}-\mathrm{TiO}_{2}$} & & \multirow[t]{2}{*}{ Boric acid and $\mathrm{NH}_{4} \mathrm{Cl}$} & & $\mathrm{Cr}(\mathrm{VI})$ & 83.0 & 0.50 & \\
\hline & & & & Benzoic acid & 77.0 & 2.00 & \\
\hline \multirow[t]{2}{*}{$\mathrm{B}, \mathrm{N}, \mathrm{F}-\mathrm{TiO}_{2}$} & & \multirow[t]{2}{*}{ Boric acid and $\mathrm{NH}_{4} \mathrm{~F}$} & & $\mathrm{Cr}(\mathrm{VI})$ & 81.0 & 0.50 & \\
\hline & & & & Benzoic acid & 80.0 & 2.00 & \\
\hline $\mathrm{N}-\mathrm{TiO}_{2}$ & Titanium butoxide & Ethylenediamine & Visible light & $\mathrm{RhB}$ & 90.0 & 2.00 & Li et al. (2016) \\
\hline $\mathrm{B}-\mathrm{TiO}_{2}$ & Tetrabutyl titanate & Boric acid & UV-VIS & $\begin{array}{l}\text { 2-methyl-4- } \\
\text { chlorophenoxyacetic } \\
\text { acid }\end{array}$ & 90.0 & 2.00 & Quinones et al. (2015) \\
\hline $\mathrm{N}^{-\mathrm{TiO}_{2}}$ & \multirow{3}{*}{$\begin{array}{l}\text { Tetraisopropyl- } \\
\text { orthotitanate }\end{array}$} & Urea and HP & \multirow[t]{3}{*}{ Visible light } & \multirow[t]{3}{*}{ MO } & 88.5 & \multirow[t]{3}{*}{3.00} & \multirow{3}{*}{$\begin{array}{l}\text { Saien and Mesgari } \\
(2016)\end{array}$} \\
\hline $\mathrm{HP} / \mathrm{TiO}_{2}$ & & Urea & & & 51.4 & & \\
\hline $\mathrm{HP} / \mathrm{N}-\mathrm{TiO}_{2}$ & & HP & & & 33.1 & & \\
\hline $\mathrm{P}-\mathrm{TiO}_{2}$ & $\mathrm{Ti}\left(\mathrm{OC}_{4} \mathrm{H}_{9}\right)_{4}$ & $\mathrm{H}_{3} \mathrm{PO}_{4}$ & Visible light & MO & 83.5 & 8.00 & Xia et al. (2014) \\
\hline $\mathrm{C}, \mathrm{N}, \mathrm{S}-\mathrm{TiO}_{2}$ & Titanium butoxide & Thiourea & Visible light & $\mathrm{X}-3 \mathrm{~B}$ & 83.1 & 2.00 & Lin et al. (2013) \\
\hline $\mathrm{N}, \mathrm{S}-\mathrm{TiO}_{2}$ & $\mathrm{Ti}$ & Thiourea and urea & Visible light & RhB & 82.0 & 2.00 & $\begin{array}{l}\text { Bakar and Ribeiro } \\
\text { (2016) }\end{array}$ \\
\hline $\mathrm{S}-\mathrm{TiO}_{2}$ & Titanium isopropoxide & $\mathrm{H}_{2} \mathrm{SO}_{4}$ & Visible light & MC-LR & 76.0 & 5.00 & Han et al. (2014) \\
\hline
\end{tabular}




\begin{tabular}{|c|c|c|c|c|c|c|c|}
\hline Photocatalyst & Titanium precursors & Doping precursors & Source of Energy & Organic Pollutants & $\begin{array}{l}\text { Degradation } \\
(\%)\end{array}$ & $\begin{array}{l}\text { Degradation } \\
\text { Time (h) }\end{array}$ & Reference \\
\hline $\mathrm{S}-\mathrm{TiO}_{2}$ & Titanium butoxide & Thiourea & Visible light & $4-\mathrm{CP}$ & 57.0 & 8.00 & Szatmary et al. (2011) \\
\hline $\mathrm{F}-\mathrm{TiO}_{2}$ & Titanium isopropoxide & Trifluoroacetic acid & Visible light & Atrazine & 43.2 & 3.00 & Samsudin et al. (2016) \\
\hline $\mathrm{N}, \mathrm{S}-\mathrm{TiO}_{2}$ & Tetrabutyl titanate & $\mathrm{HNO}_{3}$, thiourea & Visible light & $\begin{array}{l}\text { Organophosphorus } \\
\text { pesticide }\end{array}$ & 25.0 & 2.00 & Lin et al. (2011) \\
\hline $\mathrm{B}, \mathrm{S}-\mathrm{TiO}_{2}$ & Tetrabutyl titanate & Boric acid, thiourea & Visible light & $\mathrm{MB}$ & 21.0 & 4.00 & Sun et al. (2016) \\
\hline $\mathrm{P}-\mathrm{TiO}_{2}$ & $\begin{array}{l}\text { Titanium } \\
\text { tetraisopropoxide, } \mathrm{TiCl}_{4}\end{array}$ & Cyclohexyl phosphine & Visible light & Phenol & 4.50 & 5.00 & Iwase et al. (2013) \\
\hline $\mathrm{C}, \mathrm{N}-\mathrm{TiO}_{2}$ & $\mathrm{TiF}_{4}$ & Thiourea & Visible light & Reactive red 4 & - & - & Azami et al. (2016) \\
\hline $\mathrm{S}-\mathrm{TiO}_{2}$ & $\begin{array}{l}\text { Titanium } \\
\text { tetraisopropoxide }\end{array}$ & Thiourea & - & - & - & - & $\begin{array}{l}\text { Shvadchina et al. } \\
\text { (2015) }\end{array}$ \\
\hline
\end{tabular}


According to Table 6.2, the studies on $\mathrm{N}-\mathrm{TiO}_{2}, \mathrm{~S}-\mathrm{TiO}_{2}, \mathrm{~N}, \mathrm{~S}-\mathrm{TiO}_{2}$, and C,N,S-TiO 2 by Gao et al. (2011), Lei et al. (2015), McManamon et al. (2015), and Nolan et al. (2012), could achieve complete degradation of the methyl orange (MO), chromium (Cr(VI)), malachite green (MG), and 4-chlorophenol (4-CP) in 120, 50, 30, and 20 min, respectively. The developed N,S- $\mathrm{TiO}_{2}$ by Gao et al. (2011), presented the best photocatalytic efficiency such that it can reach a complete degradation of organic pollutants in the shortest time.

The N,S- $\mathrm{TiO}_{2}$ composite was synthesized by first, dissolving the titanium precursor in its solvent to form solution A. Solution B was prepared by dissolving the doping precursor into another solvent. Then, solution B was added dropwise to solution A to form a precipitate via hydrolysis. The products were then dried at $60^{\circ} \mathrm{C}$ for $24 \mathrm{~h}$ and calcined at $450^{\circ} \mathrm{C}$ for $3 \mathrm{~h}$.

\subsubsection{Hydrothermal method}

The general hydrothermal doping method is very similar to the sol-gel method except that the doping reaction for the hydrothermal method is usually carried out in an autoclave, which is kept at a specific temperature for an amount of time to promote complete doping reaction. When the reaction is carried out in an autoclave, the solution can be heated to a temperature above its boiling point due to the ability of a closed system to withstand high pressure for the solution to reach its vapor pressure (Figure 6.6).

The hydrothermal doping method is a simple, time-effective, and environmentally friendly method for preparing non-metal doped $\mathrm{TiO}_{2}$. On the other hand, the consumption of energy and using special laboratory devices are two main concerns in such preparation method (Byranvand et al., 2013; Bakar and Ribeior (2016a); Bakar and Ribeiro (2016b). 


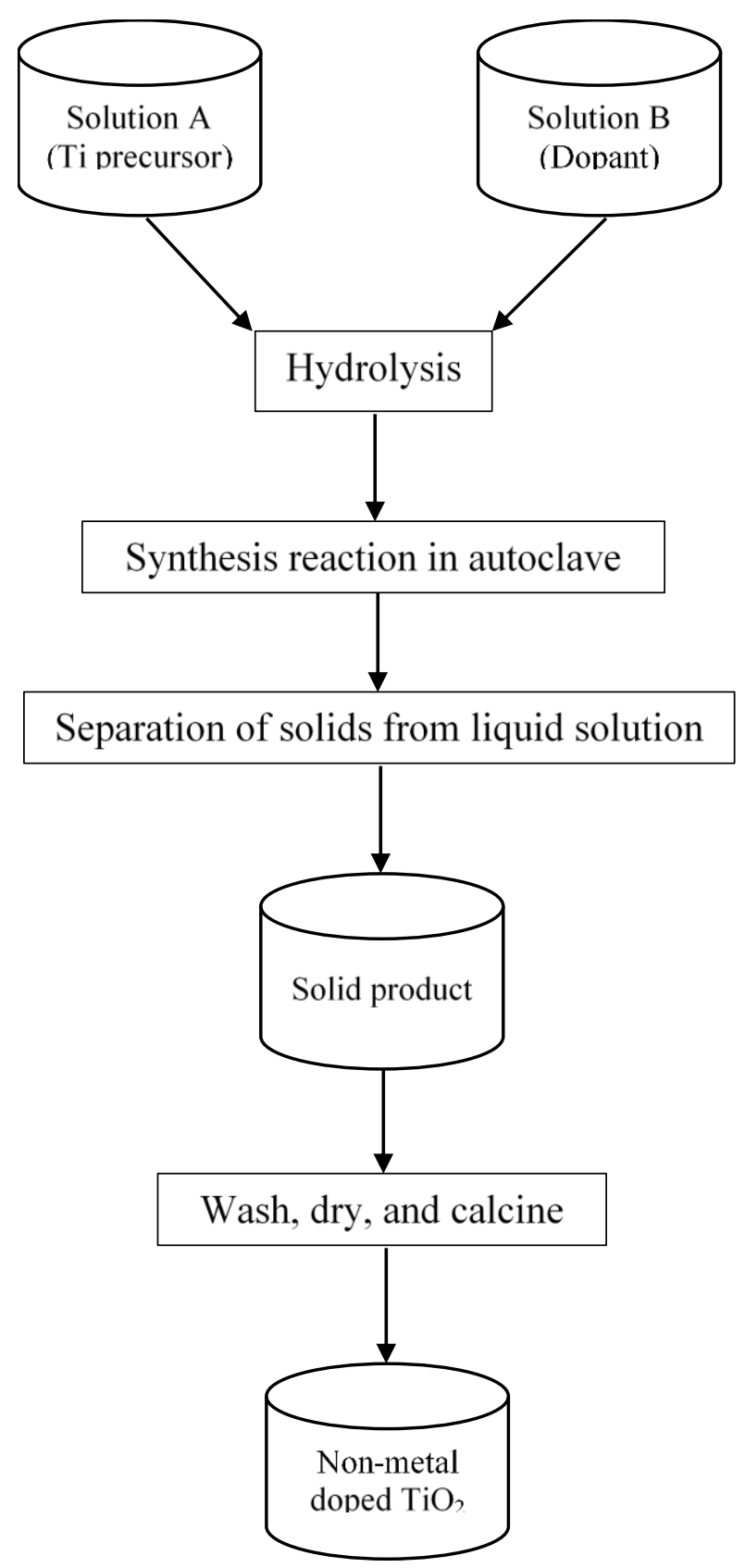

Figure 6.6. Hydrothermal method for doping non-metal onto $\mathrm{TiO}_{2}$ photocatalyst. Submitted to Int. J. Environ. Sci. Technol. (2017). 
Table 6.3. Non-metal doped onto $\mathrm{TiO}_{2}$ by hydrothermal method.

Submitted to Int. J. Environ. Sci. Technol. (2017).

\begin{tabular}{|c|c|c|c|c|c|c|c|}
\hline Photocatalyst & $\begin{array}{l}\text { Titanium } \\
\text { precursors }\end{array}$ & Doping precursors & $\begin{array}{l}\text { Source of } \\
\text { Energy }\end{array}$ & $\begin{array}{l}\text { Organic } \\
\text { Pollutants }\end{array}$ & $\begin{array}{l}\text { Degradation } \\
(\%)\end{array}$ & $\begin{array}{l}\text { Degradation } \\
\text { Time (h) }\end{array}$ & Reference \\
\hline $\mathrm{C}, \mathrm{N}-\mathrm{TiO}_{2}$ & $\mathrm{Ti}_{2}\left(\mathrm{SO}_{4}\right)_{3}$ & Glycine & Visible light & Ibuprofen & 100 & 6.0 & El-Sheikh et al. (2017) \\
\hline \multirow[t]{3}{*}{$\mathrm{N}-\mathrm{TiO}_{2}$} & \multirow[t]{3}{*}{ Ti-peroxo complex } & \multirow[t]{3}{*}{ Urea } & \multirow[t]{2}{*}{ UV-C } & $\mathrm{RhB}$ & 100 & 1.0 & \multirow[t]{3}{*}{ Bakar and Ribeiro (2016) } \\
\hline & & & & Atrazine & 49.0 & 3.0 & \\
\hline & & & Visible light & RhB & 57.0 & 4.5 & \\
\hline \multirow[t]{2}{*}{$\mathrm{N}, \mathrm{S}-\mathrm{TiO}_{2}$} & \multirow{2}{*}{$\begin{array}{l}\text { Titanium (IV) } \\
\text { isopropoxide }\end{array}$} & \multirow[t]{2}{*}{ Thiourea } & \multirow[t]{2}{*}{ Visible light } & RhB & 100 & 2.0 & \multirow[t]{2}{*}{ Chung et al. (2015) } \\
\hline & & & & MB & 98.0 & 3.0 & \\
\hline \multirow[t]{2}{*}{$\mathrm{N}, \mathrm{S}-\mathrm{TiO}_{2}$} & \multirow[t]{2}{*}{ Titanium butoxide } & \multirow[t]{2}{*}{ Thiourea } & \multirow[t]{2}{*}{ Visible light } & Naproxen & $>99$ & 1.5 & \multirow[t]{2}{*}{ Eslami et al. (2016) } \\
\hline & & & & Ibuprofen & 82.0 & 1.5 & \\
\hline $\mathrm{F}, \mathrm{N}-\mathrm{TiO}_{2}$ & $\mathrm{Ti}\left(\mathrm{SO}_{4}\right)_{2}$ & $\mathrm{HF}, \mathrm{NH}_{3} \mathrm{H}_{2} \mathrm{O}$ & Visible light & $\mathrm{MB}$ & 97.3 & 5.0 & Cheng et al. (2015) \\
\hline $\mathrm{N}-\mathrm{TiO}_{2}$ & $\begin{array}{l}\text { Titanium (IV) } \\
\text { isopropoxide }\end{array}$ & Chitosan & Visible light & RhB & 96.8 & 0.5 & Shao et al. (2015) \\
\hline $\mathrm{P}-\mathrm{TiO}_{2} / \mathrm{CNT}$ & Tetrabutyl titanate & Hypophosphorus acid & Visible light & MO & 92.5 & 4.0 & Wang and Zhou (2011) \\
\hline $\mathrm{N}-\mathrm{TiO}_{2}$ & $\begin{array}{l}\text { Titanium } \\
\text { isopropoxide }\end{array}$ & $\mathrm{HF}$ & $\begin{array}{l}\text { Simulated } \\
\text { solar light }\end{array}$ & Diazinon & 86.0 & 3.0 & Salarian et al. (2016) \\
\hline $\mathrm{N}-\mathrm{TiO}_{2} / \mathrm{CNT}$ & $\mathrm{TiCl}_{4}$ & Urea & $\begin{array}{l}\text { Visible light } \\
\text { (LED) }\end{array}$ & Ibuprofen & 86.0 & 2.5 & Yuan et al. (2016) \\
\hline $\mathrm{N}-\mathrm{TiO}_{2}$ & $\begin{array}{l}\text { Titanium } \\
\text { isopropoxide }\end{array}$ & N-methyl-2-pyrrolidone & Visible light & RhB & 80.0 & 1.0 & Ali and Sandhya (2016) \\
\hline $\mathrm{N}, \mathrm{S}-\mathrm{TiO}_{2}$ & $\mathrm{TiS}_{2}$ & $\mathrm{HNO}_{3}$ & Visible light & MB & 80.0 & 4.0 & Lin et al. (2015) \\
\hline $\mathrm{N}, \mathrm{S}-\mathrm{TiO}_{2}$ & $\mathrm{Ti}\left(\mathrm{SO}_{4}\right)_{2}$ & Thiourea, urea & Visible light & Atrazine & 64.0 & 6.0 & Zhang et al. (2015) \\
\hline $\mathrm{N}-\mathrm{TiO}_{2}$ & $\mathrm{TiCl}_{4}$ & $\mathrm{NH}_{3}$ & Visible light & Alachlor & 53.0 & 3.0 & $\begin{array}{l}\text { Suwannaruang and Wantala } \\
\text { (2016) }\end{array}$ \\
\hline \multirow[t]{2}{*}{$\mathrm{S}-\mathrm{TiO}_{2}$} & \multirow[t]{2}{*}{$\mathrm{Ti}$} & \multirow[t]{2}{*}{ Carbon disulfide, thiourea } & \multirow[t]{2}{*}{ Visible light } & $\mathrm{MO}$ & 48.0 & 2.0 & \multirow[t]{2}{*}{ Bakar and Ribeiro (2016a) } \\
\hline & & & & Phenol & 44.0 & 2.0 & \\
\hline
\end{tabular}


As Table 6.3 shows, the studies on $\mathrm{C}, \mathrm{N}-\mathrm{TiO}_{2}, \mathrm{~N}-\mathrm{TiO}_{2}, \mathrm{~N}, \mathrm{~S}-\mathrm{TiO}_{2}, \mathrm{~N}, \mathrm{~S}-\mathrm{TiO}_{2}, \mathrm{~F}, \mathrm{~N}-\mathrm{TiO}_{2}$, and N-TiO 2 by El-Sheikh et al. (2017), Bakar and Ribeiro (2016c), Chung et al. (2015), Eslami et al. (2016), Cheng et al. (2015), and Shao et al. (2015), were able to achieve a 100, 100, 100, >99, 97.31, and $96.8 \%$ degradation of organic pollutants in $6,1,2,1.5,5$, and $0.5 \mathrm{~h}$, respectively.

\subsubsection{Microwave-assisted method}

The microwave-assisted method is often a combination of the sol-gel and microwave methods, or a microwave assisted hydrothermal method. The microwave method uses a microwave reactor to speed up the formation of the products in the doping process (Lin et al., 2015; Du et al., 2016; Martins et al., 2016). In the microwave reactor, the solution can be heated above its boiling point by electromagnetic radiation in a closed system, and the reactor can withstand the high pressure created from the doping process (Figure 6.7). Hence, the reaction time would be greatly shortened (Azami et al., 2016).

The microwave-assisted method is time-efficient, energy-efficient, and environmentally friendly. On the other hand, the cost of the instrument, such as the microwave reactor and other related equipment, could be considerably high when compared to that of other methods (Lin et al., 2015; Du et al., 2016; Martins et al., 2016). As Table 6.4 shows, studies on $\mathrm{P}_{-}-\mathrm{TiO}_{2}$ and $\mathrm{N}-\mathrm{TiO}_{2}$ by Niu et al. (2014), and Yan et al. (2014), could achieve over 99\% degradation of the organic pollutants in 1.67 and $1.5 \mathrm{~h}$, respectively. 


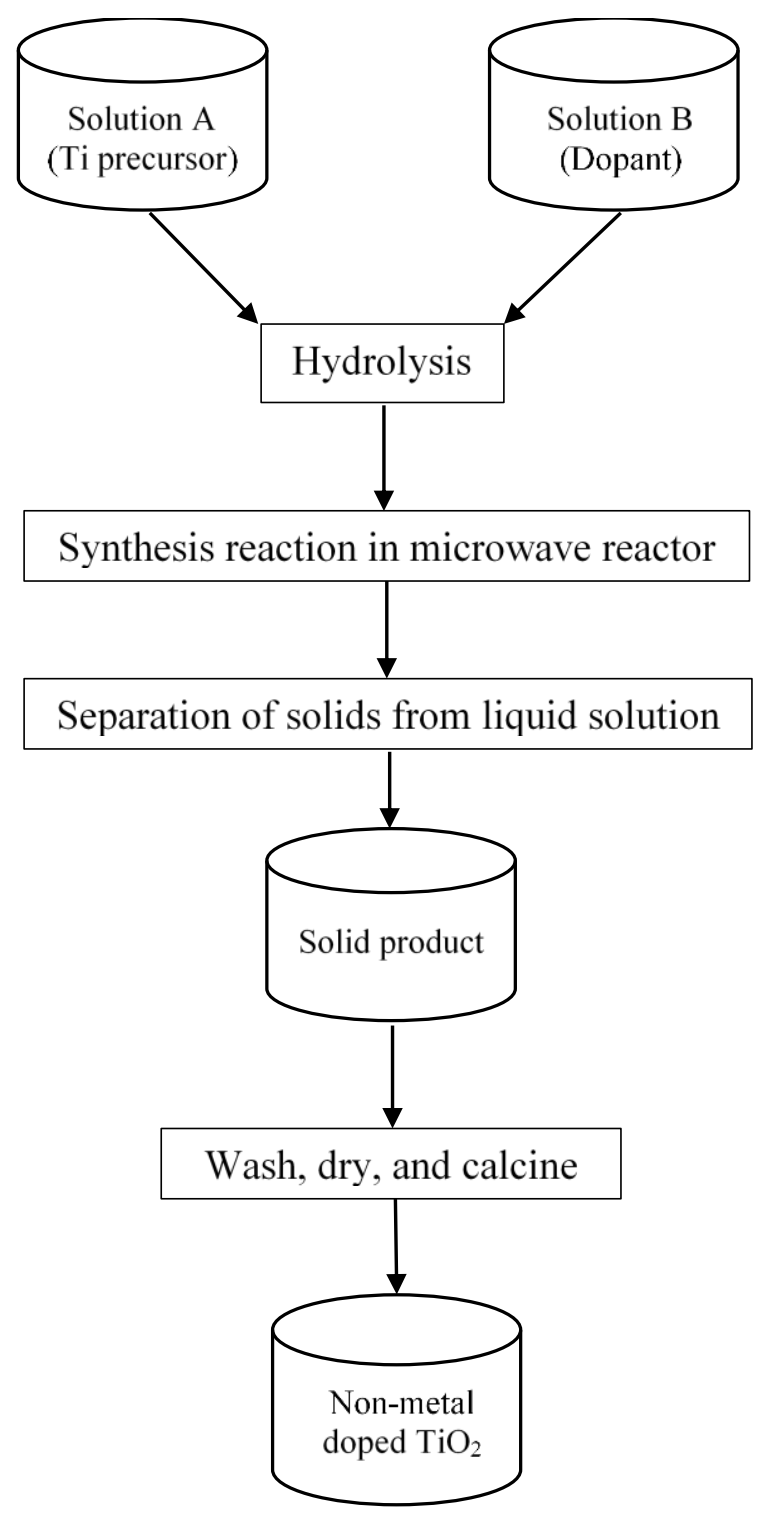

Figure 6.7. Microwave assisted method for doping non-metal onto $\mathrm{TiO}_{2}$ photocatalyst. Submitted to Int. J. Environ. Sci. Technol. (2017). 
Table 6.4. Non-metal doped onto $\mathrm{TiO}_{2}$ by microwave method.

Submitted to Int. J. Environ. Sci. Technol. (2017).

\begin{tabular}{|c|c|c|c|c|c|c|c|}
\hline Photocatalyst & $\begin{array}{l}\text { Titanium } \\
\text { precursors }\end{array}$ & $\begin{array}{l}\text { Doping } \\
\text { precursors }\end{array}$ & $\begin{array}{l}\text { Source of } \\
\text { Energy }\end{array}$ & $\begin{array}{l}\text { Organic } \\
\text { Pollutants }\end{array}$ & $\begin{array}{l}\text { Degradatio } \\
\text { n }(\%)\end{array}$ & $\begin{array}{l}\text { Degradatio } \\
\text { n Time (h) }\end{array}$ & Reference \\
\hline $\mathrm{P}_{-} \mathrm{TiO}_{2}$ & Titanium butoxide & $\mathrm{NaH}_{2} \mathrm{PO}_{4}$ & Visible light & MB & 100.00 & 1.67 & Niu et al. (2014) \\
\hline $\mathrm{N}-\mathrm{TiO}_{2}$ & $\mathrm{P} 25 \mathrm{TiO}_{2}$ & $\mathrm{NH}_{4} \mathrm{Cl}$ & Visible Light & $\mathrm{RhB}$ & $>99.00$ & 1.50 & Yan et al. (2014) \\
\hline $\begin{array}{l}\mathrm{N} \text {-carbon quantum } \\
\text { dots } / \mathrm{TiO}_{2}\end{array}$ & $\mathrm{P} 25 \mathrm{TiO}_{2}$ & $\begin{array}{l}\text { Ammonium } \\
\text { phosphate diabasic }\end{array}$ & Visible light & MB & 99.995 & 2.00 & Martins et al. (2016) \\
\hline $\mathrm{N}-\mathrm{TiO}_{2}$ & $\mathrm{P} 25 \mathrm{TiO}_{2}$ & $\mathrm{NH}_{4} \mathrm{OH}$ & UV-VIS light & 5-fluorouracil & 88.000 & 3.00 & Lin et al. (2015) \\
\hline $\mathrm{C}, \mathrm{N}-\mathrm{TiO}_{2}$ & Anatase $\mathrm{TiO}_{2}$ & $\mathrm{CH}_{5} \mathrm{~N}_{3} \mathrm{HCl}$ & Visible light & MO & 86.300 & 0.50 & Du et al. (2016) \\
\hline
\end{tabular}




\subsubsection{Other methods}

\subsubsection{Anodic oxidation}

The anodic oxidation could be used to synthesize non-metal doped $\mathrm{TiO}_{2}$ nanotubes, especially highly ordered nanotube arrays. $\mathrm{TiO}_{2}$ nanotubes could be synthesized using this approach with a unique structure, high specific area, high absorption ability (compared to that of powder $\mathrm{TiO}_{2}$ ), and unidirectional charge transfer.

The preparation of $\mathrm{TiO}_{2}$ nanotubes can be classified into two categories. In a typical twostep synthesis process, the first step involves the formation of $\mathrm{TiO}_{2}$ nanotubes through anodization; and the second phase includes the blending of the non-metal element into the $\mathrm{TiO}_{2}$ nanotubes by immersing the as-prepared $\mathrm{TiO}_{2}$ in hot ammonia solutions, annealing with ammonia at high temperature, hydrothermal treatment, and chemical deposition. However, the two-step synthesis approach is cost intensive and difficult to operate for industrial applications.

The one-step synthesis process involves the formation of non-metal doped $\mathrm{TiO}_{2}$ by anodization of Ti-containing alloy in ethylene glycol-based electrolytes containing a small amount of non-metal precursor. Such approach is a more straightforward and cost-effective method to prepare non-metal doped $\mathrm{TiO}_{2}$ with high purity at relatively low temperature (Mazierski et al., 2016).

As shown in Figure 6.8, the $\mathrm{N}-\mathrm{TiO}_{2}$, prepared by Mazierski et al. (2016) via one-step synthesis process, showed $24 \%$ phenol degradation in $1 \mathrm{~h}$. In their synthesis, the Ti foil was cleaned, and air dried followed by the anodic oxidation of the Ti foil at room temperature in the electrolyte solution composed of ethylene glycol, water, $0.09 \mathrm{M} \mathrm{NH}_{4} \mathrm{~F}$, and urea as the dopant, with an anodizing power of 20 to $50 \mathrm{~V}$ for 30 to $120 \mathrm{~min}$. Finally, the products were rinsed, air dried, and calcined at $450^{\circ} \mathrm{C}$ for $1 \mathrm{~h}$ with a $2^{\circ} \mathrm{C} /$ min heating rate. 


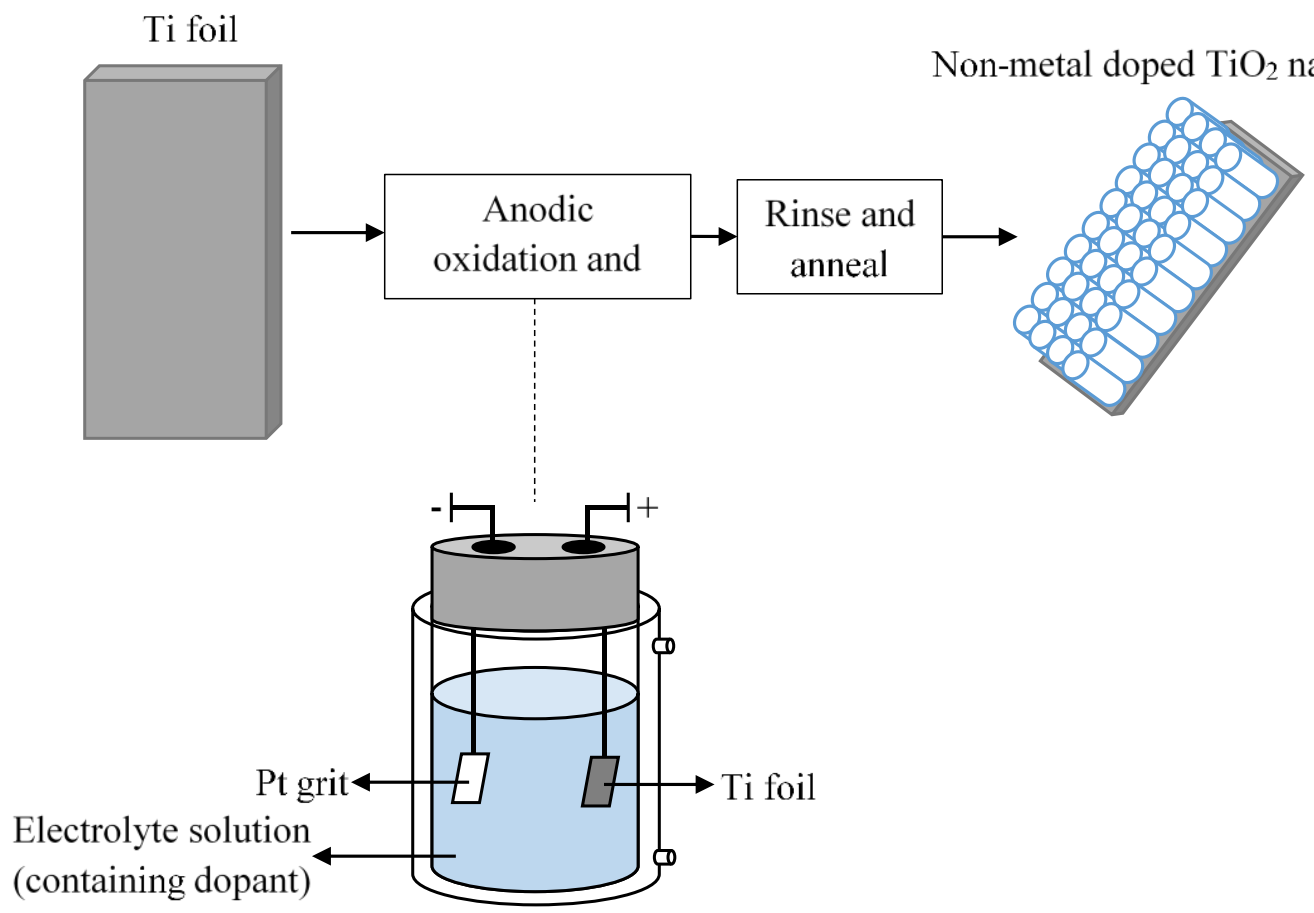

Figure 6.8. Anodic oxidation method for doping non-metal onto $\mathrm{TiO}_{2}$ photocatalyst. Submitted to Int. J. Environ. Sci. Technol. (2017).

\subsubsection{Electrochemical anodization}

As shown in Figure 6.9, the complex process of electrochemical anodization is another approach in anodic oxidation methods. This approach provides a greater possibility of controlling the morphology of the obtained nanostructure of non-metal doped $\mathrm{TiO}_{2}$.

The electrochemical anodization is used to synthesize non-metal doped $\mathrm{TiO}_{2}$ nanotubes from Ti plate (foil). For instance, non-metal $(\mathrm{B}, \mathrm{I}, \mathrm{N})$ doped $\mathrm{TiO}_{2}$ photocatalysts prepared by Szkoda et al. (2016), using electrochemical anodization achieved methylene blue (MB) removal efficiencies of $94,70,50 \%$, respectively, in $2 \mathrm{~h}$. 


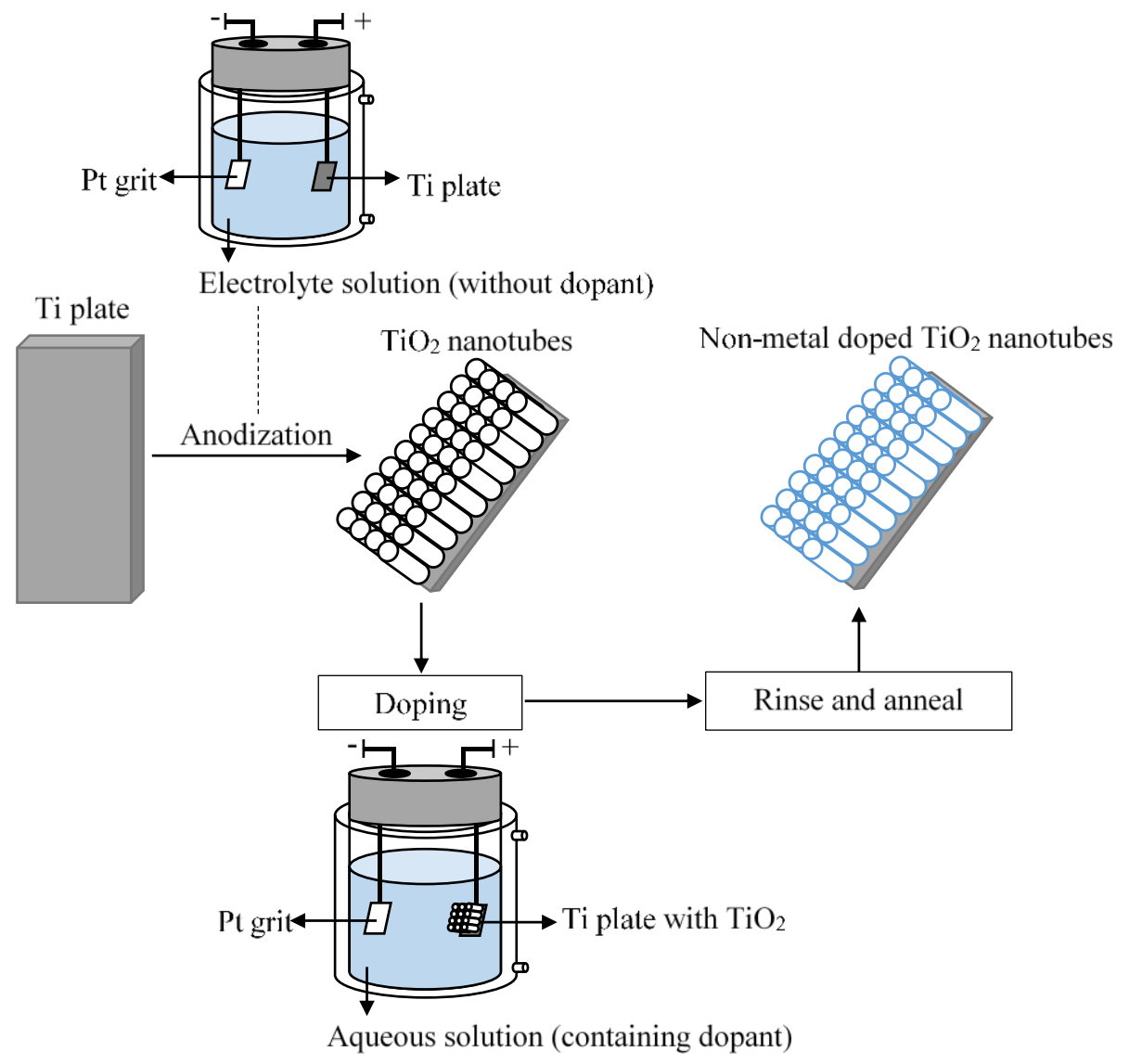

\section{Figure 6.9. Electrochemical anodization method for doping of non-metal onto $\mathrm{TiO}_{2}$ photocatalyst.}

Submitted to Int. J. Environ. Sci. Technol. (2017).

The $\mathrm{TiO}_{2}$ nanotubes were prepared via electrochemical anodization of a Ti plate in a fluoride-containing solution for two stages of reaction under the same temperature $\left(23^{\circ} \mathrm{C}\right)$, electrolyte solution composition $\left(0.27 \mathrm{M}\right.$ of $\mathrm{NH}_{4} \mathrm{~F}$ in the ratio of $1 / 99 \mathrm{v} / \mathrm{v}$ water/ethylene glycol solution), and anodization parameters (40V, $2 \mathrm{~h})$. After the first stage, the formed nanotubes were removed by overnight etching in an oxalic acid solution and the second stage was carried out. The $\mathrm{TiO}_{2}$ plate was ultrasonically cleaned to remove any surface debris. Doping of $\mathrm{TiO}_{2}$ nanotubes was performed by the electrochemical doping of the $\mathrm{TiO}_{2}$ plate in the solution of dopant under a power of 1.5 to $3 \mathrm{~V}$ for 15 to $60 \mathrm{~min}$. Lastly, the as-prepared $\mathrm{TiO}_{2}$ nanotubes were rinsed and annealed at 
$450^{\circ} \mathrm{C}$ for $2 \mathrm{~h}$ with the heating rate of $2^{\circ} \mathrm{C}$ min to transform the amorphous $\mathrm{TiO}_{2}$ to the crystalline phase.

\subsubsection{Solvothermal method}

The solvothermal method is very similar to the hydrothermal synthesis, excepting the selection of the solvent in the synthetic reaction. The polymer solution is a common type of solvent used in the solvothermal method (Wang et al., 2016; Simsek, 2017). As Table 6.5 shows, $\mathrm{B}-\mathrm{TiO}_{2}$ and $\mathrm{N}^{-\mathrm{TiO}_{2}}$ photocatalysts prepared by Simsek (2017), and Wang et al. (2016), presented Bisphenol-A and methyl orange (MO) removal efficiencies of 99.1 and $91 \%$ in 4 and $3.5 \mathrm{~h}$, respectively.

\subsection{Characterization of non-metal doped $\mathrm{TiO}_{2}$}

The non-metal doped $\mathrm{TiO}_{2}$ prepared by annealing, sol-gel, hydrothermal, and microwaveassisted methods are usually characterized by their chemical structure, physical structure, and optical properties. These characteristics are determined using $\mathrm{N}_{2}$ adsorption-desorption isotherms using Brunauer, Emmett, and Teller (BET) theory to analyze the specific surface area, scanning or transmission electron microscopy (SEM or TEM) to analyze the morphology and crystal structure, X-ray diffraction (XRD) to analyze the crystal structure, X-ray photoelectron spectroscopy (XPS) or energy dispersive spectroscopy (EDS) to analyze the chemical composition, and UV-Visible diffuse reflection spectroscopy (DRS) to analyze the absorption wavelength (Gao et al., 2011; Yan et al., 2014; Nasirian and Mehrvar, 2016). 
Table 6.5. Non-metal doped onto $\mathrm{TiO}_{2}$ by other methods.

Submitted to Int. J. Environ. Sci. Technol. (2017).

\begin{tabular}{|c|c|c|c|c|c|c|c|c|}
\hline Photocatalyst & Method & $\begin{array}{l}\text { Titanium } \\
\text { precursor }\end{array}$ & $\begin{array}{l}\text { Doping } \\
\text { precursor }\end{array}$ & $\begin{array}{l}\text { Source of } \\
\text { Energy }\end{array}$ & $\begin{array}{l}\text { Organic } \\
\text { Pollutants }\end{array}$ & $\begin{array}{c}\text { Degradation } \\
(\%)\end{array}$ & $\begin{array}{c}\text { Degradation } \\
\text { Time (h) }\end{array}$ & Ref. \\
\hline $\mathrm{N}-\mathrm{TiO}_{2}$ & Anodic oxidation & Ti foil & Urea & Visible light & Phenol & 24 & 1 & Mazierski et al. (2016) \\
\hline $\mathrm{B}-\mathrm{TiO}_{2}$ & \multirow{3}{*}{$\begin{array}{l}\text { Electrochemical } \\
\text { anodization }\end{array}$} & \multirow[t]{3}{*}{ Ti plate } & Boric acid & \multirow[t]{3}{*}{ UV-VIS } & \multirow[t]{3}{*}{ MB } & 94 & \multirow[t]{3}{*}{2} & \multirow[t]{3}{*}{ Szkoda et al. (2016) } \\
\hline $\mathrm{N}-\mathrm{TiO}_{2}$ & & & $\begin{array}{l}\text { Diethylene } \\
\text {-triamine }\end{array}$ & & & 70 & & \\
\hline $\mathrm{I}-\mathrm{TiO}_{2}$ & & & $\begin{array}{l}\text { Sodium } \\
\text { iodide }\end{array}$ & & & 50 & & \\
\hline \multirow[t]{4}{*}{$\mathrm{B}-\mathrm{TiO}_{2}$} & \multirow[t]{4}{*}{ Solvothermal } & \multirow{4}{*}{$\begin{array}{l}\text { Tetrabutyl } \\
\text { titanate }\end{array}$} & \multirow[t]{4}{*}{ Boric acid } & \multirow[t]{4}{*}{ UV-A } & Bisphenol-A & 99.1 & \multirow[t]{4}{*}{4} & \multirow[t]{4}{*}{ Simsek (2017) } \\
\hline & & & & & Flurbiprofen & 98 & & \\
\hline & & & & & Ibuprofen & 96 & & \\
\hline & & & & & $\begin{array}{l}\text { 2,4- } \\
\text { dichlorophen } \\
\text { ol }\end{array}$ & 89.7 & & \\
\hline $\mathrm{N}-\mathrm{TiO}_{2}$ & Solvothermal & $\begin{array}{l}\text { Tetrabutyl } \\
\text { titanate }\end{array}$ & Urea & UV-VIS & MO & 91 & 3.5 & Wang (2016) \\
\hline
\end{tabular}




\subsubsection{Chemical structure}

As the mass ratio of the non-metal compound and the photocatalyst increases, the photocatalytic efficiency of the non-metal doped photocatalyst increases until an optimum point and then decreases (Shi et al., 2012; Shao et al., 2015; Yan et al., 2014; Mazierski et al., 2016 and

Wang et al., 2016). The mass ratio of the dopant is determined by XPS to control the amount of the non-metal component from the doping precursor (Shi et al., 2012; Yan et al., 2014; Shao et al., 2015).

The optimum doping ratio of non-metal onto the original photocatalyst of the $\mathrm{N}, \mathrm{S}-\mathrm{TiO}_{2}$ prepared by Shi et al. (2012), were 0.089 atomic ratio for $\mathrm{N}(\mathrm{N}: \mathrm{Ti}=0.089$ atomic ratio) and 0.01 atomic ratios for $\mathrm{S}\left(\mathrm{S}: \mathrm{Ti}=0.01\right.$ atomic ratio). The optimum doping ratio of the $\mathrm{N}-\mathrm{TiO}_{2}$ developed by Shao et al. (2015), was 0.0048 atomic ratio for $\mathrm{N}\left(\mathrm{N}: \mathrm{TiO}_{2}=0.0048\right.$ atomic ratio). The $\mathrm{N}-\mathrm{TiO}_{2}$ designed by Yan et al., (2014), contained 0.025 atomic ratio of $\mathrm{N}\left(\mathrm{N}: \mathrm{TiO}_{2}=0.025\right.$ atomic ratio). The optimum doping ratio of the $\mathrm{N}-\mathrm{TiO}_{2}$ prepared by Mazierski et al. (2016), was 0.0034 atomic ratio for $\mathrm{N}\left(\mathrm{N}: \mathrm{TiO}_{2}=0.0034\right.$ atomic ratio). The best photoactivity of $\mathrm{N}-\mathrm{TiO}_{2}$ developed by Wang et al. (2016), was the one prepared by urea to $\mathrm{TiO}_{2}$ with a mass ratio of $1: 8$, showing a favorable incorporation of the non-metal element $(\mathrm{N})$ into the arrays of $\mathrm{TiO}_{2}$. Overall, the proportion of nonmetal to $\mathrm{TiO}_{2}$ prepared by different methods ranges from 0.0034 to 0.40 atomic ratio $\left(\mathrm{N}: \mathrm{TiO}_{2}\right)$.

\subsubsection{Physical structure: morphology and crystal structure}

The N,S-TiO 2 photocatalyst developed by Shi et al. [1], doped by annealing method, showed a well-faceted crystal structure in TEM observation, and the XRD peaks belonged to the anatase phase of $\mathrm{TiO}_{2}$ with no rutile phase observed. Furthermore, under calcination temperature of $300^{\circ} \mathrm{C}$, a highly reactive anatase face could be maintained and a specific surface area of 70 
$\mathrm{cm}^{2} / \mathrm{g}$ could be achieved [1]. On the other hand, the $\mathrm{N}, \mathrm{S}-\mathrm{TiO}_{2}$ photocatalyst prepared by Gao et al., (2011), doped by the sol-gel method, contained $75 \%$ anatase phase and $25 \%$ rutile phase of $\mathrm{TiO}_{2}$ photocatalyst. The grain diameter of the N,S- $\mathrm{TiO}_{2}$ was $11.42 \mathrm{~nm}$, which indicates a nano-rod crystal structure.

The $\mathrm{N}-\mathrm{TiO}_{2}$ prepared by Mazierski et al. (2016), doped by the anodic oxidation method, yielded nanorods with an average crystal size ranging from 27 to $34 \mathrm{~nm}$, where the best activity of $\mathrm{N}-\mathrm{TiO}_{2}$ was found with a mean crystal size of $27 \mathrm{~nm}$ and an estimated specific surface area of 757 $\mathrm{cm}^{2} / 4 \mathrm{~cm}^{2}$ of titanium foil. The synthesized $\mathrm{TiO}_{2}$ nano-rods in this method were mainly made up of anatase phase (Mazierski et al., 2016). The $\mathrm{N}^{-\mathrm{TiO}_{2}}$ prepared by Shao et al. (2015), doped by hydrothermal method, was observed to contain only the anatase phase of $\mathrm{TiO}_{2}$ with an average crystal size of $12 \mathrm{~nm}$ and a specific surface area of $189.09 \mathrm{~cm}^{2} / \mathrm{g}$. The $\mathrm{N}-\mathrm{TiO}_{2}$ prepared by Yan et al. (2014), doped by the microwave-assisted method, was also observed to contain pure anatase phase with a measured specific area of $221.9 \mathrm{~cm}^{2} / \mathrm{g}$. The $\mathrm{N}-\mathrm{TiO}_{2}$ prepared by Wang et al. (2016), doped by the solvothermal method, was observed to contain $82 \%$ anatase phase and $18 \%$ rutile phase with an average crystal size from 30 to $50 \mathrm{~nm}$ and specific surface area of $116.3 \mathrm{~cm}^{2} / \mathrm{g}$.

\subsubsection{Optical properties}

As non-metal is doped onto a photocatalyst, the energy band gap narrows, providing the ability for the photocatalyst to absorb light at a higher wavelength in the UV region of the spectrum (Shao et al., 2015). According to Shi et al. (2012), the doping of nitrogen and sulfur onto the original $\mathrm{TiO}_{2}$ photocatalyst greatly attributed to the red shift or higher wavelength absorption in the photocatalyst, which further increases the absorbance in the visible range of the spectrum as the absorption edge extended to $800 \mathrm{~nm}$. 
Table 6.6. Characteristics of non-metal doped $\mathrm{TiO}_{2}$ prepared via seven different doping methods.

Submitted to Int. J. Environ. Sci. Technol. (2017).

\begin{tabular}{|c|c|c|c|c|c|c|c|c|c|}
\hline \multirow[b]{2}{*}{ Doping Method } & \multirow[b]{2}{*}{ Photocatalyst } & \multicolumn{2}{|c|}{ Crystal Phase } & \multirow[b]{2}{*}{$\begin{array}{l}\text { Crystal } \\
\text { size }(\mathbf{n m})\end{array}$} & \multirow[b]{2}{*}{$S_{\text {BET }}\left(\mathrm{cm}^{2} / \mathrm{g}\right)$} & \multirow{2}{*}{$\begin{array}{l}\text { Energy } \\
\text { gap } \\
(\mathrm{eV})\end{array}$} & \multirow{2}{*}{$\begin{array}{l}\text { Chemical } \\
\text { composition } \\
\text { (atomic ratio) }\end{array}$} & \multirow{2}{*}{$\begin{array}{l}\text { Absorption } \\
\text { edges }(\lambda) \\
(\mathrm{nm})\end{array}$} & \multirow[b]{2}{*}{ Reference } \\
\hline & & $\begin{array}{l}\text { Anatase } \\
(w t \%)\end{array}$ & $\begin{array}{l}\text { Rutile } \\
(w t \%)\end{array}$ & & & & & & \\
\hline Annealing & $\mathrm{N}, \mathrm{S}-\mathrm{TiO}_{2}$ & 100 & 0 & 40 & 70 & - & $\begin{array}{l}0.089(\mathrm{~N} / \mathrm{Ti}) \\
0.01(\mathrm{~S} / \mathrm{Ti})\end{array}$ & 800 & Shi et al. (2012) \\
\hline $\begin{array}{l}\text { Anodic } \\
\text { oxidization }\end{array}$ & $\mathrm{N}-\mathrm{TiO}_{2}$ & - & - & 27 & $189 \mathrm{~cm}^{2} / \mathrm{cm}^{2}$ foil & 2.94 & $0.0034 \mathrm{~N} / \mathrm{TiO}_{2}$ & 575 & Mazierski et al. (2016) \\
\hline $\begin{array}{l}\text { Electrochemical } \\
\text { anodization }\end{array}$ & $\mathrm{B}-\mathrm{TiO}_{2}$ & - & - & - & - & 2.87 & - & 700 & Szkoda et al. (2016) \\
\hline Hydrothermal & $\mathrm{N}-\mathrm{TiO}_{2}$ & 100 & 0 & 12 & 189.09 & 2.88 & $0.0048\left(\mathrm{~N} / \mathrm{TiO}_{2}\right)$ & 650 & Shao et al. (2015) \\
\hline Microwave & $\mathrm{N}-\mathrm{TiO}_{2}$ & 100 & 0 & - & 221.9 & 2 & $0.025\left(\mathrm{~N} / \mathrm{TiO}_{2}\right)$ & 620 & Yan et al. (2014) \\
\hline Sol-gel & $\mathrm{N}, \mathrm{S}-\mathrm{TiO}_{2}$ & 75 & 25 & 11.42 & - & 2.89 & - & 429 & Gao et al. (2011) \\
\hline Solvothermal & $\mathrm{N}-\mathrm{TiO}_{2}$ & 82 & 18 & $30-50$ & 116.3 & 2.64 & $\begin{array}{l}\mathrm{N}(\text { substitutional): } \\
\mathrm{N}(\text { interstitial }) \\
(2.12: 1)\end{array}$ & 470 & Wang et al. (2016) \\
\hline
\end{tabular}


Similarly, the B-TiO 2 photocatalyst prepared by Szkoda et al. (2016), N-TiO 2 by Shao et al. (2015), $\mathrm{N}-\mathrm{TiO}_{2}$ developed by Yan et al. (2014), $\mathrm{N}-\mathrm{TiO}_{2}$ by Mazierski et al. (2016), N-TiO2 by Wang et al. (2016), and N, S-TiO 2 by Gao et al. (2011), could absorb light to an absorption edge of 700, $650,620,575,470$, and $429 \mathrm{~nm}$, respectively. Moreover, the energy band gap of the non-metal doped $\mathrm{TiO}_{2}$ prepared by Gao et al. (2011), Shao et al. (2015), Yan et al. (2014), Mazierski et al. (2016), Szkoda et al. (2016), and Wang et al. (2016) were found at 2.89, 2.88, 2.00, 2.94, 2.87, and $2.64 \mathrm{eV}$, respectively.

A summary of the characteristics of non-metal doped $\mathrm{TiO}_{2}$ prepared via seven different doping approaches, including annealing, anodic oxidation, electrochemical anodization, hydrothermal, microwave, sol-gel, and solvothermal methods is presented in Table 6.6.

\subsection{Potential parameters during synthesis and photocatalytic reactions}

During the synthesis of the non-metal doped $\mathrm{TiO}_{2}$ photocatalyst, several factors would affect the efficiency of a photocatalyst. These factors include the source of doping, the solvent used in the synthesis process, the concentration of dopants used in the photocatalyst, the calcination temperature, the catalyst and organic pollutant loading, and the $\mathrm{pH}$ of the solution. Some of these factors are found to possess clear and positive effects on the resultant photocatalytic efficiency, and some are not clear due to lack of studies carried out. Moreover, studies in the stability and recycling of photocatalysts and the degradation of organic pollutants in tap water are analyzed to prove possibility in industrial applications. 


\subsubsection{Source of doping}

In this review, several non-metals doped $\mathrm{TiO}_{2}$ photocatalysts were discussed, and most of them presented with relatively high photocatalytic efficiency in the degradation of different targeted organic pollutants. Szkoda et al. (2016), studied $\mathrm{B}-\mathrm{TiO}_{2}, \mathrm{I}_{-} \mathrm{TiO}_{2}, \mathrm{~N}-\mathrm{TiO}_{2}$, and bare $\mathrm{TiO}_{2}$ synthesized by electrochemical anodization method, which $\mathrm{B}-\mathrm{TiO}_{2}$ presented best photocatalytic efficiency in the degradation of methylene blue dye.

Overall, doping with non-metal compounds, such as B, C, F, I, N, and S, onto the $\mathrm{TiO}_{2}$ photocatalyst all presented an enhancement in the photocatalytic efficiency under visible light irradiation, but the resultant photocatalytic efficiency cannot be easily related to the dopant source. Instead, $\mathrm{N}-\mathrm{TiO}_{2}$ and $\mathrm{N}, \mathrm{S}-\mathrm{TiO}_{2}$ are the most commonly studied non-metal doped photocatalysts owing to their availability and have shown the best photocatalytic efficiencies in most of the synthetic methods. The two common dopants in generating $\mathrm{N}-\mathrm{TiO}_{2}$ and $\mathrm{N}, \mathrm{S}-\mathrm{TiO}_{2}$ are urea and thiourea, respectively. Other sources of nitrogen and sulfur such as ammonia, $\mathrm{N}_{2}$ (gas), chitosan, $\mathrm{HNO}_{3}, \mathrm{NH}_{4} \mathrm{Cl}$, and $\mathrm{NH}_{4} \mathrm{OH}$ have been used.

Nitrogen doping is an encouraging method because of its comparable atomic size with oxygen, small ionization energy, and high stability. Moreover, nitrogen doping suppresses the recombination rate of photogenerated electrons and holes, which further enhances the photocatalytic efficiencies of the resultant doped photocatalysts (Ansari et al., 2016). 
Table 6.7. Characteristics of $\mathrm{S}^{-\mathrm{TiO}_{2}}$ prepared via sol-gel doping methods using four different solvents.

(Adopted from Han et al., 2014)

Submitted to Int. J. Environ. Sci. Technol. (2017).

\begin{tabular}{|c|c|c|c|c|c|c|c|c|}
\hline \multirow[b]{2}{*}{ Solvent } & \multicolumn{2}{|c|}{ Crystal Phase } & \multirow[b]{2}{*}{$\begin{array}{l}\text { Crystal } \\
\text { size (nm) }\end{array}$} & \multirow[b]{2}{*}{$\begin{array}{l}\mathrm{S}_{\text {BET }} \\
\left(\mathrm{cm}^{2} / \mathrm{g}\right)\end{array}$} & \multirow[b]{2}{*}{$\begin{array}{l}\text { Average adsorption } \\
\text { pore size }(\mathbf{n m})\end{array}$} & \multirow[b]{2}{*}{$\begin{array}{l}\text { Energy } \\
\text { gap }(e V)\end{array}$} & \multirow{2}{*}{$\begin{array}{l}\text { Absorption } \\
\text { edges }(\lambda) \\
(\mathrm{nm})\end{array}$} & \multirow[b]{2}{*}{$\begin{array}{l}\text { Removal of MC-LR after } 5 \mathrm{~h} \\
\text { of visible light irradiation (\%) }\end{array}$} \\
\hline & $\begin{array}{l}\text { Anatase } \\
(w t \%)\end{array}$ & $\begin{array}{l}\text { Rutile } \\
\text { (wt\%) }\end{array}$ & & & & & & \\
\hline iPrOH & 100 & 0 & $6.2 \pm 1.4$ & $149.6 \pm 0.3$ & 3.1 & 2.86 & 53 & 53 \\
\hline $\mathrm{BtOH}$ & 100 & 0 & $6.9 \pm 0.9$ & $146.4 \pm 0.2$ & 3.2 & 2.86 & 47 & 47 \\
\hline $\mathrm{EtOH}$ & 100 & 0 & $7.3 \pm 1.0$ & $73.6 \pm 1.0$ & 3.7 & 2.86 & 61 & 61 \\
\hline $\mathrm{MeOH}$ & 100 & 0 & $12.1 \pm 1.3$ & $57.0 \pm 0.1$ & 5.2 & 2.86 & 76 & 76 \\
\hline
\end{tabular}




\subsubsection{Solvent used in the synthesis process}

The study on the choice of organic solvent in the synthetic process of $\mathrm{S}-\mathrm{TiO}_{2}$ was conducted by Han et al. (2014). In their study, $\mathrm{S}-\mathrm{TiO}_{2}$ was prepared by the sol-gel method using four different solvents: isopropanol (iPrOH), 1-butanol $(\mathrm{BtOH})$, ethanol $(\mathrm{EtOH})$, and methanol $(\mathrm{MeOH})$. The characteristics of $\mathrm{S}-\mathrm{TiO}_{2}$ are shown in Table 6.7.

The $\mathrm{S}-\mathrm{TiO}_{2}$ prepared using methanol demonstrated the best photocatalytic efficiency in the degradation of microcystin-LR (MC-LR). In general, the study concluded that the choice of organic solvent used in the synthetic process did not affect the band gap narrowing and the red shift in the absorption wavelength of the photocatalyst. On the other hand, physical properties, such as specific surface area, pore volume, porosity, and crystalline size, were affected by the type of organic solvents, which was proven to further influence the photocatalytic efficiency of the synthesized $\mathrm{S}-\mathrm{TiO}_{2}$ (Table 6.7).

\subsubsection{Concentration of dopants in the photocatalyst}

Regarding various studies on non-metal doped $\mathrm{TiO}_{2}$, two different trends were discovered in the relationship between the doping concentration, the resultant photocatalytic activity, and the characteristics of the doped $\mathrm{TiO}_{2}$.

In the first trend, as the concentration of dopant increased, the crystalline size decreased, the specific surface area increased, the pore volume increased, the porosity increased, and the relative crystallinity decreased (Xiang et al., 2011; Nawawi and Nawi, 2014; Du et al., 2016). In this trend, the best photocatalytic efficiency was observed to change proportionally to the physical properties until an optimum efficiency point, then, the photocatalytic efficiency decreased (Iwase et al., 2013; Lin et al., 2013; Bakar and Ribeiro, 2016). 
The other trend that can be found in the literature refers to an increment in the concentration of dopant, which improves the photocatalytic efficiency due to the physical properties of the photocatalysts, where the specific surface area is maximum, and the pore volume and pore size are minimal (Niu et al., 2014; Shao et al., 2015; Sun et al., 2016). Moreover, the band gap energy decreased along with the increment in the doping concentration (Wang et al., 2011). Therefore, there is an optimal mass ratio of non-metal dopant to $\mathrm{TiO}_{2}$ photocatalyst.

In general, the photocatalytic efficiency of the doped photocatalyst increased by increasing the doping concentration because a more active non-metal doped $\mathrm{TiO}_{2}$ was produced. However, the decrease in the photocatalytic effectiveness of the non-metal doped $\mathrm{TiO}_{2}$, after the optimum doping concentration, was observed owing to the increase in defects generated in the crystalline structure, which became sites of electron-hole recombination (Lin et al., 2015). The electron-hole recombination further limited the production of hydroxyl radicals.

The second reason for the reduction in the photocatalytic activity for a high amount of the dopant is related to the coverage of the surface of the photocatalyst by dopant and consequently the deactivation of the photocatalyst (Nasirian and Mehrvar, 2016). Thus, in both trends, the photocatalytic efficiencies greatly relied on the specific surface area of the photocatalysts and the production of hydroxyl radicals during the photochemical reaction (Niu et al., 2014). Therefore, it is critical to focus on the concentration of dopant when doping non-metals to $\mathrm{TiO}_{2}$ photocatalyst.

\subsubsection{Calcination temperature in the synthetic process}

Calcination is the very last step in the synthetic process of non-metal doped $\mathrm{TiO}_{2}$. During the calcination process, the dried solids are heated up and held at a specific temperature and time for grain growing. In previous studies, various calcination temperatures from 150 to $1,100^{\circ} \mathrm{C}$ were 
tested along with the resultant photocatalytic efficiencies (Nawawi and Nawi, 2014; Lei et al., 2015; Zhang et al., 2015; Bakar and Ribeiro, 2016; Nasirian and Mehrvar, 2016).

Highest photocatalytic efficiencies were observed when the non-metal doped photocatalysts were calcined at temperatures from 150 to $700^{\circ} \mathrm{C}$ (Szatmary et al., 2011; Wang et al., 2011; Nolan et al., 2012; Mohamed et al., 2015). In general, the efficiency of a photocatalyst increases with the calcination temperature but decreases after a maximum effectiveness. This trend is mainly attributed to the reduction in the specific surface area, and the increase in the crystalline size as the calcination temperature increased (Iwase et al., 2013; Chung et al., 2015). Moreover, rutile phase begins to form at higher calcination temperatures (more than $700^{\circ} \mathrm{C}$ ), which further decreases the photocatalytic efficiency because rutile phase is less efficient compared to that of anatase phase (McManamon et al., 2015). In addition, at lower calcination temperature, a lower band gap energy is observed, which is more favorable in the photochemical reaction under visible light irradiation (Park et al., 2014). Therefore, the photocatalytic efficiency greatly relies on the physical and chemical properties of the photocatalyst generated under the specific calcination. However, the optimum calcination temperature varies by different non-metal dopants.

\subsubsection{Catalyst loading and initial concentration of organic pollutant}

The N,S-TiO 2 nanosheets and nanoparticles synthesized by Eslami et al. (2016), were tested for the optimum catalyst loading in the slurry, which ranged from 0.5 to $5 \mathrm{~g} / \mathrm{L}$. The photocatalytic efficiency of $\mathrm{N}, \mathrm{S}-\mathrm{TiO}_{2}$ nanosheets increased as the catalyst loading increased, which was described by the expansion in the number of active sites. Moreover, the optimum loading of $\mathrm{N}, \mathrm{S}-\mathrm{TiO}_{2}$ nanoparticles was found to be at $2 \mathrm{~g} / \mathrm{L}$, beyond which photocatalytic 
efficiency decreased owing to the turbidity of the solution and hindered light transmission through the solution.

The $\mathrm{N}, \mathrm{S}-\mathrm{TiO}_{2}$ nanosheets and nanoparticles were also tested for the optimum initial concentration of the organic pollutant from 2.5 to $10 \mathrm{mg} / \mathrm{L}$. As the initial concentration of the organic pollutant increased, the photocatalytic efficiency increased up to a maximum value and then decreased. The optimum value was observed at $5 \mathrm{mg} / \mathrm{L}$ for both $\mathrm{N}, \mathrm{S}-\mathrm{TiO}_{2}$ nanosheets and nanoparticles. At a very low concentration of organic materials, pollutants could not be trapped by hydroxyl radicals due to an infinite short lifetime of hydroxyl radicals.

\subsubsection{Effect of $\mathrm{pH}$ on the efficiency of photocatalytic reactions}

The $\mathrm{pH}$ of the solution in the photocatalytic process plays an important role owing to its ability to affect the photocatalytic efficiency by affecting the surface charge and the state of ionization of the compound. The doped photocatalyst particle surfaces become positively charged at a $\mathrm{pH}$ lower than $\mathrm{pH}_{\mathrm{pzc}}\left(\mathrm{pH}\right.$ at the point of zero charge) and more negatively charged at $\mathrm{pH}$ greater than $\mathrm{pH}_{\mathrm{pzc}}$ (Eslami et al., 2016).

Moreover, at lower $\mathrm{pH}$, the solution contains more $\mathrm{H}^{+}$ions. These $\mathrm{H}^{+}$ions serve as electron scavengers on producing superoxide radicals and inhibit the recombination of electron-hole pairs (Yuan et al., 2016). However, the photocatalytic degradation of organic compounds is mainly contributed by the hydroxyl radicals generated in the photochemical reaction. For example, Simsek (2017), conducted a study on the effect of the pH of the solution with bisphenol-A, flurbiprofen, ibuprofen, and 2,4-dichlorophenol. The degradation of bisphenol-A and flurbiprofen presented the best photocatalytic efficiency at $\mathrm{pH} 6.5$; moreover, the acidic solution ( $\mathrm{pH} 3$ ) was more favorable than the basic solution ( $\mathrm{pH} \mathrm{10).} \mathrm{On} \mathrm{the} \mathrm{other} \mathrm{hand,} \mathrm{the} \mathrm{degradation} \mathrm{of} \mathrm{ibuprofen} \mathrm{and} \mathrm{2,4-}$ 
dichlorophenol showed the best photocatalytic efficiency when the solution was more acidic $(\mathrm{pH}$ $3>$ pH $6.5>$ pH 10) (Simsek, 2017).

In brief, the relationship of the solution $\mathrm{pH}$ and the degradation of organic materials should be experimentally conducted. It means the best degradation and the best $\mathrm{pH}$ are varied due to characteristics of pollutants and photocatalysts. Similarly, the $\mathrm{N}-\mathrm{TiO}_{2}$ photocatalyst synthesized by Yan et al. (2014), presented the best photocatalytic efficiency at lower pH. Furthermore, the N$\mathrm{TiO}_{2} /$ carbon nanotube (CNT) synthesized by Yuan et al. (2016), presented the best photocatalytic efficiency at $\mathrm{pH} 5$ owing to the higher production of superoxide radicals which greatly contributed to the degradation of ibuprofen at lower $\mathrm{pH}$.

\subsubsection{Degradation of organic pollutants in tap water}

As tap water contains various types of salts and organic matters, the photocatalytic efficiency of the non-metal doped $\mathrm{TiO}_{2}$ under such condition could be affected when compared to that of distilled water. It was shown that a decrease of $10 \%$ in the degradation of organic pollutants, under the same visible light irradiation time, was observed when the slurry was prepared using tap water (Simsek, 2017). The decrease in the photodegradation is mainly attributed to the interfering anions such as sulfate and phosphate in tap water. These interfering anions hold the potential to scavenge the $\mathrm{HO}^{\circ}$ radicals or absorb a portion of the UV radiation.

\subsubsection{Photocatalyst stability and recycling}

In previous studies (Sun et al., 2016; Saien and Mesgari, 2016; Samsudin et al., 2016), the non-metal doped $\mathrm{TiO}_{2}$ were reused to evaluate their overall stability of the photocatalyst after recycling. The $\mathrm{HF}_{-} \mathrm{TiO}_{2}$ synthesized by Samsudin et al. (2016), demonstrated the best stability in 
photocatalytic efficiency for ten consecutive reuse cycles. Simsek (2017), conducted the study on the stability of $\mathrm{B}-\mathrm{TiO}_{2}$ by studying the photo-efficiency of the photocatalyst for four or five recycling tests.

Overall, the photocatalyst endured its photocatalytic efficiency in the first two cycles, and a decrease in efficiency was observed in the third and fourth cycle. The stability of the photocatalyst also depends on the organic pollutants, for example, the degradation of bisphenol-A was relatively high after five cycles. Similarly, the B- $\mathrm{TiO}_{2}$ prepared by Quinones et al. (2015), demonstrated stability each time it was recycled for up to three cycles.

The $\mathrm{N}-\mathrm{TiO}_{2}$ synthesized by Li et al. (2016), and Bakar and Ribeiro (2016), were tested for its stability for four and five cycles, respectively. The photocatalytic activity slightly decreased along each cycle, but still demonstrated high photocatalytic activity. Overall, these two synthesized $\mathrm{N}-\mathrm{TiO}_{2}$ photocatalysts presented good stability, reliability, and durability for practical applications.

Similarly, the $\mathrm{N}^{-\mathrm{TiO}_{2}}$ synthesized by both Shao et al. (2015), and Ha et al. (2015), presented good stability over five times of recycling. However, the $\mathrm{N}, \mathrm{S}-\mathrm{TiO}_{2}$ nanoparticles synthesized by Eslami et al. (2016), demonstrated a decrease in photocatalytic activity after each photodegradation cycle owing to the absorption of incompletely photo-decomposed compounds on the surface of the photocatalyst. On the other hand, in most cases, the $\mathrm{N}, \mathrm{S}-\mathrm{TiO}_{2}$ nano-sheets did not exhibit any loss in photocatalytic efficiency after seven cycles of photodegradation process.

\subsection{Applications of non-metal doped $\mathrm{TiO}_{2}$}

In general, the photocatalytic activity of a non-metal doped $\mathrm{TiO}_{2}$ photocatalyst is enhanced. Non-metal doped $\mathrm{TiO}_{2}$ photocatalyst could be applied in many fields such as industrial textile 
effluent degradation, self-cleaning technologies, air purification techniques, water treatment systems, and environmental remediation (Ansari et al., 2016). Among them, the focus is on the application of photocatalysts in wastewater treatment systems. The targeted pollutants tested in many studies, listed in Tables 6.1 to 6.5, include 4-chlorophenol (4-CP), acephate (organophosphate insecticide), benzene, ibuprofen, naproxen, microcystin-LR (MC-LR), methylene blue (MB), methyl orange (MO), naproxen, phenol, rhodamine $\mathrm{B}(\mathrm{RhB})$, reactive red 4 , reactive brilliant red dye, reactive red 2 (X-3B), among others. These pollutants are found in different industrial wastewater. For example, ibuprofen and naproxen can be found in pharmaceutical wastewater, and methylene blue (MB), $\mathrm{RhB}$, and methyl orange (MO) can be found in wastewater produced by textile industries. According to the studies referred in this review, the non-metal doped $\mathrm{TiO}_{2}$ shown superior photocatalytic efficiency in the degradation of the targeted organic pollutant; therefore, non-metal doped $\mathrm{TiO}_{2}$ possess high potential in the degradation of organic pollutants in industrial wastewaters.

Although the non-metal doped $\mathrm{TiO}_{2}$ showed an enhancement in the photocatalytic activity under visible light, the following limitations provide future focus on the study of photocatalysts. First, there is a need to control between substitutional and interstitial types of doping in the $\mathrm{TiO}_{2}$ lattice, which may provide a relationship between the location of the non-metal element in the $\mathrm{TiO}_{2}$ lattice and the resultant photo-efficiency (Ansari et al., 2016).

Similarly, the fabrication of different nanostructures should be studied because studies had shown the possible impact of nanostructures on resultant photocatalytic efficiency. The practical application should be investigated regarding various sources of energy, from natural sunlight to artificial visible light irradiation conditions, and the conditions of photodegradation, such as $\mathrm{pH}$, temperature, and photo-transmittance. Nevertheless, the precise mechanism of band gap reduction 
or mid-band gap introduction by non-metal doping is still unclear. On the other hand, the stability and recycle of non-metal doped $\mathrm{TiO}_{2}$ has been promising.

Other interesting studies in non-metal doped $\mathrm{TiO}_{2}$ may include the synthesis of doped photocatalyst using simple, facile techniques utilizing green routes and upscaling the synthesis process from the practical point of view. Considering upscaling the synthesis of the doped photocatalyst include efficiency, optimization, and safety of the synthetic processes. The most efficient, cost-effective, time-effective, facile, and safe method for photocatalyst preparation needs to be determined for the upscaling of the synthesis of non-metal doped $\mathrm{TiO}_{2}$ from the practical point of view. As most of the photocatalytic degradation of organic pollutants in the studies of non-metal doped $\mathrm{TiO}_{2}$ were carried out in suspension form, the immobilization of the photocatalysts should be explored when upscaling the photocatalytic reactor because an immobilized form of the photocatalyst is more practical than suspension form due to the simplicity in application.

\subsection{Conclusions}

Several photocatalysts, including $\mathrm{B}, \mathrm{C}, \mathrm{N} \mathrm{S}, \mathrm{P}$, and F-doped $\mathrm{TiO}_{2}$, prepared by different synthesis methods were analyzed to prove the promotion of visible light photoactivity of the photocatalyst. The annealing method and hydrothermal method were found to be more efficient regarding preparation materials, treatment time, and costs. When choosing between these two approaches, the hydrothermal method can be practiced using a variety of precursors; whereas, the annealing methods is restricted to solid form precursors. Furthermore, the size of the doped

photocatalyst could be easily controlled by changing the conditions in a hydrothermal reaction and conditions in calcination process; whereas, the crystal structure of the non-metal doped 
photocatalyst, prepared by the annealing method, is restricted by the calcination conditions. Therefore, the hydrothermal method is a more favorable method for doping non-metal onto $\mathrm{TiO}_{2}$. Among all non-metal doped $\mathrm{TiO}_{2}, \mathrm{~N}-\mathrm{TiO}_{2}$ and $\mathrm{N}, \mathrm{S}-\mathrm{TiO}_{2}$ have been commonly studied and proven the most efficient route of non-metal doping. Meanwhile, more studies need to be conducted focusing on the effect of different factors involved in each synthetic method to determine optimal synthetic conditions for each method. 


\title{
CHAPTER 7
}

PHOTOCATALYTIC DEGRADATION OF AQUEOUS METHYL ORANGE USING NITROGEN-DOPED TiO 2 PHOTOCATALYST

PREPARED B Y NOVEL METHOD OF UV-ASSISTED

\section{THERMAL SYNTHESIS}

\begin{abstract}
A nitrogen doped titanium dioxide composite photocatalyst $\left(\mathrm{N}-\mathrm{TiO}_{2}\right)$ with heterojunction structures is synthesized by three different approaches: a novel UV-assisted thermal synthesis, annealing, and microwave technique. Photocatalytic activities of synthesized photocatalysts are evaluated by the degradation of Methyl Orange under UV-A, UV-B, UV-C, visible light, and direct sunlight irradiation. Results show that by using $\mathrm{N}-\mathrm{TiO}_{2}$ photocatalyst prepared by the UV-assisted thermal synthesis and annealing, the degradation increases by 16.5 and $20.4 \%$, respectively, compared to that by bare $\mathrm{TiO}_{2}$. The best results are obtained at a nitrogen to $\mathrm{TiO}_{2}$ mass ratio of $0.15\left(\mathrm{~N}: \mathrm{TiO}_{2}\right)$. The enhancement of the photocatalytic activity observed in the visible range is mainly attributed to the increasing separation rate of photogenerated charge carriers. The novel $\mathrm{UV}$-assisted thermal synthesis has produced encouraging results as a preparation method for the
\end{abstract}

\footnotetext{
* Reprinted, with minor editorial changes to fulfill formatting requirements, from:

Nasirian, M., Mehrvar, M. (in press). Photocatalytic degradation of aqueous Methyl Orange using nitrogen doped $\mathrm{TiO}_{2}$ photocatalyst prepared by novel method of ultraviolet-assisted thermal synthesis. Journal of Environmental Sciences. https://doi.org/10.1016/j.jes.2017.05.032.
} 
nitrogen-doped $\mathrm{TiO}_{2}$ photocatalyst; thus, further studies are recommended for process optimization, immobilization, and scale-up to evaluate its applicability in wastewater treatment.

Keywords: UV-assisted thermal synthesis, N-doped $\mathrm{TiO}_{2}$, Photocatalysis, Advanced oxidation processes. $^{*}$

* Reprinted, with minor editorial changes to fulfill formatting requirements, from:

Nasirian, M., Mehrvar, M. (in press). Photocatalytic degradation of aqueous Methyl Orange using nitrogen doped $\mathrm{TiO}_{2}$ photocatalyst prepared by novel method of ultraviolet-assisted thermal synthesis. Journal of Environmental Sciences. https://doi.org/10.1016/j.jes.2017.05.032. 


\subsection{Introduction}

Photocatalysis, an advanced oxidation process (AOP), is an environmentally friendly technology for wastewater treatment and even indoor air purification because it does not generate any harmful by-products during the degradation of organic materials. Photocatalysis is one of the efficient methods among AOPs for the degradation of recalcitrant organic compounds into harmless materials. AOPs are based on the production of highly reactive and oxidizing hydroxyl radicals (HO') with a potential oxidation of 2.85 V (Valenzuela et al., 2002; Choi, 2006; BustilloLecompte and Mehrvar, 2016; Bustillo-Lecompte et al., 2016; Nasirian and Mehrvar, 2016). In the 1970s, Fujishima and Honda (1972) split water into oxygen and hydrogen using $\mathrm{TiO}_{2}$. This innovation initiated the field of photocatalysis and the photocatalytic detoxification was considered a capable tool for the treatment of wastewater (Hashimoto et al., 2005). The process of photocatalytic wastewater treatment can significantly lower the amounts of organic wastes in the environment due to the generation of potent oxidation radicals such as $\mathrm{HO}^{\bullet}$ and $\mathrm{O}_{2}{ }^{-}$, making it useful for breaking down complex organic compounds (Agustina et al., 2005).

However, the $\mathrm{TiO}_{2}$ photocatalytic process still has several limitations including the fast recombination of electron/hole pairs and its photoactivity under the ultraviolet (UV) irradiation only. In addition, only $5 \%$ of the sunlight could be absorbed by $\mathrm{TiO}_{2}$ because of its large band gap energy of $3.2 \mathrm{eV}$ (Nasirian and Mehrvar, 2016). Zhang et al. (2010) showed that more than $90 \%$ of the generated electron/hole pairs are lost within nanoseconds of their generation, leading to an insufficient photoactivity of photocatalysts. $\mathrm{TiO}_{2}$ requires UV light irradiation to excite and generate electron/hole pairs (Lin et al., 2012). Therefore, the $\mathrm{TiO}_{2}$ photocatalyst enhancement to absorb visible light and to be activated under sunlight with high efficiency is of interest. 
Several semiconductors $\left(\mathrm{TiO}_{2}, \mathrm{ZnO}, \mathrm{Fe}_{2} \mathrm{O}_{3}, \mathrm{CdS}\right.$, and $\left.\mathrm{ZnS}\right)$ have already been used as photocatalysts for the degradation of aqueous organics. $\mathrm{TiO}_{2}$ is the most commonly used photocatalyst due to its chemical and physical stability, nontoxicity, high reactivity, and ability to break down organic pollutants (Shi et al., 2012). Numerous attempts have been made to enhance the activity of semiconductor photocatalysts by improving their surface or bulk properties, including the doping metals or non-metals into photocatalysts as well as their combination with other semiconductors and metal oxides such as $\mathrm{MgO}, \mathrm{ZnO}, \mathrm{SnO}_{2}, \mathrm{Fe}_{2} \mathrm{O}_{3}$, and $\mathrm{SrTiO}_{3}$. Furthermore, the efficacy of the photoactivity of $\mathrm{TiO}_{2}$ has been improved through other alternative methods including the addition of photosensitizers (Ola and Maroto-Valer, 2015), oxidants such as $\mathrm{H}_{2} \mathrm{O}_{2}$ (Cuerda-Correa et al., 2016), peroxide disulfate and periodate ions (Oyama, 2000), or $\mathrm{O}_{3}$ (Kopf et al., 2000). These methods have shown an improvement of semiconductors by doping metals, nonmetals, or metals/non-metal composites into the photocatalyst and they have extended their photoactivity into the visible light region. In other words, by improving the surface properties of semiconductors, a red shift (higher wavelength absorption with lower energy) occurs and therefore, the photocatalytic activity increases. As a result, it is necessary to keep the electron/hole pairs apart as efficiently as possible to increase the efficiency of the photocatalytic process. Moreover, developing a preparation method of the photocatalyst to facilitate and expand the absorption into the visible light region is extremely of interest.

The surface amendment of $\mathrm{TiO}_{2}$ by metal doping along with substitution of metal doped with $\mathrm{Ti}^{4+}$ causes a crystal distortion and an increase in the specific surface area, which finally results in an increased photocatalytic activity (Wellia et al., 2011; Nasralla et al., 2013, Nasirian and Mehrvar, 2016). In the process of doping with non-metals, the dopant might be substituted with $\mathrm{O}^{2-}$ sites to modify the band gap energy of $\mathrm{TiO}_{2}$ and to enhance the visible light activity of $\mathrm{TiO}_{2}$ 
(Ola and Maroto-Valer, 2015). The substitution of $p$-block nonmetals such as B, C, N, F, S, P, and $\mathrm{I}$ at $\mathrm{Ti}^{4+}$ and especially $\mathrm{O}^{2-}$ sites is an effective approach to hinder the fast electron/hole recombination and to activate the doped photocatalyst in the visible range. Doping nitrogen into $\mathrm{TiO}_{2}$ is a valuable alternative to other methods because of its similar atomic size with oxygen, small ionization energy, and stability (Devi and Kavitha, 2013).

One of the main objectives in modifying a photocatalyst by non-metal doping of $\mathrm{TiO}_{2}$ is to narrow its band gap (Zaleska, 2008). When a non-metal species, such as nitrogen with slightly higher energy level than that of oxygen, is introduced into the $\mathrm{TiO}_{2}$ lattice, a new mid-gap energy state is generated (Xu et al., 2014; Ansari et al., 2016). The generated mid-gap energy level allows the photoexcitation process to happen as electrons from the mid-gap energy level can be excited upon absorbing visible light; whereas, electrons in the $2 p$ valence band of oxygen could not be excited by the visible light. The excited electron from the mid-gap energy level then migrates to the conduction band generating a hole in the mid-gap energy level. Later, the electron and hole migrate to the surface of $\mathrm{TiO}_{2}$ and participate in the redox reactions.

There are several methods for non-metal doping such as sol-gel, hydrothermal, microwave, and annealing methods (Gao et al., 2010; Lv et al., 2011; Shi et al., 2012). Each method has its own advantages and disadvantages with different photocatalytic activity, time of reaction, cost, and preparation technique. The surface amendment of $\mathrm{TiO}_{2}$ photocatalyst by doping with metals and non-metals has already been investigated using these methods to reduce its band gap energy or its activation in the visible range. To date, the reported studies on non-metal doped $\mathrm{TiO}_{2}$ are mostly focused on the preparation via wet methods such as sol-gel or hydrothermal methods. There is a lack of information on other methods such as annealing or microwave assisted for synthesizing non-metal doped $\mathrm{TiO}_{2}$ photocatalysts. Different preparation methods, characterization, and the 
effects of various parameters on the effectiveness of nitrogen-doped $\mathrm{TiO}_{2}$ photocatalysts for wastewater treatment have not been widely investigated.

In this study, nitrogen-doped titanium dioxide $\left(\mathrm{N}-\mathrm{TiO}_{2}\right)$ photocatalysts with heterojunction structures were synthesized using different mass ratios of $\mathrm{N}: \mathrm{TiO}_{2}$ by three different methods of doping, including the novel UV-assisted thermal synthesis, annealing, and microwave techniques. For the preparation of the photocatalyst, commercial $\mathrm{TiO}_{2}$ powders were used as precursors. Before making the non-metal doped photocatalysts, experiments were conducted to evaluate the photocatalytic activity of different types of $\mathrm{TiO}_{2}$ under different light sources for the degradation of aqueous Methyl Orange. The performance of the as-prepared $\mathrm{N}-\mathrm{TiO}_{2}$ photocatalyst to that of the bare $\mathrm{TiO}_{2}$ for the degradation of aqueous Methyl Orange as a target pollutant, a typical azo dye in the textile industry, was also compared.

\subsection{Materials and Methods}

\subsubsection{Materials}

All chemicals were of analytical grade, purchased from Sigma-Aldrich (Oakville, ON) and Van Waters and Nat Rogers (VWR, Mississauga, ON), and they were used as received without additional purification.

\subsubsection{Instrumentation}

The photocatalytic activity of the as-prepared photocatalysts was assessed by measuring the degradation of Methyl Orange using an automated total organic carbon (TOC) analyzer (Apollo 9000, Teledyne Tekmar, USA), which accounts for the overall concentration of organic materials in the samples. All samples were first centrifuged at $4000 \mathrm{rpm}$ for $30 \mathrm{~min}$ using a centrifuge 
(Heraeus Multifuge X1, Thermo Fisher Scientific, Canada). After centrifugation, samples were passed through a filter paper (Qualitative 410, VMR, Canada) and then transferred to the TOC analyzer for analysis.

The specific surface area of the photocatalyst powder was analyzed using the Brunauer-Emmett--Teller (BET) technique (Nova 1200e, Quantachrome Instruments, USA). X-ray diffraction (XRD) (X'pert PRO, PANalytical, Canada) was used to investigate the crystal structure and conversion phase of $\mathrm{TiO}_{2}$. The scanning range of XRD was $10-100^{\circ}(2 \theta)$. Scanning electron microscopy (SEM) (JSM-6370LV, JEOL, Canada) coupled with the energy dispersive spectroscopy (EDS) (X-Max-N-80, Oxford Instrument, USA) was used to obtain the combined information of morphology and chemical composition of individual particles. An auto sputter coater (Vacuum Desk IV, Denton Vacuum, USA) was used for coating samples with a thin layer of gold before analysis by SEM. A microwave synthesizer (Initiator +, Biotage ${ }^{\circledR}$, USA) was used in the microwave-assisted method to synthesize the $\mathrm{N}-\mathrm{TiO}_{2}$ photocatalyst.

\subsubsection{Experimental setup and procedure}

The photocatalytic degradation of aqueous Methyl Orange was conducted by different as-prepared photocatalysts using a batch photoreactor as shown in Fig. 1. The batch photoreactor includes a glass container with the total volume of $3.5 \mathrm{~L}$ and a lid for holding different irradiation sources. Different irradiation sources and up to five lamps were used with various wavelengths of the light spectrum (UV-C, UV-B, UV-A, and Visible). The light sources were UV-C (PL-S 9W/TUV-UV Germicidal 110-120V G23 Base, Philips, USA), UV-B (9W 110-120V Desert Series 50 Fluorescent Compact Bulb, Zilla, USA), UV-A (BL PL-S 9 W 110-120 V, Philips, USA), and visible light (PL 2-PIN 9 W G23 Base, Philips, USA), with peak irradiations at 254, 310, 365, and 
$470 \mathrm{~nm}$, respectively. All lamps have been vertically inserted into the photoreactor. The solution was continuously stirred using a magnetic stirrer. The reactor was covered with aluminum foil to avoid interference from any light and to reflect the inner light. All suspension samples were centrifuged before TOC analysis. The temperature of the solution was controlled by a cooling bath (RTE-211 Chiller, NESLAB Instruments, Inc., USA) by recirculating the water in the cooling tank. In each experiment, the powder photocatalyst was added into the photoreactor in form of a slurry.

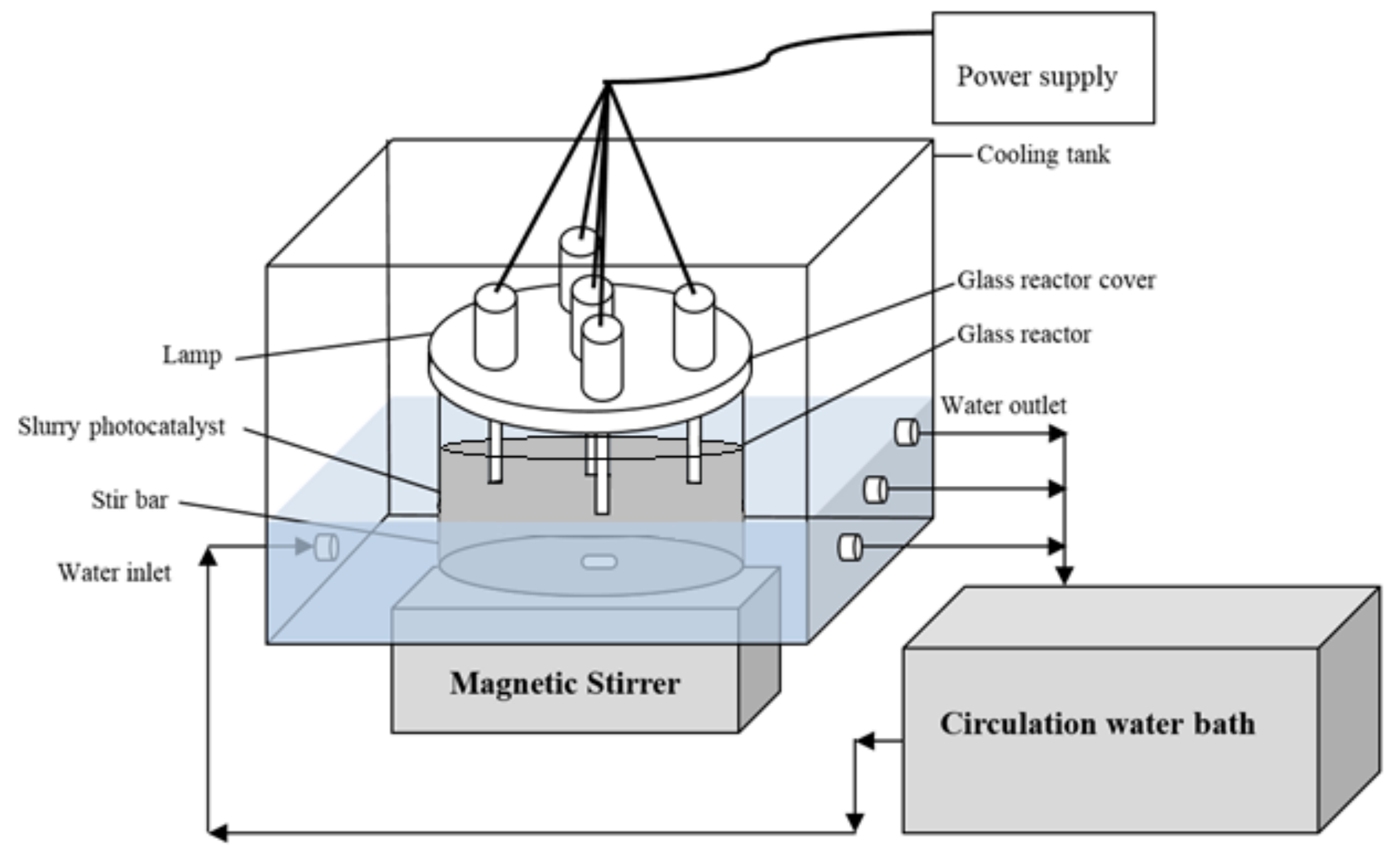

Figure 7.1. Schematic diagram of the laboratory-scale batch photoreactor. Reprinted from J. Environ. Sci. (in press) (2017). 


\subsubsection{Doping methods for the synthesis of the $\mathrm{N}-\mathrm{TiO}_{2}$ photocatalyst}

\subsubsection{Sol-gel method}

In a sol-gel process, a sol is a dispersion of colloidal particles in a solvent that makes a stable colloidal solution. It is made from the hydrolysis and polymerization reactions of the reactant, and the particles may be crystalline or amorphous. A gel consists of a continuous three-dimensional network, in which a liquid phase is enclosed. The agglomeration of colloidal particles creates the network between particles. Van der Waals forces or hydrogen bonds make the interaction between particles in a sol-gel reaction possible. In gel systems, covalent bonds are the main interaction between particles (Konishi et al., 2008).

The sol-gel process is usually prepared in five steps including the formation of the solution, making of the gel, drying, washing to remove impurities, and the final calcination step at a specific temperature. Except for the calcination, all these steps are carried out at room temperature. The characteristics of the final product are controlled by setting the $\mathrm{pH}$, the solvent amount, and the calcination temperature (Gao et al., 2010). For instance, for the preparation of $\mathrm{TiO}_{2}$, the solution is made by suspending the titanium reagent in an aqueous solvent (alcohol or water). A wet chemical method, such as sol-gel, avoids solutions from high-temperature and appropriately changes the surface of materials. Correspondingly, it has a good control of the particle size with other advantages comprising low temperature and energy consumption (Zhang et al., 2015).

\subsubsection{Annealing method}

In annealing method, the $\mathrm{TiO}_{2}$ powder is mixed with the non-metal dopant; then the mixture of solids is heated and calcined simultaneously at a specific temperature to remove all impurities in order to produce the final non-metal doped photocatalyst. Such doping method is considerably 
faster and simpler than other doping methods when the required titanium precursor is already available for use (Shi et al., 2012). A complete mixing and milling of the two solids have to be ensured in order to obtain a completely doped photocatalyst. Otherwise, a portion of the final product might be made up of only the original photocatalyst while the other portion is the doped photocatalyst. Due to its single calcination step for doping, the characteristics of the final product can be easily controlled by the dopant concentration, the temperature, and the time in the calcination process. Thus, a high amount of photocatalyst can be produced in a short time. Annealing is a heat treatment technique that can change some physical and chemical properties of materials. Three processes occur during annealing of metals including the recovery of the metal, the recrystallization, and the grain growth. In the doping process by annealing, a chemical reaction occurs between two reactants and a new material is produced.

To prepare, for example, $\mathrm{N}-\mathrm{TiO}_{2}$ photocatalysts at the mass ratio of $0.05 \mathrm{~N}: \mathrm{TiO}_{2}, 0.0535 \mathrm{~g}$ of ground urea was added to $1 \mathrm{~g}$ of $\mathrm{P} 25 \mathrm{TiO}_{2}$ and mechanically mixed for $15 \mathrm{~min}$. The white solid product was calcined at $350^{\circ} \mathrm{C}$ for $3 \mathrm{~h}$, and then it was washed with water and ethanol. The solid product was dried at $105^{\circ} \mathrm{C}$. Similarly, different amounts of urea as a nitrogen source were used to prepare various photocatalysts with mass ratios of $0.1,0.15,0.25$, and $0.35 \mathrm{~N}: \mathrm{TiO}_{2}$.

\subsubsection{Microwave assisted method}

The microwave-assisted method is often a combination of the sol-gel and microwave methods. A microwave reactor is used to speed up the formation of products during the doping process. In the microwave reactor, the solution can be heated above its vapor pressure while the reactor can resist the high pressure created from the doping process. Hence, the reaction time would be shortened. The microwave-assisted method is time-effective, energy efficient, and 
environmentally friendly (Zhu and Chen, 2014). However, the cost of the instrument, such as the microwave reactor and other related equipment, could be considerably high when compared to that of other methods. This has limited the broad application of this method. Moreover, the produced amount of photocatalyst depends on the capacity of the microwave reactor, which is often lower than that of other methods because vials have limited volume. Valodkar et al. (2011) reported that improved microwave heating systems are being developed to increase its capacity and efficiency when compared to thermal heating. The use of microwave irradiation in the synthesis of nanoparticles is a fast method with uniform heating, which results in a uniform distribution of particles (Pal et al., 2007).

To prepare, for example, $\mathrm{N}-\mathrm{TiO}_{2}$ photocatalysts at the mass ratio of $0.05 \mathrm{~N}: \mathrm{TiO}_{2}, 1 \mathrm{~g}$ of $\mathrm{P} 25$ $\mathrm{TiO}_{2}$ was added into $15 \mathrm{~mL}$ distilled water followed by the addition of $1.5 \mathrm{~mL}$ of $2.5 \mathrm{M} \mathrm{HNO}_{3}$. The mixture, together with the magnetic stirrer, was transferred into a special reactor vial specifically designed for microwave reactor. After capping the container, it was placed in a $450 \mathrm{~W}$ microwave reactor. The synthesis was carried out at $200^{\circ} \mathrm{C}$ and maximum pressure of 20 bar with normal absorption for $20 \mathrm{~min}$. The solution was then cooled down to room temperature, and the white solid product was centrifuged, washed with water and ethanol, and then dried at $105^{\circ} \mathrm{C}$. Finally, the $\mathrm{N}-\mathrm{TiO}_{2}$ product was calcined at $350^{\circ} \mathrm{C}$ for $3 \mathrm{~h}$. Similarly, different amounts of nitric acid as a nitrogen source were used to prepare various mass ratios of $0.1,0.15,0.25$, and 0.35 $\mathrm{N}: \mathrm{TiO}_{2}$.

\subsubsection{The novel $U V$-assisted thermal synthesis as an alternative to the hydrothermal method}

Before explaining the new method of UV-assisted thermal synthesis, it is pertinent to describe the hydrothermal method. The hydrothermal doping method is similar to the sol-gel 
method; the only difference is that the doping reaction for the hydrothermal method is carried out in an autoclave, which is kept at a specific temperature and pressure for a specific amount of time to promote a complete reaction. The hydrothermal method is typically described as crystal synthesis at high temperature and high pressure (Hayashi and Hakuta, 2010). The hydrothermal synthesis is suitable for some materials that are insoluble at normal temperature and pressure; thus, it requires a temperature above $100^{\circ} \mathrm{C}$ and pressure of more than one atmosphere. Since the reaction is carried out in an autoclave, the solution can be heated to a temperature above its boiling point because of the ability of the closed system to stand high pressure for the solution to reach its vapor pressure.

Advantages of the hydrothermal method are related to high purity from raw materials and process control. This method could control the crystal phase, morphology, and particle size. Disadvantages of the hydrothermal method include the long process time, the considerable shrinkage, and the usage of organic solutions. Overall, the hydrothermal doping method is simple, cost-effective, and environmentally friendly (Lv et al., 2011). However, it might require significant amount of time to complete the reaction. On the other hand, the cost of the instrument, such as a Teflon-lined autoclave, is higher than that of the sol-gel method. The amount of products formed by this approach depends on the capacity of the autoclave.

In this study, an alternative to the hydrothermal method was used to avoid the disadvantages related to the high pressure, the high temperature, the high cost of the instrument, and the time consumption of the conventional hydrothermal method. The UV-assisted thermal method was proposed as a cost-effective alternative, where the UV light was employed in the thermal process to assist the synthesis of the photocatalyst in a significant shorter time. This method was carried out in an ordinary glassware equipped with a condenser at normal pressure and temperature of less 
than $100^{\circ} \mathrm{C}$. The as-prepared $\mathrm{N}-\mathrm{TiO}_{2}$ provided a photocatalyst with a large specific surface area and relatively high photocatalytic activity.

The UV light, especially UVC, is able to initiate or develop the speed of chemical reactions similar to those of high temperature. The UVC light is a good source of energy that can overcome the barrier of activation energy to dissociate chemical bonds and produce new products. Parameters such as the concentration of reactants, temperature, surface area, and light with proper energy affect the rate of chemical reactions. If the UV light intensity increases, more particles will be activated, collisions are more frequent, and the speed of reaction increases (Ranjan and Sasselov, 2016). Based on the Arrhenius law, by increasing the temperature of reactants, the constant rate of the reaction also increases. It has been proven that the electron irradiation significantly speeds up the synthetic process at low temperatures for various oxide systems $\left(\mathrm{NaFeO}_{2}, \mathrm{BaTiO}_{3}, \mathrm{NiFe}_{2} \mathrm{O}_{4}, \mathrm{LiFe}_{5} \mathrm{O}_{8}, \mathrm{MnFe}_{2} \mathrm{O}_{4}, \mathrm{ZnFe}_{2} \mathrm{O}_{4}\right.$, among others) (Surzhikov et al., 2014). UV photons are very energetic to change the structure of molecules by splitting bonds (photolysis), exciting molecules into a higher level of energy (photoexcitation), or ionization of molecules (photo-ionization) (Ranjan and Sasselov, 2016).

Similar to previous methods, to prepare, for example, the $\mathrm{N}-\mathrm{TiO}_{2}$ photocatalyst at the mass ratio of $0.05 \mathrm{~N}: \mathrm{TiO}_{2}, 1 \mathrm{~g} \mathrm{P} 25 \mathrm{TiO}_{2}$ was added to $15 \mathrm{~mL}$ of distilled water followed by the addition of $1.5 \mathrm{~mL}$ of $2.5 \mathrm{M} \mathrm{HNO}_{3}$. The solution was transferred into a Pyrex flat bottom flask (125 mL), and then the flask was placed on the electrical heater with magnetic stirrer plate. A long glass condenser was used to return the condensed vapor to the flask. Four UVC lamp (PL-S- 9W /TUVUV Germicide, 110-120V- G23 Base) were placed vertically outside the glass container at $2 \mathrm{~cm}$ from the flask. The content of the flask was stirred with a magnetic stirrer continuously and heated at lower than its boiling point for $6 \mathrm{~h}$. Then, the solution was cooled down to room temperature, 
and the white solid product was centrifuged, washed with water and ethanol, and dried at $105^{\circ} \mathrm{C}$. The $\mathrm{N}-\mathrm{TiO}_{2}$ product was calcined at $350^{\circ} \mathrm{C}$ for $3 \mathrm{~h}$.

\subsubsection{Light intensity and wavelength}

A successful photocatalytic reaction requires an adequate radiation source, a photoactive catalyst, and a photoreactor. Radiation sources in a photocatalytic process are artificial UV lamps and direct sunlight. The sunlight can be utilized as a UV source, but less than $5 \%$ of its rays that struck the earth surface are in the wavelength range of $300-400 \mathrm{~nm}$, while $42 \%$ of the sunlight is in the visible range. The radiation of UV spectrum is classified as UV-A, UV-B, and UV-C. UVA has a light wavelength in the range of $315-400 \mathrm{~nm}(3.10-3.94 \mathrm{eV}), \mathrm{UV}-\mathrm{B}$ is in the range of 280$315 \mathrm{~nm}(3.94-4.43 \mathrm{eV})$, and UV-C ranges from 100 to $280 \mathrm{~nm}(4.43-12.4 \mathrm{eV})$. UV-C can be divided into germicide (200-280nm) and vacuum-UV (VUV) (100-200nm). UV-A is mostly used in photocatalysis.

Light wavelength and light intensity are two key parameters that must be considered in photocatalysis. The effect of the light intensity in the presence of a photocatalyst for the degradation of aqueous Methyl Orange was investigated in the previous study (Nasirian and Mehrvar, 2016). It was shown that by increasing the light intensity, the rate of the photocatalytic degradation was increased due to the production of more electron/hole pairs. It was reported that there is a linear relationship between the light intensity and the rate of eradication of organics up to an optimum light intensity (Yang and Liu, 2007; Chong et al., 2009, 2010; Chen et al., 2010; Gao, et al., 2010; Hou and $\mathrm{Ku}, 2013$ ); while others observed a square root relationship between the two parameters (Umar and Aziz, 2013). The effect of light wavelength in the presence and 
absence of photocatalysts for the degradation of organic materials was also investigated in this study.

\subsection{Results and Discussion}

\subsubsection{Photolytic degradation of aqueous Methyl Orange using different light sources}

In this study, different irradiation sources including visible, UV-A, UV-B, and UV-C with maximum light intensities at 470,365, 310, and $254 \mathrm{~nm}$, respectively, were used. The effect of the light wavelength on the photolysis of Methyl Orange was studied by different light sources (9W each). The degradation of Methyl Orange was monitored using the TOC analyzer as shown in Figure 7.2a. Results show that the photolysis (light alone) was not able to eradicate Methyl Orange and only a negligible amount of methyl orange was degraded after $3 \mathrm{~h}$ of irradiation.

A digital radiometer (DRC-100X, Spectroline, USA) was used to measure the light intensity of the lamps. Table 7.1 shows the light intensity of different lamps used in this study at different distances from the source and compared with the sunlight intensity on a sunny day of summer 2016 at Ryerson University campus at 1:00 p.m. Table 7.1 confirms that none of the lamps have pure spectra and they produce light in a wide range. For instance, visible lamps produce a wide range of spectra centered at $470 \mathrm{~nm}$ and irradiated UV-A $\left(365 \mu \mathrm{W} / \mathrm{cm}^{2}\right)$ and UV-B $\left(12 \mu \mathrm{W} / \mathrm{cm}^{2}\right)$ as well. UV-B lamps mainly irradiate light in the range of $280-320 \mathrm{~nm}$, but it has irradiation in the range of UV-A $\left(1182 \mu \mathrm{W} / \mathrm{cm}^{2}\right)$ and UV-C $\left(22 \mu \mathrm{W} / \mathrm{cm}^{2}\right)$. A similar trend was observed for all lamps. Different intensities and wavelengths were compared while using P25 as the photocatalyst as depicted in Figure 7.2b. It was found that the light wavelength is more significant than the light intensity for the photocatalytic degradation of organics. It is remarkable that the photocatalytic degradation of organic materials under visible light and UV-C reached steady-state after 30 and 
60 min, respectively, while under in the cases of UV-A and UV-B, the decomposition of organic continued to progress over time.
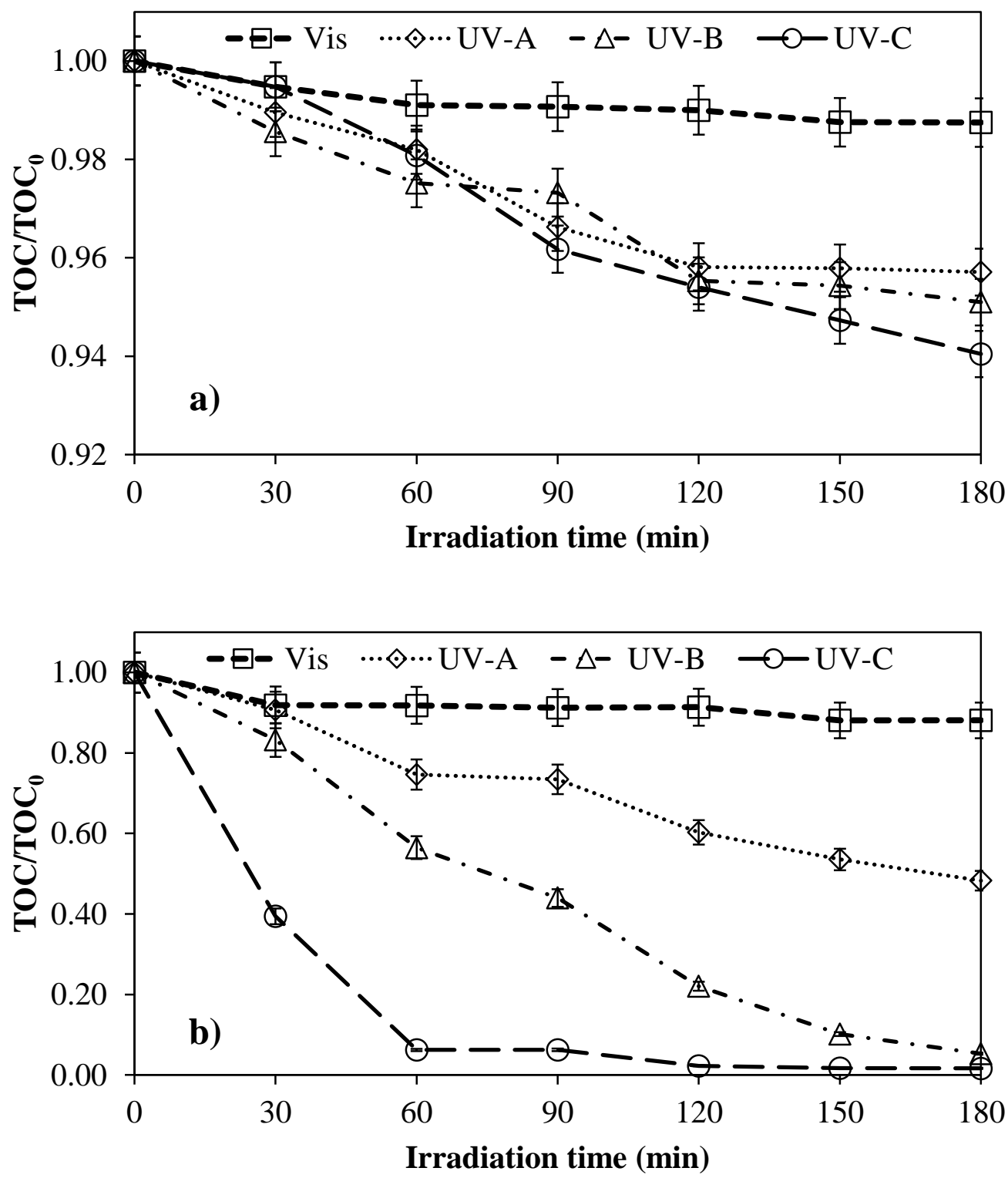

Figure 7.2. Effects of (a) photolysis on the degradation of Methyl Orange solution with the initial concentration of $30 \mathrm{mg} / \mathrm{L}$ using different light wavelengths; and (b) degradation of Methyl Orange in the presence of $\mathrm{P} 25$ with the $\mathrm{TiO}_{2}$ concentration of $500 \mathrm{mg} / \mathrm{L}$.

Reprinted from J. Environ. Sci. (in press) (2017). 
Table 7.1. Light intensity of several lamps and sunlight at different distances (The solar light intensity was measured on a sunny day at 1:00 p.m.).

Reprinted from J. Environ. Sci. (in press) (2017).

\begin{tabular}{|c|c|c|c|c|c|c|c|c|c|c|}
\hline \multirow{2}{*}{ Lamp } & \multicolumn{2}{|c|}{ Visible Lamp } & \multicolumn{2}{|c|}{ UV-A Lamp } & \multicolumn{2}{|c|}{ UV-B Lamp } & \multicolumn{2}{|c|}{ UV-C Lamp } & \multicolumn{2}{|c|}{ Solar } \\
\hline & UV-A & UV-C & UV-A & UV-C & UV-A & UV-C & UV-A & UV-C & UV-A & UV-C \\
\hline Distance & Intensity & Intensity & Intensity & Intensity & Intensity & Intensity & Intensity & Intensity & Intensity & Intensity \\
\hline (cm) & $\left(\mu \mathrm{W} / \mathrm{cm}^{2}\right)$ & $\left(\mu \mathrm{W} / \mathrm{cm}^{2}\right)$ & $\left(\mu \mathrm{W} / \mathrm{cm}^{2}\right)$ & $\left(\mu \mathrm{W} / \mathrm{cm}^{2}\right)$ & $\left(\mu \mathrm{W} / \mathrm{cm}^{2}\right)$ & $\left(\mu \mathrm{W} / \mathrm{cm}^{2}\right)$ & $\left(\mu \mathrm{W} / \mathrm{cm}^{2}\right)$ & $\left(\mu \mathrm{W} / \mathrm{cm}^{2}\right)$ & $\left(\mu \mathrm{W} / \mathrm{cm}^{2}\right)$ & $\left(\mu \mathrm{W} / \mathrm{cm}^{2}\right)$ \\
\hline 0 & 326 & 12 & 14922 & 6 & 1182 & 22 & 408 & 10322 & 2140 & $0-1$ \\
\hline 3 & 176 & 8 & 7556 & 2 & 450 & 6 & 162 & 5274 & & \\
\hline 6 & 104 & 4 & 4196 & 2 & 208 & 4 & 92 & 3042 & & \\
\hline 9 & 64 & 2 & 1894 & 0 & 122 & 2 & 60 & 1990 & & \\
\hline 12 & 38 & 2 & 1226 & 0 & 72 & 0 & 36 & 1190 & & \\
\hline 15 & 28 & 0 & 866 & 0 & 38 & 0 & 24 & 822 & & \\
\hline
\end{tabular}

\subsubsection{Photocatalytic degradation of aqueous Methyl Orange using different $\mathrm{TiO}_{2}$}

The photocatalytic activities of three different types of $\mathrm{TiO}_{2}$ under different irradiation light sources were investigated for the degradation of Methyl Orange with an initial concentration of 30 mg/L TOC. Results showed that under all four different sources of irradiation (Vis, UV-A, UV-B, and UV-C), the degradation of Methyl Orange in the presence of P25 was the highest among all forms of $\mathrm{TiO}_{2}$. The degradation efficiency of Methyl Orange in the presence of P25 under Vis, UV-A, UV-B, and UV-C reached 11.90, 51.74, 74.72, and 98.36\%, respectively. It is clear that UV-C light is the most powerful light source due to its lower wavelength and higher energy compared to those of other light sources. It also produces more electron/hole pairs; thus, the degradation of Methyl Orange was higher and faster since $\mathrm{TiO}_{2}$ can only be activated under UV with a light wavelength of less than $389 \mathrm{~nm}$. Figure 7.3 also shows that after P25, the most active form of $\mathrm{TiO}_{2}$ under four different sources of irradiation for the degradation of Methyl Orange was anatase followed by rutile. The degradation efficiency of Methyl Orange in the presence of anatase 
under visible light, UV-A, UV-B, and UV-C reached 2.17, 26.54, 34.92, and 75.88\%, respectively, while for rutile reached $0.95,5.13,8.66$, and $25.73 \%$, accordingly.

The band gap energies of $\mathrm{TiO}_{2}$ for pure anatase and rutile phase are 3.20 and $3.05 \mathrm{eV}$, respectively. Considering the mass ratio between anatase and rutile in P25 (75\% anatase and 25\% rutile), the band gap energy for P25 should be less than $3.2 \mathrm{eV}$. Eskandarian et al. (2016) reported that UV-A light could effectively activate P25 photocatalyst. In other words, a combination of P25 with UV-A is considered as a standard practice for the photocatalytic degradation of organics. It is clear that at a wavelength of less than $389 \mathrm{~nm}$ and in the presence of P25, hydroxyl radicals are produced. These hydroxyl radicals non-selectively attack organic chemicals and can break down the organic materials.

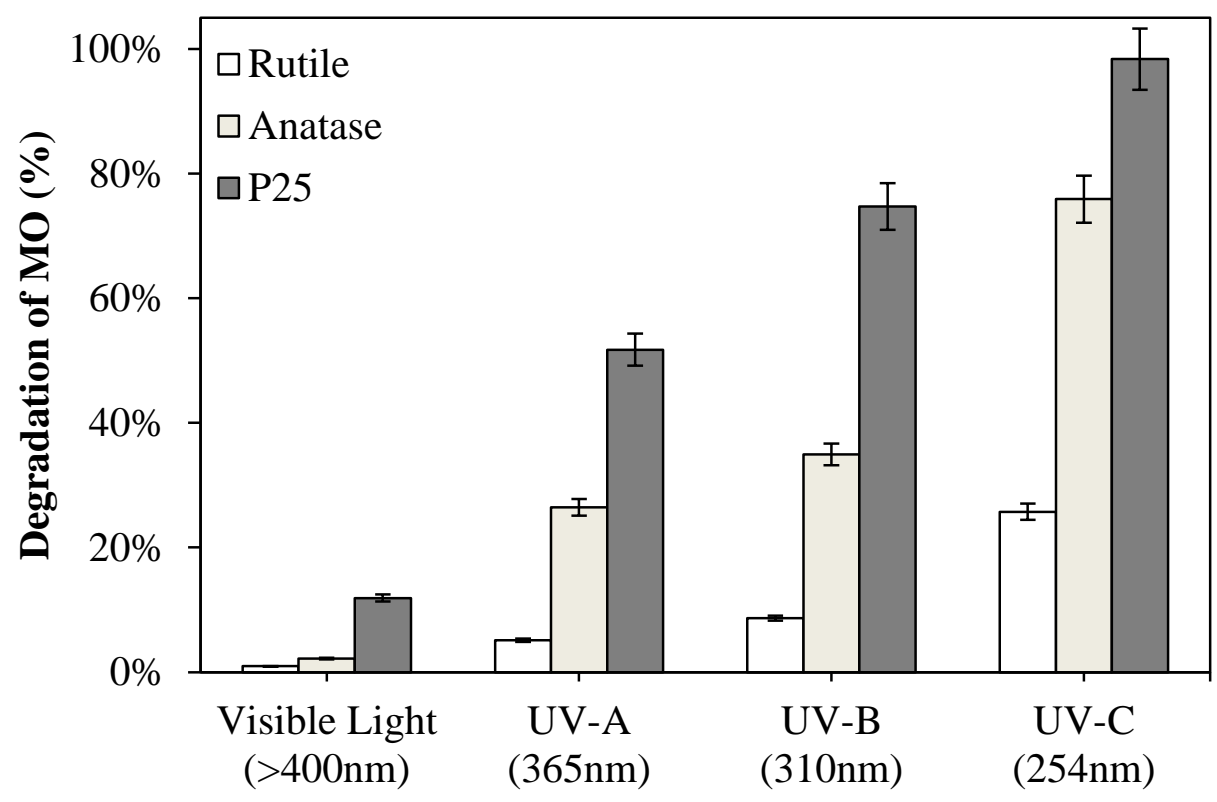

Light wavelength

Figure 7.3. Effects of different wavelengths on the degradation of Methyl Orange in the presence of three commercial forms of $\mathrm{TiO}_{2}$ photocatalyst. The initial concentrations of Methyl Orange and $\mathrm{TiO}_{2}$ are $30 \mathrm{mg} / \mathrm{L}$ and $250 \mathrm{mg} / \mathrm{L}$, respectively. Reprinted from J. Environ. Sci. (in press) (2017). 
The morphology of P25 showed that the particles of anatase and rutile are separate in P25. Sun and Smirniotis (2003) showed that there is a synergistic effect between joining anatase and rutile particles in $\mathrm{P} 25$. Based on the electronic configuration of rutile and anatase in $\mathrm{P} 25$, the band gap energy is lower in rutile than that of anatase (3.05 eV compared to $3.2 \mathrm{eV})$. Therefore, electrons from the conduction band of rutile can easily transfer to the conduction band of anatase through the agglomerates since the conduction band in anatase is lower than that in rutile (Shi and Weng, 2008). Blake et al. (1999) reported that the ratio between anatase and rutile is crucial. Commercial P25 comprising $75 \%$ anatase and $25 \%$ rutile has both a high crystallinity and a high photocatalytic activity. The interaction of anatase and rutile particles is related to the particle size and the specific surface area of the catalyst. The synergistic effect between anatase and rutile particles in P25 is not general but associated with the relative Fermi levels of particles in P25 preceding to their connection to each other and the shape of the particle (Shi and Weng, 2008). Under normal conditions, all electrons are located in the valence band; when $E_{\text {irradiation }}>\mathrm{E}_{\mathrm{bg}}$, electrons are displaced from the equilibrium state.

\subsubsection{Specific surface area analysis}

Two important characteristics of a semiconductor photocatalyst are the surface area and porosity, which affect the efficiency of the photocatalyst for the degradation of pollutants (Legagneux et al., 2002; Gaya and Abdullah, 2008). It is evident that a photocatalyst with a higher specific surface area has a higher adsorption capacity of organic materials and a higher degradation efficiency. Table 7.2 shows the specific surface area of three types of commercial $\mathrm{TiO}_{2}$ photocatalysts and several types of as-prepared $\mathrm{N}-\mathrm{TiO}_{2}$ composites with different $\mathrm{N}: \mathrm{TiO}_{2}$ mass ratios. 
Table 7.2. Specific surface area of several photocatalysts with different synthesis methods, sources of doping, and concentrations.

Reprinted from J. Environ. Sci. (in press) (2017).

\begin{tabular}{|c|c|c|c|c|}
\hline Photocatalyst & Synthesis method & Source of doping & Mass ratio (w:w) & $\mathrm{SSA}\left(\mathrm{m}^{2} / \mathrm{g}\right)$ \\
\hline Commercial Anatase & - & - & Pure anatase & 42.28 \\
\hline Commercial Rutile & - & - & Pure rutile & 2.238 \\
\hline Commercial P25 & - & - & $0.25: 0.75$ rutile:anatase & 39.77 \\
\hline \multirow[t]{5}{*}{$\mathrm{N}-\mathrm{TiO}_{2}$} & \multirow[t]{5}{*}{ Annealing } & \multirow[t]{5}{*}{ Urea } & $0.05 \mathrm{~N}: \mathrm{TiO}_{2}$ & 92.88 \\
\hline & & & $0.10 \mathrm{~N}: \mathrm{TiO}_{2}$ & 94.26 \\
\hline & & & $0.15 \mathrm{~N}: \mathrm{TiO}_{2}$ & 110.0 \\
\hline & & & $0.25 \mathrm{~N}: \mathrm{TiO}_{2}$ & 86.33 \\
\hline & & & $0.35 \mathrm{~N}: \mathrm{TiO}_{2}$ & 78.24 \\
\hline \multirow[t]{5}{*}{$\mathrm{N}-\mathrm{TiO}_{2}$} & \multirow{5}{*}{$\begin{array}{l}\text { UV-assisted thermal } \\
\text { synthesis }\end{array}$} & \multirow[t]{5}{*}{ Urea } & $0.05 \mathrm{~N}: \mathrm{TiO}_{2}$ & 73.67 \\
\hline & & & $0.10 \mathrm{~N}: \mathrm{TiO}_{2}$ & 45.20 \\
\hline & & & $0.15 \mathrm{~N}: \mathrm{TiO}_{2}$ & 84.75 \\
\hline & & & $0.25 \mathrm{~N}: \mathrm{TiO}_{2}$ & 82.81 \\
\hline & & & $0.35 \mathrm{~N}: \mathrm{TiO}_{2}$ & 74.20 \\
\hline \multirow[t]{5}{*}{$\mathrm{N}-\mathrm{TiO}_{2}$} & \multirow[t]{5}{*}{ Microwave } & \multirow[t]{5}{*}{ Urea } & $0.05 \mathrm{~N}: \mathrm{TiO}_{2}$ & 100.0 \\
\hline & & & $0.10 \mathrm{~N}: \mathrm{TiO}_{2}$ & 98.01 \\
\hline & & & $0.15 \mathrm{~N}: \mathrm{TiO}_{2}$ & 107.2 \\
\hline & & & $0.25 \mathrm{~N}: \mathrm{TiO}_{2}$ & 95.52 \\
\hline & & & $0.35 \mathrm{~N}: \mathrm{TiO}_{2}$ & 91.87 \\
\hline \multirow[t]{5}{*}{$\mathrm{N}-\mathrm{TiO}_{2}$} & \multirow{5}{*}{$\begin{array}{l}\text { UV-assisted thermal } \\
\text { synthesis }\end{array}$} & \multirow[t]{5}{*}{$\mathrm{HNO}_{3}$} & $0.05 \mathrm{~N}: \mathrm{TiO}_{2}$ & 67.53 \\
\hline & & & $0.10 \mathrm{~N}: \mathrm{TiO}_{2}$ & 72.84 \\
\hline & & & $0.15 \mathrm{~N}: \mathrm{TiO}_{2}$ & 77.20 \\
\hline & & & $0.25 \mathrm{~N}: \mathrm{TiO}_{2}$ & 66.49 \\
\hline & & & $0.35 \mathrm{~N}: \mathrm{TiO}_{2}$ & 60.56 \\
\hline \multirow[t]{5}{*}{$\mathrm{N}-\mathrm{TiO}_{2}$} & \multirow[t]{5}{*}{ Microwave } & \multirow[t]{5}{*}{$\mathrm{HNO}_{3}$} & $0.05 \mathrm{~N}: \mathrm{TiO}_{2}$ & 63.82 \\
\hline & & & $0.10 \mathrm{~N}: \mathrm{TiO}_{2}$ & 65.47 \\
\hline & & & $0.15 \mathrm{~N}: \mathrm{TiO}_{2}$ & 75.93 \\
\hline & & & $0.25 \mathrm{~N}: \mathrm{TiO}_{2}$ & 80.22 \\
\hline & & & $0.35 \mathrm{~N}: \mathrm{TiO}_{2}$ & 59.03 \\
\hline
\end{tabular}

Table 7.2 also shows that among three commercial photocatalysts, anatase has the highest specific surface area, followed by $\mathrm{P} 25$, and then rutile with $42.28,39.77$, and $2.24 \mathrm{~m}^{2} / \mathrm{g}$, 
respectively. Although the specific surface area of anatase is higher than that of P25, the commercial photocatalyst $\mathrm{P} 25$ was used in this study to synthesize $\mathrm{N}-\mathrm{TiO}_{2}$ due to the synergetic effect between anatase and rutile in the P25 photocatalyst as described in the previous section. In the case of the as-prepared photocatalyst, the highest specific surface area of $\mathrm{N}-\mathrm{TiO}_{2}$ was observed at the mass ratio of $0.15 \mathrm{~N}: \mathrm{TiO}_{2}$ prepared by the annealing method with a specific surface area of $110.01 \mathrm{~m}^{2} / \mathrm{g}$. After the photocatalyst prepared by annealing method, the $\mathrm{N}-\mathrm{TiO}_{2}$ photocatalyst $\left(\mathrm{N}: \mathrm{TiO}_{2}=0.15 \mathrm{w}: \mathrm{w}\right)$ prepared by the microwave method had the highest specific surface area $\left(107.16 \mathrm{~m}^{2} / \mathrm{g}\right)$. All non-metal doped $\mathrm{TiO}_{2}$ photocatalysts, regardless of different doping method and the $\mathrm{N}: \mathrm{TiO}_{2}$ mass ratio had a higher specific surface areas than those of the bare anatase, rutile, and $\mathrm{P} 25$. These results confirm that doping non-metal onto $\mathrm{TiO}_{2}$ increases the specific surface area and improves the photocatalytic activity of the photocatalyst. It was observed that the optimum mass ratio of $\mathrm{N}: \mathrm{TiO}_{2}$ in the $\mathrm{N}-\mathrm{TiO}_{2}$ photocatalyst was 0.15 . The specific surface area increases by augmenting the $\mathrm{N}: \mathrm{TiO}_{2}$ mass ratio up to 0.15 and then reduces at higher $\mathrm{N}: \mathrm{TiO}_{2}$ mass ratios as illustrated in Figure 7.4. It might be concluded that at high $\mathrm{N}: \mathrm{TiO}_{2}$ mass ratios, i.e., more nitrogen as a dopant, nitrogen covers the surface of the $\mathrm{TiO}_{2}$ photocatalyst and there is not enough surface for the photocatalyst to absorb light and generate electron/hole pairs. Another reason is that there is not enough surface to adsorb organics on the surface of photocatalyst at high $\mathrm{N}: \mathrm{TiO}_{2}$ mass ratios. Thus, the photocatalytic activity increases at an optimum amount of dopant. 


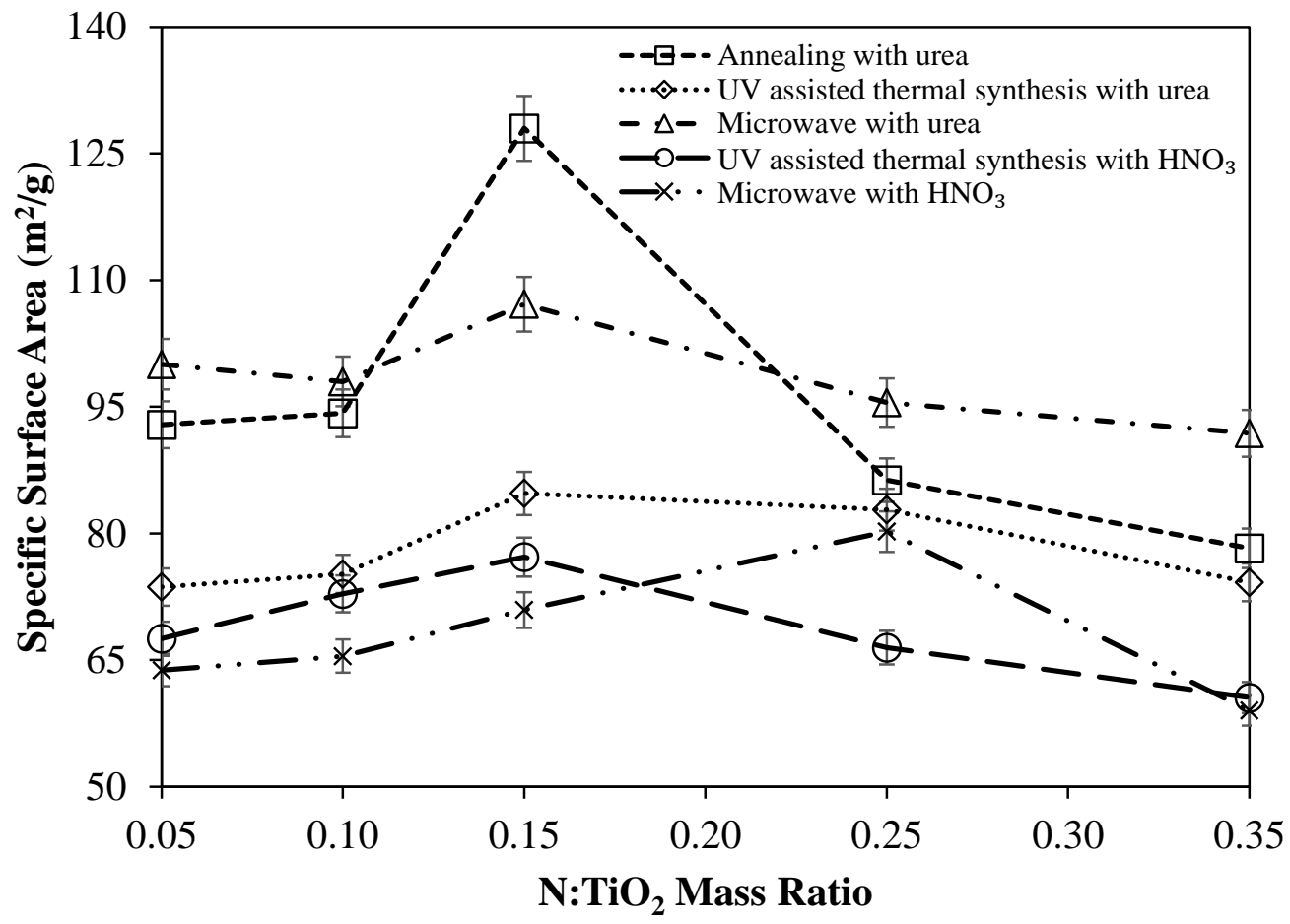

Figure 7.4. Specific surface area for all $\mathrm{N}-\mathrm{TiO}_{2}$ photocatalyst synthesized by different methods.

Reprinted from J. Environ. Sci. (in press) (2017).

\subsubsection{Photocatalytic degradation of aqueous Methyl Orange using synthetized $\mathrm{N}-\mathrm{TiO}_{2}$}

Figure 7.5 illustrates the photocatalytic degradation of aqueous Methyl Orange in the presence of different $\mathrm{N}-\mathrm{TiO}_{2}$ along with a comparison of the specific surface area of photocatalysts. As shown in this figure, by increasing the mass ratio of $\mathrm{N}: \mathrm{TiO}_{2}$, the degradation of Methyl Orange improves, it reaches a maximum at mass ratio of $0.15 w: w \mathrm{~N}^{2} \mathrm{TiO}_{2}$, and then decreases beyond the optimum mass ratio. The same trend was observed for the specific surface area of all photocatalysts. Thus, at large surface area of the photocatalysts, a higher degradation was observed. 

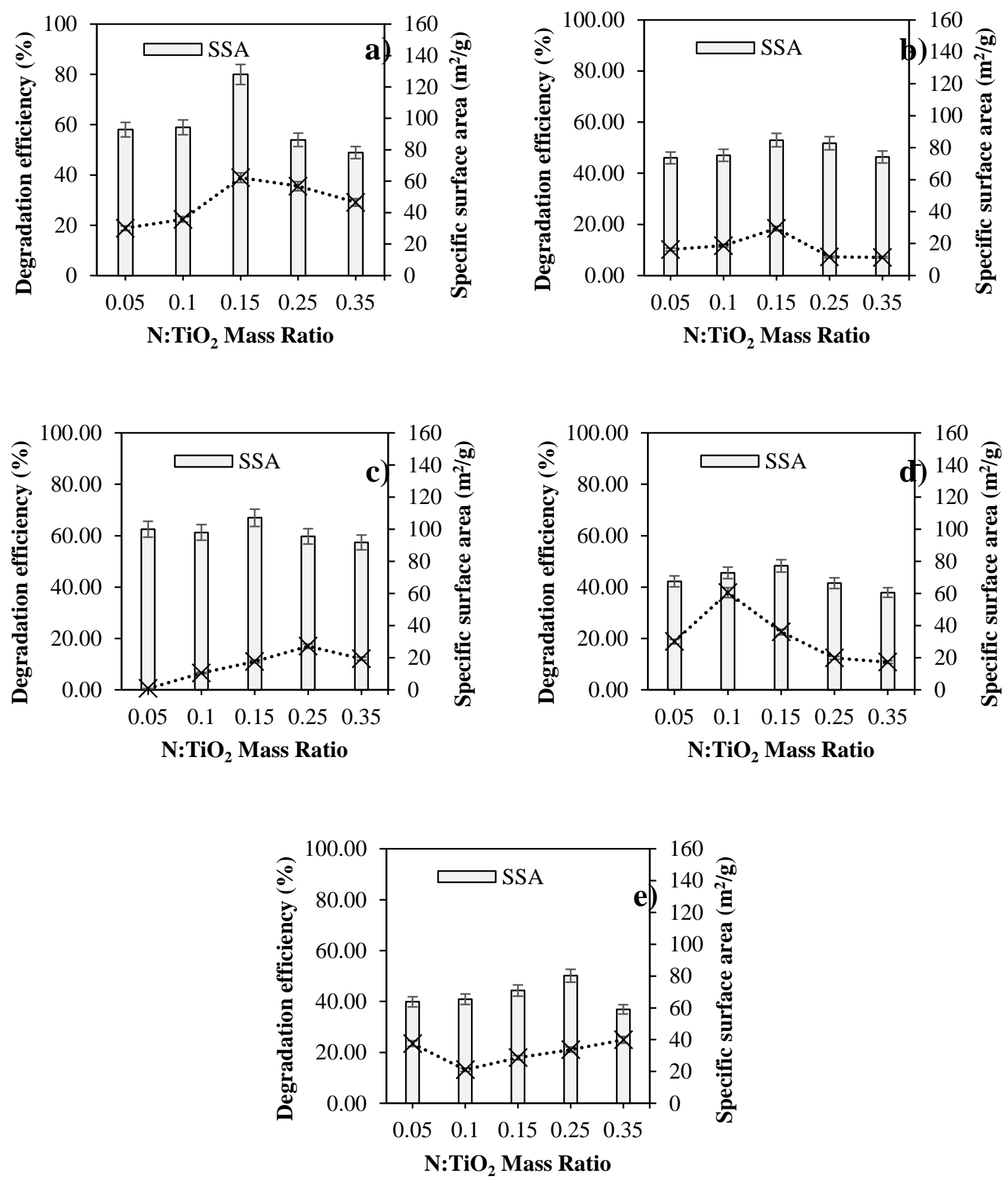

Figure 7.5. Degradation of Methyl Orange and comparison of specific surface area (SSA) for the $\mathrm{N}-\mathrm{TiO}_{2}$ photocatalyst synthesized with different methods: (a) annealing with urea;

(b) UV-assisted thermal synthesis with urea; (c) microwave with urea; (d) UV-assisted thermal synthesis with $\mathrm{HNO}_{3}$; and (e) microwave method with $\mathrm{HNO}_{3}$ (The initial concentrations of Methyl Orange and $\mathrm{TiO}_{2}$ concentrations are 30 and $500 \mathrm{mg} / \mathrm{L}$, respectively). UV: ultraviolet

Reprinted from J. Environ. Sci. (in press) (2017). 
Results show that the preparation method of $\mathrm{N}^{-\mathrm{TiO}_{2}}$ photocatalyst has various effects on the degradation of an azo dye. The best results were obtained by the annealing method, where the degradation of Methyl Orange reached $40.91 \%$ with the mass ratio $0.15 \mathrm{~N}: \mathrm{TiO}_{2}$. Other methods including microwave with urea, microwave with $\mathrm{HNO}_{3}, \mathrm{UV}$-assisted thermal synthesis with urea, and UV-assisted thermal synthesis with $\mathrm{HNO}_{3}$ reached a maximum of 16.97, 23.50, 18.44, and $31.36 \%$, under the same conditions, respectively. It is remarkable that in almost all methods, the maximum degradation was observed at the mass ratio $0.15 \mathrm{~N}: \mathrm{TiO}_{2}$, except the photocatalyst prepared by the microwave method with $\mathrm{HNO}_{3}$ at the mass ratio $0.25 \mathrm{~N}: \mathrm{TiO}_{2}$. Results confirmed that doping $\mathrm{TiO}_{2}$ with a non-metal increases the specific surface area and the photocatalytic activity for the organics removal simultaneously. Figure 7.6 shows the degradation efficiency of Methyl Orange by different methods of $\mathrm{N}-\mathrm{TiO}_{2}$ photocatalyst synthesis (at the mass ratio $0.15 \mathrm{~N}: \mathrm{TiO}_{2}$ ). Among all doping methods, the methods of annealing and UV-assisted thermal synthesis are more efficient in degradation of aqueous organic matters due to the preparation time and total costs.

There are several possibilities for the higher production yield of $\mathrm{N}-\mathrm{TiO}_{2}$ prepared by annealing method compared to that by UV-assisted thermal synthesis. These include the optimum nitrogen level in the photocatalyst, different sources of nitrogen, different sources and temperatures of the activation energy for the synthesis $\left(300^{\circ} \mathrm{C}\right.$ in annealing compared to $90^{\circ} \mathrm{C}$ in UV-assisted thermal synthesis), or the occurrence of more red shift in the photocatalyst prepared by the annealing method. On the other hand, the UV-assisted thermal synthesis method can be applied using a variety of precursors; whereas, the annealing method is restricted to the solid form of precursors; thus, making the novel UV-assisted thermal synthesis an interesting alternative to conventional methods. 


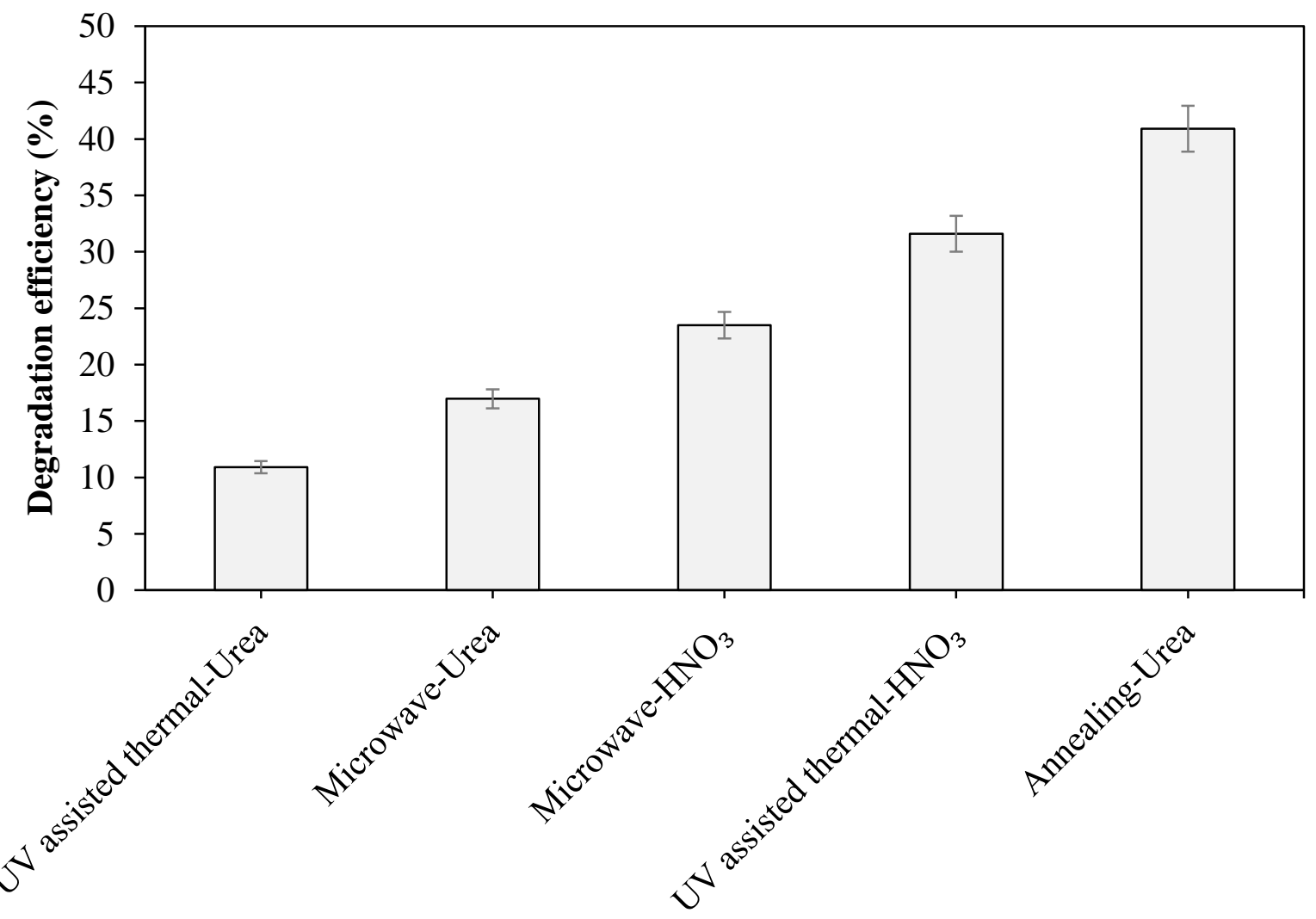

Photocatalyst synthesis method

Figure 7.6. Efficiency of different photocatalysts for the degradation of Methyl Orange under UV-A irradiation using $500 \mathrm{mg} / \mathrm{L} \mathrm{N}-\mathrm{TiO}_{2}$ at the mass ratio $0.15 \mathrm{~N}: \mathrm{TiO}_{2}$. The initial concentration of Methyl Orange was $30 \mathrm{mg} / \mathrm{L}$.

Reprinted from J. Environ. Sci. (in press) (2017).

It is evident that the photocatalyst characteristics are related to the structure, the crystal size, and the morphology of the crystal. There are two theories for doping $\mathrm{TiO}_{2}$ with a metal or a nonmetal. According to Zhang et al. (2015), nitrogen atoms are doped at the interstitial sites, where these nitrogen atoms are in charge for visible-light response; thus, the surface of the photocatalyst is covered by the dopant. The second theory is based on substitution of dopant with ions in the crystal lattice of the photocatalyst (Asahi et al., 2001). Peng et al. (2010) stated that in the process of nitrogen doping, both interstitial and substitutional nitrogen doping occur and both processes are responsible for the visible-light sensitivity of $\mathrm{TiO}_{2}$ photocatalyst. Zhang et al. (2015) reported 
that the radius of nitrogen in $\mathrm{N}$-doped $\mathrm{TiO}_{2}$ is a little larger than that of oxygen. Thus, nitrogen is possibly located at the surface of the catalysts and formed chemical bonds or adsorbed at the mesopores. In another study, Di Valentin et al. (2004) reported that at low concentrations of nitrogen (as dopant), interstitial doping happens, but at higher concentrations of nitrogen as a dopant substitution occurs. Although this may occur for certain preparation methods, based on the solubility of two solids in high concentration of dopant, the interstitial occurs. Therefore, both interstitial and substitution would occur in doping $\mathrm{TiO}_{2}$ with non-metals. Substitution occurs if the size of dopant is close to oxygen in the crystal lattice of $\mathrm{TiO}_{2}$ and then after certain amount of substitution, interstitial happens. It is notable that during the process of $\mathrm{N}-\mathrm{TiO}_{2}$ preparation, most of the nitrogen atoms on the surface of $\mathrm{TiO}_{2}$ (as terrestrial) generate nitrogen oxide during calcination treatment. Therefore, several types of NOx species, such as $\mathrm{NO}, \mathrm{NO}_{2}, \mathrm{NO}_{2}^{-}, \mathrm{NO}_{2}{ }^{2-}$, $\mathrm{NO}_{3}{ }^{-}$, and $\mathrm{N}_{2} \mathrm{O}_{2}{ }^{2-}$, exist in the nitrogen doped $\mathrm{TiO}_{2}$ photocatalyst. In brief, the $\mathrm{N}-\mathrm{TiO}_{2}$ photocatalyst can exist either as substitutional in the form of $\mathrm{Ti}-\mathrm{N}-\mathrm{Ti}$ bond or interstitial in the form of $\mathrm{Ti}-\mathrm{O}-\mathrm{N}$ or $\mathrm{Ti}-\mathrm{N}-\mathrm{O}$ bond (Zhang et al., 2015).

\subsubsection{Diffractogram analysis of synthetized $\mathrm{N}^{-T i O} \mathrm{O}_{2}$ photocatalyst by $\mathrm{U}$-assisted thermal synthesis}

Figure 7.7 shows a diffractogram of the $\mathrm{N}-\mathrm{TiO}_{2}$, with the mass ratio of $0.15 \mathrm{~N}: \mathrm{TiO}_{2}$, prepared by the UV-assisted thermal synthesis with $\mathrm{HNO}_{3}$ as the nitrogen source. The diffractogram of the photocatalyst confirmed that it has mostly anatase form with a small peak of rutile. Therefore, it is confirmed that the structure of $\mathrm{P} 25$ as a main precursor is still stable after the preparation process of $\mathrm{N}-\mathrm{TiO}_{2}$ by the $\mathrm{UV}$-assisted method. Moreover, the P25 phase (mixture of anatase and rutile) was confirmed by comparing the attained diffractograms with the standards, which present the 
location of the $\mathrm{TiO}_{2}$ peaks, based on the Joint Committee on Powder Diffraction Standards of JCPDS-21-1272 and JCPDS-21-1276 databank (Dai et al., 2010; Nasirian and Mehrvar, 2016). P25 has one main peak at $2 \theta=25.4$ and two other peaks at $2 \theta=37.8$ and 48.0 , belonging to anatase and corresponding to the related planes. It also has a peak at $2 \theta=27.4$, which belongs to rutile. The comparison of the $\mathrm{N}-\mathrm{TiO}_{2}$ photocatalyst diffractogram with the standard $\mathrm{P} 25$ showed that both diffractograms were similar and no change in the location of peaks was observed. Thus, the crystal structures of pure $\mathrm{P} 25$ and $\mathrm{N}-\mathrm{TiO}_{2}$ are in the same position. It can be concluded that nitrogen is a part of the crystal lattice of $\mathrm{TiO}_{2}$ due to the relatively same size of the two ions (Asahi et al., 2001; Peng et al., 2010). It seems that a crystal defect happened and this is the reason for increasing the specific surface area and photocatalytic activity of the $\mathrm{N}-\mathrm{TiO}_{2}$.

Irie et al. (2003) and Kobayakawa et al. (2005) showed that $\mathrm{N}$ doping of $\mathrm{TiO}_{2}$ leads to the formation of oxygen vacancies and substitution of nitrogen instead of oxygen ( $\mathrm{N}$ impurity), accounting for the observed visible light catalytic behavior of the $\mathrm{N}-\mathrm{TiO}_{2}$ photocatalyst. Using both experimental data and theoretical calculations, Woicik et al. (2002) confirmed the density of states (DOS) for $\mathrm{N}-\mathrm{TiO}_{2}$ with and without oxygen vacancies. Thus, the combination of the $\mathrm{N}$ impurity and oxygen vacancies is responsible for the UV-vis light absorption as well as the photocatalytic activity of the $\mathrm{N}-\mathrm{TiO}_{2}$ photocatalyst in the visible region.

The oxygen vacancy relates to the defect level and the formation in the optical absorbance spectra of the $\mathrm{N}$-doped $\mathrm{TiO}_{2}$. Thus, the band gap reduction, due to the high concentration of $\mathrm{N}$ doping into $\mathrm{TiO}_{2}$, is related to the defect levels. On the other hand, the electronic structure of $\mathrm{TiO}_{2}$ is modified, in which the electrons of $\mathrm{N}$ transfer into the orbitals of Ti near the Fermi level. The valence-band structure tails to lower binding energies due to the incorporation of the less tightly electrons in the orbitals of $2 \mathrm{p}$ level in $\mathrm{N}$, which is hybridized with the electrons in the orbitals of 
$2 \mathrm{p}$ level in $\mathrm{O}$ causing a reduction in the band gap. In other words, the $\mathrm{N}$ atoms occupy the vacant sites of $\mathrm{Ti}$ ions or $\mathrm{O}$ in the $\mathrm{TiO}_{2}$ lattice (Rumaiz et al., 2009; Sundaram et al., 2017).

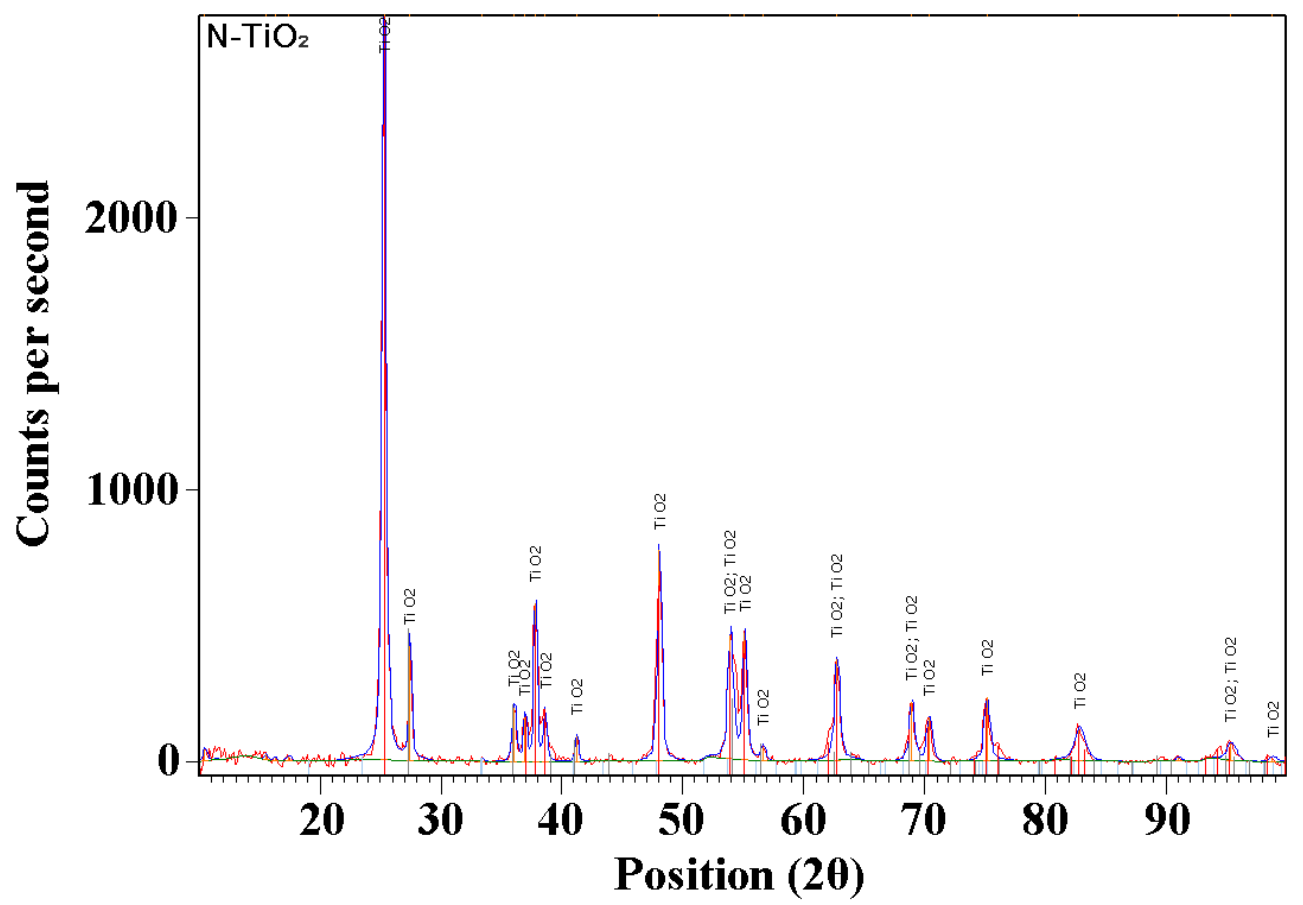

Figure 7.7. Diffractogram of the $\mathrm{N}_{-} \mathrm{TiO}_{2}$, with the mass ratio of $0.15 \mathrm{~N}: \mathrm{TiO}_{2}$, prepared by $\mathrm{UV}$-assisted thermal synthesis with $\mathrm{HNO}_{3}$ as the nitrogen source. Reprinted from J. Environ. Sci. (in press) (2017).

\subsubsection{SEM and mapping of $\mathrm{N}-\mathrm{TiO}_{2}$ synthetized by $\mathrm{UV}$-assisted thermal method}

The method of elemental mapping of chemicals using electron excited X-ray spectrometer started from 1956 (Newbury and Ritchie, 2013). The principle technique is based on the generation of X-ray by elastic or inelastic scattering of electrons with high energy from an X-ray beam focused on a very small diameter of the sample. When the primary or incident energetic electrons strike the sample, several signals are generated. The most important signals are secondary, backscattered, and augur electrons. Secondary electrons are inelastic electrons, which are produced from the top surface of the atom, and show some information about the morphology of the sample. Backscattered electrons are incident electrons, which are elastic and reflected from the atom, and 
show an atomic number of the elements in the sample. The third one is augur electrons, which are generated when a primary beam of electrons strikes the atom in the sample, and they cause shell transition and emission of X-ray. The emitted X- ray from each atom is specific that can provide fast qualitative and quantitative analysis of elements in the sample. The emitted X-ray is used to form map or lines, which show the elemental distribution in the sample.

Figure 7.8a illustrates the SEM image of the $\mathrm{N}^{-\mathrm{TiO}_{2}}$ photocatalyst $\left(0.15 \mathrm{w}: \mathrm{w} \mathrm{N}: \mathrm{TiO}_{2}\right)$ synthesized by the UV-assisted thermal method with $\mathrm{HNO}_{3}$ as the nitrogen source. In Figure 7.8a, particles have a heterogeneous flat shape with the size of particles in the range of $1-10 \mu \mathrm{m}$ (based on the scale and the magnification factor in SEM). Particles contain numerous light and dark nanoparticles, which are supposed to contain more pores on the surface. The elemental analysis of $\mathrm{N}-\mathrm{TiO}_{2}$ was not conclusive since nitrogen and oxygen peaks were overlapped. This circumstance is usually caused by the resemblances between nitrogen and oxygen, which present similar characteristics in EDS. The instrument was not also able to separate their elemental peaks properly. Consequently, mapping of the $\mathrm{N}-\mathrm{TiO}_{2}$ photocatalyst was used to illustrate the distribution and relative proportion of the compounds and elements over the scanned area. Thus, Figures $8 \mathrm{~b}$, c, and d show three mapping images of the $\mathrm{N}$-doped $\mathrm{TiO}_{2}$ photocatalyst for nitrogen, titanium, and oxygen elements, respectively, produced from the most intense X-ray emission (with the highest energy) of $\mathrm{K}_{\alpha}$ radiation of each atom in the photocatalyst.

Figures $7.8 \mathrm{~b}$, c, and d were obtained from backscattered electron images in the SEM and display compositional contrast that results from different atomic number elements and their distribution. In other words, EDS allows to identify what those particular elements are and their relative proportions. The mapping image confirmed that the $\mathrm{N}$-doped $\mathrm{TiO}_{2}$ photocatalyst comprises nitrogen as a dopant in the structure of the composite of $\mathrm{N}-\mathrm{TiO}_{2}$. 

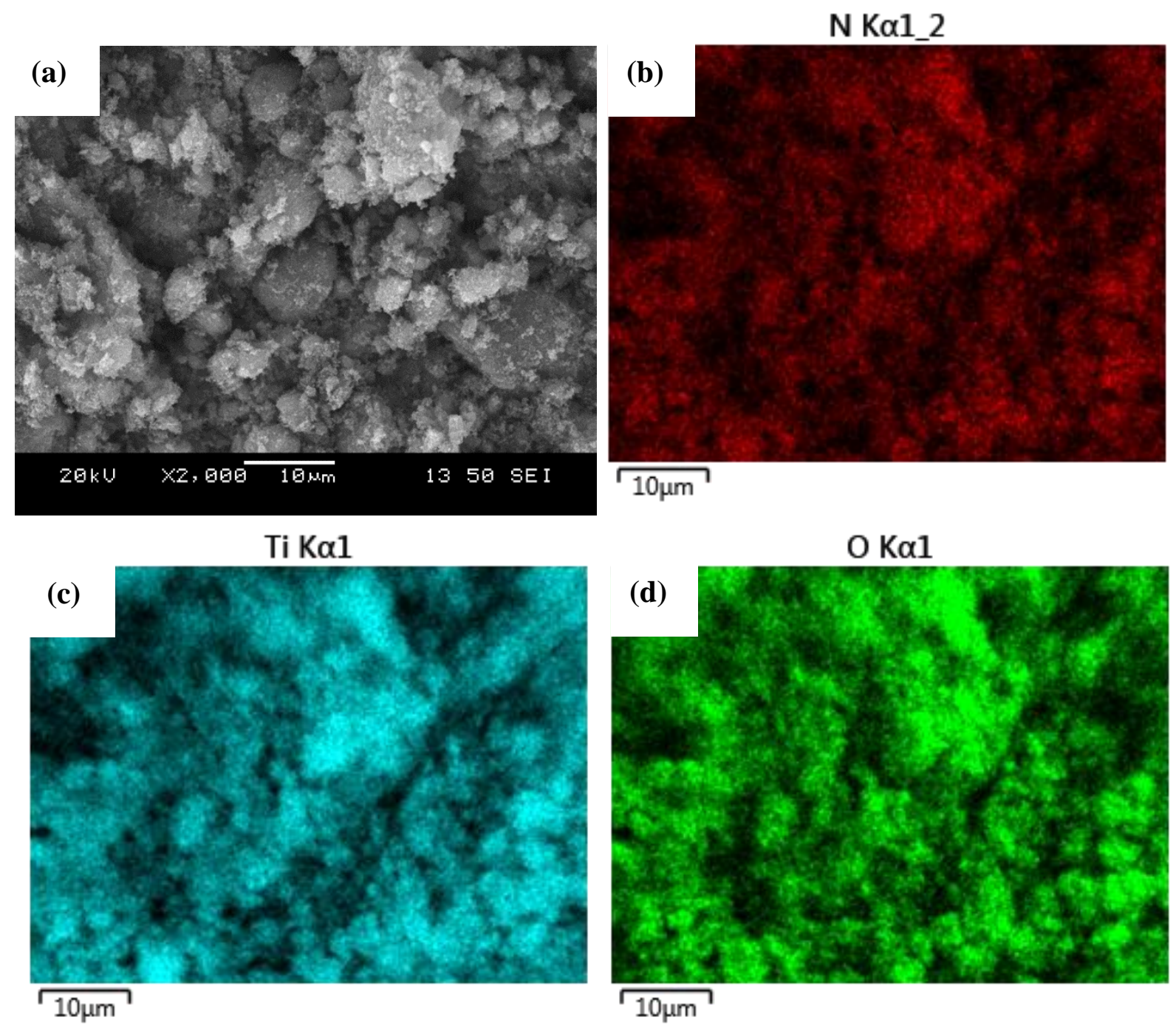

Figure 7.8. SEM and mapping images of the (a) $\mathrm{N}-\mathrm{TiO}_{2}$ photocatalyst $\left(0.15 \mathrm{~N}^{\mathrm{TiO}} \mathrm{Ti}_{2} \mathrm{w}: \mathrm{w}\right.$ and $\mathrm{HNO}_{3}$ as the nitrogen source) by the $\mathrm{UV}$-assisted thermal method and the elemental distribution of (b) nitrogen, (c) titanium, and (d) oxygen for the photocatalyst prepared by UV-assisted thermal synthesis. UV: ultraviolet.

Reprinted from J. Environ. Sci. (in press) (2017). 


\subsection{Conclusions}

In this study, nitrogen doped $\mathrm{TiO}_{2}$ was synthesized using three different methods with two precursors (urea and $\mathrm{HNO}_{3}$ ) and different mass ratios of $\mathrm{N}: \mathrm{TiO}_{2}(0.05,0.10,1.5,0.25$, and 0.35$)$. The $\mathrm{N}-\mathrm{TiO}_{2}$ photocatalyst was prepared and evaluated by three methods including UV-assisted thermal synthesis with urea and $\mathrm{HNO}_{3}$, the annealing with urea, and the microwave assisted with urea and $\mathrm{HNO}_{3}$. It was shown that the photocatalytic decomposition of Methyl Orange was more significant than photolytic decomposition regardless of different light wavelengths. It was also shown that $\mathrm{N}-\mathrm{TiO}_{2}$ photocatalysts prepared by annealing and $\mathrm{UV}$-assisted thermal synthesis had a better photocatalytic activity for the degradation of organics. By applying annealing method and UV-assisted thermal synthesis, an increase in the Methyl Orange degradation of 20.4 and $16.5 \%$, respectively, was observed when compared to that of the bare $\mathrm{TiO}_{2}$. It was also observed that by increasing the mass ratio of nitrogen as a dopant to $\mathrm{TiO}_{2}$, the degradation of Methyl Orange was increased up to an optimum mass ratio of $\mathrm{N}: \mathrm{TiO}_{2}$ and then the degradation decreased. It was also confirmed that by increasing the specific surface area, the photocatalytic activity increased. The diffractograms of the $\mathrm{N}-\mathrm{TiO}_{2}$ photocatalyst prepared by the UV-assisted thermal synthesis showed that the as-prepared photocatalyst was in the P25 form, nitrogen ions penetrated in the crystal, substitution of nitrogen with oxygen occurred, and distortion in the crystal appeared. The novel UV-assisted thermal synthesis produced encouraging results as an alternative preparation method for the nitrogen doped $\mathrm{TiO}_{2}$ photocatalyst; thus, further studies are recommended for process optimization, immobilization, and scale-up to evaluate its applicability in wastewater treatment. 


\title{
CHAPTER 8
}

\section{OPTIMIZATION OF THE PHOTOCATALYTIC ACTIVITY OF N-DOPED TIO 2 FOR THE PHOTOCATALYTIC DEGRADATION OF AN AZO DYE*}

\begin{abstract}
Methyl orange, a well-known detrimental azo dye, is treated by $\mathrm{N}$-doped $\mathrm{TiO}_{2}$ photocatalyst. In this study, the effects of light intensity in terms of irradiance by the number of lamps, photon energy and radiation source, initial concentration of total organic carbon (TOC), and $\mathrm{pH}$ on the degradation efficiency of methyl orange are investigated. A four-factor Box-Behnken Design along with Response Surface Methodology is used to maximize the removal of TOC and color from an azo dye wastewater. Statistical models are developed to predict both color and total organic carbon removals as response variables. In all cases, the light intensity and TOC concentration cross-factor interaction with the light wavelength is intensified when the latter is at the lowest range value while $\mathrm{pH}$ does not require adjustments. Maximum total organic carbon and color removals of 93.69 and $94.98 \%$, respectively, were achieved at the optimum operating conditions of light intensity in terms of 5 lamps, light wavelength of $418 \mathrm{~nm}$ (visible light range), initial TOC concentration of $10.54 \mathrm{mg} / \mathrm{L}$, and $\mathrm{pH}$ of 5.14 . The model was validated by an additional experiment at the optimal operating conditions. The agreement between experimental values and

\footnotetext{
* Submitted to Journal of Materials Research Innovations (2017).
} 
model predictions demonstrate the proposed models could effectively describe the degradation of azo dyes by photocatalysis using the $\mathrm{N}$-doped $\mathrm{TiO}_{2}$ composite under visible light.

Keywords: Advanced Oxidation Processes, Photocatalysis, Azo Dyes, Experimental Design, Process Optimization. *

\footnotetext{
* Submitted to Journal of Materials Research Innovations (2017).
} 


\subsection{Introduction}

The textile manufacturing industry produces large volumes of industrial wastewater containing azo dyes, which may have considerable adverse effects when released into water bodies. Chemical reactions taking place in the wastewater, such as oxidation or hydrolysis, can produce dye by-products that are detrimental to the environment. Nearly $20 \%$ of the global dye production during dyeing, being released as textile wastewater (Akpan and Hameed, 2009).

Advanced oxidation processes (AOPs) are an attractive alternative to conventional treatment methods for the removal of dyes from industrial wastewater because of the ability of these methods to mineralize the target contaminants, avoiding the formation of hazardous byproducts (Visa et al., 2011; Mohajerani et al., 2011, 2016; De Andrade et al., 2012; Zou, 2015; Buthiyappan et al., 2016; Nasirian and Mehrvar, 2016). AOPs are based on the production of hydroxyl radicals, which can oxidize almost all organic materials in wastewater effluents due to its strong oxidation potential of $2.8 \mathrm{eV}$ (Bustillo-Lecompte et al., 2013, 2014, 2015, 2016a, 2016b; Mowla et al., 2014; Hamad et al., 2014, 2016; Bustillo-Lecompte and Mehrvar, 2015, 2016).

Photocatalysis is one of the diverse types of $\mathrm{AOPs}$, and $\mathrm{TiO}_{2}$, among all photocatalysts, has been widely studied as one of the most promising photocatalysts for environmental treatment because of its superior properties, including high reactivity, non-toxicity, high physicochemical stability, and low price (Akpan and Hameed, 2009; Nasirian and Mehrvar, 2016). However, $\mathrm{TiO}_{2}$ has some disadvantages that limit its application in wastewater treatment, including its large band gap energy of $3.2 \mathrm{eV}$, which restricts the use of solar irradiation and increases the production costs, and the high recombination rate of electron-hole pairs, which reduces the photocatalytic activity of $\mathrm{TiO}_{2}$ (Nasirian and Mehrvar, 2016; Veisi et al., 2016). 
Non-metal doping of $\mathrm{TiO}_{2}$ using $\mathrm{N}, \mathrm{S}, \mathrm{F}$, or $\mathrm{C}$ has been considered an efficient method for expanding the absorption band gap of $\mathrm{TiO}_{2}$ to the visible-light region. $\mathrm{N}$-doped $\mathrm{TiO}_{2}$, with a band gap energy of $2.3 \mathrm{eV}$, has a high photodegradation efficiency, is less expensive than other semiconductors, and mitigates the electron-hole recombination processes (Veisi et al., 2016; Salarian et al., 2016; Shivaraju et al., 2016).

On the other hand, AOPs are multifactor systems because of the cross-factor interaction of different parameters during the treatment process, including organics concentration, $\mathrm{pH}$, light intensity, light wavelength, reaction time, and oxidant/catalyst concentration, among others (Bustillo-Lecompte et al., 2016a; Salarian et al., 2016). Therefore, the use of design of experiments (DOE) is an appropriate approach to identify the influencing factors in the multivariable system in terms of single factor and interaction effects. DOE is also used to overcome the limitations of conventional procedures regarding time and materials required, and subsequently optimize the variables involved while using the response surface methodology (RSM) to attain optimal responses using the minimum number of experiments (Hamad et al., 2016; Bustillo-Lecompte and Mehrvar, 2016; Bustillo-Lecompte et al., 2016a, 2016b).

In this study, the effects of the light intensity, wavelength, initial concentration of total organic carbon (TOC), and $\mathrm{pH}$, as well as their interaction on the degradation efficiency of methyl orange, a well-known detrimental azo dye, are investigated. The DOE was used to find the optimum conditions for the photocatalytic treatment of the azo dye by maximizing the removal of TOC and color from the methyl orange aqueous solution under visible light. The optimal parametric values for the DOE were obtained using a four-factor Box-Behnken Design (BBD) along with RSM. Then, statistical models were developed to predict both percentual removal of 
TOC and color as process responses. Lastly, the statistical quadratic models were validated in another set of experimental runs at optimum operating conditions.

\subsection{Materials and Methods}

\subsubsection{Materials}

All chemical materials were analytical grade, purchased from Sigma-Aldrich (Oakville, ON) and Van Waters and Nat Rogers (VWR) Canada (Mississauga, ON). They were used as received without additional purification.

\subsubsection{Photocatalyst synthesis}

In this study, the annealing method was used for the synthesis of nitrogen doped $\mathrm{TiO}_{2}$. The annealing method involves the mixing of the $\mathrm{TiO}_{2}$ powder and the source of non-metal dopant, urea in this case, and then heating and calcining simultaneously the mixture in the furnace to obtain the resulting non-metal doped photocatalyst $\left(\mathrm{N}-\mathrm{TiO}_{2}\right)$.

Different amounts of precursors were used to prepare $\mathrm{N}-\mathrm{TiO}_{2}$ photocatalysts by the annealing technique at different mass ratios $\left(0.05-0.35 \mathrm{w}: \mathrm{w} \mathrm{N}: \mathrm{TiO}_{2}\right)$. To prepare $\mathrm{N}-\mathrm{TiO}_{2}$ with mass ratio of $0.05 \mathrm{w}: \mathrm{w} \mathrm{N}: \mathrm{TiO}_{2}, 0.107 \mathrm{~g}$ grinded urea was added to $1 \mathrm{~g} \mathrm{P} 25 \mathrm{TiO}_{2}$, and the content was mixed for $10 \mathrm{~min}$. The white solid product was calcined at $350^{\circ} \mathrm{C}$ for $3 \mathrm{~h}$, and then it was washed with water and ethanol. The solid product was dried at $105^{\circ} \mathrm{C}$ in an oven. The annealing method is considerably faster and simpler than other doping methods when the required $\mathrm{TiO}_{2}$ precursor is already available for use (Shi et al., 2012).

It must be ensured a comprehensive mixing and milling of the two solids to obtain a completely doped photocatalyst. Otherwise, a portion of the final product might be made up of only the original photocatalyst, while the other portion is the doped photocatalyst. Due to its single 
calcination step for doping, the characteristics of the final product can be easily controlled by the dopant concentration, temperature, and time during the calcination process. Thus, a high amount of photocatalyst can be produced in a short period of time. The final product of the as prepared N$\mathrm{TiO}_{2}$ provided a photocatalyst with a large specific surface area and high photocatalytic activity.

\subsubsection{Instrumentation}

Scanning electron microscopy (SEM) (JEOL, JSM-6370LV, Calgary, AB) coupled with energy dispersive spectroscopy (EDS) (Oxford Instrument Model X-Max-N-80, Concord, MA) was used to characterize both morphology and chemical composition of individual particles. An auto sputter coater (Denton Vacuum Desk IV, Moorestown, NJ) was used for coating samples with a thin layer of gold before analysis by SEM.

The specific surface area of the photocatalyst powder was obtained based on the Brunauer, Emmet, and Teller (BET) technique (Nova e-Series 1200, Quantachrome Instruments, Boynton Beach, FL), in which physical adsorption of nitrogen occurred at $77 \mathrm{~K}$. X-ray diffraction (XRD) model PANalytical X'pert PRO (St Laurent, QC) was used to characterize the crystal structure and conversion phase of $\mathrm{TiO}_{2}$ with the scanning range of $10-100^{\circ}(2 \theta)$.

The photoactivity of the as-prepared photocatalyst was assessed by measuring the degradation of methyl orange using two different methods. The first method was based on the TOC concentration measured by an automated TOC analyzer (Model Apollo 9000, Teledyne Tekmar, Mason, $\mathrm{OH}$ ). The second method was based on the measurement of color by an Orbeco-Hellige colorimeter model MC500-Multiparameter (Sarasota, FL, USA).

Before analysis either by TOC analyzer or colorimeter, all samples were first centrifuged at $4000 \mathrm{rpm}$ for 30 min using a centrifuge (Thermo Scientific Heraeus Multifuge X1, Mississauga, 
ON) followed by filtration using a filter paper (VMR Qualitative 410, Mississauga, ON). All experimental runs and analytical measurements were repeated in triplicates. Thus, the mean values were reported.

\subsubsection{Experimental setup and procedure}

A lab-scale batch photoreactor with uniform light distribution was used for the degradation of methyl orange in the presence of as-prepared photocatalysts. The schematic diagram of the experimental setup is presented in Figure 8.1. The batch photoreactor is made of a glass container with a total working volume of 3.5 L (Figure 8.1a) and a lid for holding different irradiation sources (Figure 8.1b). The irradiation sources were varied depending on the experimental run and included 5 lamps at centered peak wavelengths of 254, 365, and $476 \mathrm{~nm}$ for UV-C (PL-S- 9W /TUV-UV Germicide, 110-120V- G23 Base), UV-A (Philips BL PL-S 9W 110-120V, 2P Actinic G23 Base), and Visible (PL-2PIN-9 W 110-120V -G23 Base) lights, respectively. All lamps have been vertically located on the top of the reactor. The degradation process of aqueous methyl orange was performed with continuous stirring using a magnet stirrer. The reactor was covered with aluminum foil to prevent interference from any external light source and temperature variations. The TOC and color were monitored every $30 \mathrm{~min}$ for each experiment to measure the degree of mineralization and decolourization of methyl orange, respectively. The temperature of the solution in the main reactor was controlled by applying a cooling bath (RTE-211, NESLAB Instruments, Inc., Newington, $\mathrm{NH}$ ) to recirculate the bath water in the cooling tank for temperature control. The powder photocatalyst was added into the slurry photoreactor. 
A solution of $1 \mathrm{~N}$ sulfuric acid $\left(\mathrm{H}_{2} \mathrm{SO}_{4}\right)$ and a solution of $1 \mathrm{~N}$ sodium hydroxide $(\mathrm{NaOH})$ were used for $\mathrm{pH}$ adjustment. The photocatalytic activity of as-prepared photocatalysts was evaluated by the degradation rate of methyl orange calculated by Equation (8.1):

$$
\operatorname{TOC}_{\text {removal }}(\%)=\left(\text { TOC }_{0}-T O C / \text { TOC }_{0}\right) \times 100
$$

Where $\mathrm{TOC}_{0}$ and TOC are the initial and remaining concentrations of TOC, respectively.

The photocatalytic degradation of methyl orange was carried out in the presence of $\mathrm{N}-\mathrm{TiO}_{2}$ photocatalysts with different mass ratios of $\mathrm{N}$ to $\mathrm{TiO}_{2}\left(0.05-0.35 \mathrm{w}: \mathrm{w} \mathrm{N}: \mathrm{TiO}_{2}\right)$.

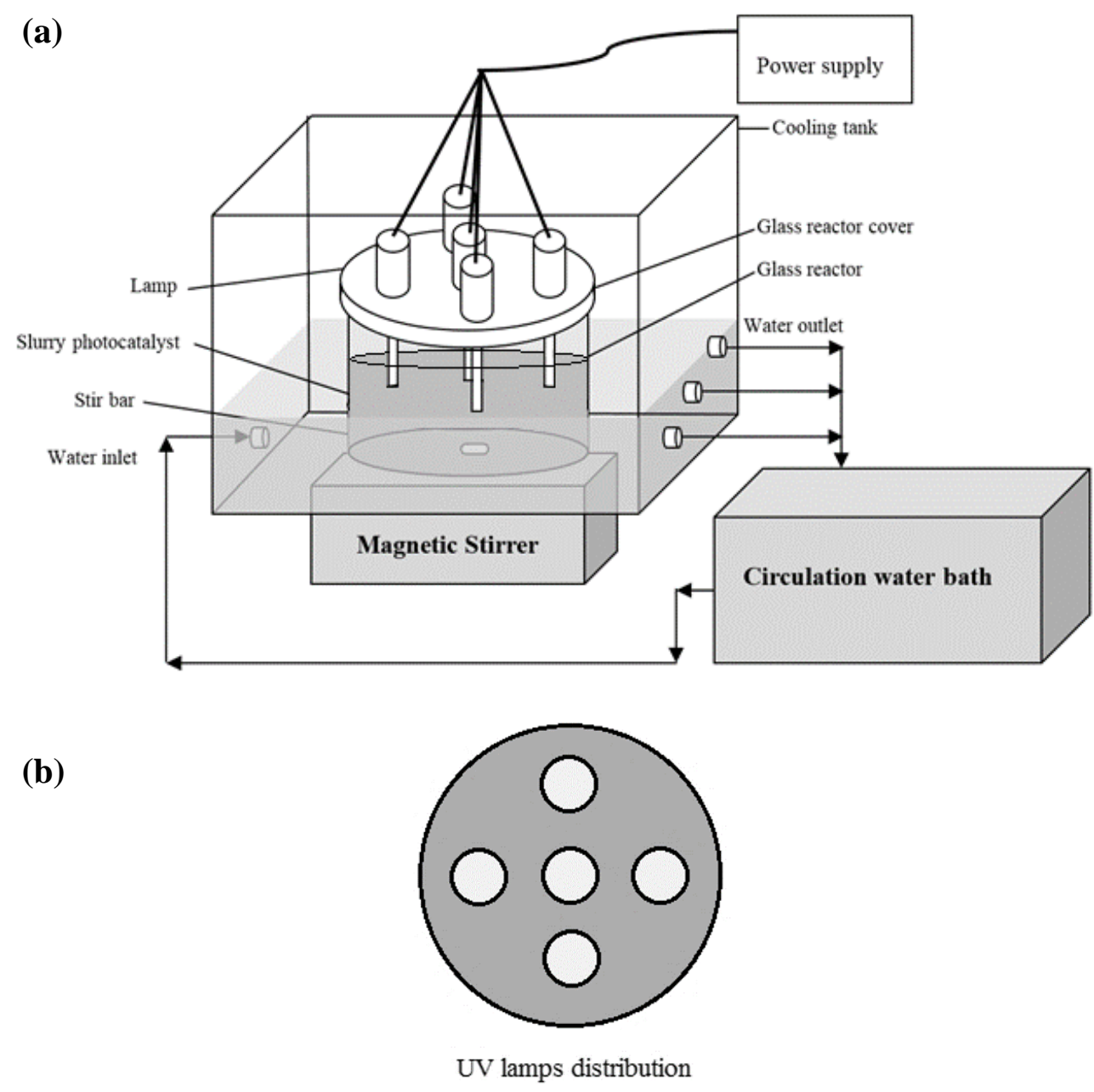

Figure 8.1. Schematic diagram of (a) the laboratory-scale batch suspension reactor and (b) the lid for UV lamps distribution.

Submitted to Mater. Res. Innov. (2017). 


\subsubsection{Statistical experimental design}

A four-factor BBD with RSM was used to maximize the percentage of the TOC and color removals. The light wavelength $\left(X_{1}\right)$, the initial concentration of TOC $\left(X_{2}\right)$, the light intensity in terms of irradiance by the number of lamps $\left(X_{3}\right)$, and the $\mathrm{pH}\left(X_{4}\right)$ were used as independent variables (i.e. predictors) while the TOC removal $\left(Y_{1}\right)$ and color removal $\left(Y_{2}\right)$ were considered as dependent variables (i.e. process responses) in the DOE. Accordingly, each studied predictor was coded at three levels (from -1 to +1 ), as shown in Table 8.1.

Table 8.1. Experimental design and independent variables based on RSM for the optimization of the photocatalytic activity of $\mathrm{N}$-doped $\mathrm{TiO}_{2}$ in the degradation of methyl orange.

Submitted to Mater. Res. Innov. (2017).

\begin{tabular}{lcccc}
\hline & & \multicolumn{3}{c}{ Range and levels } \\
\cline { 3 - 5 } \multicolumn{1}{c}{ Independent variables } & Symbol & $\mathbf{- 1}$ & $\mathbf{0}$ & $\mathbf{1}$ \\
\hline Light wavelength (nm) & $X_{1}$ & 254 & 365 & 476 \\
TOCo (mg/L) & $X_{2}$ & 10 & 30 & 50 \\
Light intensity (Number of lamps) & $X_{3}$ & 1 & 3 & 5 \\
pH & $X_{4}$ & 5 & 7 & 9 \\
\hline
\end{tabular}

A quadratic model was used to estimate the parametric coefficients of the statistical models by correlating both predictors and responses using the least-squares regression as shown in Equation (8.2) (Hamad et al., 2016; Bustillo-Lecompte and Mehrvar, 2016; Bustillo-Lecompte et al., 2016a, 2016b):

$Y_{i}=\beta_{o}+\sum_{i=1}^{k} \beta_{i} X_{i}+\sum_{i=1}^{k} \beta_{i i} X_{i}^{2}+\sum_{i=1}^{k-1} \sum_{j=2}^{k} \beta_{i j} X_{i} X_{j}+c$

where $\beta_{o}, \beta_{i}, \beta_{i i}$, and $\beta_{i j}$, are the constant, linear, quadratic, and cross-factor interaction coefficients, respectively; whereas $X_{i}$ and $X_{j}$ represent the predictors, $Y_{i}$ is the response under evaluation, and $k$ and $c$ are the number of predictors of the model and the residual term, respectively.

The statistical software Design-Expert 10.0.3.1 was employed for the DOE as well as the estimation of the coefficients for each response. The significance of each model equation, 
individual parameters, and factor interactions was evaluated via analysis of variance (ANOVA) at the confidence interval of $95 \%(\alpha=0.05)$. Two-dimensional (2D) contour plots and threedimensional (3D) surface responses were obtained with the quadratic models. Additional experimental runs were conducted to validate the quadratic models for the maximum removals of TOC and color at the optimum operating conditions, calculated by the software numerical optimization method.

On the other hand, the desirability multiple-response approach was utilized to obtain a concurrent objective function to represent all transformed responses by combining the desired ranges for each response as shown in Equation (8.3) (Myers et al., 2004; Bustillo-Lecompte et al., 2016; Bustillo-Lecompte and Mehrvar, 2016):

$D=\left(Y_{1} \times Y_{2} \times \ldots \times d_{n}\right)^{1 / n}=\left(\prod_{i=1}^{n} Y_{i}\right)^{1 / n}$

In this equation, $D, Y_{i}$, and $n$ are the desirability term, each evaluated response, and the total number of process responses, respectively. For a simultaneous optimization, each response function requires low and high values for the optimization. Otherwise, if any response is found outside of the desirability range, the global desirability becomes equal to zero. In this case, two responses are being optimized: the percent TOC removal $\left(Y_{1}\right)$ and the color removal $\left(Y_{2}\right)$.

\subsection{Results and Discussion}

\subsubsection{Preliminary studies}

Figure 8.2 illustrates the degradation of methyl orange in the presence of as-synthesized $\mathrm{N}-\mathrm{TiO}_{2}$ with different mass ratios of nitrogen doped onto $\mathrm{TiO}_{2}$ at 180 min of $\mathrm{UV}-\mathrm{A}$ irradiation. Results showed the degradation of methyl orange in the presence of $\mathrm{N}-\mathrm{TiO}_{2}$ improved when the mass ratio of nitrogen in $\mathrm{N}-\mathrm{TiO}_{2}$ increased to $0.15 \mathrm{w}: \mathrm{w} \mathrm{N}-\mathrm{TiO}_{2}$ and efficiency reached to $40.9 \%$. 
It is concluded that at high concentrations of nitrogen after the optimal value, the surface of $\mathrm{TiO}_{2}$ photocatalyst is shielded by nitrogen and there is not enough surface for the photocatalyst to absorb light to generate electron and hole for degradation of organics.

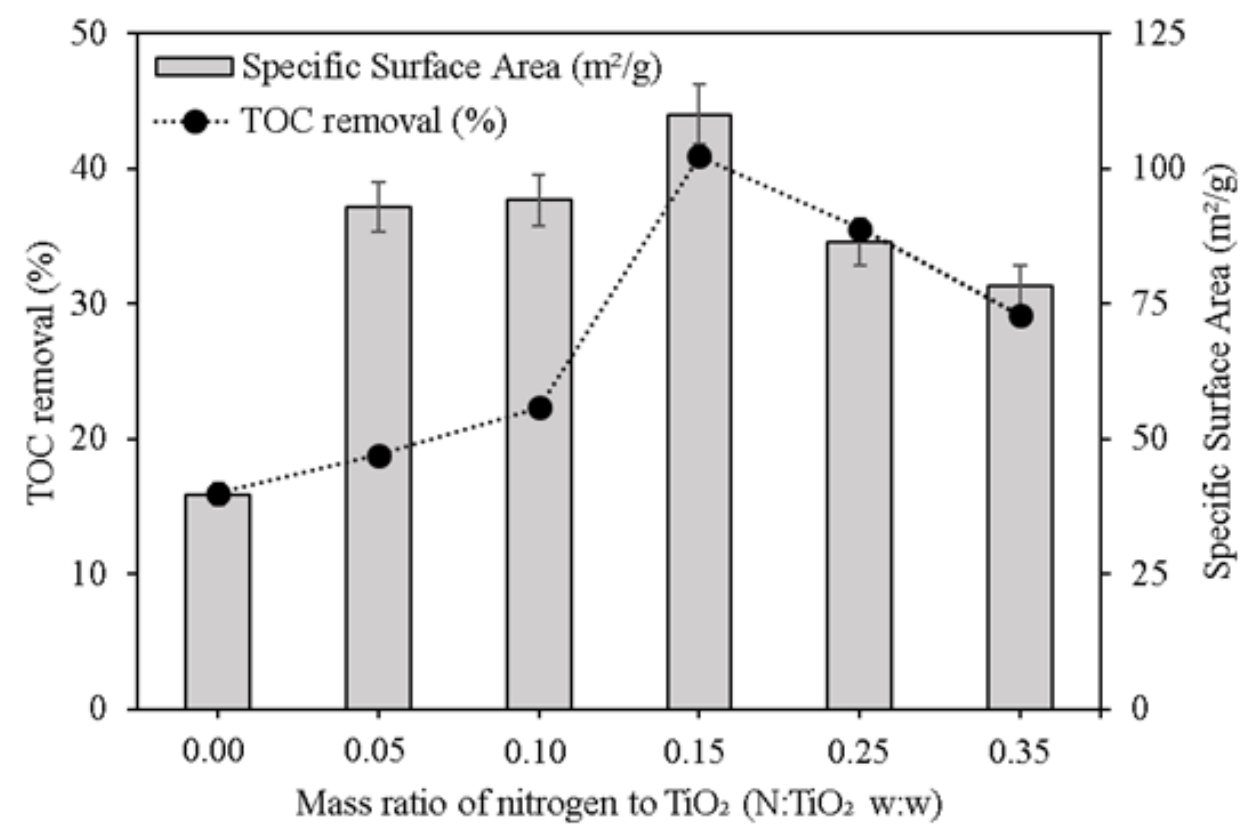

Figure 8.2. Degradation of methyl orange in the presence of the synthesized N-TiO photocatalyst $(500 \mathrm{mg} / \mathrm{L})$ with different mass ratios of nitrogen at $180 \mathrm{~min}$ of $\mathrm{UV}$-A irradiation time, and comparison with the specific surface area of photocatalysts.

Submitted to Mater. Res. Innov. (2017).

A similar trend was observed in the specific surface area of $\mathrm{N}-\mathrm{TiO}_{2}$ photocatalyst. When nitrogen is doped onto the $\mathrm{TiO}_{2}$ photocatalyst, there are two possibilities, interstitial and substitutional doping (Nasirian and Mehrvar, 2016). In the interstitial doping, the dopant is not incorporated into the crystal lattice and resides between the crystal on an interstitial site, which might introduce states in the band gap, but generally, it does not dope n-type or p-type semiconductors (Lynch et al., 2015).

On the other hand, substitutional doping causes a crystal defect and decreases the band gap energy. In other words, when a non-metal species, such as nitrogen that has a slightly higher energy 
level than oxygen, is introduced into the $\mathrm{TiO}_{2}$ lattice, a new mid-gap energy state is generated. This substitution holds the potential of absorbing energy from a radiation of light with higher wavelengths to produce a significant amount of HO· (Shi et al., 2012; Xu et al., 2014; Lynch et al., 2015). Thus, the UV radiation excites the electrons in both the valence band and the mid-gap energy level; whereas, visible light can only excite the electrons in the mid-gap energy level (Zaleska, 2008; Xu et al., 2014; Lynch et al., 2015; Nikhil et al., 2015).

Specific surface area of photocatalysts with different mass ratios of doped nitrogen were measured by BET technique using adsorption of nitrogen gas at $77 \mathrm{~K}$. Results showed that the N$\mathrm{TiO}_{2}$ photocatalyst with a mass ratio of $0.15 \mathrm{w}: \mathrm{w} \mathrm{N}: \mathrm{TiO}_{2}$ had the highest specific surface area of $110.01 \mathrm{~m}^{2} / \mathrm{g}$ compared to that of bare $\mathrm{P} 25,39.77 \mathrm{~m}^{2} / \mathrm{g}$, and bare urea, $34.36 \mathrm{~m}^{2} / \mathrm{g}$.

By increasing the concentration of doped nitrogen in $\mathrm{N}-\mathrm{TiO}_{2}$ above its optimal value, its specific surface area was decreased. Therefore, the $\mathrm{N}-\mathrm{TiO}_{2}$ photocatalyst with a $\mathrm{N}: \mathrm{TiO}_{2}$ mass ratio of $0.15 \mathrm{w}: \mathrm{w} \mathrm{N}-\mathrm{TiO}_{2}$ was chosen for the statistical experimental design.

\subsubsection{Photocatalyst characterization}

Figure 8.3a illustrates a SEM image of the $\mathrm{N}-\mathrm{TiO}_{2} 0.15 \mathrm{w}: \mathrm{w} \mathrm{N}-\mathrm{TiO}_{2}$ photocatalyst, prepared by the annealing method. In this figure, particles have a heterogeneous flat shape variable particle size in the range of $1-10 \mu \mathrm{m}$ based on the scale. Particles contain several bright and dark nanoparticles, which are supposed to contain more pores on the surface.

In the EDS elemental analysis of $\mathrm{N}-\mathrm{TiO}_{2}$ photocatalyst, nitrogen and oxygen peaks are overlapped; therefore, the elemental analysis of $\mathrm{N}-\mathrm{TiO}_{2}$ is not conclusive. This circumstance is caused by the resemblances between nitrogen and oxygen, which present similar characteristic in EDS; thus, the instrument is not able to properly separate their elemental peaks. 

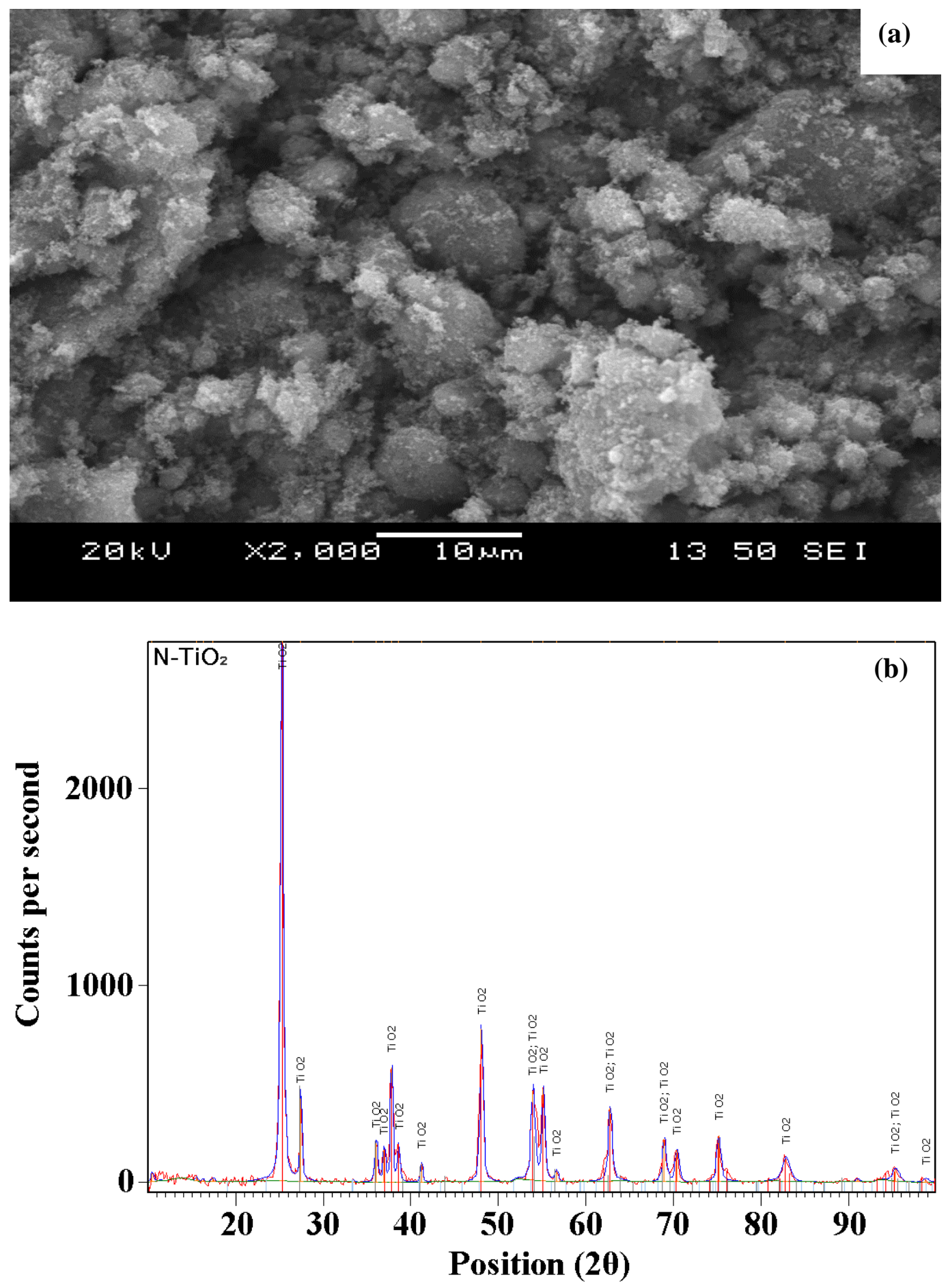

Figure 8.3. (a) SEM image of the as-prepared $\mathrm{N}-\mathrm{TiO}_{2}$ photocatalyst $\left.(0.15 \mathrm{w} \text { : w } \mathrm{N}-\mathrm{TiO})_{2}\right)$ by the annealing method and (b) Diffractogram of the as prepared $\mathrm{N}-\mathrm{TiO}_{2}$ photocatalyst taken by XRD.

Submitted to Mater. Res. Innov. (2017). 
Consequently, XRD and mapping of the $\mathrm{N}-\mathrm{TiO}_{2}$ photocatalyst were instead used to illustrate the distribution and relative proportion of the compounds and elements over the scanned area, respectively.

Figure $8.3 \mathrm{~b}$ shows an XRD diffractogram of the $\mathrm{N}$-doped $\mathrm{TiO}_{2}$ photocatalyst $(0.15 \mathrm{w}: \mathrm{w} \mathrm{N}$ $\mathrm{TiO}_{2}$ ) prepared using annealing method. The diffractogram indicates the presence of only the anatase form, including small crystal size particles, and there was no rutile peak.

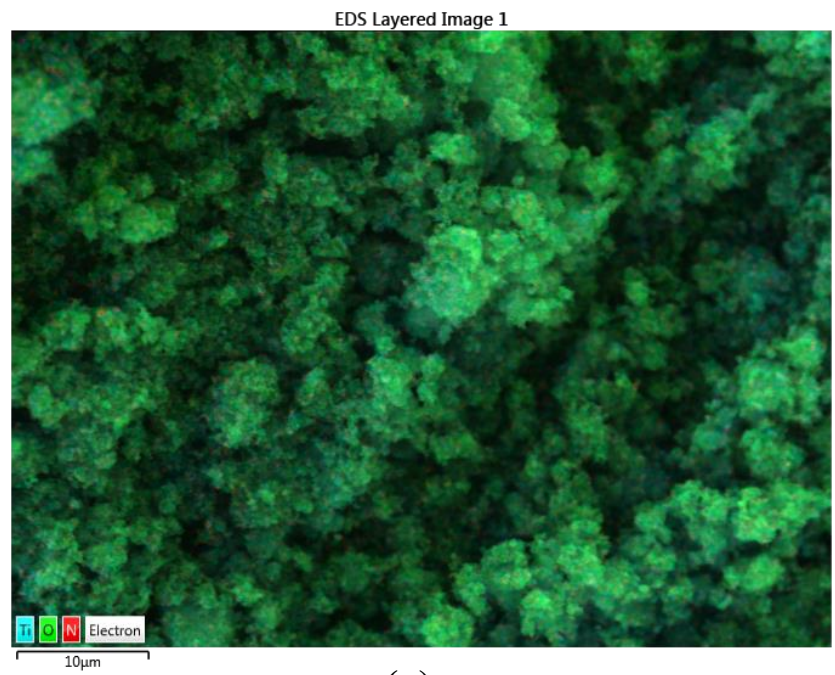

(a)

$\mathrm{Ti} K \alpha 1$

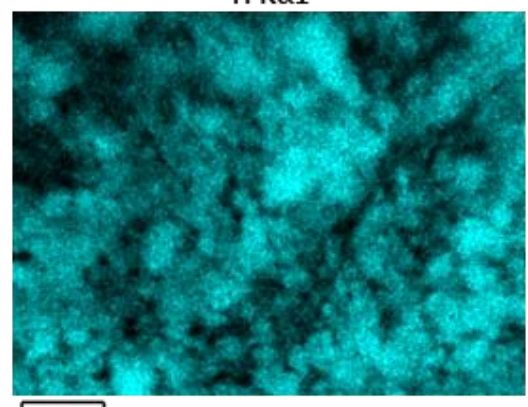

(b)

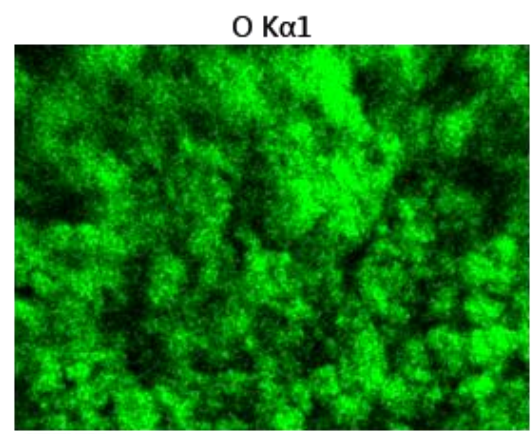

(c)

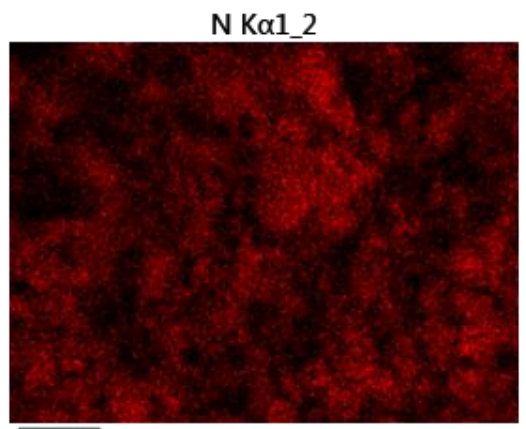

(d)

Figure 8.4. Mapping images of (a) $\mathrm{N}-\mathrm{TiO}_{2}\left(0.15 \mathrm{w}\right.$ :w $\left.\mathrm{N}-\mathrm{TiO}_{2}\right)$ photocatalyst and the elemental distribution of (b) titanium, (c) oxygen, and (d) nitrogen in the photocatalyst prepared by annealing method.

Submitted to Mater. Res. Innov. (2017). 
The anatase phase was confirmed by comparing the attained diffractograms with the standard, which present the location of the $\mathrm{TiO}_{2}$ peaks, based on the Joint Committee on Powder Diffraction Standards (JCPDS-21-1272) databank (Dai et al., 2010).

Figure 8.4 comprises four mapping images of the $\mathrm{N}$-doped $\mathrm{TiO}_{2} 0.15 \mathrm{w}$ :w $\mathrm{N}-\mathrm{TiO}_{2}$ photocatalyst prepared by annealing technique. Figure $8.4 \mathrm{a}$ illustrates the whole sample of $\mathrm{N}-\mathrm{TiO}_{2}$ while Figures $8.4 \mathrm{~b}$, c, and d show images of the titanium, oxygen, and nitrogen elements ejected from $\mathrm{K} \alpha$ (the most intensive peak) shells of each atom in the photocatalyst, respectively. The mapping image confirmed that the $\mathrm{N}$-doped $\mathrm{TiO}_{2}$ photocatalyst comprises nitrogen as a dopant in the structure of the $\mathrm{N}-\mathrm{TiO}_{2}$ composite.

\subsubsection{Statistical analysis and optimization studies}

Table 8.2 presents the four-factor BBD with experimental and predicted values for both the percent TOC and color removals by the developed quadratic statistical models for the degradation of methyl orange by photocatalysis using the $\mathrm{N}-\mathrm{TiO}_{2}$ photocatalyst $\left(0.15 \mathrm{w}: \mathrm{w} \mathrm{N}-\mathrm{TiO}_{2}\right)$ in a laboratory-scale slurry batch photoreactor. The RSM was used to indicate the relationship between the predictors and the process responses. Hence, to predict the response functions for both the TOC removal $\left(Y_{1}\right)$ and the color removal $\left(Y_{2}\right)$, Equations (8.4) and (8.5) were developed in terms of the coded factors, respectively:

$$
\begin{aligned}
& Y_{1}=57.02-11.62 X_{1}-18.87 X_{2}+3.49 X_{3}-3.74 X_{4}-15.11 X_{1} X_{2}-0.01 X_{1} X_{3}-0.99 X_{1} X_{4} \\
& -12.56 X_{2} X_{3}+6.49 X_{2} X_{4}-5.86 X_{3} X_{4}+1.75 X_{1}{ }^{2}-0.33 X_{2}{ }^{2}-4.44 X_{3}{ }^{2}-8.48 X_{4}{ }^{2} \\
& Y_{2}=40.62-7.10 X_{1}-16.01 X_{2}+9.97 X_{3}-4.46 X_{4}+16.25 X_{1} X_{2}-5.68 X_{1} X_{3}+3.25 X_{1} X_{4} \\
& -9.14 X_{2} X_{3}+4.54 X_{2} X_{4}-9.29 X_{3} X_{4}+0.28 X_{1}{ }^{2}+4.96 X_{2}{ }^{2}+9.22 X_{3}{ }^{2}+1.20 X_{4}{ }^{2}
\end{aligned}
$$


The evaluation of the coefficient signs offers a quick scrutiny of the parametrical effects of the model variables on the responses. Negative coefficients point out unfavorable effects on both the percent TOC and color removals for the model components $X_{1}, X_{2}, X_{4}, X_{1} X_{2}, X_{1} X_{3}, X_{1} X_{4}, X_{2} X_{3}$, $X_{3} X_{4}, X_{2}^{2}, X_{3}^{2}$, and $X_{4}^{2}$ in $Y_{1}$ and $X_{1}, X_{2}, X_{4}, X_{1} X_{3}, X_{2} X_{3}$, and $X_{3} X_{4}$ in $Y_{2}$. Positive coefficients refer to favorable effects on both the percent TOC and color removals for the model components $X_{3}$, $X_{2} X_{4}$, and $X_{1}^{2}$ in $Y_{1}$ and $X_{3}, X_{1} X_{2}, X_{1} X_{4}, X_{2} X_{4}, X_{1}^{2}, X_{2}^{2}, X_{3}^{2}$, and $X_{4}^{2}$ in $Y_{2}$. Factors with coefficient values close to zero indicate a lower relative intensity than those above. Thus, $X_{1} X_{3}, X_{1} X_{4}, X_{1}^{2}$, and $X_{2}^{2}$ do not strongly affect the percent TOC removal while $X_{1}^{2}$ and $X_{4}^{2}$ do not intensely affect the percent color removal.

The statistical significance of the developed models and predictors was further evaluated using the ANOVA with 95\% confidence intervals for the percent TOC and color removals as shown in Tables 8.3 and 8.4, respectively. The statistical significance of each factor coefficient was determined by the Fisher's $(F)$ exact test, using probability $(p)$ values.

As shown in Tables 8.3 and 8.4, the $F$-values 202.96 and 41.13 for the developed models related to percent TOC and color removals, respectively, indicate the significance of the models. Moreover, low probability values $(p<0.05)$ imply the significance of the model variables while confirming the model accuracy.

On the other hand, $p$-values higher than 0.10 imply the model variables are not significant. In this study, $X_{1} X_{3}, X_{1} X_{4}$, and $X_{2}^{2}$ are not significant for the removal of TOC while $X_{1} X_{4}, X_{1}^{2}$, and $X_{4}^{2}$ are not significant for color removal. The goodness of fit for each model was validated using both the determination coefficient $\left(R^{2}\right)$ and the adjusted $R^{2}$ to ensure a suitable variation of the model predictions to the observed values. 
Table 8.2. Four-factor BBD for RSM, along with the observed and predicted percent TOC and color removals in the optimization of the photocatalytic activity of $\mathrm{N}$-doped $\mathrm{TiO}_{2}$ for the degradation of an azo dye.

Submitted to Mater. Res. Innov. (2017).

\begin{tabular}{|c|c|c|c|c|c|c|c|c|}
\hline \multirow[b]{2}{*}{ Run } & \multicolumn{4}{|c|}{ Independent coded variables } & \multicolumn{2}{|c|}{ TOC removal $(\%)$} & \multicolumn{2}{|c|}{ Color removal (\%) } \\
\hline & $X_{1}$ & $X_{2}$ & $X_{3}$ & $X_{4}$ & Observed & Predicted & Observed & Predicted \\
\hline 1 & -1 & -1 & 0 & 0 & 72.64 & 73.82 & 84.50 & 85.21 \\
\hline 2 & 1 & -1 & 0 & 0 & 81.86 & 80.81 & 37.85 & 38.53 \\
\hline 3 & -1 & 1 & 0 & 0 & 65.81 & 66.30 & 21.31 & 20.70 \\
\hline 4 & 1 & 1 & 0 & 0 & 14.59 & 12.85 & 39.65 & 39.00 \\
\hline 5 & 0 & 0 & -1 & -1 & 38.91 & 38.49 & 39.04 & 36.24 \\
\hline 6 & 0 & 0 & 1 & -1 & 58.28 & 57.19 & 73.84 & 74.76 \\
\hline 7 & 0 & 0 & -1 & 1 & 42.20 & 42.73 & 46.75 & 45.89 \\
\hline 8 & 0 & 0 & 1 & 1 & 38.14 & 38.00 & 44.40 & 47.27 \\
\hline 9 & -1 & 0 & 0 & -1 & 64.77 & 64.66 & 53.46 & 56.90 \\
\hline 10 & 1 & 0 & 0 & -1 & 42.70 & 43.41 & 38.57 & 36.21 \\
\hline 11 & -1 & 0 & 0 & 1 & 59.56 & 59.16 & 38.71 & 41.48 \\
\hline 12 & 1 & 0 & 0 & 1 & 33.53 & 33.95 & 36.82 & 33.79 \\
\hline 13 & 0 & -1 & -1 & 0 & 54.08 & 55.07 & 49.33 & 51.70 \\
\hline 14 & 0 & 1 & -1 & 0 & 42.35 & 42.45 & 37.98 & 37.95 \\
\hline 15 & 0 & -1 & 1 & 0 & 86.97 & 87.18 & 89.48 & 89.92 \\
\hline 16 & 0 & 1 & 1 & 0 & 24.99 & 24.31 & 41.58 & 39.63 \\
\hline 17 & -1 & 0 & -1 & 0 & 63.75 & 62.44 & 43.81 & 41.55 \\
\hline 18 & 1 & 0 & -1 & 0 & 39.12 & 39.23 & 35.15 & 38.73 \\
\hline 19 & -1 & 0 & 1 & 0 & 69.31 & 69.45 & 76.92 & 72.86 \\
\hline 20 & 1 & 0 & 1 & 0 & 44.63 & 46.19 & 45.53 & 47.31 \\
\hline 21 & 0 & -1 & 0 & -1 & 77.65 & 77.31 & 73.26 & 71.80 \\
\hline 22 & 0 & 1 & 0 & -1 & 25.36 & 26.60 & 28.44 & 30.70 \\
\hline 23 & 0 & -1 & 0 & 1 & 57.85 & 56.86 & 56.53 & 53.79 \\
\hline 24 & 0 & 1 & 0 & 1 & 31.50 & 32.09 & 29.87 & 30.85 \\
\hline 25 & 0 & 0 & 0 & 0 & 57.79 & 57.02 & 40.27 & 40.62 \\
\hline 26 & 0 & 0 & 0 & 0 & 54.18 & 57.02 & 46.80 & 40.62 \\
\hline 27 & 0 & 0 & 0 & 0 & 54.12 & 57.02 & 43.60 & 40.62 \\
\hline 28 & 0 & 0 & 0 & 0 & 58.98 & 57.02 & 37.35 & 40.62 \\
\hline 29 & 0 & 0 & 0 & 0 & 57.18 & 57.02 & 40.43 & 40.62 \\
\hline 30 & 0 & 0 & 0 & 0 & 59.87 & 57.02 & 35.27 & 40.62 \\
\hline
\end{tabular}


Table 8.3. ANOVA of percent TOC removal by quadratic modeling in the optimization of the photocatalytic activity of $\mathrm{N}$-doped $\mathrm{TiO}_{2}\left(0.15 \mathrm{w}\right.$ : $\mathrm{w}$ - $\left.-\mathrm{TiO}_{2}\right)$ for the degradation of an azo dye.

Submitted to Mater. Res. Innov. (2017).

\begin{tabular}{|c|c|c|c|c|c|c|}
\hline Source & Sum of squares & $d f^{a}$ & Mean square & $F$ value $^{b}$ & $p$-value ${ }^{\text {c }}$ & Remark \\
\hline TOC Model & 8713.4 & 14 & 622.39 & 202.96 & $<0.0001$ & Significant \\
\hline$X_{I}=$ Light Wavelength & 1619.6 & 1 & 1619.6 & 528.14 & $<0.0001$ & Significant \\
\hline$X_{2}=$ TOCo & 4273.3 & 1 & 4273.3 & 1393.5 & $<0.0001$ & Significant \\
\hline$X_{3}=$ Light Intensity & 146.37 & 1 & 146.37 & 47.731 & $<0.0001$ & Significant \\
\hline$X_{4}=p H$ & 167.93 & 1 & 167.93 & 54.760 & $<0.0001$ & Significant \\
\hline$X_{1} X_{2}$ & 913.25 & 1 & 913.25 & 297.81 & $<0.0001$ & Significant \\
\hline$X_{1} X_{3}$ & 0.0006 & 1 & 0.0006 & 0.0002 & 0.9888 & Not significant \\
\hline$X_{1} X_{4}$ & 3.9204 & 1 & 3.9204 & 1.2784 & 0.2759 & Not significant \\
\hline$X_{2} X_{3}$ & 631.27 & 1 & 631.27 & 205.85 & $<0.0001$ & Significant \\
\hline$X_{2} X_{4}$ & 168.22 & 1 & 168.22 & 54.856 & $<0.0001$ & Significant \\
\hline$X_{3} X_{4}$ & 137.24 & 1 & 137.24 & 44.754 & $<0.0001$ & Significant \\
\hline$X_{I}^{2}$ & 21.020 & 1 & 21.020 & 6.8546 & 0.0194 & Significant \\
\hline$X_{2}^{2}$ & 0.7317 & 1 & 0.7317 & 0.2386 & 0.6323 & Not significant \\
\hline$X_{3}^{2}$ & 135.28 & 1 & 135.28 & 44.115 & $<0.0001$ & Significant \\
\hline$X_{4}^{2}$ & 492.71 & 1 & 492.71 & 160.67 & $<0.0001$ & Significant \\
\hline Residual & 45.999 & 15 & 3.0666 & & & \\
\hline Lack of Fit & 16.940 & 10 & 1.6940 & 0.2915 & 0.9540 & Not significant \\
\hline Pure error & 29.058 & 5 & 5.8116 & & & \\
\hline Corrected total SS & 8759.4 & 29 & & & & \\
\hline$R^{2}$ & 0.9947 & & & & & \\
\hline Adjusted $R^{2}$ & 0.9898 & & & & & \\
\hline Adequate Precision & 60.029 & & & & & \\
\hline
\end{tabular}

The values of $R^{2}$ and adjusted $R^{2}$ reached 0.9947 and 0.9898 for the TOC removal and 0.9746 and 0.9509 for the color removal, respectively. Thus, high $R^{2}$ and adjusted $R^{2}$ values represent that the model is highly significant. The closer the values of $R^{2}$ and adjusted $R^{2}$ are to 1.0, the better the model prediction is (Botha et al., 2012; Bustillo-Lecompte et al., 2016a).

Furthermore, the adequate precision of both the percent TOC and color removal models were found to be 60.03 (Table 8.3) and 26.61 (Table 8.4), respectively; thus, the models can be used to navigate the BBD design space (Bustillo-Lecompte et al., 2016a). 
Table 8.4. ANOVA of percent color removal by quadratic modeling in the optimization of the photocatalytic activity of $\mathrm{N}$-doped $\mathrm{TiO}_{2}(0.15 \mathrm{w}$ : $\mathrm{N}$-TiO 2$)$ for the degradation of an azo dye.

Submitted to Mater. Res. Innov. (2017).

\begin{tabular}{|c|c|c|c|c|c|c|}
\hline Source & Sum of squares & $d f^{u}$ & Mean square & $F$ value $^{b}$ & $p$-value ${ }^{\mathrm{c}}$ & Remark \\
\hline Color Model & 7794.0 & 14 & 556.72 & 41.13 & $<0.0001$ & Significant \\
\hline$X_{I}=$ Light Wavelength & 604.07 & 1 & 604.07 & 44.63 & $<0.0001$ & Significant \\
\hline$X_{2}=T O C o$ & 3075.8 & 1 & 3075.8 & 227.2 & $<0.0001$ & Significant \\
\hline$X_{3}=$ Light Intensity & 1193.8 & 1 & 1193.8 & 88.201 & $<0.0001$ & Significant \\
\hline$X_{4}=p H$ & 238.79 & 1 & 238.79 & 17.642 & 0.0008 & Significant \\
\hline$X_{1} X_{2}$ & 1055.9 & 1 & 1055.9 & 78.01 & $<0.0001$ & Significant \\
\hline$X_{1} X_{3}$ & 129.16 & 1 & 129.16 & 9.5428 & 0.0075 & Significant \\
\hline$X_{1} X_{4}$ & 42.250 & 1 & 42.250 & 3.1215 & 0.0976 & Not significant \\
\hline$X_{2} X_{3}$ & 333.98 & 1 & 333.98 & 24.67 & 0.0002 & Significant \\
\hline$X_{2} X_{4}$ & 82.446 & 1 & 82.446 & 6.091 & 0.0261 & Significant \\
\hline$X_{3} X_{4}$ & 345.03 & 1 & 345.03 & 25.492 & 0.0001 & Significant \\
\hline$X_{I}^{2}$ & 0.5217 & 1 & 0.5217 & 0.0385 & 0.8470 & Not significant \\
\hline$X_{2}^{2}$ & 168.92 & 1 & 168.92 & 12.4804 & 0.0030 & Significant \\
\hline$X_{3}^{2}$ & 582.55 & 1 & 582.55 & 43.040 & $<0.0001$ & Significant \\
\hline$X_{4}^{2}$ & 9.9086 & 1 & 9.9086 & 0.73 & 0.4057 & Not significant \\
\hline Residual & 203.03 & 15 & 13.535 & & & \\
\hline Lack of Fit & 116.48 & 10 & 11.648 & 0.6729 & 0.7227 & Not significant \\
\hline Pure error & 86.547 & 5 & 17.309 & & & \\
\hline Corrected total SS & 7997.1 & 29 & & & & \\
\hline$R^{2}$ & 0.9746 & & & & & \\
\hline Adjusted $R^{2}$ & 0.9509 & & & & & \\
\hline Adequate Precision & 26.610 & & & & & \\
\hline
\end{tabular}

The lack of fit approach was also considered to measure how well the developed models fit the observed values. Accordingly, the $p$-values of the lack of fit for the TOC and color removal models were 0.9540 (Table 8.3) and 0.7227 (Table 8.4), respectively. An insignificant lack of fit $(p>0.10)$ is a desirable property because it suggests the models fit the data well.

The continuous variance assumption was confirmed graphically using the plot of predicted values versus the internally studentized residuals (Figure $8.5 \mathrm{a}$ ), where the studentized residual values were obtained by dividing the residual values by their respective standard deviation. Figure 8.5a also show randomly scattered points between the outlier detection limits from -3 to +3 . 
Additionally, the observed and predicted value correlations for both the percent TOC and color removals are presented in Figure 8.5b. A straight-line trend shows minor discrepancies and an agreement between predicted and experimental values. Therefore, the model predictions for both TOC removal, Equation (8.4), and color removal, Equation (8.5), are satisfactory.

(a)
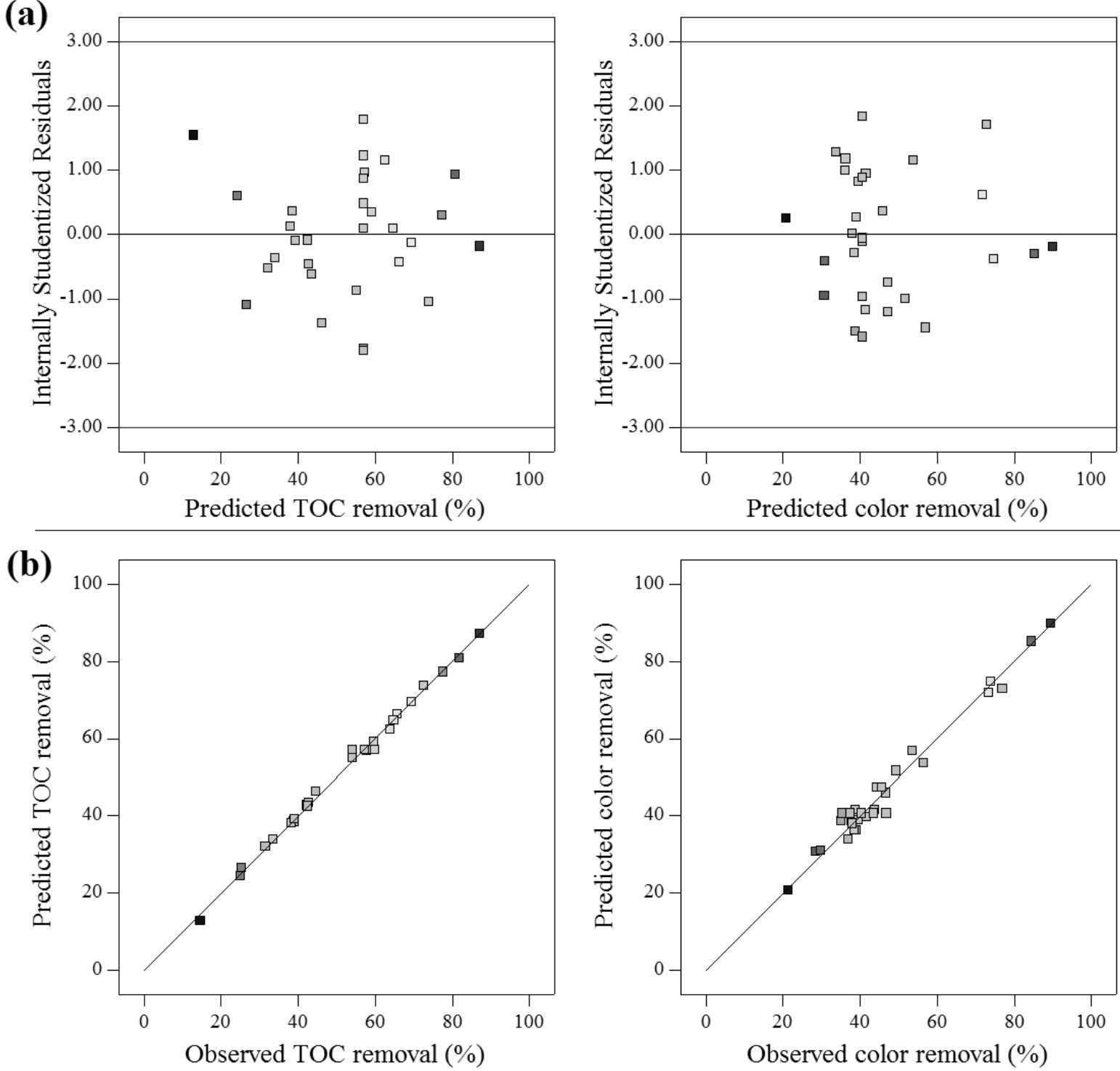

Figure 8.5. Validation of the percent TOC removal (left side) and color removal (right side) models using different plots: (a) internally studentized residuals versus predicted values and (b) observed experimental data versus predicted values.

Submitted to Mater. Res. Innov. (2017). 


\subsubsection{Individual effect of model parameters}

Since the significance of the TOC removal and color removal models (Tables 8.3 and 8.4, respectively) and the accuracy of the model predictions (Figure 8.5) were confirmed, it was required to examine the significance of the model factors. This evaluation was performed using both the $F$-exact test and $p$-values, similar to the model significance evaluation, for each variable including linear, cross-factor, and quadratic interaction.

As presented in Tables 8.3 and 8.4, model coefficients with $p$-values lower than 0.05 are significant. Therefore, all four predictors, the light wavelength $\left(X_{1}\right)$, the initial TOC concentration $\left(X_{2}\right)$, the light intensity in terms of the number of lamps $\left(X_{3}\right)$, and the $\mathrm{pH}\left(X_{4}\right)$, have significant effects on both responses, the TOC removal $\left(Y_{1}\right)$ and the color removal $\left(Y_{2}\right)$, based on their $p$-value.

Figure 8.6 illustrates the individual effect of the light wavelength, initial TOC concentration, light intensity, and $\mathrm{pH}$ on the percent TOC and color removals. It can be observed that both the light wavelength and the initial TOC concentration as they increase, both the percent TOC and color removals decrease. In the case of the light intensity, as the number of lamps increases, both the TOC and color removals rise to a point where there is no further increase in efficiency regardless of the number of lamps.

Conversely, results indicate an inversely proportional relationship of the light wavelength and initial TOC concentration with both the percent TOC and color removals. Therefore, the efficiency increases when the light spectrum is closest to the UV-C range with the peak at $254 \mathrm{~nm}$ and at the lowest initial concentration of TOC. Finally, no $\mathrm{pH}$ adjustments are required to achieve maximum TOC and color removal efficiencies. 

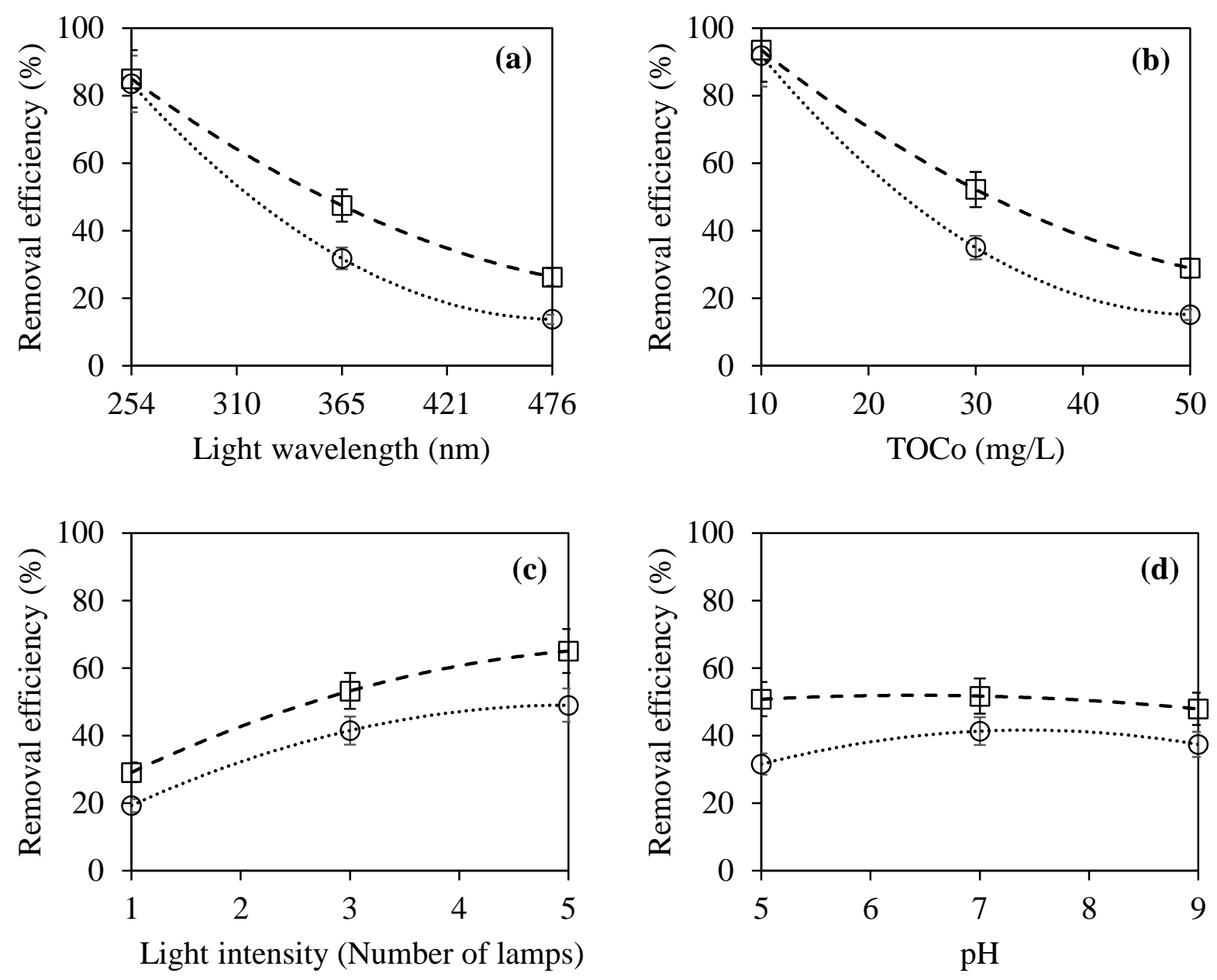

Figure 8.6. Individual effect of the (a) light wavelength; (b) initial TOC concentration; (c) light intensity; and (d) $\mathrm{pH}$ on the percent TOC removal and color removal using $0.15 \mathrm{w}$ : $\mathrm{w}$ $\mathrm{N}_{-T i O}$. The dashed lines represent the model TOC removal, whereas the marker points represent the model color removal. Error bars represent the standard deviation of the experimental data.

Submitted to Mater. Res. Innov. (2017).

\subsubsection{Interaction of model parameters, $2 D$ contour plots, and $3 D$ response surface}

As shown in Tables 8.3 and 8.4, among all model parameters only the interaction between the light wavelength and $\mathrm{pH}\left(X_{1} X_{4}\right)$ did not indicate a significant effect on both the percent TOC and color removals. Additionally, the interaction between the light wavelength and the light intensity $\left(X_{1} X_{3}\right)$ did not show a significant effect on the percent TOC removal while being 
significant on the color removal. In contrast, the cross-factor interaction between the light wavelength and the initial TOC concentration $\left(X_{1} X_{2}\right)$ and those of the light intensity with the initial TOC concentration $\left(X_{2} X_{3}\right)$ and the $\mathrm{pH}\left(X_{3} X_{4}\right)$ were found to have a high significant effect on both TOC and color removals. Thus, it can be stated that there is space for optimization in terms of an adequate number and type of lamps, and the organics concentration of pollutants (regardless of the components and $\mathrm{pH}$ ) in the photocatalytic treatment of azo dyes to minimize treatment-related costs, especially for activation under visible light.

The cross-factor interaction effects between independent factors were plotted into the 3D surfaces and 2D contour plots shown in Figures 8.7 and 8.8 for the removal of TOC and color, respectively, representing the graphical regression analysis; thus, the response functions of the variation and interaction of two predictors are presented while all other factors are fixed at the center levels (Hamad et al., 2016; Bustillo-Lecompte and Mehrvar, 2016; Bustillo-Lecompte et al., 2016a, 2016b).

Figures 8.7 and $8.8(a, b, c)$ depict the effects of the light wavelength on the percent TOC and color removals. Results show that by decreasing the wavelength, both the percent TOC and color removal increase.

In all cases, the light intensity and initial TOC concentration cross-factor interactions with the light wavelength are intensified when the latter is at the lowest range value while $\mathrm{pH}$ does not require adjustments (Figures $8.7 \mathrm{c}$ and $8.8 \mathrm{c}$ ). The interaction of the initial TOC concentration with other independent variables tends to intensify their effect at low concentrations as confirmed in Figures 8.7 and $8.8(\mathrm{a}, \mathrm{d}, \mathrm{e})$ as expected. 
(a)

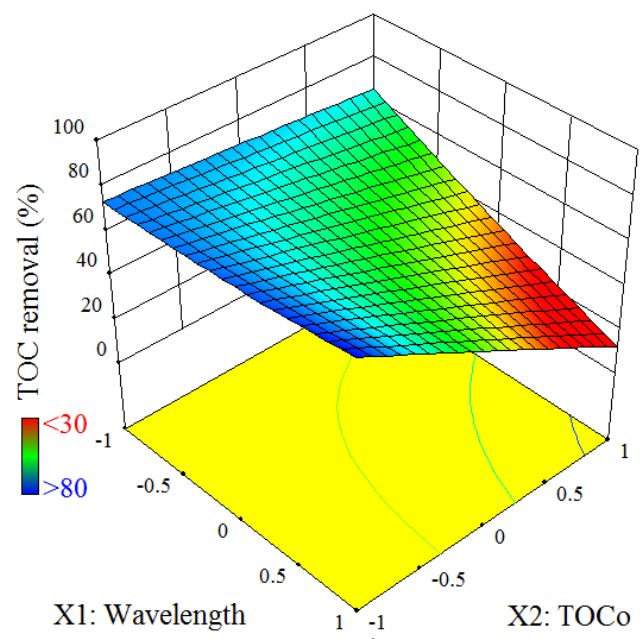

(c)

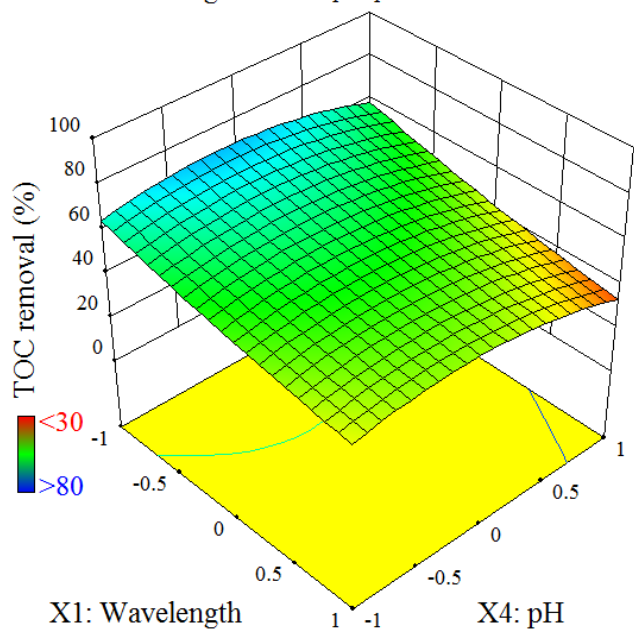

(e)

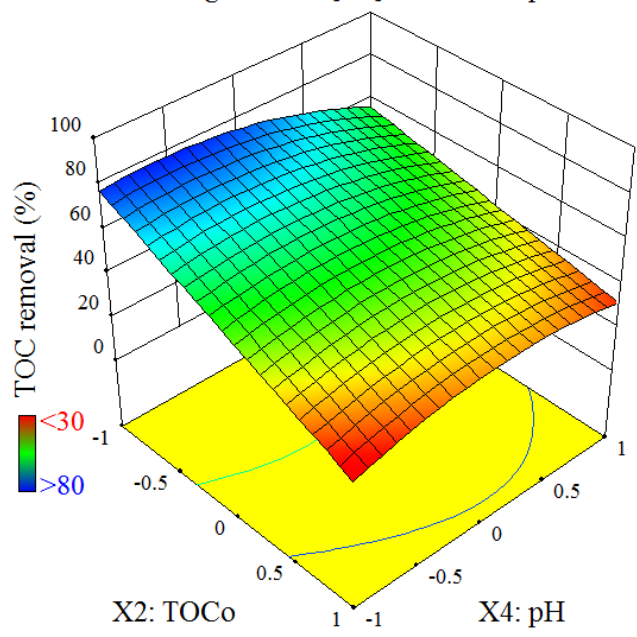

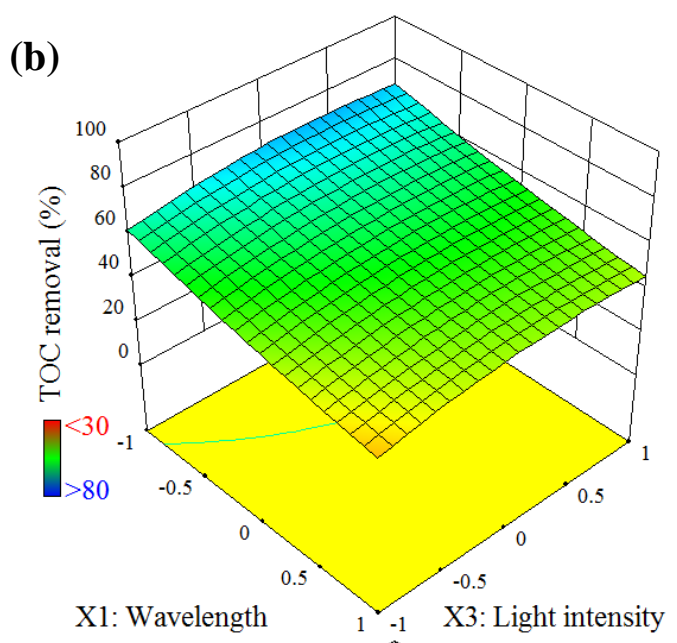
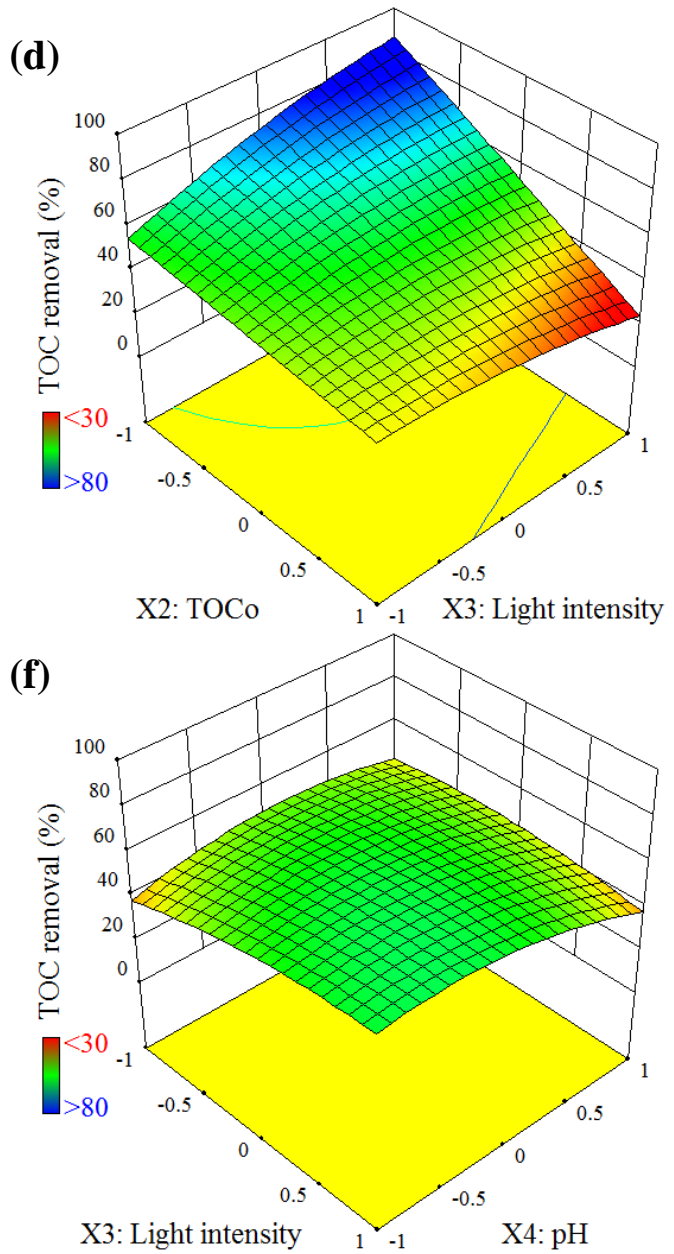

Figure 8.7. Interaction effects of different parameters on the percent TOC removal using 3D response surface and $2 D$ contours: (a) light wavelength and initial TOC concentration $\left(X_{1} X_{2}\right)$; (b) light wavelength and intensity $\left(X_{1} X_{3}\right)$; (c) light wavelength and pH $\left(X_{1} X_{4}\right)$; (d) initial TOC concentration and light intensity $\left(X_{2} X_{3}\right)$; (e) initial TOC concentration and pH $\left(X_{2} X_{4}\right)$; and (f) light intensity and $\mathrm{pH}\left(X_{3} X_{4}\right)$.

Submitted to Mater. Res. Innov. (2017). 
(a)
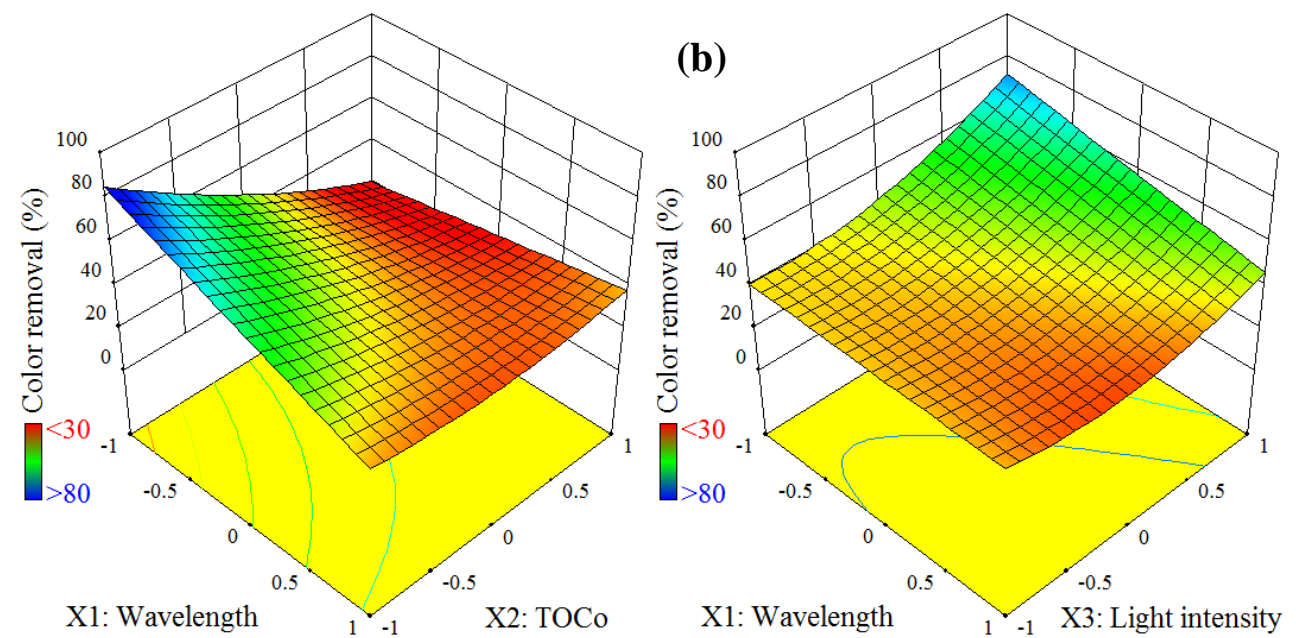

(c)
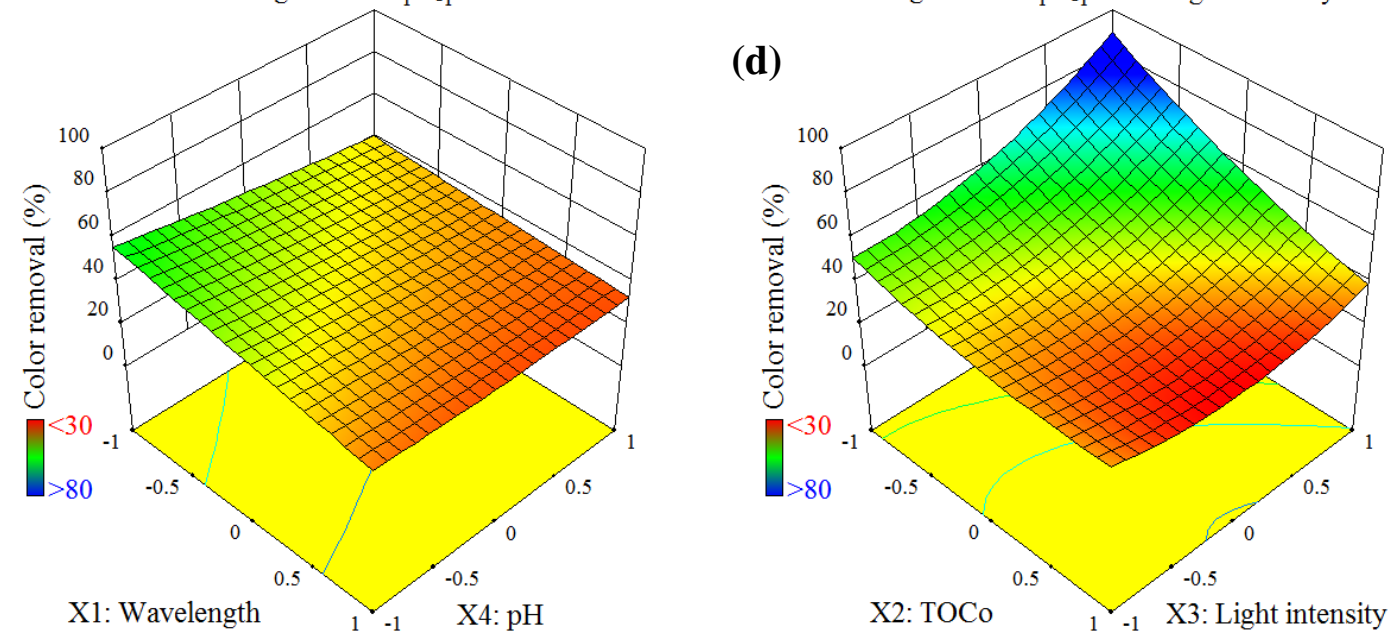

(e)
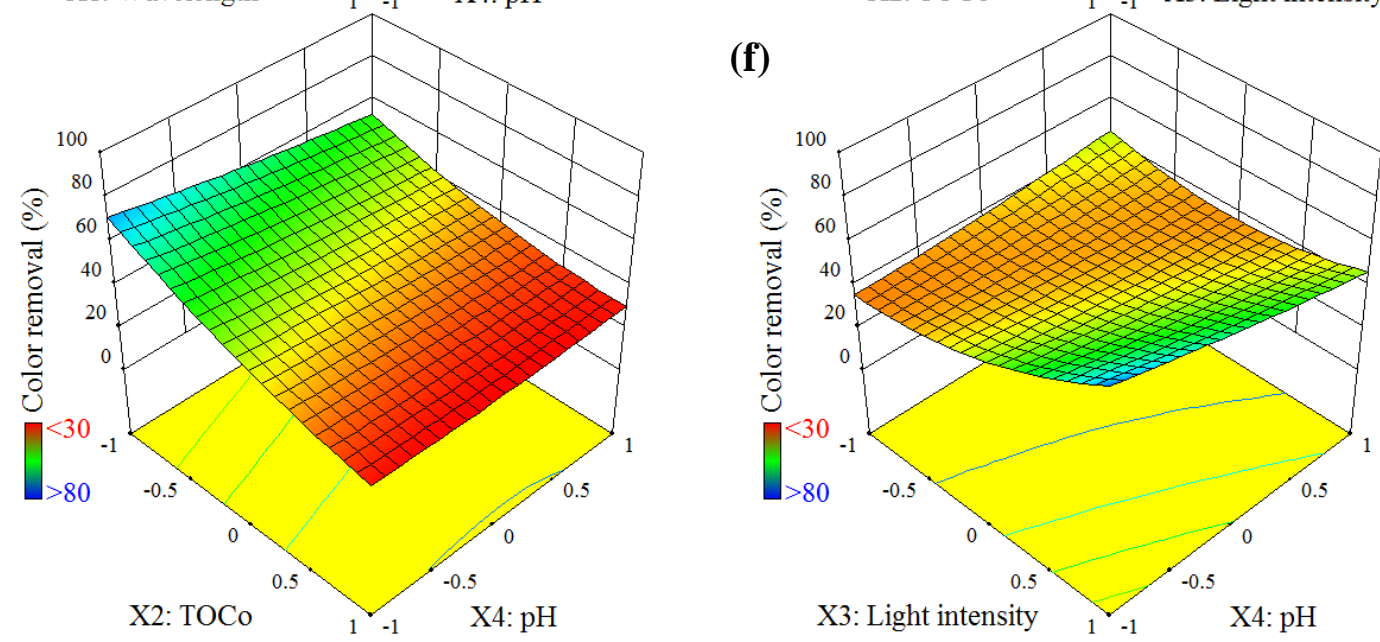

Figure 8.8. Interaction effects of different parameters on the percent color removal using 3D response surface and $2 D$ contours: (a) light wavelength and initial TOC concentration $\left(X_{1} X_{2}\right)$; (b) light wavelength and intensity $\left(X_{1} X_{3}\right)$; (c) light wavelength and $\mathrm{pH}\left(X_{1} X_{4}\right)$; (d) initial TOC concentration and light intensity $\left(X_{2} X_{3}\right)$; (e) initial TOC concentration and pH $\left(X_{2} X_{4}\right)$; and (f) light intensity and $\mathrm{pH}\left(X_{3} X_{4}\right)$.

Submitted to Mater. Res. Innov. (2017). 
Figures 8.7 and $8.8(a, b, c)$ depict the effects of the light wavelength on the percent TOC and color removals. Results show that by decreasing the wavelength, both the percent TOC and color removal increase. In all cases, the light intensity and initial TOC concentration cross-factor interactions with the light wavelength are intensified when the latter is at the lowest range value while $\mathrm{pH}$ does not require adjustments (Figures $8.7 \mathrm{c}$ and $8.8 \mathrm{c}$ ). The interaction of the initial TOC concentration with other independent variables tends to intensify their effect at low concentrations as confirmed in Figures 8.7 and 8.8 (a, d, e) as expected.

On the other hand, as shown in Figures 8.7 and 8.8 (b, d, f), both the percent TOC and color removals increase by increasing the light intensity in terms of the number of lamps. The effect of the light intensity on both the percent TOC and color removals is essentially attributable to the absorption of the UV radiation by organic compounds along with intermediates formed during the photocatalytic reactions, which as the light intensity increases there is a more uniform radiation distribution within the photoreactor. This effect is intensified at a lower light wavelength due to the photoactivity of the composite $\mathrm{N}-\mathrm{TiO}_{2}$ photocatalyst (Figures $8.7 \mathrm{~b}$ and $8.8 \mathrm{~b}$ ) and at low initial concentration of TOC (Figures $8.7 \mathrm{~d}$ and $8.8 \mathrm{~d}$ ) while being slight while interacting with the $\mathrm{pH}$ (Figures 8.7f and 8.8f), which results in an adequate value for each parameter within the range in terms of optimization potential.

Lastly, Figures 8.7 and 8.8 (c, e, f) depict the interaction effects of the $\mathrm{pH}$ with other variables, including the light wavelength $\left(X_{1} X_{4}\right)$, the initial TOC concentration $\left(X_{2} X_{4}\right)$, and the light intensity $\left(X_{3} X_{4}\right)$ on the percent TOC and color removals. Results demonstrate that there is no need for further $\mathrm{pH}$ adjustments. These interactions also confirm that both the percent TOC and color removals are directly proportional to the light intensity while being inversely proportional to the light wavelength and initial TOC concentration, and confirms there is no need for $\mathrm{pH}$ adjustment. 


\subsubsection{Optimization of experimental conditions and process parameters}

The RSM was used to determine the optimal experimental conditions of the four predictors, including the light wavelength $\left(X_{1}\right)$, the initial TOC concentration $\left(X_{2}\right)$, the light intensity in terms of the number of lamps $\left(X_{3}\right)$, and the $\mathrm{pH}\left(X_{4}\right)$, to obtain the maximum percent TOC removal $\left(Y_{1}\right)$ and color removal $\left(Y_{2}\right)$. The optimization was accomplished by maximizing both the percent TOC and color removals at defined operating conditions using the numerical optimization method built into the statistical software Design-Expert 10.0.3.1. Both Equations (8.4) and (8.5) were used as the objective functions for the percent TOC and color removals, respectively, while the independent variables were used as constraints in their critical ranges. The numerical optimization explores the BBD design space using the developed statistical models to find the optimal operating conditions that meet the set goal of optimization for maximum TOC and color removals simultaneously.

The multiple-response function shown in Equation (8.3) was used to obtain the parameter interaction plots, as depicted in Figure 8.9, by maximizing the TOC removal $\left(Y_{1}\right)$ and color removal $\left(Y_{2}\right)$ by the numerical optimization using the optimum factor settings.

Therefore, the desirability value of 1.00 was found for achieving the maximum TOC and color removals of 96.11 and $91.88 \%$, respectively, at the optimum conditions of light intensity in terms of 5 lamps, light wavelength of $418 \mathrm{~nm}$ (visible light range), initial TOC concentration of $10.54 \mathrm{mg} / \mathrm{L}$, and $\mathrm{pH}$ of 5.14 for the photocatalytic treatment of azo dyes in aqueous solution using the composite $\mathrm{N}-\mathrm{TiO}_{2}$ photocatalyst.

As a final point, the obtained optimum experimental conditions were tested in another experiment to validate the response values. Consequently, the TOC removal of $93.69 \%$ and color removal of $94.98 \%$ were obtained experimentally, confirming the accuracy and reliability of the 
developed models since they both are between the $95 \%$ CI of $92-100 \%$ for TOC removal and $83-$ $100 \%$ for color removal.
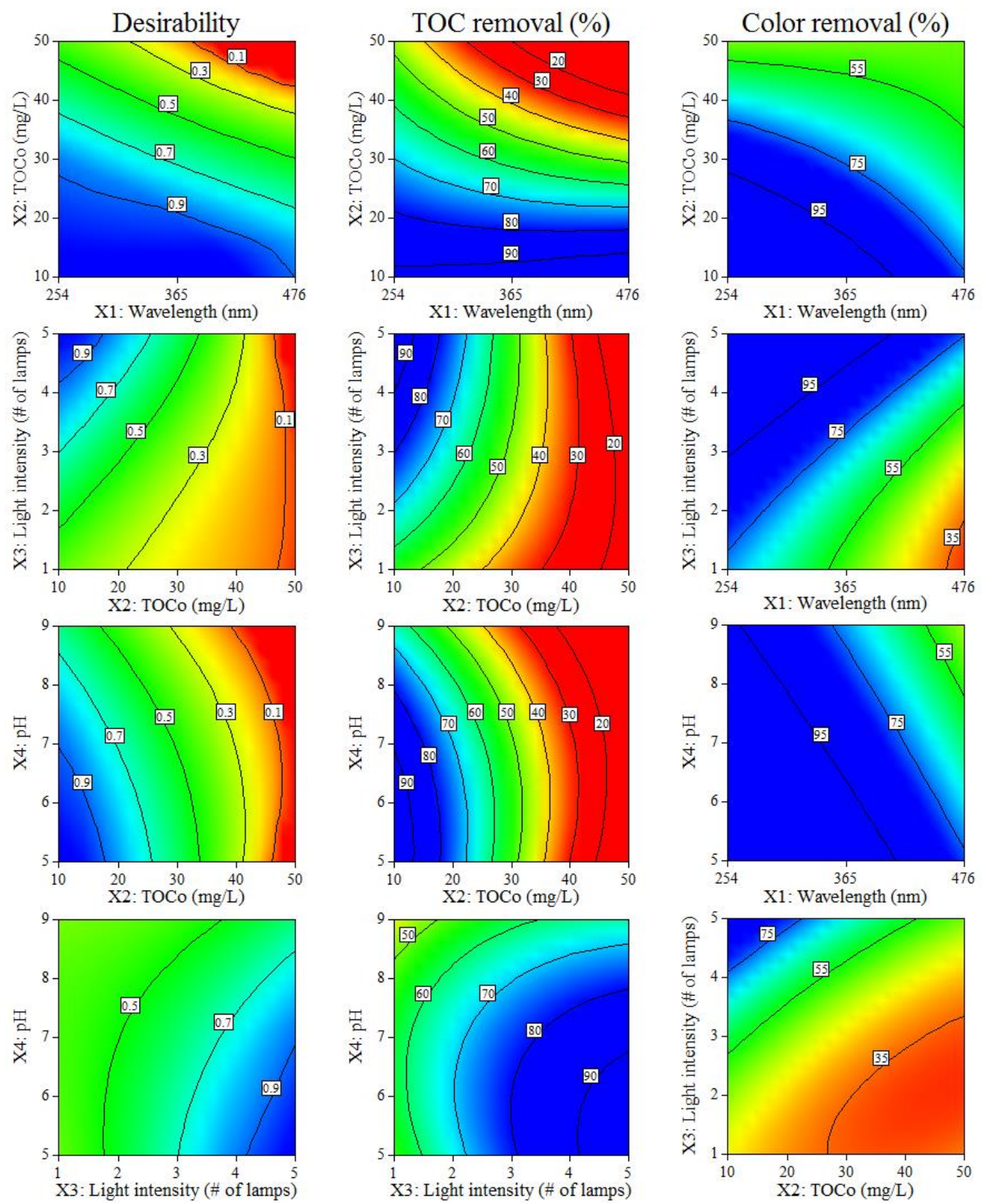

Figure 8.9. Desirability 2D plots maximizing the percent TOC and color removals at optimum factor settings of light intensity in terms of 5 lamps, light wavelength of $418 \mathrm{~nm}$ (visible light range), initial TOC concentration of $10.54 \mathrm{mg} / \mathrm{L}$, and $\mathrm{pH}$ of 5.14 for the photocatalytic treatment of azo dyes in aqueous solution using the composite $\mathrm{N}-\mathrm{TiO}_{2}$ photocatalyst.

Submitted to Mater. Res. Innov. (2017). 


\subsection{Conclusions}

The RSM combined with a four-factor BBD revealed reliable results for the treatment of azo dyes in aqueous solution by photocatalysis in a batch reactor using the composite $\mathrm{N}-\mathrm{TiO}_{2}$ photocatalyst. The accuracy of the developed quadratic models was evaluated using ANOVA. Results demonstrated that the light intensity, light wavelength, initial TOC concentration, and $\mathrm{pH}$ presented considerable effects on both the percent TOC and color removals. The cross-factor interaction effects between independent factors were also evaluated.

In this study, the interaction between the light wavelength and the light intensity presented a significant effect on the color removal while being not significant on the TOC removal. In the case of TOC removal; whereas the interaction effect between light wavelength and $\mathrm{pH}$ was found not significant on both the TOC and color removal efficiencies. In contrast, the cross-factor interaction between the light wavelength and the initial TOC concentration and those of the light intensity with the initial TOC concentration and the $\mathrm{pH}$ were found to have a high significant effect

on both TOC and color removals for the photocatalytic treatment of azo dyes to minimize treatment-related costs.

Maximum TOC and color removal efficiencies of 96.11 and $91.88 \%$, respectively, were achieved at the optimum operating conditions of light intensity in terms of 5 lamps, light wavelength of $418 \mathrm{~nm}$ (visible light range), initial TOC concentration of $10.54 \mathrm{mg} / \mathrm{L}$, and $\mathrm{pH}$ of 5.14 based on the developed quadratic models and the desirability multiple-response method. An additional experiment validated the model predictions for the maximum TOC and color removals at the obtained optimum operating conditions with values within the $95 \%$ CI. The developed statistical models presented a detailed examination of the simultaneous interaction effects of the predictors on the model responses. Therefore, the proposed statistical models could successfully 
describe the degradation of azo dyes by photocatalysis using the $\mathrm{N}$-doped $\mathrm{TiO}_{2}$ composite under visible light and could be utilized as a base for future research on photoreactor design, process optimization, and scale-up studies. 


\title{
CHAPTER 9
}

\section{DEVELOPMENT OF A NOVEL PHOTOCATALYST FOR WASTEWATER TREATMENT APPLYING UV-ASSISTED THERMAL SYNTHESIS AS AN ALTERNATIVE PREPARATION METHOD*}

\begin{abstract}
Photocatalysis, an advanced oxidation process (AOP), is a promising method of eradicating organics of almost all ranges in wastewater. This study aims to develop a novel photocatalyst for wastewater treatment by combining two semiconductor oxides and then doping a noble metal onto the combined photocatalysts simultaneously. An alternative preparation method of UV-assisted thermal synthesis is used to synthetize the new photocatalyst. The two photocatalysts, $\mathrm{Fe}_{2} \mathrm{O}_{3}$ and $\mathrm{TiO}_{2}$, were combined with different mass ratios of $\mathrm{Fe}: \mathrm{TiO}_{2}$ followed by doping the synthesized $\mathrm{Fe}_{2} \mathrm{O}_{3} / \mathrm{TiO}_{2}$ with silver ion with different mass ratios of $\mathrm{Ag}: \mathrm{TiO}_{2}$ to produce the novel photocatalyst $\mathrm{Ag} / \mathrm{TiO}_{2} / \mathrm{Fe}_{2} \mathrm{O}_{3}$. Scanning electron microscopy (SEM) coupled with energydispersive X-ray spectroscopy (EDS) is employed to evaluate the formation, morphology, and elemental analysis of the composite photocatalyst. The phase and crystal structure of new composites are investigated by X-ray diffraction (XRD). The specific surface area of all photocatalysts is investigated based on the Brunauer-Emmett-Teller (BET) method by adsorption of nitrogen gas at $77 \mathrm{~K}$. The aqueous solution of methyl orange is used to examine the

\footnotetext{
* Submitted to Journal of Environmental Management (2017).
} 
photocatalytic efficiency of the photocatalysts. Results indicate that the photocatalytic activity of the new photocatalyst is enhanced for the degradation of methyl orange. The new composite has the potential to absorb a higher wavelength in the visible region where a red shift occurs. By applying the $\mathrm{Ag} / \mathrm{TiO}_{2} / \mathrm{Fe}_{2} \mathrm{O}_{3}$ photocatalyst with a mass ratio of $0.01 \mathrm{Ag}: \mathrm{TiO}_{2}$ and $0.01 \mathrm{Fe}: \mathrm{TiO}_{2}$, the maximum degradation of methyl orange reaches to 89.5 and $95.5 \%$ under UV-A radiation and natural sunlight, respectively. Diffractograms confirm that the substitutions occurs in the crystal lattice of the main photocatalyst. It is also observed that the surface area of the $\mathrm{Ag} / \mathrm{TiO}_{2} / \mathrm{Fe}_{2} \mathrm{O}_{3}$ increased significantly.

Keywords: $\mathrm{Ag} / \mathrm{TiO}_{2} / \mathrm{Fe}_{2} \mathrm{O}_{3}$ photocatalyst; photocatalysis; AOPs; metal doping; UV-assisted thermal synthesis; wastewater treatment. ${ }^{*}$

\footnotetext{
* Submitted to Journal of Environmental Management (2017).
} 


\subsection{Introduction}

Recent studies have been devoted to the use of advanced oxidation processes (AOPs) for the elimination of organic materials from wastewater, mainly because AOPs are able to totally eradicate organics (Visa et al., 2011; De Andrade et al., 2012; Zou, 2015; Mohajerani et al., 2011, 2016; Nasirian and Mehrvar, 2016). Advanced oxidation processes (AOPs) are based on the generation of hydroxyl radicals $\left(\mathrm{HO}^{\circ}\right)$, which can oxidize almost all organic materials in wastewater, with an oxidation potential of $2.8 \mathrm{eV}$ which is the strongest oxidant after fluorine (3.06 eV) (Hamad et al., 2014, 2016; Mowla et al., 2014; Bustillo-Lecompte and Mehrvar, 2013, 2015, 2016; Bustillo-Lecompte et al., 2016; Nasirian et al., 2017).

The application of heterogeneous photocatalysis in degradation of organics from wastewater is an emerging method in recent years. Photocatalysis is one of the diverse types of AOPs. Titanium dioxide $\left(\mathrm{TiO}_{2}\right)$ is a typical well-known semiconductor material, which is commercialized as a photocatalyst. Among all photocatalysts, $\mathrm{TiO}_{2}$ is considered as an effective photocatalyst in the removal of organics in wastewater. Despite all advantages of $\mathrm{TiO}_{2}$, there are two major limitations in its photocatalytic activity, including its activation only in the ultraviolet range below $387 \mathrm{~nm}(3.2 \mathrm{eV})$ and a high rate of electron-hole recombination (Akpan and Hameed, 2009; Nasirian and Mehrvar, 2016). The efficiency of the photocatalysis depends on how well a photocatalyst can prevent electron-hole pair recombination.

The focus on heterogeneous photocatalysis has been on expanding its UV absorption into the visible region to improve the photocatalytic activity of $\mathrm{TiO}_{2}$ and to overcome its limitations by several methods. For example, there are several studies on doping and deposition of metals (e.g., $\mathrm{Au}, \mathrm{Ag}, \mathrm{Pt}, \mathrm{Rh}, \mathrm{Ru}, \mathrm{Y}, \mathrm{La}, \mathrm{Mn}, \mathrm{V}$, and Fe) or non- metals (e.g., N, S, P) onto $\mathrm{TiO}_{2}$ (Shah et al., 2002; Zhang et al., 2003; Barakat et al., 2005; Colón et al., 2006; Bandara and Ranasinghe, 2007; 
Cao et al., 2008; Silva et al., 2009; Gao et al., 2010; Grabowska et al., 2012; Devi and Kavitha, 2013; Kim et al., 2016). In addition, there are studies on dye adsorption/sensitization, various hybrid composites or combining semiconductor photocatalysts with narrower band gaps, such as $\mathrm{CdS} / \mathrm{TiO}_{2} / \mathrm{Pt}, \mathrm{TiO}_{2} / \mathrm{Y}-\mathrm{Zeolite}, \mathrm{Ag}_{2} \mathrm{O} / \mathrm{TiO}_{2}, \mathrm{Ag}_{-} \mathrm{Bi}_{2} \mathrm{MoO}_{4}$, Zeolite/WO $3-\mathrm{Pt}, \mathrm{CdS}-\mathrm{SnO}_{2}$, and adding some oxidant species (Etacheri et al., 2015; Sudha and Sivakumar, 2015; Fagan et al., 2016; Reddy et al., 2016; Kim et al., 2016). The co-deposition of noble metals such as Au, Ag, and Pt, resistant to oxidation or corrosion, on $\mathrm{TiO}_{2}$ is used as an alternative method to improve photocatalytic activity of $\mathrm{TiO}_{2}$ (Zhang et al., 2003; Bandara and Ranasinghe, 2007). Each method has its own strengths and weaknesses. Doping metal or non-metal onto $\mathrm{TiO}_{2}$ not only increases the surface area of the photocatalyst, but also the crystallinity and molecular structure of the photocatalyst are changed. Some parameters such as specific surface area, crystalline phase, size, and pore distribution, are crucial to improve the photocatalytic activity of a photocatalyst (Bandara and Ranasinghe, 2007; Cao et al., 2008: Cai et al., 2016).

Iron (III) oxide $\left(\mathrm{Fe}_{2} \mathrm{O}_{3}\right)$ is considered a photocatalyst with the advantages of low cost, nontoxic, and high chemical and physical stability. It has a low band gap energy of $2.2 \mathrm{eV}$, which can be activated under visible light. Despite its advantages, $\mathrm{Fe}_{2} \mathrm{O}_{3}$ has drawbacks of the low electrical conductivity and the difficulty to isolate photo-induced electrons and holes to prevent their fast recombination. Therefore, $\mathrm{Fe}_{2} \mathrm{O}_{3}$ has been considered as an alternative semiconductor to be combined with $\mathrm{TiO}_{2}$ to improve its photocatalytic activity in degradation of organic materials.

In the present study, a series of $\mathrm{Ag} / \mathrm{TiO}_{2}$ and $\mathrm{Fe}_{2} \mathrm{O}_{3} / \mathrm{TiO}_{2}$ photocatalysts at various mass ratios of $\mathrm{Ag}: \mathrm{TiO}_{2}$ and $\mathrm{Fe}: \mathrm{TiO}_{2}$ were synthesized using the novel $\mathrm{UV}$-assisted thermal method, as an alternative approach to conventional individual methods, to improve the photocatalytic activity. Then, the new composite photocatalyst of $\mathrm{Ag} / \mathrm{TiO}_{2} / \mathrm{Fe}_{2} \mathrm{O}_{3}$ with different mass ratio of $\mathrm{Ag}$ : $\mathrm{TiO}_{2}$ and 
Fe: $\mathrm{TiO}_{2}$ was synthesized and the degradation efficiency of methyl orange (MO) was investigated under UV-A and visible (natural) light.

\subsection{Materials and Methods}

\subsubsection{Materials and instrumentation}

All chemical materials were analytical grades, purchased from Sigma-Aldrich (Oakville, ON) and Van Waters and Nat Rogers (VWR, Mississauga, ON). All chemicals were used as received.

\subsubsection{Analytical techniques and instrumentation}

A total organic carbon (TOC) analyzer, Teledyne Tekmar model Apollo 9000, was used to measure the concentrations of organic materials in samples. All water samples were first centrifuged for $30 \mathrm{~min}$ at $4000 \mathrm{rpm}$ (Thermo Scientific Heraeus Multifuge X1, Mississauga, ON). The samples were then filtered by filter papers (VMR Qualitative 410, Mississauga, ON) and were analyzed by the TOC analyzer. The specific surface area of photocatalyst samples was determined by the Brunauer-Emmet and Teller (BET) method (Quantachrome Nova-e 1200, Burlington, ON) using nitrogen gas, which is adsorbed at $77 \mathrm{~K}$. For measuring topography, morphology, and structure of the prepared crystals of photocatalysts, scanning electron microscopy (SEM) (JEOL, model JSM-6370 LV, Calgary, AB), with accelerating voltage of $30 \mathrm{keV}$ was used to measure topography, morphology, and structure of the prepared crystals of photocatalysts. Energy dispersive X-ray spectroscopy (EDS) (Oxford Instrument, model X-Max-N-80, Concord, MA), which is coupled with SEM, was employed for elemental analysis. An auto sputter coater (Denton Vacuum Desk IV, Moorestown, NJ) was used for coating samples with a thin layer of gold before 
analysis by SEM. X-ray diffraction (XRD) model PANalytical X'pert PRO was used to investigate the structure of crystal and conversion phase of photocatalysts. The scanning range of XRD was $10-100^{\circ}(2 \theta)$. All instruments were calibrated according to their procedures. All prepared photocatalysts were dried in an oven (Binder, model ED 115- UL). A programmable furnace (Thermo Scientific model Lindberg Blue M) was used for the calcination of samples at different temperatures.

\subsubsection{Experimental setup and procedure}

The photocatalytic activities of as-prepared photocatalysts were tested using a batch photoreactor. The experimental setup consisted of a 3.5-L cylindrical glass container for the degradation of organic materials. Five UV-A or visible lamps (9 W, Philips-Actinic BLPL-S, G23 Base) with a maximum peak of $365 \mathrm{~nm}$ and $470 \mathrm{~nm}$, respectively, were vertically immersed in the photoreactor. Aluminum foil was wrapped around the external surface of the cooling water tank to reflect the UV radiation back to the sample and isolate the sample from any external radiation. The whole photoreactor was placed inside a water container to control the temperature of the photoreactor contents using a cooling bath (RTE-211, NESLAB Instruments, Inc., Newington, $\mathrm{NH})$. The photoreactor temperature was set at $25^{\circ} \mathrm{C}$ for all experiments. A magnetic stirrer was used to mix the solution thoroughly in the main photoreactor. The initial concentration of MO as an organic pollutant was $30 \mathrm{mg} / \mathrm{L}$. The photocatalyst powder was added into the photoreactor as slurry. The photoreactor was placed on a magnetic stirrer, so that the contents of the photoreactor were mixed thoroughly during the course of reactions. 


\subsection{4. $U V$-assisted thermal synthesis}

There are several methods of synthesis for the metal and non-metal doping of $\mathrm{TiO}_{2}$. These methods include sol-gel, hydrothermal, annealing, thermal microwave assisted, electrochemical anodization, and solvothermal method (Zaleska, 2008; Gao, et al., 2011; Shi, et al., 2012; Nasirian and Mehrvar, 2016). Different doping methods are proposed to enhance the activity of photocatalysts, especially in the range of visible region.

Several factors affect the rate of photochemical reactions such as the concentration of reactants, temperature and light with proper energy. UV-C which has very short wavelength (200$280 \mathrm{~nm}$ ) can be contemplated as a source of energy and can overcome the activation energy. At high UV light intensity, collisions are more frequent, more particles are activated, and consequently, the speed of reaction will be increased (Ranjan and Sasselov, 2016). It has been already confirmed that the high intensity of electron irradiation expressively increased the speed of reactions at lower temperatures for different oxide systems such as $\mathrm{NaFeO}_{2}, \mathrm{BaTiO}_{3}, \mathrm{NiFe}_{2} \mathrm{O}_{4}$, $\mathrm{LiFe}_{5} \mathrm{O}_{8}, \mathrm{MnFe}_{2} \mathrm{O}_{4}$, and $\mathrm{ZnFe}_{2} \mathrm{O}_{4}$ (Surzhikov et al., 2014). UV photons are very strong to alter the structure of molecules by breaking down bonds in photolysis reactions, exciting molecules into a higher level of energy (photoexcitation), or ionization of molecules (photo-ionization) (Ranjan and Sasselov, 2016).

In this study, a novel method of UV-assisted thermal synthesis, as an alternative to conventional methods, was used due to its effectiveness for the enhancement of the photocatalytic activity. This approach is presented to increase the productivity, and the latest advances in photocatalytic treatment. UV-C lamps were vertically placed at the exterior of the reactor flask (almost $6 \mathrm{~cm}$ far from flask) to assist the thermal treatment method while minimizing the additional heating requirements. Moussavi et al., 2016 reported that UV-C glass tubes are transparent without any phosphorus coating and maximum light emission is occurred at $254 \mathrm{~nm}(85-90 \%)$ and $185 \mathrm{~nm}$ 
(10-15\%) respectively. In brief, the UV-C lamp irradiates light centered at $254 \mathrm{~nm}$ because fuse quarts eliminate light centered at $185 \mathrm{~nm}$.

In order to synthesize the novel $\mathrm{Ag} / \mathrm{TiO}_{2} / \mathrm{Fe}_{2} \mathrm{O}_{3}$ photocatalyst, the $\mathrm{Fe}_{2} \mathrm{O}_{3} / \mathrm{TiO}_{2}$ was synthesized followed by silver ion doping onto the combined photocatalyst. In the following sections, the details of procedures to synthesize photocatalysts are explained.

\subsubsection{Synthesis of Ag-doped $\mathrm{TiO}_{2}$}

There are several methods to synthesize metal-doped $\mathrm{TiO}_{2}$. In this study, sol-gel method was utilized because it is the most convenient and important method for synthesis of metal-doped $\mathrm{TiO}_{2}$. Sol-gel method can be performed at ambient pressure and temperature, and the procedure is simple and cost-effective with a high yield of production (Tryba et al., 2006; Nasralla et al., 2013).

In order to prepare $\mathrm{Ag} / \mathrm{TiO}_{2}$ based on the sol-gel method, $2.00 \mathrm{~g}$ of anatase nano- $\mathrm{TiO}_{2}$ (prepared using a precursor of tetrabutoxy titanium and ethylene glycol) were weighed and mixed with $50 \mathrm{~mL}$ distilled water to make a suspended sol. Then, a stoichiometry amount of $\mathrm{AgNO}_{3}$ was dissolved in distilled water. The silver nitrate solution was added to a flat bottom flask, equipped with a condenser, comprising $\mathrm{TiO}_{2}$ sol particles suspended in water. In order to obtain a higher

yield of Ag-doped $\mathrm{TiO}_{2}$, the sol-gel thermal assisted method was used. The composition was mixed and heated at $95^{\circ} \mathrm{C}$ for at least $24 \mathrm{~h}$ by employing a heater-stirrer continuously. The obtained solgel was then centrifuged, washed, dried at $105^{\circ} \mathrm{C}$, and heated in a muffle furnace at $300^{\circ} \mathrm{C}$ for $8 \mathrm{~h}$. Based on the stoichiometry of the reaction, the mass ratio of $\mathrm{Ag}: \mathrm{TiO}_{2}$ was 0.005 . In addition, the Ag-doped $\mathrm{TiO}_{2}$ catalysts were synthesized with the mass ratios of $\mathrm{Ag}: \mathrm{TiO}_{2}=0.01,0.05$, and 0.1 . Figure 9.1a shows the actual photos of the synthesized nano- $\mathrm{TiO}_{2}$ and $\mathrm{Ag}-\mathrm{TiO}_{2}$ photocatalysts. 
a)

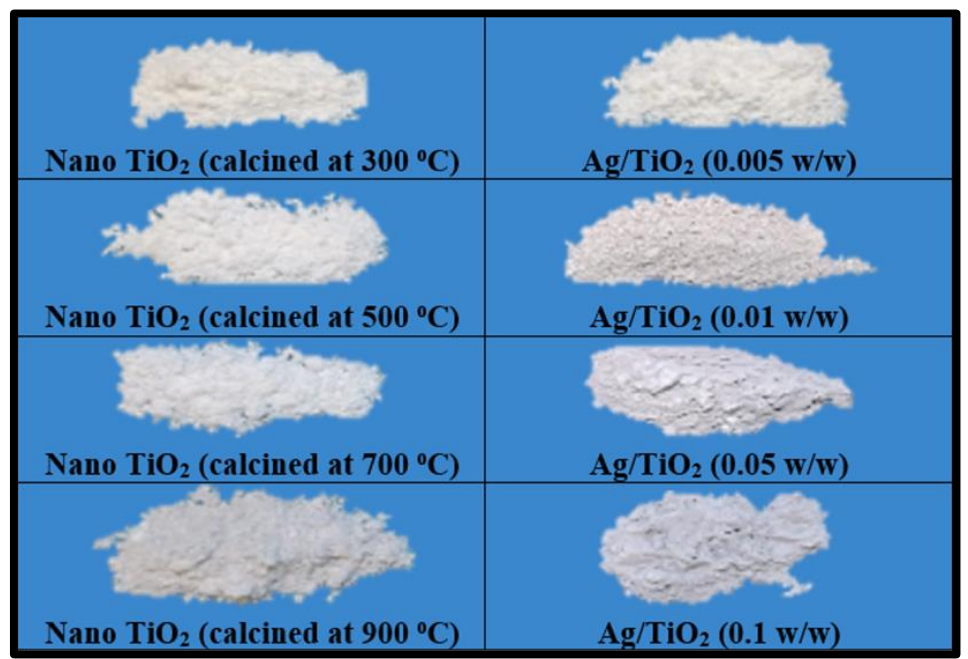

b)

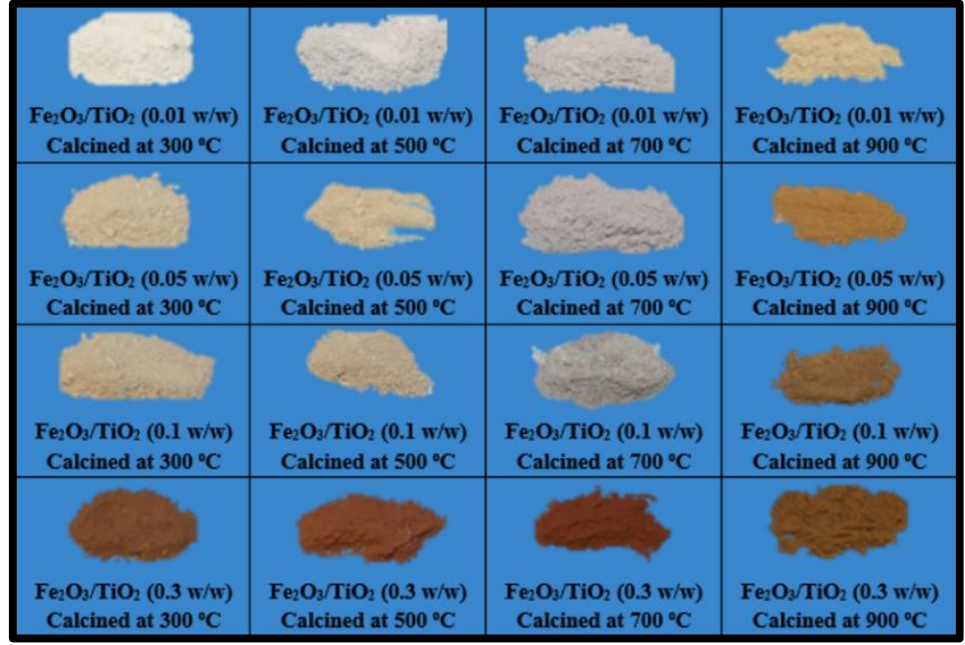

c)

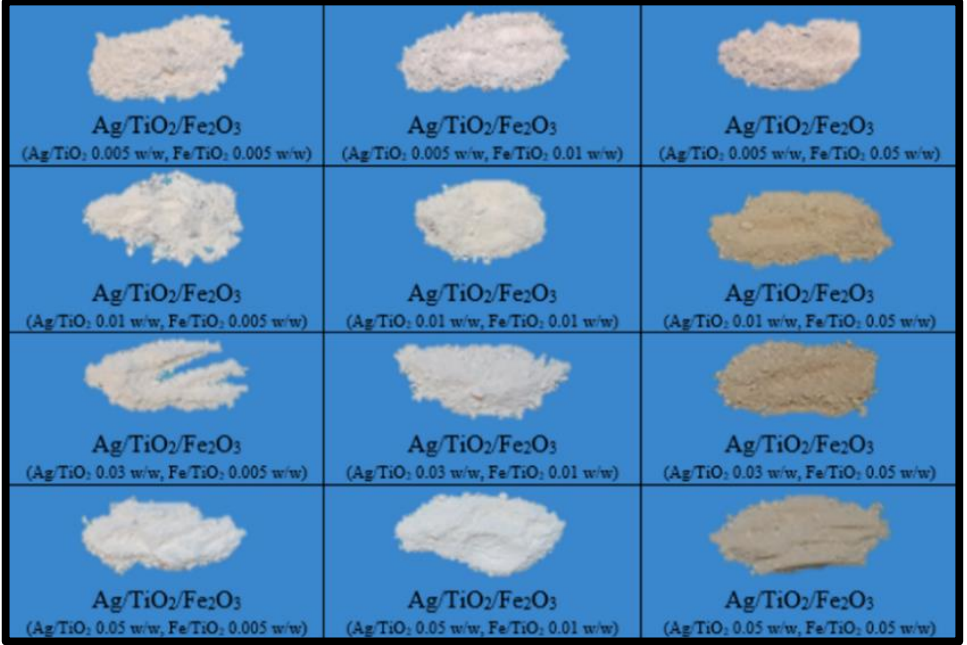

Figure 9.1. The actual photos of (a) the nano-synthesized $\mathrm{TiO}_{2}$ and $\mathrm{Ag} / \mathrm{TiO}_{2}$ photocatalysts;

(b) the synthesized $\mathrm{Fe}_{2} \mathrm{O}_{3} / \mathrm{TiO}_{2}$ at different calcination temperatures with different mass ratios of $\mathrm{Fe}: \mathrm{TiO}_{2}\left(\mathrm{Fe}: \mathrm{TiO}_{2}=0.01,0.05,0.1\right.$, and 0.30$)$; and (c) the synthesized $\mathrm{Ag} / \mathrm{TiO}_{2} / \mathrm{Fe}_{2} \mathrm{O}_{3}$ photocatalysts with different mass ratio of $\mathrm{Ag}: \mathrm{TiO}_{2}$ and $\mathrm{Fe}: \mathrm{TiO}_{2}$. Submitted to J. Environ. Manage. (2017). 


\subsubsection{Synthesis of $\mathrm{Fe}_{2} \mathrm{O}_{3} / \mathrm{TiO}_{2}$}

The $\mathrm{Fe}_{2} \mathrm{O}_{3} / \mathrm{TiO}_{2}$ photocatalyst was synthesized using the precursor of as-prepared nano$\mathrm{TiO}_{2}, \mathrm{Fe}\left(\mathrm{NO}_{3}\right)_{3} .9 \mathrm{H}_{2} \mathrm{O}$ in ethanol, and applying the UV-assisted thermal synthesis by setting up a glassware reactor at ambient pressure and $90^{\circ} \mathrm{C}$ temperature.

In order to prepare $\mathrm{Fe}_{2} \mathrm{O}_{3} / \mathrm{TiO}_{2}$ photocatalyst, specific amounts of each precursors were put in a Pyrex flat bottom flask $(100 \mathrm{~mL})$. Then, the flask was placed on an electrical heater with magnetic stirrer plate to mix the reactants continuously. The new method of UV-C assisted thermal synthesis was applied to enhance the reaction. Three UV-C lamps (PL-S-9W/TUV-UV Germicide, 110-120V-G23 Base) were placed vertically $6 \mathrm{~cm}$ away from the flask. A long glass condenser was used to recover the condensed vapor and return it to the sol-gel. The reaction was set at $90^{\circ} \mathrm{C}$ in a conventional glassware for $5 \mathrm{~h}$ to produce the $\mathrm{Fe}_{2} \mathrm{O}_{3} / \mathrm{TiO}_{2}$ photocatalyst. Samples were centrifuged and dried at $120^{\circ} \mathrm{C}$, washed and dried again at $120^{\circ} \mathrm{C}$, and then the composite photocatalyst was calcined at $300^{\circ} \mathrm{C}$ for $4 \mathrm{~h}$. Based on the stoichiometry of the reaction and by applying different amounts of the components, the $\mathrm{Fe}_{2} \mathrm{O}_{3} / \mathrm{TiO}_{2}$ photocatalyst was prepared with mass ratios of $\mathrm{Fe}: \mathrm{TiO}_{2}=0.005,0.01,0.05,0.10$, and 0.30 .

Nasirian et al. (2017) reported that the best calcination temperature to prepare $\mathrm{Fe}_{2} \mathrm{O}_{3} / \mathrm{TiO}_{2}$ photocatalyst is in the range $300-400^{\circ} \mathrm{C}$ in order to achieve a high degradation of organic materials in water. At higher calcination temperatures (over $400^{\circ} \mathrm{C}$ ), anatase converts to rutile because of $\mathrm{Fe}^{3+}$, which facilitates the conversion. The conversion of anatase to rutile starts at $600^{\circ} \mathrm{C}$ (Dai et al., 2010), but Pal et al. (1999) reported that at calcination temperature of $500^{\circ} \mathrm{C}$, a small amount of rutile starts to be introduced. This fact might be related to the existence of $\mathrm{Fe}^{3+}$, which facilitates the transformation of anatase to a stable form of rutile. Figure $9.1 \mathrm{~b}$ shows the photos of synthesized 
$\mathrm{Fe}_{2} \mathrm{O}_{3} / \mathrm{TiO}_{2}$ photocatalysts with different mass ratios of $\mathrm{Fe}: \mathrm{TiO}_{2}$ at various calcination temperatures.

\subsubsection{Synthesis of $\mathrm{Ag} / \mathrm{TiO}_{2} / \mathrm{Fe}_{2} \mathrm{O}_{3}$}

Two procedures could be used to synthesize the $\mathrm{Ag} / \mathrm{TiO}_{2} / \mathrm{Fe}_{2} \mathrm{O}_{3}$ photocatalyst. First, the prepared $\mathrm{Fe}_{2} \mathrm{O}_{3} / \mathrm{TiO}_{2}$ photocatalyst can react with a silver solution to produce the $\mathrm{Ag} / \mathrm{TiO} \mathrm{O}_{2} / \mathrm{Fe}_{2} \mathrm{O}_{3}$ photocatalyst. In the second method, $\mathrm{Ag} / \mathrm{TiO}_{2}$ is first prepared and then can react with a salt of $\mathrm{Fe}^{3+}$. The percent yield of production using the second method was lower than that of using the first method. In this study, the $\mathrm{Ag} / \mathrm{TiO}_{2} / \mathrm{Fe}_{2} \mathrm{O}_{3}$ photocatalyst was synthesized based on the first method using the new preparation method of UV-assisted thermal synthesis. In order to synthesize the new composite photocatalyst based on the first method, $2.00 \mathrm{~g}$ of $\mathrm{Fe}_{2} \mathrm{O}_{3} / \mathrm{TiO}_{2}$ were added to a flat bottom flask and then $0.031 \mathrm{~g}$ of silver nitrate dissolved in $40 \mathrm{~mL}$ of distilled water was added to the flask. The flask was equipped with a long glass condenser to recover the condensed vapor and return it to the sol-gel flask. Nitrogen gas was continuously injected to the reactants to remove oxygen from the sol-gel. The mixture was heated at $90-95^{\circ} \mathrm{C}$ under continuous magnetic stirring and UV-C irradiation for $12 \mathrm{~h}$. Then, the slurry was cooled to ambient temperature, centrifuged, and washed with water and ethanol to remove nitrate ion. The solid material was then dried at $105^{\circ} \mathrm{C}$ for $4 \mathrm{~h}$. The product was calcined at $300^{\circ} \mathrm{C}$ for $6 \mathrm{~h}$. Based on the molecular weight and the stoichiometry of the reaction, the $\mathrm{Ag} / \mathrm{TiO}_{2} / \mathrm{Fe}_{2} \mathrm{O}_{3}$ photocatalyst was obtained $\left(\mathrm{Ag}: \mathrm{TiO}_{2}=0.01 \mathrm{w}: \mathrm{w}\right.$, and $\left.\mathrm{Fe}: \mathrm{TiO}_{2}=0.01 \mathrm{w}: \mathrm{w}\right)$. Figure 9.1c shows the illustrations of the synthesized $\mathrm{Ag} / \mathrm{Fe}_{2} \mathrm{O}_{3} / \mathrm{TiO}_{2}$ photocatalysts with different mass ratios of $\mathrm{Ag}: \mathrm{TiO}_{2}$ and $\mathrm{Fe}: \mathrm{TiO}_{2}$.

Results from recent studies (Hamadanian et al., 2010; Mazinani et al., 2014) confirm that at high calcination temperatures of more than $500^{\circ} \mathrm{C}$, the photocatalytic activity is significantly 
decreased due to the phase conversion as well as the specific surface area of the photocatalyst was decreased. At high calcination temperatures, the particle size, the thickness of the crystal, and the degree of crystallinity increase. This is the main reason to keep the calcination temperature of all photocatalysts to a maximum of $300^{\circ} \mathrm{C}$.

\subsection{Results and Discussion}

\subsubsection{Photocatalytic degradation of methyl orange: preliminary results}

Degradation of MO in presence of different types of commercial bare $\mathrm{TiO}_{2}$ photocatalysts including rutile, Degussa P25, anatase, and nano-synthesized $\mathrm{TiO}_{2}$ under UV-A irradiation is shown in Figure 9.2a. It is obvious that the range of degradation of $\mathrm{MO}$ using bare $\mathrm{TiO}_{2} / \mathrm{UV}$ is not high. The best results were obtained in presence of anatase with the degradation of $37.9 \%$ after 3 h of irradiation. After anatase, nano-synthesized $\mathrm{TiO}_{2}$ and $\mathrm{P} 25$ with almost same efficiency had the highest, and rutile $\mathrm{TiO}_{2}$ had the minimum degradation efficiency.

Figure $9.2 \mathrm{~b}$ shows the degradation efficiency of $\mathrm{MO}$ in presence of commercial bare $\mathrm{Fe}_{2} \mathrm{O}_{3}$, bare anatase $\left(\mathrm{TiO}_{2}\right)$, and composite $\mathrm{Fe}_{2} \mathrm{O}_{3} / \mathrm{TiO}_{2}$ with different mass ratios of dopant $\left(\mathrm{Fe}: \mathrm{TiO}_{2}=\right.$ $0.005,0.01,0.05,0.10$, and $0.30 \mathrm{w}: \mathrm{w})$. It is evident that the degradation range of MO using bare $\mathrm{TiO}_{2} / \mathrm{UV}$ and bar $\mathrm{Fe}_{2} \mathrm{O}_{3} / \mathrm{UV}$ for dyes is not high (38.1 and 24.9\%, respectively). Figure 9.2b also shows that the maximum degradation efficiencies of $\mathrm{MO}$ in present of composite $\mathrm{Fe}_{2} \mathrm{O}_{3} / \mathrm{TiO}_{2}$ $\left(\mathrm{Fe}: \mathrm{TiO}_{2}=0.01 \mathrm{w}: \mathrm{w}\right)$ reached to $61.5 \%$. This is an improvement of $23.6 \%$ compared to the efficiency of bare $\mathrm{TiO}_{2}$ that was $37.9 \%$. 

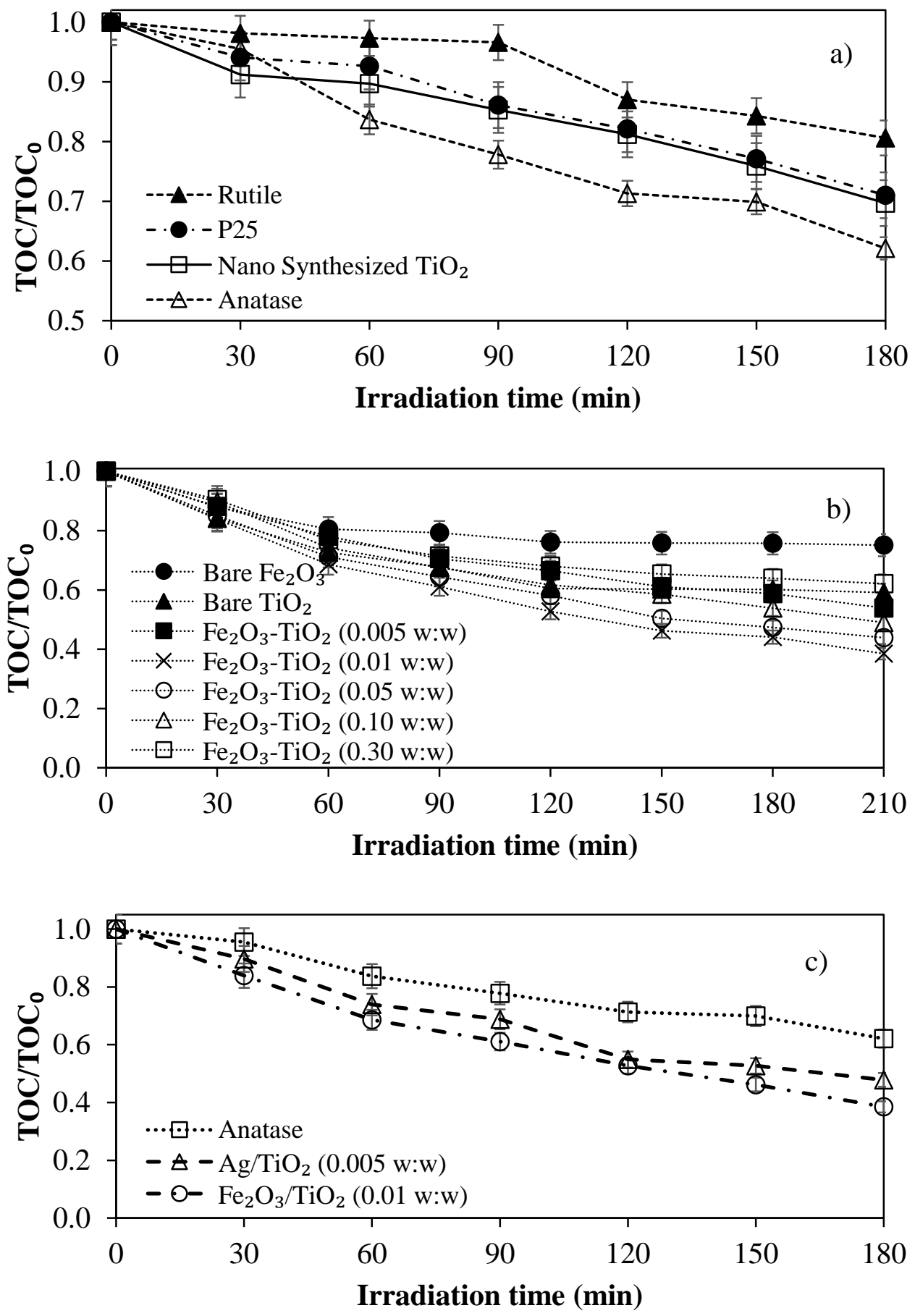

Figure 9.2. Comparison in degradation efficiencies of methyl orange in the presence of (a) several types of $\mathrm{TiO}_{2}$ photocatalysts; (b) commercial $\mathrm{Fe}_{2} \mathrm{O}_{3}$, bare anatase $\left(\mathrm{TiO}_{2}\right)$ and composite $\mathrm{Fe}_{2} \mathrm{O}_{3}-\mathrm{TiO}_{2}$ with different mass ratios of $\mathrm{Fe}_{2} \mathrm{TiO}_{2}$; and (c) anatase $\mathrm{TiO}_{2}, \mathrm{Ag}$ doped $\mathrm{TiO}_{2}\left(\mathrm{Ag}: \mathrm{TiO}_{2}=0.05\right.$ w:w) and $\mathrm{Fe}_{2} \mathrm{O}_{3} / \mathrm{TiO}_{2}\left(\mathrm{Fe}: \mathrm{TiO}_{2}=0.01\right.$ w:w $)$. The concentration of all photocatalysts was $500 \mathrm{mg} / \mathrm{L}$. The initial concentration of $M O$ was $30 \mathrm{mg} / \mathrm{L}$.

Experiments were conducted under irradiation of 5 UV-A lamps.

Submitted to J. Environ. Manage. (2017). 
Figure 9.2c depicts the comparison between the photocatalytic degradation efficiency of MO in the presence of bare $\mathrm{Fe}_{2} \mathrm{O}_{3}$, bare anatase $\left(\mathrm{TiO}_{2}\right)$, synthesized $\mathrm{Ag} / \mathrm{TiO}_{2}$ with an optimum mass ratio of $0.005 \mathrm{Ag}: \mathrm{TiO}_{2}$, and the composite $\mathrm{Fe}_{2} \mathrm{O}_{3} / \mathrm{TiO}_{2}$ photocatalyst (with mass ratio of 0.01 Fe: $\mathrm{TiO}_{2}$ ) under irradiation of UV-A light. Results showed that the degradation of MO reached up to $24.9,37.9,52.2$, and $61.5 \%$, respectively, which is an improvement in the degradation efficiency. Results from this part of the study confirmed that doping a noble metal onto $\mathrm{TiO}_{2}$ and combining two photocatalysts could improve the degradation efficiency of the bare $\mathrm{TiO}_{2}$ photocatalyst.

\subsubsection{Characterization of composite photocatalyst of $\mathrm{Ag} / \mathrm{TiO}_{2} / \mathrm{Fe}_{2} \mathrm{O}_{3}$}

Figure 9.3a shows SEM images of the composite $\mathrm{Ag} / \mathrm{Fe}_{2} \mathrm{O}_{3} / \mathrm{TiO}_{2}$ photocatalyst, prepared by the UV-assisted thermal synthesis. The $\mathrm{Ag} / \mathrm{TiO}_{2} / \mathrm{Fe}_{2} \mathrm{O}_{3}$ particles displayed a heterogeneous shape and micrometer-sized. Based on the scale of the image, the particle size of the photocatalyst varies between $0.5-2.0 \mu \mathrm{m}$. Figure 9.3b shows the results of the EDS for the elemental analysis of the composite $\mathrm{Ag} / \mathrm{TiO}_{2} / \mathrm{Fe}_{2} \mathrm{O}_{3}$ photocatalyst $\left(\mathrm{Ag}: \mathrm{TiO}_{2}=0.01 \mathrm{w}: \mathrm{w}\right.$ and $\left.\mathrm{Fe}: \mathrm{TiO}_{2}=0.05 \mathrm{w}: \mathrm{w}\right)$. Results taken from EDS were in line with the expected concentration of the elements in the photocatalyst.

The specific surface area of all powder samples was also measured based on the BET method, in which the amount of an adsorbed inert gas such as nitrogen on the photocatalyst powder is measured. The amount of the adsorbed gas corresponds to a monomolecular layer on the surface. Figure 9.4 shows the comparison of the specific surface areas of the prepared composite of $\mathrm{Ag} / \mathrm{TiO}_{2} / \mathrm{Fe}_{2} \mathrm{O}_{3}$ photocatalyst with different mass ratios (calcined at $300^{\circ} \mathrm{C}$ ) along with several other commercial photocatalysts. Results show that the commercial rutile has the lowest specific

surface area $\left(2.24 \mathrm{~m}^{2} / \mathrm{g}\right)$, whereas the commercial anatase has the highest specific surface area 
$\left(42.29 \mathrm{~m}^{2} / \mathrm{g}\right)$ among all bare crystalline forms of $\mathrm{TiO}_{2}$. This trend correlates with the photocatalytic degradation of $\mathrm{MO}$ in presence of different forms of $\mathrm{TiO}_{2}$.

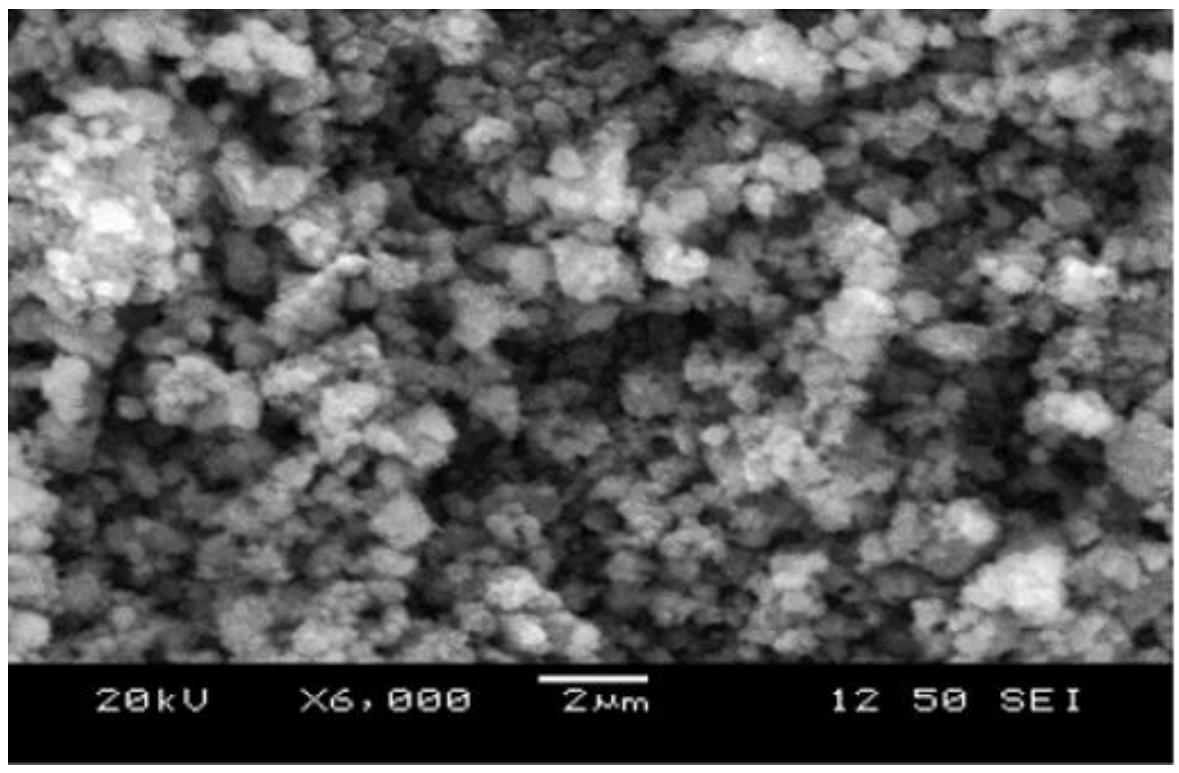

a)
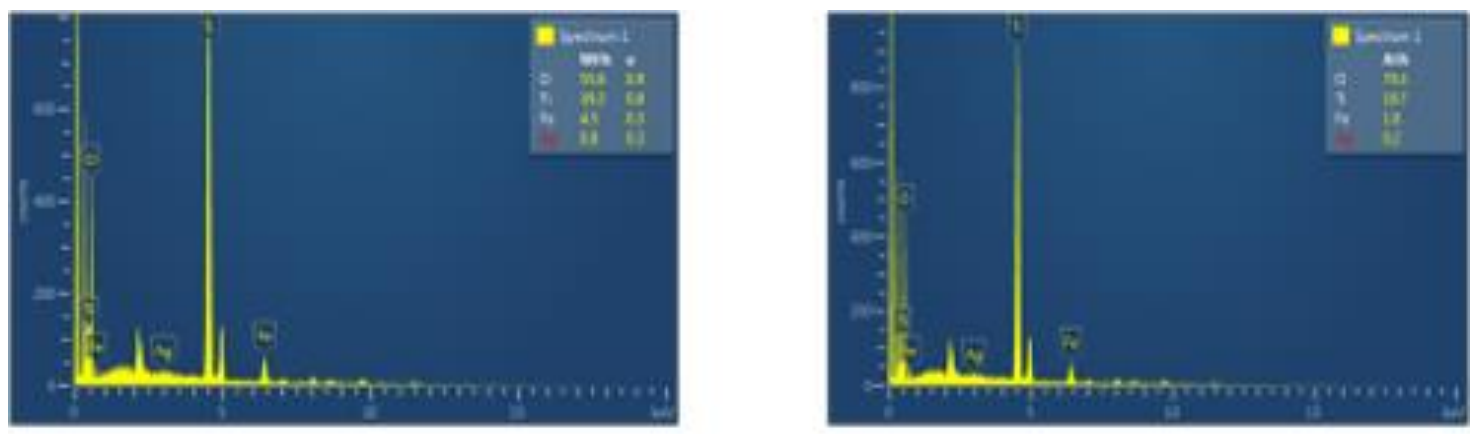

b)

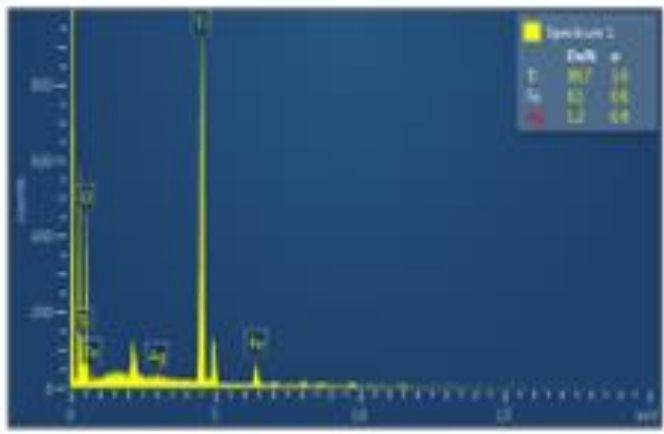

Figure 9.3. (a) $\mathrm{SEM}$ image of $\mathrm{Ag} / \mathrm{TiO}_{2} / \mathrm{Fe}_{2} \mathrm{O}_{3}\left(\mathrm{Ag}\right.$ : $\mathrm{TiO}_{2}=0.01 \mathrm{w}: \mathrm{w}$ and $\mathrm{Fe}: \mathrm{TiO}_{2}=0.05 \mathrm{w}: \mathrm{w}$ ) from whole sample; (b) Elemental analysis of whole sample of $\mathrm{Ag} / \mathrm{TiO}_{2} / \mathrm{Fe}_{2} \mathrm{O}_{3}$ $\left(\mathrm{Ag}: \mathrm{TiO}_{2}=0.01 \mathrm{w}: \mathrm{w}\right.$ and $\left.\mathrm{Fe}: \mathrm{TiO}_{2}=0.05 \mathrm{w}: \mathrm{w}\right)$.

Submitted to J. Environ. Manage. (2017). 


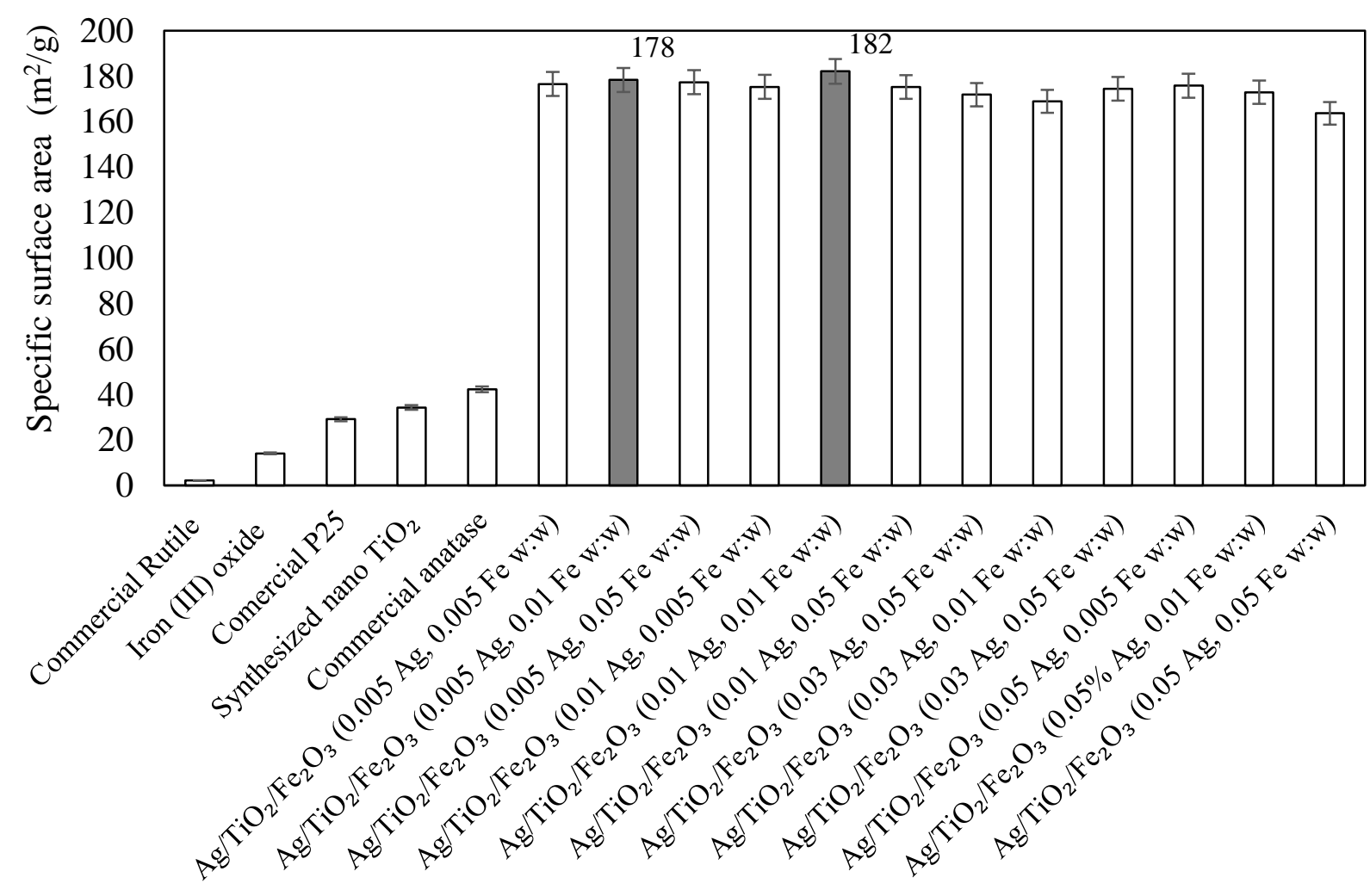

Figure 9.4. Comparison of specific surface area of photocatalysts (all mass ratios are based on $\mathrm{Ag}: \mathrm{TiO}_{2}$ and $\left.\mathrm{Fe}: \mathrm{TiO}_{2}\right)$.

Submitted to J. Environ. Manage. (2017).

In heterogeneous photocatalysis, the photocatalytic activity is related to catalyst species, doping, and amount of metal or non-metal doping. According to the previous study (Nasirian et al., 2017), the highest specific surface area of composite $\mathrm{Fe}_{2} \mathrm{O}_{3} / \mathrm{TiO}_{2}$ photocatalyst was observed at $0.01 \mathrm{Fe}: \mathrm{TiO}_{2} \mathrm{w}: \mathrm{w}$ which was $98.73 \mathrm{~m}^{2} / \mathrm{g}$. It is remarkable that the specific surface areas of the bare $\mathrm{Fe}_{2} \mathrm{O}_{3}$ and anatase were 14.15 and $42.28 \mathrm{~m}^{2} / \mathrm{g}$, respectively, in the present study. Thus, it means bare $\mathrm{TiO}_{2}$ and bare $\mathrm{Fe}_{2} \mathrm{O}_{3}$ do not have high specific surface areas, but the combination of these two photocatalysts has a significantly higher specific surface area.

Photocatalytic processes are surface phenomena. Therefore, there is a direct relationship between the specific surface area and the performance of a photocatalyst. It means when the 
specific surface area is high, the photocatalyst adsorbs more organics as pollutant. High specific surface area is well known as a characteristic for the high activity of a photocatalyst (Akpan and Hameed, 2009). The photocatalytic degradation of organic materials is almost proportional to the number of reactants adsorbed on the surface of the photocatalyst. In other words, degradation rates of organic materials follow a kinetic model based on Langmuir isotherm surface-adsorbed reactants (Yan et al., 2006; Amano et al., 2010; Hamadanian et al., 2010; Mazinani et al., 2014). Based on this model, the amount of adsorbed pollutants on the surface has a direct relationship to the specific surface area of the photocatalyst. These results confirm that the combination of metal oxide photocatalysts increases the specific surface area, and therefore, the degradation efficiency. The highest specific surface area of $\mathrm{Ag} / \mathrm{TiO}_{2} / \mathrm{Fe}_{2} \mathrm{O}_{3}(182.17 \mathrm{~m} / \mathrm{g})$ was observed at the mass ratios of $0.01 \mathrm{Ag}: \mathrm{TiO}_{2}$ and $0.01 \mathrm{Fe}: \mathrm{TiO}_{2}$, while it was $178.37 \mathrm{~m}^{2} / \mathrm{g}$ at the mass ratios of $0.005 \mathrm{Ag}: \mathrm{TiO}_{2}$ and $0.01 \mathrm{Fe}: \mathrm{TiO}_{2}$. Results confirmed that combining of the two photocatalysts $\left(\mathrm{TiO}_{2}\right.$ and $\left.\mathrm{Fe}_{2} \mathrm{O}_{3}\right)$ followed by doping noble metals (Ag) significantly increased the specific surface are of photocatalysts, adsorption of pollutants, and therefore, the photoactivity. Results also show that by increasing the concentration of iron and silver doped into $\mathrm{TiO}_{2}$, the specific surface area increases and after a certain ratio $\left(\mathrm{Fe}: \mathrm{TiO}_{2}=0.01 \mathrm{w}: \mathrm{w}\right.$ and $\left.\mathrm{Ag} / \mathrm{TiO}_{2}=0.01 \mathrm{w}: \mathrm{w}\right)$, it reduces again (Figure 9.4). It seems that at high concentration of the dopant, the surface of the photocatalyst is entirely covered by the dopant and there is not enough surface area for the photocatalyst to absorb light and generate electrons and holes.

\subsubsection{Crystallinity of $\mathrm{Ag} / \mathrm{TiO}_{2} / \mathrm{Fe}_{2} \mathrm{O}_{3}$ photocatalyst}

Although there are numerous reports in the open literature on the preparation of various photocatalysts with different photo-efficiencies to treat organics in wastewater, the configuration 
and the structure of doped (with metals or non-metals) and combined photocatalysts are still not clear and therefore, this needs to be investigated. It is obvious that photocatalytic properties are intensively related to several parameters such as the specific surface area, the structure, the size, and the morphology of the crystal. There are two main perspectives, terrestrial and substitution, for doping metals or combining another photocatalyst onto bare $\mathrm{TiO}_{2}$. The terrestrial is related to the metal/non-metal covering the surface of the photocatalyst (Agustina et al., 2005; Liu et al., 2015), whereas in the substitution, the metal/non-metal ions penetrate into the crystal lattice of $\mathrm{TiO}_{2}$ (Wellia et al., 2011; Nasralla et al., 2013; Banisharif et al., 2015). Figure 9.5a shows a diffractogram $(\mathrm{XRD})$ of the $\mathrm{Ag} / \mathrm{TiO}_{2} / \mathrm{Fe}_{2} \mathrm{O}_{3}$ photocatalyst $\left(\mathrm{Ag}: \mathrm{TiO}_{2}=0.01 \mathrm{w}: \mathrm{w}\right.$ and $\mathrm{Fe}: \mathrm{TiO}_{2}=0.01$ w:w) which calcined at $300^{\circ} \mathrm{C}$. Results show that the photocatalyst is in the anatase phase with small crystal size, where there is no rutile peak present.

Figure 9.5b shows three diffractograms of $\mathrm{Ag} / \mathrm{TiO}_{2} / \mathrm{Fe}_{2} \mathrm{O}_{3}$ with different mass ratio of $\mathrm{Ag}^{+}$ and $\mathrm{Fe}^{3+}$, whereas Figure 9.5c shows diffractogram of the pure commercial anatase. The location of the peaks in the three diffractograms of photocatalysts were in line with that of the pure anatase. According to the Joint Committee on Powder Diffraction Standards (JCPDS-21-1272) databank, anatase has a main peak at $2 \theta=25.4$ matching the 101 planes and two other peaks located at 37.8 and 48.0 corresponding to planes 004 and 200, respectively (Dai et al., 2010; Kim et al., 2016). Results revealed that all three diffractograms are similar without any alteration in the location of peaks other than their relative heights, which are related to different concentrations of $\mathrm{Ag}^{+}$and $\mathrm{Fe}^{3+}$. From these diffractograms, one can conclude that due to same size of the silver and especially iron ions with titanium, these two ions most likely become parts of the crystal lattice of $\mathrm{TiO}_{2}$. Substitution of iron or silver into the crystal lattice caused a crystal defect with an increase in the specific surface area of photocatalyst. 


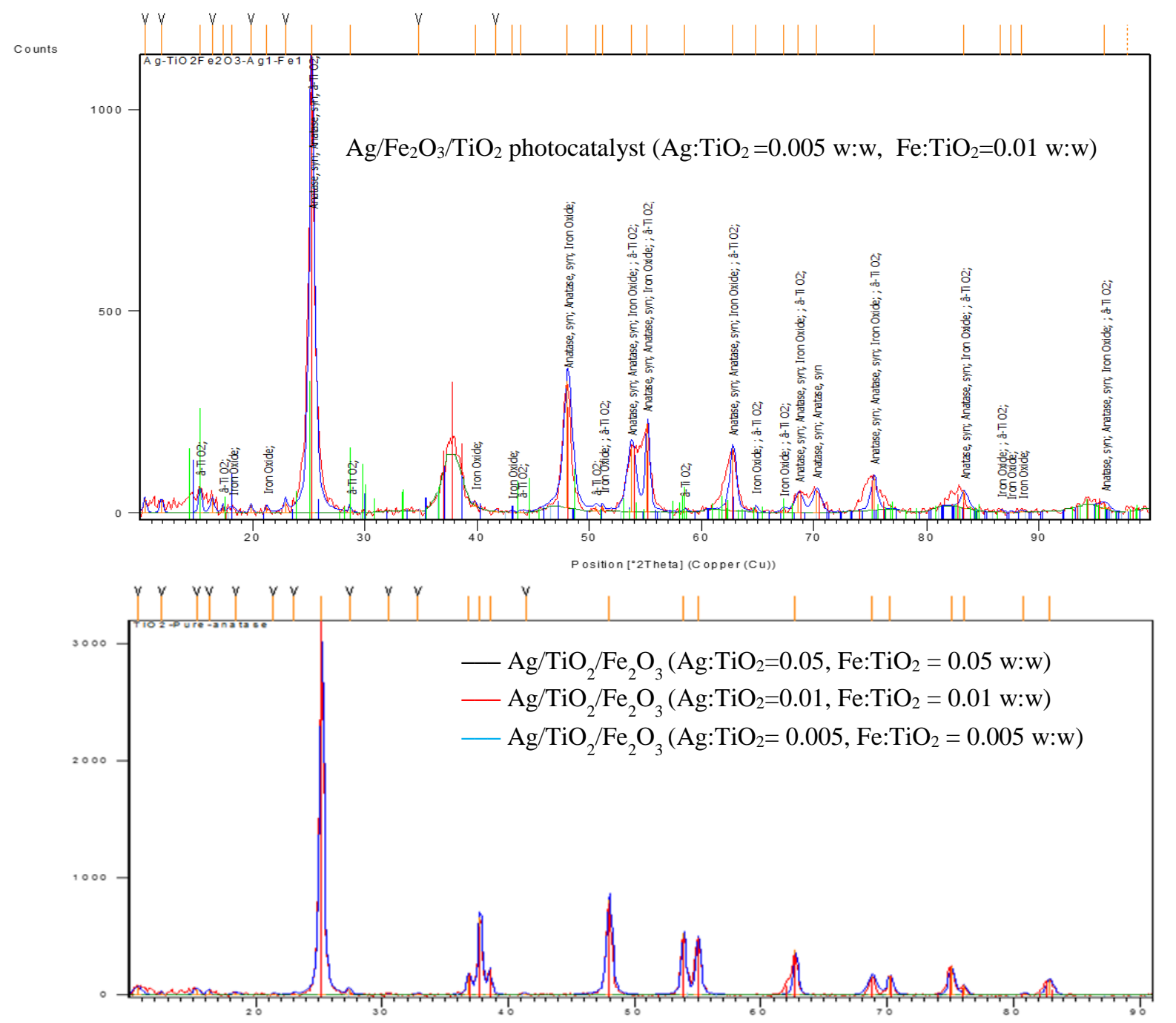

a)

b)

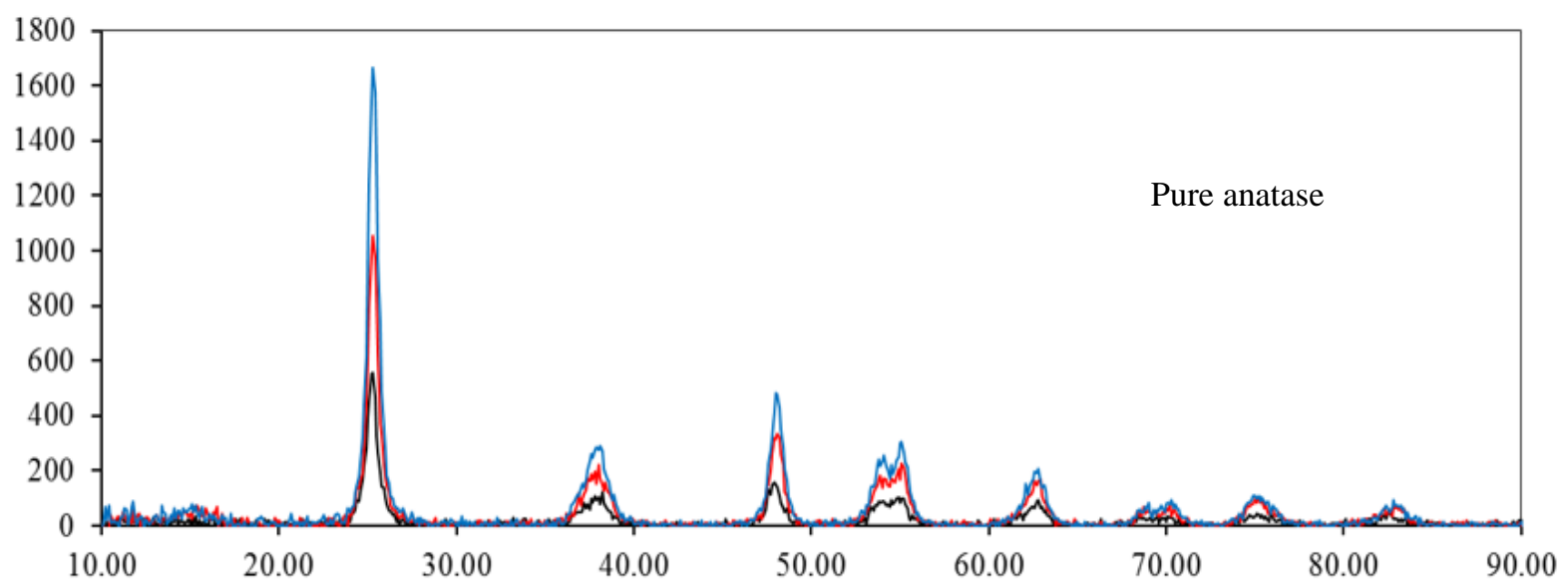

Figure 9.5. (a) Diffractogram of the as-prepared $\mathrm{Ag} / \mathrm{Fe}_{2} \mathrm{O}_{3} / \mathrm{TiO}_{2}$ photocatalyst $\left(\mathrm{Ag}: \mathrm{TiO}_{2}=0.005\right.$ w:w and Fe:TiO $=0.01$ w:w); (b) Comparison of three diffractograms (XRD) of $\mathrm{Ag} / \mathrm{Fe}_{2} \mathrm{O}_{3} / \mathrm{TiO}_{2}$ with different mass ratios of $\mathrm{Ag}$ and $\mathrm{Fe}$; and (c) diffractogram of pure commercial anatase.

Submitted to J. Environ. Manage. (2017). 
Wellia et al. (2011) reported that a metal might be placed in the lattice crystal of $\mathrm{TiO}_{2}$, where it causes some changes in the electronic properties of the photocatalyst. It can be concluded that most of silver and especially iron ions in the process of doping are substituted with titanium in the crystal lattice of $\mathrm{TiO}_{2}$ with low amount of $\mathrm{Fe}_{2} \mathrm{O}_{3}$ located on the surface of $\mathrm{TiO}_{2}$. However, the XRD diffractograms show a very low amount of bare $\mathrm{Fe}_{2} \mathrm{O}_{3}$ particles in the mixed oxide system of the $\mathrm{Ag} / \mathrm{TiO}_{2} / \mathrm{Fe}_{2} \mathrm{O}_{3}$ photocatalyst.

In the previous study (Nasirian et al., 2017), it was found that the best calcination temperature was $300^{\circ} \mathrm{C}$ for $\mathrm{Ag} / \mathrm{TiO}_{2}$ or combined photocatalysts $\left(\mathrm{Fe}_{2} \mathrm{O}_{3} / \mathrm{TiO}_{2}\right)$. It was also found that the sample calcined at $300^{\circ} \mathrm{C}$ contained only the anatase form. According to Pal et al. (1999) and Dai et al. (2010), by increasing the calcination temperature, the intensity of anatase peak decreases while the intensity of the rutile peak is amplified. At $900^{\circ} \mathrm{C}$, there is only the rutile phase with the maximum crystallinity. Results also show that a specific calcination temperature is required to make a purer photocatalyst crystal, whereas at high calcination temperatures (more than $600^{\circ} \mathrm{C}$ ), the activity of photocatalysts is reduced. It is obvious that at high calcination temperatures, the magnetic properties of iron oxides are strongly reduced (Kim et al., 2016). Doping $\mathrm{TiO}_{2}$ with noble metals, such as $\mathrm{Ag}, \mathrm{Au}$ and $\mathrm{Pt}$, increases the photocatalytic activity of the $\mathrm{TiO}_{2}$ photocatalyst.

Images taken using SEM and result from EDS elemental analysis showed that $\mathrm{Ag}^{+}$and $\mathrm{Fe}^{3+}$ particles are uniformly dispersed in the mixed oxide samples of $\mathrm{Ag} / \mathrm{TiO}_{2} / \mathrm{Fe}_{2} \mathrm{O}_{3}$. In other words, the ratio of atomic percentage of $\mathrm{Ag}, \mathrm{Ti}$, and $\mathrm{Fe}$ found by EDS are closed to the expected concentrations. At high mass ratios of $\mathrm{Fe}_{2} \mathrm{O}_{3}: \mathrm{TiO}_{2}$, due to the limitation of solubility of $\mathrm{Fe}^{3+}$ ions, the composite photocatalysts contain an excess of $\mathrm{Fe}_{2} \mathrm{O}_{3}$, which has not been diffused into the $\mathrm{TiO}_{2}$ 
lattice. In other words, the excess of $\mathrm{Fe}_{2} \mathrm{O}_{3}$ in the composite photocatalyst is dispersed on the surface of $\mathrm{TiO}_{2}$.

\subsubsection{Photocatalytic degradation of organics using $\mathrm{UV} / \mathrm{Ag} / \mathrm{TiO}_{2} / \mathrm{Fe}_{2} \mathrm{O}_{3}$}

Figure 9.6a shows the photocatalytic degradation of MO using the synthesized $\mathrm{Ag} / \mathrm{Fe}_{2} \mathrm{O}_{3} / \mathrm{TiO}_{2}$ photocatalyst and UV-A at different mass ratios of $\mathrm{Ag}$ and $\mathrm{Fe}$ to $\mathrm{TiO}_{2}$ (Ag: $: \mathrm{TiO}_{2}=0.01$ and $\mathrm{Fe}: \mathrm{TiO}_{2}=0.05$ w:w; $\mathrm{Ag}: \mathrm{TiO}_{2}=0.01$ and $\mathrm{Fe}: \mathrm{TiO}_{2}=0.01$ w:w; and $\mathrm{Ag}: \mathrm{TiO}_{2}=0.005$ and $\left.\mathrm{Fe}: \mathrm{TiO}_{2}=0.01 \mathrm{w}: \mathrm{w}\right)$. The photocatalytic activity of $\mathrm{Ag} / \mathrm{TiO}_{2} / \mathrm{Fe}_{2} \mathrm{O}_{3}$ composite photocatalyst is strongly dependent on the mass ratio of $\mathrm{Fe}$ and $\mathrm{Ag}$ to $\mathrm{TiO}_{2}$. Results show that composite photocatalyst of $\mathrm{Ag} / \mathrm{TiO}_{2} / \mathrm{Fe}_{2} \mathrm{O}_{3}$ with the mass ratio of $0.005 \mathrm{Ag}: \mathrm{TiO}_{2}$ and $0.01 \mathrm{Fe}: \mathrm{TiO}_{2}$ has the highest photocatalytic activity for the degradation of $\mathrm{MO}(79.5 \%)$ in aqueous solutions.

Results also show that the degradation efficiency of the $\mathrm{Ag} / \mathrm{TiO}_{2} / \mathrm{Fe}_{2} \mathrm{O}_{3}$ at optimum mass ratio is higher than that of $\mathrm{Fe}_{2} \mathrm{O}_{3} / \mathrm{TiO}_{2}$ at optimum amount mass ratio and that of bare $\mathrm{TiO}_{2}$. High amount of silver or iron loadings, beyond the optimum level, onto the $\mathrm{TiO}_{2}$ decreases the available surface area for the adsorption of organic materials and blocks the light absorption, consequently a decrease in the photocatalytic activity. Based on the photo-generation of electron/hole pair in photocatalysts, electron is reducer and hole is oxidizer. Although holes are oxidizers and produce hydroxyl radicals, oxygen molecules in water samples scavenge electrons generated from the photo-activation of catalysts; thus, several kinds of superoxides are produced. Subsequently, superoxides in a series of reactions react with water and produce hydroxyl radicals. According to Yang et al. (2000) and based on results obtained from thermal desorption spectroscopy (TDS), in combined photocatalysts, $\mathrm{O}_{2}^{-}, \mathrm{O}^{-}$, and $\mathrm{O}_{3}^{-}$can be adsorbed on the surface of photocatalysts and then desorb at high temperature $\left(114^{\circ} \mathrm{C}\right)$. The rate of adsorption of oxygen in the surface of 
combined photocatalysts is higher than that of bare photocatalysts. High adsorption of superoxide causes a higher degradation of organics. Kim et al. (2016) reported that in the XPS analysis of combined $\mathrm{Fe}_{2} \mathrm{O}_{3} / \mathrm{TiO}_{2}$ photocatalyst (calcined at $700^{\circ} \mathrm{C}$ ), a separate peak related to the oxygen vacancies was obtained. Oxygen defects cause an increase in the photocatalytic activity of $\mathrm{Fe}_{2} \mathrm{O}_{3} / \mathrm{TiO}_{2}$.

Kim et al. (2016) suggested a mechanism based on trapping of water molecules by oxygen vacancies and then, the adsorbed water dissociated into $\mathrm{O}_{2}^{-}, \mathrm{H}_{2} \mathrm{O}_{2}$, and $\mathrm{HO}^{\bullet}$ radicals, which are highly reactive species. Consequently, the enhancement of the photocatalytic activity of the $\mathrm{Ag} / \mathrm{TiO}_{2} / \mathrm{Fe}_{2} \mathrm{O}_{3}$ photocatalyst is mainly attributed to the titanium and oxygen defects in the crystal and to the modification of the electronic structure of $\mathrm{TiO}_{2}$, which can reduce the recombination rate of electron/hole pairs and/or reduce the band gap energy.

Figure 9.6b, shows degradation efficiency of the $\mathrm{Ag} / \mathrm{TiO}_{2} / \mathrm{Fe}_{2} \mathrm{O}_{3}$ photocatalyst with different mass ratio under natural sunlight. The highest amount of the MO degradation reached to 95.6\%. In other words, the photocatalyst could absorb visible light to generate electron/hole pairs to degrade organic materials, which means a red shift occurred. Another advantage of applying the $\mathrm{Ag} / \mathrm{TiO}_{2} / \mathrm{Fe}_{2} \mathrm{O}_{3}$ photocatalyst is its easy separation from the slurry due to its electromagnetic characteristic of $\mathrm{Ag} / \mathrm{TiO}_{2} / \mathrm{Fe}_{2} \mathrm{O}_{3}$. This separation is easily done by applying a proper electromagnetic field or, at least, applying a ferromagnetic material and passing suspension through the field. 

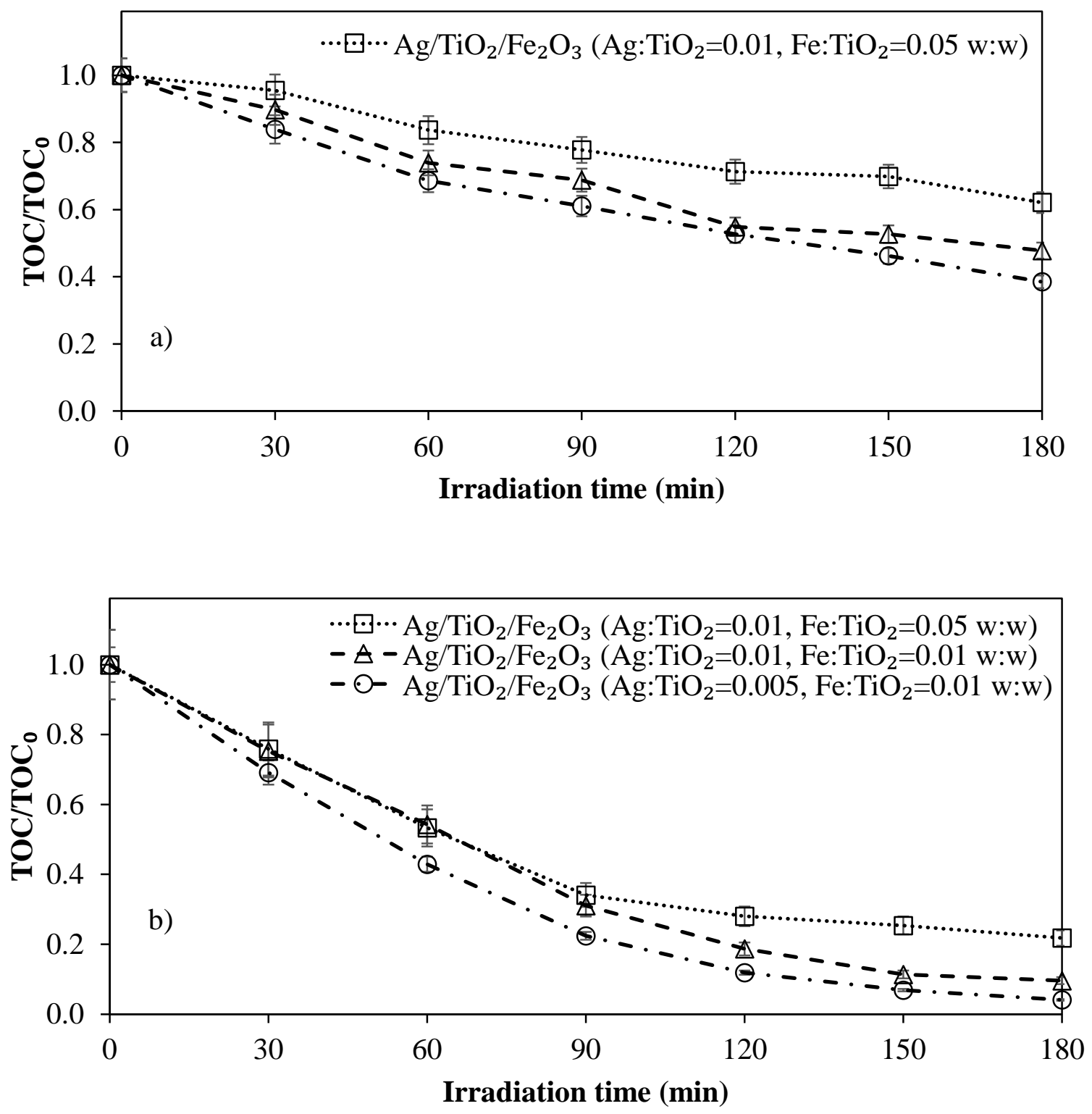

Figure 9.6. Degradation of methyl orange in presence of composites of $\mathrm{Ag} / \mathrm{Fe}_{2} \mathrm{O}_{3} / \mathrm{TiO}_{2}$ photocatalyst at different mass ratios of $\mathrm{Fe}$ and $\mathrm{Ag}$ under (a) UV-A 45W and (b) natural sunlight irradiation (Concentration of photocatalyst in each case $=500 \mathrm{mg} / \mathrm{L}$ ). Submitted to J. Environ. Manage. (2017). 


\subsection{Conclusions}

Doping transition metals onto $\mathrm{TiO}_{2}$ and the combination of two semiconductor oxides are two appropriate alternatives to improve photocatalytic activity of the bare $\mathrm{TiO}_{2}$ in order to degrade organics. This could change the electronic structure and the band gap energy of the main photocatalyst. To get past current restrictions of the fast rate of electron-hole recombination, a novel $\mathrm{Ag} / \mathrm{TiO}_{2} / \mathrm{Fe}_{2} \mathrm{O}_{3}$ photocatalyst was synthesized to improve the photocatalytic activity of $\mathrm{TiO}_{2}$.

Results show that the degradation of methyl orange using $\mathrm{Ag} / \mathrm{TiO}_{2} / \mathrm{Fe}_{2} \mathrm{O}_{3}\left(\mathrm{Ag}: \mathrm{TiO}_{2}=0.005 \mathrm{w}\right.$ : w and $\left.\mathrm{Fe}: \mathrm{TiO}_{2}=0.01 \mathrm{w}: \mathrm{w}\right)$ reached to $89.5 \%$ under UV-A radiation and $95.6 \%$ under natural sun light. In other words, by applying $\mathrm{Ag} / \mathrm{TiO}_{2} / \mathrm{Fe}_{2} \mathrm{O}_{3}$ a red shift was observed. In this study, the new composite of $\mathrm{Ag} / \mathrm{TiO}_{2} / \mathrm{Fe}_{2} \mathrm{O}_{3}$ was synthesized by the novel UV-assisted thermal method as an alternative method to enhance the generation and the lifetime of electron/hole pairs as well as to improve its photocatalytic activity for the degradation of an azo dye. Results also showed that combining of two photocatalyst of $\mathrm{TiO}_{2}$ and $\mathrm{Fe}_{2} \mathrm{O}_{3}$ and then doping silver ion onto combined photocatalyst caused the substitution impurity and point defect in the crystal. The diffractogram of $\mathrm{Ag} / \mathrm{TiO}_{2} / \mathrm{Fe}_{2} \mathrm{O}_{3}$ with different concentration of dopant ( $\mathrm{Ag}$ and $\mathrm{Fe}$ ) calcined at $300^{\circ} \mathrm{C}$ showed that all photocatalysts are in anatase form. 


\section{CHAPTER 10}

\section{CONCLUSIONS AND RECOMMENDATIONS}

\subsection{Conclusions}

The following conclusions are drawn from this thesis:

- To overcome the restrictions of the fast rate of electron-hole recombination and slight excitation in solar irradiation, doping with noble metals/non-metals and combination of two semiconductor oxides are two convenient alternatives.

- In the first part of the study, $\mathrm{Ag} / \mathrm{TiO}_{2}$ and $\mathrm{Fe}_{2} \mathrm{O}_{3} / \mathrm{TiO}_{2}$ with the different mass ratios of $\mathrm{Ag}: \mathrm{TiO}_{2}$ and $\mathrm{Fe}: \mathrm{TiO}_{2}$ were synthesized. A series of experiments was carried out for the photocatalytic treatment of two azo dyes, methyl orange (MO) and Congo red (CR), under UV-visible irradiation. Results showed that the combined $\mathrm{Fe}_{2} \mathrm{O}_{3} / \mathrm{TiO}_{2}$ photocatalyst with mass ratio of $\mathrm{Fe}: \mathrm{TiO}_{2}=0.005$ (w:w) had the highest efficiency for the degradation of $\mathrm{MO}$ (16.7\%) and $\mathrm{CR}(10.6 \%)$ compared to that of $\mathrm{Ag} / \mathrm{TiO}_{2}$. Results also showed that silver doped $\mathrm{TiO}_{2}$ increases the degradation of $\mathrm{MO}(12.2 \%)$ and CR $(14.5 \%)$ compared to that of bare $\mathrm{TiO}_{2}$.

- Doping metals into $\mathrm{TiO}_{2}$ hinders the recombination of electron-hole pairs. Doping different metal ions showed different photoactivities because of various electron affinities (charge transferability) of doped metals, difference in surface area, and their physicochemical properties.

- In the second part of the study, effects of calcination temperature of $\mathrm{Fe}_{2} \mathrm{O}_{3} / \mathrm{TiO}_{2}$ for the degradation of typical dyes (MO and CR) in textile industries were investigated. Results confirmed that at high calcination temperatures of $900^{\circ} \mathrm{C}$, the composite $\mathrm{Fe}_{2} \mathrm{O}_{3} / \mathrm{TiO}_{2}$ 
photocatalyst (regardless of the mass ratio of $\mathrm{Fe}: \mathrm{TiO}_{2}$ ) is entirely in the rutile phase; thus, the photocatalyst had the lowest specific surface area, a high degree of crystallinity, bigger size, but a reduced photocatalytic activity.

- At the optimum calcination temperature of $300^{\circ} \mathrm{C}$ for the photocatalyst preparation, the specific surface area was at maximum and the photocatalyst had the highest photoactivity, at which the degradation of organic materials was maximum.

- The calcination temperatures can change the activity of a photocatalyst because of the variations in the specific surface area, the degree of crystallinity, and the phase conversion.

- Results from this study also demonstrated that the synthesis of composite $\mathrm{Fe}_{2} \mathrm{O}_{3} / \mathrm{TiO}_{2}$ by the novel UV-assisted thermal method, as an alternative method to synthesize combined photocatalysts, enhanced the lifetime of photo-generated electron/hole pairs and increased its photocatalytic activity for the degradation of typical dyes in textile industries.

- In the third part of this thesis, nitrogen as a non-metal was doped onto $\mathrm{TiO}_{2}$ using three different methods with two precursors (source of nitrogen) of urea and $\mathrm{HNO}_{3}$ and different mass ratio of $\mathrm{N}: \mathrm{TiO}_{2}$. To synthesize $\mathrm{N}-\mathrm{TiO}_{2}$ photocatalyst three different methods including UV-assisted thermal synthesis with urea and $\mathrm{HNO}_{3}$, the annealing with urea, and the microwave assisted with urea and $\mathrm{HNO}_{3}$, was utilized. By applying annealing method and UV-assisted thermal synthesis, an increase in the MO degradation of 20.4 and 16.5\%, was respectively observed when compared to that of the bare $\mathrm{TiO}_{2}$. It was also observed that by increasing the mass ratio of nitrogen as dopant to $\mathrm{TiO}_{2}$, the degradation of $\mathrm{MO}$ was increased up to an optimum amount of the $\mathrm{N}: \mathrm{TiO}_{2}$ (mass ratio of $\mathrm{N}: \mathrm{TiO}_{2}=0.15 \mathrm{w}: \mathrm{w}$ ) and then the degradation decreased. 
- The annealing method and UV-assisted thermal synthesis were found to be more efficient regarding preparation materials, treatment time, and costs. The UV-assisted thermal synthesis can be practiced using a variety of precursors; whereas, the annealing methods is restricted to solid form precursors.

- The diffractograms of the $\mathrm{N}-\mathrm{TiO}_{2}$ photocatalyst prepared by the novel UV-assisted thermal synthesis showed that the as prepared photocatalyst was in the P25 form, nitrogen ions penetrated in the crystal, substitution of nitrogen with oxygen occurred, and distortion in the crystal appeared.

- The effects of the light intensity, light wavelength and radiation source, initial concentration of TOC, and $\mathrm{pH}$ on the degradation efficiency of methyl orange in presence of $\mathrm{N}-\mathrm{TiO}_{2}$ photocatalyst was investigated. A four-factor Box-Behnken Design along with response surface methodology (RSM) was used to maximize the removal of total organic carbon and color from the azo dye wastewater. Results from this part of study demonstrated that the light intensity, light wavelength, initial TOC concentration, and $\mathrm{pH}$ presented considerable effects on both the percent TOC and color removals. The cross-factor interaction effects between independent factors were also evaluated. The cross-factor interaction between the light wavelength with the initial TOC concentration and those of the light intensity with the initial TOC concentration and light intensity with the $\mathrm{pH}$ were found to have a high significant effect on both TOC and color removals for the photocatalytic treatment of azo dyes to minimize treatment-related costs.

- Maximum TOC and color removal efficiencies of 96.11 and $91.88 \%$, respectively, were achieved at the optimum operating conditions of light intensity in terms of 5 lamps, light wavelength of $418 \mathrm{~nm}$ (visible light range), initial TOC concentration of $10.54 \mathrm{mg} / \mathrm{L}$, and 
$\mathrm{pH}$ of 5.14 based on the developed quadratic models and the desirability multiple-response method. Result confirm the proposed statistical models could successfully describe the degradation of azo dyes by photocatalysis using the $\mathrm{N}$-doped $\mathrm{TiO}_{2}$ composite under visible light and could be utilized as a base for future research on photoreactor design, process optimization, and scale-up studies.

- Results from a comprehensive review study showed that among all non-metal doped $\mathrm{TiO}_{2}$, (including B, C, N, F, S, P and F-doped $\mathrm{TiO}_{2}$ ), $\mathrm{N}$ doped $\mathrm{TiO}_{2}$ and N/S doped $\mathrm{TiO}_{2}$ have been commonly studied and were proven to be the most efficient route of non-metal doping.

- An improved light absorption in the visible region of the spectrum was experienced after doping non-metal elements onto $\mathrm{TiO}_{2}$ using doping methods. Results also showed that the annealing and hydrothermal methods are found to be more efficient for non-metal doped $\mathrm{TiO}_{2}$ regarding preparation time and cost.

- In the last part of the study, a novel composite photocatalyst of $\mathrm{Ag} / \mathrm{TiO}_{2} / \mathrm{Fe}_{2} \mathrm{O}_{3}$ was synthesized by combining of two photocatalysts $\left(\mathrm{TiO}_{2}\right.$ and $\left.\mathrm{Fe}_{2} \mathrm{O}_{3}\right)$ and then doping with a noble metal (Ag) to the combined photocatalyst. Results showed that degradation of MO in presence of the novel $\mathrm{Ag} / \mathrm{TiO}_{2} / \mathrm{Fe}_{2} \mathrm{O}_{3}$ (with mass ratio of $\mathrm{Ag}: \mathrm{TiO}_{2}=0.005$, and mass ratio of $\left.\mathrm{Fe}: \mathrm{TiO}_{2}=0.01 \mathrm{w}: \mathrm{w}\right)$ photocatalyst reached to $89.5 \%$ under UV-A radiation and $95.6 \%$ under natural sun light. Results showed that doping metals or combining photocatalysts could change the electronic structure and band gap energy of the main photocatalyst. By applying the $\mathrm{Ag} / \mathrm{TiO}_{2} / \mathrm{Fe}_{2} \mathrm{O}_{3}$ photocatalyst, a red shift towards the visible light was observed.

- The novel UV-assisted thermal method as an alternative method for synthesis of new composite of $\mathrm{Ag} / \mathrm{TiO}_{2} / \mathrm{Fe}_{2} \mathrm{O}_{3}$ showed an enhancement to increase lifetime of electron/hole pairs and improve its photocatalytic activity for the degradation of organics. Results also 
showed that combining $\mathrm{TiO}_{2}$ with $\mathrm{Fe}_{2} \mathrm{O}_{3}$ photocatalyst and then $\mathrm{Ag}$ doped to the combined photocatalysts caused a substitution impurity and point defect in the crystal.

\subsection{Recommendations}

- It is recommended to apply experimental design along with response surface methodology in order to find optimum conditions for the removal of organics and understand the effect of each parameter and their cross-factor interactions in the presence of the novel $\mathrm{Ag} / \mathrm{TiO} 2 / \mathrm{Fe}_{2} \mathrm{O}_{3}$ photocatalyst.

- Separation of photocatalysts in the slurry form reactor is a problem limiting widespread application of photocatalytic oxidation. In order to escape of the problem after degradation of organics in slurry form, it is recommended to design an immobilize reactor and then degradation of organics in presence of new photocatalyst of $\mathrm{Ag} / \mathrm{TiO}_{2} / \mathrm{Fe}_{2} \mathrm{O}_{3}$ examine.

- The novel UV-assisted thermal synthesis produced encouraging results as a preparation method for the metal/non-metal and combined photocatalysts; thus, further studies are recommended for photoreactor design to absorb more UV-C light, process optimization, immobilazation, and scale-up to evaluate its applicability in actual wastewater treatment.

- It is recommended to apply sonolysis along with $\mathrm{N}_{-}-\mathrm{TiO}_{2}$ photocatalyst prepared by UVassisted thermal synthesis to underestand effect of sonolysis in degradation proficiency of organics.

- It is recommended to dope nitrogen or sulphur (as an non-metal) onto composite photocatalyst of $\mathrm{Ag} / \mathrm{TiO}_{2} / \mathrm{Fe}_{2} \mathrm{O}_{3}$ to prepare a new photocatalyst of $\mathrm{N} / \mathrm{Ag} / \mathrm{TiO}_{2} / \mathrm{Fe}_{2} \mathrm{O}_{3}$ and $\mathrm{S} / \mathrm{Ag} / \mathrm{TiO}_{2} / \mathrm{Fe}_{2} \mathrm{O}_{3}$, then degradation efficiency of organic materials in presence of new photocatalyst investigate. 
- Results from review study showed that among all non-metal doped $\mathrm{TiO}_{2}, \mathrm{~N}-\mathrm{TiO}_{2}$ and N/S$\mathrm{TiO}_{2}$ have been commonly studied and were the most efficient route of non-metal doping. Meanwhile, more studies need to be conducted focusing on the effect of different factors involved in each synthetic method to determine optimal synthetic conditions for each method.

- It is recommended to synthesize a co-non-metal doped $\mathrm{TiO}_{2}$ photocatlyst $\left(\mathrm{N}-\mathrm{S} / \mathrm{TiO}_{2}\right)$ by applying UV-assissted thermal sythesis method and then investigate degradation efficiency of organic materials in presence of the photocatalyst.

- It is recommended to measure nitrogen in addition to carbon in the organic samples, such as $\mathrm{MO}$ and $\mathrm{CR}$, during photocatalytic degradation of organic materials.

- It is recommended to study the effects of employing $\mathrm{TiO}_{2}$ in $\mathrm{AOPs}$ as it is considered as one of the major pollutant found in wastewater containing pharmaceutical personal care products (PPCPs) and the reuse efficiencies of the novel photocatalyst.

Bare $\mathrm{TiO}_{2}$, metal or non-metal doped $\mathrm{TiO}_{2}$ are considered as nano particles and they have high surface area and tend to agglomerate to diminish their surface area and their energy. It is recommended to investigate effect of agglomeration in photocatalytic activity. 


\begin{tabular}{ll} 
ABBREVIATIONS \\
AOPs & advanced oxidation processes \\
BET & Brunauer, Emmet, and Teller (BET) \\
$\mathrm{Cb}$ & conduction band \\
$\mathrm{CR}$ & Congo red \\
${ }^{\circ} \mathrm{C}$ & degree celcius \\
$\mathrm{e}$ & electron \\
$\mathrm{e} / \mathrm{h}$ & electron/hole \\
$\mathrm{eV}$ & electron volt \\
$\mathrm{h}$ & hour \\
$\mathrm{hh}$ & hole \\
$\mathrm{HO}$ & hydroxyl radical \\
$h v$ & photon's energy \\
$\mathrm{MO}$ & methyl orange \\
$\mathrm{nm}$ & nano meter \\
$\mathrm{PPCPs}$ & pharmaceutical personal care products \\
$\mathrm{SEM}$ & scanning electron microscopy \\
TOC & total organic carbon \\
$\mu \mathrm{m}$ & micro meter \\
$\mathrm{UV}$ & ultraviolet \\
$\mathrm{VWR}$ & Van Waters and Nat Rogers UV Ultra violet \\
$\mathrm{Vb}$ & valence band \\
$\mathrm{W}$ & watt \\
w/w & weight/weight \\
XRD & x-ray diffraction \\
& \\
\hline
\end{tabular}




\title{
APPENDICES
}

\section{Appendix A. The first page of the publications}

\begin{tabular}{ccc} 
Contents lists available at ScienceDirect \\
ELSEVIER & Journal of Environmental Chemical Engineering \\
\hline
\end{tabular}

\section{Modification of $\mathrm{TiO}_{2}$ to enhance photocatalytic degradation of organics in aqueous solutions}

\author{
Mohsen Nasirian ${ }^{\mathrm{a}}$, Mehrab Mehrvar ${ }^{\mathrm{b}, *}$ \\ a Graduate Programs in Environmental Applied Science and Management, Ryerson University, 350 Victoria Street, Taronto, ON, MS B 2K3, Canada \\ ${ }^{b}$ Department of Chemical Engineering, Ryerson University, 350 Victoria Street, Toronto, ON, Canada MS B 2K3, Canada
}

\section{ARTICLE IN F O}

\section{Article history:}

Received 19 May 2016

Received in revised form 1 August 2016

Accepted 10 August 2016

Available online 11 August 2016

Keywords:

Photocatalysis

Wastewater treatment

$\mathrm{TnO}_{2}$

Daping

Combined photocatalysts
A B S T A C T

Heterogeneous photocatalysis, an advanced oxidation process (AOP), has shown to be efficient for the degradation of refractory organics in aqueous solutions into simple compounds. Two issues that arise with the use of unmodified $\mathrm{TiO}_{2}$ are the fast recombination of electron/hole pairs and the lower effectiveness in the presence of visible irradiation. This study aims to develop a photocatalyst by doping transition metals, especially noble metals such as $\mathrm{Ag}$, onto the original $\mathrm{TiO}_{2}$. The combination of photocatalysts is a method to improve the photocatalytic activity for the degradation of organic compounds in wastewater. In this study, first $\mathrm{Ag}$-doped $\mathrm{TiO}_{2}$ is prepared and then, a composite of $\mathrm{Fe}_{2} \mathrm{O}_{3} / \mathrm{TiO}_{2}$ is synthesized in different mass ratios. A series of experiments is conducted for the treatment of two azo dyes, Congo Red (CR) and Methyl Orange (MO), by photocatalysis under the UV-vis irradiation. The degradation of organic materials is measured in terms of total organic carbon (TOC). Scanning electron microscopy (SEM) combined with energy dispersive X-ray spectroscopy (EDS) along with the Brunauer, Emmet, and Teller (BET) method have been utilized to illustrate the characteristics of the prepared powder photocatalysts. X-ray diffraction (XRD) was used to identify crystallinity and phase conversion of the photocatalyst. Results show that silver doped $\mathrm{TiO}_{2}$ increases the degradation of $\mathrm{MO}$ (12.2\%) and $\mathrm{CR}(14.5 \%)$ compared to that of the bare $\mathrm{TiO}_{2}$. The degradation efficiency of MO and CR increases by applying composite photocatalyst of $\mathrm{Fe}_{2} \mathrm{O}_{3} / \mathrm{TiO}_{2}$ in the range of 28.9 and $25.1 \%$, respectively. compared to that of the bare $\mathrm{TiO}_{2}$.

\section{Introduction}

For more than three decades, it has been shown that advanced oxidation processes (AOPS) are promising technologies for the degradation of recalcitrant, refractory, dangerous, and poisonous organic materials in various wastewaters. AOPs are effective methods that are capable of transforming almost all organic pollutants into harmless materials such as water and carbon dioxide. The degradation of organic materials by AOPs is based on the production of highly powerful, reactive, and oxidizing hydroxyl radicals [1-9]. The oxidation reduction potential of hydroxyl radical is $2.85 \mathrm{~V}$, which has a strong capability of oxidizing and can eradicate unselectively all organic pollutants in wastewater [ [10-13]. Some materials such as hydrogen peroxide, ozone, semiconductor catalysts $\left(\mathrm{TiO}_{2}, \mathrm{ZnO}, \mathrm{Fe}_{2} \mathrm{O}_{3}\right)$, or some ions $\left(\mathrm{Fe}^{3+}\right)$ can generate oxidizing radicals in the presence or absence of

\footnotetext{
- Corresponding author.

E-mail address: mmehrvareryerson.ca (M. Mehrvar).
}

ultraviolet or visible light and even under an ultrasonic radiation source. Each of these methods has their own strength and weaknesses.

Photocatalysis is a chemical reaction using light that causes the activation of a substance, which adjusts the speed of a reaction without any alteration or consumption [14,15]. Fujishima and Honda [16], split water into oxygen and hydrogen using $\mathrm{TiO}_{2}$. This innovation initiated the new field of heterogeneous photocatalysis. According to Hashimoto et al. [14], a series of reports called, "autooxidation by $\mathrm{TiO}_{2}$ as a photocatalyst" may have been one of the primary cases outlining the use of $\mathrm{TiO}_{2}$ for its photochemical power.

The electronic configuration of $\mathrm{TiO}_{2}$, as a semiconductor. consists of a filled valence band, an energetic gap, and an empty conduction band. When $\mathrm{TiO}_{2}$ absorbs UV radiation, in which the photon's energy $(h v)$ is greater or equal to the band gap energy, an electron/hole pair is produced [ $17-20]$. During the procedure for oxidative degradation, ${ }^{\circ} \mathrm{OH}$ radicals are formed, which proceed to break down organic molecules. Among different kinds of semiconductor photocatalysts, $\mathrm{TiO}_{2}$ is the most evident due to 
Research article

\title{
Photocatalytic efficiency of $\mathrm{Fe}_{2} \mathrm{O}_{3} / \mathrm{TiO}_{2}$ for the degradation of typical dyes in textile industries: Effects of calcination temperature and UV- assisted thermal synthesis
}

\author{
Mohsen Nasirian ${ }^{\mathrm{a}}$, Ciro Femando Bustillo-Lecompte ${ }^{\mathrm{b}}$, Mehrab Mehrvar b, *

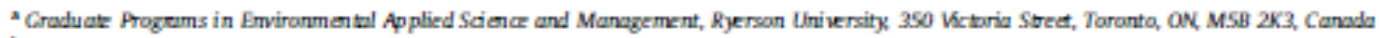 \\ "Department of Chemical Engineering, Ryerson Uniersity, 350 Victoria Street, Toranta, ON, MSB 2K3, Canada
}

\section{A R T I C L E I N F O}

Article histary:

Recrived 14 Jaury 2017

Received in revised form

23 Pebruary 2017

Accepted 12 March 2017

\section{Keywords:}

Photocatal ysis

$\mathrm{AOP}$

Cakcination temperature

$\mathrm{Fe}_{2} \mathrm{O}_{3} \mathrm{TTO}_{2}$

Dye degradation

Photacata yst synthesis

\begin{abstract}
A B S T R A C T
The inadequate management practices in industrial textile effluents have a considerable negative impact on the environment and human heal th due to the indiscriminate release of dyes Thotocatalysis is one of the diverse advance oxidation processes (AOPs) and titanium dioxide $\left(\mathrm{TiO}_{2}\right)$ is recognized for its high axidation and reduction power. A composite photocatalyst of $\mathrm{Fe}_{2} \mathrm{O}_{3} / \mathrm{TiO}_{2}$ is synthesized using different mass ratios of $\mathrm{Fe}: \mathrm{TiO}_{2}$ to improve its photoactivity. The composite photocatalyst is calcined at 300 $-900{ }^{\circ} \mathrm{C}$. Their photocatalytic activity for the degradation of Congo red (CR) and methyl orange (MO) is investigated by total organic carbon (TOC) analysis. The formation and characterization of the asprepared composite are studied by scanning electron microscopy (SEM) coupled with energy dispersive $\mathrm{X}$-ray spectroscopy (EDS). The effect of calcination temperature on the composite $\mathrm{Fe}_{2} \mathrm{O}_{3} / \mathrm{TiO}_{2}$ photocatalyst is investigated using Fourier transform infrared spectroscopy (FTIR). The photocatalytic activity and the phase comversion are studied by X-ray diffraction (XRD). The specific surface area of photocatalysts at different calcination temperatures is investigated based on Brunauer-Emmett-Teller (BET) surface area analysis. Results show that at an optimum calcination temperature of $300^{\circ} \mathrm{C}$ for the photocatalyst preparation, the specific surface area is maximum and the photocatalyst has the highest photoactivity. Thus, the degradation of organic materials reaches $62.0 \%$ for MO and $46.8 \%$ for $C R$ in the presence of $\mathrm{Fe}_{2} \mathrm{O}_{3} / \mathrm{TiO}_{2}\left(0.01 \mathrm{w}: \mathrm{W}\right.$ Fe:TiO $\mathrm{Ti}_{2}$ ) calcined at $300{ }^{\circ} \mathrm{C}$ with the highest specific surface area $\left(98.73 \mathrm{~m}^{2} / \mathrm{g}\right)$. The transformation of $\mathrm{TiO}_{2}$ from anatase to rutile is facilitated by high temperature and high concentration of iron while high crystallization and particle size increase occur. An optimum calcination temperature of $300^{\circ} \mathrm{C}$ is found at which the degradation of typical dyes in text ile industries is maximum.
\end{abstract}

Q 2017 Elsevier Ltd. All rights reserved.

\section{Introduction}

The industrial textile effluents contain a large variety of dyes that without proper treatment prior to their dis posal become toxic to microorganisms and aquatic life. The indiscriminate release of dyes has a considerable negative impact on the environment and human health. Dye byproducts could be produced through oxidation, hydrolysis, or other chemical reactions taking place in wastewater, which may cause eutrophication events. Approximately $20 \%$ of the total dye in worldwide pigment production is lost during the dyeing process and released as part of the textile wastewater effluents (Akpan and Hameed, 2009).

\footnotetext{
- Correspond ing author.

E-mail ad dress: mmehrvareryerso nca (M. Mehrva)

Conventional physicochemical technologies including activated carbon adsorption, membrane technologies, coagulationflocculation, and ion exchange have been used for the removal of dyes. However, these traditional methods only transfer organic compounds from the liquid to the solid phase, which requires further treatment and involves regeneration of the adsorbent or membrane replacement, augmenting the overall treatment costs (Tang and An, 1995; Konstantinou and Albanis, 2004). Consequently, the degradation of dyes from industrial textile effluents has received increasingattention to improve the efficiency of treatment methods. Recent studies have been devoted to the use of advanced oxidation processes (AOPs) for the removal of dyes from wastewater, particularly, because of the ability of these methods to completely mineralize the target pollutants (Aye et al., 2003, 2004; Visa et al., 2011; De Andrade et al., 2012; Zou, 2015; Mohajerani et al., 2011, 2016; Buthiyappan et al., 2016; Nas irian and Mehrvar, 2016). 


\title{
Photocatalytic degradation of aqueous Methyl Orange using nitrogen-doped $\mathrm{TiO}_{2}$ photocatalyst prepared by novel method of ultraviolet-assisted thermal synthesis
}

\author{
Q4 Q3 Mohsen Nasirian ${ }^{1}$, Mehrab Mehruar ${ }^{2, *}$ \\ 1. Graduate Programs in Environmental Applied Science and Management, Ryerson University, Toronto, ON MSB 2K3, Canada \\ 2. Department of Chemical Engineering, Ryerson University, Toronto, ON M5B 2K3, Canada
}

\section{A R T I C L I N F O}

Article history:

Received 11 January 2017

Revised 18 May 2017

Accepted 22 May 2017

Available online $\mathrm{xxxx}$

Keywords:

Ultraviolet-assisted thermal synthesis $\mathrm{N}-\mathrm{TiO}_{2}$

Photocatalysis

Advanced oxidation processes

\section{A B S T R A C T}

A nitrogen-doped titanium dioxide composite photocatalyst $\left(\mathrm{N}-\mathrm{TiO}_{2}\right)$ with heterojunction 16 structures is synthesized by three different approaches: a novel UV-assisted thermal 17 synthesis, annealing, and microwave technique. Photocatalytic activities of synthesized 18 photocatalysts are evaluated by the degradation of Methyl Orange under ultraviolet light 19 types A (UV-A), B (UV-B), and C (UV-C), visible light, and direct sunlight irradiation. Results 20 show that by using $\mathrm{N}-\mathrm{TiO}_{2}$ photocatalyst prepared by the UV-assisted thermal synthesis 21 and annealing, the degradation is increased by $16.5 \%$ and $20.4 \%$, respectively, compared 22 to that by bare $\mathrm{TiO}_{2}$. The best results are obtained at a nitrogen to $\mathrm{TiO}_{2}$ mass ratio of 23 $0.15\left(\mathrm{~N}^{\mathrm{TiO}}{ }_{2}\right)$. The enhancement of the photocatalytic activity observed in the visible range 24 is mainly attributed to the increasing separation rate of photogenerated charge carriers. The 25 novel UV-assisted thermal synthesis has produced encouraging results as a preparation 26 method for the nitrogen-doped $\mathrm{TiO}_{2}$ photocatalyst; thus, further studies are recommended 27 for process optimization, immobilization, and scale-up to evaluate its applicability in 28 wastewater treatment.

2017 The Research Center for Eco-Environmental Sciences, Chinese Academy of Sciences. 30 Published by Elsevier B.V. 31 


\section{Appendix B. Synthesis flowchart of photocatalysts}

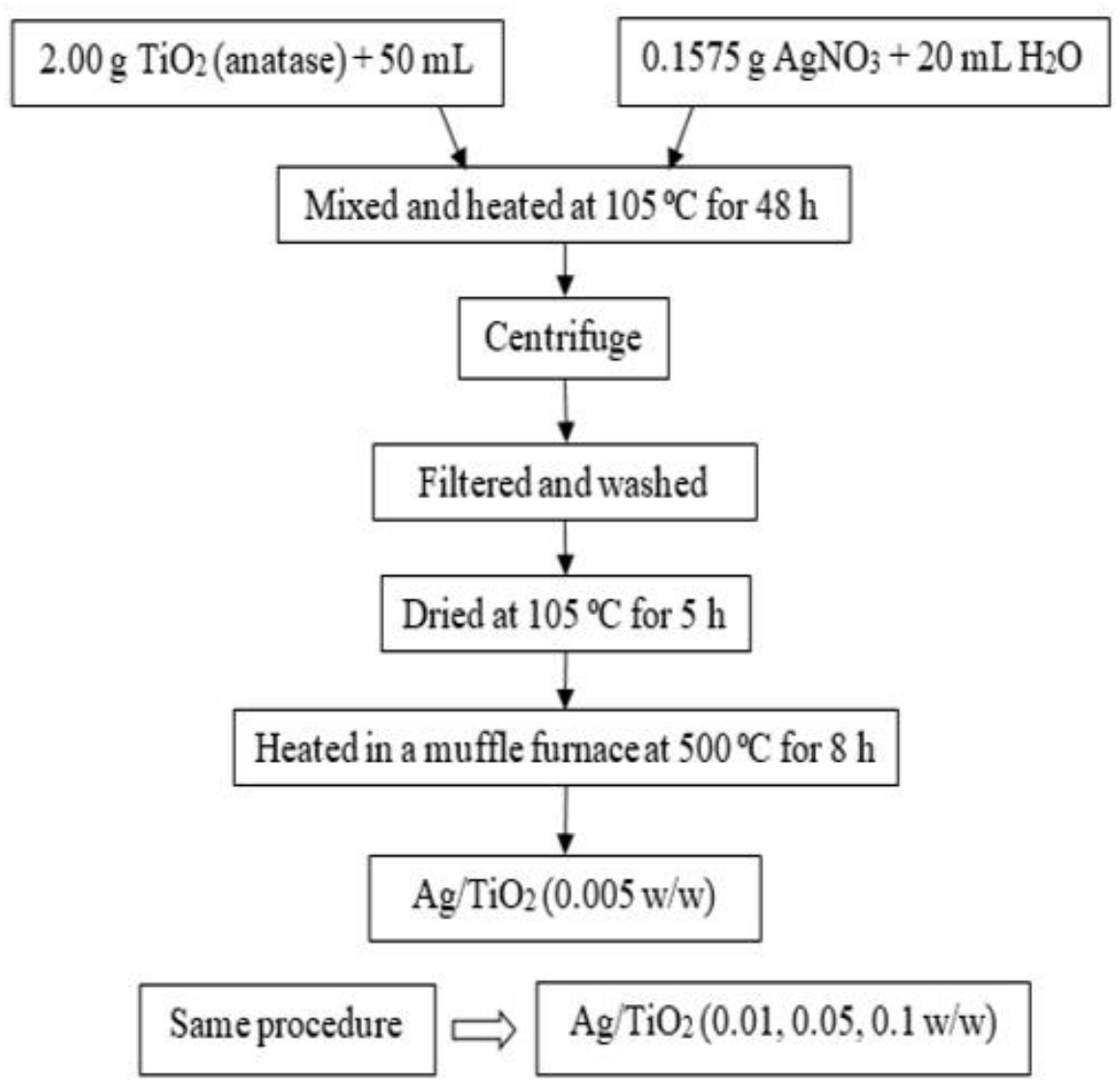

Figure B.1. Flowchart synthesis of nano $\mathrm{Ag} / \mathrm{TiO}_{2}$ photocatalyst with different mass ratio (all Ag: $\mathrm{TiO}_{2}$ are based on mass ratio, w:w). 
$30 \mathrm{~mL}$ of $\mathrm{Fe}\left(\mathrm{NO}_{3}\right)_{3}, 9 \mathrm{H}_{2} \mathrm{O}$ in ethanol was added to $1.5 \mathrm{~g}$ of nanoTiO${ }_{2}$ powder

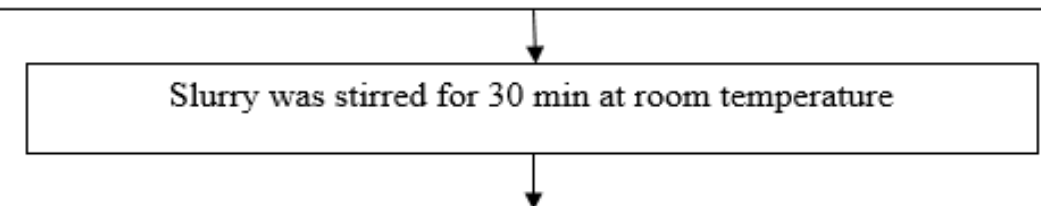

Mixture was heated for $4 \mathrm{~h}$ under continuous magnetic stirrer plus UV-C irradiation

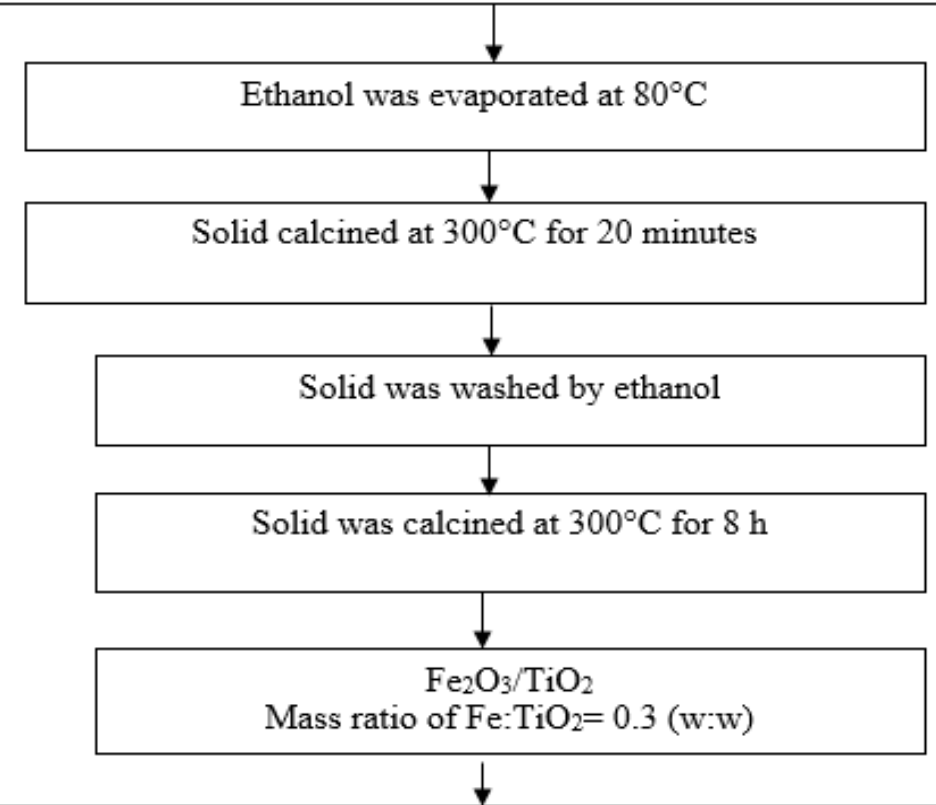

With same procedure $\mathrm{Fe}_{2} \mathrm{O}_{3} / \mathrm{TiO}_{2}$ was prepared with different mass ratio of $\mathrm{Fe}: \mathrm{TiO}_{2}$ $\left(\mathrm{Fe}: \mathrm{TiO}_{2}=0.005,0.01,0.05,0.1\right.$ and 0.3 )

Figure B.2. Flowchart synthesis of nano $\mathrm{Fe}_{2} \mathrm{O}_{3} / \mathrm{TiO}_{2}$, calcined at $300{ }^{\circ} \mathrm{C}$ (all $\mathrm{Fe}: \mathrm{TiO}_{2}$ are based on mass ratio, w:w). 


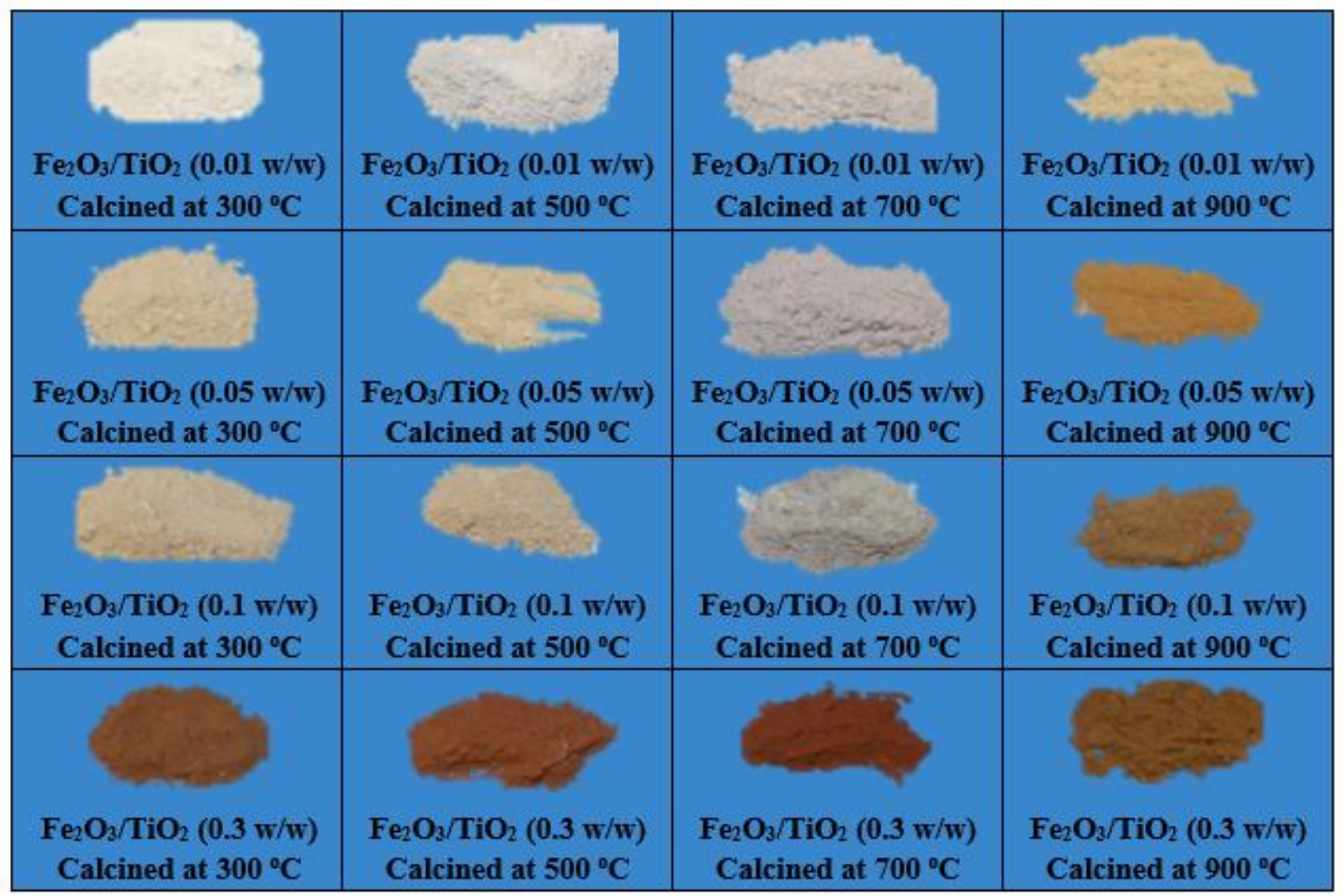

Figure B.3. Synthesized $\mathrm{Fe}_{2} \mathrm{O}_{3} / \mathrm{TiO}_{2}$ with different mass ratio of $\mathrm{Fe}: \mathrm{TiO}_{2}$ at different calcination temperatures. 


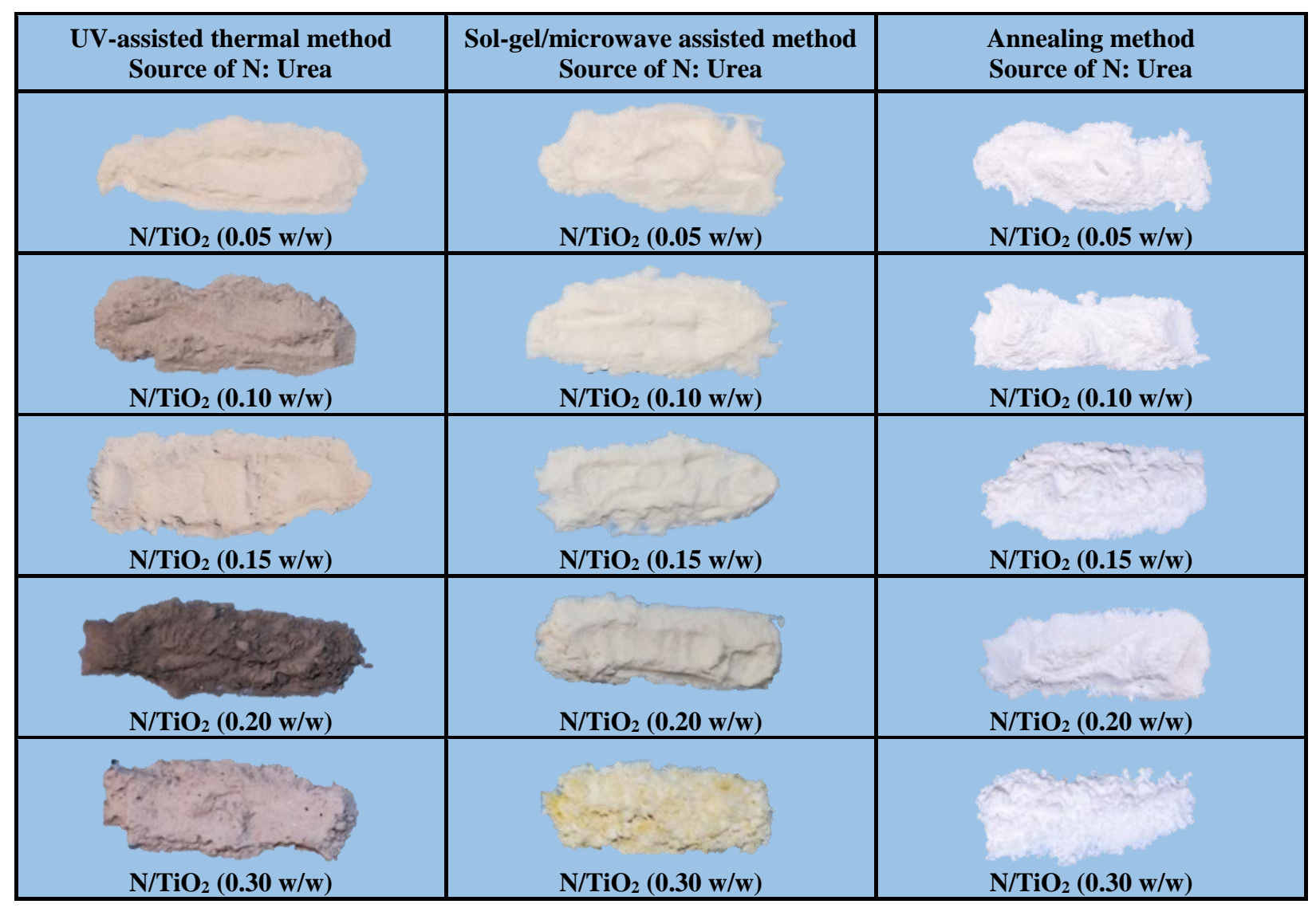

Figure B.4. Synthesized nitrogen doped $\mathrm{TiO}_{2}$ by different preparation methods and different mass ratios. 


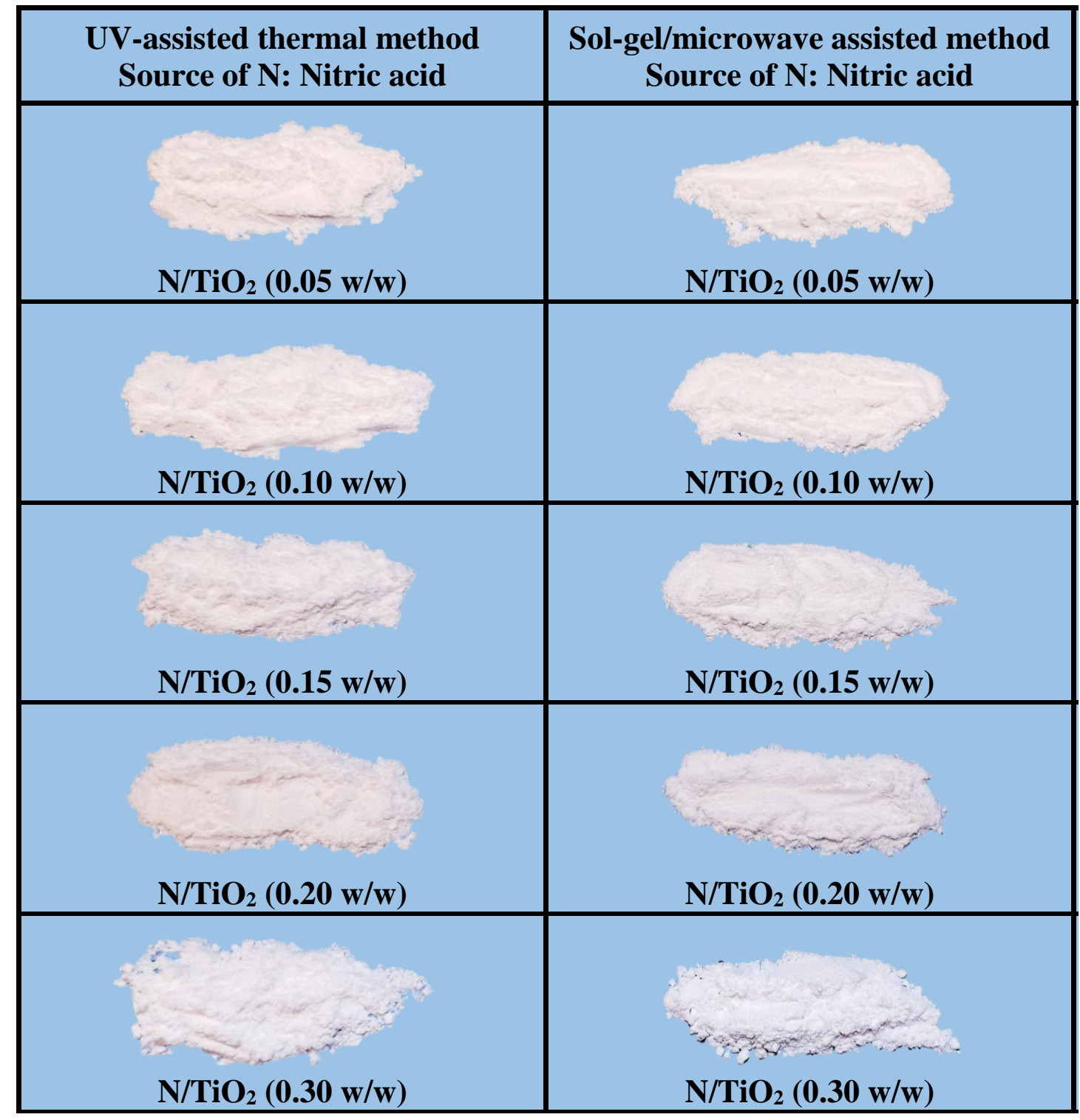

Figure B.5. Continued (synthesized nitrogen doped $\mathrm{TiO}_{2}$ by different preparation methods and different mass ratios). 


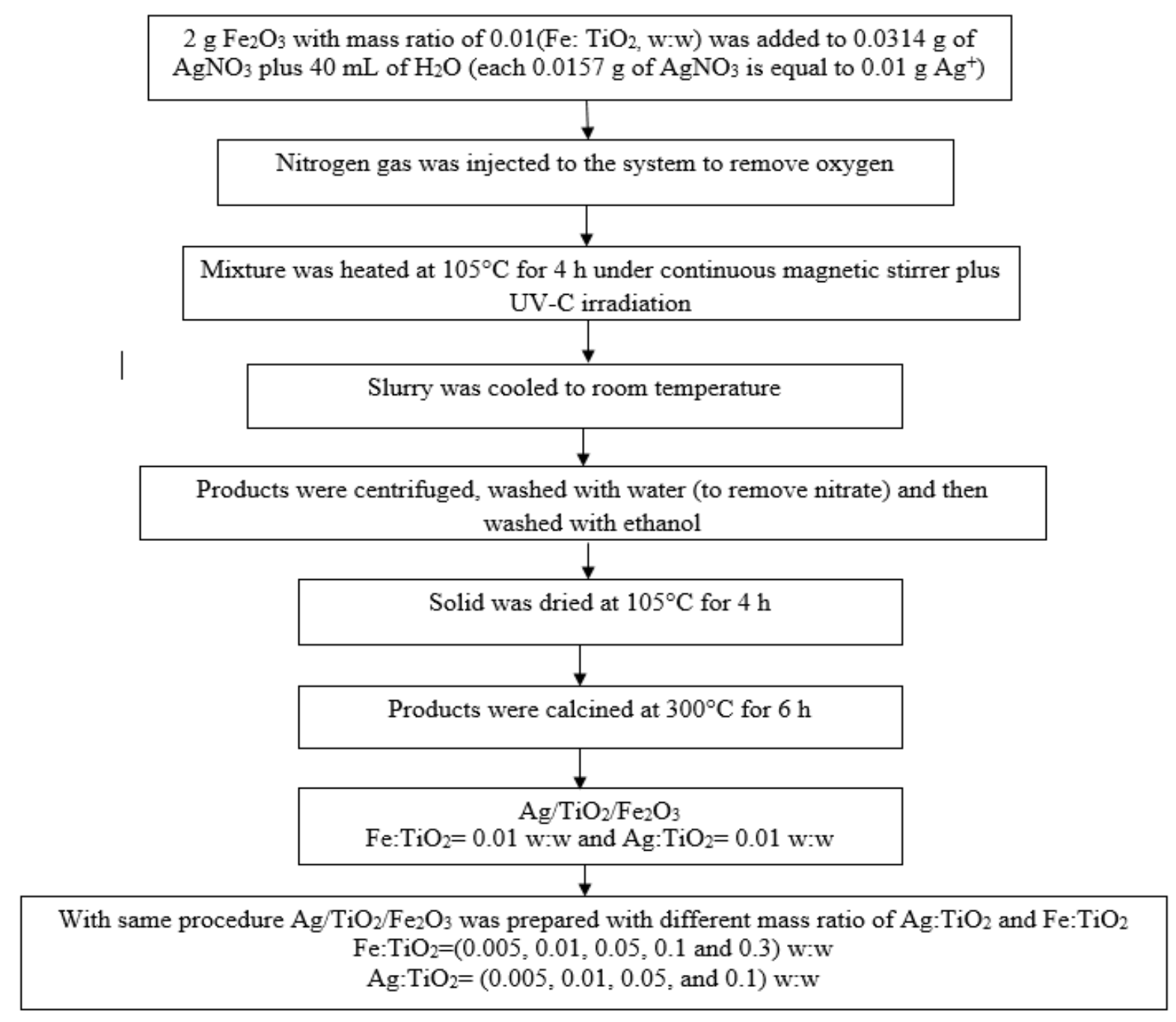

Figure B.6. Flowchart synthesis of $\mathrm{Ag} / \mathrm{TiO}_{2} / \mathrm{Fe}_{2} \mathrm{O}_{3}$ photocatalyst in different mass ratio of Fe: $\mathrm{TiO}_{2}$ and $\mathrm{Ag}: \mathrm{TiO}_{2}$. 


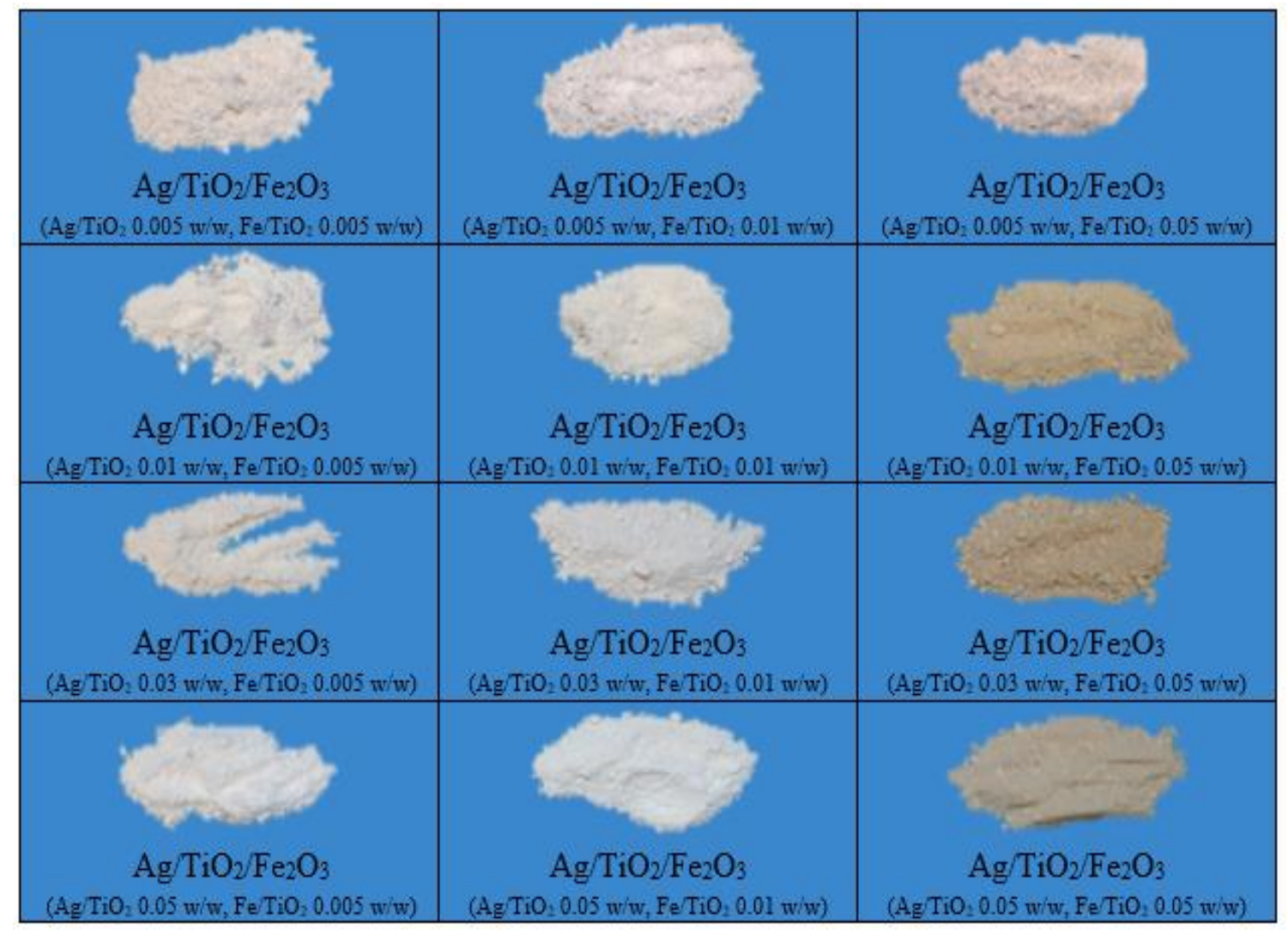

Figure B.7. Synthesized photocatalyst of $\mathrm{Ag} / \mathrm{TiO}_{2} / \mathrm{Fe}_{2} \mathrm{O}_{3}$ with different mass ratio of Ag: $\mathrm{TiO}_{2}$ and $\mathrm{Fe}: \mathrm{TiO}_{2}$ w:w (all mass ratios are based on $\mathrm{Ag}^{\mathrm{TiO}} \mathrm{Ti}_{2}$ and $\mathrm{Fe}: \mathrm{TiO}_{2}$ 


\section{REFERENCES}

Agustina, T.E., Ang, H.M., Vareek, V.K., 2005. A review of synergistic effect of photocatalysis and ozonation on wastewater treatment. Journal of Photochemistry and Photobiology C: $\begin{array}{lllll}\text { Photochemistry } & \text { Reviews, } & 6 & \text { (4), }\end{array}$ https://dx.doi.org/10.1016/j.jphotochemrev.2005.12.003

Agustina, T.E., Ang, H.M., Pareek, V.K., 2008. Treatment of winery wastewater using a photocatalytic/photolytic reactor. Chemical Engineering Journal, 135 (1-2), 151-156. https://dx.doi.org/10.1016/j.cej.2007.07.063

Akpan, U.G., Hameed, B.H., 2009. Parameters affecting the photocatalytic degradation of dyes using $\mathrm{TiO}_{2}$-based photocatalysts: A review. Journal of Hazardous Materials 170 (2-3), 520529. https://dx.doi.org/10.1016/j.jhazmat.2009.05.039

Ali, S.M.Y.M.M., Sandhya, K.Y., 2016. One step solvothermal synthesis of ultra-fine N-doped $\mathrm{TiO}_{2}$ with enhanced visible light catalytic properties. Royal Society of Chemistry Advances, 6, 60522. https://dx.doi.org/10.1039/c6ra09525a

Amano, F., Nogami, K., Tanaka, M., Ohtani, B., 2010. Correlation between surface area and photocatalytic activity for acetaldehyde decomposition over bismuth tungstate particles with a hierarchical structure. Langmuir 26 (10), 7174-7180. https://dx.doi.org/10.1021/la904274c

Ansari, S.A., Khan, M.M., Ansari, M.O., Cho, M.H., 2016. Nitrogen-doped titanium dioxide (Ndoped $\mathrm{TiO}_{2}$ ) for visible light photocatalysis. New Journal of Chemistry, 40, 3000-3009. https://dx.doi.org/10.1039/c5nj03478g

Asahi, R., Morikawa, T., Ohwaki, T., Aoki, K., Taga, Y., 2001. Visible-light photocatalysis in nitrogen-doped titanium oxides. Science, 293 (5528), 269-271. https://dx.doi.org/10.1126/science.1061051

Azami, M.S., Nawawi, W.I., Ishak, M.A.M., Ismail, K., Ahmad, Z., Jawad, A.H., 2016. Carbon nitrogen co-doped P25: Parameter study on photodegradation of reactive red 4. MATEC Web of Conferences, 47, 05018. https://dx.doi.org/10.1051/matecconf/20164705018

Bakar, S.A., Ribeiro, C., 2016a. Prospective aspects of preferential $\{001\}$ facets of N,S-co-doped $\mathrm{TiO}_{2}$ photocatalysts for visible-light-responsive photocatalytic activity. Royal Society of Chemistry Advances, 6, 89274. https://dx.doi.org/10.1039/c6ra16881g

Bakar, S.A., Ribeiro, C., 2016b. A comparative run for visible-light-driven photocatalytic activity of anionic and cationic $\mathrm{S}$-doped $\mathrm{TiO}_{2}$ photocatalysts: A case study of possible sulfur doping through chemical protocol. Journal of Molecular Catalysis A: Chemical, 421, 1-15. https://dx.doi.org/10.1016/j.molcata.2016.05.003

Bakar, S.A., Ribeiro, C., 2016c. Low temperature synthesis of $\mathrm{N}$-doped $\mathrm{TiO}_{2}$ with rice-like morphology through peroxo assisted hydrothermal route: Materials characterization and photocatalytic properties. Applied Surface Science, 377, 121-133. https://dx.doi.org/10.1016/j.apsusc.2016.03.137

Bandara, J., Ranasinghe, R.A.S.S., 2007. The effect of $\mathrm{MgO}$ coating on photocatalytic activity of $\mathrm{SnO}_{2}$ for the degradation of chlorophenol and textile colorants; the correlation between the photocatalytic activity and the negative shift of flatband potential of $\mathrm{SnO}_{2}$. Applied Catalysis A: General, 319, 58-63. https://dx.doi.org/10.1016/j.apcata.2006.11.013

Banerjee, S., Dionysiou, D.D., Pillai, S.C., 2015. Self-cleaning applications of $\mathrm{TiO}_{2}$ by photoinduced hydrophilicity and photocatalysis. Applied Catalysis B: Environmental, 176-177, 396-428. https://dx.doi.org/10.1016/j.apcatb.2015.03.058 
Banisharif, A., Khodadadi, A.A., Mortazavi, Y., Anaraki Firooz, A., Beheshtian, J., Agah, S., Menbari, S., 2015. Highly active $\mathrm{Fe}_{2} \mathrm{O}_{3}$-doped $\mathrm{TiO}_{2}$ photocatalyst for degradation of trichloroethylene in air under UV and visible light irradiation: Experimental and computational studies. Applied Catalysis B: Environmental, 165, 209-221. https://dx.doi.org/10.1016/j.apcatb.2014.10.023

Barakat, M.A., Schaeffer, H., Hayes, G., Ismat-Shah, S., 2005. Photocatalytic degradation of 2chlorophenol by Co-doped $\mathrm{TiO}_{2}$ nanoparticles. Applied Catalysis B: Environmental 57 (1), 23-30. https://dx.doi.org/10.1016/j.apcatb.2004.10.001

Beane, R.J., 2004. Using the scanning electron microscope for discovery based learning in undergraduate courses. Journal of Geoscience Education, 52 (3), 250-253. https://dx.doi.org/10.5408/1089-9995-52.3.250

Blake, D.M., Maness, P.C., Huang, Z., Wolfrum, E.J., Huang, J., Jacoby, W.A., 1999. Application of the photocatalytic chemistry of titanium dioxide to disinfection and the killing of cancer cells. Separation and Purification Methods, 28 (1), 1-50. https://dx.doi.org/10.1080/03602549909351643

Botha, G.E., Oliveira, J.C., Ahrné, L., 2012. Quality optimisation of combined osmotic dehydration and microwave assisted air drying of pineapple using constant power emission. $\begin{array}{llllll}\text { Food and } \quad \text { Bioproducts } & \text { Processing } & 90 & \text { (2), }\end{array}$ https://dx.doi.org/10.1016/j.fbp.2011.02.006

Bustillo-Lecompte, C.F., Ghafoori, S., Mehrvar, M., 2016a. Photochemical degradation of an actual slaughterhouse wastewater by continuous $\mathrm{UV} / \mathrm{H}_{2} \mathrm{O}_{2}$ photoreactor with recycle. Journal of Environmental Chemical Engineering, 4 (1), 719-732. https://dx.doi.org/10.1016/j.jece.2015.12.009

Bustillo-Lecompte, C., Mehrvar, M., Quiñones-Bolaños, E., 2016b. Slaughterhouse Wastewater Characterization and Treatment: An Economic and Public Health Necessity of the Meat Processing Industry in Ontario, Canada. Journal of Geosciences and Environment Protection, 4, 175-186. https://dx.doi.org/10.4236/gep.2016.44021

Bustillo-Lecompte, C.F., Knight, M., Mehrvar, M., 2015. Assessing the performance of $\mathrm{UV} / \mathrm{H}_{2} \mathrm{O}_{2}$ as a pretreatment process in TOC removal of an actual petroleum refinery wastewater and its inhibitory effects on activated sludge. Canadian Journal of Chemical Engineering, 93 (5), 798-807. https://dx.doi.org/10.1002/cjce.22180

Bustillo-Lecompte, C.F., Mehrvar, M., 2015. Slaughterhouse wastewater characteristics, treatment, and management in the meat processing industry: A review on trends and advances. Journal of Environmental Management, 161, 287-302. https://dx.doi.org/10.1016/j.jenvman.2015.07.008

Bustillo-Lecompte, C.F., Mehrvar, M., 2016. Treatment of an actual slaughterhouse wastewater by integration of biological and advanced oxidation processes: Modeling, optimization, and cost-effectiveness analysis. Journal of Environmental Management 182, 651-666. https://dx.doi.org/10.1016/j.jenvman.2016.07.044

Bustillo-Lecompte, C.F., Mehrvar, M., 2017. Treatment of actual slaughterhouse wastewater by combined anaerobic-aerobic processes for biogas generation and removal of organics and nutrients: An optimization study towards a cleaner production in the meat processing industry. Journal of Cleaner Production, 141, 278-289. https://dx.doi.org/10.1016/j.jclepro.2016.09.060

Bustillo-Lecompte, C.F., Mehrvar, M., Quiñones-Bolaños, E., 2013. Combined anaerobic-aerobic and $\mathrm{UV} / \mathrm{H}_{2} \mathrm{O}_{2}$ processes for the treatment of synthetic slaughterhouse wastewater. Journal 
of Environmental Science and Health - Part A Toxic/Hazardous Substances and Environmental $\quad$ Engineering, $\quad 48 \quad$ (9), 1122-1135. https://dx.doi.org/10.1080/10934529.2013.774662

Bustillo-Lecompte, C.F., Mehrvar, M., Quiñones-Bolaños, E., 2014. Cost-effectiveness analysis of TOC removal from slaughterhouse wastewater using combined anaerobic-aerobic and $\mathrm{UV} / \mathrm{H}_{2} \mathrm{O}_{2}$ processes. Journal of Environmental Management, 134, 145-152. https://dx.doi.org/10.1016/j.jenvman.2013.12.035

Buthiyappan, A., Abdul Aziz, A.R., Wan Daud, W.M.A., 2016. Recent advances and prospects of catalytic advanced oxidation process in treating textile effluents. Reviews in Chemical Engineering 32 (1), 1-47. https://dx.doi.org/10.1515/revce-2015-0034

Byranvand, M.M., Kharat, A.N., Fatholahi, L., Beiranvand, Z.M., 2013. A review on synthesis of nano- $\mathrm{TiO}_{2}$ via different methods. Journal of Nanostructures, 3 (1), 1-9. https://dx.doi.org/10.7508/jns.2013.01.001

Cai, J., Xin, W., Liu, G., Lin, D., Zhu, D., 2016. Effect of calcination temperature on structural properties and photocatalytic activity of Mn-C-codoped $\mathrm{TiO}_{2}$. Materials Research 19 (2), 401-407. https://dx.doi.org/10.1590/1980-5373-MR-2015-0381

Cao, Y., Tan, H., Shi, T., Shi, T., Tang, T., Li, J., 2008. Preparation of Ag-doped $\mathrm{TiO}_{2}$ nanoparticles for photocatalytic degradation of acetamiprid in water. Journal of Chemical Technology and Biotechnology, 83 (4), 546-552. https://dx.doi.org/10.1002/jctb.1831

Carey, J.H., Lawrence, J., Tosine, H.M., 1976. Photodechlorination of PCB's in the presence of titanium dioxide in aqueous suspensions. Bulletin of Environmental Contamination and Toxicology, 16 (6), 697-701. https://dx.doi.org/10.1007/BF01685575

Chen, H., Chen, S., Quan, X., Zhang, Y., 2010. Structuring a $\mathrm{TiO}_{2}$-based photonic crystal photocatalyst with schottky junction for efficient photocatalysis. Environmental Science and Technology, 44 (1), 451-455. https://dx.doi.org/10.1021/es902712j

Chen, Y., Crittenden, J.C., Hackney, S., Sutter, L., Hand, D.W., 2005. Preparation of a novel $\mathrm{TiO}_{2}-$ based p-n junction nanotube photocatalyst. Environmental Science and Technology, 39 (5), 1201-1208. https://dx.doi.org/10.1021/es049252g

Chen, Y., Dionysiou, D.D., 2006. Effect of calcination temperature on the photocatalytic activity and adhesion of $\mathrm{TiO}_{2}$ films prepared by the $\mathrm{P}-25$ powder-modified sol-gel method. Journal of Molecular Catalysis A: Chemical 244 (1-2), 73-82. https://dx.doi.org/10.1016/j.molcata.2005.08.056

Cheng, J., Chen, J., Lin, W., Liu, Y., Kong, Y., 2015. Improved visible light photocatalytic activity of fluorine and nitrogen co-doped $\mathrm{TiO}_{2}$ with tunable nanoparticle size. Applied Surface Science, 332, 573-580. https://dx.doi.org/10.1016/j.apsusc.2015.01.218

Choi, W., Termin, A., Hoffmann, M.R., 1994. The role of metal ion dopants in quantum-sized $\mathrm{TiO}_{2}$ : Correlation between photoreactivity and charge carrier recombination dynamics. Journal of Physical Chemistry, 98 (51), 13669-13679. https://dx.doi.org/10.1021/j100102a038

Choi, W., 2006. Pure and modified $\mathrm{TiO}_{2}$ photocatalysts and their environmental applications. Catalysis Surveys from Asia 10 (1), 16-28. https://dx.doi.org/10.1007/s10563-006-9000-2

Chong, M.N., Jin, B., Chow, C.W.K., Saint, C., 2010. Recent developments in photocatalytic water treatment technology: A review. Water Research, 44 (10), 2997-3027. https://dx.doi.org/10.1016/j.watres.2010.02.039

Chong, M.N., Lei, S., Jin, B., Saint, C., Chow, C.W.K., 2009. Optimisation of an annular photoreactor process for degradation of Congo red using a newly synthesized titania 
impregnated kaolinite nano-photocatalyst. Separation and Purification Technology, 67 (3), 355-363. https://dx.doi.org/10.1016/j.seppur.2009.04.001

Chung, J., Chung, J.W., Kwak, S.Y., 2015. Adsorption-assisted photocatalytic activity of nitrogen and sulfur codoped $\mathrm{TiO}_{2}$ under visible light irradiation. Physical Chemistry Chemical Physics, 17 (26), 17279-17287. https://dx.doi.org/10.1039/c5cp02322j

Colón, G., Maicu, M., Hidalgo, M.C., Navío, J.A., 2006. Cu-doped $\mathrm{TiO}_{2}$ systems with improved photocatalytic activity. Applied Catalysis B: Environmental 67 (1-2), 41-51. https://dx.doi.org/10.1016/j.apcatb.2006.03.019

Crittenden, J.C., Liu, J., Hand, D.W., Perram, D.L., 1997. Photocatalytic oxidation of chlorinated hydrocarbons in water. Water Research, 31 (3), 429-438. https://dx.doi.org/10.1016/S0043-1354(96)00267-9

Cuerda-Correa, E.M., Domínguez-Vargas, J.R., Muñoz-Peña, M.J., González, T., 2016. Ultraviolet-Photoassisted Advanced Oxidation of Parabens Catalyzed by Hydrogen Peroxide and Titanium Dioxide. Improving the System. Industrial and Engineering Chemistry Research, 55 (18), 5152-5160. https://dx.doi.org/10.1021/acs.iecr.5b04560

Dai, S., Wu, Y., Sakai, T., Du, Z., Sakai, H., Abe, M., 2010. Preparation of highly crystalline $\mathrm{TiO}_{2}$ nanostructures by acid-assisted hydrothermal treatment of hexagonal-structured nanocrystalline titania/cetyltrimethyammonium bromide nanoskeleton. Nanoscale Research Letters 5 (11), 1829-1835. https://dx.doi.org/10.1007/s11671-010-9720-0

De Andrade, F.V., De Lima, G.M., Augusti, R., Coelho, M.G., Ardisson, J.D., Romero, O.B., 2012. A versatile approach to treat aqueous residues of textile industry: The photocatalytic degradation of Indigo Carmine dye employing the autoclaved cellular concrete/ $\mathrm{Fe}_{2} \mathrm{O}_{3}$ $\begin{array}{lllll}\text { system. } & \text { Chemical } & \text { Engineering } & \text { Journal }\end{array}$ https://dx.doi.org/10.1016/j.cej.2011.10.089

Devi, L.G., Kavitha, R., 2013. A review on non-metal ion doped titania for the photocatalytic degradation of organic pollutants under UV/solar light: Role of photogenerated charge carrier dynamics in enhancing the activity. Applied Catalysis B: Environmental, 140-141, 559-587. https://dx.doi.org/10.1016/j.apcatb.2013.04.035

Di Valentin, C., Pacchioni, G., 2013. Trends in non-metal doping of anatase $\mathrm{TiO}_{2}$ : B, C, N and F. Catalysis Today, 206, 12-18. https://dx.doi.org/10.1016/j.cattod.2011.11.030

Di Valentin, C., Pacchioni, G., Selloni, A., 2004. Origin of the different photoactivity of N-doped anatase and rutile $\mathrm{TiO}_{2}$. Physical Review B - Condensed Matter and Materials Physics, 70 (8), 085116-1-085116-4. https://dx.doi.org/10.1103/PhysRevB.70.085116

Du, C., Zhou, J., Li, F., Li, W., Wang, Y., He, Q., 2016. Extremely fast dark adsorption rate of carbon and nitrogen co-doped $\mathrm{TiO}_{2}$ prepared by a relatively fast, facile and low-cost microwave method. Applied Physics A, 122, 714. https://dx.doi.org/10.1007/s00339-0160231-4

El-Sheikh, S.M., Khedr, T.M., Hakki, A., Ismail, A.A., Badawy, W.A., 2017. Visible light activated carbon and nitrogen co-doped mesoporous $\mathrm{TiO}_{2}$ as efficient photocatalyst for degradation of ibuprofen. Separation and Purification Technology, 173, 258-268. https://dx.doi.org/10.1016/j.seppur.2016.09.034

El-Sheikh, S.M., Zhang, G., El-Hosainy, H.M., Ismail, A.A., O’Shea, K.E., Falaras, P., Kontos, A.G., Dionysiou, D.D., 2014. High performance sulfur, nitrogen and carbon doped mesoporous anatase-brookite $\mathrm{TiO}_{2}$ photocatalyst for the removal of microcystin-LR under visible light irradiation. Journal of Hazardous Materials, 280, 723-733. https://dx.doi.org/10.1016/j.jhazmat.2014.08.038 
Eskandarian, M.R., Choi, H., Fazli, M., Rasoulifard, M.H., 2016. Effect of UV-LED wavelengths on direct photolytic and $\mathrm{TiO}_{2}$ photocatalytic degradation of emerging contaminants in $\begin{array}{llll}\text { water. } & \text { Chemical } & \text { Engineering } & \text { 30urnal, }\end{array}$ https://dx.doi.org/10.1016/j.cej.2016.05.049

Eslami, A., Amini, M.M., Yazdanbakhsh, A.R., Mohseni-Bandpei, A., Safari, A.A., Asadi, A., 2016. N,S co-doped $\mathrm{TiO}_{2}$ nanoparticles and nanosheets in simulated solar light for photocatalytic degradation of non-steroidal anti-inflammatory drugs in water: a comparative study. Journal of Chemical Technology and Biotechnology, 91, 2693-2704. https://dx.doi.org/10.1002/jctb.4877

Etacheri, V., Di Valentin, C., Schneider, J., Bahnemann, D., Pillai, S.C., 2015. Visible-light activation of $\mathrm{TiO}_{2}$ photocatalysts: Advances in theory and experiments. Journal of Photochemistry and Photobiology C: Photochemistry Reviews 25, 1-29. https://dx.doi.org/10.1016/j.jphotochemrev.2015.08.003

Fagan, R., McCormack, D.E., Dionysiou, D.D., Pillai, S.C., 2016. A review of solar and visible light active $\mathrm{TiO}_{2}$ photocatalysis for treating bacteria, cyanotoxins and contaminants of emerging concern. Materials Science in Semiconductor Processing 42, 2-14. https://dx.doi.org/10.1016/j.mssp.2015.07.052

Fan, J., Zhao, L., Yu, J., Liu, G., 2012. The effect of calcination temperature on the microstructure and photocatalytic activity of $\mathrm{TiO}_{2}$-based composite nanotubes prepared by an in-situ template dissolution method. Nanoscale 4 (20), 6597-6603. https://dx.doi.org/10.1039/c2nr32048g

Fujishima, A., Honda, K., 1972. Electrochemical photolysis of water at a semiconductor electrode. Nature, 238 (5358), 37-38. https://dx.doi.org/10.1038/238037a0

Fujishima, A., Rao, T.N., Tryk, D.A., 2000. Titanium dioxide photocatalysis. Journal of Photochemistry and Photobiology C: Photochemistry Reviews, 1 (1), 1-21. https://dx.doi.org/10.1016/S1389-5567(00)00002-2

Galian, R.E., Pérez-Prieto, J., 2010. Catalytic processes activated by light. Energy and Environmental Science, 3 (10), 1488-1498. https://dx.doi.org/10.1039/c0ee00003e

Gao, Y., Masuda, Y., Koumoto, K., 2004. Light-Excited Superhydrophilicity of Amorphous $\mathrm{TiO}_{2}$ Thin Films Deposited in an Aqueous Peroxotitanate Solution. Langmuir, 20 (8), 31883194. https://dx.doi.org/10.1021/la0303207

Gao, B., Lim, T.M., Subagio, D.P., Lim, T.-T., 2010. Zr-doped $\mathrm{TiO}_{2}$ for enhanced photocatalytic degradation of bisphenol A. Applied Catalysis A: General, 375 (1), 107-115. https://dx.doi.org/10.1016/j.apcata.2009.12.025

Gao, H.T., Liu, Y.Y., Ding, C.H., Dai, D.M., Liu, G.J., 2011. Synthesis, characterization, and theoretical study of $\mathrm{N}, \mathrm{S}$-codoped nano- $\mathrm{TiO}_{2}$ with photocatalytic activities. International Journal of Minerals, Metallurgy and Materials, 18 (5), 606-614. https://dx.doi.org/10.1007/s12613-011-0485-y

Gaya, U.I., Abdullah, A.H., 2008. Heterogeneous photocatalytic degradation of organic contaminants over titanium dioxide: A review of fundamentals, progress and problems. Journal of Photochemistry and Photobiology C: Photochemistry Reviews, 9 (1), 1-12. https://dx.doi.org/10.1016/j.jphotochemrev.2007.12.003

Ghorai, T.K., Chakraborty, M., Pramanik, P., 2011. Photocatalytic performance of nanophotocatalyst from $\mathrm{TiO}_{2}$ and $\mathrm{Fe}_{2} \mathrm{O}_{3}$ by mechanochemical synthesis. Journal of Alloys and Compounds, 509 (32), 8158-8164. https://dx.doi.org/10.1016/j.jallcom.2011.05.069 
Giannakas, A.E., Antonopoulou, M., Daikopoulos, C., Deligiannakis, Y., 2016. Characterization and catalytic performance of B-doped, B-N co-doped and B-N-F tri-doped $\mathrm{TiO}_{2}$ towards simultaneous $\mathrm{Cr}(\mathrm{VI})$ reduction and benzoic acid oxidation. Applied Catalysis B: Environmental, 184, 44-54. https://dx.doi.org/10.1016/j.apcatb.2015.11.009

Grabowska, E., Reszczyńska, J., Zaleska, A., 2012. Mechanism of phenol photodegradation in the presence of pure and modified- $\mathrm{TiO}_{2}$ : A review. Water Research, 46 (17), 5453-5471. https://dx.doi.org/10.1016/j.watres.2012.07.048

Grzechulska, J., Hamerski, M., Morawski, A.W., 2000. Photocatalytic decomposition of oil in water. Water Research, 34 (5), 1638-1644. https://dx.doi.org/10.1016/S00431354(99)00275-4

Ha, S.J., Kim, D.H., Moon, J.H, 2015. N-doped mesoporous inverse opal structures for visible$\begin{array}{lllll}\text { light photocatalysts. } & \text { RSC Advances, } 5 & \text { (95), }\end{array}$ https://dx.doi.org/10.1039/c5ra13198g

Hamad, D., Mehrvar, M., Dhib, R., 2014. Experimental study of polyvinyl alcohol degradation in aqueous solution by $\mathrm{UV} / \mathrm{H}_{2} \mathrm{O}_{2}$ process. Polymer Degradation and Stability 103 (1), 75-82. https://dx.doi.org/10.1016/j.polymdegradstab.2014.02.018

Hamad, D., Dhib, R., Mehrvar, M., 2016. Photochemical Degradation of Aqueous Polyvinyl Alcohol in a Continuous UV/ $\mathrm{H}_{2} \mathrm{O}_{2}$ Process: Experimental and Statistical Analysis. Journal of Polymers and the Environment, 24 (1), 72-83. https://dx.doi.org/10.1007/s10924-0160750-2

Hamadanian, M., Reisi-Vanani, A., Majedi, A., 2010. Synthesis, characterization and effect of calcination temperature on phase transformation and photocatalytic activity of $\mathrm{Cu}, \mathrm{S}$ codoped $\mathrm{TiO}_{2}$ nanoparticles. Applied Surface Science 256 (6), 1837-1844. https://dx.doi.org/10.1016/j.apsusc.2009.10.016

Han, C., Andersen, J., Likodimos, V., Falaras, P., Linkugel, J., Dionysiou, D.D., 2014. The effect of solvent in the sol-gel synthesis of visible light-activated, sulfur-doped $\mathrm{TiO}_{2}$ nanostructured porous films for water treatment. Catalysis Today, 224, 132-139. https://dx.doi.org/10.1016/j.cattod.2013.11.052

Hashimoto, K., Irie, H., Fujishima, A., 2005. $\mathrm{TiO}_{2}$ photocatalysis: A historical overview and future prospects. Japanese Journal of Applied Physics, Part 1: Regular Papers and Short Notes and Review Papers, 44 (12), 8269-8285. https://dx.doi.org/10.1143/JJAP.44.8269

Hayashi, H., Hakuta, Y., 2010. Hydrothermal Synthesis of metal oxide nanoparticles in supercritical water. Materials, 3 (7), 3794-3817. https://dx.doi.org/10.3390/ma3073794

Hernández-Alonso, M.D., Fresno, F., Suárez, S., Coronado, J.M., 2009. Development of alternative photocatalysts to $\mathrm{TiO}_{2}$ : Challenges and opportunities. Energy and Environmental Science, 2 (12), 1231-1257. https://dx.doi.org/10.1039/b907933e

Hou, W.M., Ku, Y., 2013. Enhanced photocatalytic decomposition of gaseous isopropyl alcohol in a polymer electrolyte cell. Aerosol and Air Quality Research, 13 (5), 1570-1581. https://dx.doi.org/10.4209/aaqr.2012.10.0298

Ince, N.H., Tezcanlí, G., 2001. Reactive dyestuff degradation by combined sonolysis and ozonation. Dyes Pigments 49 (3), 145-153. https://dx.doi.org/10.1016/S01437208(01)00019-5

Ismail, A.A., 2005. Synthesis and characterization of $\mathrm{Y}_{2} \mathrm{O}_{3} / \mathrm{Fe}_{2} \mathrm{O}_{3} / \mathrm{TiO}_{2}$ nanoparticles by sol-gel method. Applied Catalysis B: Environmental, 58 (1-2), 115-121. https://dx.doi.org/10.1016/j.apcatb.2004.11.022 
Iwase, M., Yamada, K., Kurisaki, T., Ohtani, B., Wakita, H., 2013. A study on the active sites for visible-light photocatalytic activity of phosphorus-doped titanium (IV) oxide particles prepared using a phosphide compound. Applied Catalysis B: Environmental, 140-141, 327332. https://dx.doi.org/10.1016/j.apcatb.2013.04.018

Iwasaki, M., Hara, M., Kawada, H., Tada, H., Ito, S., 2000. Cobalt ion-doped $\mathrm{TiO}_{2}$ photocatalyst response to visible light. Journal of Colloid and Interface Science, 224 (1), 202-204. https://dx.doi.org/10.1006/jcis.1999.6694

Kang, N., Lee, D.S., Yoon, J., 2002. Kinetic modeling of Fenton oxidation of phenol and monochlorophenols. Chemosphere, 47 (9), 915-924. https://dx.doi.org/10.1016/S00456535(02)00067-X

Kim, J., Lee, C.W., Choi, W., 2010. Platinized $\mathrm{WO}_{3}$ as an environmental photocatalyst that generates HO radicals under visible light. Environmental Science and Technology 44 (17), 6849-6854. https://dx.doi.org/10.1021/es101981r

Konishi, J., Fujita, K., Oiwa, S., Nakanishi, K., Hirao, K., 2008. Crystalline $\mathrm{ZrO}_{2}$ monoliths with well-defined macropores and mesostructured skeletons prepared by combining the alkoxyderived sol-gel process accompanied by phase separation and the solvothermal process. Chemistry of Materials, 20 (6), 2165-2173. https://dx.doi.org/10.1021/cm703351d

Konstantinou, I.K., Albanis, T.A., 2004. $\mathrm{TiO}_{2}$-assisted photocatalytic degradation of azo dyes in aqueous solution: Kinetic and mechanistic investigations: A review. Applied Catalysis B: Environmental 49 (1), 1-14. https://dx.doi.org/10.1016/j.apcatb.2003.11.010

Kopf, P., Gilbert, E., Eberle, S.H., 2000. $\mathrm{TiO}_{2}$ photocatalytic oxidation of monochloroacetic acid and pyridine: Influence of ozone. Journal of Photochemistry and Photobiology A: Chemistry, 136 (3), 163-168. https://dx.doi.org/10.1016/S1010-6030(00)00331-2

Legagneux, L., Cabanes, A., Dominé, F., 2002. Measurement of the specific surface area of 176 snow samples using methane adsorption at $77 \mathrm{~K}$. Journal of Geophysical Research Atmospheres, 107 (17), 5-1-5-15. https://dx.doi.org/10.1029/2001JD001016

Lei, X.F., Xue, X.X., Yang, H., Chen, C., Li, X., Niu, M.C., Gao, X.Y., Yang, Y.T., 2015. Effect of calcination temperature on the structure and visible-light photocatalytic activities of $(\mathrm{N}$, $\mathrm{S}$ and C) co-doped $\mathrm{TiO}_{2}$ nano-materials. Applied Surface Science, 332, 172-180. https://dx.doi.org/10.1016/j.apsusc.2015.01.110

Li, D., Chen, F., Jiang, D., Shi, W., Zheng, W., 2016. Enhanced photocatalytic activity of N-doped $\mathrm{TiO}_{2}$ nanocrystals with exposed $\{001\}$ facets. Applied Surface Science, 390, 689-695. https://dx.doi.org/10.1016/j.apsusc.2016.07.149

Li, E.-J., Xia, K., Yin, S.-F., Dai, W.-L., Luo, S.-L., Au, C.-T., 2011. Preparation, characterization and photocatalytic activity of $\mathrm{Bi} 2 \mathrm{O}_{3}-\mathrm{MgO}$ composites. Materials Chemistry and Physics, 125 (1-2), 236-241. https://dx.doi.org/10.1016/j.matchemphys.2010.09.013

Liao, S., Donggen, H., Yu, D., Su, Y., Yuan, G., 2004. Preparation and characterization of $\mathrm{ZnO} / \mathrm{TiO}_{2}, \quad \mathrm{SO}_{4}{ }^{2-} / \mathrm{ZnO} / \mathrm{TiO}_{2}$ photocatalyst and their photocatalysis. Journal of Photochemistry and Photobiology A: Chemistry, 168 (1-2), 7-13. https://dx.doi.org/10.1016/j.jphotochem.2004.05.010

Lin, H.H.H., Lin, A.Y.C., Hung, C.L., 2015a. Photocatalytic oxidation of cytostatic drugs by microwave-treated $\mathrm{N}$-doped $\mathrm{TiO}_{2}$ under visible light. Journal of Chemical Technology and Biotechnology, 90 (7), 1345-1354. https://dx.doi.org/10.1002/jctb.4503

Lin, Y.C., Chien, T.E., Lai, P.C., Chiang, Y.H., Li, K.L., Lin, J.L., 2015b. TiS 2 transformation into $\mathrm{S}$-doped and $\mathrm{N}$-doped $\mathrm{TiO}_{2}$ with visible-light catalytic activity. Applied Surface Science, 359, 1-6. https://dx.doi.org/10.1016/j.apsusc.2015.10.004 
Lin, X., Fu, D., Hao, L., Ding, Z., 2013. Synthesis and enhanced visible-light responsive of C,N,Stridoped $\mathrm{TiO}_{2}$ hollow spheres. Journal of Environmental Sciences (China), 25 (10), 2150 2156. https://dx.doi.org/10.1016/S1001-0742(13)60414-3

Lin, Y., Guo, S., Han, S., Zeng, C., Jiang, N., Song, B., Sun, Y., 2011. The effect of different concentration of nitrogen in $\mathrm{N}, \mathrm{S}$ codoped $\mathrm{TiO}_{2}$. Advanced Materials Research, 183-185, 1791-1794. https://dx.doi.org/10.4028/www.scientific.net/AMR.183-185.1791

Lin, Y., Li, D., Hu, J., Xiao, G., Wang, J., Li, W., Fu, X., 2012. Highly efficient photocatalytic degradation of organic pollutants by PANI-modified $\mathrm{TiO}_{2}$ composite. Journal of Physical Chemistry C, 116 (9), 5764-5772. https://dx.doi.org/10.1021/jp211222w

Liu, H., Dong, X., Nan, L., Ma, H., Chen, X., Zhu, Z., 2015. A novel fabrication of silver-modified $\mathrm{TiO}_{2}$ colloidal-assembled microstructures and enhanced visible photocatalytic activities. Materials Letters 159, 142-145. https://dx.doi.org/10.1016/j.matlet.2015.06.065

Liu, M., Qiu, X., Miyauchi, M., Hashimoto, K., 2013. Energy-level matching of Fe(III) ions grafted at surface and doped in bulk for efficient visible-light photocatalysts. Journal of the $\begin{array}{lllll}\text { American } & \text { Chemical } & \text { Society, } & 135 & \text { (27), }\end{array}$ https://dx.doi.org/10.1021/ja401541k

Liu, Y., Liu, C.-Y., Rong, Q.-H., Zhang, Z., 2003. Characteristics of the silver-doped $\mathrm{TiO}_{2}$ nanoparticles. Applied Surface Science, 220 (1-4), 7-11. https://dx.doi.org/10.1016/S01694332(03)00836-5

Lv, K., Xiang, Q., Yu, J., 2011. Effect of calcination temperature on morphology and photocatalytic activity of anatase $\mathrm{TiO}_{2}$ nanosheets with exposed $\{001\}$ facets. Applied $\begin{array}{lllll}\text { Catalysis } & \text { B: } & \text { Environmental } & 104 & (3-4),\end{array}$ https://dx.doi.org/10.1016/j.apcatb.2011.03.019

Lynch, J., Giannini, C., Cooper, J.K., Loiudice, A., Sharp, I.D., Buonsanti, R., 2015. Substitutional or interstitial site selective nitrogen doping in $\mathrm{TiO}_{2}$ nanostructures. Journal of Physical Chemistry C, 119 (13), 7443-7452. https://dx.doi.org/10.1021/jp512775s

Ma, Y.-S., Chang, C.-N., Chiang, Y.-P., Sung, H.-F., Chao, A.C., 2008. Photocatalytic degradation of lignin using $\mathrm{Pt} / \mathrm{TiO} 2$ as the catalyst. Chemosphere, 71 (5), 998-1004. https://dx.doi.org/10.1016/j.chemosphere.2007.10.061

Malato, S., Fernández-Ibáñez, P., Maldonado, M.I., Blanco, J., Gernjak, W., 2009 Decontamination and disinfection of water by solar photocatalysis: Recent overview and trends. Catalysis Today, 147 (1), 1-59. https://dx.doi.org/10.1016/j.cattod.2009.06.018

Martins, N.C.T., Ângelo, J., Girão, A.V., Trindade, T., Andrade, L., Mendes, A., 2016. N-doped carbon quantum dots/ $\mathrm{TiO}_{2}$ composite with improved photocatalytic activity. Applied Catalysis B: Environmental, 193, 67-74. https://dx.doi.org/10.1016/j.apcatb.2016.04.016

Matthews, R.W., 1991. Photooxidative degradation of coloured organics in water using supported catalysts. $\mathrm{TiO} 2$ on sand. Water Research, 25 (10), 1169-1176. https://dx.doi.org/10.1016/0043-1354(91)90054-T

Mazierski, P., Nischk, M., Golkowska, M., Lisowski, W., Gazda, M., Winiarski, M.J., Klimczuk, T., Zaleska-Medynska, A., 2016. Photocatalytic activity of nitrogen doped $\mathrm{TiO}_{2}$ nanotubes prepared by anodic oxidation: The effect of applied voltage, anodization time and amount of nitrogen dopant. Applied Catalysis B: Environmental, 196, 77-88. https://dx.doi.org/10.1016/j.apcatb.2016.05.006

Mazinani, B., Masrom, A.K., Beitollahi, A., Luque, R., 2014. Photocatalytic activity, surface area and phase modification of mesoporous $\mathrm{SiO}_{2}-\mathrm{TiO}_{2}$ prepared by a one-step hydrothermal 
$\begin{array}{lllll}\text { procedure. } & \text { Ceramics } & \text { International } & 40 & (8),\end{array}$

https://dx.doi.org/10.1016/j.ceramint.2014.03.071

McManamon, C., O'Connell, J., Delaney, P., Rasappa, S., Holmes, J.D., Morris, M.A., 2015. A facile route to synthesis of $\mathrm{S}$-doped $\mathrm{TiO}_{2}$ nanoparticles for photocatalytic activity. Journal of Molecular Catalysis A: Chemical, 406, 51-57. https://dx.doi.org/10.1016/j.molcata.2015.05.002

Mehrvar, M., Anderson, W.A., Moo-Young, M., Reilly, P.M., 2000. Non-linear parameter estimation for a dynamic model in photocatalytic reaction engineering. Chemical Engineering Science 55 (21), 4885-4891. https://dx.doi.org/10.1016/S00092509(00)00114-7

Moecher, D.P., 2004. Characterization and identification of mineral unknowns: A mineralogy term project. Journal of Geoscience Education, 52 (1), 5-9. https://dx.doi.org/10.5408/10899995-52.1.5

Mohajerani, M., Mehrvar, M., Ein-Mozaffari, F., 2011. Correlation and prediction of azo dye degradation by nonlinear least-square regression in combined ozonation and ultrasonolysis processes. Water Quality Research Journal of Canada 46 (3), 250-258. https://dx.doi.org/10.2166/wqrjc.2011.128

Mohajerani, M., Mehrvar, M., Ein-Mozaffari, F., 2016. Degradation of aqueous methylene blue using an external loop airlift sonophotoreactor: Statistical analysis and optimization. Journal of Environmental Science and Health - Part A Toxic/Hazardous Substances and $\begin{array}{lllll}\text { Environmental } & \text { Engineering, } & 51 & \text { 722-735. }\end{array}$ https://dx.doi.org/10.1080/10934529.2016.1170438

Mohamed, M.A., Salleh, W.N.W., Jaafar, J., Ismail, A.F., Nor, N.A.M., 2015. Photodegradation of phenol by $\mathrm{N}-$ Doped $\mathrm{TiO}_{2}$ anatase/rutile nanorods assembled microsphere under $\mathrm{UV}$ and visible light irradiation. Materials Chemistry and Physics, 162, art. no. 18131, 113-123. https://dx.doi.org/10.1016/j.matchemphys.2015.05.033

Mohan, R., Krishnamoorthy, K., Kim, S.-J., 2012. Enhanced photocatalytic activity of Cu-doped $\mathrm{ZnO}$ nanorods. Solid State Communications, 152 (5), 375-380. https://dx.doi.org/10.1016/j.ssc.2011.12.008

Moussavi, G., Pourakbar, M., Aghayani, E., Mahdavianpour, M., Shekoohyian, S., 2016. Comparing the efficacy of VUV and $\mathrm{UVC} / \mathrm{S}_{2} \mathrm{O}_{8}{ }^{2-}$ advanced oxidation processes for degradation and mineralization of cyanide in wastewater. Chemical Engineering Journal, 294, 273-280. https://dx.doi.org/10.1016/j.cej.2016.02.113

Mowla, A., Mehrvar, M., Dhib, R., 2014. Combination of sonophotolysis and aerobic activated sludge processes for treatment of synthetic pharmaceutical wastewater. Chemical Engineering Journal, 255, 411-423. https://dx.doi.org/10.1016/j.cej.2014.06.064

Mrowetz, M., Selli, E., 2006. Photocatalytic degradation of formic and benzoic acids and hydrogen peroxide evolution in $\mathrm{TiO}_{2}$ and $\mathrm{ZnO}$ water suspensions. Journal of Photochemistry and $\begin{array}{lllll}\text { Photobiology } & \text { A: } & \text { Chemistry, } & 180 & (1-2),\end{array}$ https://dx.doi.org/10.1016/j.jphotochem.2005.09.009

Myers, R.H., Montgomery, D.C., Vining, G.G., Borror, C.M., Kowalski, S.M., 2004. Response Surface Methodology: A Retrospective and Literature Survey. Journal of Quality Technology 36 (1), 53-77.

Nasirian, M., Mehrvar, M., 2016. Modification of $\mathrm{TiO}_{2}$ to Enhance Photocatalytic Degradation of Organics in Aqueous Solutions, Journal of Environmental Chemical Engineering, 4 (4A), 4072-4082. https://dx.doi.org/10.1016/j.jece.2016.08.008 
Nasirian, M., Bustillo-Lecompte, C.F., Mehrvar, M., 2017. Photocatalytic efficiency of $\mathrm{Fe}_{2} \mathrm{O}_{3} / \mathrm{TiO}_{2}$ for the degradation of typical dyes in textile industries: Effects of calcination temperature and UV-assisted thermal synthesis, Journal of Environmental Management,196, 487-497. http://dx.doi.org/10.1016/j.jenvman.2017.03.030

Nasirian, M., Mehrvar, M., 2017. Photocatalytic degradation of aqueous Methyl Orange using nitrogen-doped $\mathrm{TiO}_{2}$ photocatalyst prepared by novel method of ultraviolet-assisted thermal synthesis. Journal of Environmental Sciences. (in Press). https://doi.org/10.1016/j.jes.2017.05.032

Nasralla, N., Yeganeh, M., Astuti, Y., Piticharoenphun, S., Shahtahmasebi, N., Kompany, A., Karimipour, M., Mendis, B.G., Poolton, N.R.J., Šiller, L., 2013. Structural and spectroscopic study of $\mathrm{Fe}$-doped $\mathrm{TiO}_{2}$ nanoparticles prepared by sol-gel method. Scientia Iranica, 20 (3), 1018-1022. https://dx.doi.org/10.1016/j.scient.2013.05.017

Nawawi, W.I., Nawi, M.A, 2014. Carbon coated nitrogen doped P25 for the photocatalytic removal of organic pollutants under solar and low energy visible light irradiations. Journal of Molecular Catalysis A: Chemical, 383-384, 83-93. https://dx.doi.org/10.1016/j.molcata.2013.11.030

Newbury, D.E., Ritchie, N.W.M., 2013. Elemental mapping of microstructures by scanning electron microscopy-energy dispersive X-ray spectrometry (SEM-EDS): extraordinary advances with the silicon drift detector (SDD). J. Anal. At. Spectrom, 28, 973-988. https://dx.doi.org/10.1039/C3JA50026H

Nikhil, A., Anjusree, G.S., Nair, S.V., Nair, A.S., 2015. Visible light-induced photocatalytic activity of high surface area $\mathrm{N}$-doped two-dimensional (2-D) $\mathrm{TiO}_{2}$ sheets. RSC Advances, 5 (107), 88464-88470. https://dx.doi.org/10.1039/c5ra15086h

Niu, J., Lu, P., Kang, M., Deng, K., Yao, B., Yu, X., Zhang, Q., 2014. P-doped $\mathrm{TiO}_{2}$ with superior visible-light activity prepared by rapid microwave hydrothermal method. Applied Surface Science, 319 (1), 99-106. https://dx.doi.org/10.1016/j.apsusc.2014.07.048

Nolan, N.T., Synnott, D.W., Seery, M.K., Hinder, S.J., Wassenhoven, A.V., Pillai, S.C., 2012. Effect of N-doping on the photocatalytic activity of sol-gel $\mathrm{TiO}_{2}$. Journal of Hazardous Materials, 211-212, 88-94. https://dx.doi.org/10.1016/j.jhazmat.2011.08.074

Ola, O., Maroto-Valer, M., 2015. Review of material design and reactor engineering on $\mathrm{TiO}_{2}$ photocatalysis for $\mathrm{CO}_{2}$ reduction. Journal of Photochemistry and Photobiology C: Photochemistry $\quad$ Reviews, 24, 16-42. https://dx.doi.org/10.1016/j.jphotochemrev.2015.06.001

Oyama, S.T., 2000. Chemical and Catalytic Properties of Ozone. Catalysis Reviews - Science and Engineering, 42 (3), 279-322. https://dx.doi.org/10.1081/CR-100100263

Padmanabhan, P.V.A., Sreekumar, K.P., Thiyagarajan, T.K., Satpute, R.U., Bhanumurthy, K., Sengupta, P., Dey, G.K., Warrier, K.G.K., 2006. Nano-crystalline titanium dioxide formed by reactive plasma synthesis. Vacuum, $80 \quad(11-12), \quad 1252-1255$. https://dx.doi.org/10.1016/j.vacuum.2006.01.054

Pal, B., Sharon, M., Nogami, G., 1999. Preparation and characterization of $\mathrm{TiO}_{2} / \mathrm{Fe}_{2} \mathrm{O}_{3}$ binary mixed oxides and its photocatalytic properties. Materials Chemistry and Physics 59 (3), 254-261. https://dx.doi.org/10.1016/S0254-0584(99)00071-1

Pal, A., Shah, S., Devi, S., 2007. Synthesis of Au, Ag and Au-Ag alloy nanoparticles in aqueous polymer solution. Colloids and Surfaces A: Physicochemical and Engineering Aspects, 302 (1-3), 51-57. https://dx.doi.org/10.1016/j.colsurfa.2007.01.054 
Park, E.J., Jeong, B., Jeong, M.-G., Kim, Y.D., 2014.Synergetic effects of hydrophilic surface modification and $\mathrm{N}$-doping for visible light response on photocatalytic activity of $\mathrm{TiO}_{2}$. Current Applied Physics, 14 (3), 300-305. https://dx.doi.org/10.1016/j.cap.2013.12.004

Peng, L., Xie, T., Lu, Y., Fan, H., Wang, D., 2010. Synthesis, photoelectric properties and photocatalytic activity of the $\mathrm{Fe}_{2} \mathrm{O}_{3} / \mathrm{TiO}_{2}$ heterogeneous photocatalysts. Physical Chemistry Chemical Physics, 12 (28), 8033-8041. https://dx.doi.org/10.1039/c002460k

Philippopoulos, C. J., Nikolaki, M.D., 2010. Photocatalytic Processes on the Oxidation of Organic Compounds in Water, New Trends in Technologies, Blandna ramov (Ed.), InTech, https://dx.doi.org/10.5772/7588

Pignatello, J. J., 1992. Dark and Photoassisted $\mathrm{Fe}^{3+-}$ catalyzed degradation of chlorophenoxy herbicides by hydrogen peroxide, Environmental Science and Technology, 26, 944-951. https://dx.doi.org/10.1021/es00029a012

Qu, X., Alvarez, P.J.J., Li, Q., 2013. Applications of nanotechnology in water and wastewater treatment. Water $\quad$ Research, $47 \quad$ (12), https://dx.doi.org/10.1016/j.watres.2012.09.058

Quiñones, D.H., Rey, A., Alvarez, P.M., Beltran, F.J., Li Puma, G., 2015. Boron doped $\mathrm{TiO}_{2}$ catalysts for photocatalytic ozonation of aqueous mixtures of common pesticides: Diuron, o-phenylphenol, MCPA and terbutylazine. Applied Catalysis B: Environmental, 178, 7481. https://dx.doi.org/10.1016/j.apcatb.2014.10.036

Ranjan, S., Sasselov, D.D., 2016. Influence of the UV Environment on the Synthesis of Prebiotic Molecules. Astrobiology, 16 (1), 68-88. https://dx.doi.org/10.1089/ast.2015.1359

Reddy, P.A.K., Reddy, P.V.L., Kwon, E., Kim, K.-H., Akter, T., Kalagara, S., 2016. Recent advances in photocatalytic treatment of pollutants in aqueous media. Environment International 91, 94-103. https://dx.doi.org/10.1016/j.envint.2016.02.012

Rincón, A.-G., Pulgarin, C., 2005. Use of coaxial photocatalytic reactor (CAPHORE) in the $\mathrm{TiO}_{2}$ photo-assisted treatment of mixed E. coli and Bacillus sp. and bacterial community present in wastewater. Catalysis Today, $101 \quad$ (3-4 SPEC. ISS.), 331-344. https://dx.doi.org/10.1016/j.cattod.2005.03.022

Robles-Águila, M.J., Elizalde-González, M.P., Mendoza, M.E., Silva-González, R., Yee-Madeira, H., 2012. Bulk and surface analysis of $\mathrm{Ti}_{1-\mathrm{x}} \mathrm{Fe}_{\mathrm{x}} \mathrm{O}_{2} / \mathrm{Fe}_{2} \mathrm{O}_{3}$ composites prepared by solid state reaction for photocatalytic applications. Surface and Interface Analysis 44 (4), 484-490. https://dx.doi.org/10.1002/sia.3879

Rulkens, W., 2008. Sewage sludge as a biomass resource for the production of energy: Overview and assessment of the various options. Energy and Fuels, 22 (1), 9-15. https://dx.doi.org/10.1021/ef700267m

Saien, J., Mesgari, Z., 2016. Highly efficient visible-light photocatalyst of nitrogen-doped TiO2 nanoparticles sensitized by hematoporphyrin. Journal of Molecular Catalysis A: Chemical, 414, 108-115. https://dx.doi.org/10.1016/j.molcata.2015.12.027

Sakthivel, S., Geissen, S.-U., Bahnemann, D.W., Murugesan, V., Vogelpohl, A., 2002. Enhancement of photocatalytic activity by semiconductor heterojunctions: $\alpha-\mathrm{Fe}_{2} \mathrm{O}_{3}, \mathrm{WO}_{3}$ and $\mathrm{CdS}$ deposited on $\mathrm{ZnO}$. Journal of Photochemistry and Photobiology A: Chemistry, 148 (1-3), 283-293. https://dx.doi.org/10.1016/S1010-6030(02)00055-2

Salarian, A.-A., Hami, Z., Mirzaie, N., Mohseni, S.M., Asadi, A., Bahrami, H., Vosoughi, M., Alinejad, A., Zare, M.-R., 2016. N-doped $\mathrm{TiO}_{2}$ nanosheets for photocatalytic degradation and mineralization of diazinon under simulated solar irradiation: Optimization and 
modeling using a response surface methodology. Journal of Molecular Liquids 220, 183191. https://dx.doi.org/10.1016/j.molliq.2016.04.060

Samsudin, E.M., Hamid, S.B.A., Juan, J.C., Basirun, W.J., Centi, G., 2016. Synergetic effects in novel hydrogenated F-doped $\mathrm{TiO}_{2}$ photocatalysts. Applied Surface Science, 370, 380-393. https://dx.doi.org/10.1016/j.apsusc.2016.02.172

Samsudin, E.M., Hamid, S.B.A., Juan, J.C., Basirun, W.J., Kandjani, A.E., Bhargava, S.K., 2016. Effective role of trifluoroacetic acid (TFA) to enhance the photocatalytic activity of Fdoped $\mathrm{TiO}_{2}$ prepared by modified sol-gel method. Applied Surface Science, 365, 57-68. https://dx.doi.org/10.1016/j.apsusc.2016.01.016

Sánchez, L., Peral, J., Domènech, X., 1998. Aniline degradation by combined photocatalysis and ozonation. Applied Catalysis B: Environmental, 19 (1), 59-65. https://dx.doi.org/10.1016/S0926-3373(98)00058-7

Serpone, N., 2006. Is the band gap of pristine $\mathrm{TiO}_{2}$ narrowed by anion- and cation-doping of titanium dioxide in second-generation photocatalysts? Journal of Physical Chemistry B, 110 (48), 24287-24293. https://dx.doi.org/10.1021/jp065659r

Shah, S.I., Li, W., Huang, C.P., Jung, O., Ni, C., 2002. Study of $\mathrm{Nd}_{3}{ }^{+}, \mathrm{Pd}_{2}{ }^{+}, \mathrm{Pt}_{4}{ }^{+}$, and $\mathrm{Fe}_{3}{ }^{+}$dopant effect on photoreactivity of $\mathrm{TiO}_{2}$ nanoparticles. Proceedings of the National Academy of Sciences of the United States of America 99 (2), 6482-6486. https://dx.doi.org/10.1073/pnas.052518299

Shao, Y., Cao, C., Chen, S., He, M., Fang, J., Chen, J., Li, X., Li, D., 2015. Investigation of nitrogen doped and carbon species decorated $\mathrm{TiO}_{2}$ with enhanced visible light photocatalytic activity by using chitosan. Applied Catalysis B: Environmental, 179, 344351. https://dx.doi.org/10.1016/j.apcatb.2015.05.023

Shaogui, Y., Xie, Q., Xinyong, L., Yazi, L., Shuo, C., Guohua, C., 2004. Preparation, characterization and photoelectrocatalytic properties of nanocrystalline $\mathrm{Fe}_{2} \mathrm{O}_{3} / \mathrm{TiO}_{2}$, $\mathrm{ZnO} / \mathrm{TiO}_{2}$, and $\mathrm{Fe}_{2} \mathrm{O}_{3} / \mathrm{ZnO} / \mathrm{TiO}_{2}$ composite film electrodes towards pentachlorophenol degradation. Physical Chemistry Chemical Physics, 6 (3), 659-664.

Shi, L., Weng, D., 2008. Highly active mixed-phase $\mathrm{TiO}_{2}$ photocatalysts fabricated at low temperature and the correlation between phase composition and photocatalytic activity. Journal of Environmental Sciences, 20 (10), 1263-1267. https://dx.doi.org/10.1016/S10010742(08)62219-6

Shi, W., Yang, W., Li, Q., Gao, S., Shang, P., Shang, J.K., 2012. The synthesis of nitrogen/sulfur co-doped $\mathrm{TiO}_{2}$ nanocrystals with a high specific surface area and a high percentage of $\{001\}$ facets and their enhanced visible-light photocatalytic performance. Nanoscale Research Letters 7, 1-9. https://dx.doi.org/10.1186/1556-276X-7-590

Shivaraju, H.P., Muzakkira, N., Shahmoradi, B., 2016. Photocatalytic treatment of oil and grease spills in wastewater using coated $\mathrm{N}$-doped $\mathrm{TiO}_{2}$ polyscales under sunlight as an alternative driving energy. International Journal of Environmental Science and Technology 13 (9), 2293-2302. https://dx.doi.org/10.1007/s13762-016-1038-8

Shvadchina, Y.O., Cherepivskaya, M.K., Vakulenko, V.F., Sova, A.N., Stolyarova, I.V., Prikhodko, R.V., 2015. The study of properties and catalytic activity of titanium dioxide doped with sulphure. Journal of Water Chemistry and Technology, 37 (6), 283-288. https://dx.doi.org/10.3103/S1063455X15060041

Silva, A.M.T., Silva, C.G., Dražić, G., Faria, J.L., 2009. Ce-doped $\mathrm{TiO}_{2}$ for photocatalytic degradation of chlorophenol. Catalysis Today, 144 (1-2), 13-18. https://dx.doi.org/10.1016/j.cattod.2009.02.022 
Simsek, E.B., 2017. Solvothermal synthesized boron doped $\mathrm{TiO}_{2}$ catalysts: Photocatalytic degradation of endocrine disrupting compounds and pharmaceuticals under visible light irradiation. Applied Catalysis B: Environmental, 200, 309-322. https://dx.doi.org/10.1016/j.apcatb.2016.07.016

Sökmen, M., Özkan, A., 2002. Decolourising textile wastewater with modified titania: The effects of inorganic anions on the photocatalysis. Journal of Photochemistry and Photobiology A: Chemistry, 147 (1), 77-81.

Sudha, D., Sivakumar, P., 2015. Review on the photocatalytic activity of various composite catalysts. Chemical Engineering and Processing: Process Intensification 97, 112-133. https://dx.doi.org/10.1016/j.cep.2015.08.006

Sun, B., Smirniotis, P.G., 2003. Interaction of anatase and rutile $\mathrm{TiO}_{2}$ particles in aqueous

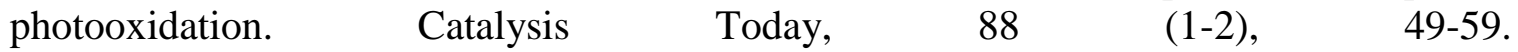
https://dx.doi.org/10.1016/j.cattod.2003.08.006

Sun, J., Zhang, H., Ma, D., Chen, Y., Bao, X., Klein-Hoffmann, A., Pfänderb, N., Su, D.S., 2005. Alkanes-assisted low temperature formation of highly ordered SBA-15 with large cylindrical mesopores. Chemical Communications 42, 5343-5345. https://dx.doi.org/10.1039/B509713D

Sun, S., Sun, M., Fang, Y., Wang, Y., Wang, H., 2016. One -step in situ calcinations synthesis of g- $\mathrm{C}_{3} \mathrm{~N}_{4} / \mathrm{N}-\mathrm{TiO}_{2}$ hybrids with enhances photoactivity. RSC Advances, 6, $13063-13071$. https://dx.doi.org/10.1039/c5ra26700e

Sun, X., Xing, J., Qiu, J., 2016. Preparation and photocatalytic activity of nonmetal Co-doped titanium dioxide photocatalyst. Russian Journal of Physical Chemistry A, 90 (6), 11511156. https://dx.doi.org/10.1134/S0036024416060303

Suresh, R., Giribabu, K., Manigandan, R., Stephen, A., Narayanan, V., 2014. Fabrication of Ni$\mathrm{Fe}_{2} \mathrm{O}_{3}$ magnetic nanorods and application to the detection of uric acid. Royal Society of Chemistry 4, 17146-17155. https://dx.doi.org/10.1039/C4RA00725E

Surzhikov, A.P., Vasendina, E.A., Lysenko, E.N., Nikolaev, E.V., 2014. Kinetics of phase formation in a $\mathrm{Li}_{2} \mathrm{CO}_{3}-\mathrm{TiO}_{2}-\mathrm{Fe}_{2} \mathrm{O}_{3}$ system during radiation-thermal synthesis. Inorganic Materials: $\quad$ Applied $\quad$ Research, 5 (2), 102-106. https://dx.doi.org/10.1134/S207511331402021X

Suwannaruang, T., Wantala, K., 2016. Single-step uncalcined $\mathrm{N}-\mathrm{TiO}_{2}$ synthesis, characterizations and its applications on alachlor photocatalytic degradations. Applied Surface Science, 380, 257-267. https://dx.doi.org/10.1016/j.apsusc.2016.01.117

Szatmary, L., Bakardjieva, S., Subrt, J., Bezdicka, P., Jirkovsky, J., Bastl, Z., Brezova, V., Korenko, M., 2011. Sulphur doped nanoparticles of $\mathrm{TiO}_{2}$. Catalysis Today, 161, 23-28. https://dx.doi.org/10.1016/j.cattod.2010.11.082

Szkoda, M., Siuzdak, K., Lisowska-Oleksiak, A., 2016. Non-metal doped $\mathrm{TiO}_{2}$ nanotube arrays for high efficiency photocatalytic decomposition of organic species in water. Physica E, 84, 141-145. https://dx.doi.org/10.1016/j.physe.2016.06.004

Tang, W.Z., An, H., 1995. UV/TiO 2 photocatalytic oxidation of commercial dyes in aqueous solutions. Chemosphere 31 (9), 4157-4170. https://dx.doi.org/10.1016/00456535(95)80015-D

Tryba, B., Piszcz, M., Morawski, A.W., 2010. Photocatalytic and self-cleaning properties of Agdoped $\mathrm{TiO}_{2}$. Open Materials Science Journal, 4, 5-8. https://dx.doi.org/10.2174/1874088X01004020005 
Tung, W.S., Daoud, W.A., 2011. Self-cleaning fibers via nanotechnology: A virtual reality. $\begin{array}{lllll}\text { Journal of } & \text { Materials }\end{array}$ https://dx.doi.org/10.1039/c0jm03856c

Umar, M., Aziz, H. A., 2013. Photocatalytic degradation of organic pollutants in water. Organic Pollutants - Monitoring, Risk and Treatment, Chapter 8. INTECH Open Access Publisher. https://dx.doi.org/10.5772/53699

Vaiano, V., Sacco, O., Iervolino, G., Sannino, D., Ciambelli, P., Liguori, R., Bezzeccheri, E., Rubino, A., 2015. Enhanced visible light photocatalytic activity by up-conversion phosphors modified N-doped $\mathrm{TiO}_{2}$. Applied Catalysis B: Environmental, 176-177, 594600. https://dx.doi.org/10.1016/j.apcatb.2015.04.049

Valenzuela, M.A., Bosch, P., Jiménez-Becerrill, J., Quiroz, O., Páez, A.I., 2002. Preparation characterization and photocatalytic activity of $\mathrm{ZnO}, \mathrm{Fe}_{2} \mathrm{O}_{3}$ and $\mathrm{ZnFe}_{2} \mathrm{O}_{4}$. Journal of Photochemistry and Photobiology A: Chemistry 148 (1-3), 177-182. https://dx.doi.org/10.1016/S1010-6030(02)00040-0

Valodkar, M., Modi, S., Pal, A., Thakore, S., 2011. Synthesis and anti-bacterial activity of $\mathrm{Cu}, \mathrm{Ag}$ and $\mathrm{Cu}-\mathrm{Ag}$ alloy nanoparticles: A green approach. Materials Research Bulletin, 46 (3), 384-389. https://dx.doi.org/10.1016/j.materresbull.2010.12.001

Venkatachalam, N., Palanichamy, M., Arabindoo, B., Murugesan, V., 2007. Enhanced photocatalytic degradation of 4-chlorophenol by $\mathrm{Zr}_{4}{ }^{+}$doped nano $\mathrm{TiO}_{2}$. Journal of Molecular Catalysis A: Chemical, $266 \quad$ (1-2), 158-165. https://dx.doi.org/10.1016/j.molcata.2006.10.051

Veisi, F., Zazouli, M.A., Ebrahimzadeh, M.A., Charati, J.Y., Dezfoli, A.S., 2016. Photocatalytic degradation of furfural in aqueous solution by $\mathrm{N}$-doped titanium dioxide nanoparticles. Environmental Science and Pollution Research, 23 (21), 21846-21860. https://dx.doi.org/10.1007/s11356-016-7199-7

Vijayan, B., Dimitrijevic, N.M., Rajh, T., Gray, K., 2010. Effect of calcination temperature on the photocatalytic reduction and oxidation processes of hydrothermally synthesized titania nanotubes. Journal of Physical Chemistry C 114 (30), 12994-13002. https://dx.doi.org/10.1021/jp104345h

Visa, M., Pricop, F., Duta, A., 2011. Sustainable treatment of wastewaters resulted in the textile dyeing industry. Clean Technologies and Environmental Policy 13 (6), 855-861. https://dx.doi.org/10.1007/s10098-011-0362-4

Wang, P., Yap, P.S., Lim, T.T., 2011. C-N-S tridoped $\mathrm{TiO}_{2}$ for photocatalytic degradation of tetracycline under visible-light irradiation. Applied Catalysis A: General, 399 (1-2), 252261. https://dx.doi.org/10.1016/j.apcata.2011.04.008

Wang, S., Zhou, S., 2011. Photodegradation of methyl orange by photocatalyst of CNTs/P-TiO under UV and visible-light irradiation. Journal of Hazardous Materials, 185 (1), 77-85. https://dx.doi.org/10.1016/j.jhazmat.2010.08.125

Wang, W., Liu, Y., Qu, J., Chen, Y., Shao, Z., 2016. Nitrogen-doped $\mathrm{TiO}_{2}$ microspheres with hierarchical micro/nanostructures and rich dual-phase junctions for enhanced photocatalytic activity. Royal Society of Chemistry Advances, 6, 40923-40931. https://dx.doi.org/10.1039/c6ra02966c

Wellia, D.V., Xu, Q.C., Sk, M.A., Lim, K.H., Lim, T.M., Tan, T.T.Y., 2011. Experimental and theoretical studies of $\mathrm{Fe}$-doped $\mathrm{TiO}_{2}$ films prepared by peroxo sol-gel method. Applied Catalysis A: General, 401 (1-2), 98-105. https://dx.doi.org/10.1016/j.apcata.2011.05.003 
Xia, H., Zhuang, H., Zhang, T., Xiao, D., 2008. Visible-light-activated nanocomposite photocatalyst of $\mathrm{Fe}_{2} \mathrm{O}_{3} / \mathrm{SnO}_{2}$. Materials Letters, 62 (6-7), 1126-1128. https://dx.doi.org/10.1016/j.matlet.2007.07.062

Xia, Y., Jiang, Y., Li, F., Xia, M., Xue, B., Li, Y., 2014. Effect of calcined atmosphere on the photocatalytic activity of P-doped $\mathrm{TiO}_{2}$. Applied Surface Science, 289, 306-315. https://dx.doi.org/10.1016/j.apsusc.2013.10.157

Xiang, Q., Yu, J., Jaroniec, M., 2011. Nitrogen and sulfur co-doped $\mathrm{TiO}_{2}$ nanosheets with exposed $\{001\}$ facets: Synthesis, characterization and visible-light photocatalytic activity. Physical Chemistry Chemical Physics, 13 (11), 4853-4861. https://dx.doi.org/10.1039/c0cp01459a

Xu, H., Ouyang, S., Liu, L., Reunchan, P., Umezawa, N., Ye, J., 2014. Recent advances in $\mathrm{TiO}_{2}$ based photocatalysis. Journal of Materials Chemistry A, 2 (32), 12642-12661. https://dx.doi.org/10.1039/c4ta00941j

Yan, C., Chen, K.F., Lai, C.H., Lai, S.W., Chang, Q., Peng, Y.P., 2014. Photocatalytic degradation of Rhodamine B by microwave-assisted hydrothermal synthesized N-doped titanate nanotubes. Journal of Environmental Sciences, 26, 1505-1512. https://dx.doi.org/10.1016/j.jes.2014.05.017

Yan, Q.Z., Su, X.T., Huang, Z.Y., Ge, C.C., 2006. Sol-gel auto-igniting synthesis and structural property of cerium-doped titanium dioxide nanosized powders. Journal of the European Ceramic Society 26 (6), 915-921. https://dx.doi.org/10.1016/j.jeurceramsoc.2004.11.017

Yang, L., Liu, Z., 2007. Study on light intensity in the process of photocatalytic degradation of indoor gaseous formaldehyde for saving energy. Energy Conversion and Management, 48 (3), 882-889. https://dx.doi.org/10.1016/j.enconman.2006.08.023

Yu, J., Yu, J.C., Ho, W., Jiang, Z., 2002. Effects of calcination temperature on the photocatalytic activity and photo-induced super-hydrophilicity of mesoporous $\mathrm{TiO}_{2}$ thin films. New Journal of Chemistry 26 (5), 607-613. https://dx.doi.org/10.1039/b200964a

Yuan, C., Hung, C.H., Li, H.W., Chang, W.H., 2016. Photodegradation of ibuprofen by $\mathrm{TiO}_{2}$ codoping with urea and functionalized CNT irradiated with visible light - Effect of doping $\begin{array}{llll}\text { content } \quad \text { and } & \text { Chemosphere, } & \text { 155, } & \text { 471-478. }\end{array}$ https://dx.doi.org/10.1016/j.chemosphere.2016.04.055

Zaleska, A., 2008. Doped-TiO 2 : A review. Recent Patents on Engineering, 2 (3), 157-164. https://dx.doi.org/10.2174/187221208786306289

Zeng, L., Lu, Z., Li, M., Yang, J., Song, W., Zeng, D., Xie, C., 2016. A modular calcination method to prepare modified $\mathrm{N}$-doped $\mathrm{TiO}_{2}$ nanoparticle with high photocatalytic activity. Applied $\begin{array}{llll}\text { Catalysis } & \text { B: } & \text { Environmental, } & \text { 183, }\end{array}$ https://dx.doi.org/10.1016/j.apcatb.2015.10.048

Zhang, D., Zeng, F., 2012. Visible light-activated cadmium-doped ZnO nanostructured photocatalyst for the treatment of methylene blue dye. Journal of Materials Science, 47 (5), 2155-2161. https://dx.doi.org/10.1007/s10853-011-6016-4

Zhang, H., Wu, X., Wang, Y., Chen, X., Li, Z., Yu, T., Ye, J., Zou, Z., 2007. Preparation of $\mathrm{Fe} 2 \mathrm{O} 3 / \mathrm{SrTiO} 3$ composite powders and their photocatalytic properties. Journal of Physics and Chemistry of Solids, 68 (2), 280-283. https://dx.doi.org/10.1016/j.jpcs.2006.11.007

Zhang, L., Kanki, T., Sano, N., Toyoda, A., 2003. Development of $\mathrm{TiO}_{2}$ photocatalyst reaction for water purification. Separation and Purification Technology 31 (1), 105-110. https://dx.doi.org/10.1016/S1383-5866(02)00157-0 
Zhang, M., An, T., Liu, X., Hu, X., Sheng, G., Fu, J., 2010. Preparation of a high-activity ZnO/TiO 2 photocatalyst via homogeneous hydrolysis method with low temperature crystallization. Materials Letters, 64 (17), 1883-1886. https://dx.doi.org/10.1016/j.matlet.2010.05.054

Zhang, Y., Liu, P., Wu, H., 2015. Development of high efficient visible light-driven N, S-codoped $\mathrm{TiO}_{2}$ nanowires photocatalysts. Applied Surface Science, 328, 335-343. https://dx.doi.org/10.1016/j.apsusc.2014.12.043

Zhang, W., Jia, B., Wang, Q., Dionysiou, D., 2015. Visible-light sensitization of $\mathrm{TiO}_{2}$ photocatalysts via wet chemical $\mathrm{N}$-doping for the degradation of dissolved organic compounds in wastewater treatment: a review. Journal of Nanoparticle Research, 17 (5), Art. 221, 1-12. https://dx.doi.org/10.1007/s11051-015-3026-1

Zhou, M., Yu, J., Liu, S., Zhai, P., Jiang, L., 2008. Effects of calcination temperatures on photocatalytic activity of $\mathrm{SnO}_{2} / \mathrm{TiO}_{2}$ composite films prepared by an EPD method. Journal $\begin{array}{lllll}\text { of Hazardous } & \text { Materials } & 154 & (1-3), & 1141-1148 .\end{array}$ https://dx.doi.org/10.1016/j.jhazmat.2007.11.021

Zhu, Y.-J., Chen, F., 2014. Microwave-assisted preparation of inorganic nanostructures in liquid phase. Chemical Reviews, 114 (12), 6462-6555. https://dx.doi.org/10.1021/cr400366s

Zou, X.L., 2015. Combination of ozonation, activated carbon, and biological aerated filter for advanced treatment of dyeing wastewater for reuse. Environmental Science and Pollution Research 22 (11), 8174-8181. https://dx.doi.org/10.1007/s11356-015-4423-9

Zou, X.X., Li, G.D., Guo, M.Y., Li, X.H., Liu, D.P., Su, J., Chen, J.S., 2008. Heterometal alkoxides as precursors for the preparation of porous $\mathrm{Fe}-$ and $\mathrm{Mn}-\mathrm{TiO}_{2}$ photocatalysts with high efficiencies. Chemistry - A European Journal, 14 (35), 11123-11131. https://dx.doi.org/10.1002/chem.200801236 